\title{
POLÍTICAS PÚBLICAS NA ECONOMIA BRASILEIRA: UMA APLICAÇÃO DO MODELO MIBRA, UM MODELO INTER- REGIONAL APLICADO DE EQUILÍBRIO GERAL
}

\author{
MARCOS MINORU HASEGAWA
}

Tese apresentada à Escola Superior de Agricultura "Luiz de Queiroz", Universidade de São Paulo, para obtenção do título de Doutor em Ciências, Área de Concentração: Economia Aplicada.

P IR A C I C A B A

Estado de São Paulo - Brasil

Janeiro - 2003 


\section{POLÍTICAS PÚBLICAS NA ECONOMIA BRASILEIRA: UMA APLICAÇÃO DO MODELO MIBRA, UM MODELO INTER- REGIONAL APLICADO DE EQUILÍBRIO GERAL}

\section{MARCOS MINORU HASEGAWA}

Engenheiro Agrônomo

\section{Orientador: Prof. Dr. JOAQUIM JOSÉ MARTINS GUILHOTO}

\footnotetext{
Tese apresentada à Escola Superior de Agricultura "Luiz de Queiroz", Universidade de São Paulo, para obtenção do título de Doutor em Ciências, Área de Concentração: Economia Aplicada.
}

P I R A C I C A B A

Estado de São Paulo - Brasil

Janeiro - 2003 


\title{
Dados Internacionais de Catalogação na Publicação (CIP)
}

DIVISÃO DE BIBLIOTECA E DOCUMENTAÇÃO - ESALQ/USP

\author{
Ha segawa, Marcos Minoru \\ Polític as públic as na ec onomia brasileira : uma a plic ação do modelo \\ MIBRA, um modelo inter-regional a plic a do de equilíbrio geral/ Marcos \\ Minoru Ha segawa. - - Piracic aba, 2003.
}

$258 \mathrm{p}$.

Tese (doutora do) - Escola Superior de Agric ultura Luiz de Queiroz, 2003. Bibliografia.

1. Economia regional - Brasil 2. Polític as públicas I. Título

CDD 330.9

"Permitida a cópia total ou parcial deste documento, desde que citada a fonte - $\mathrm{O}$ autor" 
Dedico aos meus avôs Toshiji (in memorian) e Takayassu (in memorian) 


\section{AGRADECIMENTOS}

Ao Departamento de Economia, Administração e Sociologia da Escola Superior de Agricultura “Luiz de Queiroz" da Universidade de São Paulo.

Ao Professor Doutor Joaquim José Martins Guilhoto pela orientação e amizade.

Ao Conselho Nacional de Desenvolvimento Científico e Tecnológico - CNPq pelo suporte financeiro durante o período do programa através da Bolsa de Doutorado e da Bolsa Doutorado "Sanduíche".

Ao Prof. Dr. Geoffrey John Dennis Hewings, diretor do Laboratório de Aplicação em Economia Regional - REAL, pela oportunidade desenvolver parte da tese na Universidade de Illinois em Urbana-Champaign, Estados Unidos.

Ao Prof. Dr. Geraldo Sant'Ana de Camargo Barros pela amizade e incentivo antes e durante o programa de Doutorado.

Aos pesquisadores visitantes do REAL, Prof. Euijune Kim, Massayo Makino, Prof. Russel Coopers, Prof. Manuel Alejandro Cardenete Flores, Prof. Michael Sonis e Eduardo Simões de Almeida pelas discussões e sugestões sobre investimento e modelagem aplicada em equilíbrio geral.

À minha família que deu o apoio necessário para a realização do Doutorado.

Aos velhos e novos amigos de Piracicaba e Urbana-Champaign, de modo especial a: Francisco Casimiro Filho, Maria da Piedade Araújo, Ricardo Luis Lopes, Mônica Amaral Haddad, Carlos Eduardo Lobo e Silva, Carolyn Dong Guo, Ferhan Gezici e Suahasil Nazara.

Aos integrantes da equipe de Projeções Econômicas do CEPEA.

A todos que contribuíram direta e indiretamente. 


\section{SUMÁRIO}

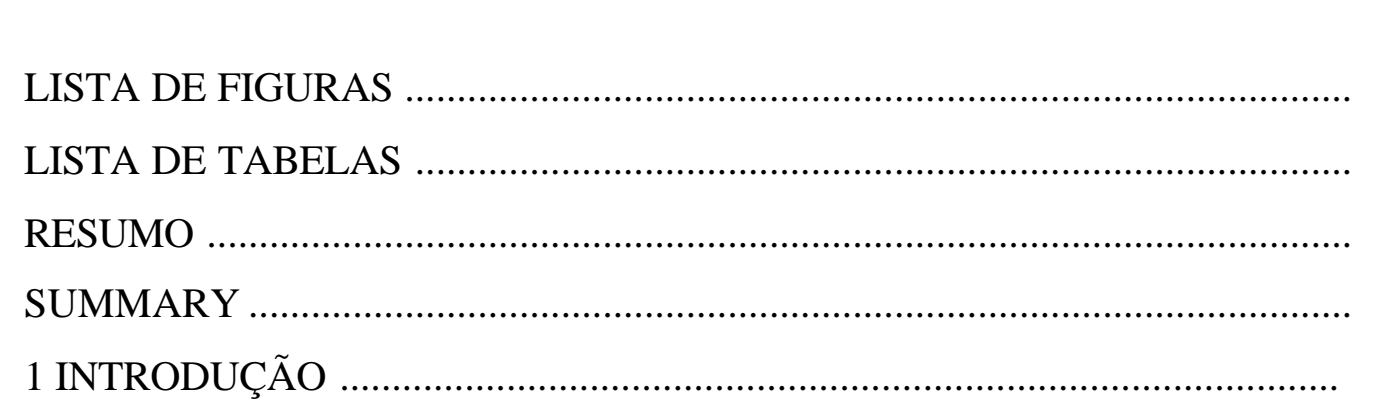

Página

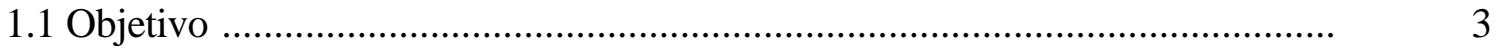

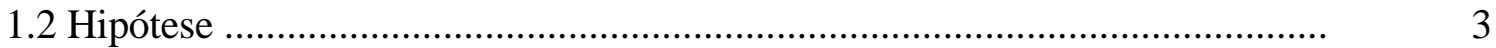

2 REVISÃO DE LITERATURA .................................................................

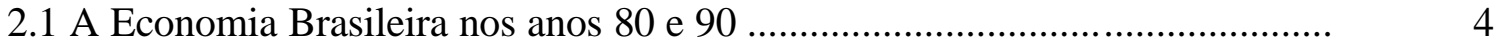

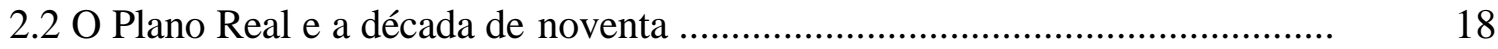

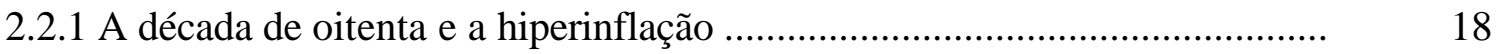

2.2.2 A década de noventa e o Plano Real ........................................................ 19

2.3 Modelos Aplicados de Equilíbrio Geral .................................................. 24

2.3.1 Um pouco de história sobre os modelos AEG e Modelos Econométricos .. 25

2.3.2 Modelos AEG vs. Modelos Econométricos: uma breve discussão .............. 27

2.3.3 MAEG dinâmicos recursivos e não-recursivos ........................................ 30

2.3.4 Modelos AEG desenvolvidos para a Economia Brasileira ........................ 32

2.3.5 Modelos AEG Inter-regionais, Dinâmicos e de Previsão ........................... 37

2.3.6 Os modelos AEG do tipo Johansen-Orani .............................................. 41

2.4 Programa de Governo do Partido dos Trabalhadores (PT) ............................ 47

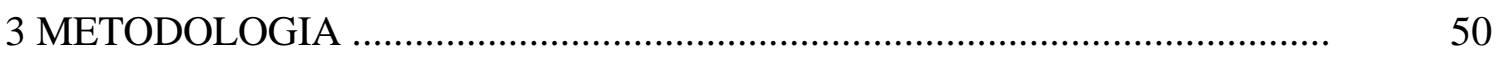

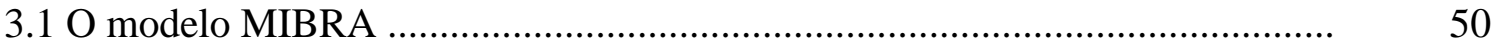

3.1.1 Módulo Central ............................................................................... 122 
3.1.2 Módulo de Finanças Governamentais ........................................................... 123

3.1.3 Módulo de Acumulação de Capital e Investimento ........................................ 123

3.1.4 Módulo da Acumulação da Dívida Externa ................................................... 125

3.1.5 Mercado de Trabalho e Migração Regional ..................................................... 125

3.2 Endogenização do Investimento ............................................................... 126

3.2.1 Investimento exógeno e solução recursiva ……………………………….... 127

3.2.2 Investimento endógeno e Solução recursiva .................................................. 130

3.3 Equações auxiliares para simulação ano a ano …………………………….... 132

3.3.1 Taxa de retorno e Investimento ................................................................. 133

3.3.2 Equações de simulação ano a ano: investimento e capital, investimento e

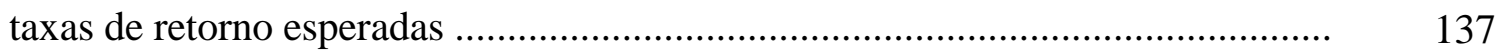

3.3.3 Equações miscelâneas para facilitar as simulações ano a ano ...................... 144

3.4 Dados e Calibração .................................................................................. 146

3.4.1 Complementação do banco de dados do modelo MIBRA ............................. 150

3.5 Linearização e a Eliminação do seu Erro ………………………………….... 151

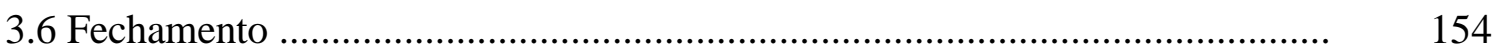

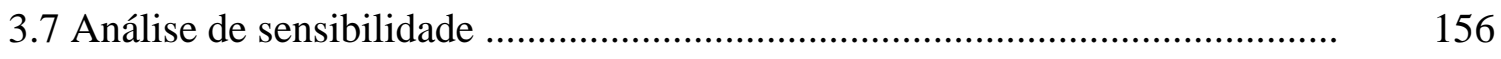

4 RESULTADOS E DISCUSSÃO ........................................................... 160

4.1 Fechamentos utilizados ......................................................................... 160

4.1.1 Fechamento Básico ................................................................................ 160

4.1.2 Fechamentos para simulação das políticas do governo do PT ...................... 163

4.2 Teste de Homogeneidade ............................................................................ 166

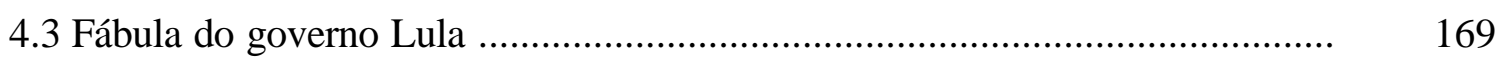

4.3.1 Aumento do salário nominal ................................................................ 178

4.3.2 Aumento dos gastos do governo e dos investimentos ...................... 180

4.3.3 Aumento da produtividade ................................................................... 182

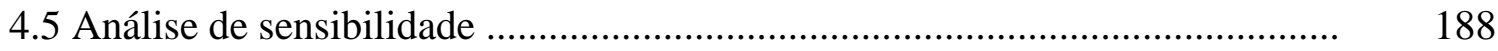

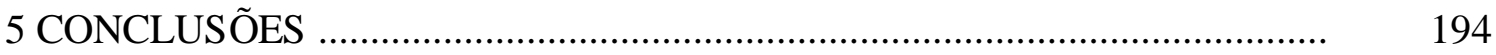

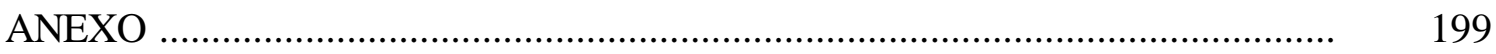


REFERÊNCIAS BIBLIOGRÁFICAS 


\section{LISTA DE FIGURAS}

Página

1 População residente brasileira em milhões de pessoas de 1980 a 2000, com base no dia primeiro de julho

2 População economicamente ativa, média anual de 1980 a 2000

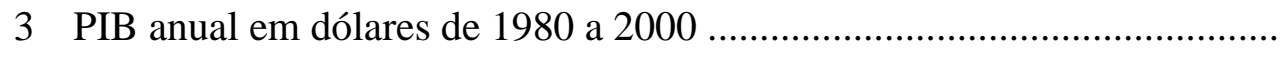

4 Índice Geral de Preços - disponibilidade interna (IGP-DI) mensal e a taxa de câmbio comercial do Real em relação ao Dólar, média mensal para venda, para o período de janeiro de 1980 a dezembro de 2000, transformados em logaritmos na base 100

5 Taxa de juros Over/Selic mensal de 1980 a 2000 ................................. 9

6 Balança Comercial, Exportação e Importação Brasileira em milhões de dólares de 1980 a 2000

7 Balança de pagamentos em milhões de dólares de 1980 a 2000 ............... 10

8 Taxa de investimento em porcentagem do PIB de 1980 a $2000 \ldots \ldots \ldots \ldots \ldots . . . . . .11$

9 Reservas Internacionais em milhões de dólares de 1980 a 2000 .............. 11

10 Taxa de investimento em termos de porcentagem do PIB anual de 1980 a 2000

11 Índice dessazonalizado mensal da produção Industrial, de janeiro de 1985 a dezembro de 2000 - ano base em 1991

12 Dívida total líquida do setor público mensal em porcentagem do PIB de janeiro de 1991 a dezembro de 2000 
13 Necessidade de financiamento do setor público em porcentagem do PIB de 1985 a 2000

14 Taxa de desemprego aberto (30 dias) mensal de 1980 a 2000 ................

15 Duração e distribuição dos eventos no tempo no modelo multi-periódico

16 O esquema da taxa de retorno esperada de equilíbrio para o setor $\mathrm{j}$...........

17 Matriz de absorção do MIBRA

18 Resultados em nível nacional das simulações para as variáveis relevantes 


\section{LISTA DE TABELAS}

Página

1 Área, População e Densidade Demográfica do Brasil por grandes regiões

2 PIB per capita em Reais no período de 1995 a 1998 no Brasil e nas grandes regiões em valores de 1999

3 PIB a preços de mercado em milhões de Reais no período de 1995 a 1998, no Brasil e nas grandes regiões em valores de 1999

4 Participação percentual das cinco macrorregiões brasileiras no PIB a preços correntes de mercado de 1985 a 1998

5 Índice de Desenvolvimento Humano: comparações regionais para 1995 e 1996 no Brasil

6 As equações do modelo MIBRA

7 As variáveis do MIBRA

8 Os coeficientes e parâmetros do MIBRA

9 Dimensões do MIBRA

10 Setores utilizados pelo MIBRA

11 Relação das informações solicitadas pela s novas equações

12 Fechamento básico com a relação das variáveis exógenas do modelo MIBRA

13 Relação de trocas de variáveis no fechamento básico para simulação das políticas de governo do PT.

14 Teste de homogeneidade para as variáveis macro do modelo MIBRA 
15 Relação dos choques aplicados que diferenciam as simulações realizadas

16 Resultados em nível nacional das simulações para as variáveis relevantes

17 Resultados em nível regional das simulações para as variáveis relevantes

18 Resultados em nível setorial das simulações para o Emprego por setor

19 Resultados em nível setorial nas simulações para o nível de atividade

20 Resultados em nível setorial nas simulações para o índice de preços no comércio inter-regional por produto

21 Resultados das simulações para o índice de preços no fluxo de comércio inter-regional, por regiões de origem e de destino

22 Resultados das simulações para a variável quantidade do fluxo de comércio inter-regional, por regiões de origem e de destino

23 Resultados em nível setorial e regional para o nível de atividades na simulação de aumento dos gastos do governo e dos investimentos privilegiando as regiões Norte e Nordeste

24 Resultados em nível setorial e regional para o nível de atividades na simulação de aumento dos gastos do governo e dos investimentos com alocação menos concentrada

25 Resultados em nível setorial e regional para o nível de atividades na simulação do aumento da produtividade em $0,1 \%$

26 Resultados em nível setorial e regional para o nível de atividades na simulação do aumento da produtividade em $0,5 \%$

27 Resultado em nível nacional da análise de sensibilidade sobre a variável produtividade do fator trabalho

28 Resultados da Análise de Sensibilidade do choque sobre a variável produtividade do fator de produção trabalho

29 Resultado em nível nacional da análise de sensibilidade sobre o parâmetro de distribuição de investimento (BETR) 
30 Resultados da Análise de Sensibilidade do choque sobre o parâmetro distribuição de investimento (BETR) ............................................ 


\title{
POLÍTICAS PÚBLICAS NA ECONOMIA BRASILEIRA: UMA APLICAÇÃO DO MODELO MIBRA, UM MODELO INTER-REGIONAL APLICADO DE EQUILÍBRIO GERAL
}

\author{
Autor: MARCOS MINORU HASEGAWA \\ Orientador: Prof. Dr. JOAQUIM JOSÉ MARTINS GUILHOTO
}

\section{RESUMO}

Os Modelos Aplicados de Equilíbrio Geral (modelos AEG) são úteis para analisar o impacto de políticas do governo sobre a economia de um país sem perder os detalhes em nível setorial. Os modelos AEG inter-regionais fornecem detalhes adicionais em nível regional, o que é interessante para a análise de políticas públicas para o Brasil que tem diferenças econômicas e sociais em nível regional. Dessa forma, o Modelo Inter-regional para a Economia Brasileira - MIBRA foi trabalhado para analisar as políticas econômicas e sociais propostas pelo governo federal, com mandato de 2003 a 2006. Além do objetivo de analisar as políticas públicas brasileiras, o tratamento endógeno do investimento foi incorporado no modelo MIBRA, o que permite melhorias nos resultados tanto para a análise de estática comparativa como para a dinâmica recursiva. A hipótese básica verificada neste trabalho é que as propostas de políticas apresentadas pelo novo governo federal são efetivamente realizadas se existir uma combinação do aumento dos investimentos e gastos públicos com o aumento da produtividade dos fatores de produção. O modelo MIBRA foi trabalhado com 16 setores e cinco macrorregiões brasileiras. Foram utilizados a matriz inter-regional brasileira de 
1995 e dados obtidos do Instituto Brasileiro de Geografia e Estatística, do Banco Central do Brasil, da Fundação Getúlio Vargas e de vários trabalhos de pesquisas. O teste de homogeneidade mostrou que o modelo é consistente. Os resultados apontam que um aumento nominal do salário de $5,5 \%$ piora a situação da economia brasileira tendo como cenário a aplicação das propostas do novo governo. O aumento dos gastos do governo e dos investimentos privilegiando as regiões Norte e Nordeste não é tão eficiente, em termos de crescimento econômico em nível regional e nacional, quando se compara com a situação de aumentos dos gastos públicos e dos investimentos realizados de forma menos concentrado entre as regiões. Isso mostra que a regiões Sudeste e Sul devem crescer juntamente com as demais, pois a maior parte dos insumos e bens de capital necessários para a produção nas regiões menos desenvolvidas é proveniente das regiões mais desenvolvidas, especialmente da região Sudeste. O aumento da produtividade dos fatores de produção é importante para a efetiva realização das política públicas propostas pelo novo governo federal. A combinação do aumento de investimentos e gastos do governo com aumento da produtividade dos fatores de produção podem garantir o desejado desenvolvimento e crescimento sustentado da economia brasileira no médio e longo prazos. Ou seja, consegue-se aumentar a produção real, o consumo real, diminuir desemprego, manter inflação e a necessidade de financiamento do governo sob controle. A política para desenvolvimento e crescimento sustentado deve garantir que parte dos gastos do governo seja convertida tanto em melhorias sociais como em aumentos da produtividade do trabalho. Os modelos AEG inter-regionais são instrumentos poderosos para a formulação das políticas públicas de um país como o Brasil que precisa resolver os problemas das diferenças econômicas e sociais nos níveis setorial e regional. 


\title{
THE PUBLIC POLICY ON THE BRAZILIAN ECONOMY: AN APPLICATION OF MIBRA MODEL, AN INTER-REGIONAL APPLIED GENERAL EQUILIBRIUM MODEL
}

\author{
Author: MARCOS MINORU HASEGAWA \\ Advisor: Prof. Dr. JOAQUIM JOSÉ MARTINS GUILHOTO
}

\section{SUMMARY}

The Applied General Equilibrium Models (AGE model) are useful to analyze the impact of public policy on the nationwide economy without loss of details in sector level. The Inter-regional AGE models give additional details in regional level, which is interesting for the Brazilian public policy analysis due to the social and economic differences in regional level. Thus, the Inter-regional Applied General Equilibrium Model for the Brazilian Economy - MIBRA, a regional AGE model, is used in order to analyze the public policy proposal presented by the new Brazilian president elected, Luiz Inácio Lula da Silva, who will govern from 2003 until 2006. The specific aim of this research is the incorporation of endogenous investment in the MIBRA model. This modification improves both static-comparative and recursive-dynamic analysis. The basic hypothesis verified in this research is: the success of public policy proposed by the new federal government depends on the increase of governmental investment and expenditure combined with productivity growth of primary factors. In this research the MIBRA model is used with sixteen sectors and five Brazilian macro-regions. The MIBRA model database was constructed based on the Brazilian regional input-output matrix of 1995 and as well as on other statistics and information from Instituto 
Brasileiro de Geografia e Estatística, Banco Central do Brasil, Fundação Getúlio Vargas and many research papers. According to the Homogeneity test, the MIBRA model is consistent. The results have shown that the increase of $5.5 \%$ in the nominal wage worsens the Brazilian economic performance, concerning the public policy proposed by the new federal government. The increase of expenditure by the federal government combined with the increase of investments concentrated in the North and Northeast regions, is not efficient for the Brazilian Economy in regional and national levels if compared with less concentrated allocation among regions. This result shows that the Southeast and South regions must grow along with the other regions. This is due to the need of inputs and capital goods for production in the less developed regions be supplied by developed regions, specially the Southeast region. The increase of productivity of production factors is important for the success of the public policy proposed by the new federal government. Hence, the combination of the increase of government expenditure and investment with production factor productivity can assure the desirable development and growth of the Brazilian economy in the mid and long term. Which means, the policy suggested by results increases the real gross national product and the real consumption, decreases unemployment and, keeps the inflation and the governmental financing needs under control. The sustained development and economic growth policy must enforce the conversion of part of public expenditure into both social improvement and higher labor productivity. The Inter-regional AGE models have shown to be powerful tools for the public policy formulations in countries that need to solve social and economic differences in sector and regional level like Brazil. 


\section{INTRODUÇÃO}

Os Modelos Aplicados de Equilíbrio Geral (AEG) são instrumentos de análise importantes para o planejamento público e privado. Os modelos AEG permitem analisar o impacto das políticas governamentais em nível setorial. Se o modelo é interssetorial e inter-regional, é possível realizar análises em nível regional, o que é de grande importância para a análise das diferenças regionais da economia brasileira. Além da análise de estática comparativa, os modelos AEG são utilizados na obtenção de previsões de variáveis econômicas, o que é importante tanto para o setor privado como para o setor público da economia de qualquer país. Para tanto, o modelo AEG precisa incorporar o caráter dinâmico através das equações que modelam o investimento e a acumulação do capital. É com base nos resultados dos modelos AEG que as empresas podem realizar o planejamento das suas atividades durante o ano fiscal e no período maior que um ano fiscal para posicionarem-se no mercado, realizarem ou não novos investimentos. É também com base nos modelos AEG que o setor público pode planejar os seus investimentos, orientar as suas políticas para os diferentes setores da economia e para os distintos grupos da população. Adicionalmente, os modelos dinâmicos AEG são úteis também para a análise de políticas públicas ao longo do tempo, bem como para obtenção de previsões econômicas.

De forma geral, as previsões de variáveis econômicas têm sido obtidas através dos modelos econométricos e dos modelos de séries temporais. Apesar do bom desempenho destes modelos na realização de previsões, os mesmos simplificam a realidade e por isso muitos detalhes são perdidos. Além disso, qualquer mudança em termos de preços relativos, como por exemplo o aumento dos custos com energia devido à crise do petróleo ocorrida na década de setenta, podem ser captadas pela função de produção dos 
diferentes setores (Dixon \& Parmenter, 1996). Utilizando-se os modelos aplicados de equilíbrio geral interssetorial e inter-regional, consegue-se obter informações mais detalhadas que podem ser de maior interesse tanto para a empresa como para o governo.

Dentro dos modelos AEG, destacam-se os modelos que seguem a tradição de Johansen, também denominados modelos AEG da classe Johansen-Orani. Neste tipo de modelo AEG, as equações são linearizadas e, por isso, os resultados apresentados na forma de taxas de crescimento.

O Modelo Inter-regional para a Economia Brasileira (MIBRA), desenvolvido desde 1999 pelo Departamento de Economia, Administração e Sociologia da Escola Superior de Agricultura "Luiz de Queiroz"-USP, segue a tradição de Johansen e tem gerado resultados interessantes em termos de análise de estática comparativa (Casimiro Filho et al., 2000). O modelo MONASH-MRF desenvolvido para a economia australiana, no qual é baseado o modelo MIBRA, tem sido utilizado tanto para a análise de estática comparativa como para a obtenção de previsões setoriais regionais(Navqi \& Peter, 1996). Na Revisão de Literatura foi encontrado apenas o próprio modelo MIBRA com tratamento exóge no do investimento, que foi utilizado para verificar o impacto da restrição da emissão de poluentes sobre a atividade econômica brasileira (Guilhoto et al., 2002). Por isso é mais do que oportuno melhorar cada vez mais o modelo para que se permita obter previsões também com tratamento endógeno do investimento.

No Capítulo 2 é realizada uma breve revisão sobre a economia brasileira nas décadas de oitenta e noventa, discutem-se o uso de modelos econométricos e de modelos AEG, além da abordagem sobre os modelos aplicados de equilíbrio geral desenvolvidos para a economia brasileira e os modelos AEG dinâmicos. No Capítulo 3, é apresentado o modelo MIBRA, o seu banco de dados, as pressuposições, a eliminação do erro de linearização, as suas equações, uma breve apresentação dos módulos que constituem os blocos de equações do modelo e detalhes sobre o fechamento do modelo. É dada especial atenção aos blocos de acumulação de capital e investimento. Uma breve apresentação sobre a análise de sensibilidade também é apresentada no final do Capítulo 3. No Capítulo 4 são apresentados e discutidos os resultados e, no Capítulo 5, têm-se as conclusões e sugestões para pesquisas futuras. 


\subsection{Objetivos}

O objetivo principal deste trabalho é analisar as políticas governamentais para a economia brasileira utilizando o Modelo Inter-regional da Economia Brasileira (MIBRA), tendo como referência as propostas do novo governo federal que são de caráter mais social.

O objetivo específico é incorporar um tratamento endógeno do investimento que permita melhorias tanto para a análise de estática comparativa como para a análise dinâmica de políticas e obtenção de previsões para a economia brasileira.

\subsection{Hipótese}

A hipótese básica deste trabalho é que as políticas públicas orientadas para o social não proporcionam benefícios para a economia brasileira se não forem realizadas com a combinação de investimentos e gastos do governo e aumentos de produtividade dos fatores de produção, especialmente do fator trabalho. 


\section{REVISÃO DE LITERATURA}

\subsection{A Economia Brasileira nos anos 80 e 90}

Nesta seção são apresentados alguns números de natureza geográfica, demográfica e, principalmente, econômica que caracterizam a população e a economia brasileira nos anos 80 e 90 . O Brasil é um país de dimensões continentais como pode ser observado na Tabela 1. Quase metade da área do Brasil está na região Norte. Mas, por outro lado, a sua população não está bem distribuída. As maiores densidades populacionais são encontradas nas regiões Sudeste e Sul. A região Norte é a menos densa.

Tabela 1. Área, População e Densidade Demográfica do Brasil por grandes regiões.

\begin{tabular}{|c|c|c|c|c|}
\hline & $\begin{array}{c}\text { Área } \\
(\mathrm{km} 2)\end{array}$ & $\%$ & $\begin{array}{c}\text { População } \\
\text { (hab. em 1997) }\end{array}$ & $\begin{array}{l}\text { Densidade } \\
\text { (hab/km2) }\end{array}$ \\
\hline Brasil & $8.547 .403,5$ & 100,00 & 156.128 .003 & 18,27 \\
\hline Norte & $3.869 .637,9$ & 45,27 & 7.357 .494 & 1,90 \\
\hline Nordeste & $1.561 .177,8$ & 18,26 & 45.448 .490 & 29,11 \\
\hline Sudeste & $927.286,2$ & 10,85 & 68.280 .153 & 73,63 \\
\hline Sul & $577.214,0$ & 6,75 & 23.932 .379 & 41,46 \\
\hline Centro-Oeste & $1.612 .077,2$ & 18,86 & 10.823 .207 & 6,71 \\
\hline
\end{tabular}

Fonte: Anuário Estatístico do Brasil (1998)

A população residente brasileira que totalizava menos de 120 milhões de habitantes em 1980 (Figura 1) aumenta para mais de 160 milhões de habitantes no ano 2000 , que se traduz num aumento superior a 30\% na população residente em 20 anos. 


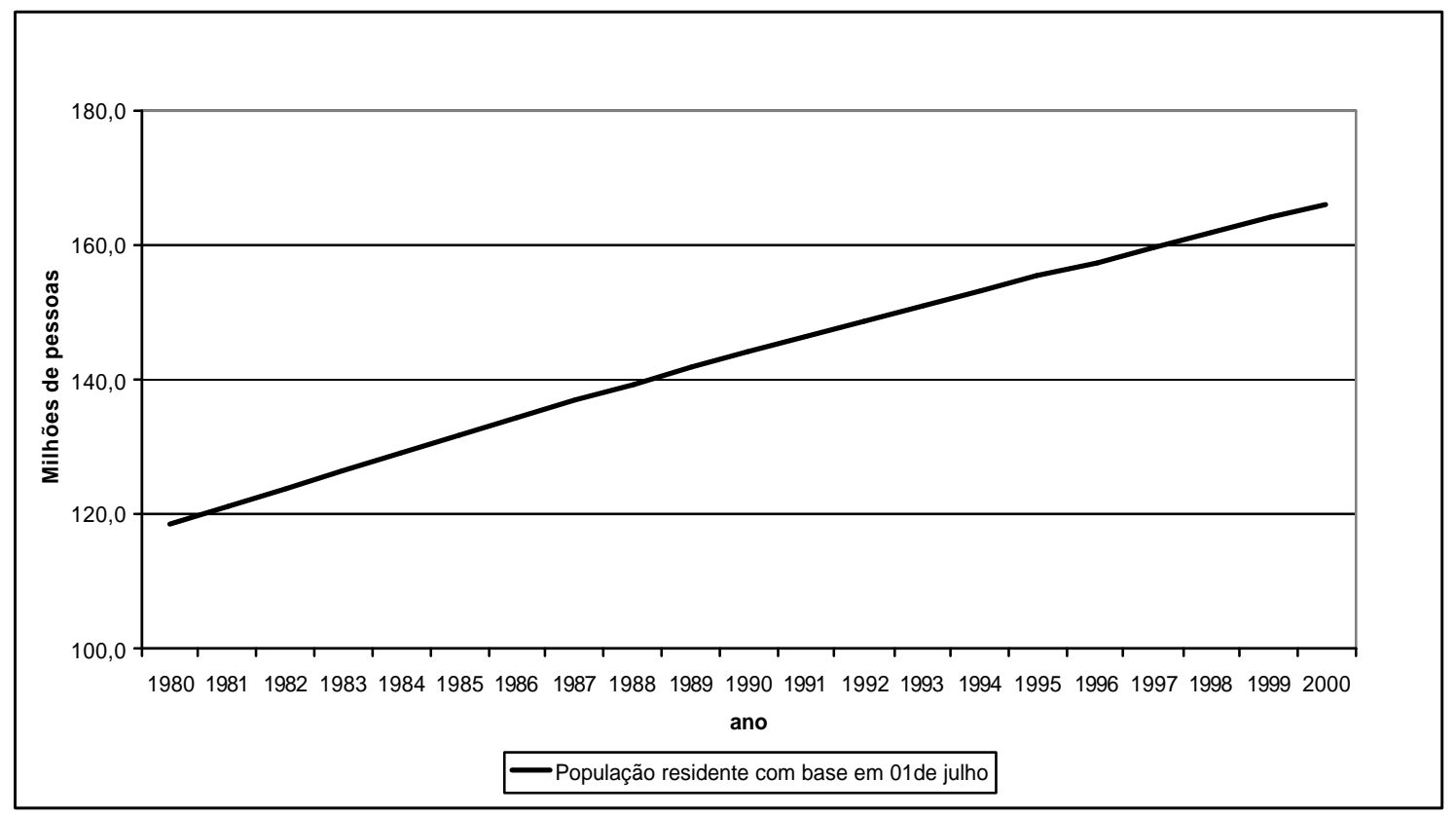

Figura 1 - População residente brasileira em milhões de pessoas de 1980 a 2000, com base no dia primeiro de julho.

Fonte: Instituto de Pesquisa Econômica Aplicada - IPEA (2001)

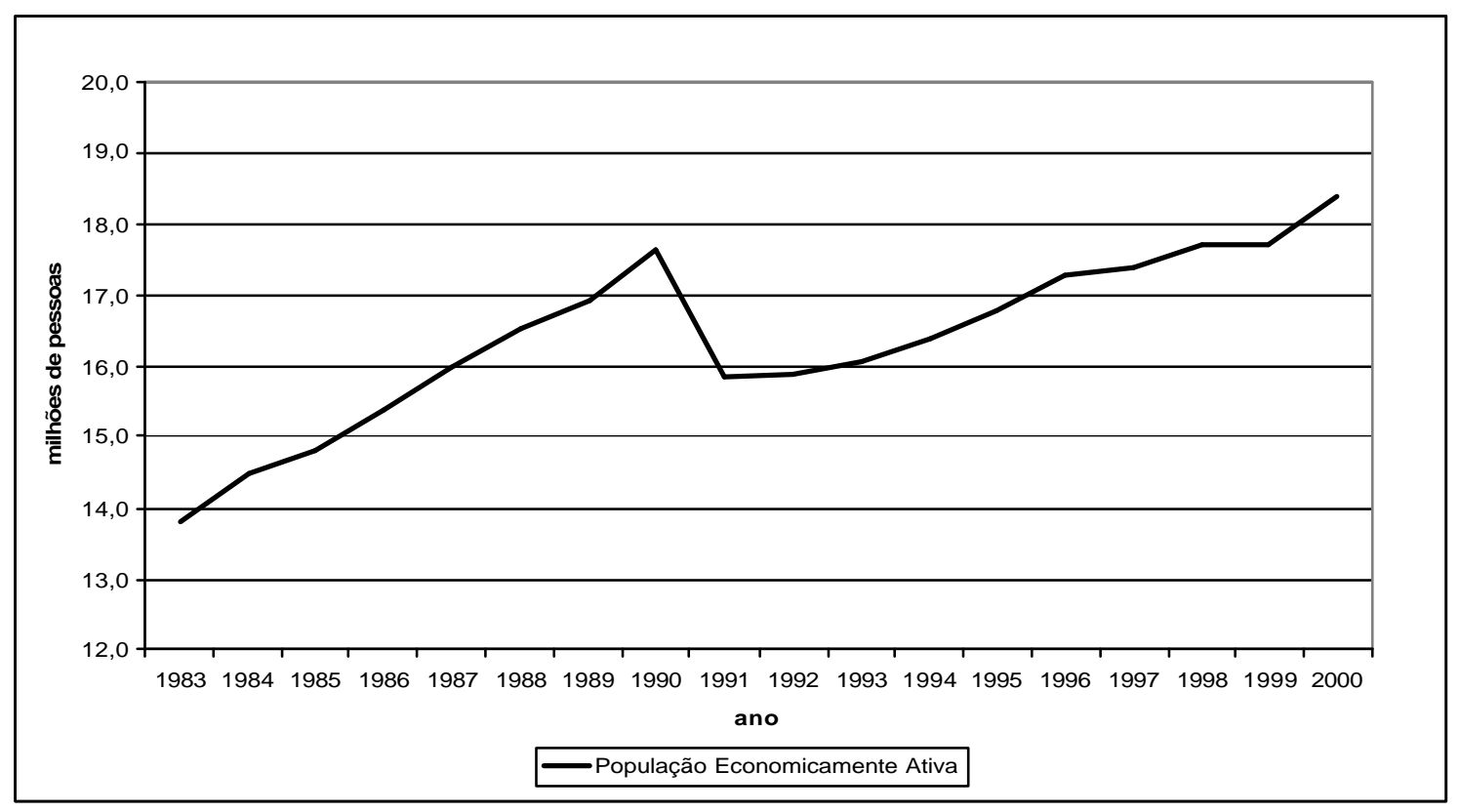

Figura 2 - População economicamente ativa, média anual de 1980 a 2000.

Fonte: IPEA (2001) 
Desta população em 1980, de acordo com a Figura 2, menos de 14 milhões de pessoas eram consideradas economicamente ativas e em 2000 houve um incremento de mais de 4 milhões de pessoas economicamente ativas. Ou seja, um aumento de aproximadamente $30 \%$.

Para um melhor entendimento, antes de entrar nos números econômicos, é interessante lembrar quando e como foram os vários planos econômicos aplicados na economia brasileira nos anos 80 e 90 para entender melhor as variações ocorridas nas principais variáveis macroeconômicas. De acordo com o Depec (2000), foram seis planos econômicos e dois programas de 1986 a 2000: o Plano Cruzado em fevereiro de 1986 aplicado pelo ministro da fazenda Dílson Funaro no governo de José Sarney; o Plano Bresser em junho de 1987 aplicado pelo ministro da fazenda Luis Carlos Bresser Pereira no governo de José Sarney; o Plano Verão em janeiro de 1989 aplicado pelo ministro da fazenda Maílson da Nóbrega ainda no governo de José Sarney; Plano Collor I em março de 1990 aplicado pela ministra da fazenda Zélia Cardoso de Mello no governo do recém-empossado Fernando Collor de Mello; o Plano Collor II em janeiro de 1991 aplicado pela Ministra da Fazenda Zélia Cardoso de Mello no governo de Fernando Collor de Mello; o Programa de Ação Imediata (PAI) em 1993 aplicado pelo ministro da fazenda Fernando Henrique Cardoso no governo de Itamar Franco; o Plano Real no final de junho de 1994 aplicado pelo ministro da fazenda Rubens Ricúpero ainda no governo de Itamar Franco, medidas complementares ao Plano Real aplicadas em junho de 1995 já pelo ministro da fazenda Pedro Malan no governo de Fernando Henrique Cardoso e o Programa de Estabilização Macroeconômica em outubro de 1998 também aplicado pelo ministro da fazenda Pedro Malan.

Estes planos econômicos e programas tinham como principal objetivo a redução da inflação, um dos principais problemas na economia brasileira. A maioria dos planos econômicos tentou controlar a inflação através de congelamento de preços, combinado com a redução da liquidez, e da tentativa de eliminar a indexação de preços. A inflação foi efetivamente controlada com a aplicação do Plano Real. Um discussão mais detalhada sobre o mecanismo utilizado no plano Real para reduzir a inflação é apresentada na seção seguinte. Nos últimos planos econômicos, além de tentar controlar 
a inflação, foi dada uma atenção especial a outros problemas importantes como o controle dos gastos públicos, as reformas estruturais e até a mudança do papel do Estado como é levantado no Plano Real ${ }^{1}$. Os gastos públicos, ao contrário da inflação, não estão sendo efetivamente controlados e reduzidos.

Como fatores externos, as crises no mercado financeiro internacional afetaram significativamente a economia brasileira na década de noventa. As crises foram: a Crise do México no primeiro semestre de 1995, a Crise da Ásia no segundo semestre de 1997 , a Crise da Rússia no segundo semestre de 1998 e a crise na Argentina no segundo semestre de 1999. É interessante lembrar que o mercado brasileiro também passou por uma crise no início do primeiro semestre de 1999.

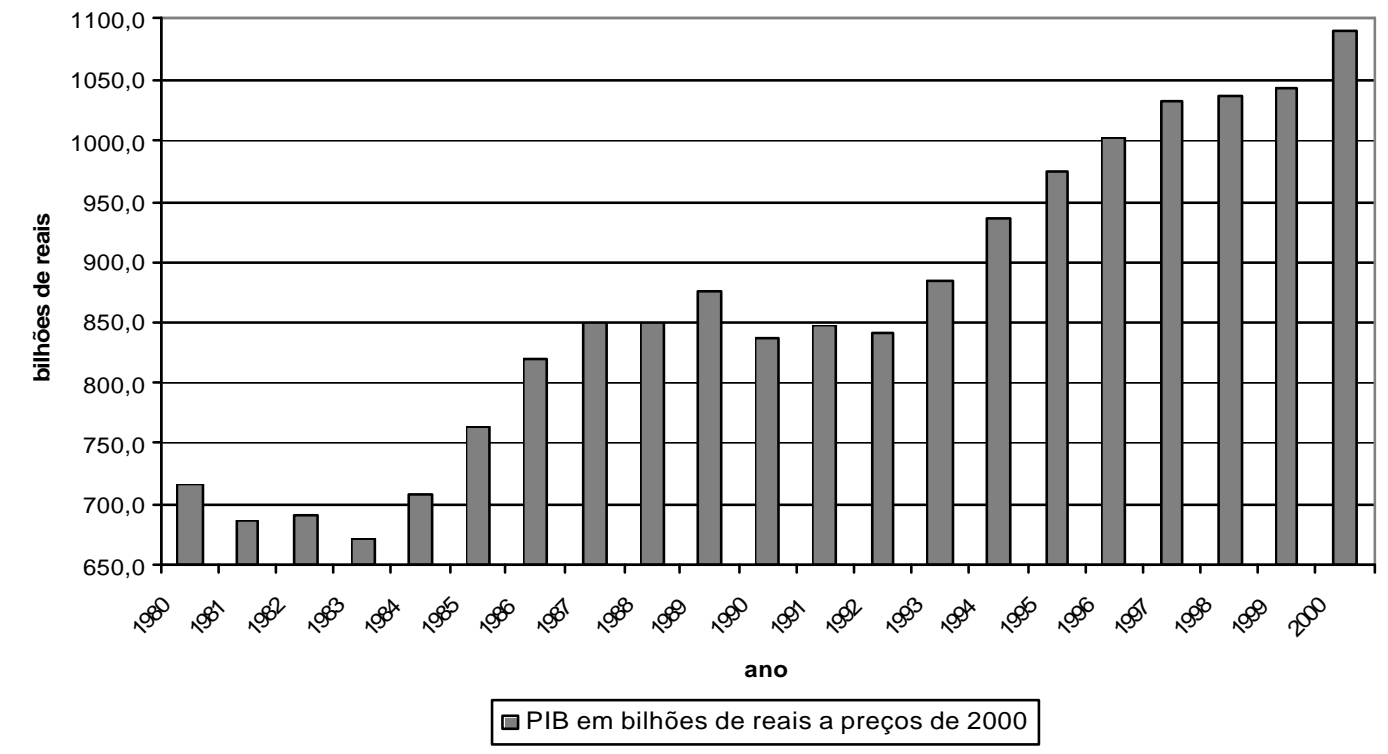

Figura 3 - PIB anual em dólares de 1980 a 2000.

Fonte: IPEA (2001)

Na seqüência são apresentadas algumas estatísticas macroeconômicas dos anos 80 e 90 para entender a trajetória da economia brasileira considerando as várias tentativas de controle da inflação. Na Figura 3 é apresentado o PIB em reais de 2000 no período de 1980 a 2000. Os maiores valores do PIB entre 1980 e 2000 são observados

\footnotetext{
${ }^{1}$ Informações mais detalhadas de cada plano econômico citado podem ser encontrados em Depec(2000).
} 
após o Plano Real, sendo que de 1998 a 1999 as variações foram muito pequenas. As variações negativas ocorreram tanto no início da década de oitenta como no início da década de noventa.

Como a inflação em toda a década de oitenta e início da década de noventa foi muito alta, foi necessário aplicar logaritmo de base 100 na taxa de câmbio do Real em relação ao Dólar comercial para venda e no Índice Geral de Preços - Disponibilidade Interna (IGP-DI) da Fundação Getúlio Vargas para tornar visível a evolução tanto da taxa de câmbio como da inflação ao longo das duas décadas apresentada na Figura 4. Note que a base 100 do IGP-DI está em agosto de 1994, um mês depois da aplicação do Plano Real. A variação da inflação foi reduzida efetivamente após a aplicação do Plano Real.

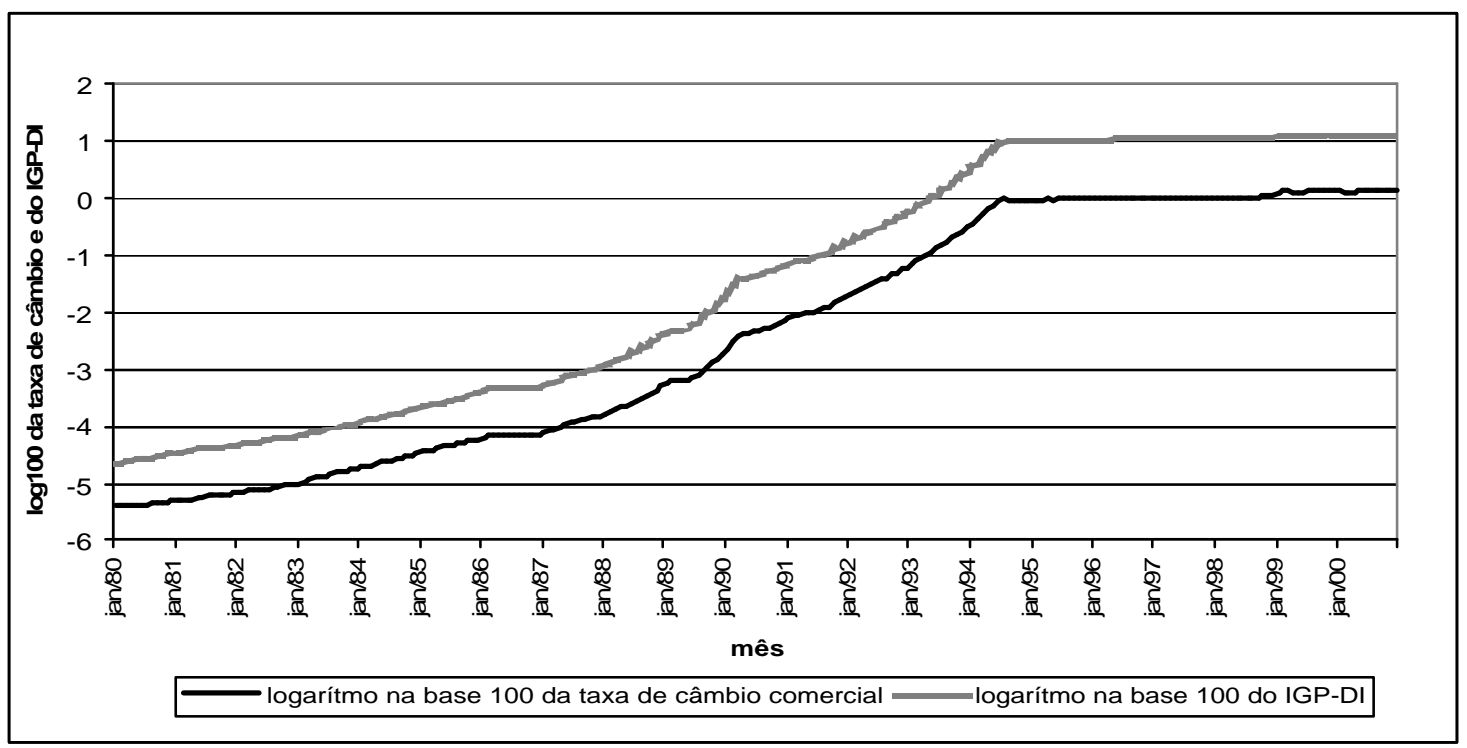

Figura 4 - Índice Geral de Preços - disponibilidade interna (IGP-DI) mensal e a taxa de câmbio comercial do Real em relação ao Dólar, média mensal para venda, para o período de janeiro de 1980 a dezembro de 2000, transformados em logarítmos na base 100 .

Fonte: Conjuntura Econômica (2001) e Banco Central do Brasil - BCB (2001)

A taxa de câmbio do Real em relação ao Dólar tem, de acordo com a Figura 4, uma evolução muito parecida com a inflação medida pelo IGP-DI. Para a taxa de câmbio 
também foi utilizada a transformação logarítmica para uma melhor visualização da evolução da taxa de câmbio ao longo das duas décadas.

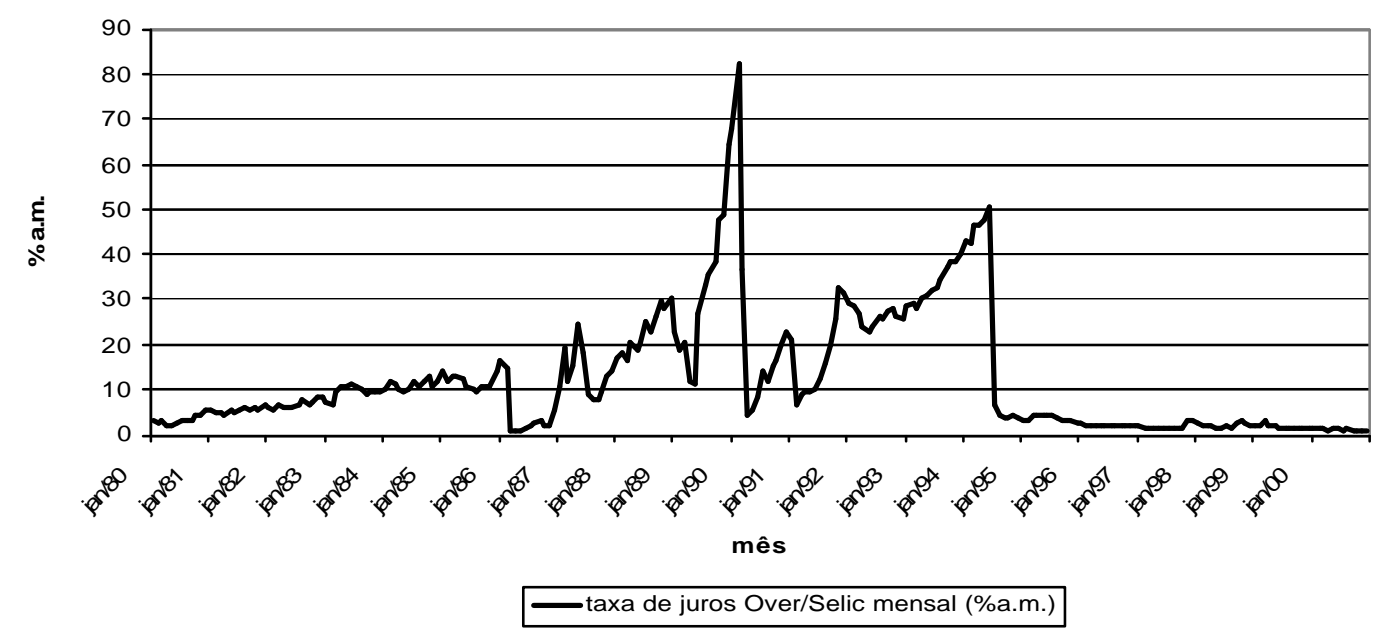

Figura 5 - Taxa de juros Over/Selic mensal de 1980 a 2000.

Fonte: BCB (2001)

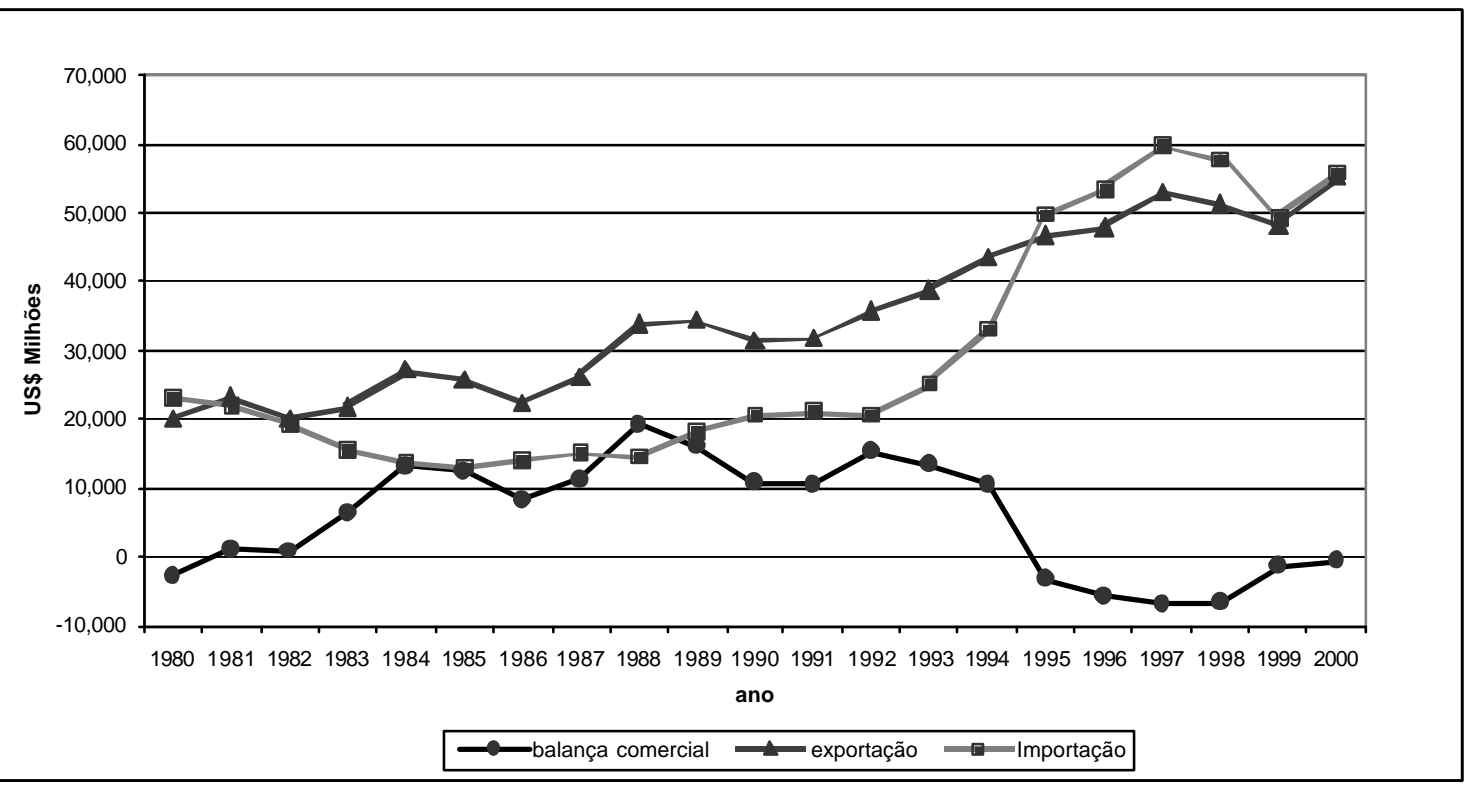

Figura 6 - Balança Comercial, Exportação e Importação Brasileira em milhões de dólares de 1980 a 2000.

Fonte: BCB (2001) 
A taxa de juros Over/Selic mensal apresentada na Figura 5 em porcentagem ao mês mostra a evolução do custo do dinheiro na economia brasileira nas décadas de oitenta e noventa.

Associado a taxa de câmbio, verifica-se na Figura 6 a situação bastante favorável para a balança comercial nos anos de 1982 a 1994. Note que os picos observados na balança comercial acompanham de forma bem próxima os picos de taxas de juros observados na Figura 5.

Esta balança comercial bastante favorável é responsável pela reserva internacional um pouco antes da implantação do Plano Real, observada na Figura 7. Note que as reservas internacionais poderiam ser melhores devido ao bom desempenho do país em termos de balança comercial. Mas como é possível verificar na Figura 8, o Brasil teve anos de balanço de pagamentos negativos que explicam em boa parte a ausência de aumentos expressivos das reservas internacionais nestes mesmos anos, observada na Figura 9. As reservas internacionais foram muito importantes no sucesso do Plano Real, principalmente, para suportar o impacto da Crise Mexicana em função da política cambial adotada.

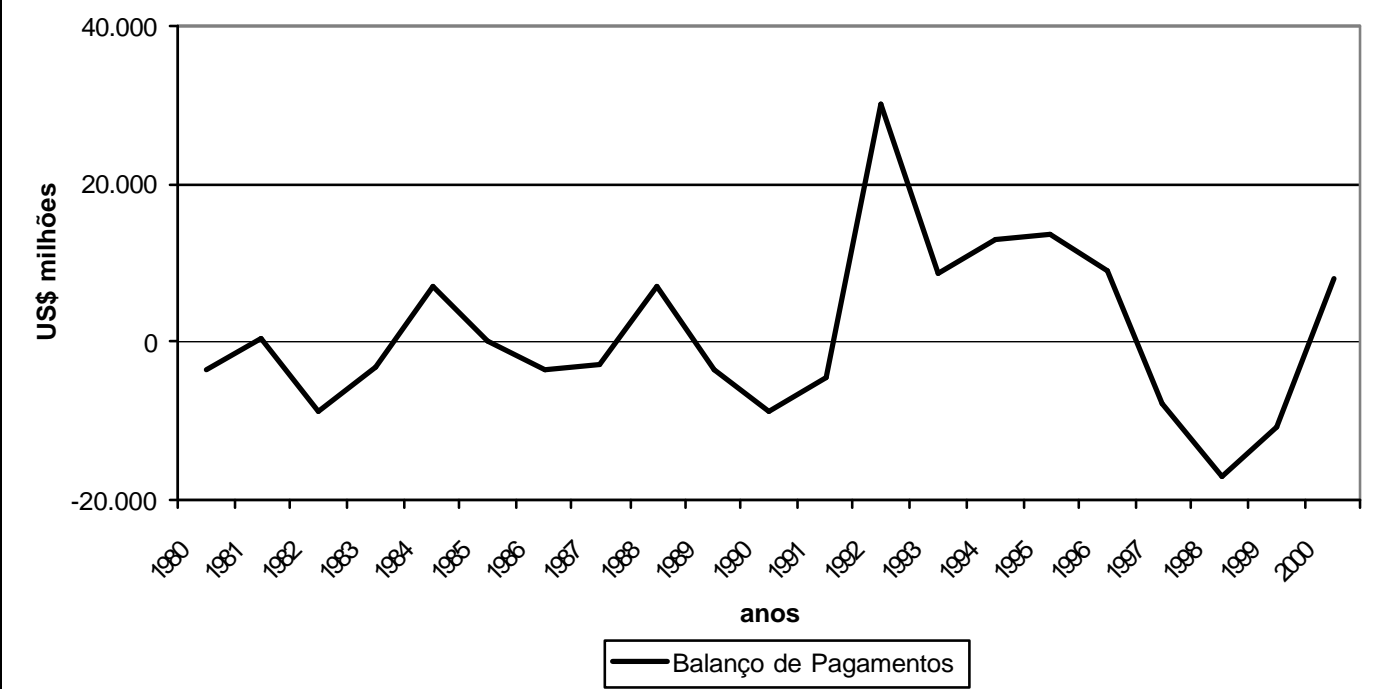

Figura 7 - Balança de pagamentos em milhões de dólares de 1980 a 2000.

Fonte: BCB (2001) 


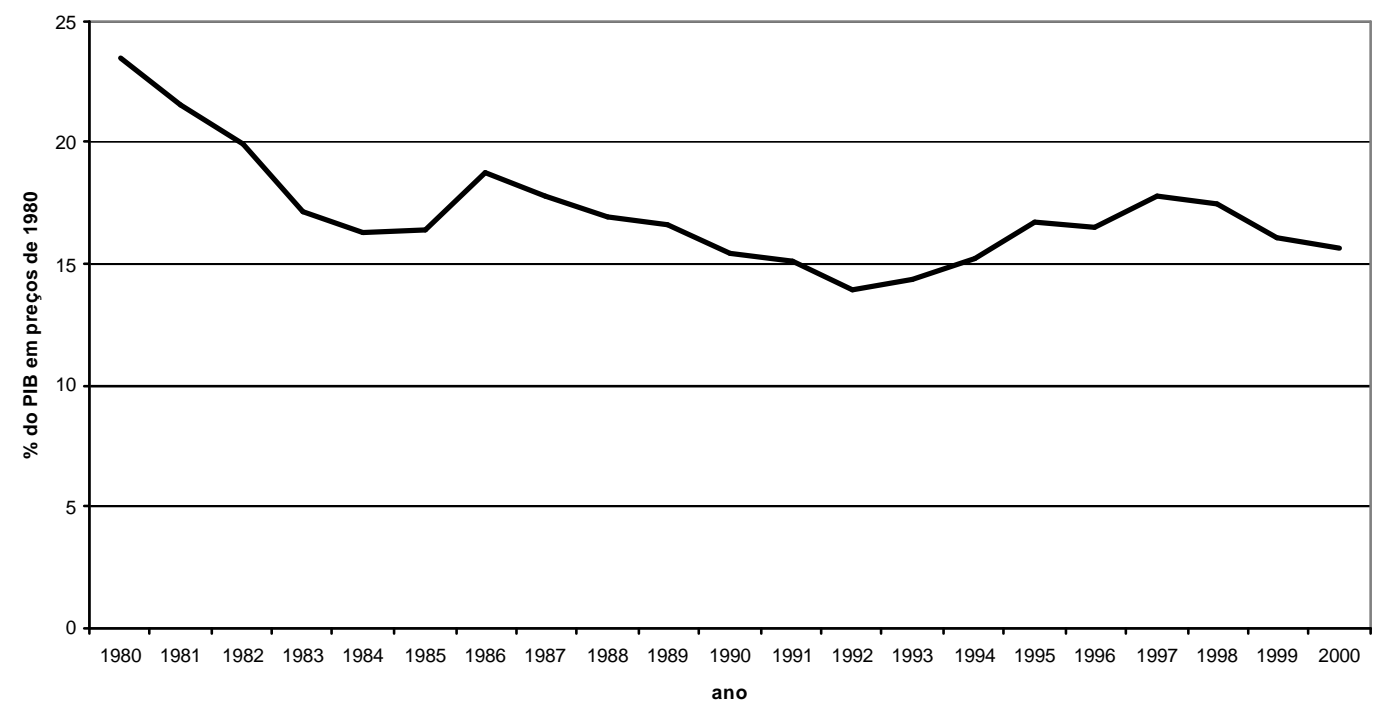

Taxa de investimento

Figura 8 - Taxa de investimento em porcentagem do PIB de 1980 a 2000.

Fonte: IPEA (2001)

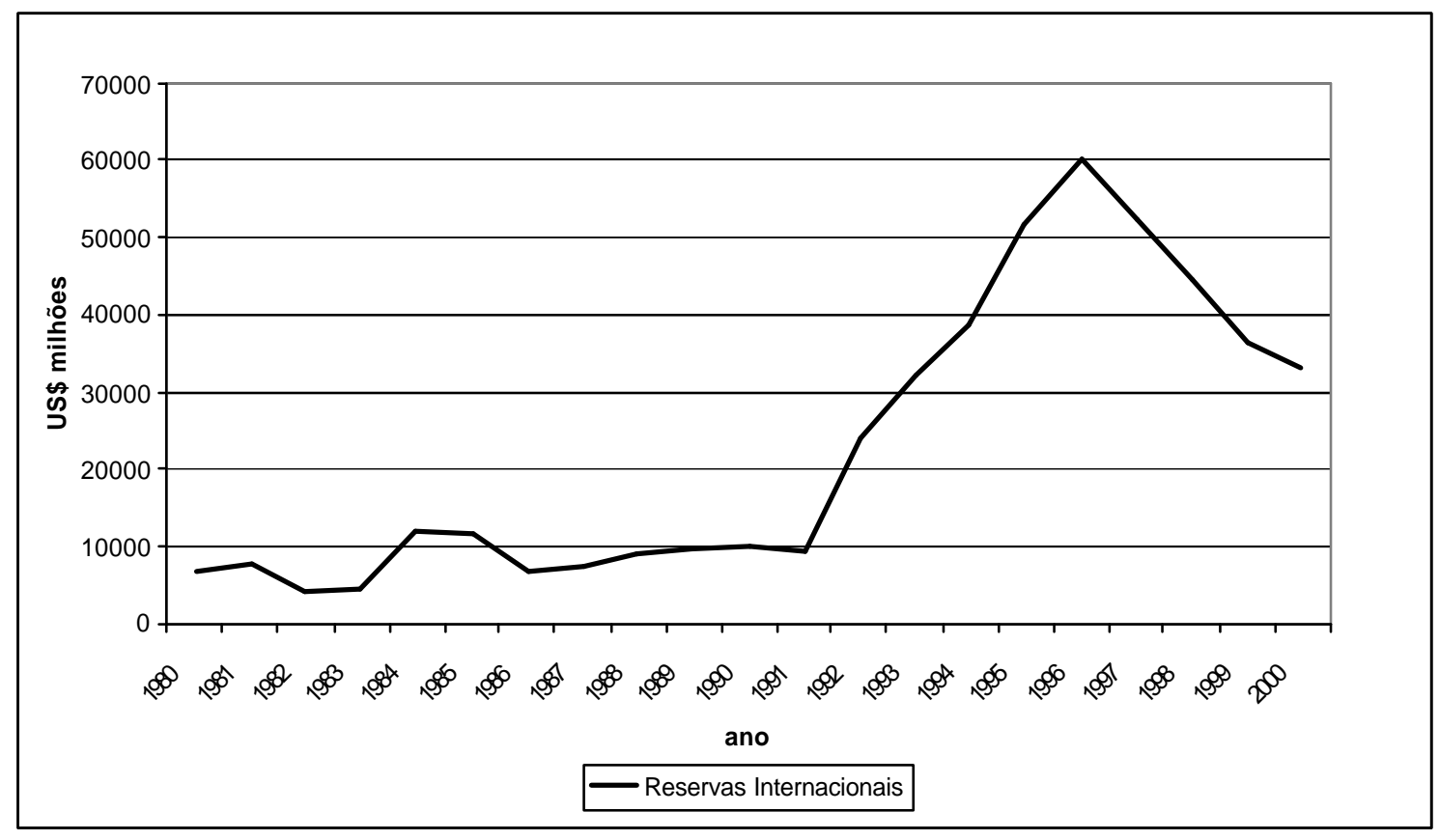

Figura 9 - Reservas Internacionais em milhões de dólares de 1980 a 2000.

Fonte: BCB (2001) 


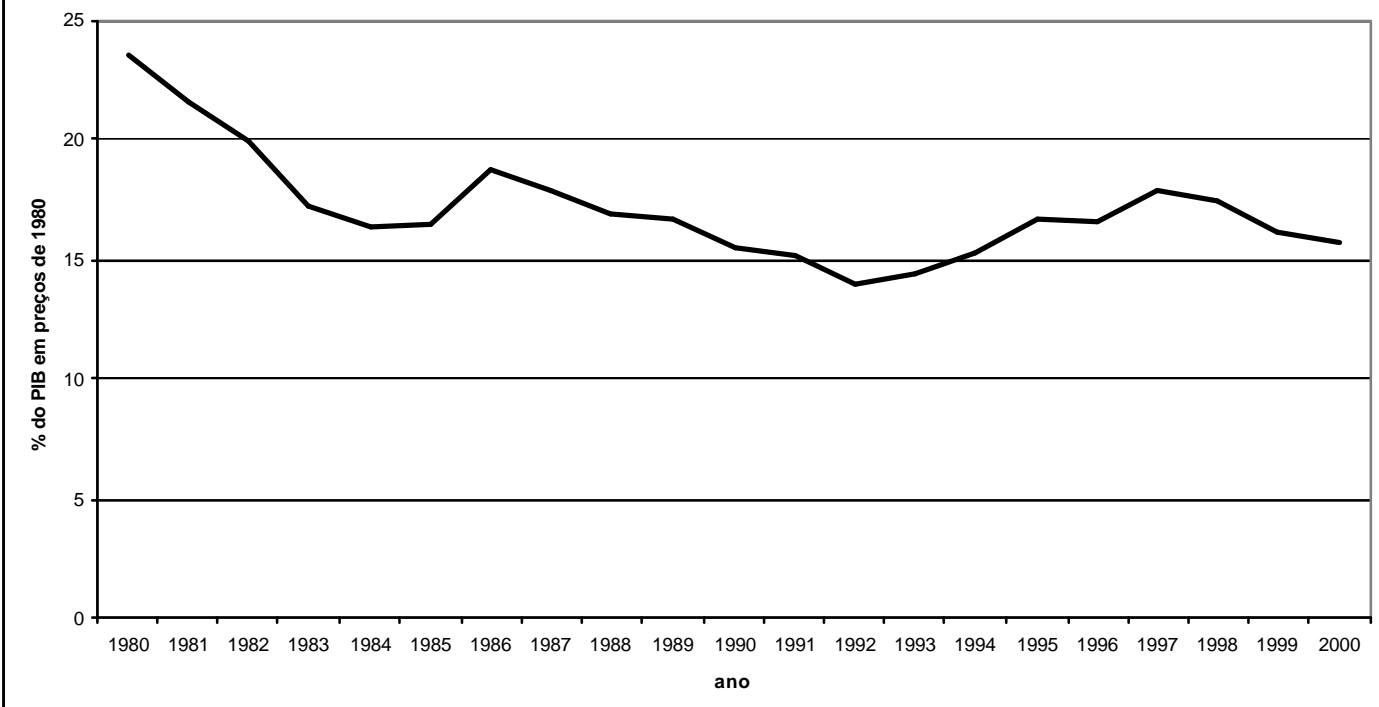

Taxa de investimento

Figura 10 - Taxa de investimento em termos de porcentagem do PIB anual de 1980 a 2000.

Fonte: IPEA (2001)

De acordo com o Figura 10, é possível verificar que apesar dos problemas com altas taxas de inflação no início da década de noventa, a taxa de investimento em termos de porcentagem do PIB apresentou tendência de aumento enquanto que na década de oitenta foi nitidamente declinante. Em parte esta tendência de aumento da taxa de investimento pode ser verificada no índice de produção industrial apresentada na Figura 11. Através do índice de produção industrial podem ser verificados os impactos dos planos econômicos, principalmente Collor I e Collor II, e das crises econômicas externas, como a mexicana, a economia brasileira.

As finanças públicas têm sido muito discutidas a partir de 1995, pois o sucesso do Plano Real e o bom desempenho da economia brasileira dependem do bom desempenho das finanças públicas, principalmente os gastos públicos. 


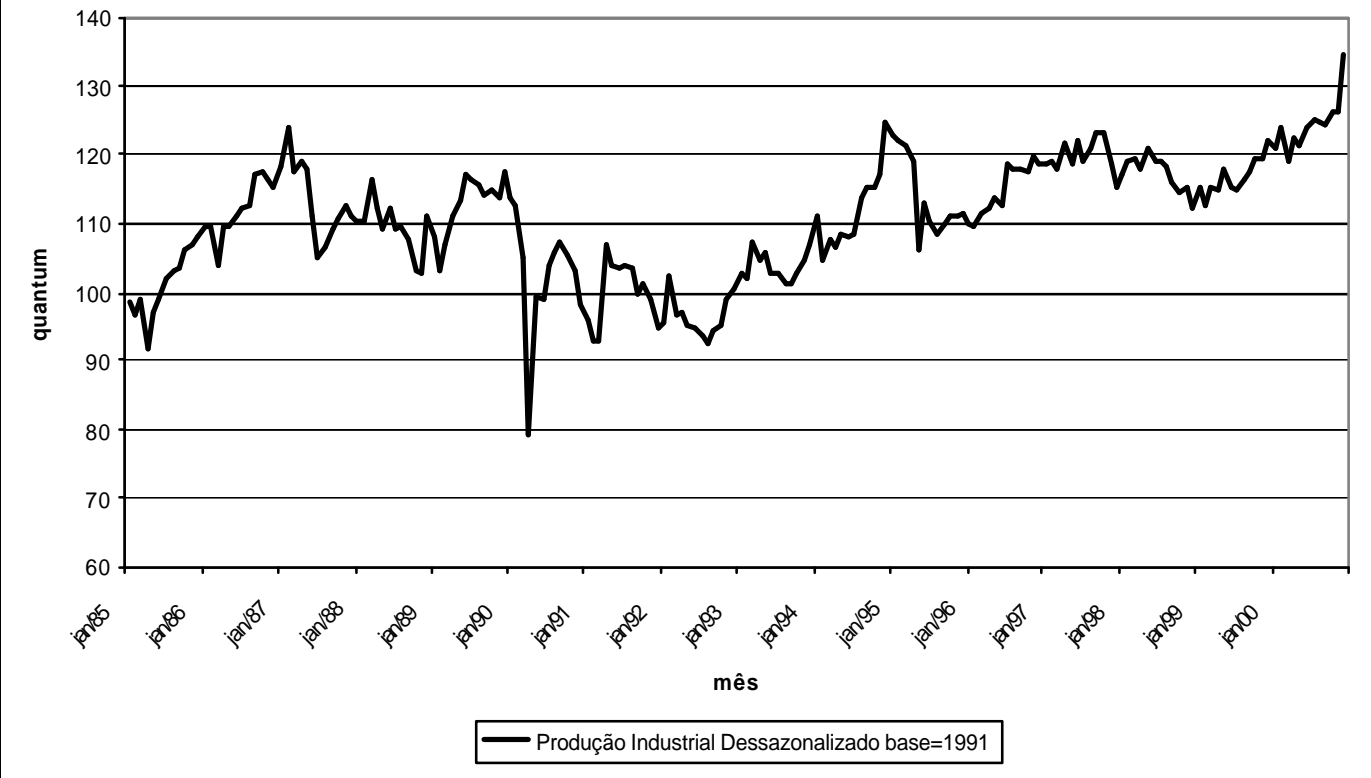

Figura 11 - Índice dessazonalizado mensal da produção Industrial, de janeiro de 1985 a dezembro de 2000 - ano base em 1991.

Fonte: IPEA (2001)

Para ilustrar bem a situação das finanças públicas nas décadas de oitenta e noventa são apresentadas a dívida total líquida do setor público e a necessidade de financiamento do setor público nas Figuras 12 e 13 respectivamente, ambas em termos de porcentagem do PIB. A dívida do setor público aumentou consideravelmente a partir de janeiro de 1998. Pela piora da situação macroeconômica brasileira e das finanças públicas, o governo implantou no final de 1998 o Programa de Estabilização Macroeconômica que parece ter melhorado sensivelmente a necessidade de financiamento do setor público e estabilizado a dívida total líquida do setor público.

No gráfico 14 é possível perceber que apesar da elevada inflação a taxa de desemprego aberto vinha caindo consideravelmente ao longo da década de oitenta. Nos anos 90 a taxa de desemprego começou a aumentar até atingir o mesmo patamar do início da década de oitenta. 


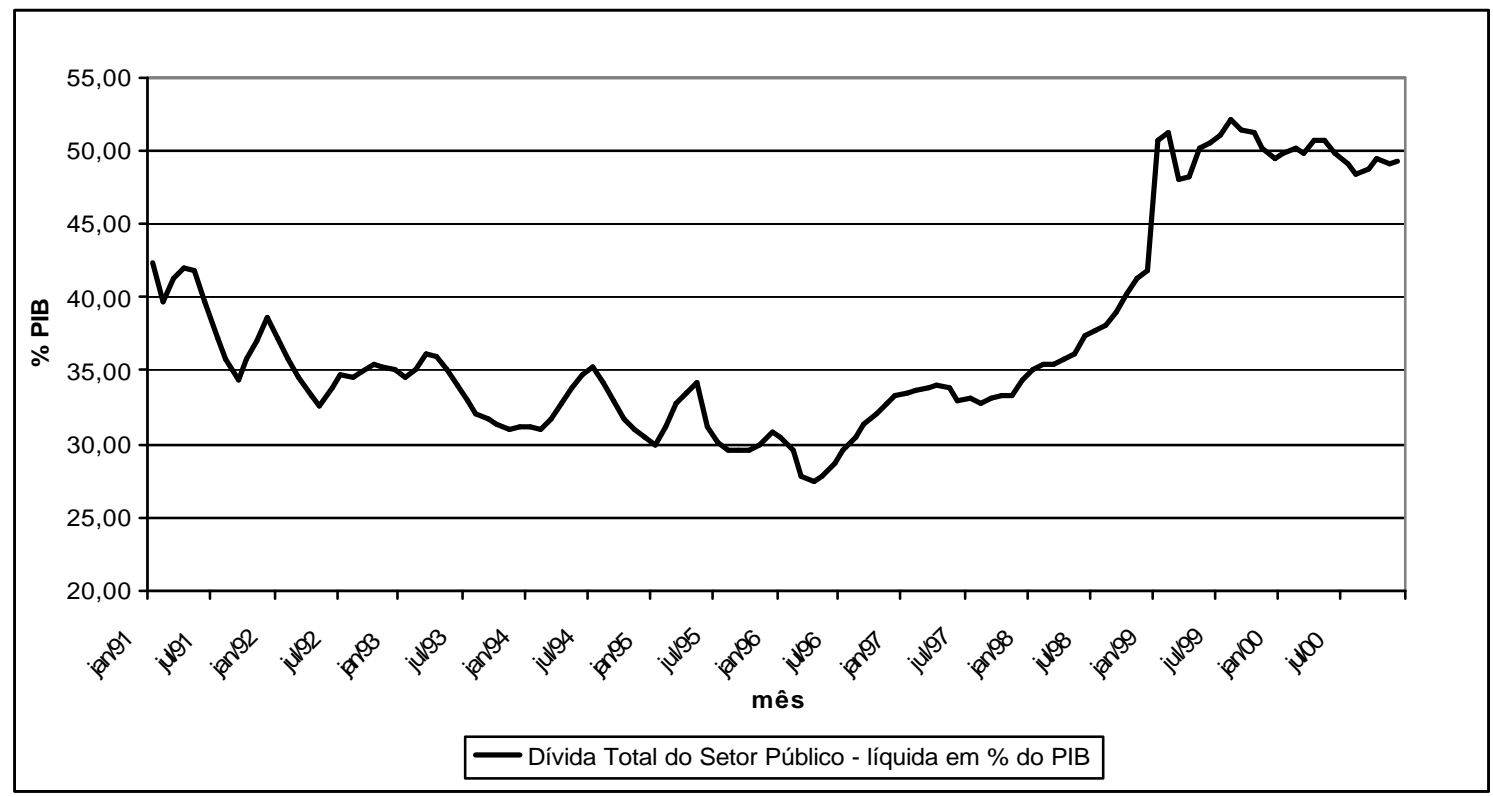

Figura 12 - Dívida total líquida do setor público mensal em porcentagem do PIB de janeiro de 1991 a dezembro de 2000.

Fonte: BCB (2001)

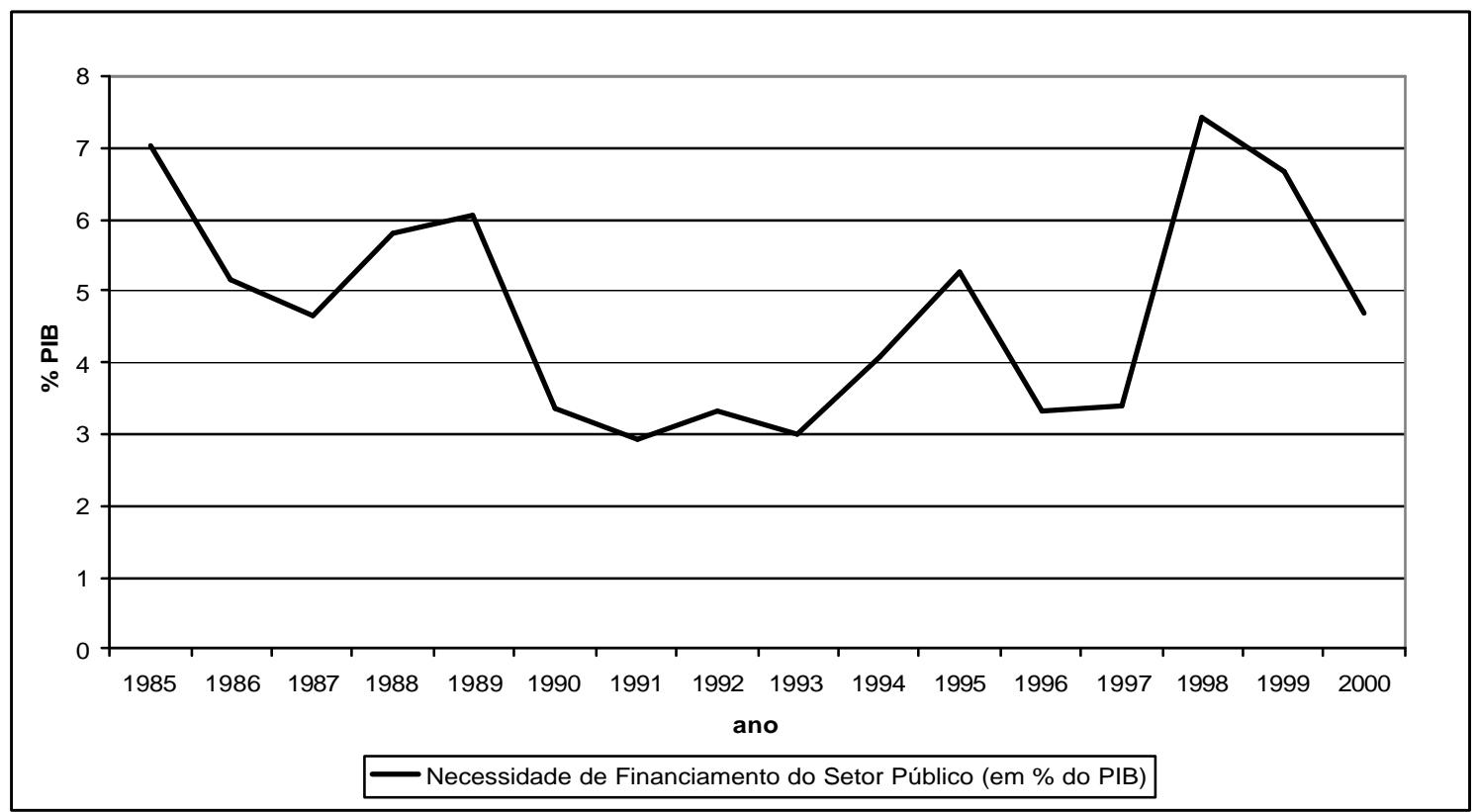

Figura 13 - Necessidade de financiamento do setor público em porcentagem do PIB de 1985 a 2000.

Fonte: BCB (2001) 


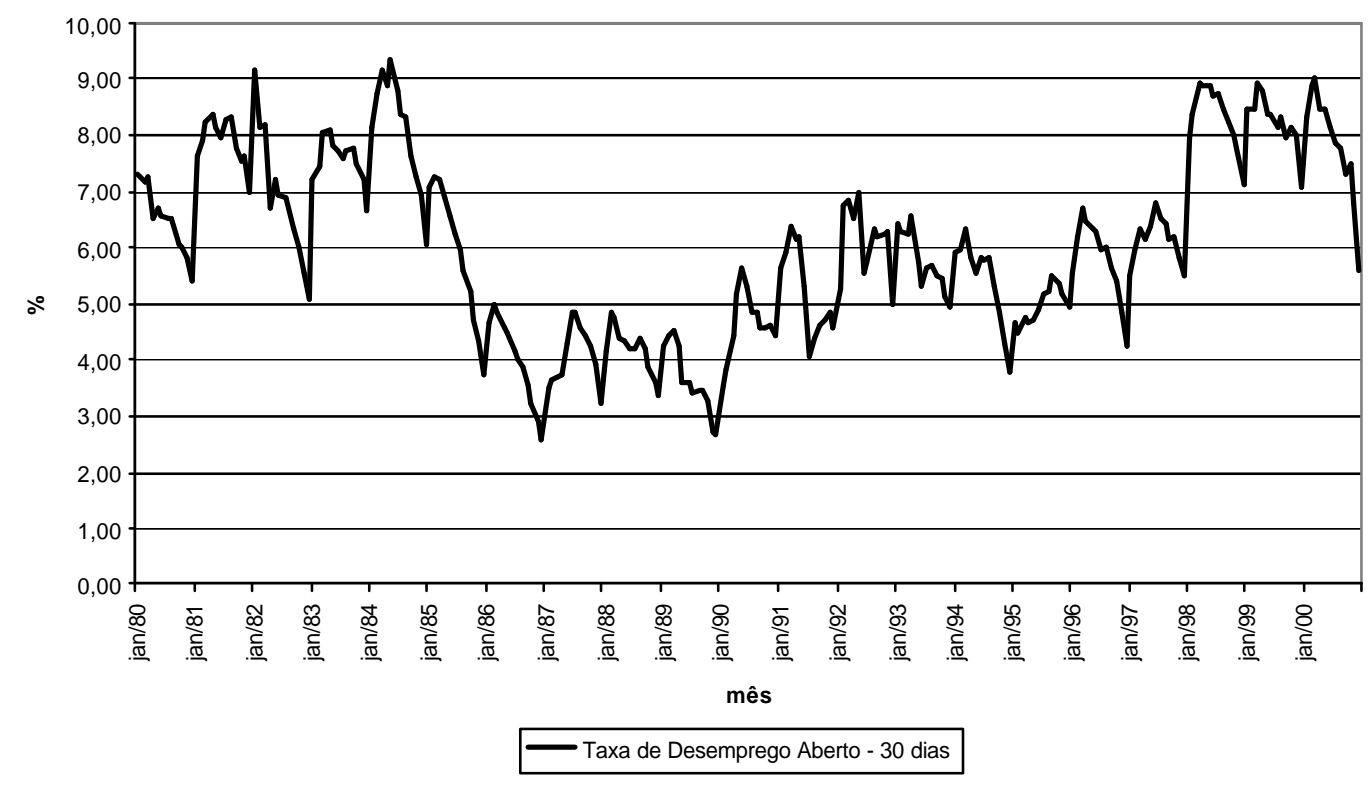

Figura 14 - Taxa de desemprego aberto (30 dias) mensal de 1980 a 2000.

Fonte: IPEA (2001)

$\mathrm{Na}$ seqüência são apresentadas algumas diferenças regionais brasileiras perceptíveis através dos números do PIB nas cinco macrorregiões apresentadas nas Tabelas 2 e 3. Destes dados vale destacar a importância da região Sudeste que responde por mais da metade do PIB brasileiro.

Tabela 2. PIB per capita em Reais no período de 1995 a 1998 no Brasil e nas grandes regiões em valores de 1999.

\begin{tabular}{lcccc}
\hline & 1995 & 1996 & 1997 & 1998 \\
\hline Brasil & 4160 & 4946 & 5455 & 5648 \\
& & & & \\
Norte & 2.705 & 3.188 & 3.318 & 3.447 \\
Nordeste & 1.861 & 2.287 & 2.513 & 2.603 \\
Sudeste & 5.726 & 6.734 & 7.492 & 7.706 \\
Sul & 4.966 & 5.958 & 6.451 & 6.611 \\
Centro-Oeste & 3.742 & 4.495 & 5.050 & 5.681 \\
& & & & \\
\hline
\end{tabular}

Fonte: IBGE (2001a) 
Tabela 3. PIB a preços de mercado em milhões de Reais no período de 1995 a 1998, no Brasil e nas grandes regiões em valores de 1999.

\begin{tabular}{lrrrr}
\hline & 1995 & 1996 & 1997 & 1998 \\
\hline Brasil & 646.191 & 778.886 & 870.743 & 913.734 \\
& & & & \\
Norte & 29.960 & 36.153 & 38.507 & 40.909 \\
Nordeste & 82.588 & 102.597 & 113.942 & 119.254 \\
Sudeste & 379.438 & 452.306 & 509.961 & 531.429 \\
Sul & 115.594 & 140.436 & 153.945 & 159.679 \\
Centro-Oeste & 38.611 & 47.394 & 54.389 & 62.463 \\
& & & & \\
\hline
\end{tabular}

Fonte: IBGE (2001b)

Silva \& Medina (1999) calcularam o PIB por unidades da federação e macrorregiões entre 1985 e 1998. A participação do PIB para cada macrorregião para período de 1985 a 1998 é apresentada na Tabela 4. Note que a região Sudeste é responsável por praticamente $60 \%$ do PIB brasileiro desde 1985. A região Centro-Oeste vem ganhando participação no PIB, saltando de 5,55\% em 1985 para 7,06\% em 1998. Existem algumas diferenças numéricas entre os valores calculados pelo IBGE e os números obtidos por Silva \& Medina (1999) que podem ser explicados pelas diferenças metodológicas dos seus respectivos cálculos.

Tabela 4. Participação percentual das cinco macrorregiões brasileiras no PIB a preços correntes de mercado de 1985 a 1998.

\begin{tabular}{rrrrrr}
\hline & Norte & Nordeste & Sudeste & Sul & Centro Oeste \\
\hline 1985 & 4,11 & 13,53 & 59,11 & 17,70 & 5,55 \\
1986 & 4,28 & 13,39 & 59,37 & 17,40 & 5,56 \\
1987 & 3,99 & 13,32 & 60,00 & 17,02 & 5,66 \\
1988 & 4,16 & 12,96 & 60,23 & 16,92 & 5,74 \\
1989 & 4,63 & 12,85 & 59,65 & 16,81 & 6,06 \\
1990 & 4,89 & 13,10 & 58,32 & 16,74 & 6,95 \\
1991 & 4,77 & 12,66 & 59,06 & 16,40 & 7,10 \\
1992 & 4,63 & 12,25 & 59,67 & 16,68 & 6,77 \\
1993 & 4,72 & 11,84 & 59,54 & 17,34 & 6,56 \\
1994 & 4,54 & 12,37 & 58,91 & 17,11 & 7,06 \\
1995 & 4,72 & 12,39 & 59,27 & 16,59 & 7,04
\end{tabular}


Tabela 4. Participação percentual das cinco macrorregiões brasileiras no PIB a preços correntes de mercado de 1985 a 1998.

\begin{tabular}{rrrrrr}
\hline & Norte & Nordeste & Sudeste & Sul & Centro Oeste \\
\hline 1996 & 4,70 & 12,35 & 60,16 & 15,85 & 6,94 \\
1997 & 4,72 & 12,26 & 60,24 & 15,82 & 6,96 \\
1998 & 4,83 & 12,62 & 59,60 & 15,88 & 7,06 \\
\hline
\end{tabular}

Fonte: Silva \& Medina (1999)

As desigualdades ou diferenças econômicas entre as regiões podem estar associadas ao desenvolvimento humano da população em cada uma destas regiões apresentadas na Tabela 5.

Tabela 5. Índice de Desenvolvimento Humano: comparações regionais para 1995 e 1996 no Brasil.

\begin{tabular}{lccc}
\hline & 1991 & 1995 & 1996 \\
\hline Brasil & 0,787 & 0,814 & 0,830 \\
& & & \\
Norte & 0,676 & 0,720 & 0,727 \\
Nordeste & 0,557 & 0,596 & 0,608 \\
Sudeste & 0,832 & 0,853 & 0,857 \\
Sul & 0,834 & 0,855 & 0,860 \\
Centro-Oeste & 0,817 & 0,839 & 0,848 \\
& & & \\
\hline
\end{tabular}

Fonte: Programa das Nações Unidas para o Desenvolvimento - PNUD (1998)

Estas diferenças ou desigualdades verificadas através dos números apresentados justificam o desenvolvimento e aplicação de modelos econômicos que possibilitem a análise da economia brasileira de forma regional, mas sem perder o enfoque nos problemas de natureza macroeconômica. O uso dos modelos aplicados de equilíbrio geral permite visualizar a economia como um todo sem perder os detalhes regionais, 0 que é mais difícil na abordagem econométrica. 


\subsection{O Plano Real e a década de noventa}

Para entender o que se passou ao longo dos anos 90 na economia brasileira é importante saber como a economia brasileira caminhou nos anos 80 e quais foram os seus principais problemas. Após discutir a economia brasileira na década de oitenta na subseção 2.2.1, o Plano Real bem como a economia brasileira nos anos 90 são discutidos na subseção 2.2.2.

\subsubsection{A década de oitenta e a hiperinflação}

A década de oitenta foi marcada pela estagnação do nível de atividade, por grandes desequilíbrios macroeconômicos e principalmente pela hiperinflação. Na medida em que se tentava conter a inflação e iam sendo criados mecanismos que objetivavam torná-la suportável, acabava-se facilitando a sua aceleração. O fracasso de uma sequiência de planos heterodoxos de estabilização em curto período de tempo, ou seja, cinco planos econômicos em cinco anos, contribuiu para aumentar a instabilidade na economia, intensificando a aceleração da inflação. Tão ou mais importantes que a estagnação da indústria foram o atraso tecnológico e a forte redução da taxa de investimentos no país. Por outro lado, é importante destacar que, com a geração de superávits na balança comercial, o Brasil conseguiu enfrentar, ao longo da década de oitenta, a crise cambial que se iniciou a partir do segundo choque do petróleo e da moratória mexicana. As contas do setor público sofreram uma forte deterioração, como resultado da queda de receitas devido ao baixo crescimento econômico e de uma política expansionista de incentivos e subsídios fiscais. A década de oitenta foi caracterizada também pelo esgotamento do processo de industrialização por meio da substituição das importações, no qual o Estado era a força motriz para a implantação de um diversificado parque industrial nacional, muitas vezes assumindo diretamente a posição de investidor direto. Os déficits públicos crescentes, a dificuldade do Estado em garantir a estabilidade e a provisão de serviços sociais básicos (educação, saúde e segurança) e o ônus imposto por sua agenda de empreendedor direto originaram, ainda na década de oitenta, um

processo de redefinição do papel do Estado na economia que viria a amadurecer nos anos 90 (Pinheiro et al., 1999). 


\subsubsection{A década de noventa e o Plano Real}

Para retratar bem o que foi a década de noventa para a economia brasileira é preciso ver o período anterior e posterior a junho de 1994, ocasião no qual iniciou-se o Plano Real.

No período anterior a junho de 1994, o Brasil teve inflação elevada e crescente; déficit fiscal verificado pela necessidade de financiamento do setor público; taxa de câmbio bastante desvalorizada como reflexo da crise da dívida dos anos 80 e a situação externa folgada observada pela conta corrente superavitária e reservas internacionais chegando a mais de US\$ 40 bilhões na ocasião do lançamento do Plano Real. Depois de junho de 1994, o Brasil caracterizou-se por inflação muito baixa e declinante para os padrões históricos do país; contas públicas com elevado desequilíbrio; taxa de câmbio significativamente valorizada em relação ao nível de 1991-1994 e a rápida deterioração do resultado da conta corrente (Pinheiro et al., 1999).

\section{O Plano Real}

Na sequência são apresentados o Plano Real e os seus detalhes do ponto de vista de quem participou da elaboração e implantação do plano econômico baseado em Bacha $^{2}$ (1998). O principal objetivo do Plano Real era de combater a inflação, pois não adiantava ter o déficit operacional equilibrado, que inclui apenas pagamentos de juros reais, se o déficit nominal, que inclui os pagamentos de juros nominais sobre a dívida pública, continuasse aumentando devido à inflação. Desta forma, a oferta monetária no seu conceito amplo continuaria a se expandir realimentando a inflação.

Portanto, controlar o déficit orçamentário nominal era um problema monetário e não fiscal, ou seja, sem inflação o déficit nominal seria igual ao déficit operacional. Assim, a idéia básica do Plano Real para quebrar o ciclo vicioso entre inflação e oferta monetária ampla foi uma reforma monetária envolvendo um procedimento em dois

\footnotetext{
${ }^{2}$ Edmar Bacha foi um dos integrantes da equipe econômica responsável pela elaboração e implantação do Plano Real.
} 
estágios de substituição da velha moeda inflacionada por uma nova e estável, inicialmente como unidade de valor e em seguida como meio de pagamento.

O Plano Real foi um programa de estabilização preanunciado em três estágios, cuja natureza seqüencial foi apresentada ao país pelo então ministro Fernando Henrique Cardoso em 7 de setembro de 1993. O primeiro estágio era um mecanismo de equilíbrio orçamentário. O segundo introduzia uma unidade de conta estável para alinhar os preços relativos mais importantes da economia. O terceiro estabelecia a conversão dessa unidade de conta na nova moeda do país, a uma taxa de paridade semi-fixa com o dólar.

$\mathrm{O}$ primeiro estágio consistiu em equilibrar o orçamento fiscal operacional exante, por intermédio de cortes profundos na proposta orçamentária para 1994. A implementação desses cortes exigiu a aprovação pelo Congresso de uma emenda constitucional, conhecida como Fundo Social de Emergência, permitindo a esterilização, para os anos fiscais de 1994 e 1995, de $20 \%$ das destinações orçamentárias.

Com a aprovação da emenda pelo Congresso em fevereiro de 1994, o governo iniciou o segundo estágio do Plano Real introduzindo, em primeiro de março de 1994, uma unidade de conta estável (denominada de Unidade Real de Valor ou URV), aproximadamente em paridade com o dólar. Com poucas exceções, requereutse que os contratos fossem redenominados nessa nova unidade de conta. Excluindo-se salários, aluguéis residenciais, mensalidades escolares e preços e tarifas públicas, os termos das conversões poderiam ser regociados livremente entre as partes contratantes, desde que fossem abolidos os prazos de reajuste inferiores a um ano. Os salários, aluguéis residenciais e mensalidades escolares seriam convertidos pelo valor real médio do quadrimestre anterior.

A conversão de todos os contratos numa unidade de conta estável significava que todos os contratos vigentes na economia poderiam se beneficiar, dali em diante, da indexação diária, tendo sido também anunciado que o valor da nova unidade de conta seria reajustado diariamente, mantendo a paridade com o dólar, de acordo com evolução de três índices de preços muito utilizados. Depois de convertidos em URV, os contratos não podiam mais conter cláusulas de indexação de curto prazo, e as revisões contratuais 
só poderiam ocorrer depois de um ano. No caso dos contratos salariais, as revisões poderiam acontecer na próxima data-base de negociação.

A principal finalidade da segunda etapa do plano era alinhar os preços relativos mais importantes da economia, uma vez que a existência de contratos indexados com datas de reajustes diferentes implicava uma grande dispersão desses preços a qualquer momento do tempo, com alguns deles tendo sido reajustados recentemente e outros apresentando uma grande defasagem. Em tais circunstâncias, uma súbita interrupção do processo inflacionário surpreenderia alguns preços em seu valor de pico e outros no vale. Estes desalinhamentos de preços tenderiam a impor pressões inflacionárias adicionais, na medida em que a cláusulas prévias de reajuste continuariam a forçar para cima os preços defasados. Esse mecanismo de indexação não-sincronizado fornecia o componente inercial da inflação brasileira, distinto do componente estrutural associado ao déficit operacional ex-ante do orçamento federal.

Em primeiro de julho de 1994, após um período de quatro meses de conversões de contratos, o Banco Central começou a emitir a URV como a nova moeda do país, agora denominada Real, para cuja paridade cambial foi estabelecido o teto máximo de R $\$ 1,00 /$ US $\$ 1,00$. O Banco Central comprometeurse a vender dólares toda vez que seu valor de mercado alcançasse $\mathrm{R} \$ 1,00$, mas não era obrigado a intervir caso esse valor se mantivesse em patamares inferiores. Isso ficou conhecido como a política cambial da banda assimétrica, com um Imite superior de $\mathrm{R} \$ 1,00$ e um limite inferior indefinido, que na prática provou estar em torno de US $\$ 0,83$ por Real. De acordo com a proposta inicial do programa, a data de conversão da moeda foi anunciada com 30 dias de antecedência. O governo também fixou uma taxa de conversão de $\mathrm{R} \$ 1,00$ para CR $\$ 2.750,00$ (este era o valor em cruzeiros reais da URV em 30 de junho de 1994) para troca do estoque de moeda e para a redenominação em reais dos contratos e preços ainda não convertidos de cruzeiros reais em URV. Isso complementou a reforma monetária em três estágios que compreendia o Plano Real. Com a substituição do Cruzeiro Real pelo Real como a moeda oficial do país, todos os contratos cujo valor haviam sido estipulados previamente em termos reais (em URV) passaram a ter seu valor fixo em termos nominais (em Reais). A segunda fase ou período do Plano Real ocorreu a partir 
de março de 1995. O governo adotou uma série de medidas de política econômica para reagir aos desequilíbrios identificados, entre os quais a acentuada queda das reservas internacionais e o aumento da demanda interna, que ameaçavam a sustentação do Plano Real. As taxas básicas de juros foram substancialmente elevadas e impostas mais restrições à expansão creditícia. Simultaneamente a esse aperto monetário, em março de 1995 o governo promoveu uma desvalorização de 5\% do Real em relação ao dólar, substituiu a banda assimétrica por uma banda flutuante de câmbio, e decretou uma aguda elevação, de 20 para 70\%, das tarifas de importação de automóveis e eletrodomésticos. A partir de setembro de 1995 o Banco Central vem sistematicamente desvalorizando o Real em relação ao dólar a uma taxa mensal de aproximadamente $0,6 \%{ }^{3}$. Em junho de 1995, o governo editou um decreto de desindexação abolindo o IPCr, instituindo um regime de livre negociação salarial a partir de julho. Apesar de ter revertido timidamente a diminuição das reservas internacionais através de discretos superávits na balança comercial, o aperto creditício trouxe consequiências negativas como o declínio do nível de atividade econômica, o aumento dos atrasados creditícios e falências, que mostravam a fragilidade financeira ${ }^{4}$, e o déficit do setor público que sofreu forte impacto com a política de elevação das taxas de juros.

\section{Resultados e desafios do Plano Real}

De acordo com Pinheiro et al. (1999), o principal êxito do Plano Real foi a eliminação de um dos principais problemas da economia brasileira até junho de 1994: a inflação elevada. Outro bom resultado do Plano Real foi o aumento da taxa de investimento no final da década de noventa, principalmente, de investimento estrangeiro direto, o que provavelmente irá refletir em crescimento econômico futuro a partir de 2000. Pois, o investimento estrangeiro trata-se de uma poupança externa que contribui

\footnotetext{
${ }^{3}$ Note que depois, no início de 1999 a taxa de câmbio sofreu uma forte desvalorização e foi liberada.

${ }^{4}$ Em parte a fragilidade financeira está associada ao fim dos ganhos fáceis dos bancos comerciais com o imposto inflacionário, obtidos anteriormente de forma plena sobre depósitos à vista e transferências financeiras, e parcialmente sobre os depósitos a prazo.
} 
significativamente para aumentar a taxa de investimento e incorporar novas e modernas tecnologias ao processo produtivo brasileiro.

Aparentemente o governo poderia ter agido melhor e de forma mais efetiva no que diz respeito ao déficit do setor público, o setor externo e na redução da taxa de juros que afeta diretamente a dívida do setor público. É o que vários trabalhos de autores como Netto (1998), Bacha (1998), Almonacid \& Scrimini (1999), Batista Jr.(1999), Pinheiro et al. (1999) que analisam e avaliam o Plano Real apontam como falhas na continuidade do Plano Real.

De acordo com Pinheiro et al. (1999) o Brasil tem três grandes desafios para acelerar o seu potencial de crescimento econômico de forma adequada. Primeiramente, o país precisa consolidar a estabilidade macroeconômica, o que passa pelo estabelecimento de um regime fiscal equilibrado e pela promoção do crescimento das exportações. Se o ajuste fiscal for completado com êxito e com isso a percepção de risco do país ceder, poderá ocorrer uma queda significativa das taxas de juros. Isso também é importante para que o déficit em conta corrente seja mantido em níveis compatíveis com a estabilidade do passivo externo líquido ampliado como fração do PIB. O segundo desafio é o avanço das reformas estruturais implementadas nos anos 90 . Tem muito a fazer em termos de privatização, abertura comercial e desregulamentação. Por fim, o terceiro desafio é promover a chamada "segunda geração" de reformas, voltadas para o aprimoramento das instituições e para a solução dos novos problemas, como os resultantes das transformações demográficas por que vem passando o país. A reforma das instituições ganhou importância a partir do avanço das reformas de primeira geração na qual incluem-se reformas políticas, reforma do judiciário, das relações federativas, tributárias e das instituições de regulação. Estas reformas objetivam tornar o Estado mais eficiente e aumentar a competitividade do setor privado. Entre as reformas voltadas para os novos problemas, vale citar a reforma da previdência, do setor de saúde e do setor da educação.

Nas seções seguintes, são discutidas as vantagens e desvantagens na utilização de modelos econométricos e de modelos AEG. 


\subsection{Modelos Aplicados de Equilíbrio Geral}

Na modelagem econômica existem os modelos específicos e os modelos de uso geral. Os modelos específicos são aqueles construídos para o estudo de um problema econômico particular, para uma dada situação particular. Os modelos de uso geral são aqueles utilizados na análise e previsão da economia como um todo. Ou seja, são modelos gerais da economia.

Os modelos específicos são agrupados em modelos econométricos e modelos multissetoriais. Os modelos econométricos ou macroeconométricos estudam os agregados macroeconômicos, apresentam resultados globais, são direcionados para previsão e simulação de variáveis econômicas ao longo do tempo e descrevem as principais relações entre os agregados macroeconômicos. Os modelos multissetoriais ${ }^{5}$ usam a teoria de insumo-produto como um dos principais elementos na sua construção e os seus resultados são setoriais. Ou seja, um modelo de insumo-produto é construído a partir de informações econômicas de uma dada região que é dividida, por sua vez, em um determinado número de setores produtivos.

Os modelos de uso geral são agrupados em modelos econométricos e modelos aplicados de equilíbrio geral. Os modelos econométricos de uso geral também estudam os agregados econômicos, apresentam resultados agregados ou globais da economia, são voltados para simulação e previsão de variáveis econômicas ao longo do tempo, descrevem as principais relações entre os agregados macroeconômicos e diferem dos modelos aplicados de equilíbrio geral (AEG) por considerar o lado monetário do sistema econômico. Ou seja, os modelos econométricos de uso geral tratam a moeda dentro do sistema e por isso a produção é afetada por ela. Os modelos AEG consideram o lado real do sistema econômico. Ou seja, a moeda não influencia a economia. Nos modelos AEG a quantidade de moeda na economia não afeta os preços relativos sendo que o índice de preços dos modelos AEG capta somente as mudanças de preços relativos. De acordo com a teoria neoclássica, a moeda tem a função de meio de troca e reserva de valor no

\footnotetext{
${ }^{5}$ Para mais detalhes sobre os modelos multissetoriais veja Miller e Blair (1985), Robinson (1989) e Guilhoto (1995).
} 
sistema econômico, por isso não afeta a produção. Os modelos AEG apresentam resultados desagregados. Existe um outro grupo de modelos que resulta da integração dos modelos econométricos e dos modelos AEG. Os modelos integrados são interessantes por proporcionarem uma dinâmica aos modelos AEG e permitirem uma análise setorial ao longo do tempo. Se o modelo AEG é inte-regional ${ }^{6}$, ou seja, divide a economia analisada em várias regiões, é possível analisar, não só as relações intersetoriais, mas também as relações inter-regionais e as relações intersetoriais entre diferentes regiões.

\subsubsection{Um pouco de história sobre os modelos AEG e modelos econométricos}

A discussão sobre o uso dos modelos econométricos e dos modelos AEG começou na década de setenta. Por isso é interessante resgatar alguns fatos históricos que ocorreram no desenvolvimento da modelagem aplicada em equilíbrio geral e da modelagem econométrica que explicam a situação da pesquisa para cada uma delas atualmente. Este breve histórico é baseado em Dixon \& Parmenter (1996).

De acordo com estes autores, o primeiro modelo AEG (ou computável de equilíbrio geral) foi o de Johansen ${ }^{7}$. A década de sessenta foi um período em que os economistas desenvolveram e refinaram as proposições teóricas sobre a unicidade, o ótimo e a estabilidade das soluções para os modelos de equilíbrio geral. Por isso, houve uma longa pausa na modelagem de equilíbrio geral na década de sessenta depois da contribuição de Johansen, interrompida com o trabalho de Scarf $(1967,1973)^{8}$ citado por Dixon \& Parmenter (1996).

\footnotetext{
${ }^{6}$ Uma discussão mais detalhada sobre os modelos regionais pode ser encontrada em Isard et al. (1998).

${ }^{7}$ Note que o trabalho de Johansen foi publicado inicialmente em 1960 e depois foi revisada e publicado novamente em 1974. Portanto trata-se do mesmo modelo.

${ }^{8} \mathrm{SCARF}, \mathrm{H}$. E. The appromaxition of fixed points of a continuous mapping. SIAM Journal of applied Mathematics, v.15, n.5, p. 328-343. 1967.

SCARF, H. E. The computation of economic equilibria. New Haven: Yale University Press. 1973, 249 p.
} 
Scarf desenvolveu um algoritmo com propriedades de convergência finita, ou seja, para uma extensa classe de modelos de Equilíbrio Geral, que garantia uma solução aos modelos especificados numericamente com um número finito de passos ligando a aplicação à teoria dos modelos AEG. Dixon \& Parmenter (1996) destacam que o método de solução de Johansen, desenvolvido antes da técnica de Scarf, é simples e eficiente na solução de modelos AEG relativamente grandes.

Apesar da década de sessenta não ter sido um período ativo na modelagem aplicada em equilíbrio geral, foi uma década chave no desenvolvimento dos modelos econométricos da economia com um todo e de grande escala. Em relação aos modelos AEG, os modelos econométricos deram menos importância à teoria econômica e mais atenção aos dados das séries de tempo. Nos modelos AEG, as especificações das funções de oferta e de demanda são completamente consistentes com a teoria do comportamento otimizador dos atores econômicos. Nos modelos econométricos, o papel das teorias de otimização do comportamento dos atores econômicos individuais ficava restrito a sugestão das variáveis para serem testadas nas equações de regressões. Na década de sessenta, a filosofia da abordagem econométrica de deixar os dados falarem por si, pareceu bastante atrativa para os economistas aplicados. Esta razão pode ser parte da explicação da pausa no desenvolvimento da abordagem dos modelos AEG.

$\mathrm{Na}$ década de setenta dois fatores estimularam o interesse na abordagem AEG, além do trabalho de Scarf.

O primeiro foi a existência de choques importantes para a economia mundial incluindo uma repentina alta dos preços de energia, uma acentuada mudança no sistema monetário internacional e um rápido crescimento das taxas de salário real. Sem uma especificação teórica adequada, os modelos econométricos não poderiam prover simulações úteis dos efeitos de choques tais quais levaram economias para fora das tendências estabelecidas. Os modelos AEG são freqüentemente vulneráveis à crítica que as suas especificações comportamentais (isto é, maximização da utilidade e minimização do custo) são impostos sem validação empírica. Entretanto, com estas especificações estabelecidas, os modelos AEG podem oferecer informações novas dentro dos efeitos de choques para os quais não se tem experiência histórica. 
Por exemplo, até 1973 não existia experiência com mudanças acentuadas no preço do petróleo. Conseqüentemente equações de regressões baseadas em dados de séries de tempo anteriores a 1973, tinham coeficientes associados ao preço do petróleo não significativos ou iguais a zero. Assim os modelos que confiavam pesadamente na análise de séries de tempo indicariam que os movimentos no preço do petróleo não seriam importantes determinantes na atividade econômica. Nos modelos AEG insumos proveniente do petróleo aparecem como variáveis em funções de produção. Por isso através dos cálculos de minimização dos custos, os aumentos nos preços do petróleo atuariam sobre a atividade econômica em simulações dos modelos AEG da mesma forma como os aumentos de preços de outros insumos.

Por isso houve um aumento significativo do interesse na modelagem AEG na década de setenta, após os economistas aplicados terem reconhecido o poder das pressuposições de otimização em traduzir experiência de um modo geral em previsões plausíveis dos efeitos de um choque particular para os quais pode-se não ter experiência.

$\mathrm{O}$ segundo fator que tem orientado o crescimento da modelagem AEG nos últimos vinte anos tem sido o aumento da habilidade de manusear detalhes. Os ingredientes chaves, como disponibilidade de microdados, têm melhorado as bases de dados e os programas também têm evoluído significativamente. Como os modeladores AEG aprenderam a manusear mais detalhes, resultados dos modelos AEG tornam-se interessantes tanto para o setor público como para o setor privado que estão preocupados com as questões como: setores de atividades, regiões, emprego, educação e treinamento, distribuição de renda, bem-estar social e meio ambiente. Portanto a modelagem AEG é, de acordo com Dixon \& Parmenter (1996), um campo estabelecido da economia aplicada.

\subsubsection{Modelos AEG vs. modelos econométricos: uma breve discussão}

A discussão sobre o uso ou não de modelagem AEG como alternativa a modelagem econométrica continua atualmente, sendo que ainda existe uma linha de pesquisa que tenta fundir as duas abordagens. Por isso existem várias linhas de pesquisa na modelagem AEG que têm diferenças peculiares, mas nem sempre bem evidentes. $\mathrm{Na}$ 
sequência são apresentadas algumas questões atualmente discutidas entre a modelagem AEG e a modelagem econométrica.

De acordo com Mckibbin \& Wang (1998), até recentemente os modelos aplicados de equilíbrio geral e os modelos econométricos co-existiram com pouca interação entre os modeladores das duas linhas de modelagens e com pouca mistura entre as duas abordagens. Ambas as técnicas de modelagem têm realizado significativas contribuições para o entendimento de vários aspectos da economia ainda que esforços para combinar os modelos existentes das diferentes abordagens tenham sido infrutíferos. A distinção entre os modelos AEG que têm incorporado a dinâmica e a nova geração de modelos macro-econométricos baseados solidamente na teoria de otimização tem ficado cada vez menos clara. Além da base teórica dos modelos, existe uma significativa variedade de técnicas de parametrização para ambas as linhas de modelos. Os parâmetros são baseados nas estimativas econométricas ou calibrados com base na evidência empírica. Os modelos AEG são derivados da teoria de otimização microeconômica, com considerável atenção para o comportamento individual enquanto os modelos macro-econométricos baseiam-se no comportamento agregado confiando-se nas correlações encontradas nas séries temporais de dados agregados. Total ou excessiva confiança nos dados agregados com muito pouca consideração para a estrutura teórica é, de acordo com Mckibbin \& Wang (1998), a estratégia errada de modelagem para ser seguida por várias razões:

a) os dados no seu nível agregado são tão pobres que as restrições teóricas são requeridas para qualquer análise útil da informação contida nos dados;

b) vários choques importantes para a análise não estão na amostragem dos dados ou - no mínimo - em número insuficiente de observações;

c) para um modelo ser útil no sentido prático, é necessário ser capaz de replicar adequadamente os dados para uma significativa extensão, mas também deve ser compreensível para que o usuário obtenha informações quantitativas e uma melhor intuição dos principais pontos em qualquer análise.

De acordo com estes autores, tais motivos acima colocados sugerem uma compensação entre restringir um modelo para uma estrutura teórica bem definida e 
adequada e seguir abordagens dado-intensivas para modelagem. Ou seja, aparentemente existe uma compensação entre capturar o fenômeno macroeconômico e detalhes setoriais, embora Mckibbin \& Wang (1998) insistirem que os recentes desenvolvimentos na modelagem dinâmica aplicada de equilíbrio geral resolveram esta necessidade de compensação.

Os econometristas, por outro lado, também têm suas críticas em relação aos modelos AEG. A maior crítica, segundo Yang (1999), é direcionada as especificações dos parâmetros dos modelos AEG, para os quais falham por não ter uma adequada justificativa estatística. Ou seja, os resultados dos modelos AEG são potencialmente compromissados pela sua sensibilidade às pressuposições. Mas apesar de todas as críticas, o autor complementa que os modelos AEG ainda são ferramentas analíticas efetivas para finalidades indicativas.

Mckitrick (1998) destaca que a principal crítica aos modelos AEG, apesar de serem ferramentas importantes na economia aplicada, é o critério de seleção de parâmetro que parece não ser adequado e o uso de formas funcionais de primeira ordem (classe CES) impõe uma restrição que influencia a estrutura do modelo. Esse autor, além de apresentar uma estratégia alternativa baseada em modelagem econométrica, verificou que a escolha das formas funcionais afeta não somente os resultados setoriais específicos, mas também resultados agregados, mesmo para choques de política pequenos.

Do lado dos modelos econométricos também existem alguns problemas que não podem ser deixados fora dessa discussão. A presença da raiz unitária comum nas séries temporais econômicas faz com que as variáveis precisem ser trabalhadas em diferença nos modelos econométricos. Esta discussão iniciourse com os trabalhos de Granger \& Newbold (1974), Nelson \& Plosser (1982), Stock \& Watson (1988) e King et al. (1991). Além disso, existe a possibilidade das variáveis econômicas com raiz unitária serem cointegradas, situação na qual se faz necessário o uso de um modelo econométrico com variáveis em diferença e vetor de correção de erro, discutida amplamente nos trabalhos de Engle \& Granger (1987), Johansen (1988), Johansen \& Juselius (1990) e Johansen (1991). Desta forma, a discussão predominante na década de noventa entre os 
econometristas foi sobre as presenças de raiz unitária e da relação de cointegração entre as séries econômicas. Note que com raiz unitária e relação de cointegração, o processo de estimação ${ }^{9}$ das equações de regressão torna-se muito mais complicado assim como a interpretação dos resultados.

Não há evidências concretas, mas esta complexidade na estimação econométrica pode ter motivado os modeladores AEG preferirem incorporar um mecanismo de dinâmica no modelo AEG a buscar um caminho futuro através de variáveis exógenas baseadas em séries de tempo, obtidas de modelos econométricos de previsão. Mas a incorporação da dinâmica em modelos AEG também não é tão simples.

\subsubsection{Modelos AEG dinâmicos recursivos e não-recursivos}

Uma outra característica na modelagem AEG dinâmica é a recursividade ou não dos modelos para a obtenção do caminho da previsão.

Se o modelo AEG é desenvolvido não somente para análise política, mas também para previsão, situação na qual os dados para calibração não existem, a dimensão tempo e mecanismos de dinâmica intertemporal devem ser incluídas no modelo. Na prática, os modeladores AEG têm adotado bastante o mecanismo recursivo. $\mathrm{O}$ modelo baseado $\mathrm{m}$ princípio da modelagem dinâmica recursiva é efetivamente uma série de modelos estáticos resolvidos seqüencialmente. Pelo fato da calibração ser somente imposta no período inicial as variáveis no período subsequente no caminho de referência (previsão) são calculadas com variações na dotação das variáveis exógenas e endógenas. Ou seja, o cenário de referência em modelo AEG dinâmico recursivo é uma série de equilíbrios contrafactuais baseados no período inicial. Na prática da modelagem AEG, decisões intertemporais sobre a poupança, investimento e formação de capital são baseadas em pressuposições ad hoc convencionais. Duas pressuposições usualmente adotadas são: caminho de crescimento balanceado e expectativas míopes. No caso do caminho de crescimento balanceado as razões de estoque de capital para a oferta de trabalho em

\footnotetext{
${ }^{9}$ Para mais detalhes sobre o teste da raiz unitária, o teste de cointegração e a estimação das equações de regressões, ver Enders (1995) e Harris (1995).
} 
períodos futuros são os mesmos que a razão no período base calibrado. Alternativamente, no caso das expectativas míopes, as decisões sobre poupança e investimento em um modelo AEG recursivo é determinado em cada período pelas duas variáveis defasadas. Ou seja, a pressuposição neste caso é que a economia ajusta o seu nível de investimento em cada período de acordo com a escassez relativa de capital no período anterior (Yang, 1999).

Enquanto nos modelos AEG dinâmicos recursivos a solução de cada ano depende do ano corrente e dos anos anteriores, nos modelos AEG dinâmicos não-recursivos a solução de cada ano depende dos períodos anteriores como do período posteriores. Existem duas formas de resolver modelos $\mathrm{AEG}$ dinâmicos não recursivos. O primeiro é resolver todos os anos simultaneamente apresentando um conjunto de equações cobrindo as relações entre variáveis dentro cada ano e entre variáveis de anos diferentes. Como exemplo de aplicação desta forma de solução pode-se citar Mercenier \& Souza (1994).

Como é possível notar pelos trabalhos realizados até então, não existe um consenso do que é o certo, ou pelo menos melhor, para o desenvolvimento e aplicação de modelos AEG dinâmicos. Mas todos concordam que os modelos AEG são efetivamente ferramentas importantes para o economista aplicado na análise de políticas.

De acordo com Robinson (1989), os teóricos tendem a analisar a dinâmica em termos de ótimo intertemporal e estado estável (steady state) e evitar a discussão de quanto tempo leva-se para chegar ao estado estável, se isto é possível de fato. Os modelos "forward-looking" que incorporam a noção de equilíbrio intertemporal baseados em expectativas racionais são teoricamente interessantes e analiticamente manuseáveis, mas não parecem ser muito realistas. Os modeladores aplicados têm respondido construindo modelos dinâmicos adaptativos (recursivos), os quais são recursivos no tempo, com comportamento corrente dependendo somente das soluções dos períodos anteriores. Esta abordagem mais aplicada é justificável em termos teóricos como representação de uma seqüência de equilíbrios temporários. Mas têm pouco suporte teórico no que diz respeito à velocidade de ajustamento e a noção de equilíbrio intertemporal não é satisfatória. Robinson (1989) conclui que as questões sobre a 
dinâmica não são apenas problemas para os modelos multissetoriais, mas também são para os modelos macroeconômicos.

Partridge \& Rickman (1998) comentam que a calibração para a obtenção de um caminho de crescimento balanceado pode produzir resultados que põem em dúvida a validade do modelo AEG dinâmico regional. Os autores comentam que os parâmetros poderiam ser escolhidos de modo a produzir um caminho razoável no futuro e sugerem que os dados de séries temporais poderiam ser usados para produzir um caminho futuro satisfatório. Um exemplo desta aplicação é o modelo REMI desenvolvido por Treiz et al. (1992).

\subsubsection{Modelos AEG desenvolvidos para a Economia Brasileira}

Para a economia brasileira, foram desenvolvidos vários modelos AEG com diferentes enfoques. Com base em Guilhoto (1995) e levantamento dos trabalhos realizados de 1995 a 2001, os principais modelos AEG para a economia brasileira podem ser divididos em vários grupos:

a) Modelos de consistência cujos resultados são apresentados em nível: Rijckeghem (1969), Werneck (1984), Garcia (1988), Moreira (1992) e Moreira \& Urani (1994);

b) Modelos AEG que têm a sua solução dada em taxas de crescimento e o método de solução é linear: Guilhoto (1986), Guilhoto (1995), Rodrigues et al. (1998); Haddad (1999), Casimiro Filho et al. (2000) e Haddad \& Domingues (2001);

c) Modelos AEG em que o método de solução é não linear e os seus resultados são apresentados em nível: Lysy \& Taylor (1980), Adelman \& Robinson (1988), Sousa (1985), Sousa (1987a), Sousa \& Hidalgo (1988), Najberg et al. (1995); Willunsen \& Cruz (1990), Willunsen et al. (1997), Ferreira Filho (1997); Teixeira (1998); Ferreira Filho (1999);

d) Modelos híbridos que utilizam o enfoque descrito no item "c" e a análise de atividades com resultados em nível: Sousa (1987b);

e) Modelos que utilizam o enfoque do valor de transação e os seus resultados são em nível: Kadota \& Prado (1985); 
f) Modelos que incorporam elementos monetários na estrutura do modelo AEG e com resultados são em nível: Urani (1993);

g) Modelos AEG intertemporais com resultados em nível: Mercenier \& Sousa (1994); Cavalcante \& Mercenier (1999);

h) Modelos AEG que consideram a economia de escala e o mercado imperfeito e, os seus resultados são em nível: Campos Filho (1998) e;

i) Modelos AEG que incorporam a mobilidade no mercado de trabalho: Gonzaga et al. (1998).

Alguns trabalhos anteriormente citados são discutidos com um pouco mais de detalhes na sequiência por serem relevantes nesta pesquisa.

Guilhoto (1986) construiu um modelo AEG do tipo Johansen (Johansen, 1974) para o uso de planejamento e análise econômica para a economia brasileira. $\mathrm{O}$ método de solução foi linear e os seus resultados apresentados na forma de taxa de crescimento. O autor baseou-se no modelo ORANI, um modelo AEG para a economia australiana e o ano da matriz de insumo-produto utilizada foi a do ano de 1975.

Tendo como objeto de estudo o setor agrícola, Guilhoto (1995) desenvolveu um modelo AEG para o planejamento e análise de políticas agrícolas (PAPA) na economia brasileira que apresenta a solução em taxas de crescimento. O modelo PAPA é baseado no modelo ORANI, construído para a economia australiana, e por isso pode ser utilizado para estudar o impacto de políticas agrícolas não só sobre o setor agrícola como também sobre outros setores e sobre a economia como um todo. Da mesma forma, o modelo também permite que se estude o impacto de políticas não-agrícolas sobre o setor agrícola.

Note que os modelos AEG de Guilhoto (1986) e Guilhoto (1995) são modelos nacionais que ainda não têm a abordagem multirregional incorporada. Por isso, Haddad (1999) desenvolveu o modelo aplicado de equilíbrio geral B-MARIA (Brazilian Multisectoral and Regional/Interregional Analysis Model) para três regiões, quarenta setores em cada região e calibrado para o ano de 1985. O B-MARIA é um modelo AEG interregional relativamente detalhado e, por isso, é um dos primeiros modelos AEG inter-regional para o Brasil. É baseado no modelo MONASH-MRF (Multiregional 
Multisectoral Model of Australian Economy) e voltado para previsão e análise de políticas sendo que o seu principal objetivo foi analisar as diferenças regionais e as mudanças estruturais da economia brasileira.

$\mathrm{Na}$ mesma linha do modelo MONASH-MRF, Casimiro Filho et al. (2000) apresentaram um modelo AEG inter-regional, MIBRA, construído para os 16 setores mais importantes na economia, assim como para as cinco macrorregiões brasileiras (regiões Norte, nordeste, Centro-Oeste, Sudeste e sul) e calibrado para o ano de 1995. Este modelo segue a tradição do modelo MONASH-MRF construído para a economia australiana. O principal objetivo deste trabalho foi desenvolver um instrumento para a avaliação do impacto das políticas econômicas sobre o desenvolvimento regional da economia brasileira.

Mais recentemente, Haddad \& Domingues (2001) desenvolveram o modelo EFES (Economic Forecasting Equilibrium System) um modelo de equilíbrio geral computável, determinista e em tempo discreto, para o Brasil. O modelo foi utilizado para projetar um cenário consistente de médio prazo para o período 1999-2004, com base na combinação de projeções macroeconômicas derivadas de um modelo satélite de consistência macroeconômica, de projeções de exportações, de mudanças tecnológicas e "expert advice". Resultados setoriais preliminares apontaram para um melhor desempenho de setores relacionados ao ciclo de investimentos e produtores de bens de exportação dinâmicos. Além disso, verificou-se uma tendência em direção a uma fraca substituição de importações no período de análise.

Com o objetivo de avaliar quantitativamente as consequiências de políticas econômicas alternativas sobre o desempenho da agricultura brasileira, Sousa (1985) desenvolveu um modelo de equilíbrio geral, não linear e dinâmico para a economia brasileira. O modelo é desagregado com ênfase nas interações ruralurbanas e o seu mecanismo de preços tem uma atuação muito importante na alocação dos recursos. $\mathrm{O}$ método de solução usado foi o de Gauss-Seidl e a matriz de insumo-produto utilizada foi a do ano de 1970.

$\mathrm{Na}$ mesma linha, Sousa (1987a) analisou as implicações do protecionismo através de um modelo AEG em um contexto econômico onde existe rigidez. Uma 
especial atenção foi dada aos aspectos alocativos e distributivos da proteção. Foram examinados os efeitos da proteção sobre a alocação setorial do crescimento e a distribuição de renda entre o campo e a cidade.

Devido à necessidade de uma avaliação quantitativa dos efeitos econômicos do PROÁLCOOL dentro de um modelo de equilíbrio geral, Sousa (1987b) utilizou um modelo que combina a abordagem dos modelos AEG na linha de Adelman e Robinson com os métodos de análise de atividades. Ou seja, aplicou-se o método de análise de atividades unicamente ao setor álcool, onde era realmente apropriado, enquanto que o funcionamento do resto da economia foi explicado dentro de um modelo do tipo AEG. Trata-se de um modelo misto, não-linear e dinâmico. Assim o método de solução foi o de Gauss-Seidl combinado com o método Simplex e a matriz de insumo-produto usada foi a do ano de 1970.

Com o objetivo de estudar as políticas de comércio exterior no Brasil Sousa e Hidalgo (1988) desenvolveram um modelo AEG formado por um conjunto de equações não-lineares e simultâneas, no qual o mecanismo dos preços desempenha um papel importante na alocação dos recursos. A obtenção da solução de equilíbrio foi obtida através de um processo de ajustamento próximo ao tâtonnement walrasiano. Os preços dos produtos e os salários ajustam-se até que os excessos de demanda desapareçam. A calibração do modelo e a simulação de referência foram feitas utilizando como base os dados da matriz de insumo-produto do ano de 1975.

Mercenier \& Sousa (1994) desenvolveram um modelo descentralizado, multissetorial, intertemporal de equilíbrio geral para o Brasil para mostrar que a rápida liberalização do comércio exterior poderia não ser a estratégia mais apropriada para os países da América Latina. Os autores comentaram que as decisões de poupança e investimento baseados nas expectativas do modelo consistente são realizadas independentemente pelas firmas e famílias para maximizar a soma dos lucros descontados ou utilidades instantâneas, sujeito a restrições intertemporais. Além disso, apesar dos custos de ajustamento tornar o capital específico ao setor, o mercados de ativo garante uma eficiente alocação intertemporal, internacional, e interssetorial de recursos. O arcabouço foi delineado para incorporar vários graus de imperfeições de 
mercado de curto-prazo tais como rigidez de preço e salário até um estado estável (steady state) de longo-prazo caracterizado pelo "clearing market". Os autores destacaram que o modelo desenvolvido é uma generalização intertemporal estrita dos modelos AEG, considerando que nenhuma característica dos modelos AEG foi sacrificada. Uma das maiores dificuldades encontrada na realização na construção deste modelo AEG intertemporal foi a calibração do modelo. Os resultados mostraram que, no ambiente econômico mundial no início dos anos 80 , o Brasil iria requerer uma estratégia baseada em subsídios para investimentos direcionados aos setores exportadores mais competitivos e não uma drástica redução das tarifas.

Ainda tendo os impactos do Mercosul como objeto de estudo, Cavalcante e Mercenier (1999) avaliaram os efeitos de bem-estar do Mercosul usando um modelo calculável (computável) de equilíbrio geral intertemporal, multissetorial e multipaís com comércio e produção, rendimentos crescentes de escala interno à firma, concorrência imperfeita e diferenciação do produto ao ńvel do produtor individual. $\mathrm{O}$ ano-base da simulação foi 1992, para o qual foram disponibilizadas informações setoriais da estrutura da economia como as matrizes de insumo-produto, bem como os fluxos de comércio bilaterais. Note que o trabalho mostra como foi o impacto da nova estrutura tarifária em vigor a partir de 1995. Os resultados obtidos mostraram que o ganhador potencial dessa integração é o Uruguai, com o Brasil tendo um ganho modesto e eventualmente nulo, e a Argentina sendo, entre os países analisados, o que apresenta os piores resultados. Esse resultado reflete o fato de que os diferentes países encontravamse em estágios de desenvolvimento industriais diferenciados, bem como com estruturas tarifárias distintas.

Como é possível verificar através da literatura, ainda não existe um modelo AEG inter-regional com tratamento endógeno do investimento ou inter-regional e dinâmico recursivo para a economia brasileira. Os modelos AEG regionais, dinâmicos e de previsão, bem como os principais trabalhos empíricos realizados para a aplicação destes modelos são discutidos com mais detalhes na seção seguinte. 


\subsubsection{Modelos AEG Inter-regionais, Dinâmicos e de Previsão}

Os modelos AEG estáticos podem responder o que ocorre quando a economia regional move-se de um estado de condições exógenas para outra. Mas, por construção, a análise de estática comparativa omite o caminho ao longo do tempo da resposta. Por isto, a introdução do comportamento dinâmico nos modelos AEG é uma forma de incorporar a dimensão de tempo na análise de políticas. Quando os modelos AEG destinam-se a previsão, a inclusão do comportamento dinâmico é obrigatória (Partridge \& Rickman, 1998).

Como Pereira \& Shoven (1988) fizeram um levantamento dos principais modelos AEG dinâmicos desenvolvidos para avaliação de política fiscal e Partridge \& Rickman (1998) sobre os modelos AEG regionais, o presente trabalho procurou levantar e discutir os trabalhos mais recentes, abrangendo modelos AEG dinâmicos, de previsão e interregionais.

Kildergaard (1996) avaliou o choque da desvalorização do peso mexicano utilizando um modelo computável de equilíbrio geral multissetorial dinâmico para o México e a sua implicação na alocação de recursos intertemporal e intersetorial. Seguindo a desvalorização, o modelo previu uma reavaliação real e gradual ao longo de vários anos nos vários setores. No curto prazo, os recursos deslocaram-se para os setores de exportação e substituição de importação, principalmente mineração e manufatura, enquanto que a conta corrente ficou em superávit e a dívida externa líquida foi reduzida. No médio prazo e longo prazo, os impactos observados no curto-prazo foram revertidos, ou seja, a produção de bens não-exportados (non traded) aumentou, as exportações e a produção de produtos substitutos de importados diminuíram deixando o México com um pequeno volume de dívida e de comércio internacional que não teria tido se não ocorresse o choque. O modelo empregado na análise é caracterizado por ter nove setores produtivos, perfeita mobilidade de capital, perfeita previsão de necessidades futuras, um consumidor representativo, governo, e uma conta externa. Firmas competitivas e representativas em cada setor maximizam o valor do estoque de capital no setor específico através de escolha ótima de insumos e investimentos (sujeito a um 
ajustamento convexo de custos), enquanto o consumidor representativo maximiza o valor presente de uma função de utilidade intertemporal separável no tempo. O estado estável (steady state) é imposto após 85 anos. Este trabalho não apresenta muitos detalhes sobre a dinâmica do modelo.

Berck et al.(1997) desenvolveram e aplicaram um modelo AEG dinâmico para prever o efeito da mudança das taxas de impostos sobre o emprego e outras variáveis macroeconômicas na Califórnia. Este modelo foi chamado de modelo de análise da receita dinâmica (Dynamic Revenue Analysis Model) e a sua estrutura é bastante similar aos outros modelos AEG para a Califórnia no que diz respeito à produção, ao comércio e ao consumo. Mas é um pouco diferente no balanço de orçamento do governo, investimento e migração. Um dos pontos fracos do modelo de análise da receita dinâmica, de acordo com os próprios autores, é o fato de o modelo ignorar o valor implícito da educação como uma importante fonte de retroalimentação dinâmica. $\mathrm{O}$ modelo indicou que o corte nos impostos sobre o capital pode ser melhor para a economia californiana do que um corte no imposto de renda pessoal.

Uma aplicação de modelo AEG dinâmico na Índia é realizada por Storm (1997) para avaliar quantitativamente a reforma da política de comércio agrícola. A finalidade é estender o processo de liberalização do comércio dentro dos setores agrícolas. Para isto, é utilizado um modelo AEG dinâmico com nove setores e sete classes de renda, desenvolvido para o sétimo plano da Índia no período de 1985 a 1990. Os resultados sugeriram que os ganhos, através da liberalização da agricultura, podem não ser tão grandes ou não-ambíguos com é freqüentemente sugerido. Poucos detalhes são apresentados sobre a dinâmica do modelo que efetivamente não é de previsão, como o próprio autor destaca.

Uma outra aplicação de modelos AEG dinâmicos na avaliação de cortes de impostos foi realizado por Kraybill \& Seung (1999). Estes autores empregaram um modelo AEG dinâmico de Ohio para avaliar o efeito de um corte dos impostos estaduais para empresas considerando os bens públicos. Ou seja, as inovações deste trabalho foram: o uso do conceito de custo do capital, os mecanismos de ajuste nos mercados de fatores e a incorporação dos bens públicos na função utilidade das famílias e nas funções 
de produção das firmas. Os resultados do modelo indicaram que os efeitos do estímulo dos cortes de impostos para o desenvolvimento econômico mudam quando os efeitos dos gastos públicos na produtividade do capital privado e a migração das famílias são considerados no modelo.

Na linha do trabalho de Urani (1993), Kim (1999) analisou os efeitos do investimento em transportes na economia coreana usando uma análise contrafactual através de um modelo AEG dinâmico. Os resultados mostraram que, por um lado, a política de investimento em infra-estrutura tem o crescimento econômico como vantagem, mas, por outro lado, tem a inflação nos preços como desvantagem. As elasticidades do investimento em infra-estrutura com respeito a PIB, exportações, utilidade privada e inflação, dependem das restrições institucionais na entrada doméstica de capital estrangeiro e das alternativas de financiamento de projetos de infra-estrutura. A dinâmica é obtida através da incorporação do investimento depreciado de cada período dentro do estoque de capital do período seguinte, atualizando a oferta de trabalho total e as variáveis de política do governo. Como uma ligação entre os períodos adjacentes, equações intertemporais repõem todos os valores exógenos necessários para o próximo período de tempo. $\mathrm{O}$ autor destaca que o modelo foi desenvolvido com a intenção de analisar as estratégias de políticas econômicas e não prever valores de variáveis econômicas. O método de solução é do tipo não-linear.

Com o aumento do interesse pelas questões relacionadas ao meio ambiente, os modelos AEG dinâmicos têm sido uma interessante ferramenta de análise de políticas e de impactos do controle da poluição sobre a economia de uma região ou país.

Nesta linha, Zhang (1998) estudou os efeitos macroeconômicos da limitação da emissão de $\mathrm{CO}_{2}$ pela China, usando um modelo AEG dinâmico recursivo da economia chinesa. O autor desenvolve um cenário básico até 2010, a partir do qual são desenvolvidos outros cenários considerando cortes na emissão de $\mathrm{CO}_{2}$ de $20 \%$ e $30 \%$ e as diferentes formas de imposto sobre a emissão de $\mathrm{CO}_{2}$ cobrado pelo governo chinês. $\mathrm{O}$ autor destaca que nos modelos AEG dinâmicos recursivos uma sequiência de equilíbrios é computada para cada $n$ períodos de tempo que estão relacionados através da 
atualização de algumas variáveis exógenas, tais como estoque de capital e demografia. $\mathrm{O}$ modelo utilizou a MCS construída com base nos dados do ano de 1987.

Dessus \& Bussolo (1998) também utilizaram um modelo AEG dinâmico recursivo para a Costa Rica para avaliar quantitativamente a interdependência entre as políticas de liberalização do comércio externo e de redução da emissão de poluentes. $\mathrm{O}$ modelo foi calibrado com dados de uma MCS estimada para o ano de 1991, considerando 13 tipos de emissão de poluentes e resolvido recursivamente a partir do ano de 1992 até o ano de 2010. Os autores destacaram que a estrutura dinâmica do modelo resultou das condições de equilíbrio entre poupança e investimento. Ou seja, uma mudança no volume de poupança influencia a acumulação de capital no período seguinte. Taxas de crescimento determinadas exogenamente são assumidas para vários outros fatores que afetam o caminho de crescimento da economia, tais como taxas de crescimento da população e da oferta de trabalho, taxas de crescimento da produtividade do capital e do trabalho e a taxa de crescimento do fator de eficiência energética. Assume-se que os agentes são "míopes" e baseiam suas decisões sobre expectativas estáticas sobre preço e quantidade. A dinâmica do modelo é, portanto recursiva, mostrando uma seqüência de equilíbrios estáticos. Em termos de resultados, os autores mostraram que os impostos ambientais reduzem marginalmente o crescimento e reduzem significativamente a emissão de poluentes. Por outro lado, apenas a política de liberalização do comércio externo promove crescimento, mas induz um risco de especialização em atividades econômicas sujas para o meio ambiente.

A linha dos modelos australianos é a que tem proporcionado inúmeras aplicações incorporando o caráter dinâmico, o detalhamento interssetorial e inter-regional e, a capacidade de geração de previsões para variáveis econômicas. Estes modelos têm como características o uso do método de solução numérica linear através da linearização das equações e apresentar resultados na forma de taxas de crescimento (Dixon et al., 1992 e Peter et al. 1996a).

Nesta linha dos modelos australianos destacam-se os modelos: o modelo MONASH (Adams et al., 1994 e Dixon \& Rimmer, 1996), desenvolvido a partir do modelo ORANI (Dixon et al., 1982) e, por isso, para análise de estática comparativa de 
uma única região; o modelo multirregional e multissetorial de previsão MONASH-MRF (Peter et al., 1996a), desenvolvido para a economia australiana que permite análises de estática comparativa, análise dinâmica de políticas e geração de previsões; o B-MARIA (Haddad, 1999), um modelo interssetorial e inter-regional para três macrorregiões desenvolvido para a economia brasileira e baseado no modelo MONASH-MRF; o MIBRA (Casimiro Filho et al. 2000), um modelo interssetorial e inter-regional para a economia brasileira que difere do BMARIA por ter sido desenvolvido com base na matriz de insumo-produto do ano de 1995 e para cinco macrorregiões, o modelo MMRF-GREEN (Adams et al., 2000) que incorpora meio ambiente no modelo MONASH multirregional; o modelo EFES (Haddad \& Domingues, 2001) desenvolvido para a obtenção de projeções setoriais na economia brasileira em nível nacional.

\subsubsection{Os modelos AEG do tipo Johansen-Orani}

Como o objetivo do presente trabalho é incorporar o tratamento endógeno do investimento no modelo MIBRA, os trabalhos encontrados na literatura que utilizam os modelos interssetoriais e inter-regionais na linha australiana são discutidos na sequiência.

Adams et al. (1994) obtiveram previsões para a economia australiana para o período de 1990-91 a 1996-97 usando o modelo MONASH. Isto foi antes de Peter et al. (1996a) ter definido a estrutura teórica do MONASH-MRF, quando os autores ainda não tinham uma adequada especificação do investimento. Por isso, em cada cálculo dos resultados anuais através do modelo MONASH o crescimento do investimento agregado era tomado exogenamente a partir de previsões macroeconômicas obtidas da Syntec

Economic Services e de algumas variáveis estruturais do Australian Bureau of Agricultural and Resource Economics (ABARE), do Bureau of Tourism Research (BTR) e do Industry Commission (IC). A alocação entre os setores era orientada pelas taxas de retorno esperadas que, por simplificação, os autores consideraram estáticas por pressuposição. Mas o principal ponto fraco levantado pelos autores neste trabalho foi a condição ad hoc das conexões entre o modelo AEG, o modelo de previsão macroeconômica e as perspectivas de comércio do ABARE, do BTR e do IC. Tal fato criava dificuldades na realização de análise de sensitividade sobre as previsões. Ou seja, 
existia dificuldade em decidir como as mudanças nas definições de políticas afetariam as variáveis que são tomadas como exóge nas nos cálculos do modelo AEG. Os autores sugeriram uma integração das partes na forma de um único sistema.

Peter \& Rimmer (1996), da mesma forma que Adams et al. (1994), geraram previsões de produto e emprego para 112 setores australianos para o período de 1994-95 a 2002-03. Ou seja, utilizaram o modelo MONASH com um conjunto de variáveis exógenas derivadas das mesmas fontes utilizadas por Adams et. al. (1994). Peter \& Rimmer (1996) destacaram a necessidade de estar revisando as previsões através de correções e reinterpretações de dados. Pois os modelos dependem de um conjunto de dados diversos e freqüentemente inconsistentes. Outro ponto levantado pelos autores é a necessidade de previsões confiáveis e desagregadas que permitam aos formuladores de políticas, investidores e famílias formarem expectativas realistas levando em conta a composição setorial e regional da atividade econômica e a composição ocupacional do emprego. Assim os modelos AEG apresentam duas características que, de acordo com os autores, os tornam potencialmente atrativos como ferramentas geradoras destas previsões: sua transparente e consistente estrutura teórica e sua habilidade de manusear detalhes.

Navqi \& Peter (1996) realizaram uma aplicação do modelo MONASH-MRF na análise do impacto do investimento estadual em infra-estrutura rodoviária para a cidade de Melbourne. Esta aplicação mostrou a importância das relações inter-regionais através do comércio de produtos, fluxos de fatores e as restrições de recursos na economia como um todo. As restrições de ofertas globais e padrões de demanda específica da região, explicaram a expansão da economia do estado de Victoria a custas das economias de outros estados. Variações no desempenho das economias estadua is não- vitorianas foram explicadas pela estrutura setorial das economias e padrões de fluxos de comércio. Os autores destacaram a dificuldade de aplicação de modelos como o MONASH-MRF devido à dependência da disponibilidade de dados regionais. A dinâmica do modelo MONASH-MRF está confinada nas relações de acumulação conectando o setor de estoque de capital com o setor de investimento, população regional com crescimento natural na população e migrações estrangeira e inter-regional e a dívida externa com a 
balança comercial. Os autores destacaram que nos modelos do tipo bottom-up que é o caso do MONASH-MRF, o comportamento dos agentes econômicos é especificado em nível regional sendo que os resultados em nível nacional são as somas dos resultados regionais. Assim, atendem-se às necessidades dos formuladores de políticas e dos tomadores de decisões das empresas na análise de mudanças e desenvolvimento não só em uma região ou duas regiões, mas em todas as regiões simultaneamente. Outro aspecto interessante do modelo é o fato das economias regionais estarem relacionadas através do fluxo de comércio, movimento da população e da política econômica. Como o ano base dos dados utilizados nesta aplicação foi 1990-1991, foram feitas previsões de 1996/97 a 2000/01.

Adams et al. (1997) utilizaram os modelos AEG GTAP e MONASH para simular a eliminação das barreiras de comércio entre os membros da APEC (Asian-Pacific Economy Countries). Estes modelos enfocam, respectivamente, as relações de comércio global e as detalhadas dimensões regionais, ocupacionais e setoriais da economia australiana. Uma limitação da combinação destes dois modelos foi a incapacidade de seguir o curso da propriedade dos ativos. Por isso, aumentos no PIB não necessariamente implicam aumentos do bem-estar.

Dixon \& Rimmer (1998) aplicaram o modelo MONASH para previsão e análise de política no setor automotivo australiano para o período de 1987 a 2016. Estes autores demonstraram através desta aplicação que os modelos AEG podem ser usados para previsão e que as previsões são importantes para análise de políticas. Neste trabalho foram apresentados os detalhes sobre os fechamentos usados no modelo MONASH para a análise de políticas e para a geração de previsão. Ou seja, foram apresentadas quatro classes de fechamento: fechamentos históricos, fechamentos de decomposição, fechamentos de previsão e fechamentos de desvio ou política. O fechamento histórico e o fechamento de decomposição foram usados na análise computacional simples para o período de 1987 a 1994. Os fechamentos de previsão e política foram utilizados para criar projeções ano a ano para o período de 1998 a 2016. Os fechamentos de decomposição e histórico são utilizados para obter uma descrição dos desenvolvimentos na economia australiana, particularmente no setor de automotivo ao longo do período de 
1987 a 1994. No fechamento de decomposição são consideradas como exógenas todas as variáveis naturalmente exógenas. Ou seja, são as variáveis normalmente não explicadas no modelo AEG. No fechamento histórico são considerados exógenos dois tipos de variáveis: as observáveis e as assinaláveis. As variáveis observáveis são aquelas cujos movimentos podem ser prontamente observados através de fontes estatísticas para o período de interesse. Já as assinaláveis são variáveis naturalmente exógenas, portanto exógenas tanto no fechamento de decomposição como no fechamento histórico. Os autores utilizaram o fechamento de previsão para gerar as previsões básicas para o setor automotivo australiano no período de 1998 a 2016, assumindo que não há mudanças nas tarifas para importação de veículos além de 2001. Aí então, utilizando o fechamento de política, foram gerados os desvios em relação às previsões básicas que seriam causados pelos cortes nas tarifas de importação de veículos. Estes autores apresentaram os detalhes sobre o tratamento dado ao investimento e à acumulação de capital no modelo MONASH. Em cada ano das simulações, foi assumido que o crescimento do capital dos setores, portanto do nível de investimentos, é determinado de acordo com as funções que especificam que os investidores estão desejando ofertar fundos maiores para um setor $j$, em resposta aos aumentos da taxa de retorno esperada desse setor. Entretanto os investidores são cautelosos e, por isso, em qualquer ano, as funções de oferta de capital no modelo MONASH limitam o crescimento do estoque de capital no setor $j$ de modo que perturbações na taxa de retorno desse setor são eliminadas apenas gradualmente. No tratamento dado ao capital e ao investimento nas simulações ano a ano, o modelo MONASH assume que o nível de investimento num setor $j$ no ano $t$ tem somente um efeito pouco importante nos custos por unidade do capital do setor. Em vez de assumir custos de instalação crescentes, assume-se que o crescimento do capital no setor $j$ é limitado pela percepção de risco do investidor. Por isso, na teoria do modelo MONASH, investidores estão desejando permitir que a taxa de crescimento no setor $j$ no ano $t$ mova acima da taxa de crescimento do capital historicamente normal somente se os mesmos esperarem ser compensados por uma taxa de retorno acima no nível historicamente normal. 
Utilizando o modelo MONASH, Dixon \& Rimmer (1999) analizaram os efeitos das variações dos impostos indiretos sobre a economia australiana. Este autores destacaram a vantagem da abordagem dinâmica sobre a análise de estática comparativa por permitir análisar os efeitos de uma política ao longo tempo.

Haddad \& Domingues (2001) desenvolveram e aplicaram o modelo EFES para geração de projeções setoriais da economia brasileira de 1999 a 2004. Os autores baseando-se em Adams et al. (1994) e Dixon \& Rimmer (1996) combinaram o modelo AEG com projeções macroeconômicas derivados do modelo de consistência macroeconômica desenvolvido pela parceria entre o Banco Mundial e a Fundação Instituto de Pesquisas Econômicas (FIPE), das previsões de exportações, das mudanças tecnológicas e das informações de especialistas.

Adams et al. (2000) apresentaram e aplicaram o modelo Monash Multi-regional Forecasting - Green (MMRF-Green), um modelo dinâmico, multirregional, multissetorial e de previsão da Austrália com capacidades estendida para análise de políticas ambientais. O MMRF-Green, por ser um modelo dinâmico, gera sequiências de soluções anuais conectados por relações como acumulação de capital físico. A análise de política usando o MMRF-Green, envolve a comparação entre duas seqüências alternativas de solução: uma gerada sem a mudança de política e outra com a mudança de política aplicada. A primeira seqüência, chamada de projeção básica, serve com um caminho de controle a partir dos quais os desvios são mensurados na avaliação dos efeitos do choque da política. Além disso, o modelo MMRF-Green também inclui facilidades de desagregação regional que permitiu gerar resultados para oito estados/território s desagregados em 57 sub-regiões estaduais. Note que o MMRF-Green vai além do que se pretende desenvolver neste presente trabalho.

Como foi possível verificar nesta breve revisão de literatura sobre os modelos AEG para a economia brasileira, ainda não existe um modelo inter-regional AEG para a economia brasileira cuja dinâmica, recursiva ou não, seja obtida através das relações de acumulação de capital e do investimento. Haddad (1999) argumenta que os resultados obtidos não são coerentes com a realidade quando a dinâmica origina-se do próprio modelo AEG devido, principalmente, a disponibilidade de dados regionais. Mas como 
exemplo de que é possível gerar um caminho de soluções ao longo do tempo, pode-se citar o trabalho de Dixon \& Rimmer (1998). Estes autores demonstraram que os modelos AEG podem ser utilizados em previsões e que as previsões são relevantes para a análise de políticas através da aplicação do modelo MONASH para o setor automobilístico. A sua dinâmica foi gerada pelo próprio modelo através de equações de investimento e de acumulação de capital. Mas é importante observar que o modelo MONASH não é multirregional. Peter et al. (1996a) faz uma abordagem teórica de como é incorporada a dinâmica necessária ao modelo AEG inter-regional MONASH-MRF para a realização de previsões de variáveis econômicas.

A proposta de tornar dinâmico o modelo MIBRA e assim aplicá-lo na geração de previsões setoriais para a economia brasileira é bastante interessante e oportuna. Apesar da dificuldade levantada na aplicação dos modelos dinâmicos multissetoriais e multirregionais de previsão devido a questões de disponibilidade de dados regionais, é necessário testar a capacidade do MIBRA para previsão. Pois, para análise de estática comparativa, o MIBRA já proporcionou resultados interessantes para a avaliação de políticas de estabilização da economia brasileira. Mas de qualquer forma é importante que se incorpore o tratamento endógeno do investimento, seja para análise estática comparativa ou para análise dinâmica.

Rocha et al. (2000) avaliaram, utilizando o modelo MIBRA - USP, os diferentes impactos causados pelas mudanças na taxa de câmbio e nas tarifas sobre a economia brasileira e as suas cinco macrorregiões. Os seus resultados mostraram que a desvalorização da taxa de câmbio ou o aumento das tarifas podem causar um aumento no nível de emprego bem como no nível de atividades.

Casimiro Filho et al. (2000) destaca que o maior detalhamento regional é muito importante, uma vez que há diferenças bastante significativas entre as regiões consideradas quanto à evolução de seu desenvolvimento, à participação dos setores na economia, à distribuição de renda entre as classes sociais, e às condições de infraestrutura e mão-de-obra. 
Recentemente o modelo MIBRA com equações originais de investimento exógeno foi utilizado para verificar o impacto da redução da emissão de poluentes sobre a atividade econômica brasileira em nível setorial e regional (Guilhoto et al., 2002).

\subsection{Programa de Governo do Partido dos Trabalhadores (PT)}

Como um dos objetivos deste trabalho é analisar o impacto das políticas governamentais utilizando o modelo MIBRA, uma breve discussão das principais propostas de governo em termos de políticas que deverão ser praticadas pelo novo presidente do Brasil, Luiz Inácio Lula da Silva do Partido dos Trabalhadores (PT) é realizada nesta seção.

As propostas apresentadas no programa de governo do PT (Comissão de Programa de Governo do Partido dos Trabalhadores, 2002) deixam bem claro o enfoque social, tendo como objetivos a geração de emprego, geração e distribuição de renda e ampliação da infra-estrutura social. Além disso, percebe-se claramente a preocupação do futuro governo com o déficit do orçamento público e a inserção do Brasil na economia mundial. Nesta seção são discutidas os principais pontos do programa de governo do PT para serem incorporados nas simulações utilizando o modelo MIBRA.

O saneamento das finanças públicas parece ser ponto mais importante do programa pois só são viáveis as políticas de cunho social se existirem recursos disponíveis.

Para controlar o déficit do orçamento público, o PT propõe reforma tributária efetiva para diminuir carga tributária combinada com uma administração mais eficiente dos recursos públicos para viabilizar os programas sociais. A reforma tributária basicamente acabaria com o caráter regressivo e cumulativo dos impostos.

Combinado com a reforma tributária, o novo governo pretende tornar a coleta dos impostos mais eficientes reduzindo drasticamente a sonegação. Por isso espera-se uma receita semelhante através de uma carga tributária menor, mas coletadas de forma eficiente. Para realizar os programas sociais e assim pôr em prática as políticas sociais, o novo governo conta com o aumento mais que proporcional das receitas provenientes dos impostos e com o aumento da atividade econômica. De acordo com o programa do PT, o 
crescimento de $4 \%$ ao ano do PIB, provocaria uma expansão da receita proveniente dos impostos de $5 \%$ a $7 \%$. Assim, é proposto um crescimento da economia brasileira dos atuais $2,5 \%$ para $7 \%$ ao ano.

Outra questão importante para as finanças públicas é a reforma da previdência social. Para este problema o PT propõe a gestão quadripartite com a participação do estado, trabalhadores da ativa, aposentados e empresários. A essência desta proposta é a gestão mais eficiente da previdência social com participação de todas as partes interessadas.

Para complementar os recursos necessários para a realização das políticas sociais, o novo governo conta com a reorientação dos fundos como Fundo de Garantia por Tempo de Serviço (FGTS) e Fundo de Amparo ao Trabalhador (FAT), instrumentos como o Banco Nacional de Desenvolvimento Econômico e Social (BNDES) e a Caixa Econômica Federal (CEF) e a Financiadora de Estudos e Projetos (FINEP).

Uma vez garantido o saneamento das finanças públicas, o governo pode investir e gastar orientado pelas políticas sociais propostas que são basicamente geração e distribuição de renda, investimento em infra-estrutura social e aumento do emprego.

A melhor distribuição de renda, de acordo com o programa de governo, seria conseguida com o aumento do salário mínimo, diminuição da tributação regressiva e cumulativa e através do aumento dos investimentos do governo com moradia, saneamento, transporte coletivo, saúde, educação, previdência e proteção do emprego. Adicionalmente será usado a Bolsa-escola, a Bolsa-alimentação, o Programa de Renda Mínima entre outros programas sociais e a redução da carga tributária sobre os bens de consumo de massa como alimento, vestuário e material de construção.

Em relação a geração de renda, o novo governo, além de estimular o aumento da atividade econômica através dos seus gastos, pretende investir em educação e pesquisa com objetivo de aumentar a produtividade do trabalho e do capital. Além disso, vai estimular os setores com baixo coeficiente de importados como os setores de serviços, calçados, vestuários, têxtil, móveis, alimentos e sobretudo a construção civil. Com todos estes estímulos, aumenta-se demanda que, por sua vez, estimula o aumento da produção aumentando o nível de emprego. 
A agricultura irá ter uma atenção especial por parte do novo governo por ter sido responsável pelos constantes superávits da balança comercial.

No que diz respeito às desigualdades regionais, as regiões Norte e Nordeste serão privilegiadas quanto aos investimentos do governo federal.

Os investimentos em pesquisa e educação também têm o objetivo de diminuir o coeficiente de importados dos setores como eletroeletrônicos e bens de capital.

Todos os investimentos do governo têm, além da orientação social, o objetivo de fortalecer a economia brasileira internacionalmente, tornando a produção competitiva através da melhor capacitação da força de trabalho e da melhor infra-estrutura social e econômica.

Desta forma, o novo governo pretende fazer a economia crescer com a inflação controlada que denominam de crescimento "sustentado" da economia. 


\section{METODOLOGIA}

\subsection{O modelo MIBRA}

O MIBRA é um modelo multirregional e multissetorial da economia brasileira que está sendo desenvolvido na ESALQ-USP desde 1999 (Casimiro Filho et al., 2000). A estrutura básica é formada a partir do modelo de previsão multirregional MONASHMRF (Peter et al., 1996a), desenvolvido para a economia australiana.

Assim, de acordo com Casimiro Filho et al. (2000), o modelo MIBRA apresenta as equações em cinco módulos: módulo central do modelo, finanças do governo, capital e investimento, acumulação de débitos, e mercado de trabalho e migração regional.

O módulo central é separado em quatro blocos principais de equações determinando: demandas do consumidor, preços do produtor e ao consumidor, condições de equilíbrio do mercado, variáveis macroeconômicas como somatórios das variáveis microeconômicas.

O módulo de capital e investimento e acumulação de débito são adicionados como forma de incorporar no modelo as mudanças no investimento total e no estoque de capital num dado período previsto e o acúmulo de dívida externa. Estas mudanças pode ser realizadas de forma exógena, como ocorre nas equações originais do modelo e de forma endógena, como ocorre no modelo MIBRA com as novas equações de investimento.

O módulo mercado de trabalho e de migração regional define equações que determinam a população regional considerando o crescimento natural, a migração interregional e a migração estrangeira. O módulo inclui também equações que determinam mudanças nas taxas regionais de desemprego. 
Como o sistema de equações na forma de mudanças percentuais do modelo MIBRA é baseado no sistema de equações do modelo MONASH-MRF que é bastante extenso, as equações, as suas variáveis, os seus coeficientes e parâmetros, bem como as denominações das dimensões das variáveis, dos coeficientes e dos parâmetros são apresentados nas Tabelas 6, 7, 8 e 9.

Tabela 6. As equações do modelo MIBRA.

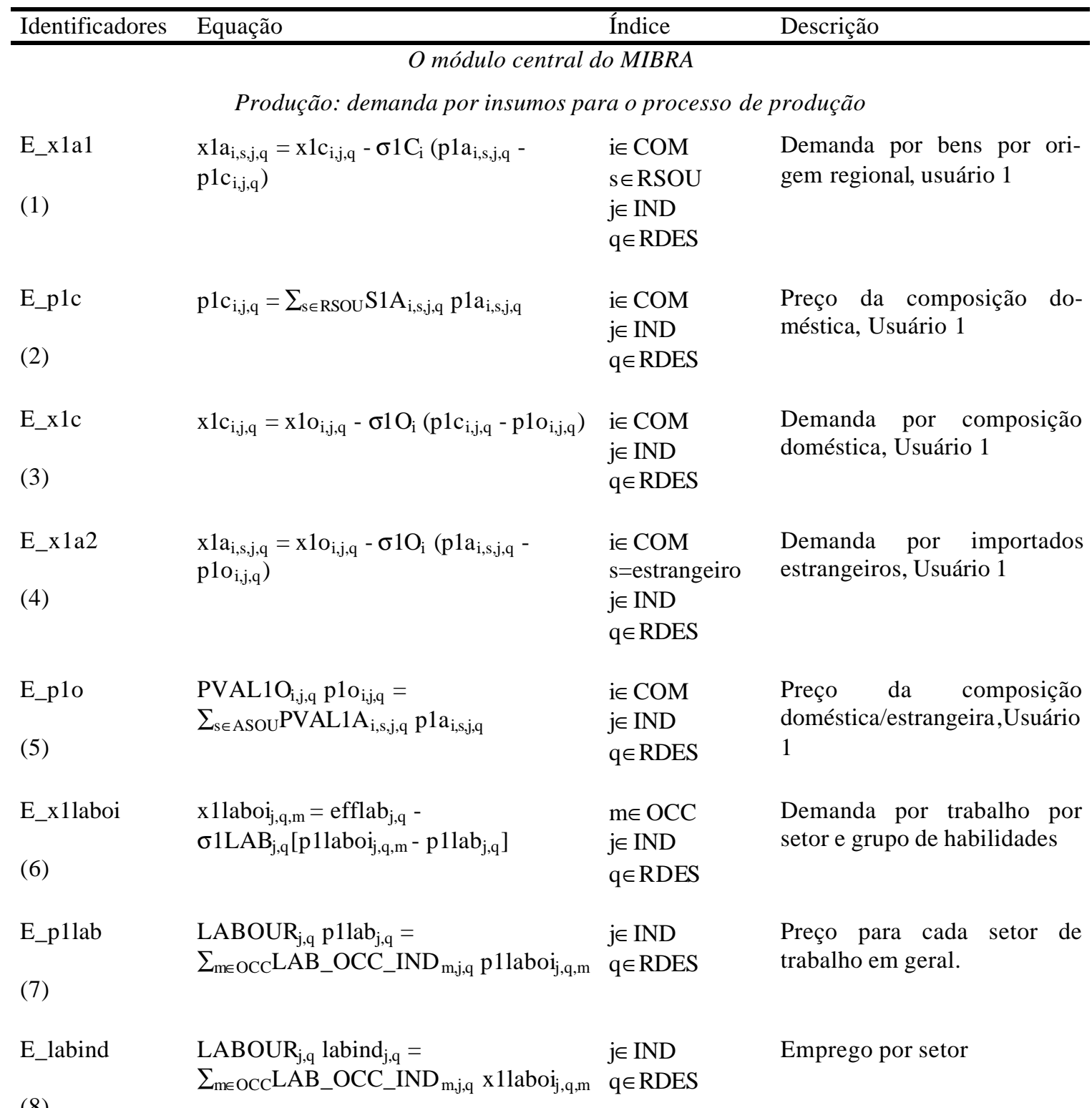


Tabela 6. As equações do modelo MIBRA.

\begin{tabular}{|c|c|c|c|}
\hline Identificadores & Equação & Índice & Descrição \\
\hline E_efflab & $\begin{array}{l}\text { efflab }_{\mathrm{j}, \mathrm{q}}=\mathrm{x} 1 \mathrm{prim}_{\mathrm{j}, \mathrm{q}}+\mathrm{a} 11 \mathrm{lab_{ \textrm {j } , \mathrm { q } } -} \\
\sigma 1 \mathrm{FAC} \mathrm{C}_{\mathrm{j}, \mathrm{q}}\left[\mathrm{p} 11 \mathrm{lab} \mathrm{j}_{\mathrm{j}, \mathrm{q}}+\mathrm{a} 11 \mathrm{lab} \mathrm{b}_{\mathrm{j}, \mathrm{q}}-\mathrm{xi} \mathrm{fac}_{\mathrm{j}, \mathrm{q}}\right]\end{array}$ & $\begin{array}{l}\mathrm{j} \in \mathrm{IND} \\
\mathrm{q} \in \mathrm{RDES}\end{array}$ & $\begin{array}{l}\text { Demandas dos setores por } \\
\text { trabalho efetivo }\end{array}$ \\
\hline $\begin{array}{l}\text { E_curcap } \\
\text { (10) }\end{array}$ & $\begin{array}{l}\operatorname{curcap}_{\mathrm{j}, \mathrm{q}}=\mathrm{x} 1 \mathrm{prim}_{\mathrm{j}, \mathrm{q}}+\mathrm{a} 1 \mathrm{cap} \mathrm{j, \textrm {q }} \\
\mathrm{\sigma} \mathrm{FAC}_{\mathrm{j}, \mathrm{q}}\left[\mathrm{p} 1 \mathrm{cap}_{\mathrm{j}, \mathrm{q}}+\mathrm{a} 1 \mathrm{cap} \mathrm{p}_{\mathrm{j}, \mathrm{q}}-\mathrm{xi} \mathrm{fac}_{\mathrm{j}, \mathrm{q}}\right]\end{array}$ & $\begin{array}{l}j \in I N D \\
q \in \text { RDES }\end{array}$ & $\begin{array}{l}\text { Demandas dos setores por } \\
\text { capital }\end{array}$ \\
\hline $\begin{array}{l}\text { E_n } \\
(11)\end{array}$ & $\begin{array}{l}\mathrm{n}_{\mathrm{j}, \mathrm{q}}=\mathrm{x} 1 \operatorname{prim}_{\mathrm{j}, \mathrm{q}}+\mathrm{a} 1 \mathrm{land}_{\mathrm{j}, \mathrm{q}}-\sigma 1 \mathrm{FAC}_{\mathrm{j}, \mathrm{q}} \\
\left.\text { [p1land }_{\mathrm{j}, \mathrm{q}}+\mathrm{a} 1 \operatorname{lland}_{\mathrm{j}, \mathrm{q}}-\mathrm{xi} \mathrm{fac}_{\mathrm{j}, \mathrm{q}}\right]\end{array}$ & $\begin{array}{l}j \in I N D \\
q \in \text { RDES }\end{array}$ & $\begin{array}{l}\text { Demandas dos setores por } \\
\text { terra }\end{array}$ \\
\hline $\begin{array}{l}\text { E_xi_fac } \\
\text { (12) }\end{array}$ & 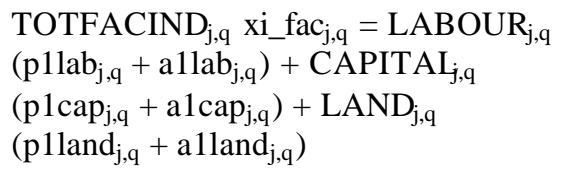 & $\begin{array}{l}\mathrm{j} \in \mathrm{IND} \\
\mathrm{q} \in \mathrm{RDES}\end{array}$ & $\begin{array}{l}\text { Termo de preço efetivo para } \\
\text { equações de demanda de } \\
\text { fatores }\end{array}$ \\
\hline $\begin{array}{l}\text { E_x1o } \\
\text { (13) }\end{array}$ & $x 1 o_{i, j, q}=z_{j, q}+a 1_{j, q}$ & $\begin{array}{l}i \in \mathrm{COM} \\
j \in \mathrm{IND} \\
\mathrm{q} \in \mathrm{RDES}\end{array}$ & $\begin{array}{l}\text { Demandas por combinações } \\
\text { de insumos domésticos / } \\
\text { estrangeiros, usuário } 1\end{array}$ \\
\hline $\begin{array}{l}\text { E_x1prim } \\
\text { (14) }\end{array}$ & $\mathrm{x} 1 \operatorname{prim}_{\mathrm{j}, \mathrm{q}}=\mathrm{z}_{\mathrm{j}, \mathrm{q}}+\mathrm{a} 1_{\mathrm{j}, \mathrm{q}}+\mathrm{a} 1 \operatorname{prim}_{\mathrm{j}, \mathrm{q}}$ & $\begin{array}{l}\mathrm{j} \in \mathrm{IND} \\
\mathrm{q} \in \mathrm{RDES}\end{array}$ & $\begin{array}{l}\text { Demandas setoriais por } \\
\text { fatores primários combinados }\end{array}$ \\
\hline $\begin{array}{l}\text { E_x } 1 \text { loct } \\
\text { (15) }\end{array}$ & $\mathrm{x} 1 \operatorname{loct}_{\mathrm{j}, \mathrm{q}}=\mathrm{z}_{\mathrm{j}, \mathrm{q}}+\mathrm{a} 1_{\mathrm{j}, \mathrm{q}}+\mathrm{a} 1 \operatorname{loct}_{\mathrm{j}, \mathrm{q}}$ & $\begin{array}{l}\mathrm{j} \in \mathrm{IND} \\
\mathrm{q} \in \mathrm{RDES}\end{array}$ & $\begin{array}{l}\text { Demandas setoriais por } \\
\text { outros custos }\end{array}$ \\
\hline & Demandas por bens de & investimentos & \\
\hline $\begin{array}{l}E_{-} \times 2 \mathrm{al} \\
\text { (16) }\end{array}$ & $\begin{array}{l}x 2 a_{i, s, j, q}=x 2 c_{i, j, q}-\sigma 2 C_{i}\left(p 2 a_{i, s, j, q}-\right. \\
\left.p 2 c_{i, j, q}\right)\end{array}$ & $\begin{array}{l}i \in \mathrm{COM} \\
\mathrm{s} \in \mathrm{RSOU} \\
\mathrm{j} \in \mathrm{IND} \\
\mathrm{q} \in \mathrm{RDES}\end{array}$ & $\begin{array}{l}\text { Demanda por bens por } \\
\text { origem regional, usuário } 2\end{array}$ \\
\hline $\begin{array}{l}E_{-} \times 2 \mathrm{a} 2 \\
(17)\end{array}$ & $\begin{array}{l}x 2 a_{i, s, j, q}=x 2 o_{i, j, q}-\sigma 2 O_{i}\left(p 2 a_{i, s, j, q}-\right. \\
\left.p 2 o_{i, j, q}\right)\end{array}$ & $\begin{array}{l}i \in \text { COM } \\
s=\text { estrangeiro } \\
j \in \text { IND } \\
q \in \text { RDES }\end{array}$ & $\begin{array}{l}\text { Demanda por importados } \\
\text { estrangeiros , usuário } 2\end{array}$ \\
\hline $\begin{array}{l}E_{-} \times 2 c \\
(18)\end{array}$ & $\mathrm{x} 2 \mathrm{c}_{\mathrm{i}, \mathrm{j}, \mathrm{q}}=\mathrm{x} 2 \mathrm{o}_{\mathrm{i}, \mathrm{j}, \mathrm{q}}-\sigma 2 \mathrm{O}_{\mathrm{i}}\left(\mathrm{p} 2 \mathrm{c}_{\mathrm{i}, \mathrm{j}, \mathrm{q}}-\mathrm{p} 2 \mathrm{o}_{\mathrm{i}, \mathrm{j}, \mathrm{q}}\right)$ & $\begin{array}{l}i \in \mathrm{COM} \\
j \in \mathrm{IND} \\
\mathrm{q} \in \mathrm{RDES}\end{array}$ & $\begin{array}{l}\text { Demanda por combinados } \\
\text { domésticos, usuário } 2\end{array}$ \\
\hline
\end{tabular}


Tabela 6. As equações do modelo MIBRA.

\begin{tabular}{|c|c|c|c|}
\hline Identificadores & Equação & Índice & Descrição \\
\hline $\begin{array}{l}E_{-} p 2 c \\
\text { (19) }\end{array}$ & $\begin{array}{l}\text { PVAL2T }_{\mathrm{i}, \mathrm{ss}, \mathrm{j}, \mathrm{q}} \mathrm{p} 2 \mathrm{c}_{\mathrm{i}, \mathrm{j}, \mathrm{q}}= \\
\sum_{\mathrm{s} \in \mathrm{RSOU}} \text { PVAL2A } 2 \mathrm{~A}_{\mathrm{i}, \mathrm{s}, \mathrm{j}, \mathrm{q}} \mathrm{p} 2 \mathrm{a}_{\mathrm{i}, \mathrm{s}, \mathrm{j}, \mathrm{q}}\end{array}$ & $\begin{array}{l}\mathrm{i} \in \mathrm{COM} \\
\mathrm{ss}=\text { doméstico } \\
\mathrm{j} \in \mathrm{IND} \\
\mathrm{q} \in \mathrm{RDES}\end{array}$ & $\begin{array}{l}\text { Preços de combinados } \\
\text { domésticos, usuário } 2\end{array}$ \\
\hline $\begin{array}{l}E_{-} p 2 o \\
(20)\end{array}$ & $\begin{array}{l}\text { PVAL2O }_{i, j, q} \mathrm{p} \mathrm{o}_{\mathrm{i}, \mathrm{j}, \mathrm{q}}= \\
\sum_{\mathrm{s} \in \text { ASOUPVAL2A }} \text { PVA,s,j,q } 2 \mathrm{a}_{\mathrm{i}, \mathrm{s}, \mathrm{j}, \mathrm{q}}\end{array}$ & $\begin{array}{l}\mathrm{i} \in \mathrm{COM} \\
\mathrm{j} \in \mathrm{IND} \\
\mathrm{q} \in \mathrm{RDES}\end{array}$ & $\begin{array}{l}\text { Preços de combinados } \\
\text { domésticos/estrangeiros, } \\
\text { usuário } 2\end{array}$ \\
\hline $\begin{array}{l}E_{-} \times 20 \\
(21)\end{array}$ & $\mathrm{x} 2 \mathrm{o}_{\mathrm{i}, \mathrm{j}, \mathrm{q}}=\mathrm{y}_{\mathrm{j}, \mathrm{q}}+\mathrm{a} 2 \mathrm{ind}_{\mathrm{j}, \mathrm{q}}$ & $\begin{array}{l}\mathrm{i} \in \mathrm{COM} \\
\mathrm{j} \in \mathrm{IND} \\
\mathrm{q} \in \mathrm{RDES}\end{array}$ & $\begin{array}{lc}\text { Demanda } & \text { por insumos } \\
\text { combinados } & \text { domésticos } \\
\text { estrangeiros, } & \text { usuário } \\
\text { usuário 2 } & \end{array}$ \\
\hline \multicolumn{4}{|c|}{ Demandas das famílias } \\
\hline $\begin{array}{l}E_{-} \times 3 a 1 \\
(22)\end{array}$ & $x 3 a_{i, s, q}=x 3 c_{i, q}-\sigma 3 C_{i}\left(p 3 a_{i, s, q}-p 3 c_{i, q}\right)$ & $\begin{array}{l}\mathrm{i} \in \mathrm{COM} \\
\mathrm{s} \in \mathrm{RSOU} \\
\mathrm{q} \in \mathrm{RDES}\end{array}$ & $\begin{array}{l}\text { Demanda de bens por origem } \\
\text { regional, Usuário } 3\end{array}$ \\
\hline $\begin{array}{l}E_{-} \times 3 a 2 \\
(23)\end{array}$ & $x 3 a_{i, s, q}=x 3 o_{i, q}-\sigma 3 O_{i}\left(p 3 a_{i, s, q}-p 3 o_{i, q}\right)$ & $\begin{array}{l}\mathrm{i} \in \mathrm{COM} \\
\mathrm{s}=\text { estrangeiro } \\
\mathrm{q} \in \mathrm{RDES}\end{array}$ & $\begin{array}{l}\text { Demanda por importados } \\
\text { estrangeiros, usuário } 3\end{array}$ \\
\hline $\begin{array}{l}E_{-} \times 3 c \\
(24)\end{array}$ & $x 3 c_{i, q}=x 3 o_{i, q}-\sigma 3 O_{i}\left(p 3 c_{i, q}-p 3 o_{i, q}\right)$ & $\begin{array}{l}\mathrm{i} \in \mathrm{COM} \\
\mathrm{q} \in \mathrm{RDES}\end{array}$ & $\begin{array}{l}\text { Demanda por combinado } \\
\text { doméstico, usuário } 3\end{array}$ \\
\hline $\begin{array}{l}E_{-} p 3 c \\
(25)\end{array}$ & $\begin{array}{l}\text { PVAL3T }_{\mathrm{i}, \text { doméstico,q }} \text { p3 } \mathrm{c}_{\mathrm{i}, \mathrm{q}}= \\
\sum_{\mathrm{s} \in \text { RSOU }} \text { PVAL3A } \mathrm{A}_{\mathrm{i}, \mathrm{s}, \mathrm{q}} \mathrm{p} 3 \mathrm{a}_{\mathrm{i}, \mathrm{s}, \mathrm{q}}\end{array}$ & $\begin{array}{l}\mathrm{i} \in \mathrm{COM} \\
\mathrm{q} \in \mathrm{RDES}\end{array}$ & $\begin{array}{l}\text { Preço de combinado } \\
\text { doméstico, usuário } 3\end{array}$ \\
\hline $\begin{array}{l}\text { E_p3o } \\
(26)\end{array}$ & $\begin{array}{l}\text { PVAL3O } \mathrm{i}_{\mathrm{i}, \mathrm{q}} \mathrm{p} 3 \mathrm{o}_{\mathrm{i}, \mathrm{q}}= \\
\sum_{\mathrm{s} \in \text { ASOUPVAL } 3 \mathrm{~A}_{\mathrm{i}, \mathrm{s}, \mathrm{q}} \mathrm{p} 3 \mathrm{a}_{\mathrm{i}, \mathrm{s}, \mathrm{q}}}\end{array}$ & $\begin{array}{l}\mathrm{i} \in \mathrm{COM} \\
\mathrm{q} \in \mathrm{RDES}\end{array}$ & $\begin{array}{l}\text { Preço de } \\
\text { doméstico / estrangeiro, } \\
\text { usuário 3 }\end{array}$ \\
\hline $\begin{array}{l}E_{-} \times 30 \\
(27)\end{array}$ & $\begin{array}{l}\text { x3o } o_{i, q}=\left[1-\text { ALPHA_I }_{i, q}\right]\left[\text { qhous }_{q}+\right. \\
\left.\mathrm{a} 3 \mathrm{sub}_{\mathrm{i}, \mathrm{q}}\right]+\mathrm{ALPHA}_{-} \mathrm{I}_{\mathrm{i}, \mathrm{q}}\left[\operatorname{luxexp}_{\mathrm{q}}+\right. \\
\left.\mathrm{a} 3 \operatorname{lux}_{\mathrm{i}, \mathrm{q}}-\mathrm{p} 3 \mathrm{o}_{\mathrm{i}, \mathrm{q}}\right]\end{array}$ & $\begin{array}{l}\mathrm{i} \in \mathrm{COM} \\
\mathrm{q} \in \mathrm{RDES}\end{array}$ & $\begin{array}{l}\text { Demandas das famílias por } \\
\text { produtos combinados } \\
\text { domésticos / estrangeiros }\end{array}$ \\
\hline $\begin{array}{l}\text { E_ utility } \\
(28)\end{array}$ & $\begin{array}{l}\text { utility }_{\mathrm{q}}=\operatorname{luxexp}_{\mathrm{q}}-\text { qhous }_{\mathrm{q}}- \\
\sum_{\mathrm{i} \in \mathrm{COM}} \operatorname{DELTA}_{\mathrm{i}, \mathrm{q}} \mathrm{p} 3 \mathrm{o}_{\mathrm{i}, \mathrm{q}}\end{array}$ & $q \in \operatorname{RDES}$ & $\begin{array}{lll}\text { Variação na utilidade } \\
\text { desconsiderando a mudança } \\
\text { das preferências }\end{array}$ \\
\hline $\begin{array}{l}E_{-} \text {a3sub } \\
\text { (29) }\end{array}$ & $\begin{array}{l}\mathrm{a}^{3} \operatorname{sub}_{\mathrm{i}, \mathrm{q}}=\mathrm{a} 3 \operatorname{com}_{\mathrm{q}, \mathrm{q}}-\sum_{\mathrm{k} \in \mathrm{COM}} \mathrm{S} 3 \mathrm{COM}_{\mathrm{k}, \mathrm{q}} \\
\mathrm{a} 3 \operatorname{com}_{\mathrm{k}, \mathrm{q}}\end{array}$ & $\begin{array}{l}\mathrm{i} \in \mathrm{COM} \\
\mathrm{q} \in \mathrm{RDES}\end{array}$ & $\begin{array}{l}\text { Definição padrão para o } \\
\text { deslocador da preferência de } \\
\text { subsistência }\end{array}$ \\
\hline
\end{tabular}


Tabela 6. As equações do modelo MIBRA.

\begin{tabular}{|c|c|c|c|}
\hline Identificadores & Equação & Índice & Descrição \\
\hline $\begin{array}{l}\text { E_a3lux } \\
(30)\end{array}$ & $\begin{array}{l}\text { a3lux }_{i, q}=a 3 \operatorname{sub}_{i, q}-\sum_{k \in C O M} \text { DELTA }_{k, q} \\
\text { a3sub }_{k, q}\end{array}$ & $\begin{array}{l}\mathrm{i} \in \mathrm{COM} \\
\mathrm{q} \in \mathrm{RDES}\end{array}$ & $\begin{array}{l}\text { Definição padrão para o } \\
\text { deslocador da preferência de } \\
\text { luxo }\end{array}$ \\
\hline \multicolumn{4}{|c|}{ Demandas por exportações estrangeiras } \\
\hline $\begin{array}{l}\text { E_x } 4 r \\
(31)\end{array}$ & $\begin{array}{l}x 4 r_{i, s}-f_{e q}=E X P \_E L A S T \\
\text { - natfep }]\end{array}$ & $\begin{array}{l}i \in \mathrm{TEXP} \\
\mathrm{s} \in \mathrm{RSOU}\end{array}$ & $\begin{array}{l}\text { Funções de demanda de } \\
\text { exportação tradicional }\end{array}$ \\
\hline $\begin{array}{l}\text { E_aggnt_x4r } \\
(32)\end{array}$ & $\begin{array}{l}\text { aggnt_x4r } \mathrm{r}_{\mathrm{s}}-\text { aggnt_feq } \\
\text { EXP_ELAST } \\
\text { manufact }\left[\text { aggnt_p4r } \mathrm{r}_{\mathrm{s}}-\right. \\
\text { aggnt_fep } \mathrm{s} \text { - natfep] }\end{array}$ & $\mathrm{s} \in \mathrm{RSOU}$ & $\begin{array}{l}\text { Demanda por agregado de } \\
\text { exportação não-tradicional }\end{array}$ \\
\hline $\begin{array}{l}\text { E_nt_x4r } \\
(33)\end{array}$ & $\begin{array}{l}\mathrm{x} 4 \mathrm{r}_{\mathrm{i}, \mathrm{s}}=\text { aggnt_x} 4 \mathrm{r}_{\mathrm{s}}+\text { faggnt_i } \mathrm{i}_{\mathrm{i}}+ \\
\text { faggnt_s} \mathrm{s}_{\mathrm{s}}+\text { faggnt_is is }\end{array}$ & $\begin{array}{l}\mathrm{i} \in \mathrm{NTEXP} \\
\mathrm{s} \in \mathrm{RSOU}\end{array}$ & $\begin{array}{l}\text { Funções de demanda de } \\
\text { exportação não-tradicional }\end{array}$ \\
\hline $\begin{array}{l}\text { E_aggnt_p4r } \\
(34)\end{array}$ & $\begin{array}{l}\text { AGGEXPNT }_{\mathrm{s}} \text { aggnt_p4 } \mathrm{r}_{\mathrm{s}}= \\
\sum_{\mathrm{i} \in \mathrm{NTEXP}} \text { PVAL4R } \mathrm{R}_{\mathrm{is}} \mathrm{p} 4 \mathrm{r}_{\mathrm{is}}+\text { faggnt_p4r }\end{array}$ & $\begin{array}{l}\mathrm{i} \in \mathrm{NTEXP} \\
\mathrm{s} \in \mathrm{RSOU}\end{array}$ & $\begin{array}{l}\text { Preço médio das exportações } \\
\text { não-tradicionais }\end{array}$ \\
\hline \multicolumn{4}{|c|}{ Demandas de consumo do Governo } \\
\hline $\begin{array}{l}\text { E_x5a } \\
(35)\end{array}$ & $\begin{array}{l}\mathrm{x} 5 \mathrm{a}_{\mathrm{i}, \mathrm{s}, \mathrm{q}}=\mathrm{cr}_{\mathrm{q}}+\mathrm{f} 5 \mathrm{a}_{\mathrm{i}, \mathrm{s}, \mathrm{q}}+\mathrm{f} 5 \mathrm{gen}_{\mathrm{q}}+ \\
\text { natf5gen }\end{array}$ & $\begin{array}{l}\mathrm{i} \in \mathrm{COM} \\
\mathrm{s} \in \mathrm{ASOU} \\
\mathrm{q} \in \mathrm{RDES}\end{array}$ & Outras demandas regionais \\
\hline $\begin{array}{l}\text { E_x6a } \\
(36)\end{array}$ & $\begin{array}{l}\text { x6a } a_{i, s, q}=\text { natcr }+\mathrm{f} 6 \mathrm{a}_{\mathrm{i}, \mathrm{s}, \mathrm{q}}+\mathrm{f} 6 \mathrm{gen}_{\mathrm{q}}+ \\
\text { natf6gen }\end{array}$ & $\begin{array}{l}\mathrm{i} \in \mathrm{COM} \\
\mathrm{s} \in \mathrm{ASOU} \\
\mathrm{q} \in \mathrm{RDES}\end{array}$ & Outras demandas federais \\
\hline \multicolumn{4}{|c|}{ Demandas por margens } \\
\hline $\begin{array}{l}\text { E_x1marg } \\
\text { (37) }\end{array}$ & $\mathrm{x} 1 \operatorname{marg}_{\mathrm{i}, \mathrm{s}, \mathrm{j}, \mathrm{q}, \mathrm{r}}=\mathrm{x} 1 \mathrm{a}_{\mathrm{i}, \mathrm{s}, \mathrm{j}, \mathrm{q}}$ & $\begin{array}{l}\mathrm{i} \in \mathrm{COM} \\
\mathrm{j} \in \mathrm{IND} \\
\mathrm{q} \in \mathrm{RDES} \\
\mathrm{s} \in \mathrm{ASOU} \\
\mathrm{r} \in \mathrm{MARG}\end{array}$ & $\begin{array}{l}\text { Margens sobre as vendas para } \\
\text { produtores }\end{array}$ \\
\hline $\begin{array}{l}\text { E_x2marg } \\
\text { (38) }\end{array}$ & $\mathrm{x} 2 \operatorname{marg}_{\mathrm{i}, \mathrm{s}, \mathrm{j}, \mathrm{q}, \mathrm{r}}=\mathrm{x} 2 \mathrm{a}_{\mathrm{i}, \mathrm{s}, \mathrm{j}, \mathrm{q}}$ & $\begin{array}{l}i \in \text { COM } \\
j \in \text { IND } \\
q \in \text { RDES } \\
s \in \text { ASOU } \\
r \in \text { MARG }\end{array}$ & $\begin{array}{l}\text { Margens sobre as vendas para } \\
\text { os investidores }\end{array}$ \\
\hline
\end{tabular}


Tabela 6. As equações do modelo MIBRA.

\begin{tabular}{|c|c|c|c|}
\hline Identificadores & Equação & Índice & Descrição \\
\hline $\begin{array}{l}\text { E_x3marg } \\
\text { (39) }\end{array}$ & $x 3 \operatorname{marg}_{\mathrm{i}, \mathrm{s}, \mathrm{q}, \mathrm{r}}=\mathrm{x} 3 \mathrm{a}_{\mathrm{i}, \mathrm{s}, \mathrm{q}}$ & $\begin{array}{l}i \in \mathrm{COM} \\
\mathrm{s} \in \mathrm{ASOU} \\
\mathrm{q} \in \mathrm{RDES} \\
\mathrm{r} \in \mathrm{MARG}\end{array}$ & $\begin{array}{l}\text { Margens sobre as vendas para } \\
\text { o consumo das famílias }\end{array}$ \\
\hline $\begin{array}{l}\text { E_x4marg } \\
\text { (40) }\end{array}$ & $\mathrm{x} 4 \operatorname{marg}_{\mathrm{i}, \mathrm{s}, \mathrm{r}}=\mathrm{x} 4 \mathrm{r}_{\mathrm{i}, \mathrm{s}}$ & $\begin{array}{l}i \in \mathrm{COM} \\
\mathrm{r} \in \mathrm{MARG} \\
\mathrm{s} \in \mathrm{RSOU}\end{array}$ & $\begin{array}{lll}\text { Margens } & \text { sobre } & \text { as } \\
\text { exportações: do portão } & \text { da } \\
\text { fábrica para o porto } & \end{array}$ \\
\hline $\begin{array}{l}\text { E_x5marg } \\
\text { (41) }\end{array}$ & $\mathrm{x} 5 \operatorname{marg}_{\mathrm{i}, \mathrm{s}, \mathrm{q}, \mathrm{r}}=\mathrm{x} 5 \mathrm{a}_{\mathrm{i}, \mathrm{s}, \mathrm{q}}$ & $\begin{array}{l}i \in \mathrm{COM} \\
\mathrm{s} \in \mathrm{ASOU} \\
\mathrm{q} \in \mathrm{RDES} \\
\mathrm{r} \in \mathrm{MARG}\end{array}$ & $\begin{array}{l}\text { Margens sobre as vendas para } \\
\text { outras demandas regionais }\end{array}$ \\
\hline $\begin{array}{l}\text { E_x6marg } \\
\text { (42) }\end{array}$ & $\mathrm{x} 6 \operatorname{marg}_{\mathrm{i}, \mathrm{s}, \mathrm{q}, \mathrm{r}}=\mathrm{x} 6 \mathrm{a}_{\mathrm{i}, \mathrm{s}, \mathrm{q}}$ & $\begin{array}{l}\mathrm{i} \in \mathrm{COM} \\
\mathrm{r} \in \mathrm{MARG} \\
\mathrm{s} \in \mathrm{ASOU} \\
\mathrm{q} \in \mathrm{RDES}\end{array}$ & $\begin{array}{l}\text { Margens sobre as vendas para } \\
\text { outras demandas federais em } \\
\text { cada região }\end{array}$ \\
\hline \multicolumn{4}{|c|}{ Preços } \\
\hline $\begin{array}{l}\text { E_p0a } \\
\text { (43) }\end{array}$ & 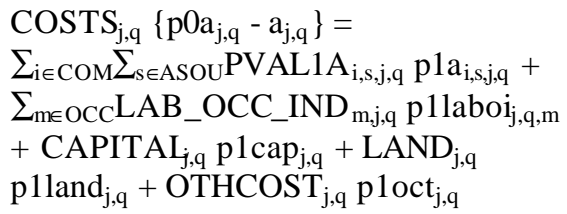 & $\begin{array}{l}j \in I N D \\
q \in \text { RDES }\end{array}$ & $\begin{array}{l}\text { Lucros puros zeros na } \\
\text { produção corrente }\end{array}$ \\
\hline $\begin{array}{l}\text { E_a } \\
(44)\end{array}$ & $\begin{array}{l}\operatorname{COSTS}_{\mathrm{j}, \mathrm{q}}\left[\mathrm{a}_{\mathrm{j}, \mathrm{q}}-\mathrm{a} 1_{\mathrm{j}, \mathrm{q}}\right]=\text { TOTFACIND }_{\mathrm{j}, \mathrm{q}} \\
\text { alprim }_{\mathrm{j}, \mathrm{q}}+\text { LABOUR }_{\mathrm{j}, \mathrm{q}} \text { allab }_{\mathrm{j}, \mathrm{q}}+ \\
\text { CAPITAL }_{\mathrm{j}, \mathrm{q}} \text { alcap }_{\mathrm{j}, \mathrm{q}}+\text { LAND }_{\mathrm{j}, \mathrm{q}} \\
\text { alland }_{\mathrm{j}, \mathrm{q}}+\text { OTHCOST }_{\mathrm{j}, \mathrm{q}} \text { aloct } \\
\mathrm{j}, \mathrm{q}\end{array}$ & $\begin{array}{l}j \in I N D \\
q \in \text { RDES }\end{array}$ & $\begin{array}{lcc}\text { Mudança } & \text { tecnológica } & \text { por } \\
\text { produção } & \text { corrente } & \text { das } \\
\text { indústrias } & & \end{array}$ \\
\hline $\begin{array}{l}\text { E_pi } \\
\text { (45) }\end{array}$ & $\begin{array}{l}\operatorname{INVEST}_{\mathrm{j}, \mathrm{q}}\left(\mathrm{pi}_{\mathrm{j}, \mathrm{q}}-\mathrm{a} 2 \mathrm{ind}_{\mathrm{j}, \mathrm{q}}\right)= \\
\sum_{\mathrm{i} \in \mathrm{COM}} \sum_{\mathrm{s} \in \mathrm{ASOU}} \text { PVAL2 } \mathrm{A}_{\mathrm{i}, \mathrm{s}, \mathrm{j}, \mathrm{q}} \mathrm{p} 2 \mathrm{a}_{\mathrm{i}, \mathrm{s}, \mathrm{j}, \mathrm{q}}\end{array}$ & $\begin{array}{l}j \in I N D \\
q \in \text { RDES }\end{array}$ & $\begin{array}{l}\text { Lucros puros zeros na criação } \\
\text { de capital }\end{array}$ \\
\hline $\begin{array}{l}\text { E_p0ab } \\
\text { (46) }\end{array}$ & $\begin{array}{l}\text { p0a }(\mathrm{i}, \text { "estrangeiro" })=\mathrm{pm}+\text { natphi }+ \\
\text { powtaxm }_{\mathrm{i}}\end{array}$ & $\mathrm{i} \in \mathrm{COM}$ & $\begin{array}{l}\text { Lucros puros zeros na } \\
\text { Importação }\end{array}$ \\
\hline $\begin{array}{l}\text { E_pla } \\
(47)\end{array}$ & $\begin{array}{l}\text { PVAL1A }_{\mathrm{i}, \mathrm{s}, \mathrm{j}, \mathrm{q}} \mathrm{p} 1 \mathrm{a}_{\mathrm{i}, \mathrm{s}, \mathrm{j}, \mathrm{q}}=\left[\mathrm{BAS} 1_{\mathrm{i}, \mathrm{s}, \mathrm{j}, \mathrm{q}}+\right. \\
\left.\text { TAX } 1_{\mathrm{i}, \mathrm{s}, \mathrm{j}, \mathrm{q}}\right]_{\mathrm{p}} 0 \mathrm{a}_{\mathrm{i}, \mathrm{s}}+\mathrm{BAS}_{\mathrm{i}, \mathrm{s}, \mathrm{j}, \mathrm{q}} \\
\operatorname{deltax} 1_{\mathrm{i}, \mathrm{s}, \mathrm{j}, \mathrm{q}}+\sum_{\mathrm{r} \in \mathrm{MARG}} \mathrm{MAR} 1_{\mathrm{i}, \mathrm{s}, \mathrm{j}, \mathrm{q}, \mathrm{r}} \mathrm{p} 0 \mathrm{a}_{\mathrm{q}, \mathrm{r}}\end{array}$ & $\begin{array}{l}i \in \text { COM } \\
j \in \text { IND } \\
q \in \text { RDES } \\
s \in \text { ASOU }\end{array}$ & $\begin{array}{l}\text { Preços dos compradores - } \\
\text { usuário } 1\end{array}$ \\
\hline
\end{tabular}


Tabela 6. As equações do modelo MIBRA.

\begin{tabular}{|c|c|c|c|}
\hline Identificadores & Equação & Índice & Descrição \\
\hline $\begin{array}{l}\text { E_p2a } \\
(48)\end{array}$ & $\begin{array}{l}\text { PVAL2A }_{\mathrm{i}, \mathrm{s}, \mathrm{j}, \mathrm{q}} \mathrm{p} 2 \mathrm{a}_{\mathrm{i}, \mathrm{s}, \mathrm{j}, \mathrm{q}}=\left[\mathrm{BAS} 2_{\mathrm{i}, \mathrm{s}, \mathrm{j}, \mathrm{q}}+\right. \\
\left.\text { TAX } 2_{\mathrm{i}, \mathrm{s}, \mathrm{j}, \mathrm{q}}\right] \mathrm{p} 0 \mathrm{a}_{\mathrm{i}, \mathrm{s}}+\mathrm{BAS} 2_{\mathrm{i}, \mathrm{s}, \mathrm{j}, \mathrm{q}} \\
\operatorname{deltax} 2_{\mathrm{i}, \mathrm{s}, \mathrm{j}, \mathrm{q}}+\sum_{\mathrm{r} \in \mathrm{MARG}} \mathrm{MAR} 2_{\mathrm{i}, \mathrm{s}, \mathrm{j}, \mathrm{q}, \mathrm{r}} \mathrm{p} 0 \mathrm{a}_{\mathrm{q}, \mathrm{r}}\end{array}$ & $\begin{array}{l}i \in \text { COM } \\
j \in I N D \\
q \in \text { RDES } \\
s \in \text { ASOU }\end{array}$ & $\begin{array}{l}\text { Preços dos compradores - } \\
\text { usuário } 2\end{array}$ \\
\hline $\begin{array}{l}\text { E_p3a } \\
\text { (49) }\end{array}$ & $\begin{array}{l}\text { PVAL3A }_{\mathrm{i}, \mathrm{s}, \mathrm{q}} \mathrm{p} 3 \mathrm{a}_{\mathrm{i}, \mathrm{s}, \mathrm{q}}=\left[\mathrm{BAS} 3_{\mathrm{i}, \mathrm{s}, \mathrm{q}}+\right. \\
\left.\text { TAX }_{\mathrm{i}, \mathrm{s}, \mathrm{q}}\right] \mathrm{p} 0 \mathrm{a}_{\mathrm{i}, \mathrm{s}}+\mathrm{BAS} 3_{\mathrm{i}, \mathrm{s}, \mathrm{q}} \operatorname{deltax} 3_{\mathrm{i}, \mathrm{s}, \mathrm{q}}+ \\
\sum_{\mathrm{r} \in \mathrm{MARG}} \mathrm{MAR} 3_{\mathrm{i}, \mathrm{s}, \mathrm{q}, \mathrm{r}} \mathrm{p} 0 \mathrm{a}_{\mathrm{q}, \mathrm{r}}\end{array}$ & $\begin{array}{l}i \in \mathrm{COM} \\
\mathrm{q} \in \mathrm{RDES} \\
\mathrm{s} \in \mathrm{ASOU}\end{array}$ & $\begin{array}{l}\text { Preços dos compradores - } \\
\text { usuário } 3\end{array}$ \\
\hline $\begin{array}{l}\text { E_p4r } \\
(50)\end{array}$ & $\begin{array}{l}\text { PVAL4R }_{\mathrm{i}, \mathrm{s}}\left(\text { natphi }+\mathrm{p} 4 \mathrm{r}_{\mathrm{i}, \mathrm{s}}\right)=\left[\mathrm{BAS} 4_{\mathrm{i}, \mathrm{s}}\right. \\
\left.+\mathrm{TAX}_{\mathrm{i}, \mathrm{s}}\right]_{\mathrm{p}} 0 \mathrm{a}_{\mathrm{i}, \mathrm{s}}+\mathrm{BAS} 4_{\mathrm{i}, \mathrm{s}} \operatorname{deltax} 4_{\mathrm{i}, \mathrm{s}}+ \\
\sum_{\mathrm{r} \in \mathrm{MARG}} \mathrm{MAR} 4_{\mathrm{i}, \mathrm{s}, \mathrm{r}} \mathrm{p} 0 \mathrm{a}_{\mathrm{r}, \mathrm{s}}\end{array}$ & $\begin{array}{l}i \in \mathrm{COM} \\
\mathrm{s} \in \mathrm{RSOU}\end{array}$ & $\begin{array}{l}\text { Preços dos compradores - } \\
\text { usuário } 4\end{array}$ \\
\hline $\begin{array}{l}\text { E_p5a } \\
(51)\end{array}$ & $\begin{array}{l}\text { PVAL5A }_{\mathrm{i}, \mathrm{s}, \mathrm{q}} \mathrm{p} 5 \mathrm{a}_{\mathrm{i}, \mathrm{s}, \mathrm{q}}=\left[\mathrm{BAS} 5_{\mathrm{i}, \mathrm{s}, \mathrm{q}}+\right. \\
\left.\text { TAX5 }_{\mathrm{i}, \mathrm{s}, \mathrm{q}}\right]_{\mathrm{p} 0 \mathrm{a}_{\mathrm{i}, \mathrm{s}}+\mathrm{BAS}_{\mathrm{i}, \mathrm{s}, \mathrm{q}}} \operatorname{deltax} 5_{\mathrm{i}, \mathrm{s}, \mathrm{q}}+ \\
\sum_{\mathrm{r} \in \mathrm{MARG}_{\mathrm{M}} M A R 5_{\mathrm{i}, \mathrm{s}, \mathrm{q}, \mathrm{r}} \mathrm{p} 0 \mathrm{a}_{\mathrm{s}, \mathrm{r}}}\end{array}$ & $\begin{array}{l}\mathrm{i} \in \mathrm{COM} \\
\mathrm{q} \in \mathrm{RDES} \\
\mathrm{s} \in \mathrm{ASOU}\end{array}$ & $\begin{array}{l}\text { Preços dos compradores - } \\
\text { usuário } 5\end{array}$ \\
\hline $\begin{array}{l}\text { E_p6a } \\
(52)\end{array}$ & $\begin{array}{l}\text { PVAL6A }_{i, s, q} \text { p6a }_{i, s, q}=\left[\text { BAS6 }_{i, s, q}+\right. \\
\left.\text { TAX6 }_{i, s, q}\right]_{p 0 a_{i, s}}+\text { BAS6 } \\
\sum_{\mathrm{r}, \mathrm{s}, \mathrm{q}} \operatorname{Meltax}_{\mathrm{i}, \mathrm{s}, \mathrm{q}}+ \\
\text { MAR6 }_{\mathrm{i}, \mathrm{s}, \mathrm{q}, \mathrm{r}} \mathrm{p} 0 \mathrm{a}_{\mathrm{r}, \mathrm{s}}\end{array}$ & $\begin{array}{l}i \in \mathrm{COM} \\
\mathrm{s} \in \mathrm{ASOU} \\
\mathrm{q} \in \mathrm{RDES}\end{array}$ & $\begin{array}{l}\text { Preços dos Compradores - } \\
\text { usuário } 6\end{array}$ \\
\hline \multicolumn{4}{|c|}{ Equações de Equilíbrio para produtos } \\
\hline $\begin{array}{l}\text { E_mkt_ } \\
\text { clear_margins } \\
(53)\end{array}$ & 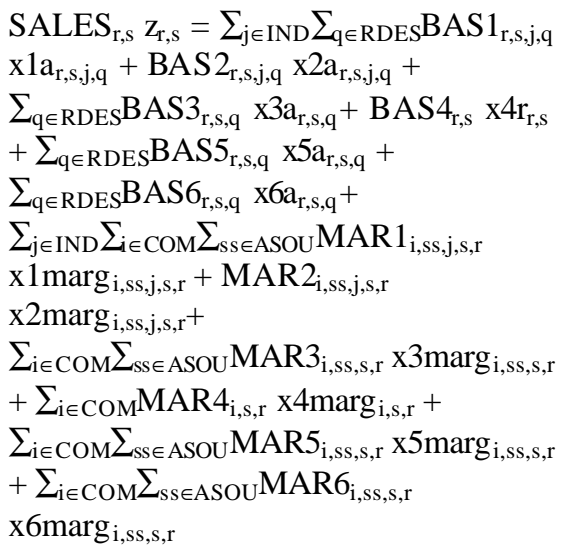 & $\begin{array}{l}\mathrm{r} \in \mathrm{MARG} \\
\mathrm{s} \in \mathrm{RSOU}\end{array}$ & $\begin{array}{l}\text { Demanda igual à Oferta para } \\
\text { margens de produtos }\end{array}$ \\
\hline $\begin{array}{l}\text { E_mkt_ } \\
\text { clear_nomarg } \\
\text { (54) }\end{array}$ & $\begin{array}{l}\text { SALES }_{\mathrm{r}, \mathrm{s}} \mathrm{z}_{\mathrm{r}, \mathrm{s}}=\sum_{\mathrm{j} \in \mathrm{IND}} \sum_{\mathrm{q} \in \mathrm{RDES}} \mathrm{BAS} 1_{\mathrm{r}, \mathrm{s}, \mathrm{j}, \mathrm{q}} \\
\mathrm{x} 1 \mathrm{a}_{\mathrm{r}, \mathrm{s}, \mathrm{j}, \mathrm{q}}+\sum_{\mathrm{j} \in \mathrm{IND}} \sum_{\mathrm{q} \in \mathrm{RDES}} \mathrm{BAS} 2_{\mathrm{r}, \mathrm{s}, \mathrm{j}, \mathrm{q}} \\
\mathrm{x} 2 \mathrm{a}_{\mathrm{r}, \mathrm{s}, \mathrm{j}, \mathrm{q}}+\sum_{\mathrm{q} \in \mathrm{RDES}} \mathrm{BAS} 3_{\mathrm{r}, \mathrm{s}, \mathrm{q}} \times 3 \mathrm{a}_{\mathrm{r}, \mathrm{s}, \mathrm{q}}+ \\
\mathrm{BAS} 4_{\mathrm{r}, \mathrm{s}} \times 4_{\mathrm{r}, \mathrm{s}}+\sum_{\mathrm{q} \in \mathrm{RDES}} \mathrm{BAS} 5_{\mathrm{r}, \mathrm{s}, \mathrm{q}} \times 5 \mathrm{a}_{\mathrm{r}, \mathrm{s}, \mathrm{q}} \\
+\sum_{\mathrm{q} \in \mathrm{RDES}} \mathrm{BAS} 6_{\mathrm{r}, \mathrm{s}, \mathrm{q}} \times 6 \mathrm{a}_{\mathrm{r}, \mathrm{s}, \mathrm{q}}\end{array}$ & $\begin{array}{l}\mathrm{r} \in \mathrm{NONMARG} \\
\mathrm{s} \in \mathrm{RSOU}\end{array}$ & $\begin{array}{l}\text { Demanda igual à Oferta para } \\
\text { não-margens de produtos }\end{array}$ \\
\hline
\end{tabular}


Tabela 6. As equações do modelo MIBRA.

\begin{tabular}{|c|c|c|c|}
\hline Identificadores & Equação & Índice & Descrição \\
\hline $\begin{array}{l}\text { E_x0impa } \\
(55)\end{array}$ & 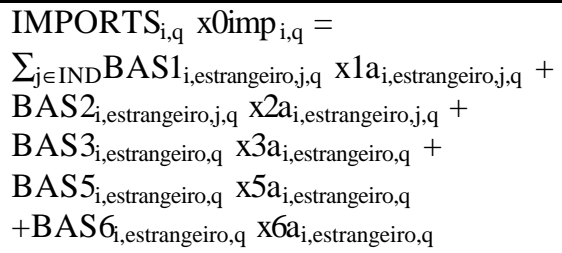 & $\begin{array}{l}\mathrm{i} \in \mathrm{COM} \\
\mathrm{q} \in \mathrm{RDES}\end{array}$ & $\begin{array}{l}\text { Volumes de importação de } \\
\text { produtos por região }\end{array}$ \\
\hline \multicolumn{4}{|c|}{ Impostos indiretos } \\
\hline $\begin{array}{l}\text { E_deltax } 1 \\
(56)\end{array}$ & $\begin{array}{l}\operatorname{deltax}_{\mathrm{i}, \mathrm{s}, \mathrm{j}, \mathrm{q}}=\text { deltax }_{\mathrm{i}}+\text { deltax } 1 \text { all }+ \\
\text { deltaxsource }_{\mathrm{s}}+\text { deltaxdest }_{\mathrm{q}}\end{array}$ & $\begin{array}{l}i \in \mathrm{COM} \\
\mathrm{s} \in \mathrm{ASOU} \\
\mathrm{j} \in \mathrm{IND} \\
\mathrm{q} \in \mathrm{RDES}\end{array}$ & $\begin{array}{l}\text { Taxa de imposto sobre vendas } \\
\text { para usuário } 1\end{array}$ \\
\hline $\begin{array}{l}\text { E_deltax } 2 \\
(57)\end{array}$ & $\begin{array}{l}\text { deltax } 2_{\mathrm{i}, \mathrm{s}, \mathrm{j}, \mathrm{q}}=\text { deltax }_{\mathrm{i}}+\text { deltax} 2 \mathrm{all}+ \\
\text { deltaxsource }_{\mathrm{s}}+\text { deltaxdest }_{\mathrm{q}}\end{array}$ & $\begin{array}{l}\mathrm{i} \in \mathrm{COM} \\
\mathrm{s} \in \mathrm{ASOU} \\
\mathrm{j} \in \mathrm{IND} \\
\mathrm{q} \in \mathrm{RDES}\end{array}$ & $\begin{array}{l}\text { Taxa de imposto sobre vendas } \\
\text { para usuário } 2\end{array}$ \\
\hline $\begin{array}{l}\text { E_deltax } 3 \\
\text { (58) }\end{array}$ & $\begin{array}{l}\text { deltax } 3_{\mathrm{i}, \mathrm{s}, \mathrm{q}}=\text { deltax }_{\mathrm{i}}+\text { deltax} 3 \text { all }+ \\
\text { deltaxsource }_{\mathrm{s}}+\text { deltaxdest }_{\mathrm{q}}\end{array}$ & $\begin{array}{l}\mathrm{i} \in \mathrm{COM} \\
\mathrm{s} \in \mathrm{SOU} \\
\mathrm{q} \in \mathrm{RDES}\end{array}$ & $\begin{array}{l}\text { Taxa de imposto sobre vendas } \\
\text { para usuário } 3\end{array}$ \\
\hline $\begin{array}{l}\text { E_deltax } 4 \\
\text { (59) }\end{array}$ & $\begin{array}{l}\text { deltax } 4_{\mathrm{i}, \mathrm{s}}=\text { deltax }_{\mathrm{i}}+\text { deltax}_{4} \text { all }+ \\
\text { deltaxsource }_{\mathrm{s}}+\text { deltaxdest }_{\mathrm{q}}\end{array}$ & $\begin{array}{l}\mathrm{i} \in \mathrm{COM} \\
\mathrm{s} \in \mathrm{RSOU} \\
\mathrm{q}=\text { estrangeiro }\end{array}$ & $\begin{array}{l}\text { Taxa de imposto sobre vendas } \\
\text { para usuário } 4\end{array}$ \\
\hline $\begin{array}{l}\text { E_deltax } 5 \\
(60)\end{array}$ & $\begin{array}{l}\text { deltax } 5_{\mathrm{i}, \mathrm{s}, \mathrm{q}}=\text { deltax }_{\mathrm{i}}+\text { deltax} 5 \text { all }+ \\
\text { deltaxsource }_{\mathrm{s}}+\text { deltaxdest }_{\mathrm{q}}\end{array}$ & $\begin{array}{l}\mathrm{i} \in \mathrm{COM} \\
\mathrm{s} \in \mathrm{ASOU} \\
\mathrm{q} \in \mathrm{RDES}\end{array}$ & $\begin{array}{l}\text { Taxa de imposto sobre vendas } \\
\text { para usuário } 5\end{array}$ \\
\hline $\begin{array}{l}\text { E_deltax6 } \\
(61)\end{array}$ & $\begin{array}{l}\text { deltax } 6_{\mathrm{i}, \mathrm{s}, \mathrm{q}}=\text { deltax }_{1}+\operatorname{deltax} 6 \mathrm{all}+ \\
\text { deltaxsource }_{\mathrm{s}}+\text { deltaxdest }_{\mathrm{k}}\end{array}$ & $\begin{array}{l}\mathrm{i} \in \mathrm{COM} \\
\mathrm{s} \in \mathrm{ASOU} \\
\mathrm{q} \in \mathrm{RDES} \\
\mathrm{k}=\text { federal }\end{array}$ & $\begin{array}{l}\text { Taxa de imposto sobre vendas } \\
\text { para usuário } 6\end{array}$ \\
\hline $\begin{array}{l}\text { E_taxrev1 } \\
(62)\end{array}$ & $\begin{array}{l}\text { AGGTAX } 1_{\mathrm{q}} \text { taxrev } 1_{\mathrm{q}}=\sum_{\mathrm{i} \in \mathrm{COM}} \\
\sum_{\mathrm{s} \in \mathrm{ASOU}} \sum_{\mathrm{j} \in \mathrm{IND} T A X} 1_{\mathrm{i}, \mathrm{s}, \mathrm{j}, \mathrm{q}}\left\{\mathrm{p} 0 \mathrm{a}_{\mathrm{i}, \mathrm{s}}+\right. \\
\left.\mathrm{x} \mathrm{a}_{\mathrm{i}, \mathrm{s}, \mathrm{j}, \mathrm{q}}\right\}+\mathrm{BAS} 1_{\mathrm{i}, \mathrm{s}, \mathrm{j}, \mathrm{q}} \operatorname{deltax} 1_{\mathrm{i}, \mathrm{s}, \mathrm{j}, \mathrm{q}}\end{array}$ & $\mathrm{q} \in \mathrm{RDES}$ & $\begin{array}{l}\text { Receita agregada proveniente } \\
\text { de impostos indiretos } \\
\text { coletados nos fluxos para } \\
\text { usuário } 1\end{array}$ \\
\hline $\begin{array}{l}\text { E_taxrev2 } \\
\text { (63) }\end{array}$ & 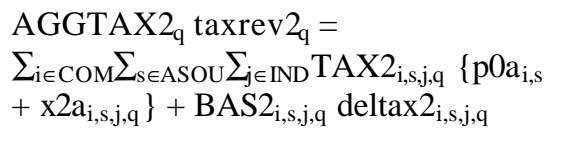 & $\mathrm{q} \in \mathrm{RDES}$ & $\begin{array}{l}\text { Receita agregada proveniente } \\
\text { de impostos indiretos } \\
\text { coletados nos fluxos para o } \\
\text { usuário } 2\end{array}$ \\
\hline
\end{tabular}


Tabela 6. As equações do modelo MIBRA.

\begin{tabular}{|c|c|c|c|}
\hline Identificadores & Equação & Índice & Descrição \\
\hline $\begin{array}{l}\text { E_taxrev3 } \\
\text { (64) }\end{array}$ & $\begin{array}{l}\text { AGGTAX } 3_{\mathrm{q}} \operatorname{taxrev}_{\mathrm{q}}= \\
\sum_{\mathrm{i} \in \mathrm{COM}} \sum_{\mathrm{s} \in \mathrm{ASOU}} \mathrm{TAX} 3_{\mathrm{i}, \mathrm{s}, \mathrm{q}}\left\{{\mathrm{p} 0 \mathrm{a}_{\mathrm{i}, \mathrm{s}}}+\right. \\
\left.\mathrm{x} 3 \mathrm{a}_{\mathrm{i}, \mathrm{s}, \mathrm{q}}\right\}+\mathrm{BAS} 3_{\mathrm{i}, \mathrm{s}, \mathrm{q}} \operatorname{deltax} 3_{\mathrm{i}, \mathrm{s}, \mathrm{q}}\end{array}$ & $\mathrm{q} \in \mathrm{RDES}$ & $\begin{array}{l}\text { Receita agregada proveniente } \\
\text { de impostos indiretos } \\
\text { coletados nos fluxos para o } \\
\text { usuário } 3\end{array}$ \\
\hline $\begin{array}{l}\text { E_taxrev4 } \\
(65)\end{array}$ & $\begin{array}{l}\text { AGGTAX4 } 4_{\mathrm{s}} \text { taxrev4 } 4_{\mathrm{s}}=\sum_{\mathrm{i} \in \mathrm{COM}} \mathrm{TAX} 4_{\mathrm{i}, \mathrm{s}} \\
\left\{\mathrm{p} 0 \mathrm{a}_{\mathrm{i}, \mathrm{s}}+\mathrm{x} 4 \mathrm{r}_{\mathrm{i}, \mathrm{s}}\right\}+\mathrm{BAS}_{\mathrm{i}, \mathrm{s}} \operatorname{deltax} 4_{\mathrm{i}, \mathrm{s}}\end{array}$ & $\mathrm{s} \in \mathrm{RSOU}$ & $\begin{array}{l}\text { Receita agregada proveniente } \\
\text { de impostos indiretos } \\
\text { coletados nos fluxos para o } \\
\text { usuário } 4\end{array}$ \\
\hline $\begin{array}{l}\text { E_taxrev5 } \\
\text { (66) }\end{array}$ & 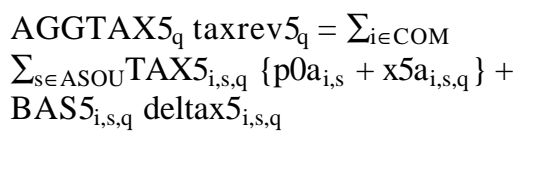 & $\mathrm{q} \in \mathrm{RDES}$ & $\begin{array}{l}\text { Receita agregada proveniente } \\
\text { de impostos indiretos } \\
\text { coletados nos fluxos para o } \\
\text { usuário } 5\end{array}$ \\
\hline $\begin{array}{l}\text { E_taxrev6 } \\
\text { (67) }\end{array}$ & $\begin{array}{l}\text { AGGTAX6 }_{\mathrm{q}} \text { taxrev6 } 6_{\mathrm{q}}=\sum_{\mathrm{i} \in \mathrm{COM}} \\
\sum_{\mathrm{s} \in \text { ASOU } \text { TAX6 }} 6_{\mathrm{i}, \mathrm{s}, \mathrm{q}}\left\{\mathrm{p} 0 \mathrm{a}_{\mathrm{i}, \mathrm{s}}+\mathrm{x} 6 \mathrm{a}_{\mathrm{i}, \mathrm{s}, \mathrm{q}}\right\}+ \\
\text { BAS6 }_{\mathrm{i}, \mathrm{s}, \mathrm{q}} \operatorname{deltax} 6_{\mathrm{i}, \mathrm{s}, \mathrm{q}}\end{array}$ & $\mathrm{q} \in \mathrm{RDES}$ & $\begin{array}{l}\text { Receita agregada proveniente } \\
\text { de impostos indiretos } \\
\text { coletados nos fluxos para o } \\
\text { usuário } 6\end{array}$ \\
\hline
\end{tabular}

\section{Rendas e gastos regionais}

E_caprev $\quad \operatorname{caprev}_{\mathrm{q}}=\left(1.0 / \operatorname{AGGCAP}_{\mathrm{q}}\right) \quad \mathrm{q} \in \mathrm{RDES}$ $\sum_{\mathrm{j} \in \mathrm{IND}}$ CAPITAL $_{\mathrm{j}, \mathrm{q}}\left\{{\text { p } 1 \text { cap }_{\mathrm{j}, \mathrm{q}}+}^{+}\right.$ curcap $\left._{\mathrm{j}, \mathrm{q}}\right\}$ $\sum_{\mathrm{m} \in \mathrm{OCC}} \mathrm{LAB} \_$OCC_IND $\mathrm{m,j, \textrm {q }}$

E_ lndrev $\quad \operatorname{lndrev}_{\mathrm{q}}=\left(1.0 / \mathrm{AGGLND}_{\mathrm{q}}\right) \sum_{\mathrm{j} \in \mathrm{IND}} \quad \mathrm{q} \in \mathrm{RDES}$ $\operatorname{LAND}_{\mathrm{j}, \mathrm{q}}\left\{\mathrm{p}_{\mathrm{pland}} \mathrm{j, \textrm {q }}+\mathrm{n}_{\mathrm{j}, \mathrm{q}}\right\}$

Pagamentos agregados para o capital

E_octrev $\quad \operatorname{octrev}_{\mathrm{q}}=\left(1.0 / \mathrm{AGGOCT}_{\mathrm{q}}\right) \quad \mathrm{q} \in \mathrm{RDES}$

$$
\sum_{\mathrm{j} \in \mathrm{IND}} \mathrm{OTHCOST}_{\mathrm{j}, \mathrm{q}}\left\{\mathrm{p} 1 \text { oct }_{\mathrm{j}, \mathrm{q}}+\mathrm{x}_{\mathrm{Loct}} \mathrm{j, \textrm {q }}\right\}
$$

Pagamentos de outros custos agregados

E_taxind

$\operatorname{taxind}_{\mathrm{q}}=\left(1.0 / \operatorname{AGGTAX}_{\mathrm{q}}\right)$ $\left(\right.$ AGGTAX $1_{\mathrm{q}}$ taxrev $1_{\mathrm{q}}+$ AGGTAX $2_{\mathrm{q}}$ $\operatorname{taxrev} 2_{\mathrm{q}}+\mathrm{AGGTAX} 3_{\mathrm{q}}$ taxrev $3_{\mathrm{q}}+$ AGGTAX5 $5_{\mathrm{q}}$ taxrev5 $5_{\mathrm{q}}$ )

E_taxrevm

AGGTAXM $_{\mathrm{q}}$ taxrevm $_{\mathrm{q}}=$ $\sum_{\mathrm{i} \in \mathrm{COM}}$ TARIFF $_{\mathrm{i}, \mathrm{q}}\left\{\mathrm{pm}_{\mathrm{i}}+\right.$ natphi + xOimp $\left._{i, q}\right\}+$ IMPORTS $_{i, q}$ powtaxm $_{i}$

$\mathrm{q} \in \mathrm{RDES}$

$\mathrm{q} \in \mathrm{RDES}$
Valor agregado de impostos indiretos

Receita de tarifa agregada 
Tabela 6. As equações do modelo MIBRA.

\begin{tabular}{|c|c|c|c|}
\hline Identificadores & Equação & Índice & Descrição \\
\hline $\begin{array}{l}E_{-} c_{-} a \\
(74)\end{array}$ & 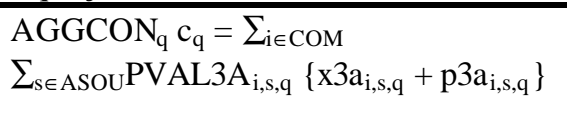 & $q \in \mathrm{RDES}$ & $\begin{array}{l}\text { Restrição orçamentária das } \\
\text { famílias }\end{array}$ \\
\hline $\begin{array}{l}E_{-} \mathrm{cr} \\
(75)\end{array}$ & $\mathrm{cr}_{\mathrm{q}}=\mathrm{c}_{\mathrm{q}}-\mathrm{xi} 3_{\mathrm{q}}$ & $\mathrm{q} \in \mathrm{RDES}$ & Consumo real das famílias \\
\hline $\begin{array}{l}\text { E_ xi3 } \\
\text { (76) }\end{array}$ & $\begin{array}{l}\mathrm{xi}_{\mathrm{q}}=\left(1.0 / \mathrm{AGGCON}_{\mathrm{q}}\right) \sum_{\mathrm{i} \in \mathrm{COM}} \\
\sum_{\mathrm{s} \in \text { ASOU }}{\text { PVAL } 3 A_{\mathrm{i}, \mathrm{s}, \mathrm{q}}}_{\mathrm{p} 3 \mathrm{a}_{\mathrm{i}, \mathrm{s}, \mathrm{q}}}\end{array}$ & $\mathrm{q} \in \mathrm{RDES}$ & $\begin{array}{l}\text { Índice de preços ao } \\
\text { consumidor }\end{array}$ \\
\hline $\begin{array}{l}\text { E_ir } \\
\text { (77) }\end{array}$ & $\begin{array}{l}\mathrm{ir}_{\mathrm{q}}=\left(1.0 / \mathrm{AGGINV}_{\mathrm{q}}\right) \sum_{\mathrm{j} \in \mathrm{IND}} \operatorname{INVEST}_{\mathrm{j}, \mathrm{q}} \\
\mathrm{y}_{\mathrm{j}, \mathrm{q}}\end{array}$ & $\mathrm{q} \in \mathrm{RDES}$ & Investimento real \\
\hline $\begin{array}{l}\text { E_othreal5 } \\
\text { (78) }\end{array}$ & $\begin{array}{l}\text { othreal5 }_{\mathrm{q}}=\left(1.0 / \text { AGGOTH5 }_{\mathrm{q}}\right) \sum_{\mathrm{i} \in \mathrm{COM}} \\
\sum_{\mathrm{s} \in \text { ASOU }_{\text {PVAL5A }}} \mathrm{i}_{\mathrm{i}, \mathrm{s}, \mathrm{q}} \times 5 \mathrm{a}_{\mathrm{i}, \mathrm{s}, \mathrm{q}}\end{array}$ & $\mathrm{q} \in \mathrm{RDES}$ & $\begin{array}{l}\text { Outras demandas regionais } \\
\text { real }\end{array}$ \\
\hline $\begin{array}{l}\text { E_othreal6 } \\
\text { (79) }\end{array}$ & $\begin{array}{l}\text { AGGOTH6 }_{\mathrm{q}} \text { othreal6 }_{\mathrm{q}}=\sum_{\mathrm{i} \in \mathrm{COM}} \\
\sum_{\mathrm{s} \in \text { ASOU }_{\text {PVAL6A }} \text { PV }_{\mathrm{s}, \mathrm{q}}} \times 6 \mathrm{a}_{\mathrm{i}, \mathrm{s}, \mathrm{q}}\end{array}$ & $\mathrm{q} \in \mathrm{RDES}$ & Outra demanda federal real \\
\hline $\begin{array}{l}\text { E_ int_exp } \\
\text { (80) }\end{array}$ & $\begin{array}{l}\text { C_XSEXP }{ }_{\mathrm{s}}\left(\operatorname{psexp}_{\mathrm{s}}+\operatorname{xsexp}_{\mathrm{s}}\right)= \\
\sum_{\mathrm{q} \in \mathrm{RDES} C \_X S F L O}{ }_{\mathrm{s}, \mathrm{q}}\left(\operatorname{psflo}_{\mathrm{s}, \mathrm{q}}+\mathrm{xsflo}_{\mathrm{s}, \mathrm{q}}\right) \\
-\mathrm{C} \_X S F L O_{\mathrm{s}, \mathrm{s}}\left(\operatorname{psflo}_{\mathrm{s}, \mathrm{s}}+\mathrm{xsflo}_{\mathrm{s}, \mathrm{s}}\right)\end{array}$ & $\mathrm{s} \in \mathrm{RSOU}$ & Exportações inter-regionais \\
\hline $\begin{array}{l}\text { E_ int_imp } \\
\text { (81) }\end{array}$ & 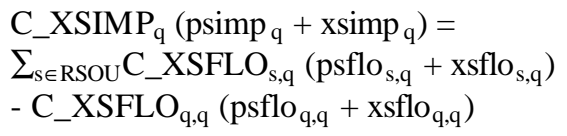 & $\mathrm{q} \in \mathrm{RDES}$ & Importações inter-regionais \\
\hline $\begin{array}{l}\text { E_expvol } \\
\text { (82) }\end{array}$ & $\operatorname{expvol}_{\mathrm{q}}=\operatorname{export}_{\mathrm{q}}+$ natphi $-\mathrm{xi}_{\mathrm{q}}$ & $\mathrm{q} \in \mathrm{RDES}$ & $\begin{array}{l}\text { Índice de volume } \\
\text { exportação }\end{array}$ \\
\hline $\begin{array}{l}\text { E_impvol } \\
(83)\end{array}$ & $\operatorname{impvol}_{q}=\operatorname{imp}_{q}+$ natphi $-\operatorname{xim}_{\mathrm{q}}$ & $\mathrm{q} \in \mathrm{RDES}$ & $\begin{array}{l}\text { Índice de volume } \\
\text { importação }\end{array}$ \\
\hline $\begin{array}{l}\text { E_ xi2 } \\
\text { (84) }\end{array}$ & $\begin{array}{l}\mathrm{xi}_{2_{\mathrm{q}}}=\left(1.0 / \mathrm{AGGINV}_{\mathrm{q}}\right) \\
\sum_{\mathrm{j} \in \mathrm{IND}} \operatorname{INVEST}_{\mathrm{j}, \mathrm{q}} \mathrm{pi}_{\mathrm{j}, \mathrm{q}}\end{array}$ & $\mathrm{q} \in \mathrm{RDES}$ & $\begin{array}{l}\text { Índice de preço } \\
\text { investimento }\end{array}$ \\
\hline E_ xi5 & $\begin{array}{l}\mathrm{xi} 5_{\mathrm{q}}=\left(1.0 / \text { AGGOTH }_{\mathrm{q}}\right) \\
\sum_{\mathrm{i} \in \mathrm{COM}} \sum_{\mathrm{s} \in \text { ASOU PVAL5A }} \mathrm{A}_{\mathrm{i}, \mathrm{s}, \mathrm{q}} \mathrm{p} 5 \mathrm{a}_{\mathrm{i}, \mathrm{s}, \mathrm{q}}\end{array}$ & $\mathrm{q} \in \mathrm{RDES}$ & $\begin{array}{l}\text { Índice de preços das outras } \\
\text { demandas regionais }\end{array}$ \\
\hline
\end{tabular}


Tabela 6. As equações do modelo MIBRA.

\begin{tabular}{|c|c|c|c|}
\hline Identificadores & Equação & Índice & Descrição \\
\hline $\begin{array}{l}\text { E_xi6 } \\
(86)\end{array}$ & 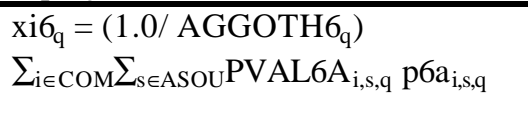 & $q \in \operatorname{RDES}$ & $\begin{array}{l}\text { Índice de preços para outra } \\
\text { demanda federal }\end{array}$ \\
\hline $\begin{array}{l}\text { E_psexp } \\
(87)\end{array}$ & $\begin{array}{l}\text { C_XSEXP } \operatorname{spexp}_{\mathrm{s}}= \\
\sum_{\mathrm{q} \in \mathrm{RDES} C \_X S F L O} \mathrm{~s}_{\mathrm{s}, \mathrm{q}} \mathrm{psflo}_{\mathrm{s}, \mathrm{q}}- \\
\mathrm{C} \_X S F L O_{\mathrm{s}, \mathrm{s}} \mathrm{psflo}_{\mathrm{s}, \mathrm{s}}\end{array}$ & $\mathrm{s} \in \mathrm{RSOU}$ & $\begin{array}{l}\text { Índice de preços para } \\
\text { exportações inter-regionais }\end{array}$ \\
\hline $\begin{array}{l}\text { E_psimp } \\
(88)\end{array}$ & 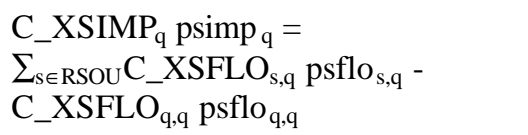 & $\mathrm{q} \in \mathrm{RDES}$ & $\begin{array}{l}\text { Índice de preços para } \\
\text { importações inter-regionais }\end{array}$ \\
\hline $\begin{array}{l}\text { E_ xi4 } \\
\text { (89) }\end{array}$ & $\begin{array}{l}\mathrm{xi}_{\mathrm{q}}-\text { natphi }=\left(1.0 / \mathrm{AGGEXP}_{\mathrm{q}}\right) \\
\sum_{\mathrm{i} \in \mathrm{COM}} \mathrm{PVAL} 4 \mathrm{R}_{\mathrm{i}, \mathrm{q}} \mathrm{p} 4 \mathrm{r}_{\mathrm{i}, \mathrm{q}}\end{array}$ & $\mathrm{q} \in \mathrm{RDES}$ & $\begin{array}{l}\text { Índice de preços para as } \\
\text { exportações estrangeiras }\end{array}$ \\
\hline $\begin{array}{l}\text { E_xim } \\
\text { (90) }\end{array}$ & $\begin{array}{l}\operatorname{xim}_{\mathrm{q}}-\text { natphi }=\left(1.0 / \operatorname{AGGIMP}_{\mathrm{q}}\right) \\
\sum_{\mathrm{i} \in \mathrm{COM}} \mathrm{IMPCOST}_{\mathrm{i}, \mathrm{q}} \mathrm{pm}_{\mathrm{i}}\end{array}$ & $\mathrm{q} \in \mathrm{RDES}$ & $\begin{array}{l}\text { Índice de preços para } \\
\text { importações estrangeiras }\end{array}$ \\
\hline $\begin{array}{l}E_{-} \text {in } \\
(91)\end{array}$ & $\mathrm{in}_{\mathrm{q}}=\mathrm{ir_{ \textrm {q } }}+\mathrm{xi} 2_{\mathrm{q}}$ & $\mathrm{q} \in \mathrm{RDES}$ & Investimento nominal \\
\hline $\begin{array}{l}\text { E_othnom5 } \\
\text { (92) }\end{array}$ & othnom $5_{\mathrm{q}}=$ othreal5 $5_{\mathrm{q}}+\mathrm{xi} 5_{\mathrm{q}}$ & $\mathrm{q} \in \mathrm{RDES}$ & $\begin{array}{l}\text { Valor nominal de outras } \\
\text { demandas regionais }\end{array}$ \\
\hline $\begin{array}{l}\text { E_othnom6 } \\
\text { (93) }\end{array}$ & othnom $6_{\mathrm{q}}=$ othreal $_{\mathrm{q}}+$ xi6 $_{\mathrm{q}}$ & $\mathrm{q} \in \mathrm{RDES}$ & $\begin{array}{l}\text { Outra demanda federal } \\
\text { nominal }\end{array}$ \\
\hline $\begin{array}{l}\text { E_export } \\
\text { (94) }\end{array}$ & $\begin{array}{l}\operatorname{export}_{\mathrm{q}}=\left(1.0 / \text { AGGEXP }_{\mathrm{q}}\right) \\
\sum_{\mathrm{i} \in \mathrm{COM}} \operatorname{PVAL} 4 \mathrm{R}_{\mathrm{i}, \mathrm{q}}\left[\mathrm{p} 4 \mathrm{r}_{\mathrm{i}, \mathrm{q}}+\mathrm{x} 4 \mathrm{r}_{\mathrm{i}, \mathrm{q}}\right]\end{array}$ & $\mathrm{q} \in \mathrm{RDES}$ & $\begin{array}{l}\text { Valor da moeda estrangeira } \\
\text { das exportações }\end{array}$ \\
\hline $\begin{array}{l}E_{-} \operatorname{imp} \\
(95)\end{array}$ & $\begin{array}{l}\operatorname{imp}_{q}=\left(1.0 / \operatorname{AGGIMP}_{\mathrm{q}}\right) \\
\sum_{\mathrm{i} \in \mathrm{COM}} \operatorname{IMPCOST}_{\mathrm{i}, \mathrm{q}}\left[\mathrm{pm}_{\mathrm{i}}+\mathrm{x} 0 \mathrm{imp}_{\mathrm{i}, \mathrm{q}}\right]\end{array}$ & $\mathrm{q} \in \mathrm{RDES}$ & $\begin{array}{l}\text { Valor da moeda estrangeira } \\
\text { das importações }\end{array}$ \\
\hline $\begin{array}{l}\text { E_trd } \\
(96)\end{array}$ & $\begin{array}{l}\text { C_XSFLO }{ }_{\mathrm{s}, \mathrm{q}}\left(\mathrm{psflo}_{\mathrm{s}, \mathrm{q}}+\mathrm{xsflo}_{\mathrm{s}, \mathrm{q}}\right)= \\
\sum_{\mathrm{i} \in \mathrm{COM}} \sum_{\mathrm{j} \in \mathrm{IND}} \mathrm{BAS} 1_{\mathrm{i}, \mathrm{s}, \mathrm{q}, \mathrm{q}}\left(\mathrm{p} 0 \mathrm{a}_{\mathrm{i}, \mathrm{s}}+\right. \\
\left.\mathrm{x} 1 \mathrm{a}_{\mathrm{i}, \mathrm{s}, \mathrm{j}, \mathrm{q}}\right)+\sum_{\mathrm{i} \in \mathrm{COM}} \sum_{\mathrm{j} \in \mathbb{I N D} \mathrm{BAS} 2_{\mathrm{i}, \mathrm{s}, \mathrm{j}, \mathrm{q}}} \\
\left(\mathrm{p} 0 \mathrm{a}_{\mathrm{i}, \mathrm{s}}+\mathrm{x} 2 \mathrm{a}_{\mathrm{i}, \mathrm{s}, \mathrm{j}, \mathrm{q}}\right)+\sum_{\mathrm{i} \in \mathrm{COM}} \mathrm{BAS} 3_{\mathrm{i}, \mathrm{s}, \mathrm{q}} \\
\left(\mathrm{p} 0 \mathrm{a}_{\mathrm{i}, \mathrm{s}}+\mathrm{x} 3 \mathrm{a}_{\mathrm{i}, \mathrm{s}, \mathrm{q}}\right)+\sum_{\mathrm{i} \in \mathrm{COM}} \mathrm{BAS} 5_{\mathrm{i}, \mathrm{s}, \mathrm{q}} \\
\left(\mathrm{p} 0 \mathrm{a}_{\mathrm{i}, \mathrm{s}}+\mathrm{x} 5 \mathrm{a}_{\mathrm{i}, \mathrm{s}, \mathrm{q}}\right)\end{array}$ & $\begin{array}{l}\mathrm{s} \in \mathrm{RSOU} \\
\mathrm{q} \in \mathrm{RDES}\end{array}$ & $\begin{array}{l}\text { Fluxos de comércio inter- } \\
\text { regionais (inclusive termo } \\
\text { diagonal) }\end{array}$ \\
\hline
\end{tabular}


Tabela 6. As equações do modelo MIBRA.

\begin{tabular}{|c|c|c|c|}
\hline Identificadores & Equação & Índice & Descrição \\
\hline $\begin{array}{l}\text { E_psflo } \\
(97)\end{array}$ & $\begin{array}{l}\text { C_XSFLO }_{\mathrm{s}, \mathrm{q}} \mathrm{psflo}_{\mathrm{s}, \mathrm{q}}=\sum_{\mathrm{i} \in \mathrm{COM}} \\
\sum_{\mathrm{j} \in \mathrm{IND}} \mathrm{BAS} 1_{\mathrm{i}, \mathrm{s}, \mathrm{j}, \mathrm{q}} \mathrm{p} 0 \mathrm{a}_{\mathrm{i}, \mathrm{s}}+\sum_{\mathrm{i} \in \mathrm{COM}} \\
\sum_{\mathrm{j} \in \mathrm{IND}} \mathrm{BAS} 2_{\mathrm{i}, \mathrm{s}, \mathrm{q}, \mathrm{q}} \mathrm{p} 0 \mathrm{a}_{\mathrm{i}, \mathrm{s}}+\sum_{\mathrm{i} \in \mathrm{COM}} \\
\mathrm{BAS} 3_{\mathrm{i}, \mathrm{s}, \mathrm{q}} \mathrm{p} 0 \mathrm{a}_{\mathrm{i}, \mathrm{s}}+\sum_{\mathrm{i} \in \mathrm{COM}} \mathrm{BAS} 5_{\mathrm{i}, \mathrm{s}, \mathrm{q}} \mathrm{p} 0 \mathrm{a}_{\mathrm{i}, \mathrm{s}}\end{array}$ & $\begin{array}{l}\mathrm{s} \in \mathrm{RSOU} \\
\mathrm{q} \in \mathrm{RDES}\end{array}$ & $\begin{array}{l}\text { Índice de preços para fluxos } \\
\text { de comércio inter-regional }\end{array}$ \\
\hline \multicolumn{4}{|c|}{ Salários semanais regionais } \\
\hline $\begin{array}{l}\text { E_p1laboi } \\
(98)\end{array}$ & p1laboi $\dot{j}_{\mathrm{j}, \mathrm{q}, \mathrm{m}}=$ pwage $_{\mathrm{j}, \mathrm{q}}+\operatorname{arpri}_{\mathrm{j}, \mathrm{q}}$ & $\begin{array}{l}\mathrm{j} \in \mathrm{IND} \\
\mathrm{q} \in \mathrm{RDES} \\
\mathrm{m} \in \mathrm{OCC}\end{array}$ & $\begin{array}{l}\text { Ajuste no imposto na folha de } \\
\text { pagamento }\end{array}$ \\
\hline $\begin{array}{l}\text { E_pwagei } \\
\text { (99) }\end{array}$ & $\begin{array}{l}\text { pwagei }_{j, q}=\text { natxi3 } 3 \text { natfwage }+ \text { fwage }_{q} \\
+ \text { fwage }_{j, q}\end{array}$ & $\begin{array}{l}\mathrm{j} \in \mathrm{IND} \\
\mathrm{q} \in \mathrm{RDES}\end{array}$ & $\begin{array}{l}\text { Definição flexível de salários } \\
\text { semanais dinheiros }\end{array}$ \\
\hline $\begin{array}{l}\text { E_wage_diff } \\
(100)\end{array}$ & $\begin{array}{l}\text { wage_diff } \\
\text { natrealwage }\end{array}$ & $q \in \operatorname{RDES}$ & $\begin{array}{l}\text { Diferencial de salário semanal } \\
\text { real regional }\end{array}$ \\
\hline $\begin{array}{l}\text { E_pwage } \\
(101)\end{array}$ & $\begin{array}{l}\text { AGGLAB }_{\mathrm{q}} \text { pwage }_{\mathrm{q}}= \\
\sum_{\mathrm{j} \in \mathrm{IND}_{\mathrm{LABOUR}} \mathrm{LABq}_{\mathrm{q}} \text { pwagei }_{\mathrm{j}, \mathrm{q}}}\end{array}$ & $\mathrm{q} \in \mathrm{RDES}$ & $\begin{array}{lcr}\text { Salário } & \text { semanal } & \text { nominal } \\
\text { regional } & \text { recebido } & \text { pelos } \\
\text { trabalhadores }\end{array}$ \\
\hline $\begin{array}{l}\text { E_natrealw } \\
(102)\end{array}$ & $\begin{array}{l}\text { NATAGGLAB natrealwage }=\sum_{\mathrm{j} \in \text { IND }} \\
\sum_{\mathrm{q} \in \text { RDES} L A B O U R_{\mathrm{j}, \mathrm{q}}}(\text { natfwage }+ \\
\left.\text { fwage }_{\mathrm{q}}+\text { fwagei }_{\mathrm{j}, \mathrm{q}}\right)\end{array}$ & & $\begin{array}{l}\text { Salário semanal real nacional: } \\
\text { consumidor }\end{array}$ \\
\hline \multicolumn{4}{|c|}{ Outras definições de fator de Mercado regional } \\
\hline $\begin{array}{l}E_{-} 1 \\
(103)\end{array}$ & $\begin{array}{l}1_{\mathrm{q}}=\left(1.0 / \mathrm{AGGLAB}_{\mathrm{q}}\right) \\
\sum_{\mathrm{j} \in \mathrm{IND}} \mathrm{LABOUR}_{\mathrm{j}, \mathrm{q}} \text { labind }_{\mathrm{j}, \mathrm{q}}\end{array}$ & $\mathrm{q} \in \mathrm{RDES}$ & $\begin{array}{l}\text { Emprego: pesos/ponderações } \\
\text { dos salários }\end{array}$ \\
\hline $\begin{array}{l}\mathrm{E}_{-} \mathrm{kt} \\
(104)\end{array}$ & $\begin{array}{l}\mathrm{kt}_{\mathrm{q}}=\left(1.0 / \operatorname{AGGCAP}_{\mathrm{q}}\right) \\
\sum_{\mathrm{j} \in \mathrm{IND}} \operatorname{CAPITAL}_{\mathrm{j}, \mathrm{q}} \operatorname{curcap}_{\mathrm{j}, \mathrm{q}}\end{array}$ & $\mathrm{q} \in \mathrm{RDES}$ & $\begin{array}{l}\text { Uso do capital: ponderações } \\
\text { dos aluguéis }\end{array}$ \\
\hline $\begin{array}{l}E_{-} z_{-} \text {tot } \\
(105)\end{array}$ & $\begin{array}{l}\text { TOTFAC }_{\mathrm{q}} \mathrm{z}_{-} \text {tot }_{\mathrm{q}}= \\
\sum_{\mathrm{j} \in \mathrm{IND}} \text { TOTFACIND }_{\mathrm{j}, \mathrm{q}} \mathrm{z}_{\mathrm{j}, \mathrm{q}}\end{array}$ & $\mathrm{q} \in \mathrm{RDES}$ & $\begin{array}{l}\text { Produto: ponderações de } \\
\text { valor adicionado }\end{array}$ \\
\hline $\begin{array}{l}\text { E_lambda } \\
\text { (106) }\end{array}$ & $\begin{array}{l}\text { LAB_OCC }_{\mathrm{m}, \mathrm{q}} \operatorname{lambda}_{\mathrm{m}, \mathrm{q}}= \\
\sum_{\mathrm{j} \in \mathrm{IND} L A B \_O C C \_I N D_{\mathrm{m}, \mathrm{j}, \mathrm{q}} \times 1 \text { laboi }_{\mathrm{j}, \mathrm{q}, \mathrm{m}}}\end{array}$ & $\begin{array}{l}\mathrm{m} \in \mathrm{OCC} \\
\mathrm{q} \in \mathrm{RDES}\end{array}$ & $\begin{array}{l}\text { Demanda por trabalho por } \\
\text { ocupação }\end{array}$ \\
\hline $\begin{array}{l}\text { E_ }_{-} \text {pwage_p } \\
(107)\end{array}$ & $\begin{array}{l}\text { AGGLAB }{ }_{\mathrm{q}} \text { pwage_p } \mathrm{p}_{\mathrm{q}}= \\
\sum_{\mathrm{j} \in \mathrm{IND}} \mathrm{LABOUR}_{\mathrm{j}, \mathrm{q}} \mathrm{p} 1 \mathrm{lab}_{\mathrm{j}, \mathrm{q}}\end{array}$ & $\mathrm{q} \in \mathrm{RDES}$ & $\begin{array}{l}\text { Salário semanal nominal pago } \\
\text { pelos produtores }\end{array}$ \\
\hline
\end{tabular}


Tabela 6. As equações do modelo MIBRA.

\begin{tabular}{|c|c|c|c|}
\hline Identificadores & Equação & Índice & Descrição \\
\hline $\begin{array}{l}\text { E_reg_p1cap } \\
(108)\end{array}$ & reg_p1cap ${ }_{q}=\operatorname{caprev}_{\mathrm{q}}-\mathrm{kt}_{\mathrm{q}}$ & $\mathrm{q} \in \mathrm{RDES}$ & 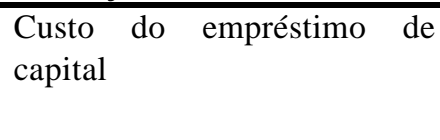 \\
\hline $\begin{array}{l}\text { E_realwage_ } \\
\text { w } \\
(109)\end{array}$ & Realwage__w $\mathrm{w}_{\mathrm{q}}=\mathrm{pwage}_{\mathrm{q}}-\mathrm{xi} 3_{\mathrm{q}}$ & $\mathrm{q} \in \mathrm{RDES}$ & $\begin{array}{l}\text { Salários semanais reais para } \\
\text { trabalhadores deflacionados } \\
\text { pelo IPC }\end{array}$ \\
\hline $\begin{array}{l}E_{-} \text {realwage_p } \\
(110)\end{array}$ & Realwage $\_p_{q}=$ pwage $\_p_{q}-x i y \_r_{q}$ & $\mathrm{q} \in \mathrm{RDES}$ & $\begin{array}{l}\text { Salários semanais reais para } \\
\text { produtores: deflacionados } \\
\text { pelo deflator implícito do PIB }\end{array}$ \\
\hline $\begin{array}{l}\mathrm{E}_{-} \mathrm{r}_{-} \text {tot } \\
(111)\end{array}$ & $\begin{array}{l}\mathrm{r} 0 \_ \text {tot }_{\mathrm{q}}=\left(1.0 / \mathrm{AGGCAP}_{\mathrm{q}}\right) \\
\sum_{\mathrm{j} \in \mathrm{IND}} \mathrm{CAPITAL}_{\mathrm{j}, \mathrm{q}} \mathrm{r}_{\mathrm{j}, \mathrm{q}}\end{array}$ & $\mathrm{q} \in \mathrm{RDES}$ & $\begin{array}{l}\text { Taxa de retorno sobre o } \\
\text { capital }\end{array}$ \\
\hline $\begin{array}{l}\text { E_ xiplpk_ind } \\
\text { (112) }\end{array}$ & xiplpk_ind $d_{j, q}=p 1 l a b_{j, q}-p 1 c a p_{j, q}$ & $\begin{array}{l}j \in \text { IND } \\
q \in \text { RDES }\end{array}$ & $\begin{array}{l}\text { Índice dos movimentos de } \\
\text { preços relativos do trabalho e } \\
\text { do capital }\end{array}$ \\
\hline $\begin{array}{l}\text { E_ xiplpk } \\
\text { (113) }\end{array}$ & 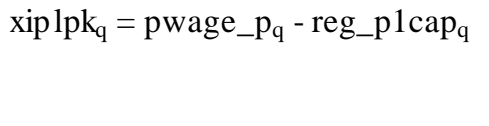 & $\mathrm{q} \in \mathrm{RDES}$ & $\begin{array}{l}\text { Índice dos movimentos do } \\
\text { preço relativo do trabalho e } \\
\text { do capital: agregado regional }\end{array}$ \\
\hline
\end{tabular}

Outras equações regionais miscelâneos

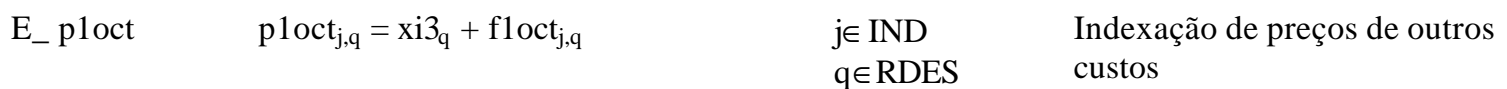

E_cr_shr $\quad \mathrm{cr}_{\mathrm{q}}=$ natcr $+\mathrm{cr}_{-} \mathrm{shr}_{\mathrm{q}} \quad \mathrm{q} \in \mathrm{RDES} \quad$ Parcelas regionais no

E_ ximp0 $\quad \operatorname{ximp}_{\mathrm{q}}=\left(1.0 /\left[\operatorname{AGGIMP}_{\mathrm{q}}+\quad \mathrm{q} \in \mathrm{RDES}\right.\right.$ Índice de preços de AGGTAXM $_{\mathrm{q}}$ ]) $\sum_{\mathrm{i} \in \text { COM IMPORTS }_{\mathrm{i}, \mathrm{q}} \quad \mathrm{s}=\text { estrangeiro }}$ $\mathrm{pOa}_{\mathrm{i}, \mathrm{s}} \quad$ importações pagos

E_totdom $\operatorname{totdom}_{\mathrm{q}}=\operatorname{psexp}_{\mathrm{q}}-\operatorname{psimp}_{\mathrm{q}} \quad \mathrm{q} \in \mathrm{RDES} \quad$ Termos domésticos de

E_totfor totfor $_{\mathrm{q}}=\mathrm{xi}_{\mathrm{q}}-\mathrm{xim}_{\mathrm{q}} \quad \mathrm{q} \in \mathrm{RDES} \quad \begin{aligned} & \text { Termos } \\ & \text { comércio }\end{aligned}$ estrangeiros de 
Tabela 6. As equações do modelo MIBRA.

\begin{tabular}{|c|c|c|c|}
\hline Identificadores & Equação & Índice & Descrição \\
\hline $\begin{array}{l}\text { E_nattaxrev1 } \\
(119)\end{array}$ & $\begin{array}{l}\text { NATAGGTAX1 nattaxrev } 1= \\
\sum_{\mathrm{q} \in \text { RDESAGGTAX } 1_{\mathrm{q}} \text { taxrev } 1_{\mathrm{q}}}\end{array}$ & & $\begin{array}{l}\text { Receita proveniente de } \\
\text { impostos indiretos coletados } \\
\text { nos fluxos para o usuário } 1\end{array}$ \\
\hline $\begin{array}{l}\text { E_nattaxrev2 } \\
(120)\end{array}$ & $\begin{array}{l}\text { NATAGGTAX2 nattaxrev } 2= \\
\sum_{\mathrm{q} \in \text { RDESAGGTAX } 2_{\mathrm{q}} \text { taxrev } 2_{\mathrm{q}}}\end{array}$ & & $\begin{array}{l}\text { Receita proveniente de } \\
\text { impostos indiretos coletados } \\
\text { nos fluxos para o usuário } 2\end{array}$ \\
\hline $\begin{array}{l}\text { E_nattaxrev3 } \\
\text { (121) }\end{array}$ & $\begin{array}{l}\text { NATAGGTAX3 nattaxrev3 = } \\
\sum_{\mathrm{q} \in \text { RDESAGGTAX } 33_{\mathrm{q}} \text { taxrev } 3_{\mathrm{q}}}\end{array}$ & & $\begin{array}{l}\text { Receita proveniente de } \\
\text { impostos indiretos coletados } \\
\text { nos fluxos para o usuário } 3\end{array}$ \\
\hline $\begin{array}{l}\text { E_nattaxrev4 } \\
(122)\end{array}$ & $\begin{array}{l}\text { NATAGGTAX4 nattaxrev } 4=\sum_{\mathrm{s} \in \mathrm{RSOU}} \\
\text { AGGTAX } 4_{\mathrm{s}} \text { taxrev } 4_{\mathrm{s}}\end{array}$ & & $\begin{array}{l}\text { Receita proveniente de } \\
\text { impostos indiretos coletados } \\
\text { nos fluxos para o usuário } 4\end{array}$ \\
\hline $\begin{array}{l}\text { E_nattaxrev5 } \\
(123)\end{array}$ & $\begin{array}{l}\text { NATAGGTAX5 nattaxrev5 = } \\
\sum_{\mathrm{q} \in \text { RDESAGGTAX } 5_{\mathrm{q}} \text { taxrev } 5_{\mathrm{q}}}\end{array}$ & & $\begin{array}{l}\text { Receita proveniente de } \\
\text { impostos indiretos coletados } \\
\text { nos fluxos para o usuário } 5\end{array}$ \\
\hline $\begin{array}{l}\text { E_nattaxrev6 } \\
(124)\end{array}$ & $\begin{array}{l}\text { NATAGGTAX6 nattaxrev6 = } \\
\sum_{\mathrm{q} \in \text { RDESAGGTAX }} 6_{\mathrm{q}} \text { taxrev } 6_{\mathrm{q}}\end{array}$ & & $\begin{array}{l}\text { Receita proveniente de } \\
\text { impostos indiretos coletados } \\
\text { nos fluxos para o usuário } 6\end{array}$ \\
\hline $\begin{array}{l}\text { E_ natx0imp }_{-} \\
(125)\end{array}$ & $\begin{array}{l}\text { NATIMPORTS }_{\mathrm{i}} \text { natxOimp }_{\mathrm{i}}= \\
\sum_{\mathrm{q} \in \text { RDESIMPORTS }_{\mathrm{i}, \mathrm{q}} \text { x0imp }} \text { IMP }_{\mathrm{q}}\end{array}$ & $\mathrm{i} \in \mathrm{COM}$ & Volumes de importação \\
\hline $\begin{array}{l}\text { E_ natlabind } \\
(126)\end{array}$ & $\begin{array}{l}\text { NATLABOUR }_{\mathrm{j}} \text { natlabind } \\
\sum_{\mathrm{q} \in \mathrm{RDES}_{\mathrm{j}} L A B O U R_{\mathrm{j}, \mathrm{q}}} \text { labind }_{\mathrm{j}, \mathrm{q}}\end{array}$ & $\mathrm{j} \in \mathrm{IND}$ & $\begin{array}{l}\text { Emprego: pesos/ponderações } \\
\text { dos salários }\end{array}$ \\
\hline $\begin{array}{l}\text { E_ natcaprev } \\
(127)\end{array}$ & $\begin{array}{l}\text { natcaprev }=(1.0 / \text { NATAGGCAP }) \\
\sum_{\mathrm{q} \in \mathrm{RDES}} \mathrm{AGGCAP}_{\mathrm{q}} \operatorname{caprev}_{\mathrm{q}}\end{array}$ & & Pagamentos para o capital \\
\hline $\begin{array}{l}\text { E_ natlabrev } \\
(128)\end{array}$ & $\begin{array}{l}\text { natlabrev }=(1.0 / \text { NATAGGLAB }) \\
\sum_{\mathrm{q} \in \text { RDES }} \text { AGGLAB }_{\mathrm{q}} \operatorname{labrev}_{\mathrm{q}}\end{array}$ & & Pagamento para o trabalho \\
\hline $\begin{array}{l}\text { E_ natlndrev } \\
(129)\end{array}$ & $\begin{array}{l}\text { natlndrev }=(1.0 / \text { NATAGGLND }) \\
\sum_{\mathrm{q} \in \text { RDES}} \text { AGGLND }_{\mathrm{q}} \operatorname{lndrev}_{\mathrm{q}}\end{array}$ & & Pagamento para a terra \\
\hline $\begin{array}{l}\text { E_ natoctrev } \\
(130)\end{array}$ & $\begin{array}{l}\text { natoctrev }=(1.0 / \text { NATAGGOCT }) \\
\sum_{\mathrm{q} \in \text { RDES}} \text { AGGOCT }_{\mathrm{q}} \text { octrev }_{\mathrm{q}}\end{array}$ & & Pagamento para outros custos \\
\hline
\end{tabular}


Tabela 6. As equações do modelo MIBRA.

\begin{tabular}{|c|c|c|c|}
\hline Identificadores & Equação & Índice & Descrição \\
\hline $\begin{array}{l}\text { E_nattaxrevm } \\
(131)\end{array}$ & $\begin{array}{l}\text { nattaxrevm = (1.0/ NATAGGTAXM }) \\
\sum_{\mathrm{q} \in \text { RDESAGGTAXM }} \text { taxrevm }_{\mathrm{q}}\end{array}$ & & Receita de tarifas \\
\hline $\begin{array}{l}\text { E_ nattaxind } \\
\text { (132) }\end{array}$ & $\begin{array}{l}\text { nattaxind }=(1.0 / \text { NATAGGTAX })( \\
\text { NATAGGTAX1 nattaxrev1 }+ \\
\text { NATAGGTAX2 nattaxrev2 + } \\
\text { NATAGGTAX3 nattaxrev3 + } \\
\text { NATAGGTAX4 nattaxrev4 + } \\
\text { NATAGGTAX5 nattaxrev5+ } \\
\text { NATAGGTAX6 nattaxrev6 + } \\
\text { NATAGGTAXM nattaxrevm) }\end{array}$ & & Valor de impostos indiretos \\
\hline $\begin{array}{l}\text { E_natgdpinc } \\
\text { (133) }\end{array}$ & $\begin{array}{l}\text { natgdpinc }=(1.0 / \text { NATGDPIN })( \\
\text { NATAGGLND natlndrev }+ \\
\text { NATAGGCAP natcaprev }+ \\
\text { NATAGGLAB natlabrev }+ \\
\text { NATAGGOCT natoctrev }+ \\
\text { NATAGGTAX nattaxind })\end{array}$ & & $\begin{array}{l}\text { PIB nominal pelo lado da } \\
\text { renda }\end{array}$ \\
\hline $\begin{array}{l}\text { E_natkt } \\
\text { (134) }\end{array}$ & $\begin{array}{l}\text { natkt }=(1.0 / \text { NATAGGCAP }) \\
\sum_{\mathrm{q} \in \text { RDES }} \text { AGGCAP }_{\mathrm{q}} \mathrm{kt}_{\mathrm{q}}\end{array}$ & & $\begin{array}{lr}\text { Utilização do capital: } \\
\text { pesos/ponderações } \\
\text { aluguéis }\end{array}$ \\
\hline $\begin{array}{l}\text { E_natl } \\
\text { (135) }\end{array}$ & $\begin{array}{l}\text { natl }=(1.0 / \text { NATAGGLAB }) \\
\sum_{\mathrm{q} \in \text { RDES }} \text { AGGLAB }_{\mathrm{q}} \mathrm{l}_{\mathrm{q}}\end{array}$ & & $\begin{array}{l}\text { Emprego: pesos/ponderações } \\
\text { dos salários }\end{array}$ \\
\hline $\begin{array}{l}E_{-} \text {natz_tot } \\
\text { (136) }\end{array}$ & $\begin{array}{l}\text { NATTOTFAC natz_tot }= \\
\sum_{q \in \text { RDES TOTFAC }_{\mathrm{q}} z_{-} \text {tot }_{\mathrm{q}}}\end{array}$ & & $\begin{array}{lr}\text { Produto } & \text { agregado: } \\
\begin{array}{l}\text { ponderações } \\
\text { adicionado }\end{array} & \text { valor }\end{array}$ \\
\hline $\begin{array}{l}\text { E_natz } \\
(137)\end{array}$ & $\begin{array}{l}\text { NATTOTFACIND }_{\mathrm{j}} \text { natz }_{\mathrm{j}}= \\
\sum_{\mathrm{q} \in \text { RDESTOTFACIND }_{\mathrm{j}, \mathrm{q}} \mathrm{z}_{\mathrm{j}, \mathrm{q}}}\end{array}$ & $\mathrm{j} \in \mathrm{IND}$ & $\begin{array}{l}\text { Produto setorial: ponderações } \\
\text { de valor adicionado }\end{array}$ \\
\hline $\begin{array}{l}\text { E_natc } \\
(138)\end{array}$ & $\begin{array}{l}\text { NATAGGCON natc }= \\
\sum_{\mathrm{q} \in \text { RDESAGGCON }_{\mathrm{q}} \mathrm{c}_{\mathrm{q}}}\end{array}$ & & $\begin{array}{l}\text { Consumo nominal das } \\
\text { famílias }\end{array}$ \\
\hline $\begin{array}{l}\text { E_natcr } \\
(139)\end{array}$ & $\begin{array}{l}\text { NATAGGCON natcr }= \\
\sum_{\mathrm{q} \in \mathrm{RDES}_{\mathrm{AGGCON}} \mathrm{Ar}_{\mathrm{q}}}\end{array}$ & & Consumo real das famílias \\
\hline E_ natin & natin $=$ natir + natxi 2 & & Investimento nominal \\
\hline
\end{tabular}


Tabela 6. As equações do modelo MIBRA.

\begin{tabular}{|c|c|c|}
\hline Identificadores & Equação & Descrição \\
\hline $\begin{array}{l}\text { E_natir } \\
(141)\end{array}$ & $\begin{array}{l}\text { natir }=(1.0 / \text { NATAGGINV } \\
\sum_{\mathrm{j} \in \text { IND }} \text { NATINVEST }_{\mathrm{j}} \text { naty }_{\mathrm{j}}\end{array}$ & Investimento real \\
\hline $\begin{array}{l}\text { E_natothnom5 } \\
(142)\end{array}$ & natothnom5 $=$ natothreal5 + natxi5 & $\begin{array}{l}\text { Valor nominal de outras } \\
\text { demandas regionais }\end{array}$ \\
\hline $\begin{array}{l}\text { E_natothnom6 } \\
\text { (143) }\end{array}$ & natothnom6 $=$ natothreal $6+$ natxi 6 & $\begin{array}{l}\text { Valor nominal de outras } \\
\text { demandas federais }\end{array}$ \\
\hline $\begin{array}{l}\text { E_ natothreal5 } \\
(144)\end{array}$ & $\begin{array}{l}\text { natothreal5 = (1.0/ NATAGGOTH5 }) \\
\sum_{\mathrm{q} \in \text { RDESAGGOTH5 }} \text { othreal5 } 5_{\mathrm{q}}\end{array}$ & $\begin{array}{l}\text { Outras demandas regionais } \\
\text { reais }\end{array}$ \\
\hline $\begin{array}{l}\text { E_ natothreal6 } \\
(145)\end{array}$ & $\begin{array}{l}\text { NATAGGOTH6 natothreal6 }= \\
\sum_{\mathrm{i} \in \mathrm{COM}} \sum_{\mathrm{s} \in \mathrm{ASOU}} \sum_{\mathrm{q} \in \mathrm{RDES}} \mathrm{PVAL}_{\mathrm{A}} 6 \mathrm{~A}_{\mathrm{i}, \mathrm{s}, \mathrm{q}} \\
\mathrm{x} 6 \mathrm{a}_{\mathrm{i}, \mathrm{s}, \mathrm{q}}\end{array}$ & $\begin{array}{l}\text { Outras demandas federais } \\
\text { reais }\end{array}$ \\
\hline $\begin{array}{l}\text { E_natexport } \\
\text { (146) }\end{array}$ & $\begin{array}{l}\text { natexport }=(1.0 / \text { NATAGGEXP } \\
\sum_{\mathrm{s} \in \text { RSOU }} \text { AGGEXP }_{\mathrm{s}} \text { export }_{\mathrm{s}}\end{array}$ & $\begin{array}{l}\text { Valor da moeda estrangeira } \\
\text { das exportações }\end{array}$ \\
\hline $\begin{array}{l}\text { E_natexpvol } \\
\text { (147) }\end{array}$ & natexpvol $=$ natexport + natphi - natxi 4 & $\begin{array}{l}\text { Índice do volume de } \\
\text { exportação }\end{array}$ \\
\hline $\begin{array}{l}\text { E_ natimp } \\
(148)\end{array}$ & $\begin{array}{l}\text { natimp }=(1.0 / \text { NATAGGIMP }) \\
\sum_{\mathrm{i} \in \mathrm{COMMNATIMPCOST}_{\mathrm{i}}\left[\mathrm{pm}_{\mathrm{i}}+\right.} \\
\left.\text { natxOimp }_{\mathrm{i}}\right]\end{array}$ & $\begin{array}{l}\text { Valor da moeda estrangeira } \\
\text { das importações }\end{array}$ \\
\hline $\begin{array}{l}\text { E_ natimpvol } \\
\text { (149) }\end{array}$ & natimpvol $=$ natimp + natphi - natxim & $\begin{array}{l}\text { Índice do volume de } \\
\text { importação }\end{array}$ \\
\hline $\begin{array}{l}E_{-} \text {natgdpexp } \\
(150)\end{array}$ & $\begin{array}{l}\text { natgdpexp }=(1.0 / \text { NATGDPEX }) \\
(\text { NATAGGCON natc + NATAGGINV } \\
\text { natin + NATAGGOTH5 natothnom5 + } \\
\text { NATAGGOTH6 natothnom6 + } \\
\text { NATAGGEXP ( natexport + natphi })- \\
\text { NATAGGIMP ( natimp + natphi) })\end{array}$ & $\begin{array}{l}\text { PIB nominal proveniente do } \\
\text { lado dos gastos }\end{array}$ \\
\hline E_natgdpreal & natgdpreal $=$ natgdpexp - natxigdp & PIB real: lado do gasto \\
\hline
\end{tabular}


Tabela 6. As equações do modelo MIBRA.

\begin{tabular}{|c|c|c|c|}
\hline Identificadores & Equação & Índice & Descrição \\
\hline $\begin{array}{l}\text { E_ natdelb } \\
(152)\end{array}$ & $\begin{array}{l}100000 \text { natdelb }=\text { NATAGGEXP } \\
\text { natexport }- \text { NATAGGIMP natimp }\end{array}$ & & $\begin{array}{l}\text { Balanço de comércio em } \\
\text { bilhões de Dólares }\end{array}$ \\
\hline $\begin{array}{l}\text { E_natxi3 } \\
(153)\end{array}$ & $\begin{array}{l}\text { NATAGGCON natxi3 = } \\
\sum_{\mathrm{q} \in \text { RDESAGGCON }_{\mathrm{q}} \text { xi } 3_{\mathrm{q}}}\end{array}$ & & $\begin{array}{l}\text { Índice de preços ao } \\
\text { consumidor }\end{array}$ \\
\hline $\begin{array}{l}\text { E_natxi2 } \\
(154)\end{array}$ & $\begin{array}{l}\text { NATAGGINV natxi } 2= \\
\sum_{\mathrm{q} \in \text { RDES}} \text { AGGINV }_{\mathrm{q}} \mathrm{xi} 2_{\mathrm{q}}\end{array}$ & & $\begin{array}{l}\text { Índice de preços ao } \\
\text { investimento }\end{array}$ \\
\hline $\begin{array}{l}\text { E_natxi4 } \\
(155)\end{array}$ & $\begin{array}{l}\text { natxi4 }=(1.0 / \text { NATAGGEXP } \\
\sum_{\mathrm{q} \in \text { RDESAGGXP }} \text { xi4 }_{\mathrm{q}}\end{array}$ & & $\begin{array}{l}\text { Índice de preços às } \\
\text { exportações }\end{array}$ \\
\hline $\begin{array}{l}\text { E_natxi5 } \\
(156)\end{array}$ & $\begin{array}{l}\text { natxi5 }=(1.0 / \text { NATAGGOTH5 }) \\
\sum_{\mathrm{q} \in \text { RDESAGGOTH5 }} \text { xi5 }_{\mathrm{q}}\end{array}$ & & $\begin{array}{l}\text { Índice de preços para outras } \\
\text { demandas regionais }\end{array}$ \\
\hline $\begin{array}{l}\text { E_natxi6 } \\
\text { (157) }\end{array}$ & $\begin{array}{l}\text { NATAGGOTH6 natxi6 }=\sum_{\mathrm{i} \in \mathrm{COM}} \\
\sum_{\mathrm{s} \in \mathrm{ASOU}} \sum_{\mathrm{q} \in \mathrm{RDES}} \mathrm{PVAL} \mathrm{A}_{\mathrm{i}, \mathrm{s}, \mathrm{q}} \mathrm{p}_{\mathrm{i}} \mathrm{a}, \mathrm{s}, \mathrm{q}\end{array}$ & & $\begin{array}{l}\text { Índice de preços para outras } \\
\text { demandas federais }\end{array}$ \\
\hline $\begin{array}{l}\text { E_natxigdp } \\
\text { (158) }\end{array}$ & $\begin{array}{l}\text { natxigdp }=(1.0 / \text { NATGDPEX) } \\
(\text { NATAGGCON natxi3 + } \\
\text { NATAGGINV natxi2 }+ \\
\text { NATAGGOTH5 natxi5 + } \\
\text { NATAGGOTH6 natxi6 + } \\
\text { NATAGGEXP natxi4 - NATAGGIMP } \\
\text { natxim) }\end{array}$ & & $\begin{array}{l}\text { Índice de preços para o PIB: } \\
\text { lado do gasto }\end{array}$ \\
\hline $\begin{array}{l}\text { E_natxim } \\
(159)\end{array}$ & $\begin{array}{l}\text { natxim }=(1.0 / \text { NATAGGIMP }) \\
\sum_{\mathrm{q} \in \text { RDES AGGIMP }} \text { xim }_{\mathrm{q}}\end{array}$ & & $\begin{array}{l}\text { Índice de preços às } \\
\text { importações }\end{array}$ \\
\hline $\begin{array}{l}\text { E_natximp } \\
(160)\end{array}$ & $\begin{array}{l}\text { natximp } 0=(1.0 /[\text { NATAGGIMP }+ \\
\text { NATAGGTAXM }]) \\
\sum_{\mathrm{i} \in \text { COMNATIMPORTS }_{\mathrm{i}} \text { p0a } \mathrm{a}_{\mathrm{i}, \mathrm{s}}}\end{array}$ & $\mathrm{s}=$ estrangeiro & $\begin{array}{l}\text { Índice de preços das } \\
\text { importações com impostos de } \\
\text { importação pagos }\end{array}$ \\
\hline $\begin{array}{l}\text { E_ nattot } \\
(161)\end{array}$ & nattot $=$ natxi4 - natxim & & Termos de comércio \\
\hline $\begin{array}{l}\text { E_ natp1cap } \\
(162)\end{array}$ & natp1cap = natcaprev - natkt & & Aluguéis nominais de capital \\
\hline
\end{tabular}


Tabela 6. As equações do modelo MIBRA.

\begin{tabular}{|c|c|c|c|}
\hline Identificadores & Equação & Índice & Descrição \\
\hline $\begin{array}{l}\text { E_natpwage } \\
(163)\end{array}$ & $\begin{array}{l}\text { NATAGGLAB natpwage }= \\
\sum_{q \in \text { RDES }_{\text {AGGLAB }} \text { pwage }_{\mathrm{q}}}\end{array}$ & & $\begin{array}{l}\text { Salários semanais nominais } \\
\text { recebidos pelos trabalhadores }\end{array}$ \\
\hline $\begin{array}{l}\text { E_natpwage_p } \\
\text { (164) }\end{array}$ & $\begin{array}{l}\text { NATAGGLAB natpwage_p = } \\
\sum_{\mathrm{q} \in \text { RDESAGGLAB }} \text { pwage_p } \mathrm{p}_{\mathrm{q}}\end{array}$ & & $\begin{array}{l}\text { Salários semanais nominais } \\
\text { pagos pelos produtores }\end{array}$ \\
\hline $\begin{array}{l}\text { E_natrwage_w } \\
\text { (165) }\end{array}$ & natrwage_w $=$ natrealwage & & $\begin{array}{l}\text { Salários semanais reais para } \\
\text { trabalhadores: deflacionados } \\
\text { pelo IPC }\end{array}$ \\
\hline $\begin{array}{l}\text { E_natrwage_p } \\
\text { (166) }\end{array}$ & natrwage $\_p=$ natpwage $\_p-$ natxigdp & & $\begin{array}{l}\text { Salários semanais reais para } \\
\text { produtores }\end{array}$ \\
\hline $\begin{array}{l}\text { E_natxiplpk } \\
\text { (167) }\end{array}$ & natxiplpk $=$ natpwage_p - natp1cap & & $\begin{array}{l}\text { Movimento nacional nos } \\
\text { preços relativos de trabalho e } \\
\text { de capital }\end{array}$ \\
\hline $\begin{array}{l}\text { E_ natlambda } \\
(168)\end{array}$ & $\begin{array}{l}\text { NATLAB_OCC }(\mathrm{m}) \text { natlambda }(\mathrm{m})= \\
\sum_{\mathrm{q} \in \mathrm{RDES}} \mathrm{LAB} \_O C C_{\mathrm{m}, \mathrm{q}} \operatorname{lambda}_{\mathrm{m}, \mathrm{q}}\end{array}$ & $\mathrm{m} \in \mathrm{OCC}$ & $\begin{array}{l}\text { Demanda por trabalho por } \\
\text { ocupação }\end{array}$ \\
\hline \multicolumn{4}{|c|}{ Finanças do Governo } \\
\hline \multicolumn{4}{|c|}{ Desagregação do valor adicionado } \\
\hline $\begin{array}{l}\mathrm{E}_{-} \mathrm{z} 01_{-} \mathrm{r} \\
(169)\end{array}$ & 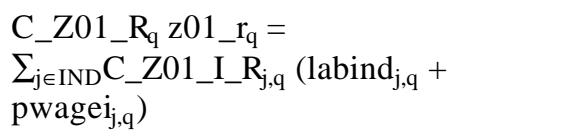 & $\mathrm{q} \in \mathrm{RDES}$ & $\begin{array}{l}\text { Salários semanais, salários } \\
\text { mensais e suplementos - } \\
\text { regiões }\end{array}$ \\
\hline $\begin{array}{l}\mathrm{E}_{-} \mathrm{zO2} 2_{-} \mathrm{r} \\
(170)\end{array}$ & $\begin{array}{l}\text { C_Z02_R R } 202 \_r_{q}= \\
\sum_{j \in I N D C} \text { _ZO2_I_R } \\
\left.\text { pwagei }_{j, q}\right)\end{array}$ & $\mathrm{q} \in \mathrm{RDES}$ & $\begin{array}{l}\text { Salários semanais imputados } \\
\text { - regiões }\end{array}$ \\
\hline $\begin{array}{l}\mathrm{E}_{-} \mathrm{z} 033_{-} \mathrm{r} \\
(171)\end{array}$ & 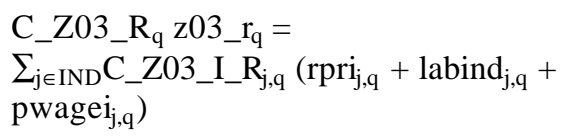 & $\mathrm{q} \in \mathrm{RDES}$ & $\begin{array}{l}\text { Impostos na folha de } \\
\text { pagamento - regiões }\end{array}$ \\
\hline $\begin{array}{l}E_{-} z 03 \\
(172)\end{array}$ & C_Z03 z03 $=\sum_{\mathrm{q} \in \mathrm{RDES} C} \mathrm{CZ}$ O3_R $\mathrm{R}_{\mathrm{q}} \mathrm{z} 03 \_\mathrm{r}_{\mathrm{q}}$ & & $\begin{array}{l}\text { Impostos na folha de } \\
\text { pagamento - nacional }\end{array}$ \\
\hline $\begin{array}{l}E_{-} \mathrm{zO}_{-} \mathrm{r} \\
(173)\end{array}$ & 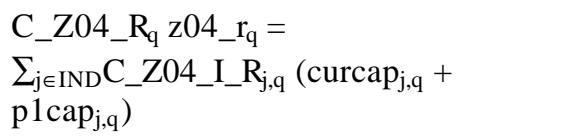 & $\mathrm{q} \in \mathrm{RDES}$ & $\begin{array}{l}\text { Retornos ao capital fixo - } \\
\text { regiões }\end{array}$ \\
\hline
\end{tabular}


Tabela 6. As equações do modelo MIBRA.

\begin{tabular}{|c|c|c|c|}
\hline Identificadores & Equação & Índice & Descrição \\
\hline $\begin{array}{l}\mathrm{E}_{-} \mathrm{z} 05_{-} \mathrm{r} \\
(174)\end{array}$ & $\begin{array}{l}\text { C_Z05_R } R_{\mathrm{q}} \mathrm{z} 05 \_\mathrm{r}_{\mathrm{q}}= \\
\sum_{\mathrm{j} \in \mathrm{IND}} \mathrm{C} \_\mathrm{Z} 05 \_I \_R_{\mathrm{j}, \mathrm{q}}\left(\text { curcap }_{\mathrm{j}, \mathrm{q}}+\right. \\
\mathrm{p} 1 \mathrm{cap}, \mathrm{p}, \mathrm{q}\end{array}$ & $\mathrm{q} \in \mathrm{RDES}$ & $\begin{array}{l}\text { Impostos sobre propriedade - } \\
\text { regiões }\end{array}$ \\
\hline $\begin{array}{l}E_{-} z 05 \\
(175)\end{array}$ & C_Z05 z05 $=\sum_{q \in R D E S C}$ _Z05_R $R_{q} z 05 \_r_{q}$ & & $\begin{array}{l}\text { Impostos sobre propriedade - } \\
\text { nacional }\end{array}$ \\
\hline $\begin{array}{l}E_{-} z_{0} 06 \\
(176)\end{array}$ & $\begin{array}{l}\text { C_Z06_R R z06_r } r_{q}= \\
\sum_{j \in I N D} \text { C_Z06_I_R } R_{j, q}\left(n_{j, q}+p 1 l_{a n d} d_{j, q}\right)\end{array}$ & $\mathrm{q} \in \mathrm{RDES}$ & $\begin{array}{l}\text { Retornos às terras agrícolas - } \\
\text { regiões }\end{array}$ \\
\hline $\begin{array}{l}\mathrm{E}_{-} \mathrm{z} 07_{-} \mathrm{r} \\
(177)\end{array}$ & $\begin{array}{l}\text { C_Z07_R } \mathrm{q}_{\mathrm{q}} \mathrm{z} 07 \_\mathrm{r}_{\mathrm{q}}= \\
\sum_{\mathrm{j} \in \mathrm{IND}} \mathrm{C} \_\mathrm{Z} 07 \_\mathrm{I} \_\mathrm{R}_{\mathrm{j}, \mathrm{q}}\left(\mathrm{n}_{\mathrm{j}, \mathrm{q}}+\mathrm{p} 1 \mathrm{land}_{\mathrm{j}, \mathrm{q}}\right)\end{array}$ & $\mathrm{q} \in \mathrm{RDES}$ & $\begin{array}{l}\text { Impostos sobre a terra - } \\
\text { regiões }\end{array}$ \\
\hline $\begin{array}{l}E_{-} z 07 \\
(178)\end{array}$ & C_Z07 z07 $=\sum_{q \in R D E S C}$ _Z07_R $\mathrm{q}_{\mathrm{q}} \mathrm{z} 07 \_\mathrm{r}_{\mathrm{q}}$ & & $\begin{array}{l}\text { Impostos sobre a terra - } \\
\text { nacional }\end{array}$ \\
\hline $\begin{array}{l}\mathrm{E}_{-} \mathrm{z} 08_{-} \mathrm{r} \\
(179)\end{array}$ & $\begin{array}{l}\text { C_Z08_R_R z08_r } r_{q}= \\
\sum_{j \in I N D C} \text { C_Z08_I_R }{ }_{j, q}\left(x 1 \text { oct }_{j, q}+p 1 \text { oct }_{j, q}\right)\end{array}$ & $\mathrm{q} \in \mathrm{RDES}$ & $\begin{array}{l}\text { Retornos para o capital } \\
\text { trabalho - regiões }\end{array}$ \\
\hline $\begin{array}{l}\mathrm{E}_{-} \mathrm{z} 09_{-} \mathrm{r} \\
(180)\end{array}$ & $\begin{array}{l}\text { C_Z09_R } \mathrm{q}_{\mathrm{q}} \mathrm{z} 09 \mathrm{r}_{\mathrm{q}}= \\
\sum_{\mathrm{j} \in \mathrm{IND}} \mathrm{C} \_\mathrm{Z} 09 \_\mathrm{I} \_\mathrm{R}_{\mathrm{j}, \mathrm{q}}\left(\mathrm{x} 1 \text { oct }_{\mathrm{j}, \mathrm{q}}+\text { ploct }_{\mathrm{j}, \mathrm{q}}\right)\end{array}$ & $\mathrm{q} \in \mathrm{RDES}$ & $\begin{array}{l}\text { Outros impostos indiretos - } \\
\text { regiões }\end{array}$ \\
\hline $\begin{array}{l}E_{-} z 09 \\
(181)\end{array}$ & 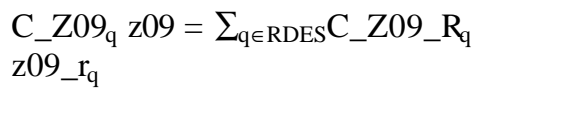 & & $\begin{array}{l}\text { Outros impostos indiretos - } \\
\text { nacional }\end{array}$ \\
\hline $\begin{array}{l}E_{-} z 10_{-} r \\
(182)\end{array}$ & 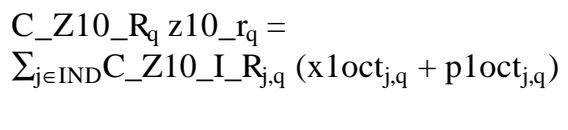 & $\mathrm{q} \in \mathrm{RDES}$ & $\begin{array}{l}\text { Vendas por compradores } \\
\text { finais - regiões }\end{array}$ \\
\hline $\begin{array}{l}E_{-} z 10 \\
(183)\end{array}$ & C_Z10 z10 $=\sum_{q \in R D E S C}$ _Z10_R $\mathrm{q}_{\mathrm{q}} \mathrm{z} 10 \_\mathrm{r}_{\mathrm{q}}$ & & $\begin{array}{l}\text { Vendas por compradores } \\
\text { finais - nacional }\end{array}$ \\
\hline $\begin{array}{l}E_{-} z_{-} r \\
(192)\end{array}$ & $\begin{array}{l}\text { C_ZG_R R zg_r } r_{q}=C \_Z 02 \_R_{q} z 02 \_r_{q}+ \\
\text { C_Z04_R } R_{q} z 04 \_r_{q}+C \_Z 06 \_R_{q} z 06 \_r_{q} \\
+ \text { C_Z08_R } R_{q} z 08 \_r_{q}\end{array}$ & $\mathrm{q} \in \mathrm{RDES}$ & $\begin{array}{l}\text { Superávit operacional bruto - } \\
\text { regiões }\end{array}$ \\
\hline $\begin{array}{l}\mathrm{E}_{-} \mathrm{zt}_{-} \mathrm{r} \\
(193)\end{array}$ & 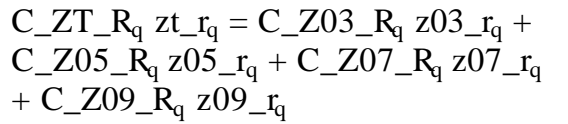 & $\mathrm{q} \in \mathrm{RDES}$ & $\begin{array}{l}\text { Impostos sobre a produção - } \\
\text { regiões }\end{array}$ \\
\hline
\end{tabular}


Tabela 6. As equações do modelo MIBRA.

\begin{tabular}{|c|c|c|c|}
\hline Identificadores & Equação & Índice & Descrição \\
\hline $\begin{array}{l}\text { E_rpr } \\
(194)\end{array}$ & $\begin{array}{l}\text { C_Z03_I_R } \mathrm{j}_{\mathrm{j}, \mathrm{q}} \mathrm{rpri}_{\mathrm{j}, \mathrm{q}}=\left(\mathrm{C} \_ \text {Z01_I_R } \mathrm{R}_{\mathrm{j}, \mathrm{q}}+\right. \\
\text { C_Z02_I_R }\end{array}$ & $\begin{array}{l}\mathrm{j} \in \mathrm{IND} \\
\mathrm{q} \in \mathrm{RDES}\end{array}$ & $\begin{array}{l}\text { Ajustamento do imposto } \\
\text { sobre a folha de pagamento }\end{array}$ \\
\hline $\begin{array}{l}\text { E_rpri }_{-} \\
(195)\end{array}$ & $\operatorname{rpri}_{\mathrm{j}, \mathrm{q}}=\operatorname{rpr}_{\mathrm{q}}+\operatorname{frpri}_{\mathrm{j}, \mathrm{q}}$ & $\begin{array}{l}j \in \text { IND } \\
q \in \text { RDES }\end{array}$ & $\begin{array}{l}\text { Definição das taxas de } \\
\text { impostos sobre a folha de } \\
\text { pagamento }\end{array}$ \\
\hline $\begin{array}{l}\text { E_xisfb2 } \\
\text { (196) }\end{array}$ & 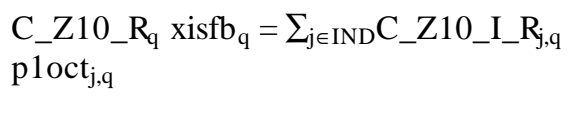 & $\mathrm{q} \in \mathrm{RDES}$ & $\begin{array}{l}\text { Índice de preços: vendas por } \\
\text { compradores finais }\end{array}$ \\
\hline
\end{tabular}

Produto regional bruto e seus componentes

E_dompy 100 dompy $100_{\mathrm{q}}=\mathrm{z} 01 \_\mathrm{r}_{\mathrm{q}}$

(197)

E_ dompy 120 dompy $120_{q}=$ dompy $100_{q}+\mathrm{rl}$

(198)

E_dompy 110 C_ DOMPY $100_{\mathrm{q}}$ dompy $100_{\mathrm{q}}=$

E_dompy 200 dompy $200_{\mathrm{q}}=\mathrm{zg}_{-} \mathrm{r}_{\mathrm{q}}$

E_dompy 220 dompy $220_{\mathrm{q}}=\operatorname{dompy} 200_{\mathrm{q}}+$ rk

E_dompy 210 C_DOMPY $200_{\mathrm{q}}$ dompy $200_{\mathrm{q}}=$

E_dompy 310

E_dompy320 C_DOMPY $320_{\mathrm{q}}$ dompy $320_{\mathrm{q}}=$ AGGTAX $1_{\mathrm{q}}$ taxrev $1_{\mathrm{q}}+\mathrm{AGGTAX}_{\mathrm{q}}$
C_DOMPY $210_{\mathrm{q}}$ dompy $210_{\mathrm{q}}+$

C_DOMPY $220_{\mathrm{q}}$ dompy $220_{\mathrm{q}}$

dompy $310_{\mathrm{q}}=\operatorname{taxrevm}_{\mathrm{q}}$

AGGTAX $_{\mathrm{q}}$ taxrev4 $_{\mathrm{q}}+$ AGGTAX5 $_{\mathrm{q}}$ taxrev $5_{\mathrm{q}}+$ AGGTAX6 $_{\mathrm{q}}$ taxrev6 $_{\mathrm{q}}$

$q \in \operatorname{RDES}$

$q \in \operatorname{RDES}$

Impostos PAYE $\mathrm{q} \in \mathrm{RDES} \quad$ Renda de salário seminal disponível (resíduo)

$\mathrm{q} \in \mathrm{RDES}$

Renda de fator primário não proveniente de salário semanal

$\mathrm{q} \in \mathrm{RDES}$

Impostos sobre a renda de fator primário não proveniente de salário semanal

$q \in \operatorname{RDES}$

Renda disponível de fator primário não proveniente de salário semanal (resíduo)

$\mathrm{q} \in \mathrm{RDES}$

Receita de tarifa

$\mathrm{q} \in \mathrm{RDES} \quad$ Outros impostos sobre produtos menos subsídios 
Tabela 6. As equações do modelo MIBRA.

\begin{tabular}{|c|c|c|c|}
\hline Identificadores & Equação & Índice & Descrição \\
\hline $\begin{array}{l}E_{-} \text {dompy330 } \\
(205)\end{array}$ & dompy330 $=$ zt_r $\mathrm{r}_{\mathrm{q}}$ & $\mathrm{q} \in \mathrm{RDES}$ & Impostos sobre a produção \\
\hline $\begin{array}{l}\text { E_dompy300 } \\
(206)\end{array}$ & $\begin{array}{l}\text { C_DOMPY } 300_{q} \text { dompy } 300_{q}= \\
\text { C_DOMPY } 310_{q} \text { dompy } 310_{q}+ \\
\text { C_DOMPY } 320_{q} \text { dompy } 320_{q}+ \\
\text { C_DOMPY } 330_{q} \text { dompy } 330_{q}\end{array}$ & $\mathrm{q} \in \mathrm{RDES}$ & $\begin{array}{l}\text { Impostos indiretos menos } \\
\text { subsídios }\end{array}$ \\
\hline $\begin{array}{l}\text { E_dompy000 } \\
\text { (207) }\end{array}$ & $\begin{array}{l}\text { C_DOMPY } 000_{q}{\text { dompy } 000_{q}=}_{\text {C_DOMPY } 100_{q} \text { dompy } 100_{q}+} \\
\text { C_DODPY } 200_{q} \text { dompy } 200_{q}+ \\
\text { C_DOMPP } \\
\text { C_DOMPY } 300_{q} \text { dompy } 300_{q}\end{array}$ & $\mathrm{q} \in \mathrm{RDES}$ & $\begin{array}{l}\text { PIB a preços de Mercado } \\
\text { (lado da renda) - regiões }\end{array}$ \\
\hline $\begin{array}{l}\text { E_dompq110 } \\
(208)\end{array}$ & $\operatorname{dompq} 110_{\mathrm{q}}=\mathrm{c}_{\mathrm{q}}$ & $\mathrm{q} \in \mathrm{RDES}$ & Consumo privado \\
\hline $\begin{array}{l}\text { E_dompq120 } \\
\text { (209) }\end{array}$ & $\operatorname{dompq} 120_{\mathrm{q}}=\mathrm{in}_{\mathrm{q}}$ & $\mathrm{q} \in \mathrm{RDES}$ & Investimento privado \\
\hline $\begin{array}{l}\text { E_dompq130 } \\
(210)\end{array}$ & dompq $130_{q}=$ othnom $5_{q}$ & $\mathrm{q} \in \mathrm{RDES}$ & $\begin{array}{l}\text { Consumo do Governo - } \\
\text { regiões }\end{array}$ \\
\hline $\begin{array}{l}\text { E_domq140 } \\
\text { (211) }\end{array}$ & dompq $140_{\mathrm{q}}=$ othnom $_{\mathrm{q}}$ & $\mathrm{q} \in \mathrm{RDES}$ & $\begin{array}{l}\text { Consumo do Governo - } \\
\text { federal }\end{array}$ \\
\hline $\begin{array}{l}\text { E_dompq150 } \\
(212)\end{array}$ & $\operatorname{dompq} 150_{\mathrm{q}}=\mathrm{in}_{\mathrm{q}}$ & $\mathrm{q} \in \mathrm{RDES}$ & Investimento do governo \\
\hline $\begin{array}{l}\text { E_dompq100 } \\
(213)\end{array}$ & $\begin{array}{l}\text { C_DOMPQ } 100_{\mathrm{q}} \text { dompq } 100_{\mathrm{q}}= \\
\text { C_DOMPQ } 110_{\mathrm{q}} \text { dompq } 110_{\mathrm{q}}+ \\
\text { C_DOMPQ } 120_{\mathrm{q}} \text { dompq } 120_{\mathrm{q}}+ \\
\text { C_DOMPQ } 130_{\mathrm{q}} \text { dompq } 130_{\mathrm{q}}+ \\
\text { C__DOMPQ140 dompq } 140_{\mathrm{q}}+ \\
\text { C_DOMPQ } 150_{\mathrm{q}} \text { dompq } 150_{\mathrm{q}}\end{array}$ & $\mathrm{q} \in \mathrm{RDES}$ & Absorção doméstica \\
\hline $\begin{array}{l}\text { E_dompq } 210 \\
(214)\end{array}$ & $\operatorname{dompq} 210_{q}=\operatorname{psexp}_{q}+\operatorname{xsexp}_{q}$ & $\mathrm{q} \in \mathrm{RDES}$ & Exportações inter-regionais \\
\hline E_dompq220 & $\operatorname{dompq}_{220_{q}}=\operatorname{psimp}_{\mathrm{q}}+\mathrm{xsimp}_{\mathrm{q}}$ & $\mathrm{q} \in \mathrm{RDES}$ & Importações inter-regionais \\
\hline
\end{tabular}


Tabela 6. As equações do modelo MIBRA.

\begin{tabular}{|c|c|c|c|}
\hline Identificadores & Equação & Índice & Descrição \\
\hline $\begin{array}{l}\text { E_dompq200 }_{-} \\
(216)\end{array}$ & 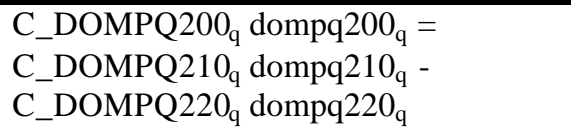 & $\mathrm{q} \in \mathrm{RDES}$ & $\begin{array}{l}\text { Balanço de comércio inter- } \\
\text { regional }\end{array}$ \\
\hline $\begin{array}{l}\text { E_dompq } 310_{-} \\
(217)\end{array}$ & $\operatorname{dompq} 310_{\mathrm{q}}=\operatorname{export}_{\mathrm{q}}+$ natphi & $\mathrm{q} \in \mathrm{RDES}$ & Exportações internacionais \\
\hline $\begin{array}{l}\mathrm{E}_{-} \text {dompq } 320 \\
(218)\end{array}$ & $\operatorname{dompq} 320_{q}=\operatorname{imp}_{q}+$ natphi & $q \in \operatorname{RDES}$ & Importações internacionais \\
\hline $\begin{array}{l}\mathrm{E}_{-} \text {dompq300 } \\
(219)\end{array}$ & $\begin{array}{l}\text { C_DOMPQ } 300_{\mathrm{q}} \text { dompq } 300_{\mathrm{q}}= \\
\text { C_DOMPQ } 310_{\mathrm{q}} \text { dompq } 310_{\mathrm{q}}- \\
\text { C_DOMPQ } 320_{\mathrm{q}} \text { dompq } 320_{\mathrm{q}}\end{array}$ & $q \in \mathrm{RDES}$ & $\begin{array}{l}\text { Balanço de comércio } \\
\text { internacional }\end{array}$ \\
\hline $\begin{array}{l}\text { E_dompq000 } \\
(220)\end{array}$ & 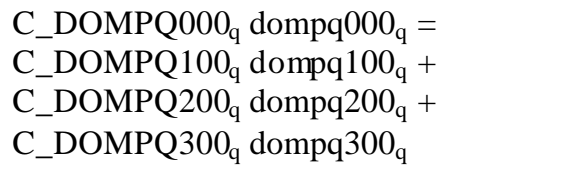 & $\mathrm{q} \in \mathrm{RDES}$ & $\begin{array}{l}\text { PIB a preços de mercado } \\
\text { (lado do gasto) }\end{array}$ \\
\hline \multicolumn{4}{|c|}{ Equações Miscelâneas } \\
\hline $\begin{array}{l}\text { E_tir } \\
(221)\end{array}$ & $\mathrm{ti} \_\mathrm{r}_{\mathrm{q}}=\operatorname{dompy} 320_{\mathrm{q}}$ & $\mathrm{q} \in \mathrm{RDES}$ & $\begin{array}{l}\text { Impostos sobre produto } \\
\text { menos subsídios } \\
\text { tarifas) }\end{array}$ \\
\hline $\begin{array}{l}\text { E_ti } \\
(222)\end{array}$ & $\begin{array}{l}\text { C_TI ti }=\sum_{\mathrm{q} \in \mathrm{RDES}} \mathrm{C} \_ \text {DOMPY } 320_{\mathrm{q}} \\
\text { dompy } 320_{\mathrm{q}}\end{array}$ & & $\begin{array}{l}\text { Impostos sobre } \\
\text { menos subsídios } \\
\text { tarifas) }\end{array}$ \\
\hline $\begin{array}{l}E_{-} y n_{-} r \\
(223)\end{array}$ & $\mathrm{yn} \_\mathrm{r}_{\mathrm{q}}=\mathrm{dompq} 000_{\mathrm{q}}$ & $\mathrm{q} \in \mathrm{RDES}$ & $\begin{array}{l}\text { Produto doméstico regional } \\
\text { nominal }\end{array}$ \\
\hline $\begin{array}{l}E_{-} \text {yn } \\
\text { (224) }\end{array}$ & 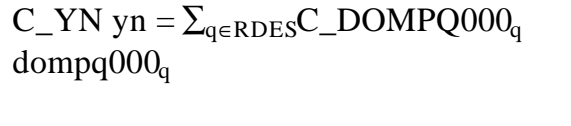 & & PIB nominal \\
\hline $\begin{array}{l}E_{-} x_{-} y_{-} r \\
(225)\end{array}$ & 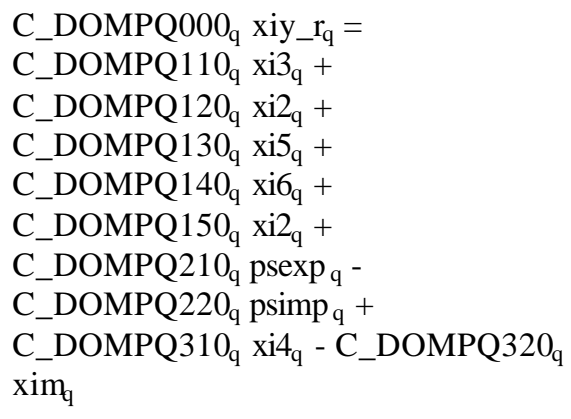 & $\mathrm{q} \in \mathrm{RDES}$ & Deflator do PIB \\
\hline
\end{tabular}


Tabela 6. As equações do modelo MIBRA.

\begin{tabular}{|c|c|c|c|}
\hline Identificadores & Equação & Índice & Descrição \\
\hline $\begin{array}{l}\text { E_xiy } \\
(226)\end{array}$ & $\begin{array}{l}\text { C_YN xiy }=\sum_{q \in \text { RDESC_CDOMPQ000 }} \\
\text { xiy_r } r_{q}\end{array}$ & & Deflator do PIB \\
\hline $\begin{array}{l}\mathrm{E}_{-} \mathrm{yr}_{-} \mathrm{r} \\
(227)\end{array}$ & $y r_{-} r_{q}=y n \_r_{q}-x i y \_r_{q}$ & $\mathrm{q} \in \mathrm{RDES}$ & $\begin{array}{l}\text { Produto doméstico regional } \\
\text { real }\end{array}$ \\
\hline $\begin{array}{l}E_{-} y r \\
(228)\end{array}$ & $y r=y n-x i y$ & & PIB real \\
\hline $\begin{array}{l}E_{-} y f \\
(229)\end{array}$ & $\begin{array}{l}\text { C_YF yf }=\sum_{\mathrm{q} \in \mathrm{RDES}} \mathrm{C} \_D O M P Y 100_{\mathrm{q}} \\
\left.\text { dompy } 100_{\mathrm{q}}\right)+\sum_{\mathrm{q} \in \text { RDESC_DOMPY } 200_{\mathrm{q}}} \\
\text { dompy } 200_{\mathrm{q}}\end{array}$ & & PIB a custo de fatores \\
\hline $\begin{array}{l}\text { E_bstar } \\
\text { (230) }\end{array}$ & $\begin{array}{l}\text { C_YN bstar }=\sum_{q \in R D E S} C_{-} D O M P Q 300_{q} \\
\left.\text { dompq } 300_{q}\right)- \text { NATBTyn }\end{array}$ & & $\begin{array}{l}\text { Superávit do Balanço de } \\
\text { comércio em relação ao PIB: } \\
\text { variação em pontos } \\
\text { percentuais }\end{array}$ \\
\hline $\begin{array}{l}\text { E_ty } \\
(231)\end{array}$ & $\begin{array}{l}\text { C_TY tY }=\sum_{\mathrm{q} \in \mathrm{RDES} C} \text { _DOMPY } 120_{\mathrm{q}} \\
\left.\text { dompy } 120_{\mathrm{q}}\right)+\sum_{\mathrm{q} \in \mathrm{RDES}} \text { _DOMPY } 220_{\mathrm{q}} \\
\text { dompy } 220_{\mathrm{q}}\end{array}$ & & Imposto de renda \\
\hline $\begin{array}{l}\text { E_yl } \\
(232)\end{array}$ & $\begin{array}{l}\text { C_YL yl }=\sum_{\mathrm{q} \in \mathrm{RDES} C} \text { _DOMPY } 100_{\mathrm{q}} \\
\text { dompy } 100_{\mathrm{q}}\end{array}$ & & $\begin{array}{l}\text { Renda salário semanal antes } \\
\text { do imposto }\end{array}$ \\
\hline $\begin{array}{l}\text { E_wn } \\
(233)\end{array}$ & $\mathrm{wn}=\mathrm{yl}-\mathrm{natl}$ & & $\begin{array}{l}\text { Taxa de salário semanal } \\
\text { nominal antes do imposto }\end{array}$ \\
\hline $\begin{array}{l}\text { E_ylstar } \\
(234)\end{array}$ & $\begin{array}{l}\text { C_YLSTAR ylstar }= \\
\sum_{\mathrm{q} \in \text { RDESC_DOMPY } 110_{\mathrm{q}} \text { dompy } 110_{\mathrm{q}}}\end{array}$ & & $\begin{array}{l}\text { Renda salário semanal após o } \\
\text { imposto }\end{array}$ \\
\hline $\begin{array}{l}\text { E_wnstar } \\
(235)\end{array}$ & wnstar $=$ ylstar - natl & & $\begin{array}{l}\text { Taxa de salário semanal } \\
\text { nominal após o imposto }\end{array}$ \\
\hline $\begin{array}{l}\text { E_wrstar } \\
\text { (236) }\end{array}$ & wrstar $=$ wnstar - natxi3 & & $\begin{array}{l}\text { Taxa de salário semanal real } \\
\text { após o imposto }\end{array}$ \\
\hline $\begin{array}{l}\mathrm{E}_{-} \mathrm{g}_{-} \mathrm{rA} \\
(237)\end{array}$ & g_ $r_{q}=$ othnom $5_{q}$ & $\mathrm{q} \in \mathrm{RDES}$ & $\begin{array}{l}\text { Consumo nominal do governo } \\
\text { - regiões }\end{array}$ \\
\hline
\end{tabular}


Tabela 6. As equações do modelo MIBRA.

\begin{tabular}{|c|c|c|c|}
\hline Identificadores & Equação & Índice & Descrição \\
\hline $\begin{array}{l}E_{-} g_{-} r B \\
(238)\end{array}$ & g_ $r_{q}=$ natothnom6 & $q=$ federal & $\begin{array}{l}\text { Consumo nominal do governo } \\
\text { - federal }\end{array}$ \\
\hline $\begin{array}{l}E_{-} \text {ip } \\
\text { (239) }\end{array}$ & C_IP ip $=\sum_{q \in \text { RDES }}$ CIP_R $R_{q}$ in $_{q}$ & & $\begin{array}{l}\text { Investimento privado nominal } \\
\text { agregado }\end{array}$ \\
\hline $\begin{array}{l}E_{-} i g_{-} r_{-} r e g \\
(240)\end{array}$ & $\operatorname{ig} \__{-} r_{q}=\operatorname{in}_{q}$ & $q \in \operatorname{RDES}$ & $\begin{array}{l}\text { Investimento nominal do } \\
\text { governo - regiões }\end{array}$ \\
\hline $\begin{array}{l}E_{-} \text {ig } \\
(241)\end{array}$ & $\begin{array}{l}\text { NATAGGINV natin = C_IP ip + C_IG } \\
\text { ig }\end{array}$ & & 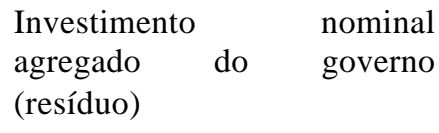 \\
\hline $\begin{array}{l}E_{-} i g_{-} r_{-} \text {fed } \\
(242)\end{array}$ & C_IG ig $=\sum_{q \in \text { DDES }}$ C_IG_R $\mathrm{R}_{\mathrm{q}}$ ig $\_\mathrm{r}_{\mathrm{q}}$ & & $\begin{array}{l}\text { Investimento nominal do } \\
\text { governo - federal (resíduo) }\end{array}$ \\
\hline $\begin{array}{l}E_{-} c_{-} b \\
(243)\end{array}$ & $\mathrm{c}_{\mathrm{q}}=\mathrm{yd}_{-} \mathrm{r}_{\mathrm{q}}+\operatorname{miscf001}_{\mathrm{q}}$ & $\mathrm{q} \in \mathrm{RDES}$ & Função de consumo \\
\hline $\begin{array}{l}E_{-} r l \\
(244)\end{array}$ & $\mathrm{rl}=\mathrm{rk}+\operatorname{miscf002}$ & & $\begin{array}{l}\text { Taxas de imposto sobre renda } \\
\text { relativa }\end{array}$ \\
\hline & Sumário das Transações Financ & eiras: as col & SOFT \\
\hline $\begin{array}{l}\text { E_ softy } 111 \\
(245)\end{array}$ & softy $111_{q}=$ ty & $q=$ federal & Impostos de renda \\
\hline $\begin{array}{l}\text { E_softy112A } \\
\text { (246) }\end{array}$ & softy $112_{q}=y n \_r_{q}+$ softfo0 $_{q}$ & $\mathrm{q} \in \mathrm{RDES}$ & Outros impostos diretos \\
\hline $\begin{array}{l}\text { E_ softy } 112 B \\
(247)\end{array}$ & softy $112_{q}=y n+\operatorname{softf} 011$ & $q=$ federal & $\begin{array}{l}\text { Outros impostos diretos } \\
\text { federais }\end{array}$ \\
\hline $\begin{array}{l}\text { E_softy } 110 \\
(248)\end{array}$ & $\begin{array}{l}\text { C_SOFTY } 110_{\mathrm{q}} \text { softy } 110_{\mathrm{q}}= \\
\text { C_SOFTY } 111_{\mathrm{q}} \text { softy } 111_{\mathrm{q}}+ \\
\text { C_SOFTY } 112_{\mathrm{q}} \text { softy } 112_{\mathrm{q}}\end{array}$ & $\mathrm{q} \in \mathrm{DDES}$ & Impostos diretos \\
\hline
\end{tabular}


Tabela 6. As equações do modelo MIBRA.

\begin{tabular}{llll}
\hline Identificadores & Equação & Índice & Descrição \\
\hline E_softy121 & softy121 $12=$ nattaxrevm & $\mathrm{q}=$ federal & Receita de tarifa \\
$(249)$ & & & \\
E_softy122A & softy122 $2_{\mathrm{q}}=\mathrm{ti}_{-} \mathrm{r}_{\mathrm{q}}$ & $\mathrm{q} \in \mathrm{RDES}$ & $\begin{array}{l}\text { Outros impostos sobre } \\
\text { produto }- \text { regiões }\end{array}$
\end{tabular}

E_softy122B C_TI ti + C_SUBSIDIES tI =

E_softy $123 \mathrm{a} \quad$ softy $123_{\mathrm{q}}=\mathrm{z} 03 \_\mathrm{r}_{\mathrm{q}}$

E_ softy $123 b \quad$ softy $123_{q}=z 09$

E_softy $124 \quad$ softy $124_{\mathrm{q}}=\mathrm{z} 05 \_\mathrm{r}_{\mathrm{q}}$

E_softy $125 \quad$ softy $125_{\mathrm{q}}=\mathrm{z} 07 \_\mathrm{r}_{\mathrm{q}}$

E_ softy $126 A \quad$ softy $126_{q}=z 09 \_r_{q}$

E_softy $126 B$

E_softy 120

E_softy 130

C_Z09 z09 $=\sum_{\mathrm{q} \in \text { DDESC_SOFTY } 126_{\mathrm{q}}}$ softy $126_{\mathrm{q}}$

$\mathrm{q} \in \mathrm{RDES}$

$\mathrm{q} \in \mathrm{RDES}$

$q=$ federal

$\mathrm{q} \in \mathrm{RDES}$

$\mathrm{q} \in \mathrm{RDES}$

Outros impostos sobre produto - federal (resíduo)

Impostos na folha de pagamento - regiões

Impostos sobre benefícios federal

Impostos de propriedade regiões

Impostos sobre a terra regiões

Outros impostos indiretos regiões

Outros impostos indiretos federal (resíduo)

$\mathrm{q} \in \mathrm{DDES} \quad$ Impostos indiretos

C_SOFTY $120_{\mathrm{q}}$ softy $120_{\mathrm{q}}=$ C_SOFTY $121_{\mathrm{q}}$ softy $121_{\mathrm{q}}+$ C_SOFTY $122_{\mathrm{q}}$ softy $122_{\mathrm{q}}+$ C_SOFTY $123_{\mathrm{q}}$ softy $123_{\mathrm{q}}+$

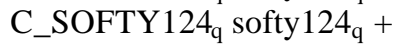
C_SOFTY $125_{\mathrm{q}}$ softy $125_{\mathrm{q}}+$ C_SOFTY $126_{\mathrm{q}}$ softy $126_{\mathrm{q}}$
$\operatorname{softy} 130_{\mathrm{q}}=\operatorname{softq} 400_{\mathrm{q}}$
$\mathrm{q} \in \mathrm{DDES}$
Juros recebidos 
Tabela 6. As equações do modelo MIBRA.

\begin{tabular}{|c|c|c|c|}
\hline Identificadores & Equação & Índice & Descrição \\
\hline $\begin{array}{l}\text { E_ softy } 141 \\
(260)\end{array}$ & softy $141_{q}=y n \_r_{q}+\operatorname{softf} 002_{q}$ & $\mathrm{q} \in \mathrm{RDES}$ & $\begin{array}{l}\text { Doações para regiões } \\
\text { corrente }\end{array}$ \\
\hline $\begin{array}{l}\text { E_softy } 142 \\
(261)\end{array}$ & softy $142_{q}=y n \_r_{q}+$ softf $003_{q}$ & $\mathrm{q} \in \mathrm{RDES}$ & $\begin{array}{l}\text { Doações para regiões } \\
\text { capital }\end{array}$ \\
\hline $\begin{array}{l}E_{-} \text {softy } 140 \\
(262)\end{array}$ & $\begin{array}{l}\text { C_SOFTY } 140_{\mathrm{q}} \text { softy } 140_{\mathrm{q}}= \\
\text { C_SOFTY } 141_{\mathrm{q}} \text { softy } 141_{\mathrm{q}}+ \\
\text { C_SOFTY } 142_{\mathrm{q}} \text { softy } 142_{\mathrm{q}}\end{array}$ & $\mathrm{q} \in \mathrm{RDES}$ & Doações para regiões \\
\hline $\begin{array}{l}\text { E_ softy } 150 A \\
(263)\end{array}$ & softy $150_{q}=y n \_r_{q}+$ softf004 $4_{q}$ & $\mathrm{q} \in \mathrm{RDES}$ & Outras receitas - regiões \\
\hline $\begin{array}{l}\text { E_ softy } 150 B \\
(264)\end{array}$ & softy $150_{q}=y n+\operatorname{softf} 004_{q}$ & $q=$ federal & Outras receitas - federal \\
\hline $\begin{array}{l}E_{-} \text {softy } 100 \\
(265)\end{array}$ & $\begin{array}{l}\text { C_SOFTY } 100_{\mathrm{q}} \text { softy } 100_{\mathrm{q}}= \\
\text { C_SOFTY } 110_{\mathrm{q}} \text { softy } 110_{\mathrm{q}}+ \\
\text { C_SOFTY } 120_{\mathrm{q}} \text { softy } 120_{\mathrm{q}}+ \\
\text { C_SOFTY } 130_{\mathrm{q}} \text { softy } 130_{\mathrm{q}}+ \\
\text { C_SOFTY } 140_{\mathrm{q}} \text { softy } 140_{\mathrm{q}}+ \\
\text { C_SOFTY } 150_{\mathrm{q}} \text { softy } 150_{\mathrm{q}}\end{array}$ & $\mathrm{q} \in \mathrm{DDES}$ & Receita do governo \\
\hline $\begin{array}{l}E_{-} \text {softy } 200 \\
(266)\end{array}$ & softy $200_{q}=g \_r_{q}$ & $\mathrm{q} \in \mathrm{DDES}$ & $\begin{array}{l}\text { Consumo de capital fixo - } \\
\text { governo geral }\end{array}$ \\
\hline $\begin{array}{l}E_{-} \text {softy } 300 \\
(267)\end{array}$ & $\begin{array}{l}\text { C_SOFTY } 300_{\mathrm{q}} \text { softy } 300_{\mathrm{q}}= \\
\text { C_SOFTQ000 } 0_{\mathrm{q}} \text { softq } 000_{\mathrm{q}}- \\
\text { C_SOFTY } 100_{\mathrm{q}} \text { softy } 100_{\mathrm{q}}- \\
\text { C_SOFTY } 200_{\mathrm{q}} \text { softy } 200_{\mathrm{q}}\end{array}$ & $\mathrm{q} \in \mathrm{DDES}$ & Transações financeiras \\
\hline $\begin{array}{l}\text { E_softy } 320 \\
(268)\end{array}$ & $\operatorname{softy} 320_{\mathrm{q}}=\operatorname{softq} 100_{\mathrm{q}}+\operatorname{softf} 005_{\mathrm{q}}$ & $\mathrm{q} \in \mathrm{DDES}$ & Aumento das provisões \\
\hline $\begin{array}{l}\text { E_ softy } 330 \\
(269)\end{array}$ & $\operatorname{softy} 330_{\mathrm{q}}=\operatorname{softy} 300_{\mathrm{q}}+\mathrm{f} \_\mathrm{oft}_{\mathrm{q}}$ & $\mathrm{q} \in \mathrm{DDES}$ & Outras transações financeiras \\
\hline $\begin{array}{l}E_{-} \text {softy } 310 \\
(270)\end{array}$ & $\begin{array}{l}\text { C_SOFTY } 300_{\mathrm{q}} \text { softy } 300_{\mathrm{q}}= \\
\text { C_SOFTY } 310_{\mathrm{q}} \text { softy } 310_{\mathrm{q}}+ \\
\text { C_SOFTY } 320_{\mathrm{q}} \text { softy } 320_{\mathrm{q}}+ \\
\text { C_SOFTY } 330_{\mathrm{q}} \text { softy } 330_{\mathrm{q}}\end{array}$ & $\mathrm{q} \in \mathrm{DDES}$ & $\begin{array}{l}\text { Empréstimo líquido tomado } \\
\text { (resíduo) }\end{array}$ \\
\hline
\end{tabular}


Tabela 6. As equações do modelo MIBRA.

\begin{tabular}{|c|c|c|c|}
\hline Identificadores & Equação & Índice & Descrição \\
\hline $\begin{array}{l}\text { E_softy000 } \\
(271)\end{array}$ & $\begin{array}{l}\text { C_SOFTY } 000_{\mathrm{q}} \text { softy } 000_{\mathrm{q}}= \\
\text { C_SOFTY } 100_{\mathrm{q}} \text { softy } 100_{\mathrm{q}}+ \\
\text { C_SOFTY } 200_{\mathrm{q}} \text { softy } 200_{\mathrm{q}}+ \\
\text { C_SOFTY } 300_{\mathrm{q}} \text { softy } 300_{\mathrm{q}}\end{array}$ & $\mathrm{q} \in \mathrm{DDES}$ & $\begin{array}{llr}\text { Sumário } & \text { das } & \text { transações } \\
\text { financeiras } & : \text { lado da renda } \\
\text { total } & & \end{array}$ \\
\hline $\begin{array}{l}\text { E_softq110 } \\
(272)\end{array}$ & softq $110_{\mathrm{q}}=\mathrm{g} \_\mathrm{r}_{\mathrm{q}}$ & $\mathrm{q} \in \mathrm{DDES}$ & Consumo do governo \\
\hline $\begin{array}{l}\text { E_softq120 } \\
(273)\end{array}$ & softq $120_{\mathrm{q}}=\mathrm{ig} \mathrm{r}_{\mathrm{q}}$ & $q \in \mathrm{DDES}$ & Investimento do governo \\
\hline $\begin{array}{l}\text { E_softq } 100 \\
(274)\end{array}$ & $\begin{array}{l}\text { C_SOFTQ } 100_{\mathrm{q}} \text { softq } 100_{\mathrm{q}}= \\
\text { C_SOFTQ110 } 10_{\mathrm{q}} \text { softq } 110_{\mathrm{q}}+ \\
\text { C_SOFTQ120 } 0_{\mathrm{q}} \text { softq } 120_{\mathrm{q}}\end{array}$ & $\mathrm{q} \in \mathrm{DDES}$ & Gastos em bens e serviços \\
\hline $\begin{array}{l}\text { E_softq } 210 \\
(275)\end{array}$ & $\operatorname{softq} 210_{\mathrm{q}}=\mathrm{upb}$ & $q=$ federal & Benefícios de desemprego \\
\hline $\begin{array}{l}E_{-} \text {softq } 200 \\
(276)\end{array}$ & softq $200_{q}=$ pbp_r $r_{q}$ & $\mathrm{q} \in \mathrm{DDES}$ & $\begin{array}{l}\text { Pagamentos de benefícios } \\
\text { pessoais }\end{array}$ \\
\hline $\begin{array}{l}\text { E_softq } 220 \\
(277)\end{array}$ & $\begin{array}{l}\text { C_SOFTQ200 } 20 \text { softq } 200_{q}= \\
\text { C_SOFTQ2 } 10_{q} \text { softq } 210_{q}+ \\
\text { C_SOFTQ220 } 20 \text { softq } 220_{q}\end{array}$ & $\mathrm{q} \in \mathrm{DDES}$ & $\begin{array}{l}\text { Outros benefícios pessoais } \\
\text { (resíduo) }\end{array}$ \\
\hline $\begin{array}{l}\text { E_ softq } 300 A \\
(278)\end{array}$ & $\operatorname{softq} 300_{\mathrm{q}}=\mathrm{ti} \_\mathrm{r}_{\mathrm{q}}$ & $\mathrm{q} \in \mathrm{RDES}$ & Subsídios - regiões \\
\hline $\begin{array}{l}\text { E_softq300B } \\
(279)\end{array}$ & $\begin{array}{l}\text { C_SUBSIDIES tI }= \\
\sum_{\mathrm{q} \in \text { DDESC_SOFTQ } 300_{\mathrm{q}} \operatorname{softq} 300_{\mathrm{q}}}\end{array}$ & & Subsídios - federal (resíduo) \\
\hline $\begin{array}{l}\text { E_softq400A } \\
(280)\end{array}$ & $\operatorname{softq} 400_{q}=y n \_r_{q}+\operatorname{softf} 007_{q}$ & $\mathrm{q} \in \mathrm{RDES}$ & $\begin{array}{l}\text { Pagamentos de juros - } \\
\text { regiões }\end{array}$ \\
\hline $\begin{array}{l}\text { E_softq400B } \\
(281)\end{array}$ & $\operatorname{softq} 400_{\mathrm{k}}=\mathrm{yn}+\operatorname{softf} 007_{\mathrm{k}}$ & $\mathrm{k}=$ federal & Pagamentos de juros - Federal \\
\hline $\begin{array}{l}\text { E_softq510 } \\
(282)\end{array}$ & $\begin{array}{l}\text { C_SOFTQ510 } 10_{\mathrm{k}} \text { softq } 510_{\mathrm{k}}= \\
\sum_{\mathrm{q} \in \mathrm{RDES} C \_S O F T Y 141_{\mathrm{q}} \text { softy } 141_{\mathrm{q}}}\end{array}$ & $\mathrm{k}=$ federal & $\begin{array}{l}\text { Doações para regiões - } \\
\text { corrente }\end{array}$ \\
\hline
\end{tabular}


Tabela 6. As equações do modelo MIBRA.

\begin{tabular}{|c|c|c|c|}
\hline Identificadores & Equação & Índice & Descrição \\
\hline $\begin{array}{l}\text { E_softq520 } \\
(283)\end{array}$ & 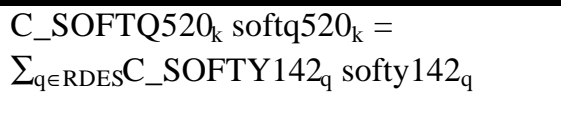 & $\mathrm{k}=$ federal & Doações para regiões - capital \\
\hline $\begin{array}{l}\text { E_ softq500 } \\
(284)\end{array}$ & 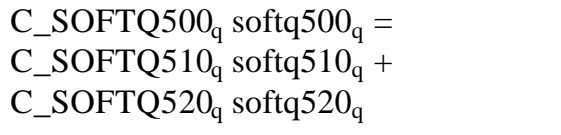 & $q=$ federal & Doações para regiões \\
\hline $\begin{array}{l}\text { E_softq600 } \\
(285)\end{array}$ & softq $600_{q}=\operatorname{softq} 000_{q}+\operatorname{softf} 006_{q}$ & $\mathrm{q} \in \mathrm{DDES}$ & Outros recursos gastos \\
\hline $\begin{array}{l}\text { E_softq000 } \\
(286)\end{array}$ & 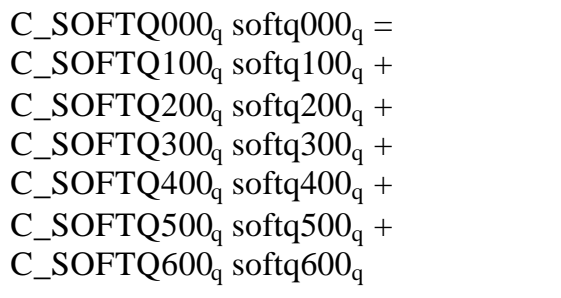 & $\mathrm{q} \in \mathrm{DDES}$ & $\begin{array}{l}\text { Sumário das transações } \\
\text { financeiras: lado do gasto } \\
\text { total }\end{array}$ \\
\hline $\begin{array}{l}\text { E_ realdefr } \\
(287)\end{array}$ & realdef $_{\mathrm{q}}=\operatorname{softy} 300_{\mathrm{q}}-\mathrm{xi} 3_{\mathrm{q}}$ & $\mathrm{q} \in \mathrm{RDES}$ & $\begin{array}{l}\text { Déficit real do orçamento } \\
\text { para região }\end{array}$ \\
\hline $\begin{array}{l}\text { E_ realdeff } \\
(288)\end{array}$ & realdef $_{q}=$ softy $300_{q}-$ natxi3 & $q=$ federal & $\begin{array}{l}\text { Déficit real do orçamento } \\
\text { federal }\end{array}$ \\
\hline $\begin{array}{l}\text { E_dGstar } \\
(289)\end{array}$ & $\begin{array}{l}\text { C_SOFTQ } 000_{q} \text { dgstar } \\
\text { C_SOFTY } 310_{q}\left(\text { softy } 310_{q}-\operatorname{softq} 000_{q}\right)\end{array}$ & $\mathrm{q} \in \mathrm{DDES}$ & $\begin{array}{l}\text { Empréstimo líquido tomado } \\
\text { para o total de recursos } \\
\text { gastos: variação em pontos } \\
\text { percentuais }\end{array}$ \\
\hline$E_{-}$tod_r & tod_r $r_{q}=$ softy $112_{q}$ & $\mathrm{q} \in \mathrm{RDES}$ & Outros impostos diretos \\
\hline
\end{tabular}

Renda disponível das famílias

E_hhldy110 hhldy110 $=$ z01_r $r_{q} \quad$ q $\in$ RDES

(301)

E_hhldy $120 \quad$ hhldy $120_{\mathrm{q}}=\mathrm{zg}_{-} \mathrm{r}_{\mathrm{q}}$ $\mathrm{q} \in \mathrm{RDES}$
Salários semanais, salários mensais e suplementos

Renda de fator primário não proveniente de salário semanal 
Tabela 6. As equações do modelo MIBRA.

\begin{tabular}{|c|c|c|c|}
\hline Identificadores & Equação & Índice & Descrição \\
\hline $\begin{array}{l}\text { E_hhldy } 100 \\
(303)\end{array}$ & $\begin{array}{l}\text { C_HHLDY } 100_{\mathrm{q}} \text { hhldy } 100_{\mathrm{q}}= \\
\text { C_HHLDY } 110_{\mathrm{q}} \text { hhldy } 110_{\mathrm{q}}+ \\
\text { C_HHLDY } 120_{\mathrm{q}} \text { hhldy } 120_{\mathrm{q}}\end{array}$ & $\mathrm{q} \in \mathrm{RDES}$ & Renda de fator primário \\
\hline $\begin{array}{l}\text { E_hhldy } 210 \\
(304)\end{array}$ & $\begin{array}{l}\text { hhldy } 210_{q}=\text { natxi3 }+ \text { C_HHLDD } 001_{q} \\
\text { labsup }_{q}-C_{-} \text {HHLDD002 } \\
{\text { hhldf } 001_{q}} 1_{q}+\end{array}$ & $\mathrm{q} \in \mathrm{RDES}$ & $\begin{array}{l}\text { Benefícios de desemprego } \\
\text { recebidos }\end{array}$ \\
\hline $\begin{array}{l}\text { E_ hhldy } 220 \\
(305)\end{array}$ & hhldy $220_{q}=$ natxi3 + pop $_{q}+$ hhldf002 $q$ & $\mathrm{q} \in \mathrm{RDES}$ & $\begin{array}{l}\text { Outros benefícios pessoais } \\
\text { recebidos }\end{array}$ \\
\hline $\begin{array}{l}\text { E_hhldy } 200 \\
(306)\end{array}$ & $\begin{array}{l}\text { C_HHLDY } 200_{\mathrm{q}} \text { hhldy } 200_{\mathrm{q}}= \\
\text { C_HHLDY } 210_{\mathrm{q}} \text { hhldy } 210_{\mathrm{q}}+ \\
\text { C_HHLDY } 220_{\mathrm{q}} \text { hhldy } 220_{\mathrm{q}}\end{array}$ & $\mathrm{q} \in \mathrm{RDES}$ & Benefícios pessoais recebidos \\
\hline $\begin{array}{l}\text { E_ hhldy300 } \\
(307)\end{array}$ & hhldy $300_{q}=y n \_r_{q}+$ hhldf $003_{q}$ & $\mathrm{q} \in \mathrm{RDES}$ & Outra renda (líquida) \\
\hline $\begin{array}{l}\text { E_hhldy } 410 \\
\text { (308) }\end{array}$ & hhldy $410_{\mathrm{q}}=$ hhldy $110_{\mathrm{q}}+\mathrm{rl}$ & $\mathrm{q} \in \mathrm{RDES}$ & Impostos PAYE \\
\hline $\begin{array}{l}\text { E_hhldy } 420 \\
\text { (309) }\end{array}$ & hhldy $420_{q}=$ hhldy $120_{q}+$ rk & $\mathrm{q} \in \mathrm{RDES}$ & $\begin{array}{l}\text { Taxas sobre renda de fator } \\
\text { primário não proveniente de } \\
\text { salário semanal }\end{array}$ \\
\hline $\begin{array}{l}\text { E_hhldy } 430 \\
(310)\end{array}$ & hhldy $430_{\mathrm{q}}=$ tod_r $\mathrm{r}_{\mathrm{q}}$ & $\mathrm{q} \in \mathrm{RDES}$ & Outros impostos diretos \\
\hline $\begin{array}{l}\text { E_hhldy } 400 \\
(311)\end{array}$ & $\begin{array}{l}\text { C_HHLDY } 400_{\mathrm{q}} \text { hhldy } 400_{\mathrm{q}}= \\
\text { C_HHLDY } 410_{\mathrm{q}} \text { hhldy } 410_{\mathrm{q}}+ \\
\text { C_HHLDY } 420_{\mathrm{q}} \text { hhldy } 420_{\mathrm{q}}+ \\
\text { C_HHLDY } 430_{\mathrm{q}} \text { hhldy } 430_{\mathrm{q}}\end{array}$ & $\mathrm{q} \in \mathrm{RDES}$ & Impostos diretos \\
\hline $\begin{array}{l}\text { E_ hhldy000 } \\
\text { (312) }\end{array}$ & $\begin{array}{l}\text { C_HHLDY000 }{ }_{\mathrm{q}} \text { hhldy } 000_{\mathrm{q}}= \\
\text { C_HHLDY } 100_{\mathrm{q}} \text { hhldy } 100_{\mathrm{q}}+ \\
\text { C_HHLDY } 200_{\mathrm{q}} \text { hhldy } 200_{\mathrm{q}}+ \\
\text { C_HHLDY } 300_{\mathrm{q}} \text { hhldy } 300_{\mathrm{q}}- \\
\text { C_HHLDY } 400_{\mathrm{q}} \text { hhldy } 400_{\mathrm{q}}\end{array}$ & $\mathrm{q} \in \mathrm{RDES}$ & Renda disponível \\
\hline E_ydr & $y d \_r_{q}=$ hhldy $000_{q}$ & $\mathrm{q} \in \mathrm{RDES}$ & Renda disponível \\
\hline
\end{tabular}


Tabela 6. As equações do modelo MIBRA.

\begin{tabular}{|c|c|c|c|}
\hline Identificadores & Equação & Índice & Descrição \\
\hline $\begin{array}{l}E_{-} \text {upb } \\
(314)\end{array}$ & \multicolumn{2}{|l|}{$\begin{array}{l}\text { C_UPB upb }=\sum_{\mathrm{q} \in \mathrm{RDES} C} \text { _HHLDY210 } \\
\text { hhldy } 210_{\mathrm{q}}\end{array}$} & $\begin{array}{l}\text { Pagamentos de benefício de } \\
\text { desemprego agregado }\end{array}$ \\
\hline $\begin{array}{l}E_{-} p_{-} p_{-} \\
(315)\end{array}$ & pbp_r $r_{q}=$ hhldy $200_{q}$ & $\mathrm{q} \in \mathrm{RDES}$ & $\begin{array}{l}\text { Pagamentos de benefício } \\
\text { pessoal - regiões }\end{array}$ \\
\hline $\begin{array}{l}E_{-} \text {pbpA } \\
(316)\end{array}$ & \multicolumn{2}{|l|}{$\begin{array}{l}\text { C_PBP pbp }=\sum_{\mathrm{q} \in \mathrm{RDES} C \_H H L D Y} 200_{\mathrm{q}} \\
\text { hhldy } 200_{\mathrm{q}}\end{array}$} & $\begin{array}{l}\text { Pagamentos de benefício } \\
\text { pessoal agregado }\end{array}$ \\
\hline $\begin{array}{l}E_{-} p b p B \\
(317)\end{array}$ & \multicolumn{2}{|l|}{$\begin{array}{l}\text { C_PBP pbp }=\sum_{q \in D D E S C} \text { _PBP_R } \\
\text { pbp_r } r_{q}\end{array}$} & $\begin{array}{l}\text { Pagamentos de benefício } \\
\text { pessoal - federal (resíduo) }\end{array}$ \\
\hline \multicolumn{4}{|c|}{ Dinâmica para Previsão } \\
\hline $\begin{array}{l}\mathrm{E}_{-} \text {yTA } \\
(318)\end{array}$ & $\begin{array}{l}\text { VALK_T }_{\mathrm{j}, \mathrm{q}} \text { curcap_t }_{\mathrm{j,q}}=\mathrm{VALKT}_{\mathrm{j}, \mathrm{q}} \\
\text { DEP }_{\mathrm{j}} \text { curcap }_{\mathrm{j}, \mathrm{q}}+\mathrm{INVEST}_{\mathrm{j}, \mathrm{q}} \mathrm{y}_{\mathrm{j}, \mathrm{q}}-100 \\
\left(\mathrm{VALK}_{\mathrm{N}}\left(1-\mathrm{DEP}_{\mathrm{j}}\right)\right)- \\
\left.\text { INVEST_0 }_{\mathrm{j}, \mathrm{q}}\right) \text { delkfudge }+ \\
\text { 100delf_rate } \\
\mathrm{j}, \mathrm{q}\end{array}$ & $\begin{array}{l}j \in I N D \\
q \in \text { RDES }\end{array}$ & $\begin{array}{l}\text { Investimento no período } \mathrm{T} \text { : } \\
\text { Previsão }\end{array}$ \\
\hline $\begin{array}{l}\text { E_curcapT1A } \\
(319)\end{array}$ & ${\text { curcap_t } 1_{\mathrm{j}, \mathrm{q}}=\mathrm{K} \_ \text {TERMcurcap } \mathrm{j}, \mathrm{q}}$ & $\begin{array}{l}\mathrm{j} \in \mathrm{IND} \\
\mathrm{q} \in \mathrm{RDES}\end{array}$ & $\begin{array}{l}\text { Estoque de capital no período } \\
\mathrm{T}+1 \text { : Previsão }\end{array}$ \\
\hline $\begin{array}{l}E_{-} \text {yTB } \\
(320)\end{array}$ & $\operatorname{curcap}_{\mathrm{j}, \mathrm{q}}=\mathrm{y}_{\mathrm{j}, \mathrm{q}}+$ 100delf_rate $\mathrm{j,q}$ & $\begin{array}{l}j \in I N D \\
q \in \text { RDES }\end{array}$ & $\begin{array}{l}\text { Investimento } \mathrm{n} \text { período } \mathrm{T} \text { : } \\
\text { Estática comparativa }\end{array}$ \\
\hline $\begin{array}{l}\text { E_ curcapT1B } \\
(321)\end{array}$ & curcap_t $1_{\mathrm{j}, \mathrm{q}}=$ curcap $_{\mathrm{j}, \mathrm{q}}$ & $\begin{array}{l}j \in I N D \\
q \in \text { RDES }\end{array}$ & $\begin{array}{l}\text { Estoque de Capital no período } \\
\mathrm{T}+1 \text { : Estática comparativa }\end{array}$ \\
\hline $\begin{array}{l}\mathrm{E}_{-} \mathrm{r} 0 \\
(322)\end{array}$ & $\mathrm{rO}_{\mathrm{j}, \mathrm{q}}=\mathrm{QCOEF}_{\mathrm{j}, \mathrm{q}}\left(\mathrm{p} 1 \mathrm{cap} \mathrm{p}_{\mathrm{j}, \mathrm{q}}-\mathrm{pi}_{\mathrm{j}, \mathrm{q}}\right)$ & $\begin{array}{l}\mathrm{j} \in \mathrm{IND} \\
\mathrm{q} \in \mathrm{RDES}\end{array}$ & $\begin{array}{l}\text { Definição de taxas de retorno } \\
\text { para o capital }\end{array}$ \\
\hline $\begin{array}{l}E_{-} f_{-} \text {rate_ } x x \\
(323)\end{array}$ & $\begin{array}{l}\mathrm{r}_{\mathrm{j}, \mathrm{q}}-\text { natr_tot }=\text { BETA_R } \mathrm{R}_{\mathrm{j}, \mathrm{q}}\left[\text { curcap }_{\mathrm{j}, \mathrm{q}}-\right. \\
\left.\mathrm{kt}_{\mathrm{q}}\right]+\mathrm{f} \_ \text {rate_ } \mathrm{xx}_{\mathrm{j}, \mathrm{q}}\end{array}$ & $\begin{array}{l}j \in I N D \\
q \in \text { RDES }\end{array}$ & $\begin{array}{l}\text { Taxas de crescimento do } \\
\text { capital relacionado às taxas } \\
\text { de retorno }\end{array}$ \\
\hline $\begin{array}{l}\text { E_naty } \\
(324)\end{array}$ & $\begin{array}{l}\text { NATINVEST }_{\mathrm{j}} \text { naty }_{\mathrm{j}}= \\
\sum_{\mathrm{q} \in \mathrm{RDES}_{\mathrm{INVEST}}} \mathrm{INV}_{\mathrm{j}, \mathrm{q}} \mathrm{y}_{\mathrm{j}, \mathrm{q}}\end{array}$ & $\mathrm{j} \in \mathrm{IND}$ & Investimento real total \\
\hline
\end{tabular}


Tabela 6. As equações do modelo MIBRA.

\begin{tabular}{|c|c|c|c|}
\hline Identificadores & Equação & Índice & Descrição \\
\hline \multicolumn{4}{|c|}{ Acumulação da dívida externa nacional } \\
\hline $\begin{array}{l}\text { E_deldebt }_{-} \\
(325)\end{array}$ & $\begin{array}{l}\text { deldebt }=\{\text { DEBT0 } \\
(\text { R_WORLD^PRIOD }-1)+ \\
\text { B0N_DEBT }\} \text { deldfudge }+ \\
\text { M_DEBTdelbt }\end{array}$ & & $\begin{array}{l}\text { Variações ordinárias na } \\
\text { dívida externa }\end{array}$ \\
\hline $\begin{array}{l}\text { E_delbt } \\
(326)\end{array}$ & $\begin{array}{l}\text { 100P_GLOBALdelbt }= \\
\text { NATAGGIMP( natimpvol) - } \\
\text { NATAGGEXP( natexpvol + natxi4 - } \\
\text { natxim) }\end{array}$ & & $\begin{array}{l}\text { Variações ordinárias no } \\
\text { déficit de comércio real }\end{array}$ \\
\hline $\begin{array}{l}\text { E_deldebt_ratio } \\
(327)\end{array}$ & $\begin{array}{l}\text { deldebt_ratio = (DEBT_RATIO/ } \\
\text { DEBT }) \text { deldebt - (DEBT_RATIO/ } \\
\text { 100)( natgdpexp - natxim })\end{array}$ & & $\begin{array}{l}\text { Variações na relação } \\
\text { dívida/PIB }\end{array}$ \\
\hline \multicolumn{4}{|c|}{ Definições da População regional e Mercado de Trabalho } \\
\hline $\begin{array}{l}\text { E_del_rm }_{-} \\
(328)\end{array}$ & $\begin{array}{l}\text { C_POP } \text { pop }_{\mathrm{q}}=\text { C_PR1 } 1_{\mathrm{q}} \text { delrpfudge }_{\mathrm{q}}+ \\
\text { C_PA2 }(\text { del_rm } \\
\text { f }\end{array}$ & $\mathrm{q} \in \mathrm{RDES}$ & $\begin{array}{l}\text { Acumulação de população } \\
\text { regional }\end{array}$ \\
\hline $\begin{array}{l}\text { E_del_labsup } \\
(329)\end{array}$ & 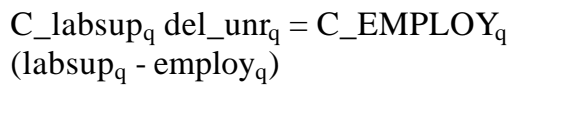 & $\mathrm{q} \in \mathrm{RDES}$ & $\begin{array}{l}\text { Variações em pontos } \\
\text { percentuais nas taxas de } \\
\text { desemprego regional }\end{array}$ \\
\hline $\begin{array}{l}\text { E_wpop } \\
(330)\end{array}$ & labsup $_{q}=\mathrm{pr}_{\mathrm{q}}+\mathrm{wpop}_{\mathrm{q}}$ & $\mathrm{q} \in \mathrm{RDES}$ & Oferta de trabalho regional \\
\hline $\begin{array}{l}\text { E_pop } \\
(331)\end{array}$ & $\mathrm{wpop}_{\mathrm{q}}=\operatorname{pop}_{\mathrm{q}}+\mathrm{f}_{-} \mathrm{wpop}_{\mathrm{q}}$ & $\mathrm{q} \in \mathrm{RDES}$ & $\begin{array}{l}\text { População em idade de } \\
\text { trabalho }\end{array}$ \\
\hline $\begin{array}{l}E_{-} r m_{-} 0 \\
(332)\end{array}$ & del_rm ${ }_{\mathrm{q}}=$ del_rm_0 $0_{\mathrm{q}}+$ delf_rm_0 & $\mathrm{q} \in \mathrm{RDES}$ & $\begin{array}{l}\text { Previsões da população que } \\
\text { podem orientar a migração } \\
\text { inter-regional }\end{array}$ \\
\hline $\begin{array}{l}\text { E_rempl_interf } \\
\text { (333) }\end{array}$ & $\mathrm{l}_{\mathrm{q}}=\operatorname{employ}_{\mathrm{q}}+\mathrm{f}_{-} \mathrm{l}_{\mathrm{q}}$ & $\mathrm{q} \in \mathrm{RDES}$ & $\begin{array}{lr}\text { Interface de } & \text { emprego } \\
\text { pesos/ponderações } & \text { dos } \\
\text { salários e pesos/ponderações } \\
\text { da pessoa. }\end{array}$ \\
\hline E_pop_interf & qhous $_{q}=\operatorname{pop}_{\mathrm{q}}+\mathrm{f}_{-} \mathrm{qhous}_{\mathrm{q}}$ & $\mathrm{q} \in \mathrm{RDES}$ & $\begin{array}{l}\text { Interface da população e } \\
\text { formação das famílias. }\end{array}$ \\
\hline
\end{tabular}


Tabela 6. As equações do modelo MIBRA.

\begin{tabular}{|c|c|c|}
\hline Identificadores & Equação & Descrição \\
\hline $\begin{array}{l}\text { E_ rm_ addup }_{-} \\
\text {(335) }\end{array}$ & delf_rm $=\sum_{\mathrm{q} \in \mathrm{RDES}}$ del_rm $\mathrm{q}$ & $\begin{array}{l}\text { Acréscimo de condição sobre } \\
\text { a migração inter-regional. }\end{array}$ \\
\hline $\begin{array}{l}\text { E_delnatfm } \\
\text { (336) }\end{array}$ & del_natfm $=\sum_{\mathrm{q} \in \mathrm{RDES}}$ del_fm $\mathrm{q}_{\mathrm{q}}$ & Migração estrangeira nacional \\
\hline $\begin{array}{l}\text { E_delnatg } \\
(337)\end{array}$ & del_natg $=\sum_{\mathrm{q} \in \text { RDES }}$ del_g $\mathrm{q}$ & $\begin{array}{l}\text { Variação natural e nacional } \\
\text { da população }\end{array}$ \\
\hline $\begin{array}{l}\text { E_ natlabsup } \\
\text { (338) }\end{array}$ & $\begin{array}{l}\text { C_NATLABSUP natlabsup = } \\
\sum_{\mathrm{q} \in \text { RDESC_LABSUP }} \text { labsup }_{\mathrm{q}}\end{array}$ & Oferta nacional de trabalho \\
\hline $\begin{array}{l}\text { E_ natemploy } \\
\text { (339) }\end{array}$ & $\begin{array}{l}\text { C_NATEMPLOY natemploy = } \\
\sum_{\mathrm{q} \in \text { RDESC_EMPLOY }} \text { employ }_{\mathrm{q}}\end{array}$ & Emprego nacional \\
\hline $\begin{array}{l}\text { E_natunr } \\
(340)\end{array}$ & $\begin{array}{l}\text { C_NATLABSUP del_natunr = } \\
\text { C_NATEMPLOY( natlabsup - } \\
\text { natemploy) }\end{array}$ & $\begin{array}{l}\text { Variações em }{ }^{2} \text { ponto } \\
\text { percentuais na taxa de } \\
\text { desemprego nacional }\end{array}$ \\
\hline
\end{tabular}

Fonte: Adaptado de Peter et al. (1996a)

Tabela 7. As variáveis do MIBRA.

\begin{tabular}{|c|c|c|}
\hline Variável & Dimensão & Descrição \\
\hline deltax1all & & $\begin{array}{l}\text { O modulo central do MIBRA } \\
\quad \text { Variáveis escalares } \\
\text { Variação em ponto percentual nas taxas de imposto indireto, } \\
\text { usuário } 1\end{array}$ \\
\hline deltax2all & & $\begin{array}{l}\text { Variação em ponto percentual nas taxas de imposto indireto, } \\
\text { usuário } 2\end{array}$ \\
\hline deltax3all & & $\begin{array}{l}\text { Variação em ponto percentual nas taxas de imposto indireto, } \\
\text { usuário } 3\end{array}$ \\
\hline deltax 4 all & & $\begin{array}{l}\text { Variação em ponto percentual nas taxas de imposto indireto, } \\
\text { usuário } 4\end{array}$ \\
\hline deltax 5all & & $\begin{array}{l}\text { Variação em ponto percentual nas taxas de imposto indireto, } \\
\text { usuário } 5\end{array}$ \\
\hline
\end{tabular}


Tabela 7. As variáveis do MIBRA.

\begin{tabular}{|c|c|c|}
\hline Variável & Dimensão & Descrição \\
\hline deltax6all & & $\begin{array}{l}\text { Variação em ponto percentual nas taxas de imposto indireto, } \\
\text { usuário } 6\end{array}$ \\
\hline Natc & & Consumo nominal total das famílias \\
\hline natcaprev & & Pagamentos agregados ao capital \\
\hline natcr & & Consumo real das famílias \\
\hline natdelb & & Variação ordinária no balanço de comércio \\
\hline natexport & & Valor da moeda estrangeira das exportações \\
\hline natexpvol & & Volumes de exportações \\
\hline natfep & & Deslocador global das curves de demanda por exportações \\
\hline Natf5gen & & Termo de deslocação total para outras demandas regionais \\
\hline Natf6gen & & Termo de deslocação total para outras demandas federais \\
\hline natfwage & & Deslocador geral do salário semanal \\
\hline natgdpexp & & PIB nominal pelo lado do gasto \\
\hline natgdpinc & & PIB nominal pelo lado da renda \\
\hline natgdpreal & & PIB real pelo lado do gasto \\
\hline natimp & & Valor da moeda estrangeira das importações \\
\hline natimpvol & & Volumes de importações \\
\hline natin & & Investimento agregado nominal \\
\hline natir & & Gasto real agregado em investimento \\
\hline natkt & & Estoque de capital agregado, pesos/ponderações dos aluguéis \\
\hline Natl & & Emprego agregado, pesos/ponderações dos salários \\
\hline natlabrev & & Pagamentos agregados ao trabalho \\
\hline natlndrev & & Pagamentos agregados a terra \\
\hline natoctrev & & Pagamentos agregados de outros custos \\
\hline natothnom5 & & Valor nominal agregado de "outras" demandas regionais \\
\hline natothnom6 & & Valor nominal agregado de "outras" demandas federais \\
\hline natothreal5 & & "Outras" demandas regionais reais agregadas \\
\hline natothreal6 & & "Outras" demandas federais reais agregadas \\
\hline natp1cap & & Aluguéis do capital nominais agregados \\
\hline natphi & & Taxa de câmbio \\
\hline natpwage & & Salário seminal nominal agregado pago aos trabalhadores \\
\hline natpwage_p & & Salário seminal nominal agregado pago pelos produtores \\
\hline natrealwage & & Salário real semanal nacional do consumidor \\
\hline
\end{tabular}


Tabela 7. As variáveis do MIBRA.

\begin{tabular}{|c|c|c|}
\hline Variável & Dimensão & Descrição \\
\hline natrwage_p & & $\begin{array}{l}\text { Salários semanais reais nacionais para os produtores: deflacionado } \\
\text { pelo deflator do PIB }\end{array}$ \\
\hline natrwage_w & & $\begin{array}{l}\text { Salários semanais reais nacionais para trabalhadores: deflacionado } \\
\text { pelo IPC }\end{array}$ \\
\hline nattaxind & & Receita agregada proveniente de todas os impostos indiretos \\
\hline nattaxrev1 & & $\begin{array}{l}\text { Receita agregada proveniente de impostos indiretos sobre o } \\
\text { intermediário }\end{array}$ \\
\hline nattaxrev2 & & $\begin{array}{l}\text { Receita agregada proveniente de impostos indiretos sobre } \\
\text { investimento }\end{array}$ \\
\hline nattaxrev3 & & $\begin{array}{l}\text { Receita agregada proveniente de impostos indiretos sobre as } \\
\text { famílias }\end{array}$ \\
\hline nattaxrev4 & & $\begin{array}{l}\text { Receita agregada proveniente de impostos indiretos sobre as } \\
\text { exportações }\end{array}$ \\
\hline nattaxrev5 & & $\begin{array}{l}\text { Receita agregada proveniente de impostos indiretos sobre "outras" } \\
\text { demandas regionais }\end{array}$ \\
\hline nattaxrev6 & & $\begin{array}{l}\text { Receita agregada proveniente de impostos indiretos sobre as } \\
\text { "outras" demandas federais }\end{array}$ \\
\hline nattaxrevm & & Receita agregada de tarifa \\
\hline nattot & & Termos de comércio geral da economia \\
\hline natxi2 & & Índice de preços ao investimento \\
\hline natxi3 & & Índice de preços ao consumidor \\
\hline natxi4 & & Índice de preços das exportações \\
\hline natxi5 & & Índice de preços das "outras" demandas regionais \\
\hline natxi6 & & Índice de preços das outras demandas federais \\
\hline natxigdp & & Índice de preços do PIB, lado do gasto \\
\hline natxim & & Índice de preços das importações \\
\hline natximp0 & & $\begin{array}{l}\text { Índice de preços das importações com impostos de importação } \\
\text { pagos }\end{array}$ \\
\hline natxiplpk & & Preços relativo de trabalho e capital \\
\hline \multirow[t]{2}{*}{ Natz_tot } & & Produção agregada: ponderações pelo valor adicionado \\
\hline & & Variáveis vetores \\
\hline aggnt_fep & $\mathrm{s} \in \mathrm{RSOU}$ & Deslocador de preços sobre exportações não tradicionais \\
\hline aggnt_p4 $\mathrm{r}_{\mathrm{s}}$ & $\mathrm{s} \in \mathrm{RSOU}$ & Preço agregado para exportações não tradicionais \\
\hline aggnt_x $4 \mathrm{r}_{\mathrm{s}}$ & $\mathrm{s} \in \mathrm{RSOU}$ & Demanda pro exportações agregadas não tradicionais \\
\hline caprev $_{\mathrm{q}}$ & $\mathrm{q} \in \mathrm{RDES}$ & Pagamentos agregados para o capital \\
\hline $\mathrm{c}_{\mathrm{q}}$ & $\mathrm{q} \in \mathrm{RDES}$ & Consumo nominal total das famílias \\
\hline
\end{tabular}


Tabela 7. As variáveis do MIBRA.

\begin{tabular}{|c|c|c|}
\hline Variável & Dimensão & Descrição \\
\hline cr_shr ${ }_{\mathrm{q}}$ & $\mathrm{q} \in \mathrm{RDES}$ & Razão entre o consumo regional e o consumo nacional \\
\hline $\mathrm{cr}_{\mathrm{q}}$ & $\mathrm{q} \in \mathrm{RDES}$ & Consumo real das famílias \\
\hline delb_dom $\mathrm{q}$ & $\mathrm{q} \in \mathrm{RDES}$ & Variação no balanço de comércio inter-regional \\
\hline delb_for_aud $\mathrm{q}_{\mathrm{q}}$ & $\mathrm{q} \in \mathrm{RDES}$ & Variação no valor em Reais do balanço de comércio internacional \\
\hline delb_tot ${ }_{\mathrm{q}}$ & $\mathrm{q} \in \mathrm{RDES}$ & $\begin{array}{l}\text { Soma da variação no balanço de comércio doméstico e } \\
\text { internacional }\end{array}$ \\
\hline deltaxdest $_{\mathrm{q}}$ & $\mathrm{q} \in \mathrm{ADES}$ & $\begin{array}{l}\text { Deslocador de imposto (variação em pontos percentuais) para } \\
\text { todos os destinos incluindo estrangeiro e federal }\end{array}$ \\
\hline deltaxsource $_{\mathrm{s}}$ & $\mathrm{s} \in \mathrm{ASOU}$ & $\begin{array}{l}\text { Deslocador de imposto (variação em pontos percentuais) por todas } \\
\text { as origens (doméstica e estrangeira) }\end{array}$ \\
\hline Exp_for_aud ${ }_{q}$ & $\mathrm{q} \in \mathrm{RDES}$ & Valor em Reais das exportações estrangeiras \\
\hline $\operatorname{export}_{\mathrm{q}}$ & $\mathrm{q} \in \mathrm{RDES}$ & Valor da moeda estrangeira das exportações \\
\hline $\operatorname{expvol}_{\mathrm{q}}$ & $\mathrm{q} \in \mathrm{RDES}$ & Volumes de exportações \\
\hline $\mathrm{f} \mathrm{gen}_{\mathrm{q}}$ & $\mathrm{q} \in \mathrm{RDES}$ & Termo de deslocamento geral para outras demandas regionais \\
\hline f6gen $_{\mathrm{q}}$ & $\mathrm{q} \in \mathrm{RDES}$ & Deslocador, "outra" demanda federal \\
\hline faggnt_i $\mathrm{i}_{\mathrm{i}}$ & $\mathrm{i} \in \mathrm{NTEXP}$ & $\begin{array}{l}\text { Deslocador por produto para exportações não tradicionais } \\
\text { agregadas }\end{array}$ \\
\hline faggnt_p4 $\mathrm{r}_{\mathrm{s}}$ & $\mathrm{s} \in \mathrm{RSOU}$ & $\begin{array}{l}\text { Deslocador sobre os preços de exportações não tradicionais } \\
\text { agregados }\end{array}$ \\
\hline faggnt_s $\mathrm{s}_{\mathrm{s}}$ & $\mathrm{s} \in \mathrm{RSOU}$ & Deslocador por região para exportações não tradicionais agregadas \\
\hline fep $_{\mathrm{i}}$ & $\mathrm{i} \in \mathrm{COM}$ & Deslocamento de Preço (para cima) em demandas por exportações \\
\hline $\mathrm{feq}_{\mathrm{i}}$ & $\mathrm{i} \in \mathrm{COM}$ & $\begin{array}{l}\text { Deslocamento de quantidade (direita) em demandas por } \\
\text { exportações }\end{array}$ \\
\hline fwage $_{\mathrm{q}}$ & $\mathrm{q} \in \mathrm{RDES}$ & Deslocador total do salário semanal real \\
\hline Imp_for_aud ${ }_{q}$ & $\mathrm{q} \in \mathrm{RDES}$ & Valor AUD das importações \\
\hline $\operatorname{imp}_{\mathrm{q}}$ & $\mathrm{q} \in \mathrm{RDES}$ & Valor da moeda estrangeira das importações \\
\hline $\operatorname{impvol}_{\mathrm{q}}$ & $\mathrm{q} \in \mathrm{RDES}$ & Índice do volume de importação \\
\hline in $_{\mathrm{q}}$ & $\mathrm{q} \in \mathrm{RDES}$ & Investimento nominal agregado \\
\hline $\mathrm{ir}_{\mathrm{q}}$ & $\mathrm{q} \in \mathrm{RDES}$ & Gasto em investimento real agregado \\
\hline $\mathrm{kt}_{\mathrm{q}}$ & $\mathrm{q} \in \mathrm{RDES}$ & Estoque de capital agregado, pesos/ponderações dos aluguéis \\
\hline $\operatorname{labrev}_{\mathrm{q}}$ & $\mathrm{q} \in \mathrm{RDES}$ & Pagamentos agregados para o trabalho \\
\hline $\operatorname{lndrev}_{\mathrm{q}}$ & $\mathrm{q} \in \mathrm{RDES}$ & Pagamentos agregados para a terra \\
\hline $1_{\mathrm{q}}$ & $\mathrm{q} \in \mathrm{RDES}$ & Emprego agregado - pesos/ponderações dos salários \\
\hline $\operatorname{luxexp}_{\mathrm{q}}$ & $\mathrm{q} \in \mathrm{RDES}$ & Gasto das famílias supernumerário total \\
\hline
\end{tabular}


Tabela 7. As variáveis do MIBRA.

\begin{tabular}{|c|c|c|}
\hline Variável & Dimensão & Descrição \\
\hline natlabind $_{j}$ & $\mathrm{j} \in \mathrm{IND}$ & Emprego por setor \\
\hline natlambda $\mathrm{m}$ & $\mathrm{m} \in \mathrm{OCC}$ & Emprego em ocupação M \\
\hline natx0imp $_{i}$ & $\mathrm{i} \in \mathrm{COM}$ & Volumes de importação \\
\hline naty $_{j}$ & $\mathrm{j} \in \mathrm{IND}$ & Criação de capital por uso do setor \\
\hline natz $_{j}$ & $\mathrm{j} \in \mathrm{IND}$ & Nível de atividade ou valor adicionado \\
\hline $\operatorname{octrev}_{\mathrm{q}}$ & $\mathrm{q} \in \mathrm{RDES}$ & Pagamentos agregados de outros custos \\
\hline othnom $5_{\mathrm{q}}$ & $\mathrm{q} \in \mathrm{RDES}$ & "Outras" demandas regionais nominais agregadas \\
\hline othnom6 ${ }_{\mathrm{q}}$ & $\mathrm{q} \in \mathrm{RDES}$ & "Outra" demanda federal nominal agregada \\
\hline othreal5 $5_{\mathrm{q}}$ & $\mathrm{q} \in \mathrm{RDES}$ & "Outras" demandas regionais reais agregadas \\
\hline othreal6 $6_{\mathrm{q}}$ & $\mathrm{q} \in \mathrm{RDES}$ & "Outra" demanda federal real agregada \\
\hline $\mathrm{pm}_{\mathrm{i}}$ & $\mathrm{i} \in \mathrm{COM}$ & Preços de importação da moeda estrangeira C.I.F. \\
\hline $\operatorname{powtaxm}_{\mathrm{i}}$ & $\mathrm{i} \in \mathrm{COM}$ & Poder das tarifas \\
\hline $\operatorname{psexp}_{\mathrm{s}}$ & $\mathrm{s} \in \mathrm{RSOU}$ & Indicadores de preço para exportações inter-regionais \\
\hline $\operatorname{psimp}_{\mathrm{q}}$ & $\mathrm{q} \in \mathrm{RDES}$ & Indicadores de preço para importações inter-regionais \\
\hline pwage $_{\mathrm{q}}$ & $\mathrm{q} \in \mathrm{RDES}$ & $\begin{array}{l}\text { Salários semanais nominais regionais recebidos pelos } \\
\text { trabalhadores }\end{array}$ \\
\hline pwage_p $\mathrm{p}_{\mathrm{q}}$ & $\mathrm{q} \in \mathrm{RDES}$ & Salário semanal nominal regional pago pelos produtores \\
\hline qhous $_{\mathrm{q}}$ & $\mathrm{q} \in \mathrm{RDES}$ & Número de famílias \\
\hline realwage_w $\mathrm{w}_{\mathrm{q}}$ & $\mathrm{q} \in \mathrm{RDES}$ & Salários semanais reais para trabalhadores: deflacionados pelo IPC \\
\hline realwage_p $\mathrm{p}_{\mathrm{q}}$ & $\mathrm{q} \in \mathrm{RDES}$ & Salários reais para produtores: deflacionados pelo deflator do PIB \\
\hline Reg_p 1 cap $q$ & $\mathrm{q} \in \mathrm{RDES}$ & Preço do aluguel regional do capital \\
\hline $\operatorname{totdom}_{\mathrm{q}}$ & $\mathrm{q} \in \mathrm{RDES}$ & Termos domésticos de comércio \\
\hline totfor $_{\mathrm{q}}$ & $\mathrm{q} \in \mathrm{RDES}$ & Termos estrangeiros de comércio \\
\hline r0_tot ${ }_{\mathrm{q}}$ & $\mathrm{q} \in \mathrm{RDES}$ & Taxa de retorno agregado regional \\
\hline $\operatorname{taxind}_{\mathrm{q}}$ & $\mathrm{q} \in \mathrm{RDES}$ & Receita agregada proveniente de todos os impostos indiretos \\
\hline $\operatorname{taxrev} 1_{\mathrm{q}}$ & $\mathrm{q} \in \mathrm{RDES}$ & Receita agregada, impostos indiretos sobre o intermediário \\
\hline $\operatorname{taxrev} 2_{\mathrm{q}}$ & $\mathrm{q} \in \mathrm{RDES}$ & Receita agregada: impostos indiretos sobre o investimento \\
\hline $\operatorname{taxrev} 3_{\mathrm{q}}$ & $\mathrm{q} \in \mathrm{RDES}$ & Receita agregada: impostos indiretos sobre as famílias \\
\hline taxrev $4_{s}$ & $\mathrm{~s} \in \mathrm{RSOU}$ & $\begin{array}{l}\text { Receita Agregada: impostos indiretos sobre as exportações } \\
\text { estrangeiras }\end{array}$ \\
\hline $\operatorname{taxrev} 5_{\mathrm{q}}$ & $\mathrm{q} \in \mathrm{RDES}$ & $\begin{array}{l}\text { Receita agregada: impostos indiretos sobre "outras" demandas } \\
\text { regionais }\end{array}$ \\
\hline $\operatorname{taxrev} 6_{\mathrm{q}}$ & $\mathrm{q} \in \mathrm{RDES}$ & Receita agregada, impostos indiretos sobre "outra" demanda \\
\hline
\end{tabular}


Tabela 7. As variáveis do MIBRA.

\begin{tabular}{|c|c|c|}
\hline Variável & Dimensão & Descrição \\
\hline & & federal \\
\hline taxrevm $m_{\mathrm{q}}$ & $\mathrm{q} \in \mathrm{RDES}$ & Receita agregada de tarifa \\
\hline utility $_{\mathrm{q}}$ & $\mathrm{q} \in \mathrm{RDES}$ & Utilidade por família \\
\hline wage_diff ${ }_{\mathrm{q}}$ & $\mathrm{q} \in \mathrm{RDES}$ & Diferencial de salário semanal real regional \\
\hline $\operatorname{xim}_{\mathrm{l}}$ & $\mathrm{q} \in \mathrm{RDES}$ & Índice de preços as importações \\
\hline $\mathrm{ximp}_{\mathrm{q}}$ & $\mathrm{q} \in \mathrm{RDES}$ & $\begin{array}{l}\text { Índice de preços as importações com impostos de importação } \\
\text { pagos }\end{array}$ \\
\hline xiplpk $_{\mathrm{q}}$ & $\mathrm{q} \in \mathrm{RDES}$ & Índice de preço relativo de capital e trabalho \\
\hline Xiy_r $r_{q}$ & $\mathrm{q} \in \mathrm{RDES}$ & Deflator regional do PIB \\
\hline $\mathrm{xi} 2_{\mathrm{q}}$ & $\mathrm{q} \in \mathrm{RDES}$ & Índice de preço ao investimento \\
\hline $\mathrm{xi} 3_{\mathrm{q}}$ & $\mathrm{q} \in \mathrm{RDES}$ & Índice de preço ao consumidor \\
\hline $\mathrm{xi}_{\mathrm{q}}$ & $\mathrm{q} \in \mathrm{RDES}$ & Índice de preço às exportações \\
\hline $\mathrm{xi}_{\mathrm{q}}$ & $\mathrm{q} \in \mathrm{RDES}$ & Índice de preço de "outras" demandas regionais \\
\hline $\mathrm{xi}_{\mathrm{q}}$ & $\mathrm{q} \in \mathrm{RDES}$ & Índice de preço de "outra" demanda federal \\
\hline $\operatorname{xsexp}_{\mathrm{s}}$ & $\mathrm{s} \in \mathrm{RSOU}$ & Volume de exportações no comércio inter-regional \\
\hline $\operatorname{xsimp}_{\mathrm{q}}$ & $\mathrm{q} \in \mathrm{RDES}$ & Volume de importações no comércio inter-regional \\
\hline $\mathrm{z}_{-}$tot $_{\mathrm{q}}$ & $\mathrm{q} \in \mathrm{RDES}$ & Produto agregado: ponderações pelo valor adicionado \\
\hline & & Variáveis matrizes \\
\hline alcap $_{\mathrm{j}, \mathrm{q}}$ & $\begin{array}{l}\mathrm{j} \in \mathrm{IND} \\
\mathrm{q} \in \mathrm{RDES}\end{array}$ & Mudança técnica do aumento de capital \\
\hline $\mathrm{a} 1_{\mathrm{j}, \mathrm{q}}$ & $\begin{array}{l}j \in I N D \\
q \in R D E S\end{array}$ & Mudança técnica do aumento de todos os insumos \\
\hline $\mathrm{a}_{11 \mathrm{ab}}^{\mathrm{j}, \mathrm{q}}$ & $\begin{array}{l}\mathrm{j} \in \mathrm{IND} \\
\mathrm{q} \in \mathrm{RDES}\end{array}$ & Mudança técnica do aumento de trabalho \\
\hline alland $_{\mathrm{j}, \mathrm{q}}$ & $\begin{array}{l}\mathrm{j} \in \mathrm{IND} \\
\mathrm{q} \in \mathrm{RDES}\end{array}$ & Mudança técnica de aumento da terra \\
\hline $\mathrm{a} 1$ oct $_{\mathrm{j}, \mathrm{q}}$ & $\begin{array}{l}\mathrm{j} \in \mathrm{IND} \\
\mathrm{q} \in \mathrm{RDES}\end{array}$ & Mudança técnica dos outros custos \\
\hline a 1 prim $_{\mathrm{j}, \mathrm{q}}$ & $\begin{array}{l}\mathrm{j} \in \mathrm{IND} \\
\mathrm{q} \in \mathrm{RDES}\end{array}$ & Mudança técnica de todos os fatores primários \\
\hline $\mathrm{a} 2 \mathrm{ind}_{\mathrm{j}, \mathrm{q}}$ & $\begin{array}{l}\mathrm{j} \in \mathrm{IND} \\
\mathrm{q} \in \mathrm{RDES}\end{array}$ & Mudança técnica na criação de capital \\
\hline $\operatorname{a} \operatorname{com}_{, \mathrm{q}}$ & $\begin{array}{l}\mathrm{i} \in \mathrm{COM} \\
\mathrm{q} \in \mathrm{RDES}\end{array}$ & Mudanças nos gostos das famílias \\
\hline $\operatorname{a3lux}_{\mathrm{q}, \mathrm{q}}$ & $\mathrm{i} \in \mathrm{COM}$ & Mudanças nos gostos das famílias: luxo \\
\hline
\end{tabular}


Tabela 7. As variáveis do MIBRA.

\begin{tabular}{|c|c|c|}
\hline Variável & Dimensão & Descrição \\
\hline & $\mathrm{q} \in \mathrm{RDES}$ & \\
\hline $\mathrm{a} 3 \mathrm{sub}_{\mathrm{i}, \mathrm{q}}$ & $\begin{array}{l}\mathrm{i} \in \mathrm{COM} \\
\mathrm{q} \in \mathrm{RDES}\end{array}$ & Mudança no gosto das famílias: subsistência \\
\hline$a_{j, q}$ & $\begin{array}{l}j \in I N D \\
q \in R D E S\end{array}$ & Média dos termos da mudança técnica na produção \\
\hline $\operatorname{arpri}_{\mathrm{j}, \mathrm{q}}$ & $\begin{array}{l}j \in I N D \\
q \in \text { RDES }\end{array}$ & Fator de ajustamento no imposto da folha de pagamento \\
\hline curcap $_{\mathrm{j}, \mathrm{q}}$ & $\begin{array}{l}j \in I N D \\
q \in \text { RDES }\end{array}$ & Estoque de capital corrente \\
\hline $\operatorname{deltax} 1_{\mathrm{i}, \mathrm{s}, \mathrm{j}, \mathrm{q}}$ & $\begin{array}{l}i \in \mathrm{COM} \\
s \in \mathrm{ASOU} \\
j \in \mathrm{IND} \\
q \in \mathrm{RDES}\end{array}$ & $\begin{array}{l}\text { Mudança em ponto percentual nas taxas de imposto sobre vendas } \\
\text { de insumos intermediários }\end{array}$ \\
\hline $\operatorname{deltax} 2_{\mathrm{i}, \mathrm{s}, \mathrm{j}, \mathrm{q}}$ & $\begin{array}{l}i \in \mathrm{COM} \\
s \in \text { ASOU } \\
j \in \text { IND } \\
q \in \text { RDES }\end{array}$ & $\begin{array}{l}\text { Mudança em ponto percentual nas taxas de imposto sobre as } \\
\text { vendas para criação de capital }\end{array}$ \\
\hline $\operatorname{deltax} 3_{\mathrm{i}, \mathrm{s}, \mathrm{q}}$ & $\begin{array}{l}\mathrm{i} \in \mathrm{COM} \\
\mathrm{s} \in \mathrm{ASOU} \\
\mathrm{q} \in \mathrm{RDES}\end{array}$ & $\begin{array}{l}\text { Mudança em ponto percentual nas taxas de imposto sobre as } \\
\text { vendas para as famílias }\end{array}$ \\
\hline deltax $4_{i, s}$ & $\begin{array}{l}i \in \mathrm{COM} \\
\mathrm{s} \in \mathrm{RSOU}\end{array}$ & $\begin{array}{l}\text { Mudança em ponto percentual nas taxas de imposto sobre a } \\
\text { exportação }\end{array}$ \\
\hline $\operatorname{deltax} 5_{\mathrm{i}, \mathrm{s}, \mathrm{q}}$ & $\begin{array}{l}i \in \mathrm{COM} \\
\mathrm{s} \in \mathrm{ASOU} \\
\mathrm{q} \in \mathrm{RDES}\end{array}$ & $\begin{array}{l}\text { Mudança em ponto percentual na taxa de imposto sobre as vendas } \\
\text { para "outras" demandas regionais }\end{array}$ \\
\hline $\operatorname{deltax} 6_{\mathrm{i}, \mathrm{s}, \mathrm{q}}$ & $\begin{array}{l}\mathrm{i} \in \mathrm{COM} \\
\mathrm{s} \in \mathrm{ASOU} \\
\mathrm{q} \in \mathrm{RDES}\end{array}$ & $\begin{array}{l}\text { Mudança em ponto percentual nas taxas de imposto sobre as } \\
\text { vendas: demandas do governo federal }\end{array}$ \\
\hline deltax & $\mathrm{i} \in \mathrm{COM}$ & $\begin{array}{l}\text { Mudança em ponto percentual nas taxas de impostos nas vendas } \\
\text { em geral }\end{array}$ \\
\hline efflab $_{\mathrm{j}, \mathrm{q}}$ & $\begin{array}{l}\mathrm{j} \in \mathrm{IND} \\
\mathrm{q} \in \mathrm{RDES}\end{array}$ & Insumo trabalho efetivo \\
\hline floct $_{\mathrm{j}, \mathrm{q}}$ & $\begin{array}{l}\mathrm{j} \in \mathrm{IND} \\
\mathrm{q} \in \mathrm{RDES}\end{array}$ & Deslocadores: outros custos \\
\hline$f 5 \mathrm{a}_{\mathrm{i}, \mathrm{s}, \mathrm{q}}$ & $\begin{array}{l}\mathrm{i} \in \mathrm{COM} \\
\mathrm{s} \in \mathrm{ASOU} \\
\mathrm{q} \in \mathrm{RDES}\end{array}$ & Deslocamento em "outras" demandas regionais \\
\hline$f 6 a_{i, s, q}$ & $\begin{array}{l}i \in \mathrm{COM} \\
\mathrm{s} \in \mathrm{ASOU} \\
\mathrm{q} \in \mathrm{RDES}\end{array}$ & Deslocamento, "outra" demanda federal \\
\hline
\end{tabular}


Tabela 7. As variáveis do MIBRA.

\begin{tabular}{|c|c|c|}
\hline Variável & Dimensão & Descrição \\
\hline faggnt_is ${ }_{i, s}$ & $\begin{array}{l}\mathrm{i} \in \mathrm{NTEXP} \\
\mathrm{s} \in \mathrm{RSOU}\end{array}$ & Produto e deslocador fonte para exportações não tradicionais \\
\hline $\mathrm{frPRi}_{\mathrm{j}, \mathrm{q}}$ & $\begin{array}{l}\mathrm{j} \in \mathrm{IND} \\
\mathrm{q} \in \mathrm{RDES}\end{array}$ & Deslocador da taxa de impostos sobre a folha de pagamento \\
\hline fwagei $_{\mathrm{j}, \mathrm{q}}$ & $\begin{array}{l}j \in I N D \\
q \in \text { RDES }\end{array}$ & Deslocador do salário semanal específico do setor \\
\hline labind $_{\mathrm{j}, \mathrm{q}}$ & $\begin{array}{l}\mathrm{j} \in \mathrm{IND} \\
\mathrm{q} \in \mathrm{RDES}\end{array}$ & Emprego por setor \\
\hline $\operatorname{lambda}_{\mathrm{m}, \mathrm{q}}$ & $\begin{array}{l}\mathrm{m} \in \mathrm{OCC} \\
\mathrm{q} \in \mathrm{RDES}\end{array}$ & Emprego por ocupação \\
\hline $\mathrm{n}_{\mathrm{j}, \mathrm{q}}$ & $\begin{array}{l}\mathrm{j} \in \mathrm{IND} \\
\mathrm{q} \in \mathrm{RDES}\end{array}$ & Uso da terra \\
\hline $\mathrm{p} 0 \mathrm{a}_{\mathrm{i}, \mathrm{s}}$ & $\begin{array}{l}\mathrm{i} \in \mathrm{COM} \\
\mathrm{s} \in \mathrm{ASOU}\end{array}$ & Preço básico do bem i, origem s \\
\hline $\mathrm{p} 1 \mathrm{a}_{\mathrm{i}, \mathrm{s}, \mathrm{j}, \mathrm{q}}$ & $\begin{array}{l}i \in \mathrm{COM} \\
\mathrm{s} \in \mathrm{ASOU} \\
\mathrm{j} \in \mathrm{IND} \\
\mathrm{q} \in \mathrm{RDES}\end{array}$ & Preços de insumos para produção corrente \\
\hline $\mathrm{p} 1 \mathrm{cap}, \mathrm{j}, \mathrm{q}$ & $\begin{array}{l}\mathrm{j} \in \mathrm{IND} \\
\mathrm{q} \in \mathrm{RDES}\end{array}$ & Preço de aluguel do capital \\
\hline $\mathrm{p} 1 \mathrm{c}_{\mathrm{i}, \mathrm{j}, \mathrm{q}}$ & $\begin{array}{l}i \in \mathrm{COM} \\
\mathrm{j} \in \mathrm{IND} \\
\mathrm{q} \in \mathrm{RDES}\end{array}$ & Preços de insumos combinados domésticos para produção corrente \\
\hline $\mathrm{p}^{11 \mathrm{lab}} \mathrm{j}_{\mathrm{j}, \mathrm{q}}$ & $\begin{array}{l}\mathrm{j} \in \mathrm{IND} \\
\mathrm{q} \in \mathrm{RDES}\end{array}$ & Preço do trabalho \\
\hline p1laboi $_{\mathrm{j}, \mathrm{q}, \mathrm{m}}$ & $\begin{array}{l}\mathrm{j} \in \mathrm{IND} \\
\mathrm{q} \in \mathrm{RDES} \\
\mathrm{m} \in \mathrm{OCC}\end{array}$ & Salário semanal do tipo de ocupação m na indústria j \\
\hline $\mathrm{p}$ lland $_{\mathrm{j}, \mathrm{q}}$ & $\begin{array}{l}\mathrm{j} \in \mathrm{IND} \\
\mathrm{q} \in \mathrm{RDES}\end{array}$ & Preço de aluguel da terra \\
\hline $\mathrm{p}$ loct $_{\mathrm{j}, \mathrm{q}}$ & $\begin{array}{l}\mathrm{j} \in \mathrm{IND} \\
\mathrm{q} \in \mathrm{RDES}\end{array}$ & Preço de outros custos \\
\hline $\mathrm{p} 1 \mathrm{o}_{\mathrm{i}, \mathrm{j}, \mathrm{q}}$ & $\begin{array}{l}i \in C O M \\
j \in I N D \\
q \in R D E S\end{array}$ & $\begin{array}{l}\text { Preço, Insumos combinados doméstico/estrangeiro para produção } \\
\text { corrente }\end{array}$ \\
\hline $\mathrm{p} 2 \mathrm{a}_{\mathrm{i}, \mathrm{s}, \mathrm{j}, \mathrm{q}}$ & $\begin{array}{l}i \in \mathrm{COM} \\
\mathrm{s} \in \mathrm{ASOU} \\
\mathrm{j} \in \mathrm{IND} \\
\mathrm{q} \in \mathrm{RDES}\end{array}$ & Preços de insumos para criação de capital \\
\hline
\end{tabular}


Tabela 7. As variáveis do MIBRA.

\begin{tabular}{|c|c|c|}
\hline Variável & Dimensão & Descrição \\
\hline $\mathrm{p} 2 \mathrm{c}_{\mathrm{i}, \mathrm{j}, \mathrm{q}}$ & $\begin{array}{l}i \in \mathrm{COM} \\
j \in \mathrm{IND} \\
\mathrm{q} \in \mathrm{RDES}\end{array}$ & Preços de insumos combinados domésticos para criação de capital \\
\hline $\mathrm{p} 2 \mathrm{o}_{\mathrm{i}, \mathrm{j}, \mathrm{q}}$ & $\begin{array}{l}i \in \mathrm{COM} \\
\mathrm{j} \in \mathrm{IND} \\
\mathrm{q} \in \mathrm{RDES}\end{array}$ & $\begin{array}{l}\text { Preço, insumos de combinados doméstico/estrangeiro para criação } \\
\text { de capital }\end{array}$ \\
\hline $\mathrm{p} 3 \mathrm{a}_{\mathrm{i}, \mathrm{s}, \mathrm{q}}$ & $\begin{array}{l}\mathrm{i} \in \mathrm{COM} \\
\mathrm{s} \in \mathrm{ASOU} \\
\mathrm{q} \in \mathrm{RDES}\end{array}$ & Preços dos compradores por produtos e origem por famílias \\
\hline $\mathrm{p} 3 \mathrm{c}_{\mathrm{i}, \mathrm{q}}$ & $\begin{array}{l}\mathrm{i} \in \mathrm{COM} \\
\mathrm{q} \in \mathrm{RDES}\end{array}$ & Preços de insumos combinados domésticos para as famílias \\
\hline $\mathrm{p} 3 \mathrm{o}_{\mathrm{i}, \mathrm{q}}$ & $\begin{array}{l}i \in \mathrm{COM} \\
\mathrm{q} \in \mathrm{RDES}\end{array}$ & Preço, insumos combinados doméstico/estrangeiro para as famílias \\
\hline $\mathrm{p} 4 \mathrm{r}_{\mathrm{i}, \mathrm{s}}$ & $\begin{array}{l}i \in \mathrm{COM} \\
\mathrm{s} \in \mathrm{RSOU}\end{array}$ & Preços das exportações em moeda estrangeira F.O.B. \\
\hline $\mathrm{p} 5 \mathrm{a}_{\mathrm{i}, \mathrm{s}, \mathrm{q}}$ & $\begin{array}{l}i \in \mathrm{COM} \\
\mathrm{s} \in \mathrm{ASOU} \\
\mathrm{q} \in \mathrm{RDES}\end{array}$ & $\begin{array}{l}\text { Preços dos compradores para produtos (por origem) por "outras" } \\
\text { demandas regionais }\end{array}$ \\
\hline $\mathrm{p} 6 \mathrm{a}_{\mathrm{i}, \mathrm{s}, \mathrm{q}}$ & $\begin{array}{l}\mathrm{i} \in \mathrm{COM} \\
\mathrm{s} \in \mathrm{ASOU} \\
\mathrm{q} \in \mathrm{RDES}\end{array}$ & $\begin{array}{l}\text { Preços dos compradores pagos por produtos pela "outra" demanda } \\
\text { federal }\end{array}$ \\
\hline $\mathrm{pi}_{\mathrm{j}, \mathrm{q}}$ & $\begin{array}{l}j \in I N D \\
q \in R D E S\end{array}$ & Custos das unidades de capital \\
\hline psflo $_{\mathrm{s}, \mathrm{q}}$ & $\begin{array}{l}\mathrm{s} \in \mathrm{RSOU} \\
\mathrm{q} \in \mathrm{RDES}\end{array}$ & Indicadores de preços nos fluxos de comércio inter-regional \\
\hline pwagei $_{\mathrm{j}, \mathrm{q}}$ & $\begin{array}{l}j \in I N D \\
q \in R D E S\end{array}$ & Taxas de salário semanal nominal \\
\hline $\mathrm{rO}_{\mathrm{j}, \mathrm{q}}$ & $\begin{array}{l}j \in I N D \\
q \in R D E S\end{array}$ & Taxas de retorno corrente sobre o capital \\
\hline $\operatorname{rpri}_{\mathrm{j}, \mathrm{q}}$ & $\begin{array}{l}j \in \mathrm{IND} \\
\mathrm{q} \in \mathrm{RDES}\end{array}$ & Taxa de imposto sobre a folha de pagamento (em porcentagem) \\
\hline $\mathrm{x} 0 \operatorname{imp}_{\mathrm{i}, \mathrm{q}}$ & $\begin{array}{l}\mathrm{i} \in \mathrm{COM} \\
\mathrm{q} \in \mathrm{RDES}\end{array}$ & Volumes de importação \\
\hline $\mathrm{x} 1 \mathrm{a}_{\mathrm{i}, \mathrm{s}, \mathrm{j}, \mathrm{q}}$ & $\begin{array}{l}i \in \mathrm{COM} \\
s \in \mathrm{ASOU} \\
j \in \mathrm{IND} \\
\mathrm{q} \in \mathrm{RDES}\end{array}$ & Demandas por insumos para produção corrente \\
\hline $\mathrm{x} 1 \mathrm{c}_{\mathrm{i}, \mathrm{j}, \mathrm{q}}$ & $\begin{array}{l}i \in \mathrm{COM} \\
\mathrm{j} \in \mathrm{IND} \\
\mathrm{q} \in \mathrm{RDES}\end{array}$ & $\begin{array}{l}\text { Demandas por insumos combinados e domésticos para produção } \\
\text { corrente }\end{array}$ \\
\hline
\end{tabular}


Tabela 7. As variáveis do MIBRA.

\begin{tabular}{|c|c|c|}
\hline Variável & Dimensão & Descrição \\
\hline x1laboi $i_{j, q, m}$ & $\begin{array}{l}\mathrm{j} \in \mathrm{IND} \\
\mathrm{q} \in \mathrm{RDES} \\
\mathrm{m} \in \mathrm{OCC}\end{array}$ & Emprego do tipo de ocupação $m$ no setor $j$ \\
\hline $\mathrm{x} 1 \operatorname{marg}_{\mathrm{i}, \mathrm{s}, \mathrm{j}, \mathrm{q}, \mathrm{r}}$ & $\begin{array}{l}\mathrm{i} \in \mathrm{COM} \\
\mathrm{s} \in \mathrm{ASOU} \\
\mathrm{j} \in \mathrm{IND} \\
\mathrm{q} \in \mathrm{RDES} \\
\mathrm{r} \in \mathrm{MARG}\end{array}$ & Margens - produção corrente \\
\hline $\mathrm{x} 1 \operatorname{loct}_{\mathrm{j}, \mathrm{q}}$ & $\begin{array}{l}j \in I N D \\
q \in \text { RDES }\end{array}$ & Demanda por outros custos \\
\hline $\mathrm{x} 1 \mathrm{o}_{\mathrm{i}, \mathrm{j}, \mathrm{q}}$ & $\begin{array}{l}i \in \mathrm{COM} \\
\mathrm{j} \in \mathrm{IND} \\
\mathrm{q} \in \mathrm{RDES}\end{array}$ & $\begin{array}{l}\text { Demandas por insumos combinados e domésticos/estrangeiros } \\
\text { para produção corrente }\end{array}$ \\
\hline $\mathrm{x} 1 \operatorname{prim}_{\mathrm{j}, \mathrm{q}}$ & $\begin{array}{l}\mathrm{j} \in \mathrm{IND} \\
\mathrm{q} \in \mathrm{RDES}\end{array}$ & Demanda por fatores primários combinados \\
\hline $\mathrm{x} 2 \mathrm{a}_{\mathrm{i}, \mathrm{s}, \mathrm{j}, \mathrm{q}}$ & $\begin{array}{l}i \in \mathrm{COM} \\
\mathrm{s} \in \mathrm{ASOU} \\
\mathrm{j} \in \mathrm{IND} \\
\mathrm{q} \in \mathrm{RDES}\end{array}$ & Demanda por insumos para criação de capital \\
\hline$x 2 c_{i, j, q}$ & $\begin{array}{l}i \in \mathrm{COM} \\
\mathrm{j} \in \mathrm{IND} \\
\mathrm{q} \in \mathrm{RDES}\end{array}$ & $\begin{array}{l}\text { Demandas por insumos combinados e domésticos para criação de } \\
\text { capital }\end{array}$ \\
\hline $\mathrm{x} 2 \operatorname{marg}_{\mathrm{i}, \mathrm{s}, \mathrm{j}, \mathrm{q}, \mathrm{r}}$ & $\begin{array}{l}i \in \mathrm{COM} \\
s \in \text { ASOU } \\
j \in \mathrm{IND} \\
\mathrm{q} \in \mathrm{RDES} \\
\mathrm{r} \in \mathrm{MARG}\end{array}$ & Margens - criação de capital \\
\hline $\mathrm{x} 2 \mathrm{o}_{\mathrm{i}, \mathrm{j}, \mathrm{q}}$ & $\begin{array}{l}i \in \text { COM } \\
j \in \text { IND } \\
q \in \text { RDES }\end{array}$ & $\begin{array}{l}\text { Demanda por insumos combinados domésticos/estrangeiros para } \\
\text { criação de capital }\end{array}$ \\
\hline $\mathrm{x} 3 \mathrm{a}_{\mathrm{i}, \mathrm{s}, \mathrm{q}}$ & $\begin{array}{l}\mathrm{i} \in \mathrm{COM} \\
\mathrm{s} \in \mathrm{ASOU} \\
\mathrm{q} \in \mathrm{RDES}\end{array}$ & Demanda da família por bens \\
\hline $\mathrm{x} 3 \mathrm{c}_{\mathrm{i}, \mathrm{q}}$ & $\begin{array}{l}\mathrm{i} \in \mathrm{COM} \\
\mathrm{q} \in \mathrm{RDES}\end{array}$ & Demandas por insumos combinados e domésticos para as famílias \\
\hline $\mathrm{x} 3 \operatorname{marg}_{\mathrm{i}, \mathrm{s}, \mathrm{q}, \mathrm{r}}$ & $\begin{array}{l}\mathrm{i} \in \mathrm{COM} \\
\mathrm{s} \in \mathrm{ASOU} \\
\mathrm{q} \in \mathrm{RDES} \\
\mathrm{r} \in \mathrm{MARG}\end{array}$ & Margens - sobre as vendas para as famílias \\
\hline $\mathrm{x} 3 \mathrm{O}_{\mathrm{i}, \mathrm{q}}$ & $\begin{array}{l}\mathrm{i} \in \mathrm{COM} \\
\mathrm{q} \in \mathrm{RDES}\end{array}$ & $\begin{array}{l}\text { Demandas por insumos combinados e domésticos/estrangeiros } \\
\text { para as famílias }\end{array}$ \\
\hline
\end{tabular}


Tabela 7. As variáveis do MIBRA.

\begin{tabular}{|c|c|c|}
\hline Variável & Dimensão & Descrição \\
\hline $\mathrm{x} 4 \operatorname{marg}_{\mathrm{i}, \mathrm{s}, \mathrm{r}}$ & $\begin{array}{l}i \in \mathrm{COM} \\
\mathrm{s} \in \mathrm{RSOU} \\
\mathrm{r} \in \mathrm{MARG}\end{array}$ & Margens - sobre as exportações \\
\hline $\mathrm{x} 4 \mathrm{r}_{\mathrm{i}, \mathrm{s}}$ & $\begin{array}{l}\mathrm{i} \in \mathrm{COM} \\
\mathrm{s} \in \mathrm{RSOU}\end{array}$ & Volumes de exportações \\
\hline $\mathrm{x} 5 \mathrm{a}_{\mathrm{i}, \mathrm{s}, \mathrm{q}}$ & $\begin{array}{l}\mathrm{i} \in \mathrm{COM} \\
\mathrm{s} \in \mathrm{ASOU} \\
\mathrm{q} \in \mathrm{RDES}\end{array}$ & "Outras" demandas regionais \\
\hline$x 5 \operatorname{marg}_{\mathrm{i}, \mathrm{s}, \mathrm{q}, \mathrm{r}}$ & $\begin{array}{l}i \in \mathrm{COM} \\
\mathrm{s} \in \mathrm{ASOU} \\
\mathrm{q} \in \mathrm{RDES} \\
\mathrm{r} \in \mathrm{MARG}\end{array}$ & Margens - "Outras" demandas regionais \\
\hline $\mathrm{x}_{6} \mathrm{a}_{\mathrm{i}, \mathrm{s}, \mathrm{q}}$ & $\begin{array}{l}\mathrm{i} \in \mathrm{COM} \\
\mathrm{s} \in \mathrm{ASOU} \\
\mathrm{q} \in \mathrm{RDES}\end{array}$ & "Outras" demandas federais em cada região \\
\hline $\mathrm{x} 6 \operatorname{marg}_{\mathrm{i}, \mathrm{s}, \mathrm{q}, \mathrm{r}}$ & $\begin{array}{l}\mathrm{i} \in \mathrm{COM} \\
\mathrm{s} \in \mathrm{ASOU} \\
\mathrm{q} \in \mathrm{RDES} \\
\mathrm{r} \in \mathrm{MARG}\end{array}$ & Margens - sobre as vendas para "outras" demandas federais \\
\hline xi_fac f $_{\mathrm{j}, \mathrm{q}}$ & $\begin{array}{l}\mathrm{j} \in \mathrm{IND} \\
\mathrm{q} \in \mathrm{RDES}\end{array}$ & Índice dos custos de fator \\
\hline xiplpk_ind $\mathrm{j}_{\mathrm{j}, \mathrm{q}}$ & $\begin{array}{l}\mathrm{j} \in \mathrm{IND} \\
\mathrm{q} \in \mathrm{RDES}\end{array}$ & Índice de razão de preço do trabalho e preço de capital \\
\hline xsflo $_{\mathrm{s}, \mathrm{q}}$ & $\begin{array}{l}\mathrm{s} \in \mathrm{RSOU} \\
\mathrm{q} \in \mathrm{RDES}\end{array}$ & Volume dos fluxos de comércio inter e intra-regionais \\
\hline $\mathrm{y}_{\mathrm{j}, \mathrm{q}}$ & $\begin{array}{l}j \in I N D \\
q \in R D E S\end{array}$ & Criação de capital por setor usuário \\
\hline \multirow[t]{3}{*}{$\mathrm{z}_{\mathrm{j}, \mathrm{q}}$} & $\begin{array}{l}\mathrm{j} \in \mathrm{IND} \\
\mathrm{q} \in \mathrm{RDES}\end{array}$ & Nível de atividade ou valor adicionado \\
\hline & & Finanças do Governo \\
\hline & & Variáveis escalares \\
\hline bstar & & Balanço do superávit de comércio como percentagem do PIB \\
\hline ig & & Investimento nominal do geverno \\
\hline ip & & Investimento nominal privado \\
\hline $\operatorname{miscf002}$ & & Variável de deslocamento: taxas de impostos de renda relativas \\
\hline $\mathrm{pbp}$ & & Pagamentos de benefícios pessoais \\
\hline $\mathrm{rl}$ & & $\begin{array}{l}\text { Taxa de imposto - salários semanais, salários mensais e } \\
\text { suplementos }\end{array}$ \\
\hline
\end{tabular}


Tabela 7. As variáveis do MIBRA.

\begin{tabular}{|c|c|c|}
\hline Variável & Dimensão & Descrição \\
\hline rk & & $\begin{array}{l}\text { Taxa de imposto - renda de fator primário não proveniente de } \\
\text { salário semanal }\end{array}$ \\
\hline softf011 & & Deslocador para coleta federal de outros impostos indiretos \\
\hline ti & & Impostos sobre produtos menos subsídios (exclusive tarifas) \\
\hline ty & & Imposto de renda \\
\hline upb & & Benefícios para desemprego \\
\hline wn & & Taxa de salário semanal nominal antes do imposto \\
\hline wnstar & & Taxa de salário semanal nominal depois do imposto \\
\hline wrstar & & Taxa de salário semanal real após o imposto \\
\hline xiy & & Deflator do PIB \\
\hline yf & & PIB a custo de fatores \\
\hline yl & & Renda salário semanal antes do imposto \\
\hline ylstar & & Renda salário semanal depois do imposto \\
\hline yn & & PIB nominal \\
\hline $\mathrm{yr}$ & & PIB real \\
\hline z03 & & Impostos sobre a folha de pagamento \\
\hline z05 & & Impostos sobre propriedade \\
\hline z07 & & Impostos sobre a terra \\
\hline z09 & & Outros impostos indiretos \\
\hline \multirow[t]{2}{*}{$\mathrm{z} 10$} & & Vendas por compradores finais \\
\hline & & Variáveis vetores \\
\hline dgstar ${ }_{\mathrm{q}}$ & $\mathrm{q} \in \mathrm{DDES}$ & Empréstimo líquido do governo/Total de recursos gastos \\
\hline $\operatorname{debtg}_{\mathrm{q}}$ & $\mathrm{q} \in \mathrm{DDES}$ & Dívida do governo \\
\hline g_r $r_{q}$ & $\mathrm{q} \in \mathrm{DDES}$ & Consumo do governo \\
\hline ig_ $r_{q}$ & $\mathrm{q} \in \mathrm{DDES}$ & Investimento do governo \\
\hline labsup $_{\mathrm{q}}$ & $\mathrm{q} \in \mathrm{RDES}$ & Oferta de trabalho \\
\hline $\mathrm{pbp} \_\mathrm{r}_{\mathrm{q}}$ & $\mathrm{q} \in \mathrm{DDES}$ & Pagamentos de benefícios pessoais \\
\hline $\operatorname{rpr}_{\mathrm{q}}$ & $\mathrm{q} \in \mathrm{RDES}$ & Taxa de Imposto sobre a folha de pagamento \\
\hline $\mathrm{ti}_{-} \mathrm{r}_{\mathrm{q}}$ & $\mathrm{q} \in \mathrm{RDES}$ & Impostos sobre produto menos subsídios (exclusive tarifas) \\
\hline tod_r $\mathrm{r}_{\mathrm{q}}$ & $\mathrm{q} \in \mathrm{RDES}$ & Outros impostos diretos \\
\hline xisfb $_{\mathrm{q}}$ & $\mathrm{q} \in \mathrm{RDES}$ & Índices de preços: vendas por compradores finais \\
\hline$y n \_r_{q}$ & $\mathrm{q} \in \mathrm{RDES}$ & PIB nominal - regiões \\
\hline $\mathrm{yr} \_\mathrm{r}_{\mathrm{q}}$ & $\mathrm{q} \in \mathrm{RDES}$ & PIB real - regiões \\
\hline
\end{tabular}


Tabela 7. As variáveis do MIBRA.

\begin{tabular}{|c|c|c|}
\hline Variável & Dimensão & Descrição \\
\hline yd_r $r_{q}$ & $\mathrm{q} \in \mathrm{RDES}$ & Renda disponível das famílias \\
\hline $\mathrm{Z} 01 \mathrm{r}_{\mathrm{q}}$ & $\mathrm{q} \in \mathrm{RDES}$ & Salários semanais, salários mensais e suplementos \\
\hline $\mathrm{Z} 02 \_\mathrm{r}_{\mathrm{q}}$ & $\mathrm{q} \in \mathrm{RDES}$ & Salários semanais imputados \\
\hline Z03_r $\mathrm{r}_{\mathrm{q}}$ & $\mathrm{q} \in \mathrm{RDES}$ & Impostos sobre a folha de pagamento \\
\hline Z04_r $\mathrm{r}_{\mathrm{q}}$ & $\mathrm{q} \in \mathrm{RDES}$ & Retornos ao capital fixo \\
\hline $\mathrm{Z} 05 \_\mathrm{r}_{\mathrm{q}}$ & $\mathrm{q} \in \mathrm{RDES}$ & Impostos sobre propriedade \\
\hline Z06_r $r_{q}$ & $\mathrm{q} \in \mathrm{RDES}$ & Retornos sobre a terra agrícola \\
\hline $\mathrm{Z} 07 \_\mathrm{r}_{\mathrm{q}}$ & $\mathrm{q} \in \mathrm{RDES}$ & Impostos sobre a terra \\
\hline $\mathrm{Z} 08 \_\mathrm{r}_{\mathrm{q}}$ & $\mathrm{q} \in \mathrm{RDES}$ & Retornos ao capital trabalho \\
\hline $\mathrm{Z} 09 \_\mathrm{r}_{\mathrm{q}}$ & $\mathrm{q} \in \mathrm{RDES}$ & Outros impostos indiretos \\
\hline $\mathrm{Z} 10 \_\mathrm{r}_{\mathrm{q}}$ & $\mathrm{q} \in \mathrm{RDES}$ & Vendas por compradores finais \\
\hline $\mathrm{zg} \_\mathrm{r}_{\mathrm{q}}$ & $\mathrm{q} \in \mathrm{RDES}$ & Superávit Operacional Bruto \\
\hline zt_r $r_{q}$ & $\mathrm{q} \in \mathrm{RDES}$ & Impostos sobre a produção \\
\hline dompy $000_{q}$ & $\mathrm{q} \in \mathrm{RDES}$ & GSP a preços de Mercado (lado da renda) \\
\hline dompy $100_{q}$ & $\mathrm{q} \in \mathrm{RDES}$ & Salários semanais, salários mensais suplementos \\
\hline dompy $110_{q}$ & $\mathrm{q} \in \mathrm{RDES}$ & Renda salário semanal disponível \\
\hline dompy $120_{\mathrm{q}}$ & $\mathrm{q} \in \mathrm{RDES}$ & Impostos PAYE \\
\hline dompy $200_{q}$ & $\mathrm{q} \in \mathrm{RDES}$ & SOB: Renda de fator primário não proveniente de salário semanal \\
\hline dompy $210_{\mathrm{q}}$ & $\mathrm{q} \in \mathrm{RDES}$ & $\begin{array}{l}\text { Renda disponível de fator primário não proveniente de salário } \\
\text { semanal }\end{array}$ \\
\hline dompy $220_{\mathrm{q}}$ & $\mathrm{q} \in \mathrm{RDES}$ & $\begin{array}{l}\text { Impostos sobre renda de fator primário não proveniente de salário } \\
\text { semanal }\end{array}$ \\
\hline dompy $300_{q}$ & $\mathrm{q} \in \mathrm{RDES}$ & Impostos indiretos menos subsídios \\
\hline dompy $310_{\mathrm{q}}$ & $\mathrm{q} \in \mathrm{RDES}$ & Receita de tarifas \\
\hline dompy $320_{q}$ & $\mathrm{q} \in \mathrm{RDES}$ & Outros impostos sobre produtos menos subsídios \\
\hline dompy $330_{\mathrm{q}}$ & $\mathrm{q} \in \mathrm{RDES}$ & Impostos sobre a produção \\
\hline dompq000 & $\mathrm{q} \in \mathrm{RDES}$ & GSP à preços de Mercado (lado do gasto) \\
\hline dompq $100_{q}$ & $\mathrm{q} \in \mathrm{RDES}$ & Absorção doméstica \\
\hline dompq $110_{q}$ & $\mathrm{q} \in \mathrm{RDES}$ & Consumo privado \\
\hline dompq $120_{q}$ & $\mathrm{q} \in \mathrm{RDES}$ & Investimento privado \\
\hline dompq $130_{q}$ & $\mathrm{q} \in \mathrm{RDES}$ & Consumo do governo - regiões \\
\hline dompq $140_{q}$ & $\mathrm{q} \in \mathrm{RDES}$ & Consumo do governo - federal \\
\hline
\end{tabular}


Tabela 7. As variáveis do MIBRA.

\begin{tabular}{|c|c|c|}
\hline Variável & Dimensão & Descrição \\
\hline dompq150 q & $\mathrm{q} \in \mathrm{RDES}$ & Investimento do governo \\
\hline dompq $200_{q}$ & $\mathrm{q} \in \mathrm{RDES}$ & Balanço de Comércio inter-regional \\
\hline dompq $210_{q}$ & $\mathrm{q} \in \mathrm{RDES}$ & Exportações inter-regionais \\
\hline dompq $220_{q}$ & $\mathrm{q} \in \mathrm{RDES}$ & Importações inter-regionais \\
\hline dompq $300_{q}$ & $\mathrm{q} \in \mathrm{RDES}$ & Balanço de comércio internacional \\
\hline dompq $310_{q}$ & $\mathrm{q} \in \mathrm{RDES}$ & Exportações internacionais \\
\hline dompq $320_{q}$ & $\mathrm{q} \in \mathrm{RDES}$ & Importações internacionais \\
\hline softy $000_{\mathrm{q}}$ & $\mathrm{q} \in \mathrm{DDES}$ & SOFT : Total do lado da renda \\
\hline softy $100_{\mathrm{q}}$ & $\mathrm{q} \in \mathrm{DDES}$ & Receita do governo \\
\hline softy $110_{\mathrm{q}}$ & $\mathrm{q} \in \mathrm{DDES}$ & Impostos diretos \\
\hline softy $111_{\mathrm{q}}$ & $\mathrm{q} \in \mathrm{DDES}$ & Impostos sobre a renda \\
\hline softy $112_{q}$ & $\mathrm{q} \in \mathrm{DDES}$ & Outros impostos diretos \\
\hline softy $120_{\mathrm{q}}$ & $\mathrm{q} \in \mathrm{DDES}$ & Impostos indiretos \\
\hline softy $121_{\mathrm{q}}$ & $\mathrm{q} \in \mathrm{DDES}$ & Receita de tarifa \\
\hline softy $122_{\mathrm{q}}$ & $\mathrm{q} \in \mathrm{DDES}$ & Outros impostos sobre produtos \\
\hline softy $123_{\mathrm{q}}$ & $\mathrm{q} \in \mathrm{DDES}$ & Impostos sobre a folha de pagamento \\
\hline softy $124_{\mathrm{q}}$ & $\mathrm{q} \in \mathrm{DDES}$ & Impostos sobre a propriedade \\
\hline softy $125_{\mathrm{q}}$ & $\mathrm{q} \in \mathrm{DDES}$ & Impostos sobre a terra \\
\hline softy $126_{\mathrm{q}}$ & $\mathrm{q} \in \mathrm{DDES}$ & Outros impostos indiretos \\
\hline softy $130_{\mathrm{q}}$ & $\mathrm{q} \in \mathrm{DDES}$ & Juros recebidos \\
\hline softy $140_{\mathrm{q}}$ & $\mathrm{q} \in \mathrm{DDES}$ & Doações para regiões \\
\hline softy $141_{\mathrm{q}}$ & $\mathrm{q} \in \mathrm{DDES}$ & Doações correntes \\
\hline softy $142_{\mathrm{q}}$ & $\mathrm{q} \in \mathrm{DDES}$ & Doações de capital \\
\hline softy $150_{\mathrm{q}}$ & $\mathrm{q} \in \mathrm{DDES}$ & Other revenue \\
\hline softy $200_{\mathrm{q}}$ & $\mathrm{q} \in \mathrm{DDES}$ & Consumo de capital fixo - governo geral \\
\hline softy $300_{\mathrm{q}}$ & $\mathrm{q} \in \mathrm{DDES}$ & Transações financeiras \\
\hline softy $310_{\mathrm{q}}$ & $\mathrm{q} \in \mathrm{DDES}$ & Empréstimo tomado líquido \\
\hline softy $320_{\mathrm{q}}$ & $\mathrm{q} \in \mathrm{DDES}$ & Aumento nas provisões \\
\hline softy $330_{\mathrm{q}}$ & $\mathrm{q} \in \mathrm{DDES}$ & Outras transações financeiras \\
\hline$f_{-}$oft $_{\mathrm{q}}$ & $\mathrm{q} \in \mathrm{DDES}$ & Deslocador de outras transações financeiras \\
\hline realdef $_{\mathrm{q}}$ & $\mathrm{q} \in \mathrm{DDES}$ & Déficit real do orçamento do governo \\
\hline softq $000_{q}$ & $\mathrm{q} \in \mathrm{DDES}$ & SOFT: total do lado do gasto \\
\hline
\end{tabular}


Tabela 7. As variáveis do MIBRA.

\begin{tabular}{|c|c|c|}
\hline Variável & Dimensão & Descrição \\
\hline softq100 q & $\mathrm{q} \in \mathrm{DDES}$ & Gasto sobre bens e serviços \\
\hline softq $110_{q}$ & $\mathrm{q} \in \mathrm{DDES}$ & Consumo do governo \\
\hline softq $120_{\mathrm{q}}$ & $\mathrm{q} \in \mathrm{DDES}$ & Investimento do governo \\
\hline $\operatorname{softq} 200_{\mathrm{q}}$ & $\mathrm{q} \in \mathrm{DDES}$ & Pagamentos de benefícios pessoais \\
\hline $\operatorname{softq} 210_{\mathrm{q}}$ & $\mathrm{q} \in \mathrm{DDES}$ & Benefícios de desemprego \\
\hline softq $220_{q}$ & $\mathrm{q} \in \mathrm{DDES}$ & Outros benefícios pessoais \\
\hline $\operatorname{softq} 300_{\mathrm{q}}$ & $\mathrm{q} \in \mathrm{DDES}$ & Subsídios \\
\hline softq $400_{\mathrm{q}}$ & $\mathrm{q} \in \mathrm{DDES}$ & Pagamentos de juros \\
\hline softq $500_{q}$ & $\mathrm{q} \in \mathrm{DDES}$ & Doações para regiões \\
\hline softq $510_{\mathrm{q}}$ & $\mathrm{q} \in \mathrm{DDES}$ & Doações correntes \\
\hline softq $520_{\mathrm{q}}$ & $\mathrm{q} \in \mathrm{DDES}$ & Doações de capital \\
\hline softq $600_{q}$ & $\mathrm{q} \in \mathrm{DDES}$ & Outros gastos \\
\hline softfO01 $_{\mathrm{q}}$ & $\mathrm{q} \in \mathrm{RDES}$ & Variável de deslocamento: outros impostos diretos \\
\hline softf002 $2_{\mathrm{q}}$ & $\mathrm{q} \in \mathrm{RDES}$ & Variável de deslocamento: doações correntes \\
\hline softf003 & $\mathrm{q} \in \mathrm{RDES}$ & Variável de deslocamento: doações de capital \\
\hline softf004 $_{\mathrm{q}}$ & $\mathrm{q} \in \mathrm{DDES}$ & Variável de deslocamento: outra receita \\
\hline softfO05 $_{\mathrm{q}}$ & $\mathrm{q} \in \mathrm{DDES}$ & Variável de deslocamento: aumento nas provisões \\
\hline softfO06 $_{\mathrm{q}}$ & $\mathrm{q} \in \mathrm{DDES}$ & Variáveis de deslocamento: outros gastos \\
\hline softfO07 $_{\mathrm{q}}$ & $\mathrm{q} \in \mathrm{DDES}$ & Variáveis de deslocamento: dívida do governo \\
\hline hhldy $000_{\mathrm{q}}$ & $\mathrm{q} \in \mathrm{RDES}$ & Renda disponível \\
\hline hhldy $100_{\mathrm{q}}$ & $\mathrm{q} \in \mathrm{RDES}$ & Renda de fator primário \\
\hline hhldy $110_{\mathrm{q}}$ & $\mathrm{q} \in \mathrm{RDES}$ & Salários semanais, salários mensais e suplementos \\
\hline hhldy $120_{\mathrm{q}}$ & $\mathrm{q} \in \mathrm{RDES}$ & Renda de fatores primários não proveniente de salário semanal \\
\hline hhldy $200_{\mathrm{q}}$ & $\mathrm{q} \in \mathrm{RDES}$ & Recebimentos de benefícios pessoais \\
\hline hhldy $210_{\mathrm{q}}$ & $\mathrm{q} \in \mathrm{RDES}$ & Benefícios de desemprego \\
\hline hhldy $220_{q}$ & $\mathrm{q} \in \mathrm{RDES}$ & Outros benefícios pessoais \\
\hline hhldy $300_{\mathrm{q}}$ & $\mathrm{q} \in \mathrm{RDES}$ & Outra renda (líquida) \\
\hline hhldy $400_{\mathrm{q}}$ & $\mathrm{q} \in \mathrm{RDES}$ & Impostos diretos \\
\hline hhldy $410_{\mathrm{q}}$ & $\mathrm{q} \in \mathrm{RDES}$ & Impostos PAYE \\
\hline hhldy $420_{q}$ & $\mathrm{q} \in \mathrm{RDES}$ & $\begin{array}{l}\text { Impostos sobre renda de fator primário não proveniente de salário } \\
\text { semanal }\end{array}$ \\
\hline hhldy $430_{\mathrm{q}}$ & $\mathrm{q} \in \mathrm{RDES}$ & Outros impostos diretos \\
\hline
\end{tabular}


Tabela 7. As variáveis do MIBRA.

\begin{tabular}{|c|c|c|}
\hline Variável & Dimensão & Descrição \\
\hline hhldf001 & $\mathrm{q} \in \mathrm{RDES}$ & Variável de deslocamento: benefícios de desemprego \\
\hline hhldf002 $2_{\mathrm{q}}$ & $\mathrm{q} \in \mathrm{RDES}$ & Variável de deslocamento: outros benefícios pessoais \\
\hline hhldf003 $3_{\mathrm{q}}$ & $\mathrm{q} \in \mathrm{RDES}$ & Variáveis de deslocamento: outra renda (líquida) - famílias \\
\hline $\operatorname{miscf001} 1_{\mathrm{q}}$ & $\mathrm{q} \in \mathrm{RDES}$ & Variável de deslocamento: função de consumo \\
\hline \multicolumn{3}{|c|}{ Acumulação de capital e investimento } \\
\hline \multicolumn{3}{|r|}{ Variáveis escalares } \\
\hline Delkfudge & & Variável binária para trocar o capital na equação de acumulação \\
\hline natr_tot & & Taxa de retorno médio \\
\hline \multicolumn{3}{|r|}{ Variáveis matrizes } \\
\hline delf_rate $_{\mathrm{j}, \mathrm{q}}$ & $\begin{array}{l}j \in I N D \\
q \in R D E S\end{array}$ & Um deslocador de mudança na equação de acumulação de capital \\
\hline f_rate_xx $x_{j, q}$ & $\begin{array}{l}j \in I N D \\
q \in R D E S\end{array}$ & Deslocador, equação da taxa de retorno \\
\hline curcap_t $1_{\mathrm{j}, \mathrm{q}}$ & $\begin{array}{l}\mathrm{j} \in \mathrm{IND} \\
\mathrm{q} \in \mathrm{RDES}\end{array}$ & Estoque de capital no período $\mathrm{T}+1$ \\
\hline \multicolumn{3}{|r|}{ Dívida Externa Nacional } \\
\hline Deldfudge & & Variável binária na equação E_delDebt \\
\hline Delbt & & Mudança ordinária no déficit real de comércio \\
\hline deldebt_ratio & & Mudança na razão Dívida/PIB \\
\hline deldebt & & Mudança ordinária na dívida externa \\
\hline \multicolumn{3}{|c|}{ População regional e mercados de trabalho } \\
\hline \multicolumn{3}{|r|}{ Variáveis escalares } \\
\hline del_natfm & & Mudança ordinária na migração estrangeira líquida nacional \\
\hline del_natg & & Mudança ordinária na população natural líquida nacional \\
\hline del_natunr & & Mudança em ponto percentual na taxa de desemprego nacional \\
\hline delf_rm & & Variável de deslocamento na equação E_rm_addup \\
\hline delf_rm_0 & & Variável de deslocamento na equação E_rm_0 \\
\hline natlabsup & & Oferta de trabalho nacional \\
\hline natemploy & & Emprego nacional \\
\hline \multicolumn{3}{|r|}{ Variáveis vetores } \\
\hline del_fm $\mathrm{fm}_{\mathrm{q}}$ & $\mathrm{q} \in \mathrm{RDES}$ & Mudança ordinária na migração estrangeira líquida regional \\
\hline del_g $g_{q}$ & $\mathrm{q} \in \mathrm{RDES}$ & Mudança ordinária na população natural líquida regional \\
\hline del_rm & $\mathrm{q} \in \mathrm{RDES}$ & Mudança ordinária na migração líquida inter-regional \\
\hline
\end{tabular}


Tabela 7. As variáveis do MIBRA.

\begin{tabular}{|c|c|c|}
\hline Variável & Dimensão & Descrição \\
\hline del_rm_0 ${ }_{\mathrm{q}}$ & $\mathrm{q} \in \mathrm{RDES}$ & Previsão exógena da migração inter-regional \\
\hline delrpfudge $_{\mathrm{q}}$ & $\mathrm{q} \in \mathrm{RDES}$ & Variável binária na equação E_del_rm. \\
\hline del_unr $r_{\mathrm{q}}$ & $\mathrm{q} \in \mathrm{RDES}$ & Mudança em ponto percentual na taxa de desemprego regional \\
\hline employ $_{\mathrm{q}}$ & $\mathrm{q} \in \mathrm{RDES}$ & Emprego regional: pessoas \\
\hline f_l $l_{q}$ & $\mathrm{q} \in \mathrm{RDES}$ & Variável deslocamento na equação E_remploy_interf. \\
\hline f_popq & $\mathrm{q} \in \mathrm{RDES}$ & Variável de deslocamento na equação E_del_rm. \\
\hline f_wpopq & $\mathrm{q} \in \mathrm{RDES}$ & Variável de deslocamento na equação E_wpop \\
\hline f_qhous ${ }_{q}$ & $\mathrm{q} \in \mathrm{RDES}$ & Variável de deslocamento na equação E_pop_interf \\
\hline pop $_{\mathrm{q}}$ & $\mathrm{q} \in \mathrm{RDES}$ & População regional \\
\hline $\mathrm{pr}_{\mathrm{q}}$ & $\mathrm{q} \in \mathrm{RDES}$ & Taxa de participação da força de trabalho regional \\
\hline wpop $_{\mathrm{q}}$ & $\mathrm{q} \in \mathrm{RDES}$ & Idade de trabalho da população regional \\
\hline
\end{tabular}

Fonte: Adaptado de Peter et al. (1996a)

Tabela 8. Os coeficientes e parâmetros do MIBRA.

\begin{tabular}{|c|c|c|}
\hline Coeficiente & Descrição & Valor \\
\hline$\sigma 1 C_{i}$ & $\begin{array}{l}\text { Elasticidade de substituição } \\
\text { entre fontes regionais do } \\
\text { bem i para uso como } \\
\text { insumo na produção. }\end{array}$ & $\begin{array}{l}\text { Definido arbitrariamente como cinco } \\
\text { vezes o valor da elasticidade de } \\
\text { substituição entre bens domésticos e } \\
\text { bens importados estrangeiros. }\end{array}$ \\
\hline $\mathrm{S} 1 \mathrm{~A}_{\mathrm{i}, \mathrm{s}, \mathrm{j}, \mathrm{q}}$ & $\begin{array}{l}\text { Parcela do valor do preço } \\
\text { de compra do bem i } \\
\text { proveniente da origem } \\
\text { regional s no setor j no total } \\
\text { de compras da região q do } \\
\text { bem i provenientes de } \\
\text { fontes domésticas para uso } \\
\text { na produção. }\end{array}$ & $\begin{array}{l}\text { O numerador desta parcela, para o } \\
\text { isjq-ésimo elemento, é a soma dos } \\
\text { correspondentes elementos das } \\
\text { matrizes BAS1, MAR1 e TAX1. O } \\
\text { denominador é a soma, dentre as q } \\
\text { fontes regionais, da soma do isjq- } \\
\text { ésimo elemento das matrizes BAS1, } \\
\text { MAR1 e TAX1. }\end{array}$ \\
\hline$\sigma 1 \mathrm{O}_{\mathrm{i}}$ & $\begin{array}{l}\text { Elasticidade de substituição } \\
\text { entre o combinado } \\
\text { doméstico e a importação } \\
\text { estrangeira do bem i para } \\
\text { uso como um insumo na } \\
\text { produção. }\end{array}$ & Estimativa econométrica \\
\hline
\end{tabular}


Tabela 8. Os coeficientes e parâmetros do MIBRA.

\begin{tabular}{|c|c|c|}
\hline Coeficiente & Descrição & Valor \\
\hline PVAL1O $_{i, j, q}$ & $\begin{array}{l}\text { Valor do } \text { compra } \\
\text { combinado doméstico e do } \\
\text { bem i importado } \\
\text { estrangeiro como um } \\
\text { insumo de produção do jq- } \\
\text { ésimo setor }\end{array}$ & $\begin{array}{l}\text { O ijq-ésimo valor é a soma, de todas } \\
\text { as } 6 \text { fontes (todas as domésticas } \\
\text { mais a estrangeira), da soma do isjq- } \\
\text { ésimos elementos das matrizes } \\
\text { BAS1, MAR1 e TAX1. }\end{array}$ \\
\hline $\operatorname{PVAL}_{1 A_{i, s, j, q}}$ & $\begin{array}{l}\text { Valor de compra do bem i } \\
\text { proveniente da s-ésima } \\
\text { fonte como um insumo na } \\
\text { produção do jq-ésimo setor }\end{array}$ & $\begin{array}{l}\text { O isjq-ésimo valor é a soma dos } \\
\text { correspondentes elementos das } \\
\text { matrizes BAS1, MAR1 e TAX1. } \\
\text { Dividindo por PVAL1O, forma a } \\
\text { participação do is -ésimo bem no } \\
\text { gasto total da firma no i-ésimo bem } \\
\text { proveniente de todas as s fontes } \\
\text { para uso na produção. }\end{array}$ \\
\hline$\sigma 1 \mathrm{LAB}_{\mathrm{j}, \mathrm{q}}$ & $\begin{array}{l}\text { Elasticidade de substituição } \\
\text { para trabalho do m tipos } \\
\text { ocupacionais usados como } \\
\text { insumos para produção por } \\
\text { setor j na região q }\end{array}$ & Estimativa econométrica \\
\hline $\mathrm{LABOUR}_{\mathrm{j}, \mathrm{q}}$ & $\begin{array}{l}\text { salário total do jq-ésimo } \\
\text { setor }\end{array}$ & $\begin{array}{l}\text { Soma dos m elementos de LABR } \\
\text { para o jq-ésimo setor. Dividindo } \\
\text { TOTFACIND fornece a participação } \\
\text { do salário no valor adicionado do jq- } \\
\text { ésimo setor }\end{array}$ \\
\hline $\mathrm{LAB}_{-} \mathrm{OCC} \_$IND $\mathrm{m, \textrm {j } , \mathrm { q }}$ & $\begin{array}{l}\text { Salário da m-ésima } \\
\text { ocupação utilizada pelo jq- } \\
\text { ésimo setor }\end{array}$ & $\begin{array}{l}\text { O jqm-ésimo elemento de LABR. } \\
\text { Dividindo por LABOUR, fornece a } \\
\text { participação do salário do mésimo } \\
\text { grupo ocupacional no salário total do } \\
\text { jq-ésimo setor. }\end{array}$ \\
\hline$\sigma 1 \mathrm{FAC}_{\mathrm{j}, \mathrm{q}}$ & $\begin{array}{l}\text { Elasticidade de substituição } \\
\text { para fatores primários (terra } \\
\text { agrícola, trabalho e capital) } \\
\text { utilizados como insumos } \\
\text { para produção por indústria } \\
\text { j e região q. }\end{array}$ & Estimativa econométrica. \\
\hline TOTFACIND $_{\mathrm{j}, \mathrm{q}}$ & $\begin{array}{l}\text { Custo total dos fatores } \\
\text { primários utilizados por } \\
\text { indústria j e região q }\end{array}$ & $\begin{array}{l}\text { Soma do jq-ésimo elemento do } \\
\text { coeficiente LABOUR e os } \\
\text { correspondentes } \\
\text { elementos das matrizes CPTL e } \\
\text { LAND }\end{array}$ \\
\hline
\end{tabular}


Tabela 8. Os coeficientes e parâmetros do MIBRA.

\begin{tabular}{|c|c|c|}
\hline Coeficiente & Descrição & Valor \\
\hline CAPITAL $_{j, q}$ & $\begin{array}{l}\text { Valor dos aluguéis para o } \\
\text { capital por indústria na } \\
\text { região q }\end{array}$ & $\begin{array}{l}\text { O jq-ésimo elemento da matriz } \\
\text { CPTL }\end{array}$ \\
\hline $\mathrm{LAND}_{\mathrm{j}, \mathrm{q}}$ & $\begin{array}{l}\text { Valor dos aluguéis para } \\
\text { terra agrícola por setor } \mathrm{j} \text { na } \\
\text { região q }\end{array}$ & $\begin{array}{l}\text { O jq-ésimo elemento da matriz } \\
\text { LAND }\end{array}$ \\
\hline$\sigma 2 C_{i}$ & $\begin{array}{l}\text { Elasticidade de substituição } \\
\text { entre fontes regionais de } \\
\text { bem i para uso com um } \\
\text { insumo na criação de } \\
\text { capital }\end{array}$ & $\begin{array}{l}\text { Arbitrariamente definido com cinco } \\
\text { vezes o valor da elasticidade de } \\
\text { substituição entre bens domésticos e } \\
\text { bens importados estrangeiros }\end{array}$ \\
\hline$\sigma 2 \mathrm{O}_{\mathrm{i}}$ & $\begin{array}{l}\text { Elasticidade de substituição } \\
\text { entre combinado doméstico } \\
\text { e bem i importado } \\
\text { estrangeiro para uso como } \\
\text { um insumo na criação do } \\
\text { capital }\end{array}$ & Estimativa econométrica \\
\hline PVAL2T $\mathrm{T}_{\mathrm{i}, \mathrm{ss}, \mathrm{j}, \mathrm{q}}$ & $\begin{array}{l}\text { Valor de compra do bem } \\
\text { combinado doméstico i } \\
\text { como um insumo da } \\
\text { criação de capital do jq- } \\
\text { ésimo setor }\end{array}$ & $\begin{array}{l}\text { A soma, todas as fontes regionais, da } \\
\text { soma do isjq-ésimos elementos das } \\
\text { matrizes BAS2, MAR2 E TAX2. }\end{array}$ \\
\hline $\begin{array}{l}\text { PVAL2A }_{i, s, j, q} \\
\text { (in E_p2c) }\end{array}$ & $\begin{array}{l}\text { Valor de compra do bem i } \\
\text { proveniente s-ésima fonte } \\
\text { regional como um insumo } \\
\text { na criação de capital do jq- } \\
\text { ésimo setor }\end{array}$ & $\begin{array}{l}\text { O isjq-ésimo valor é a soma dos } \\
\text { correspondentes elementos das } \\
\text { matrizes BAS2, MAR2 e TAX2. } \\
\text { Dividindo por PVAL2T, forma a } \\
\text { participação do is -ésimo bem no } \\
\text { gasto total das firma no i-ésimo bem } \\
\text { proveniente de todas as fontes } \\
\text { regionais para a finalidade de } \\
\text { criação de capital }\end{array}$ \\
\hline PVAL2A $_{i, s, j, q}$ & $\begin{array}{l}\text { Valor de compra do bem i } \\
\text { proveniente de todas fontes }\end{array}$ & $\begin{array}{l}\text { O isjq-ésimo valor é a soma dos } \\
\text { correspondentes elementos das }\end{array}$ \\
\hline (in E_p2o) & $\begin{array}{l}\text { como um insumo na } \\
\text { criação de capital do jq- } \\
\text { ésimo setor }\end{array}$ & $\begin{array}{l}\text { matrizes BAS2, MAR2 e TAX2. } \\
\text { Dividindo por PVAL2O, forma a } \\
\text { participação do is -ésimo bem no } \\
\text { gasto total da firma no i-ésimo bem } \\
\text { proveniente de todas as fontes para a } \\
\text { finalidade de criação de capital }\end{array}$ \\
\hline
\end{tabular}


Tabela 8. Os coeficientes e parâmetros do MIBRA.

\begin{tabular}{|c|c|c|}
\hline Coeficiente & Descrição & Valor \\
\hline PVAL2O $_{i, j, q}$ & $\begin{array}{l}\text { Valor de } \\
\text { combinado doméstico e do } \\
\text { bem i importado } \\
\text { estrangeiro como um } \\
\text { insumo na criação de } \\
\text { capital do jq-ésimo setor }\end{array}$ & $\begin{array}{l}\text { O ijq-ésimo valor é a soma de todas } \\
\text { as fontes (todas as domésticas mais a } \\
\text { estrangeira), da soma do isjq-ésimos } \\
\text { elementos das matrizes BAS2, } \\
\text { MAR2 e TAX2. }\end{array}$ \\
\hline$\sigma 3 C_{i}$ & $\begin{array}{l}\text { Elasticidade de substituição } \\
\text { entre fontes regionais de } \\
\text { bem i na demanda regional } \\
\text { das famílias }\end{array}$ & $\begin{array}{l}\text { Arbitrariamente definido como cinco } \\
\text { vezes o valor da elasticidade de } \\
\text { substituição entre bens domésticos e } \\
\text { bens importados estrangeiros }\end{array}$ \\
\hline$\sigma 2 \mathrm{O}_{\mathrm{i}}$ & $\begin{array}{l}\text { Elasticidade de substituição } \\
\text { entre combinado doméstico } \\
\text { e bem i importado } \\
\text { estrangeiro na demanda } \\
\text { regional das famílias }\end{array}$ & Estimativa econométrica \\
\hline PVAL3T $_{\mathrm{i}, \text { doméstico,q }}$ & $\begin{array}{l}\text { Valor de compra do bem } \\
\text { combinado doméstico i } \\
\text { consumido pelas famílias } \\
\text { na região q }\end{array}$ & $\begin{array}{l}\text { A soma, de todas as } 5 \text { fontes } \\
\text { regionais, da soma do isq-ésimo } \\
\text { elemento da matriz BAS3, MAR3 e } \\
\text { TAX3 }\end{array}$ \\
\hline $\begin{array}{l}\text { PVAL3A }{ }_{i, s, q} \\
\text { (in E_p3c) }\end{array}$ & $\begin{array}{l}\text { Valor de comp ra do bem i } \\
\text { proveniente da s-ésima } \\
\text { fonte regional consumido } \\
\text { pelas famílias na região q }\end{array}$ & $\begin{array}{l}\text { O isq-ésimo valor é a soma dos } \\
\text { correspondentes elementos das } \\
\text { matrizes BAS3, MAR3 e TAX3. } \\
\text { Dividindo por PVAL3T, forma a } \\
\text { participação do is -ésimo bem no } \\
\text { gasto total das famílias no iésimo } \\
\text { bem proveniente de todas as fonts } \\
\text { regionais }\end{array}$ \\
\hline $\begin{array}{l}\text { PVAL3A }_{i, s, q} \\
\text { (in E_p3o) }\end{array}$ & $\begin{array}{l}\text { Valor de compra do bem i } \\
\text { proveniente de todas as } \\
\text { fontes consumidas pela } \\
\text { família na região q }\end{array}$ & $\begin{array}{l}\text { O isq-ésimo valor é a soma dos } \\
\text { correspondentes elementos das } \\
\text { matrizes BAS3, MAR3 e TAX3. } \\
\text { Dividindo por PVAL3O, forma-se a } \\
\text { participação do is -ésimo bem no } \\
\text { gasto total das famílias no iésimo } \\
\text { bem proveniente de todas as fontes }\end{array}$ \\
\hline PVAL3O & 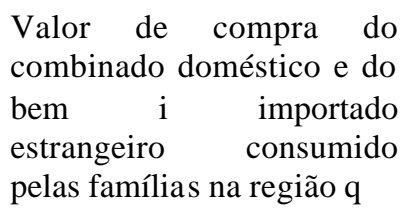 & $\begin{array}{l}\text { O iq-ésimo valor é a soma, de todas } \\
\text { as } 6 \text { fontes (todas as domésticas } \\
\text { mais a estrangeira), da soma dos } \\
\text { isq-ésimos elementos das matrizes } \\
\text { BAS3, MAR3 e TAX3 }\end{array}$ \\
\hline
\end{tabular}


Tabela 8. Os coeficientes e parâmetros do MIBRA.

\begin{tabular}{|c|c|c|}
\hline Coeficiente & Descrição & Valor \\
\hline$\overline{\text { ALPHA_I } \mathrm{i}_{\mathrm{i}, \mathrm{q}}}$ & \begin{tabular}{l} 
Gasto supernumerário no \\
bem i como uma \\
participação \\
supernumerário e gasto de \\
\multicolumn{3}{l}{ subsistência sobre o bem i } \\
por família na região q
\end{tabular} & 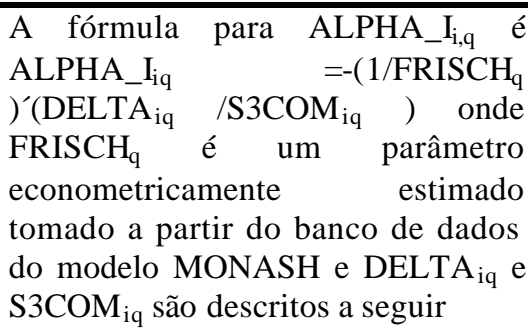 \\
\hline DELTA $_{i, q}$ & $\begin{array}{l}\text { Participação do orçamento } \\
\text { das famílias marginal do } \\
\text { bem i no gasto marginal } \\
\text { total por famílias na região } \\
\text { q }\end{array}$ & Estimativa econométrica \\
\hline $\mathrm{S}_{3} \mathrm{COM}_{\mathrm{i}, \mathrm{q}}$ & $\begin{array}{l}\text { Participação do bem i no } \\
\text { gasto das famílias total por } \\
\text { famílias na região q }\end{array}$ & $\begin{array}{l}\text { A formula para } \mathrm{S} \mathrm{COM} \\
\mathrm{iq} \\
\mathrm{S} 3 \mathrm{COM}_{\mathrm{iq}}=\mathrm{PVAL} \\
\text { onde PVAL3O } \\
\text { aq } / \mathrm{AGGCON}_{\mathrm{q}} \\
\text { anteriormente e descrito } \\
\text { descrito a seguir }\end{array}$ \\
\hline $\mathrm{EXP}_{-} \mathrm{ELAST}_{\mathrm{i}}$ & $\begin{array}{l}\text { Elasticidade da demanda de } \\
\text { exportação estrangeira do } \\
\text { bem i }\end{array}$ & Estimativa econométrica \\
\hline AGGEXPNT $_{\mathrm{s}}$ & $\begin{array}{l}\text { Ganhos da exportação não- } \\
\text { tradicional regional total }\end{array}$ & $\begin{array}{l}\text { A soma, de todas os produtos de } \\
\text { exportação não-tradicional de } \\
\text { PVAL4R is (o is é descrito a seguir). } \\
\text { No MIBRA não se considera a } \\
\text { exportação não-tradicional. }\end{array}$ \\
\hline $\begin{array}{l}\text { PVAL4R } \text { is } \\
\text { (in E_aggnt_p4r) }\end{array}$ & $\begin{array}{l}\text { Valor de compra do bem i } \\
\text { de exportação não- } \\
\text { tradicional proveniente da } \\
\text { s-ésima fonte regional ( } \mathrm{s}= \\
1, \ldots, 5 \text { ) consumidos pelo } \\
\text { estrangeiro }\end{array}$ & $\begin{array}{l}\text { O is-ésimo valor é a soma dos } \\
\text { correspondentes elementos das } \\
\text { matrizes BAS4, MAR4 e TAX4. } \\
\text { Dividindo por AGGEXPNT, forma- } \\
\text { se a participação do i-ésimo bem no } \\
\text { gasto dos estrangeiros em todos os } \\
\text { bens provenientes da região s. No } \\
\text { MIBRA não se considera a } \\
\text { exportação não tradicional. }\end{array}$ \\
\hline
\end{tabular}


Tabela 8. Os coeficientes e parâmetros do MIBRA.

\begin{tabular}{|c|c|c|}
\hline Coeficiente & Descrição & Valor \\
\hline $\operatorname{COSTS}_{\mathrm{j}, \mathrm{q}}$ & $\begin{array}{l}\text { Custos totais de produção } \\
\text { no setor j na região q }\end{array}$ & $\begin{array}{l}\text { O jq-ésimo valor é a soma em todas } \\
\text { as } 6 \text { fontes (as domésticas e a } \\
\text { estrangeira) da soma do isjq-ésimos } \\
\text { elementos das matrizes BAS1, } \\
\text { MAR1 e TAX1, mais a soma dos m } \\
\text { tipos de ocupações do } \\
\text { correspondente elemento da matriz } \\
\text { LABR e mais os correspondentes } \\
\text { elementos das matrizes CPTL e } \\
\text { OCTS }\end{array}$ \\
\hline $\mathrm{OTHCOST}_{\mathrm{j}, \mathrm{q}}$ & $\begin{array}{l}\text { Outros custos pagos pelo } \\
\text { setor } \mathrm{j} \text { na região } \mathrm{q}\end{array}$ & $\begin{array}{l}\text { O jq-ésimo valor é o correspondente } \\
\text { elemento na matriz OCTS }\end{array}$ \\
\hline INVEST $_{\mathrm{j}, \mathrm{q}}$ & $\begin{array}{l}\text { Valor do capital total } \\
\text { criado para o setor } \mathrm{j} \text { na } \\
\text { região q }\end{array}$ & $\begin{array}{l}\text { O jq-ésimo valor é a soma de todo i } \\
\text { de PVAL2O }\end{array}$ \\
\hline BAS $1_{i, s, j, q}$ & $\begin{array}{l}\text { Valor básico do bem } \mathrm{i} \\
\text { proveniente da fonte } \mathrm{s} \\
\text { (doméstico e estrangeiro) } \\
\text { usado na produção pelo } \\
\text { setor j na região q }\end{array}$ & $\begin{array}{l}\text { O isjq-ésimo valor é o } \\
\text { correspondente elemento na matriz } \\
\text { BAS } 1\end{array}$ \\
\hline $\mathrm{TAX} 1_{\mathrm{i}, \mathrm{s}, \mathrm{j}, \mathrm{q}}$ & $\begin{array}{l}\text { Valor dos impostos sobre o } \\
\text { produto pago sobre o bem i } \\
\text { proveniente da fonte s } \\
\text { (domestico e estrangeiro) } \\
\text { usado na produção pelo } \\
\text { setor j na região q }\end{array}$ & $\begin{array}{l}\text { O isjq-ésimo valor é o } \\
\text { correspondente elemento na matriz } \\
\text { TAX1 }\end{array}$ \\
\hline MAR $_{1, \mathrm{~s}, \mathrm{j}, \mathrm{q}, \mathrm{r}}$ & $\begin{array}{l}\text { Valor do gasto sobre a } \\
\text { margem do produto r, para } \\
\text { facilitar a transferência do } \\
\text { bem i proveniente da fonte } \\
\text { s (doméstico e estrangeiro) } \\
\text { para o setor j na região q } \\
\text { para ser usado na produção }\end{array}$ & $\begin{array}{l}\text { A isjqr-ésimo valor é o elemento } \\
\text { correspondente ma matriz MAR1 }\end{array}$ \\
\hline BAS2 $2_{i, s, j, q}$ & $\begin{array}{l}\text { Valor básico de bem i } \\
\text { proveniente da fonte s } \\
\text { (doméstico e estrangeiro) } \\
\text { usado na criação de capital } \\
\text { pelo setor j na região q }\end{array}$ & $\begin{array}{l}\text { O isjq-ésimo valor é o } \\
\text { correspondente elemento da matriz } \\
\text { BAS2 }\end{array}$ \\
\hline
\end{tabular}


Tabela 8. Os coeficientes e parâmetros do MIBRA.

\begin{tabular}{|c|c|c|}
\hline Coeficiente & Descrição & Valor \\
\hline$\overline{\mathrm{TAX}} 2_{\mathrm{i}, \mathrm{s}, \mathrm{j}, \mathrm{q}}$ & $\begin{array}{l}\text { Valor dos impostos de } \\
\text { produto pago pelo bem } \mathrm{i} \\
\text { proveniente da fonte } \mathrm{s} \\
\text { (doméstico e estrangeiro) } \\
\text { utilizado na criação de } \\
\text { capital pelo setor j na } \\
\text { região q }\end{array}$ & $\begin{array}{l}\text { O isjq-ésimo valor é o } \\
\text { correspondente elemento na matriz } \\
\text { TAX2 }\end{array}$ \\
\hline MAR2 $_{\mathrm{i}, \mathrm{s}, \mathrm{j}, \mathrm{q}, \mathrm{r}}$ & $\begin{array}{l}\text { Valor do gasto sobre } \\
\text { margem } \mathrm{r} \text { de produto para } \\
\text { facilitar a transferência do } \\
\text { bem i proveniente da fonte } \\
\mathrm{s} \text { (doméstico e estrangeiro) } \\
\text { para o setor j na região q } \\
\text { para ser usado na criação } \\
\text { de capital }\end{array}$ & $\begin{array}{l}\text { O isjqr-ésimo valor é o } \\
\text { correspondente elemento da matriz } \\
\text { MAR2 }\end{array}$ \\
\hline $\mathrm{BAS} 3_{\mathrm{i}, \mathrm{s}, \mathrm{q}}$ & $\begin{array}{l}\text { Valor básico de bem } \mathrm{i} \\
\text { proveniente da fonte } \mathrm{s} \\
\text { (doméstica e estrangeira) } \\
\text { consumido pelas famílias } \\
\text { na região q }\end{array}$ & $\begin{array}{l}\text { O isq-ésimo valor é o } \\
\text { correspondente elemento na matriz } \\
\text { BAS3 }\end{array}$ \\
\hline $\mathrm{TAX} 3_{\mathrm{i}, \mathrm{s}, \mathrm{q}}$ & $\begin{array}{l}\text { Valor de impostos sobre } \\
\text { produto pagos sobre o bem } \\
\text { i proveniente da fonte s } \\
\text { (doméstica e estrangeira) } \\
\text { consumida pelas famílias } \\
\text { na região q }\end{array}$ & $\begin{array}{l}\text { O isq-ésimo valor é o } \\
\text { correspondente elemento na matriz } \\
\text { TAX3 }\end{array}$ \\
\hline $\mathrm{MAR}_{\mathrm{i}, \mathrm{s}, \mathrm{q}, \mathrm{r}}$ & $\begin{array}{l}\text { Valor de gasto sobre } \\
\text { margem } r \text { de produto, para } \\
\text { facilitar a transferência de } \\
\text { bem i proveniente da fonte } \\
\text { s (doméstica e estrangeira) } \\
\text { para as famílias na região q }\end{array}$ & $\begin{array}{l}\text { O isqr-ésimo valor é o } \\
\text { correspondente elemento na matriz } \\
\text { MAR3 }\end{array}$ \\
\hline $\begin{array}{l}\text { PVAL4R } \text { is } \\
\text { (em E_p4r) }\end{array}$ & $\begin{array}{l}\text { Valor de compra do bem i } \\
(\mathrm{i}=1, \ldots, 16) \text { proveniente } \\
\text { da s-ésima fonte regional ( } \mathrm{s} \\
=1, \ldots, 5) \text { consumido pelos } \\
\text { estrangeiros }\end{array}$ & $\begin{array}{l}\mathrm{O} \text { is -ésimo valor }(\mathrm{i}=1, \ldots, 16 ; \mathrm{s}=1 \text {, } \\
\ldots, 5) \text { é a soma dos correspondentes } \\
\text { elementos das matrizes BAS4, } \\
\text { MAR4 e TAX4 }\end{array}$ \\
\hline $\mathrm{BAS} 4_{\mathrm{i}, \mathrm{s}}$ & $\begin{array}{l}\text { Valor básico de bem i } \\
\text { proveniente da fonte } \mathrm{s} \\
\text { (doméstico e estrangeiro) } \\
\text { vendido para o estrangeiro }\end{array}$ & $\begin{array}{l}\mathrm{O} \text { is -ésimo valor é o correspondente } \\
\text { elemento na matriz BAS4 }\end{array}$ \\
\hline
\end{tabular}


Tabela 8. Os coeficientes e parâmetros do MIBRA.

\begin{tabular}{|c|c|c|}
\hline Coeficiente & Descrição & Valor \\
\hline$\overline{\mathrm{TAX}} 4_{\mathrm{i}, \mathrm{s}}$ & $\begin{array}{l}\text { Valor dos impostos pagos } \\
\text { sobre o bem i proveniente } \\
\text { da fonte s (doméstica e } \\
\text { estrangeira) vendida para o } \\
\text { estrangeiro }\end{array}$ & $\begin{array}{l}\mathrm{O} \text { is-ésimo valor é o correspondente } \\
\text { elemento na matriz TAX4 }\end{array}$ \\
\hline MAR $_{i, s, r}$ & $\begin{array}{l}\text { Valor do gasto com } \\
\text { margem de produto r, para } \\
\text { facilitar a transferência do } \\
\text { bem i proveniente da fonte } \\
\text { s (doméstica e estrangeira) } \\
\text { para os portos de embarque } \\
\text { para o envio ao consumidor } \\
\text { estrangeiro }\end{array}$ & $\begin{array}{l}\text { O isr-ésimo valor é o correspondente } \\
\text { elemento na matriz MAR4 }\end{array}$ \\
\hline PVAL5A $_{\mathrm{i}, \mathrm{s}, \mathrm{q}}$ & $\begin{array}{l}\text { Valor de compra do bem i } \\
(\mathrm{i}=1, \ldots, 16) \text { proveniente } \\
\text { da s-ésima fonte } \\
\text { (doméstica e estrangeira) } \\
\text { para ser usado pelo } \\
\text { governo regional na região } \\
\text { q }\end{array}$ & $\begin{array}{l}\text { O isq-ésimo valor é a soma dos } \\
\text { correspondents elementos das } \\
\text { matrizes BAS5, MAR5 e TAX5 }\end{array}$ \\
\hline BAS5 $5_{i, s, q}$ & $\begin{array}{l}\text { Valor básico do bem } \mathrm{i} \\
\text { proveniente da fonte } \mathrm{s} \\
\text { (doméstica e estrangeira) } \\
\text { consumindo pelo governo } \\
\text { regional na região q }\end{array}$ & $\begin{array}{l}\text { O isq-ésimo valor é o } \\
\text { correspondente elemento na matriz } \\
\text { BAS5 }\end{array}$ \\
\hline TAX5 $5_{i, s, q}$ & $\begin{array}{l}\text { Valor dos impostos pagos } \\
\text { sobre o bem i proveniente } \\
\text { da fonte s (doméstica e } \\
\text { estrangeira) consumido } \\
\text { pelo governo regional na } \\
\text { região q }\end{array}$ & $\begin{array}{l}\text { O isq-ésimo valor é o } \\
\text { correspondente elemento da matriz } \\
\text { TAX5 }\end{array}$ \\
\hline MAR5 $_{\mathrm{i}, \mathrm{s}, \mathrm{q}, \mathrm{r}}$ & $\begin{array}{l}\text { Valor do gasto com } \\
\text { margem r, para facilitar a } \\
\text { transferência do bem i } \\
\text { proveniente da fonte s } \\
\text { (doméstica e estrangeira) } \\
\text { para o governo regional na } \\
\text { região q }\end{array}$ & $\begin{array}{l}\text { O isqr-ésimo valor é o } \\
\text { correspondente elemento na matriz } \\
\text { MAR5 }\end{array}$ \\
\hline
\end{tabular}


Tabela 8. Os coeficientes e parâmetros do MIBRA.

\begin{tabular}{|c|c|c|}
\hline Coeficiente & Descrição & Valor \\
\hline PVAL6A $_{i, s, q}$ & $\begin{array}{l}\text { Valor de compra do bem i } \\
\text { (i = } 1, \ldots, 16) \text { proveniente } \\
\text { s-ésima fonte (doméstica e } \\
\text { estrangeira) para ser usado } \\
\text { pelo governo federal na } \\
\text { região q }\end{array}$ & $\begin{array}{l}\text { O isq-ésimo valor é a soma dos } \\
\text { correspondentes elementos das } \\
\text { matrizes BAS5, MAR5 e TAX6 }\end{array}$ \\
\hline BAS6 $6_{i, s, q}$ & $\begin{array}{l}\text { Valor básico do bem I } \\
\text { proveniente da fonte } \mathrm{s} \\
\text { (doméstica e estrangeira) } \\
\text { consumida pelo governo } \\
\text { federal na região q }\end{array}$ & $\begin{array}{l}\text { O isq-ésimo valor é o } \\
\text { correspondente elemento na matriz } \\
\text { BAS6 }\end{array}$ \\
\hline $\mathrm{TAX}_{\mathrm{i}, \mathrm{s}, \mathrm{q}}$ & $\begin{array}{l}\text { Valor dos impostos pagos } \\
\text { sobre o bem i proveniente } \\
\text { da fonte s (doméstica e } \\
\text { estrangeira) consumido } \\
\text { pelo governo federal na } \\
\text { região q }\end{array}$ & $\begin{array}{l}\text { O isq-ésimo valor e o } \\
\text { correspondente elemento da matriz } \\
\text { TAX6 }\end{array}$ \\
\hline MAR6 $_{i, s, q, r}$ & $\begin{array}{l}\text { Valor do gasto com } \\
\text { margem r para facilitar a } \\
\text { transferência do bem i } \\
\text { proveniente da fonte s } \\
\text { (doméstica e estrangeira) } \\
\text { para o consumo do governo } \\
\text { federal na região q }\end{array}$ & $\begin{array}{l}\text { O isqr-ésimo valor é o } \\
\text { correspondente elemento da matriz } \\
\text { MAR6 }\end{array}$ \\
\hline
\end{tabular}


Tabela 8. Os coeficientes e parâmetros do MIBRA.

\begin{tabular}{ll}
\hline Coeficiente & Descrição \\
\hline SALES $_{\mathrm{r}, \mathrm{s}}$ & Valor total das vendas \\
& recebidas pelos produtores \\
(em E_mkt_clear_margins) & da r -ésima margem \\
& produzida na s-ésima \\
& região. Note que se \\
& distinguem duas finalidades \\
& para as quais as margens \\
& são apropriadas: i) para uso \\
& direto e ii) para facilitar o \\
& comércio. A convenção \\
& considerando a segunda \\
& forma de uso é que a \\
& margem é produzida pelo \\
& correspondente setor na \\
& região que comprou o \\
& produto comercializado.
\end{tabular}

SALES $_{\mathrm{r}, \mathrm{s}}$

(in E_mkt_clear_nonmargins)
Valor total das vendas recebidas pelo produtor do r-ésimo produto nãomargem na s-ésima região. Note que produtos não margens são adquiridos somente para uso direto.
Valor

O rs-ésimo valor é a soma das vendas para uso direto e vendas para uso como uma margem. As vendas diretas são a soma de: a soma em todos os $\mathrm{j}$ setores e $\mathrm{q}$ regiões dos correspondentes isjq-ésimos elementos das matrizes BAS1 e BAS2 (para $\mathrm{i}=\mathrm{r}$ ), a soma nas $\mathrm{q}$ regiões dos correspondentes isqésimos elementos das matrizes BAS3, BAS5 e BAS6 (para $i=r$ ) e o correspondente elemento da matriz BAS4 (para $r=i$ ). Para $o$ componente de margem de vendas, adicionam-se as apropriações da $\mathrm{r}$ ésima margem de produto facilitando a transferência de todos os i produtos provenientes de todas as ss fontes (regional e estrangeira) para ser usado pelo (i) os $\mathrm{j}$ setores nas q-ésima região (MAR1 e MAR2), (ii) as famílias na q-ésima região (MAR3), (iii) os governos na q-ésima região (MAR5 e MAR6), e o exportador na q-ésima região (MAR5 e MAR6), e o exportador na q-ésima região onde é assumido que a q-ésima região é a região que produz a margem (ou seja, para $\mathrm{q}=$ s).

O rs-ésimo valor e a soma de: a soma dos $\mathrm{j}$ setores e $\mathrm{q}$ regiões do isjq-ésimos elementos das matrizes BAS1 e BAS2 (para $\mathrm{i}=\mathrm{r}$ ), a soma nas $q$ regiões dos isq-ésimos elementos das matrizes BAS3,BAS5 e BAS6 (para $\mathrm{i}=\mathrm{r}$ ) e, o correspondente elemento da matriz BAS4 (para $r=i)$.

O iq-ésimo valor é a soma de: (i) a soma dos $\mathrm{j}$ setores dos correspondentes isjq-ésimos elementos ( $\mathrm{s}=$ estrangeiro $)$ das matrizes BAS1 e BAS2; (ii) os correspondentes isq-ésimos elementos das matrizes BAS3, BAS5 e BAS6. 
Tabela 8. Os coeficientes e parâmetros do MIBRA.

\begin{tabular}{|c|c|c|}
\hline Coeficiente & Descrição & Valor \\
\hline AGGTAX $1_{q}$ & $\begin{array}{l}\text { Imposto sobre vendas na } \\
\text { produção corrente coletado } \\
\text { na região q. }\end{array}$ & $\begin{array}{l}\text { O q-ésimo valor é a soma de todo i } \\
\mathrm{s} \quad\left(\begin{array}{ll}\mathrm{s}=1, \ldots, & 6\end{array}\right) \text { e j dos } \\
\text { correspondentes } \\
\text { elementos da matriz TAX } 1 .\end{array}$ \\
\hline $\operatorname{AGGTAX} 2_{\mathrm{q}}$ & $\begin{array}{l}\text { Imposto sobre vendas na } \\
\text { criação de capital coletado } \\
\text { na região q. }\end{array}$ & 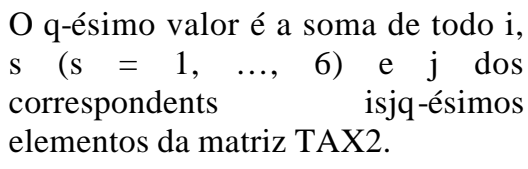 \\
\hline $\mathrm{AGGTAX}_{\mathrm{q}}$ & $\begin{array}{l}\text { Imposto sobre vendas no } \\
\text { consumo das famílias, } \\
\text { coletado na região q. }\end{array}$ & $\begin{array}{l}\text { O q-ésimo valor é a soma de todo i e } \\
\mathrm{s}(\mathrm{s}=1, \ldots, 6) \text { dos correspondentes } \\
\text { isq-ésimos elementos da matriz } \\
\text { TAX3. }\end{array}$ \\
\hline $\operatorname{AGGTAX}_{\mathrm{q}}$ & $\begin{array}{l}\text { Imposto sobre vendas nas } \\
\text { exportações, coletado na } \\
\text { região q. }\end{array}$ & $\begin{array}{l}\text { O q-ésimo valor é a soma de todo i, } \\
\text { para } \mathrm{s}=\mathrm{q} \text {, dos correspondentes iq- } \\
\text { ésimos elementos da matriz TAX } 4 \text {. }\end{array}$ \\
\hline AGGTAX $5_{q}$ & $\begin{array}{l}\text { Imposto sobre vendas no } \\
\text { consumo } \\
\text { regional do governo } \\
\text { região q. }\end{array}$ & $\begin{array}{l}\text { O q-ésimo valor e a soma de todo i e } \\
\mathrm{s}(\mathrm{s}=1, \ldots, 6) \text { dos correspondentes } \\
\text { isq-ésimos elementos da matriz } \\
\text { TAX5. }\end{array}$ \\
\hline $\operatorname{AGGTAX}_{\mathrm{q}}$ & $\begin{array}{l}\text { Imposto sobre vendas no } \\
\text { consumo do governo } \\
\text { federal, coletado na região } \\
\text { q. }\end{array}$ & $\begin{array}{l}\text { O q-ésimo valor e a soma de todo i e } \\
\mathrm{s}(\mathrm{s}=1, \ldots, 6) \text { dos correspondentes } \\
\text { isq-ésimos elementos da matriz } \\
\text { TAX6. }\end{array}$ \\
\hline $\mathrm{AGGCAP}_{\mathrm{q}}$ & $\begin{array}{l}\text { Pagamentos totais ao } \\
\text { capital na região q. }\end{array}$ & $\begin{array}{l}\text { O q-ésimo valor é a soma de todo j } \\
\text { dos correspondentes jq-ésimos } \\
\text { elementos de CAPITAL } \mathrm{L}_{\mathrm{q}} \text {. }\end{array}$ \\
\hline $\mathrm{AGGLAB}_{\mathrm{q}}$ & $\begin{array}{l}\text { Pagamentos totais para o } \\
\text { trabalho na região q. }\end{array}$ & $\begin{array}{l}\text { O q-ésimo valor é a soma de todo j } \\
\text { dos correspondentes jq-ésimos } \\
\text { elementos de } \text { LABOUR }_{\mathrm{jq}} \text {. }\end{array}$ \\
\hline AGGLND $_{\mathrm{q}}$ & $\begin{array}{l}\text { Pagamentos totais para } \\
\text { terra agrícola na região q. }\end{array}$ & $\begin{array}{l}\text { O q-ésimo valor é a soma de todo j } \\
\text { dos correspondentes jq-ésimos } \\
\text { elementos de } \text { LAND }_{\mathrm{jq}} \text {. }\end{array}$ \\
\hline $\mathrm{AGGOCT}_{\mathrm{q}}$ & $\begin{array}{l}\text { Pagamentos totais para } \\
\text { outros custos na região q. }\end{array}$ & $\begin{array}{l}\text { O q-ésimo valor e a soma de todo j } \\
\text { dos correspondentes jq-ésimos } \\
\text { elementos de OTHCOST } \mathrm{jq} \text {. }\end{array}$ \\
\hline AGGTAX $_{q}$ & $\begin{array}{l}\text { Receita de impostos indi- } \\
\text { retos agregados, coletada } \\
\text { por região q. }\end{array}$ & $\begin{array}{l}\text { O q-ésimo valor é a soma dos } \\
\text { correspondentes q-ésimos elementos } \\
\text { de AGGTAX } 1_{q} \text {, AGGTAX } 2_{q} \text {, } \\
\text { AGGTAX } 3_{\mathrm{q}} \text { e AGGTAX } 5_{\mathrm{q}} \text {. }\end{array}$ \\
\hline
\end{tabular}


Tabela 8. Os coeficientes e parâmetros do MIBRA.

\begin{tabular}{|c|c|c|}
\hline Coeficiente & Descrição & Valor \\
\hline TARIFF $_{\mathrm{i}, \mathrm{q}}$ & $\begin{array}{l}\text { O valor de tarifas coletadas } \\
\text { sobre o bem i na região q. }\end{array}$ & $\begin{array}{l}\text { O iq-ésimo valor é o correspondente } \\
\text { elemento do arquivo de dados TARF } \\
\text { do MIBRA }\end{array}$ \\
\hline $\operatorname{AGGTAXM}_{\mathrm{q}}$ & $\begin{array}{l}\text { O valor total de tarifas } \\
\text { coletadas na região } q .\end{array}$ & $\begin{array}{l}\text { O q-ésimo valor é a soma de todo i } \\
\text { dos correspondentes iq-ésimos } \\
\text { elementos de TARIFF } i q .\end{array}$ \\
\hline $\mathrm{AGGCON}_{\mathrm{q}}$ & $\begin{array}{l}\text { Valor total nos preços de } \\
\text { compra do gasto das } \\
\text { famílias na região q. }\end{array}$ & $\begin{array}{l}\text { O q-ésimo valor é a soma de todo i } \\
\text { dos correspondentes iq-ésimos } \\
\text { elementos de PVAL3O } \mathrm{iq}_{\mathrm{iq}} \text {. }\end{array}$ \\
\hline $\mathrm{AGGINV}_{\mathrm{q}}$ & $\begin{array}{l}\text { Valor total nos preços de } \\
\text { compra da criação de } \\
\text { capital na região q. }\end{array}$ & $\begin{array}{l}\text { O q-ésimo valor é a soma de todo i } \\
\text { dos correspondentes iq-ésimos } \\
\text { elementos de INVEST } \text { Iq }_{\text {. }}\end{array}$ \\
\hline $\mathrm{AGGOTH}_{\mathrm{q}}$ & $\begin{array}{l}\text { Valor total nos preços de } \\
\text { compra do gasto do } \\
\text { governo regional na região } \\
\text { q. }\end{array}$ & $\begin{array}{l}\text { O q-ésimo valor é a soma de todo i e } \\
\mathrm{s} \text { dos correspondentes isq-ésimos } \\
\text { elementos de PVAL5A } \mathrm{A}_{\mathrm{isq}} \text {. }\end{array}$ \\
\hline AGGOTH6 $_{q}$ & $\begin{array}{l}\text { Valor total nos preços de } \\
\text { compra do gasto do } \\
\text { governo federal na região } \\
\text { q. }\end{array}$ & $\begin{array}{l}\text { O q-ésimo valor é a soma de todo i e } \\
\mathrm{s} \text { dos correspondentes isq-ésimos } \\
\text { elementos de PVAL6A } \mathrm{A}_{\mathrm{isq}} \text {. }\end{array}$ \\
\hline C_XSFLO ${ }_{\mathrm{s}, \mathrm{q}}$ & $\begin{array}{l}\text { Valor básico dos fluxos } \\
\text { inter e intra-regionais de } \\
\text { comércio. }\end{array}$ & $\begin{array}{l}\text { O sq-ésimo valor é a soma de: a } \\
\text { soma de todo i e j dos } \\
\text { correspondentes } \\
\text { elementos de BAS } 1_{\text {isja }} \text {; a soma de } \\
\text { todo i e j dos correspondentes isjq- } \\
\text { ésimos elementos de BAS } 2_{\text {isjq }} \text {; e a } \\
\text { soma de todo i dos correspondentes } \\
\text { isq-ésimos elementos de BAS } 3_{\text {isq }} \text { e } \\
\text { BAS } 5_{\text {isq. }}\end{array}$ \\
\hline $\mathrm{C}_{-} \mathrm{XSEXP}_{\mathrm{s}}$ & $\begin{array}{l}\text { Valor total das exportações } \\
\text { inter-regionais provenien- } \\
\text { tes da região s. }\end{array}$ & $\begin{array}{l}\text { O s-ésimo valor é a diferença entre a } \\
\text { soma de todo q dos correspondentes } \\
\text { sq-ésimos elementos de C_XSFLO e } \\
\text { o correspondente ss-ésimo elemento } \\
\text { de C_XSFLO. }\end{array}$ \\
\hline C_XSIMP & $\begin{array}{l}\text { Valor total das importações } \\
\text { inter-regionais para região } \\
\text { q. }\end{array}$ & $\begin{array}{l}\text { O q-ésimo valor é a diferença entre a } \\
\text { soma de todo s dos correspondentes } \\
\text { sq-ésimos elementos de C_XSFLO e } \\
\text { o correspondente qq-ésimo elemento } \\
\text { de C_XSFLO. }\end{array}$ \\
\hline
\end{tabular}


Tabela 8. Os coeficientes e parâmetros do MIBRA.

\begin{tabular}{|c|c|c|}
\hline Coeficiente & Descrição & Valor \\
\hline $\mathrm{AGGEXP}_{\mathrm{q}}$ & $\begin{array}{l}\text { Valor total de ganhos da } \\
\text { exportação na região q. }\end{array}$ & $\begin{array}{l}\text { O q-ésimo valor é a soma de todo i } \\
\text { dos correspondentes iq ésimos } \\
\text { elementos de PVAL4R. }\end{array}$ \\
\hline $\operatorname{IMPCOST}_{\mathrm{i}, \mathrm{q}}$ & $\begin{array}{l}\text { Valor total de importações } \\
\text { antes dos impostos, do bem } \\
\text { i para a região q. }\end{array}$ & $\begin{array}{l}\text { O iq-ésimo valor é a soma de: a } \\
\text { soma de todo j dos correspondentes } \\
\text { isjq-ésimos elementos ( }= \\
\text { estrangeiro) das matrizes BAS1e } \\
\text { BAS2 e, os correspondentes isq- } \\
\text { ésimos elementos ( }=\text { estrangeiro) } \\
\text { das matrizes BAS3, BAS5 e BAS6. }\end{array}$ \\
\hline AGGIMP $_{\mathrm{q}}$ & $\begin{array}{l}\text { Valor total dos gastos com } \\
\text { importação estrangeira na } \\
\text { região q. }\end{array}$ & $\begin{array}{l}\text { O q-ésimo valor é a soma de todo i } \\
\text { dos correspondentes iq-ésimos } \\
\text { elementos de IMPCOST. }\end{array}$ \\
\hline TOTFAC $_{\mathrm{q}}$ & $\begin{array}{l}\text { Pagamentos de fator primá- } \\
\text { rio total na região q. }\end{array}$ & $\begin{array}{l}\text { O q-ésimo valor é a soma dos } \\
\text { correspondentes elementos de } \\
\text { AGGLA B, AGGCAP e AGGLND. }\end{array}$ \\
\hline $\mathrm{LAB} \_\mathrm{OCC}_{\mathrm{m}, \mathrm{q}}$ & $\begin{array}{l}\text { Trabalho total na ocupação } \\
\text { m na região q. }\end{array}$ & $\begin{array}{l}\text { O mq -ésimo valor e a soma de todo j } \\
\text { dos correspondentes mjq-ésimos } \\
\text { elementos de LAB_OCC_IND. }\end{array}$ \\
\hline Coeficientes NAT & $\begin{array}{l}\text { Todos os coeficientes com } \\
\text { o prefixo NAT são } \\
\text { coeficientes nacionais for- } \\
\text { mados pela soma dos q } \\
\text { elementos da correspon- } \\
\text { dente variável regional. }\end{array}$ & $\begin{array}{l}\text { Exemplo: NATAGGTAX1 } \\
\sum_{\mathrm{q}=1} \text { AGGTAX } 1_{\mathrm{q}}\end{array}$ \\
\hline NATGDPIN & $\begin{array}{l}\text { PIB nacional proveniente } \\
\text { do lado da renda. }\end{array}$ & $\begin{array}{l}\text { A soma de NATTOTFAC, } \\
\text { NATAGGOCT e NATAGGTAX. }\end{array}$ \\
\hline NATGDPEX & $\begin{array}{l}\text { PIB nacional proveniente } \\
\text { do lado do gasto. }\end{array}$ & $\begin{array}{l}\text { A soma de NATAGGCON, } \\
\text { NATAGGINV, NATAGGOTH5, } \\
\text { NATAGGOTH6, NATAGGEXP e } \\
\text { NATAGGIMP. }\end{array}$ \\
\hline C_Z01_I_R & $\begin{array}{l}\text { Valor dos salários sema- } \\
\text { nais, salários mensais e } \\
\text { suplementos por setor e } \\
\text { região. }\end{array}$ & $\begin{array}{lcr}\text { O jq-ésimo } & \text { valor é } & \text { o } \\
\text { correspondentee } & \text { elemento do } \\
\text { arquivo de dados FZ01no MIBRA. }\end{array}$ \\
\hline C_Z01_R & $\begin{array}{l}\text { Valor regional de salários } \\
\text { semanais, salários mensais } \\
\text { e suplementos. }\end{array}$ & $\begin{array}{l}\text { O q-ésimo valor é a soma de todo j } \\
\text { dos correspondentes jq-ésimos } \\
\text { elementos de C_Z01_I_R. }\end{array}$ \\
\hline
\end{tabular}


Tabela 8. Os coeficientes e parâmetros do MIBRA.

\begin{tabular}{|c|c|c|}
\hline Coeficiente & Descrição & Valor \\
\hline $\bar{C}$ C_Z02_I_R & $\begin{array}{l}\text { Valor dos salários semanais } \\
\text { imputados por setor e } \\
\text { região. }\end{array}$ & $\begin{array}{l}\text { O jq-ésimo valor é o correspondente } \\
\text { elemento no arquivo de dados FZ02 } \\
\text { do MIBRA. }\end{array}$ \\
\hline C_Z02_R & $\begin{array}{l}\text { Valor regional dos salários } \\
\text { semanais imputados. }\end{array}$ & $\begin{array}{l}\text { O q-ésimo valor e a soma, de todo j, } \\
\text { dos correspondentes jq-ésimos } \\
\text { elementos de C_Z02_I_R. }\end{array}$ \\
\hline C_Z03_I_R & $\begin{array}{l}\text { Valor dos impostos na } \\
\text { folha de pagamento por } \\
\text { setor e região. }\end{array}$ & $\begin{array}{l}\text { O jq-ésimo valor é o correspondente } \\
\text { elemento no arquivo de dados FZ03 } \\
\text { do MIBRA. }\end{array}$ \\
\hline C_Z03_R & $\begin{array}{l}\text { Valor regional dos } \\
\text { impostos na folha de } \\
\text { pagamento. }\end{array}$ & $\begin{array}{l}\text { O q-ésimo valor é a soma, de todo j, } \\
\text { dos correspondentes jq-ésimos } \\
\text { elementos de C_Z03_I_R. }\end{array}$ \\
\hline C_Z03 & $\begin{array}{l}\text { Valor nacional dos } \\
\text { impostos na folha de } \\
\text { pagamento. }\end{array}$ & A soma de elementos de C_Z03_R. \\
\hline C_Z04_I_R & $\begin{array}{l}\text { Valor dos retornos ao } \\
\text { capital fixo por setor e } \\
\text { região. }\end{array}$ & $\begin{array}{l}\text { O jq-ésimo valor é o correspondente } \\
\text { elemento do arquivo de dados FZ04 } \\
\text { no MIBRA. }\end{array}$ \\
\hline C_Z04_R & $\begin{array}{l}\text { Valor regional dos retornos } \\
\text { ao capital fixo. }\end{array}$ & $\begin{array}{l}\text { O q-ésimo valor é a soma, de todo j, } \\
\text { dos correspondentes uq-ésimos } \\
\text { elementos de C_Z04_I_R. }\end{array}$ \\
\hline C_Z05_I_R & $\begin{array}{l}\text { Valor dos impostos sobre } \\
\text { propriedade por setor e } \\
\text { região. }\end{array}$ & $\begin{array}{l}\text { O jq-ésimo valor é o correspondente } \\
\text { elemento do arquivo FZ05 no } \\
\text { MIBRA. }\end{array}$ \\
\hline C_Z05_R & $\begin{array}{l}\text { Valor regional dos } \\
\text { impostos } \\
\text { dade. }\end{array}$ & $\begin{array}{l}\text { O q-ésimo valor é a soma, de todo j, } \\
\text { dos correspondentes jq-ésimos } \\
\text { elementos do arquivo C_Z05_I_R. }\end{array}$ \\
\hline C_Z05 & $\begin{array}{l}\text { Valor nacional dos impos- } \\
\text { tos sobre proprie-dade. }\end{array}$ & A soma dos elementos de C_Z05_R. \\
\hline C_Z06_I_R & $\begin{array}{l}\text { Valor dos retornos a terra } \\
\text { agrícola por setor e região. }\end{array}$ & $\begin{array}{l}\text { O jq-ésimo valor é o correspondente } \\
\text { elemento do arquivo de dados FZ06 } \\
\text { no MIBRA. }\end{array}$ \\
\hline C_Z06_R & $\begin{array}{l}\text { Valor regional dos retornos } \\
\text { a terra agrícola. }\end{array}$ & $\begin{array}{l}\text { O q-ésimo valor é a soma de todo j, } \\
\text { dos correspondentes jq-ésimos } \\
\text { elementos de C_Z06_I_R. }\end{array}$ \\
\hline
\end{tabular}


Tabela 8. Os coeficientes e parâmetros do MIBRA.

\begin{tabular}{|c|c|c|}
\hline Coeficiente & Descrição & Valor \\
\hline C_Z07_I_R $\mathrm{j}, \mathrm{q}_{\mathrm{f}}$ & $\begin{array}{l}\text { Valor dos impostos sobre } \\
\text { terra por setor e região. }\end{array}$ & $\begin{array}{l}\text { O jq-ésimo valor é o corres pondente } \\
\text { elemento do arquivo de dados FZ07 } \\
\text { no MIBRA. }\end{array}$ \\
\hline C_Z07_R & $\begin{array}{l}\text { Valor regional dos impos- } \\
\text { tos sobre a terra. }\end{array}$ & $\begin{array}{l}\text { O q-ésimo valor é a soma, de todo j, } \\
\text { dos correspondentes jq-ésimos } \\
\text { elementos de C_Z07_I_R. }\end{array}$ \\
\hline C_Z07 & $\begin{array}{l}\text { Valor nacional dos impos- } \\
\text { tos sobre a terra. }\end{array}$ & A soma dos elementos de C_Z07_R. \\
\hline C_Z08_I_R $\mathrm{j}, \mathrm{q}$ & $\begin{array}{l}\text { Valor dos retornos ao ca- } \\
\text { pital trabalho por setor e } \\
\text { região. }\end{array}$ & $\begin{array}{l}\text { O jq-ésimo valor é o correspondente } \\
\text { elemento do arquivo FZ08 no } \\
\text { MIBRA. }\end{array}$ \\
\hline C_Z08_R & $\begin{array}{l}\text { Valor regional dos retornos } \\
\text { ao capital trabalho. }\end{array}$ & $\begin{array}{l}\text { O q-ésimo valor é a soma, de todo j, } \\
\text { dos correspondentes jq-ésimos de } \\
\text { C_Z08_I_R. }\end{array}$ \\
\hline C_Z09_I_R & $\begin{array}{l}\text { Valor de outros impostos } \\
\text { indiretos por setor e região. }\end{array}$ & $\begin{array}{l}\text { O jq-ésimo valor é o correspondente } \\
\text { elemento do arquivo de dados FZ09 } \\
\text { no MIBRA. }\end{array}$ \\
\hline C_Z09_R & $\begin{array}{l}\text { Valor regional dos outros } \\
\text { impostos indiretos. }\end{array}$ & $\begin{array}{l}\text { O q-ésimo valor é a soma, de todo j, } \\
\text { dos correspondentes jq-ésimos } \\
\text { elementos de C_Z09_I_R. }\end{array}$ \\
\hline C_Z09 & $\begin{array}{l}\text { Valor nacional dos outros } \\
\text { impostos indiretos. }\end{array}$ & A soma dos elementos de C_Z09_R. \\
\hline C_Z010_I_R $\mathrm{R}_{\mathrm{j}, \mathrm{q}}$ & $\begin{array}{l}\text { Valor das vendas } \\
\text { compradores finais } \\
\text { setor e região. }\end{array}$ & $\begin{array}{l}\text { O jq-ésimo valor é o correspondente } \\
\text { elemento do arquivo de dados FZ10 } \\
\text { no MIBRA. }\end{array}$ \\
\hline C_Z010_R & $\begin{array}{l}\text { Valor regional das vendas } \\
\text { por compradores finais. }\end{array}$ & $\begin{array}{l}\text { O q-ésimo valor é a soma, de todo j, } \\
\text { dos correspondentes jq-ésimos } \\
\text { elementos de C_Z010_I_R. }\end{array}$ \\
\hline C_Z010 & $\begin{array}{l}\text { Valor nacional das vendas } \\
\text { por compradores finais. }\end{array}$ & $\begin{array}{l}\text { A soma dos elementos de } \\
\text { C_Z010_R. }\end{array}$ \\
\hline C_ZG_R & $\begin{array}{l}\text { Valor regional do superávit } \\
\text { operacional bruto. }\end{array}$ & $\begin{array}{l}\text { O q-ésimo valor é a soma dos } \\
\text { correspondentes elementos de } \\
\text { C_Z02_R, C_Z04_R, C_Z06_R e } \\
\text { C_Z08_R. }\end{array}$ \\
\hline
\end{tabular}


Tabela 8. Os coeficientes e parâmetros do MIBRA.

\begin{tabular}{|c|c|c|}
\hline Coeficiente & Descrição & Valor \\
\hline C_ZT_R $\mathrm{R}_{\mathrm{q}}$ & $\begin{array}{l}\text { Valor regional dos impos- } \\
\text { tos sobre a produção. }\end{array}$ & $\begin{array}{l}\text { O q-ésimo valor é a soma dos } \\
\text { correspondentes elementos de } \\
\text { C_Z03_R, C_Z05_R, C_Z07_R e } \\
\text { C_Z09_R. }\end{array}$ \\
\hline C_DOMPY000 ${ }_{\mathrm{q}}$ & $\begin{array}{l}\text { Produto Operacional Bruto: } \\
\text { lado da renda. }\end{array}$ & $\begin{array}{l}\text { O q-ésimo valor é o correspondente } \\
\text { elemento do arquivo PA01 no } \\
\text { MIBRA. }\end{array}$ \\
\hline C_DOMPY $100_{q}$ & $\begin{array}{l}\text { Salários semanais, salários } \\
\text { mensais e suplementos, } \\
\text { todos regionais. }\end{array}$ & $\begin{array}{l}\text { O q-ésimo valor é o correspondente } \\
\text { elemento do arquivo de dados PA02 } \\
\text { no MIBRA. }\end{array}$ \\
\hline C_DOMPY $110_{q}$ & $\begin{array}{l}\text { Salário renda disponível } \\
\text { regional. }\end{array}$ & $\begin{array}{l}\text { O q-ésimo valor é o correspondente } \\
\text { elemento do arquivo de dados PA03 } \\
\text { no MIBRA. }\end{array}$ \\
\hline C_DOMPY $120_{q}$ & Impostos PAYE regionais. & $\begin{array}{l}\text { O q-ésimo valor é o correspondente } \\
\text { elemento no arquivo de dados PA04 } \\
\text { no MIBRA. }\end{array}$ \\
\hline C_DOMPY $200_{q}$ & $\begin{array}{l}\text { Superávit Operacional } \\
\text { Bruto Regional: renda de } \\
\text { fator primário não salário } \\
\text { semanal. }\end{array}$ & $\begin{array}{l}\text { O q-ésimo valo é o correpondent } \\
\text { elemento no arquivo PA05 no } \\
\text { MIBRA. }\end{array}$ \\
\hline C_DOMPY $210_{q}$ & $\begin{array}{l}\text { Renda não proveniente de } \\
\text { salário semanal disponível } \\
\text { regional. }\end{array}$ & $\begin{array}{l}\text { O q-ésimo valor é o correspondente } \\
\text { elemento do arquivo de dados PA06 } \\
\text { no MIBRA. }\end{array}$ \\
\hline C_DOMPY $220_{q}$ & $\begin{array}{l}\text { Imposto regional coletado } \\
\text { sobre renda não pro- } \\
\text { veniente de salário sema- } \\
\text { nal. }\end{array}$ & $\begin{array}{l}\text { O q-ésimo valor é o correspondente } \\
\text { elemento do arquivo de dados PA07 } \\
\text { no MIBRA. }\end{array}$ \\
\hline C_DOMPY $300_{q}$ & $\begin{array}{l}\text { Impostos indiretos regio- } \\
\text { nais menos subsídios. }\end{array}$ & $\begin{array}{l}\text { O q-ésimo valor é o correspondente } \\
\text { elemento no arquivo de dados PA08 } \\
\text { no MIBRA. }\end{array}$ \\
\hline C_DOMPY $310_{\mathrm{q}}$ & $\begin{array}{l}\text { Coleta regional da receita } \\
\text { de tarifa. }\end{array}$ & $\begin{array}{l}\text { O q-ésimo valor é o correspondente } \\
\text { elemento no arquivo de dados PA09 } \\
\text { no Monash-MRF. }\end{array}$ \\
\hline C_DOMPY $320_{q}$ & $\begin{array}{l}\text { Impostos regionais } \\
\text { cados sobre os outros } \\
\text { impostos indiretos } \\
\text { subsídios. }\end{array}$ & $\begin{array}{l}\text { O q-ésimo valor é o correspondente } \\
\text { valor no arquivo de dados PA10 no } \\
\text { MIBRA. }\end{array}$ \\
\hline
\end{tabular}


Tabela 8. Os coeficientes e parâmetros do MIBRA.

\begin{tabular}{|c|c|c|}
\hline Coeficiente & Descrição & Valor \\
\hline C_DOMPY330 & $\begin{array}{l}\text { Arrecadação regional de } \\
\text { impostos sobre a produção. }\end{array}$ & $\begin{array}{l}\text { O q-ésimo valor é o correspondente } \\
\text { elemento no arquivo de dados PA11 } \\
\text { no MIBRA. }\end{array}$ \\
\hline C_DOMPQ000 & $\begin{array}{l}\text { Produto Operacional Bruto: } \\
\text { lado do gasto. }\end{array}$ & $\begin{array}{l}\text { O q-ésimo valor é o correspondente } \\
\text { elemento do arquivo de dados PA12 } \\
\text { no MIBRA. }\end{array}$ \\
\hline C_DOMPQ $100_{q}$ & $\begin{array}{l}\text { Absorção doméstica regio- } \\
\text { nal. }\end{array}$ & $\begin{array}{l}\text { O q-ésimo valor é o correspondente } \\
\text { elemento no arquivo de dados PA } 13 \\
\text { no MIBRA. }\end{array}$ \\
\hline C_DOMPQ $110_{\mathrm{q}}$ & Consumo regional privado. & $\begin{array}{l}\text { O q-ésimo valor é o correspondente } \\
\text { elemento do arquivo de dados PA14. }\end{array}$ \\
\hline C_DOMPQ120 & $\begin{array}{l}\text { Investimento privado regio- } \\
\text { nal. }\end{array}$ & $\begin{array}{l}\text { O q-ésimo valor é o correspondente } \\
\text { elemento no arquivo de dados pa15 } \\
\text { no MIBRA. }\end{array}$ \\
\hline C_DOMPQ130 q & $\begin{array}{l}\text { Consumo do governo re- } \\
\text { gional. }\end{array}$ & $\begin{array}{l}\text { O q-ésimo valor é o correspondente } \\
\text { elemento do arquivo de dados PA16 } \\
\text { no MIBRA. }\end{array}$ \\
\hline C_DOMPQ140 & $\begin{array}{l}\text { Consumo do governo } \\
\text { federal. }\end{array}$ & $\begin{array}{l}\text { O q-ésimo valor é o correspondente } \\
\text { elemento do arquivo de dados PA } 17 \\
\text { no MIBRA. }\end{array}$ \\
\hline C_DOMPQ $150_{\mathrm{q}}$ & Investimento do governo. & $\begin{array}{l}\text { O q-ésimo valor é o correspondente } \\
\text { elemento no arquivo de dados PA18 } \\
\text { no MIBRA. }\end{array}$ \\
\hline C_DOMPQ200q & $\begin{array}{l}\text { Balanço de comércio inter- } \\
\text { regional. }\end{array}$ & $\begin{array}{l}\text { O q-ésimo valor é o correspondente } \\
\text { elemento no arquivo de dados PA19 } \\
\text { no MIBRA. }\end{array}$ \\
\hline C_DOMPQ210 & $\begin{array}{l}\text { Exportações } \\
\text { regionais. }\end{array}$ & $\begin{array}{l}\text { O q-ésimo valor é o correspondente } \\
\text { elemento no arquivo de dados PA20 } \\
\text { no MIBRA. }\end{array}$ \\
\hline C_DOMPQ220 q & $\begin{array}{l}\text { Importações } \\
\text { regionais. }\end{array}$ & $\begin{array}{l}\text { O q-ésimo valor é o correspondente } \\
\text { elemento do arquivo de dados PA2 } 1 \\
\text { no MIBRA. }\end{array}$ \\
\hline C_DOMPQ300 & $\begin{array}{l}\text { Balanço de comércio } \\
\text { internacional regional. }\end{array}$ & $\begin{array}{l}\text { O q-ésimo valor é o correspondente } \\
\text { elemento no arquivo de dados PA22 } \\
\text { no MIBRA. }\end{array}$ \\
\hline
\end{tabular}


Tabela 8. Os coeficientes e parâmetros do MIBRA.

\begin{tabular}{|c|c|c|}
\hline Coeficiente & Descrição & Valor \\
\hline C_DOMPQ310 & $\begin{array}{l}\text { Exportações internacionais } \\
\text { regionais. }\end{array}$ & $\begin{array}{l}\text { O q-ésimo valor é o correspondente } \\
\text { elemento do arquivo de dados PA23 } \\
\text { no MIBRA. }\end{array}$ \\
\hline C_DOMPQ320 q & $\begin{array}{l}\text { Importações internacionais } \\
\text { regionais. }\end{array}$ & $\begin{array}{l}\text { O q-ésimo valor é o correspondente } \\
\text { elemento no arquivo PA24 no } \\
\text { MIBRA. }\end{array}$ \\
\hline C_TI & $\begin{array}{l}\text { Arrecadação nacional de } \\
\text { impostos sobre produtos } \\
\text { menos subsídios (excluindo } \\
\text { tarifas). }\end{array}$ & $\begin{array}{l}\text { A soma dos elementos de } \\
\text { C_DOMPY320. }\end{array}$ \\
\hline C_YN & PIB nominal nacional. & $\begin{array}{l}\text { A soma dos elementos de } \\
\text { C_DOMPY000. }\end{array}$ \\
\hline C_YF & $\begin{array}{l}\text { PIB nominal nacional a } \\
\text { custo de fatores. }\end{array}$ & $\begin{array}{l}\text { A soma dos elementos de } \\
\text { C_DOMPY100 e C_DOMPY200. }\end{array}$ \\
\hline NATBT & $\begin{array}{l}\text { Balanço de comércio } \\
\text { nominal nacional }\end{array}$ & $\begin{array}{l}\text { A soma dos elementos de } \\
\text { C_DOMPQ300. }\end{array}$ \\
\hline $\mathrm{C}_{-} \mathrm{TY}$ & $\begin{array}{l}\text { Arrecadação dos impostos } \\
\text { de renda nacional. }\end{array}$ & $\begin{array}{l}\text { A soma dos elementos de } \\
\text { C_DOMPY120 e C_DOMPY220. }\end{array}$ \\
\hline C_YL & $\begin{array}{l}\text { Renda salário semanal pré- } \\
\text { imposto nacional. }\end{array}$ & $\begin{array}{l}\text { A soma dos elementos de } \\
\text { C_DOMPY100. }\end{array}$ \\
\hline C_YLSTAR & $\begin{array}{l}\text { Renda salário semanal pós- } \\
\text { imposto nacional. }\end{array}$ & $\begin{array}{l}\text { A soma dos elementos de } \\
\text { C_DOMPY } 110 .\end{array}$ \\
\hline C_IP_R $\mathrm{R}_{\mathrm{q}}$ & $\begin{array}{l}\text { Investimento privado } \\
\text { nominal regional. }\end{array}$ & $\begin{array}{l}\text { O q-ésimo valor é o correspondente } \\
\text { elemento do arquivo de dados } \mathrm{MI} 02 \\
\text { no MIBRA. }\end{array}$ \\
\hline C_IP & $\begin{array}{l}\text { Investimento } \quad \text { privado } \\
\text { nominal nacional. }\end{array}$ & A soma dos elementos de C_IP_R. \\
\hline C_IG_R $\mathrm{R}_{\mathrm{q}}$ & \begin{tabular}{lrr}
\multicolumn{2}{l}{ Investimento do governo } \\
nominal regional & (por \\
governos & regional & $\mathrm{e}$ \\
federal). & & \\
\end{tabular} & $\begin{array}{l}\text { O q-ésimo valor é o correspondente } \\
\text { elemento do arquivo de dados MI03 } \\
\text { no MIBRA. }\end{array}$ \\
\hline C_IG & $\begin{array}{l}\text { Investimento do governo } \\
\text { nominal nacional. }\end{array}$ & A soma dos elementos de $C_{-} I G_{-} \mathrm{R}$. \\
\hline C_SOFTY000 & $\begin{array}{l}\text { Sumário das transações } \\
\text { financeiras: total do lado da } \\
\text { renda. }\end{array}$ & $\begin{array}{l}\text { O q-ésimo valor é o correspondente } \\
\text { valor do arquivo de dados GA01 no } \\
\text { MIBRA. }\end{array}$ \\
\hline
\end{tabular}


Tabela 8. Os coeficientes e parâmetros do MIBRA.

\begin{tabular}{|c|c|c|}
\hline Coeficiente & Descrição & Valor \\
\hline C_SOFTY $100_{\mathrm{q}}$ & Receita do governo. & $\begin{array}{l}\text { O q-ésimo valor é o correspondente } \\
\text { elemento do arquivo de dados GA02 } \\
\text { no MIBRA. }\end{array}$ \\
\hline C_SOFTY $110_{\mathrm{q}}$ & Impostos diretos. & $\begin{array}{l}\text { O q-ésimo valor é o correspondente } \\
\text { elemento do arquivo de dados GA03 } \\
\text { no MIBRA. }\end{array}$ \\
\hline C_SOFTY $111_{\mathrm{q}}$ & Impostos de renda. & $\begin{array}{l}\text { O q-ésimo valor é o correspondente } \\
\text { elemento no arquivo de dados GA04 } \\
\text { no MIBRA. }\end{array}$ \\
\hline C_SOFTY $112_{\mathrm{q}}$ & Outros impostos diretos. & $\begin{array}{l}\text { O q-ésimo valor é o correspondente } \\
\text { elemento no arquivo de dados GA05 } \\
\text { no MIBRA. }\end{array}$ \\
\hline C_SOFTY $120_{\mathrm{q}}$ & Impostos indiretos. & $\begin{array}{l}\text { O q-ésimo valor é o correspondente } \\
\text { elemento no arquivo de dados GA06 } \\
\text { no MIBRA. }\end{array}$ \\
\hline C_SOFTY $121_{\mathrm{q}}$ & Receita de tarifa. & $\begin{array}{l}\text { O q-ésimo valor é o correspondente } \\
\text { elemento no arquivo de dados GA07 } \\
\text { no MIBRA. }\end{array}$ \\
\hline C_SOFTY $122_{\mathrm{q}}$ & $\begin{array}{l}\text { Outros impostos sobre } \\
\text { produtos. }\end{array}$ & $\begin{array}{l}\text { O q-ésimo valor é o correspondente } \\
\text { elemento no arquivo de dados GA08 } \\
\text { no MIBRA. }\end{array}$ \\
\hline C_SOFTY $123_{\mathrm{q}}$ & $\begin{array}{l}\text { Impostos sobre a folha de } \\
\text { pagamento. }\end{array}$ & $\begin{array}{l}\text { O q-ésimo valor é o correspondente } \\
\text { elemento no arquivo de dados GA09 } \\
\text { no MIBRA. }\end{array}$ \\
\hline C_SOFTY $124_{q}$ & $\begin{array}{l}\text { Impostos } \\
\text { propriedades. }\end{array}$ & $\begin{array}{l}\text { O q-ésimo valor é o correspondente } \\
\text { elemento no arquivo de dados GA } 10 \\
\text { no MIBRA. }\end{array}$ \\
\hline C_SOFTY $125_{\mathrm{q}}$ & Impostos sobre a terra. & $\begin{array}{l}\text { O q-ésimo valor é o correspondente } \\
\text { elemento no arquivo de dados GA } 11 \\
\text { no MIBRA. }\end{array}$ \\
\hline C_SOFTY $126_{q}$ & Outros impostos indiretos. & $\begin{array}{l}\text { O q-ésimo valor é o correspondente } \\
\text { elemento no arquivo de dados GA12 } \\
\text { no MIBRA. }\end{array}$ \\
\hline C_SOFTY $130_{\mathrm{q}}$ & Juros recebidos. & $\begin{array}{l}\text { O q-ésimo valor é o correspondente } \\
\text { elemento no arquivo de dados GA13 } \\
\text { no MIBRA. }\end{array}$ \\
\hline
\end{tabular}


Tabela 8. Os coeficientes e parâmetros do MIBRA.

\begin{tabular}{|c|c|c|}
\hline Coeficiente & Descrição & Valor \\
\hline C_SOFTY $140_{\mathrm{q}}$ & Doações para as regiões. & $\begin{array}{l}\text { O q-ésimo valor é o correspondente } \\
\text { elemento no arquivo de dados GA14 } \\
\text { no modelo MIBRA. }\end{array}$ \\
\hline C_SOFTY $141_{\mathrm{q}}$ & Doações correntes. & $\begin{array}{l}\text { O q-ésimo valor é o correspondente } \\
\text { elemento do arquivo de dados GA } 15 \\
\text { no MIBRA. }\end{array}$ \\
\hline C_SOFTY $142_{\mathrm{q}}$ & Doações de capital. & $\begin{array}{l}\text { O q-ésimo valor é o correspondente } \\
\text { elemento no arquivo de dados GA } 16 \\
\text { no MIBRA. }\end{array}$ \\
\hline C_SOFTY $150_{\mathrm{q}}$ & Outras receitas. & $\begin{array}{l}\text { O q-ésimo valor é o correspondente } \\
\text { elemento no arquivo de dados GA } 17 \\
\text { no MIBRA. }\end{array}$ \\
\hline C_SOFTY $200_{\mathrm{q}}$ & $\begin{array}{l}\text { Depreciação, governo ge- } \\
\text { ral. }\end{array}$ & $\begin{array}{l}\text { O q-ésimo valor é o correspondente } \\
\text { elemento do arquivo de dados GA } 18 \\
\text { no MIBRA. }\end{array}$ \\
\hline C_SOFTY $300_{\mathrm{q}}$ & Transações Financeiras. & $\begin{array}{l}\text { O q-ésimo valor é o correspondente } \\
\text { elemento no arquivo de dados GA } 19 \\
\text { no MIBRA. }\end{array}$ \\
\hline C_SOFTY $310_{\mathrm{q}}$ & $\begin{array}{l}\text { Empréstimos tomados lí- } \\
\text { quidos. }\end{array}$ & $\begin{array}{l}\text { O q-ésimo valor é o correspondente } \\
\text { elemento no arquivo de dados GA } 20 \\
\text { no MIBRA. }\end{array}$ \\
\hline C_SOFTY $320_{\mathrm{q}}$ & Aumento das provisões. & $\begin{array}{l}\text { O q-ésimo valor é o correspondente } \\
\text { elemento no arquivo de dados GA } 21 \\
\text { no MIBRA. }\end{array}$ \\
\hline C_SOFTY $330_{\mathrm{q}}$ & $\begin{array}{l}\text { Outras transações finan- } \\
\text { ceiras. }\end{array}$ & $\begin{array}{l}\text { O q-ésimo valor é o correspondente } \\
\text { elemento do arquivo de dados GA22 } \\
\text { no MIBRA. }\end{array}$ \\
\hline C_SOFTQ000 & $\begin{array}{l}\text { Sumário das Transações } \\
\text { Financeiras: total do lado } \\
\text { do gasto. }\end{array}$ & $\begin{array}{l}\text { O q-ésimo valor é o correspondente } \\
\text { elemento do arquivo de dados GA23 } \\
\text { no MIBRA. }\end{array}$ \\
\hline C_SOFTQ100 & Gasto em bens e serviços. & $\begin{array}{l}\text { O q-ésimo valor é o correspondente } \\
\text { elemento no arquivo de dados GA2 } 4 \\
\text { no MIBRA. }\end{array}$ \\
\hline C_SOFTQ110 $0_{\mathrm{q}}$ & Consumo do governo. & $\begin{array}{l}\text { O q-ésimo valor é o correspondente } \\
\text { ele mento no arquivo de dados GA2 } 25 \\
\text { no MIBRA. }\end{array}$ \\
\hline
\end{tabular}


Tabela 8. Os coeficientes e parâmetros do MIBRA.

\begin{tabular}{|c|c|c|}
\hline Coeficiente & Descrição & Valor \\
\hline C_SOFTQ120 & Investimento do governo. & $\begin{array}{l}\text { O q-ésimo valor é o correspondente } \\
\text { elemento do arquivo de dados GA26 } \\
\text { no MIBRA. }\end{array}$ \\
\hline C_SOFTQ200 & $\begin{array}{l}\text { Pagamentos de benefícios } \\
\text { pessoais. }\end{array}$ & $\begin{array}{l}\text { O q-ésimo valor é o correspondente } \\
\text { elemento do arquivo de dados GA27 } \\
\text { no MIBRA. }\end{array}$ \\
\hline C_SOFTQ210 & Benefícios de desemprego. & $\begin{array}{l}\text { O q-ésimo valor é o correspondente } \\
\text { elemento do arquivo de dados GA } 28 \\
\text { no MIBRA. }\end{array}$ \\
\hline C_SOFTQ220 & Outros benefícios pessoais. & $\begin{array}{l}\text { O q-ésimo valor é o correspondente } \\
\text { elemento do arquivo de dados GA29 } \\
\text { no MIBRA. }\end{array}$ \\
\hline C_SOFTQ300 & Subsídios. & $\begin{array}{l}\text { O q-ésimo valor é o correspondente } \\
\text { elemento do arquivo de dados GA } 30 \\
\text { no MIBRA. }\end{array}$ \\
\hline C_SOFTQ400 & Pagamentos de juros. & $\begin{array}{l}\text { O q-ésimo valor é o correspondente } \\
\text { elemento no arquivo de dados GA31 } \\
\text { no MIBRA. }\end{array}$ \\
\hline C_SOFTQ500 & Doações para regiões. & $\begin{array}{l}\text { O q-ésimo valor é o correspondente } \\
\text { elemento no arquivo de dados GA32 } \\
\text { no modelo MIBRA. }\end{array}$ \\
\hline C_SOFTQ510 & Doações correntes. & $\begin{array}{l}\text { O q-ésimo valor é o correspondente } \\
\text { elemento no arquivo de dados GA33 } \\
\text { no MIBRA. }\end{array}$ \\
\hline C_SOFTQ520q & Doações de capital. & $\begin{array}{l}\text { O q-ésimo valor é o correspondente } \\
\text { elemento no arquivo de dados GA34 } \\
\text { no MIBRA. }\end{array}$ \\
\hline C_SOFTQ600 & Outros gastos. & $\begin{array}{l}\text { O q-ésimo valor é o correspondente } \\
\text { elemento do arquivo de dados GA35 } \\
\text { no MIBRA. }\end{array}$ \\
\hline C_SUBSIDIES & Subsídios. & $\begin{array}{l}\text { A soma dos elementos de } \\
\text { C_SOFTQ300. }\end{array}$ \\
\hline C_HHLDY000 ${ }_{\mathrm{q}}$ & Renda disponível. & $\begin{array}{l}\text { O q-ésimo valor é o correspondente } \\
\text { elemento do arquivo de dados HA01 } \\
\text { no MIBRA. }\end{array}$ \\
\hline
\end{tabular}


Tabela 8. Os coeficientes e parâmetros do MIBRA.

\begin{tabular}{|c|c|c|}
\hline Coeficiente & Descrição & Valor \\
\hline C_HHLDY100 & Renda de fator primário. & $\begin{array}{l}\text { O q-ésimo valor é o correspondente } \\
\text { elemento do arquivo de dados HA02 } \\
\text { no MIBRA. }\end{array}$ \\
\hline C_HHLDY $110_{\mathrm{q}}$ & $\begin{array}{l}\text { Salários semanais, Salários } \\
\text { mensais e suplementos. }\end{array}$ & $\begin{array}{l}\text { O q-ésim valor é o correspondente } \\
\text { elemento no arquivo de dados HA03 } \\
\text { no MIBRA. }\end{array}$ \\
\hline C_HHLDY $120_{\mathrm{q}}$ & $\begin{array}{l}\text { Renda de fator primário } \\
\text { não proveniente de salário } \\
\text { semanal. }\end{array}$ & $\begin{array}{l}\text { O q-ésimo valor é o correspondente } \\
\text { elemento no arquivo de dados HA04 } \\
\text { no MIBRA. }\end{array}$ \\
\hline C_HHLDY200 $\mathrm{q}$ & $\begin{array}{l}\text { Benefícios pessoais rece- } \\
\text { bidos. }\end{array}$ & $\begin{array}{l}\text { O q-ésimo valor é o correspondente } \\
\text { elemento do arquivo de dados HA05 } \\
\text { no MIBRA. }\end{array}$ \\
\hline C_HHLDY $210_{\mathrm{q}}$ & Benefícios de desemprego. & $\begin{array}{l}\text { O q-ésimo valor é o correspondente } \\
\text { elemento no arquivo HA06 no } \\
\text { MIBRA. }\end{array}$ \\
\hline C_HHLDY $220_{q}$ & Outros benefícios pessoais. & $\begin{array}{l}\text { O q-ésimo valor é o correspondente } \\
\text { elemento do arquivo de dados HA07 } \\
\text { no MIBRA. }\end{array}$ \\
\hline C_HHLDY $300_{q}$ & Outra renda (líquida). & $\begin{array}{l}\text { O q-ésimo valor é o correspondente } \\
\text { elemento no arquivo de dados HA08 } \\
\text { no MIBRA. }\end{array}$ \\
\hline C_HHLDY400 & Impostos diretos. & $\begin{array}{l}\text { O q-ésimo valor é o correspondente } \\
\text { elemento no arquivo de dados HA09 } \\
\text { no MIBRA. }\end{array}$ \\
\hline C_HHLDY410 & Impostos PAYE. & $\begin{array}{l}\text { O q-ésimo valor é o correspondente } \\
\text { elemento no arquivo de dados HA10 } \\
\text { no MIBRA. }\end{array}$ \\
\hline C_HHLDY $420_{\mathrm{q}}$ & $\begin{array}{l}\text { Impostos sobre renda de } \\
\text { fator primário não pro- } \\
\text { veniente de salário sema- } \\
\text { nal. }\end{array}$ & $\begin{array}{l}\text { O q-ésimo valor é o correspondente } \\
\text { elemento no arquivo de dados HA11 } \\
\text { no MIBRA. }\end{array}$ \\
\hline C_HHLDY430 & Outros impostos diretos. & $\begin{array}{l}\text { O q-ésimo valor é o correspondente } \\
\text { elemento no arquivo de dados HA12 } \\
\text { no MIBRA. }\end{array}$ \\
\hline C_LABSUP $_{\mathrm{q}}$ & Oferta de Trabalho. & $\begin{array}{l}\text { O q-ésimo valor é o correspondente } \\
\text { elemento do arquivo de dados RLBS } \\
\text { do MIBRA. }\end{array}$ \\
\hline
\end{tabular}


Tabela 8. Os coeficientes e parâmetros do MIBRA.

\begin{tabular}{|c|c|c|}
\hline Coeficiente & Descrição & Valor \\
\hline C_EMPLOY & Pessoas empregadas. & $\begin{array}{l}\text { O q-ésimo valor é o correspondente } \\
\text { elemento do arquivo de dados } \\
\text { REMP no MIBRA. }\end{array}$ \\
\hline C_HHLDD001 $1_{\mathrm{q}}$ & $\begin{array}{l}\text { Recíproco da taxa de } \\
\text { desemprego. }\end{array}$ & $\begin{array}{l}\text { O q-ésimo valor é dado pela } \\
\text { formula: } \\
\text { C_LABSUP/(C_LABSUP- } \\
\text { C_EMPLOY). }\end{array}$ \\
\hline C_HHLDD002 $2_{\mathrm{q}}$ & $\begin{array}{l}\text { Recíproco da proporção de } \\
\text { desempregados para em- } \\
\text { pregados. }\end{array}$ & $\begin{array}{l}\text { O q-ésimo valor é dado pela } \\
\text { fórmula: } \\
\text { C_EMPLOY/(C_LABSUP- } \\
\text { C_EMPLOY). }\end{array}$ \\
\hline C_UPB & $\begin{array}{l}\text { Pagamentos nacionais de } \\
\text { benefícios de desemprego. }\end{array}$ & $\begin{array}{l}\text { A soma de elementos de } \\
\text { C_HHLDY210. }\end{array}$ \\
\hline$C_{-} P B P \_R_{q}$ & $\begin{array}{l}\text { Pagamentos de benefícios } \\
\text { pessoais. }\end{array}$ & $\begin{array}{l}\text { O q-ésimo valor é o correspondente } \\
\text { elemento do arquivo de dados } \mathrm{MI} 04 \\
\text { no MIBRA. }\end{array}$ \\
\hline C_PBP & $\begin{array}{l}\text { Pagamento nacional de } \\
\text { benefícios pessoais. }\end{array}$ & A soma dos elementos de C_PBP_R. \\
\hline VALK_T $1_{j, q}$ & $\begin{array}{l}\text { Valor de ativo do estoque } \\
\text { de capital no período } \mathrm{T}+1 \text {. }\end{array}$ & $\begin{array}{l}\text { O jq-ésimo valor é o correspondente } \\
\text { elemento no arquivo VALK no } \\
\text { MIBRA. }\end{array}$ \\
\hline $\mathrm{VALKT}_{\mathrm{j}, \mathrm{q}}$ & $\begin{array}{l}\text { Valor de ativo do estoque } \\
\text { de capital no período } \mathrm{T} \text {. }\end{array}$ & $\begin{array}{l}\text { O jq-ésimo valor é o correspondente } \\
\text { elemento do arquivo de dados } \\
\text { VALK no MIBRA. }\end{array}$ \\
\hline VALK_0 $0_{\mathrm{j}, \mathrm{q}}$ & $\begin{array}{l}\text { Valor de ativo do estoque } \\
\text { de capital no período } 0 .\end{array}$ & $\begin{array}{l}\text { O jq-ésimo valor é o correspondente } \\
\text { elemento no arquivo VALK no } \\
\text { MIBRA. }\end{array}$ \\
\hline INVEST_0, & $\begin{array}{l}\text { Valor de ativo do } \\
\text { investimento no período } 0 .\end{array}$ & $\begin{array}{l}\text { O jq-ésimo valor é o correspondente } \\
\text { elemento do coeficiente INVEST. }\end{array}$ \\
\hline $\mathrm{DEP}_{\mathrm{j}}$ & $\begin{array}{l}\text { Fator de depreciação, um } \\
\text { menos a taxa de } \\
\text { depreciação. }\end{array}$ & $\begin{array}{l}\text { O jésimo valor é o correspondente } \\
\text { elemento do arquivo de dados DPRC } \\
\text { no MIBRA. }\end{array}$ \\
\hline K_TERM & $\begin{array}{l}\text { Uma constante na equação } \\
\text { E_curcapT1A. }\end{array}$ & $\begin{array}{l}\text { Seu valor é dado pela fórmula } \\
1+(1 / \mathrm{T}) \text {. }\end{array}$ \\
\hline
\end{tabular}


Tabela 8. Os coeficientes e parâmetros do MIBRA.

\begin{tabular}{|c|c|c|}
\hline Coeficiente & Descrição & Valor \\
\hline $\mathrm{QCOEF}_{\mathrm{j}, \mathrm{q}}$ & $\begin{array}{l}\text { Razão da taxa de retorno } \\
\text { bruta em relação a taxa de } \\
\text { retorno líquida. }\end{array}$ & $\begin{array}{l}\text { O jq-ésimo valor é o correspondente } \\
\text { elemento no arquivo PO27 no } \\
\text { MIBRA. }\end{array}$ \\
\hline BETA_R $\mathrm{R}_{\mathrm{j}, \mathrm{q}}$ & $\begin{array}{l}\text { Parâmetro para distribuir } \\
\text { investimento. Pode ser } \\
\text { pensado como um prêmio } \\
\text { de risco. }\end{array}$ & $\begin{array}{l}\text { O jq-ésimo valor é o correspondente } \\
\text { elemento no arquivo de dados BETR } \\
\text { no MIBRA. }\end{array}$ \\
\hline DEBT_RATIO & $\begin{array}{l}\text { Razão da dívida externa } \\
\text { nacional e o PIB. }\end{array}$ & $\begin{array}{l}\text { Seu valor é armazenado no arquivo } \\
\text { de dados DGDP no MIBRA. }\end{array}$ \\
\hline R_WORLD & $\begin{array}{l}\text { Fator de taxa de juros real } \\
\text { mundial, um mais a taxa de } \\
\text { juros mundial real. }\end{array}$ & $\begin{array}{l}\text { Seu valor é armazenado no arquivo } \\
\text { de dados RWLD no MIBRA. }\end{array}$ \\
\hline P_GLOBAL & $\begin{array}{l}\text { Converte } \$ A \text { em termos } \\
\text { reais. }\end{array}$ & É definido igual ao NATXIM. \\
\hline B0 & $\begin{array}{l}\text { Déficit do comércio real no } \\
\text { ano } 0 .\end{array}$ & $\begin{array}{l}\text { O seu valor é dado pela formula } \\
\text { (NATAGGIMP- } \\
\text { NATAGGEXP+NATXI4- } \\
\text { NATXIM)/P_GLOBAL. }\end{array}$ \\
\hline M_DEBT \& N_DEBT & $\begin{array}{l}\text { Constantes na equação de } \\
\text { acumu lação da dívida } \\
\text { externa estrangeira. }\end{array}$ & $\begin{array}{l}\text { Funções do tempo, veja Peter et al. } \\
\left(\begin{array}{llll}(1996 a \text { a, seção } & 2.4 .2) \text { para suas } \\
\text { fórmulas. } & & \end{array}\right.\end{array}$ \\
\hline $\mathrm{C}_{-} \mathrm{POP}_{\mathrm{q}}$ & População regional. & $\begin{array}{l}\text { O q-ésimo valor é o correspondente } \\
\text { elemento no arquivo RPOP no } \\
\text { MIBRA. }\end{array}$ \\
\hline $\mathrm{C}_{-} \mathrm{RM}_{\mathrm{q}}$ & $\begin{array}{l}\text { Migração inter-regional lí- } \\
\text { quida. }\end{array}$ & $\begin{array}{l}\text { O q-ésimo valor é o correspondente } \\
\text { elemento do arquivo de dados } \\
\text { RRGM no MIBRA. }\end{array}$ \\
\hline C_FM $\mathrm{FM}_{\mathrm{q}}$ & $\begin{array}{l}\text { Migração estrangeira regio- } \\
\text { nal líquida. }\end{array}$ & $\begin{array}{l}\text { O q-ésimo valor é o correspondente } \\
\text { elemento n arquivo de dados RFRM } \\
\text { no MIBRA. }\end{array}$ \\
\hline C_ $G_{1}$ & $\begin{array}{l}\text { População natural regional } \\
\text { líquida. }\end{array}$ & $\begin{array}{l}\text { O q-ésimo valor é o correspondente } \\
\text { elemento no arquivo de dados } \\
\text { RGRO no MIBRA. }\end{array}$ \\
\hline C_PR $1_{q}$ & $\begin{array}{l}\text { Constante na equação de } \\
\text { acumulação da população. }\end{array}$ & $\begin{array}{l}\text { O q-ésimo valor é dado pela formula } \\
100 \mathrm{~T}(\mathrm{C} \text { RM }+ \text { C_FM+C_RM }) \text {. }\end{array}$ \\
\hline C_PA2 & $\begin{array}{l}\text { Constante na equação de } \\
\text { acumulação da população. }\end{array}$ & $\begin{array}{l}\text { Seu valor é dado pela fórmula } \\
50(T+1) \text {. }\end{array}$ \\
\hline
\end{tabular}


Tabela 8. Os coeficientes e parâmetros do MIBRA.

\begin{tabular}{lllll}
\hline Coeficiente & Descrição & Valor & & \\
\hline C_NATLABSUP & Oferta de trabalho nacional. & A soma dos elementos de \\
& & C_LABSUP. & \\
C_NATEMPLOY & Emprego nacional: pessoas. & A soma dos elementos de \\
& & C_EMPLOY.
\end{tabular}

Fonte: Adaptado de Peter et al. (1996a)

Tabela 9. Dimensões do MIBRA.

\begin{tabular}{|c|c|c|c|}
\hline Conjunto & Nome no TABLO & Descrição & Elementos \\
\hline$\overline{\mathrm{COM}}$ & $\mathrm{COM}$ & Produtos & \\
\hline RSOU & REGSOURCE & Fontes regionais & \\
\hline IND & IND & Setores & Os mesmos para COM \\
\hline RDES & REGDEST & Destino regional & Os mesmos para RSOU \\
\hline OCC & OCC & Tipo de ocupação & \\
\hline TEXP & TEXP & $\begin{array}{l}\text { Exportações } \\
\text { tradicionais }\end{array}$ & \\
\hline NTEXP & NTEXP & $\begin{array}{l}\text { Exportações não } \\
\text { tradicionais }\end{array}$ & $\begin{array}{l}\text { Os mesmos para COM menos os } \\
\text { quatro produtos tradicionais }\end{array}$ \\
\hline ASOU & ALLSOURCE & Origem dos bens & $\begin{array}{l}\text { Os mesmos para RSOU, mais o } \\
\text { estrangeiro. }\end{array}$ \\
\hline ADES & ALLDEST & Destino dos bens & $\begin{array}{l}\text { Os mesmos para RSOU mais } \\
\text { federal e estrangeiro }\end{array}$ \\
\hline MARG & MARCOM & $\begin{array}{l}\text { Margem de produ- } \\
\text { tos }\end{array}$ & $\begin{array}{l}\text { Margens de comércio e trans- } \\
\text { porte. }\end{array}$ \\
\hline NONMARG & NONMARCOM & $\begin{array}{l}\text { Não margem de } \\
\text { produtos }\end{array}$ & $\begin{array}{l}\text { demais setores que não sejam } \\
\text { comércio e transporte. }\end{array}$ \\
\hline DDES & DOMDEST & Destino dos bens & $\begin{array}{l}\text { Os mesmos para RSOU, mais o } \\
\text { Federal. }\end{array}$ \\
\hline
\end{tabular}

Fonte: Adaptado de Peter et al. (1996a)

Mais detalhes sobre as derivações das equações do modelo MIBRA podem ser encontrados em Peter et al. (1996a). As equações dos módulos de acúmulo de capital, 
acúmulo da dívida e mercado de trabalho e migração regional são discutidas nas próximas seções. Os módulos de acúmulo de capital e de acúmulo da dívida externa dão a dinâmica ao modelo que possibilita a geração de previsão das variáveis. Mas o investimento na concepção original do MIBRA para a obtenção de previsões ainda não é endógeno ao modelo.

\subsubsection{Módulo Central}

A estrutura teórica inclui: equações de demanda requeridas para seis usuários, equações de determinação de preços dos produtos e fatores; equações de equilíbrio; definições de taxas de imposto de produto. As equações do módulo central para o modelo MIBRA podem então ser divididas nos seguintes grupos:

a) Demandas das indústrias pelos insumos intermediários ;

b) Demandas por fatores primários, preços e ofertas;

c) Demandas por insumos para formação de capital;

d) Demandas das famílias;

e) Impostos;

f) Preços de compra dos produtos;

g) Receitas dos impostos;

h) Demandas por exportações;

i) Demandas regionais de produtos para outros gastos;

j) Margens de produtos;

k) Equilíbrio de oferta e demanda por produtos domésticos e importados;

1) Preços básicos;

m) PIB regional, real e nominal e seus componentes;

n) PIB nacional, real e nominal e seus componentes;

o) Índices de preços regional e nacional;

p) Salários;

q) Definiçõos diversas de preços de fatores;

r) Agregados de Emprego. 


\subsubsection{Módulo de Finanças Governamentais}

Neste bloco de equações são determinados o déficit orçamentário dos governos regional e federal, o consumo agregado regional das famílias e produtos estaduais brutos. Para o cálculo dos déficits do governo, é elaborado o Sumário das Transações Financeiras (SOFT) que contém a renda do governo proveniente de várias origens e gastos em diferentes contas. Para a obtenção do consumo agregado das famílias de cada região é calculada a renda das famílias disponível regional e definida a função de consumo regional. O valor adicionado em cada região é determinado com o módulo central do modelo. Dentro do bloco das finanças do governo estão equações que dividem o valor agregado das regiões entre renda pública e renda privada. Neste processo os produtos estaduais brutos são também calculados do lado da renda e do lado dos gastos. Assim sendo, o módulo de finanças governamentais é composto de cinco grupos de equações:
a) Valor adicionado desagregado;
b) Sumário das Transações Financeiras (SOFT);
c) Renda disponível das famílias;
d) Produto regional bruto e;
e) Miscelânea das finanças governamentais.

\subsubsection{Módulo de Acumulação de Capital e Investimento}

Os módulos de acumulação de capital e investimento, acumulação da dívida externa e mercado de trabalho e migração regional, facilitam os estudos de previsão de médio e longo prazo e os movimentos entre a versão de estática comparativa e a versão de previsão do modelo. As equações ligam variáveis de fluxo chaves com suas respectivas variáveis estoques.

A dinâmica do MIBRA, à semelhança do MONASH-MRF, está confinada nas relações de acumulação conectando estoque de capital setorial com investimento setorial, população regional com crescimento natural regional da população e migração inter-regional e estrangeira, e dívida externa com balanço de pagamento. Também são incluídas nestes módulos equações alternativas de estática comparativa para equações de 
previsão. As equações de investimento e capital têm uma versão para a estática comparativa e a versão para previsão. Nas outras equações tais como balanço de pagamento e dívida externa, passa-se da versão de estátic a comparativa para a versão de previsão através de diferentes conjuntos de variáveis exógenas dentro de um conjunto de equações comum.

Assim o modelo MIBRA pode produzir tanto simulações de estática comparativa como de previsão. Simulações de estática comparativa são usualmente interpretadas como mensuração tanto dos efeitos de curto prazo como dos efeitos de longo prazo de uma mudança de política. O que difere o curto prazo do longo prazo nessas simulações é o tratamento do capital setorial. As simulações são caracterizadas pela pressuposição de que os estoques de capital setorial são fixos. Ou seja, os estoques de capital são mantidos nos seus níveis pré-choque. Assim a estática comparativa é muito útil para a análise de políticas.

Entretanto, os planejadores do governo e do setor privado necessitam de previsões para produção, preços e outras variáveis para embasar as suas tomadas de decisões. A simulação estática comparativa usualmente mostra o efeito de uma ou poucas mudanças exógenas. Já a simulação de previsão normalmente mostra os efeitos de todas as mudanças exógenas pressupostas ocorridas ao longo de todo o período de tempo da simulação. O modelo da forma como foi concebido originalmente, necessita de valores obtidos externamente ao modelo, geralmente variáveis macroeconômicas, para gerar as projeções. Ou seja, o modelo é dinâmico com solução recursiva, mas o investimento ainda é exógeno ao modelo. O ideal é que o próprio modelo conseguisse definir a distribuição dos investimento entre os setores e macrorregiões. A modificação necessária para que o modelo MIBRA continue sendo resolvido de forma recursiva mas com o investimento endogenizado é realizada neste trabalho de pesquisa.

As equações do módulo de acumulação de capital e investimento do modelo MIBRA estão apresentadas na Tabela 6. 


\subsubsection{Módulo da Acumulação da Dívida Externa}

Este módulo contém as equações que modelam a dívida externa do país. Estas equações relacionam a dívida com os déficits da balança comercial acumuladas As equações deste módulo, apresentadas na Tabela 6, são derivadas de uma forma bastante semelhante às equações das relações de acumulação de capital e investimento.

\subsubsection{Mercado de Trabalho e Migração Regional}

Este módulo contém equações que calculam a população regional a partir do crescimento natural, da migração estrangeira e da migração inter-regional. O módulo também inclui várias relações de mercado de trabalho regional. Para cada região, o sistema é construído para permitir também: a) uma determinação exógena da população regional, com uma determinação endógena de, no mínimo, uma variável do mercado de trabalho regional, escolhido entre desemprego regional, taxa de participação regional ou salários relativos regionais; b) uma determinação exógena de todas as variáveis mencionadas anteriormente do mercado de trabalho regional e uma determinação endógena da migração regional, e, por esta razão, da população regional. O mecanismo de acumulação da população é similar aos mecanismos de acumulação do capital, do investimento e da dívida externa. As equações são apresentadas na Tabela 6. 


\subsection{Endogenização do Investimento}

Nesta seção é apresentada as modificações nas equações do modelo MIBRA que foram necessárias para modificar as equações de modo que o investimento no modelo MIBRA seja endogenizado.

De acordo com Parmenter \& Dixon (1996), existe quatro possibilidades de solução multiperiódica dos modelos AEG do tipo Johansen.

Na primeira forma o investimento é exógeno ao modelo e a solução é recursiva. A apresentação teórica do MONASH-MRF feita por Peter et al (1996) considera esta solução multiperiódica e, por isso, o caminho futuro da previsão depende de valores, geralmente de variáveis macroeconômicas, obtidos externamente ao modelo. O modelo EFES de Haddad e Domingues (2001) gera previsões para economia brasileira em nível nacional baseadas projeções macroeconômicas obtidas de um modelo a parte. $\mathrm{O}$ modelo MIBRA com as equações originais foi utilizado por Guilhoto et al. (2002) para analisar o impacto da restrição da emissão de poluentes sobre a atividade econômica brasileira em nível setorial e regional através da previsão ano a ano para os próximos dez anos tendo como caminho de previsão as projeções de variáveis macroeconômicas calculadas pelo IPEA.

$\mathrm{Na}$ segunda forma, o investimento passa a ser endógeno mas a solução continua sendo recursiva. Ou seja, a solução do modelo é obtida ano a ano. Este tipo de solução multiperiódica é apresentado e aplicado por Dixon e Rimmer (1998) no modelo MONASH e por Adams et al. (2000) no modelo MMRF-GREEN.

$\mathrm{Na}$ terceira forma o investimento é endógeno ao modelo e a solução do modelo passa a ser não-recursiva. Nesta situação, a solução do modelo é efetivamente intertemporal e a obtenção da solução é realizada considerando todos os períodos ou anos da análise ou previsão simultaneamente. Em nível nacional, Malakellis (2000) aplicou esta forma de solução multiperiódica para a economia australiana utilizando o modelo ORANI.

A quarta forma, ainda não implementada na prática, é a solução não-recursiva com incorporação da otimização do comportamento do investimento. Ou seja, nesta forma, a teoria de otimização do comportamento dos diferentes atores econômicos em relação ao 
investimento é incorporada no modelo AEG na derivação das equações de investimento. Esta seria a forma mais interessante de solução multiperiódica mas infelizmente existem alguns problemas na obtenção da solução que são amplamente discutidos por Dixon \& Parmenter (1996).

Na sequência as duas primeiras formas de solução multiperiódica são detalhadas com base em Dixon \& Parmenter (1996). Pois neste trabalho novas equações do módulo de investimento no modelo MIBRA são incorporadas de maneira que o investimento passe a ser tratado endogenamente.

\subsubsection{Investimento exógeno e solução recursiva}

Considere um modelo com a seguinte forma:

$$
H\left(\tilde{V}_{1}(t), \tilde{V}_{2}(t), Q(t), \Pi(t), I(t), K(t-1)\right)=0, \quad t=1,2, \ldots, T
$$

$\mathrm{e}$

$$
K(t)=(I-D) K(t-1)+I(t) \quad t=1,2, \ldots, T
$$

Onde,

$Q(t)$ é um vetor que fornece setorialmente os aluguéis ou lucros por unidade de capital no ano $t$ ( ou seja, $Q(t)$ é o aluguel por unidade de capital na indústria $j$ );

$\Pi(t)$ é um vetor que fornece os custos no ano $t$ da unidade de construção de capital para as diferentes indústrias;

$I(t)$ é um vetor de níveis de investimento no ano $t$ para as indústrias;

$K(t-1)$ é um vetor de estoques de capital setorial no final do ano $t$-1 e disponível para uso durante o ano $t$;

$D$ é uma matriz diagonal de taxas de depreciação;

$\tilde{V}_{1}(t)$ e $\tilde{V}_{2}(t)$ são outras variáveis para o ano t. $\tilde{V}_{1}(t)$ é o vetor de variáveis endógenas tais como preços domésticos e insumos e $\tilde{V}_{2}(t)$ é o vetor de variáveis exógenas tais como preços mundiais de mercadorias, impostos e coeficientes tecnológicos.

Para dado valor de $t$, por exemplo $t=\tau$, a equação (341) especifica um típico modelo AEG de um período. Isso impõe condições tais como demandas iguais as ofertas, preços iguais a custos e demanda e ofertas são consistente com o comportamento otimizador 
pelos vários atores econômicos. $K(\tau-1)$, disponibilidade de capital no ano $\tau$, pode ser considerado como um vetor de variáveis exógenas ou variáveis pré-determinadas no modelo AEG do ano $\tau$.

A equação (342) diz que o capital disponível para uso na indústria $j$ no ano $t+1$ $\left(K_{j}(t)\right)$ é igual ao capital disponível no ano $t$ depreciado a uma taxa $D j\left(\left(1-D_{j}\right) K_{j}(t-1)\right)$ mais o investimento no ano $\mathrm{t}(\mathrm{Ij}(t))$. A Figura 15 ilustra a distribuição no tempo dos eventos.

\begin{tabular}{l|ll|l|ll|} 
& Ano $t$ & Ano $t+1$ & Ano $t+2$ & \\
\hline & $Q(t)$ & & $Q(t+1)$ & $Q(t+2)$ & \\
$K(t-1)$ & $\Pi(t)$ & $K(t)$ & $\Pi(t+1)$ & $K(t+1)$ & $\Pi(t+2) \quad K(t+2)$ \\
& $I(t)$ & & $I(t+1)$ & $I(t+2)$ & \\
& $\tilde{V}(t)$ & $\tilde{V}(t+1)$ & $\tilde{V}(t+2)$ & \\
\hline
\end{tabular}

Figura 15 - Duração e distribuição dos eventos no tempo no modelo multiperiódico.

Assume-se que o modelo ano $\tau$ não contenha teoria de investimento, mas que se $I(\tau)$ é definido exogenamente, então o modelo ano $\tau$, juntamente com os valores prédeterminados para $K(\tau-1)$ e valores exogenamente dados para $\tilde{V}_{2}(t)$, são suficientes para determinar as outras variáveis para o ano $\tau: Q(\tau), \Pi(\tau)$ e $\tilde{V}_{1}(\tau)$. Isto significa que se é conhecido $K(0)$ e tem um caminho no tempo para o investimento especificado exogenamente, $I(1), I(2), \ldots, I(T)$, então o modelo descrito em (341) e (342) pode ser resolvido como uma série de cálculos computacionais usuais para um modelo AEG de um período. Primeiro utiliza-se (341) para computar o caminho no tempo para o estoque de capital, $K(1), K(2), \ldots, \mathrm{K}(T)$. Então dado $\widetilde{V}_{2}(\tau)$, pode-se, em princípio computar $\widetilde{V}_{1}(\tau)$, $Q(\tau)$ e $\Pi(\tau)$ resolvendo-se o modelo AEG de um período especificado por (341) com $t=$ $\tau$.

Para realizar os cálculos computacionais pode-se utilizar a abordagem de Johansen/Euler. Considerando que (341) mantém-se em cada ano, verifica-se que taxas 
de crescimento do ano $t$ para o ano $t+1$ satifazem, para uma aproximação de primeira ordem, o seguinte sistema:

$$
\begin{aligned}
H_{l}(t) \tilde{v}_{1} v_{l}(t+1)+H_{2}(t) & \tilde{v}_{2}(t+1)+H_{q}(t) q(t+1)+H_{\pi}(t) \pi(t+1) \\
& +H_{i}(t) i(t+1)+H_{k}(t) k(t)=0, t=1,2, \ldots, T-1 .
\end{aligned}
$$

A equação (343) é uma versão de (341) em variação percentual com os coeficientes o $H_{1}, H_{2}, H_{q}, H_{\pi}, H_{i}$ e $H_{k}$ calculado na solução para o ano $t$, ou seja, os $H$ s calculados em

$$
V(t)=\left(\tilde{V}_{1}(t), \tilde{V}_{2}(t), Q(t), \Pi(t), I(t), K(t-1)\right) .
$$

As variáveis em letras minúsculas em (343) são taxas de crescimento nas correspondentes variáveis em letra maiúscula. Por exemplo $q(t+1)$ é o vetor de taxas de crescimento percentual entre os anos $t$ e $t+1$ em aluguéis:

$$
q_{j}(t+1)=100\left(Q_{j}(t+1)-Q_{j}(t)\right) / Q_{j}(t) .
$$

As letras minúsculas na equação (343) podem também ser interpretadas como desvios percentuais a partir de uma solução inicial para uma solução do modelo no ano $(t+1)$. Esta solução inicial é $V(t)$ dado por (344).

Sob a pressuposição de que o modelo ano $(t+1)$, juntamente com $K(t), I(t+1)$ e $\tilde{V}_{2}(t+1)$, é suficiente para determinar $Q(t+1), \Pi(t+1)$, pode-se rearranjar (343) como:

$$
v_{1}(t+1)=B(t) v_{2}(t+1), t=1, \ldots, T-1,
$$

onde

$$
\begin{gathered}
v_{1}^{\prime}(t+1)=\left[\tilde{v}_{1}^{\prime}(t+1), q^{\prime}(t+1), \pi^{\prime}(t+1)\right], t=1, \ldots, T-1 \\
v_{2}^{\prime}(t+1)=\left[\tilde{v}_{2}^{\prime}(t+1), q^{\prime}(t+1), \pi^{\prime}(t+1)\right], t=1, \ldots, T-1
\end{gathered}
$$

$\mathrm{e}$

$$
B(t)=-\left[H_{l}(t), H_{q}(t), H_{\pi}(t)\right]^{-1}\left[H_{2}(t), H_{i}(t), H_{k}(t)\right], t=1, \ldots, T-1 .
$$

Com os caminhos no tempo do investimento em cada setor/indústria dados exogenamente, pode-se computar $i(2), i(3), \ldots, i(T)$, e com $K(0)$ conhecido pode-se usar (342) no cálculo de $k(1), k(2), \ldots, k(T)$. Finalmente assume-se que os dados de insumoproduto e outros dados para o período-base nos fornecem uma solução para (341) para $t$ $=1$, isto é, assumindo-se que $V(1)$ é conhecido. 
Agora é possível proceder recursivamente. Usando $V(1)$ é possível calcular $B(1)$. Então a partir de (345) pode-se computar $v_{l}(2)$. Na sequência calcula-se $V(2)$ pelo uso da fórmula na forma:

$$
V^{(j)}(2)=V^{(j)}(1)\left(1+v^{(j)}(2) / 100\right),
$$

Onde $V^{(j)}(t)$ é o valor da $j$-ésima variável no ano $t$. Com $V(2)$ no lugar, pode-se calcular $B(2)$ e computar $v_{l}(3)$ e assim por diante.

\subsubsection{Investimento endógeno e solução recursiva}

$\mathrm{O}$ investimento depende das taxas de retorno. Como primeiro passo em direção a um modelo multiperiódico com investimento endógeno, adiciona-se às equações (341) e (342) a seguinte definição de taxa de retorno no ano $t+1$ sobre o capital na industria $j$ :

$$
R_{j}(t+1)=\frac{Q(t+1) /(1+r)-\Pi_{j}(t)+\Pi_{j}(t+1)\left(1+D_{j}\right) /(1+r)}{\Pi_{j}(t)},
$$

para todo $j$ e para $t=1, \ldots, T-1$.

Onde $r$ é a taxa de juros, que será tratada como um parâmetro. Nesta definição, assumese que um montante gasto de $\Pi_{j}(t)$ no ano $t$ compra uma unidade de capital pronta para uso no ano $t+1$. Esta unidade ganha um aluguel no ano $t+1$ de $Q_{j}(t+1)$. A unidade de capital deprecia-se a uma taxa $D_{j}$ e pode ser vendida no ano $t+1$ por $\Pi_{j}(t+1)\left(1-D_{j}\right)$. Ou seja, $R j(t+1)$ é o valor presente no ano $t$ do investimento de um real na indústria $j$. A seguir é acrescentada a equação

$$
K_{j}(t) / K_{j}(t-1)=F_{k}(t) F_{k j}(t)\left(1+R_{j}^{e}(t, t+1)\right)^{\alpha j},
$$

para todo $j$ e para $t=1, \ldots, T$.

Ou seja, assume-se que a taxa de crescimento do capital através do ano $t$ depende positivamente $\left(\alpha_{j}>0\right)$ da taxa de retorno esperada no ano $t$ para aplicar no ano $t+1$. As duas variáveis $F$ na equação (346) são termos de deslocamento que podem ser usados de várias formas. Por exemplo, poderia ser definido que

$$
F_{k j}(t)=(1+\operatorname{lrrg}(j) / 100) /(1+\mathrm{NRR}(j))^{\alpha j}
$$

Onde $\operatorname{lrrg}(j)$ é a taxa de crescimento do capital na indústria/setor $j$ de tendência de longo prazo e $\mathrm{NRR}(j)$ é a taxa de retorno normal de $j . F_{k}$ poderia ser usado para simular os 
efeitos de um variação geral (não especifica de uma indústria/setor) em nível de confiança de negócio. Se $F_{k}$ é definido igual a 1 e $R_{j}^{e}(t, t+1)$ igual a $\operatorname{NRR}(j)$, então sob (347) o crescimento do capital na indústria/setor $j$ será, no ano $t$, na sua taxa de tendência de longo prazo.

Uma teoria de taxa de retorno esperada é de expectativas estáticas. Isto significa que

$$
R_{j}^{e}(t, t+1)=\frac{Q_{j}(t)}{\Pi_{j}(t)} \frac{(1+\inf )}{1+r}-1+\frac{(1+\inf )\left(1-D_{j}\right)}{1+r}
$$

para todo $j$ e para $t=1, \ldots, T$,

onde inf e a taxa de inflação. Derivando (347), é possível escrever a fórmula para $\mathrm{Rj}(\mathrm{t}+1)$ com variáveis de aluguel e preços para o ano $t+1$ substituídos pelos seus níveis em $t$ multiplicados por (1+inf). Ou seja, assume-se que as expectativas considerando ano $t+1$ são formadas no ano $t$ pelo deflacionamento de todas as variáveis nominais pela taxa geral de inflação. Assumindo-se que $r=$ inf, é possível simplificar (347) obtendo-se

$$
R_{j}^{e}(t, t+1)=\left(Q j(t) / \Pi_{j}(t)\right)-D_{j}
$$

para todo $\mathrm{j}$ e para $\mathrm{t}=1, \ldots, \mathrm{T}$.

Uma vantagem da pressuposição de expectativas tais como (347) ou (348) é que estes nos fornecem um modelo com investimento endógeno enquanto ainda permite-se resolver recursivamente, aplicando a técnica de Johansen/Euler. Para demonstrar isto, adiciona-se ao sistema Johansen/Euler (343) o seguinte

$$
\begin{aligned}
& k_{j}(t+1)-k_{j}(t)= \\
& \quad f_{k}(t+1)+f_{k j}(t+1)+\alpha_{j}\left(Q_{j}(t) /\left(Q_{j}(t)+\left(1-D_{j}\right) \Pi_{j}(t)\right)\right)\left(q_{j}(t+1)-\pi_{j}(t+1)\right),
\end{aligned}
$$

para todo $j$ e para $t=1, \ldots, T-1$

e

$$
K_{j}(t) k_{j}(t+1)=\left(1-D_{j}\right) K_{j}(t-1) k_{j}(t)+I_{j}(t) i_{j}(t+1),
$$

para todo $j$ e para $t=1, \ldots, T-1$.

Equação (349) é a versão variação percentual de (346) incorporando (348) e a equação (350) é a versão variação percentual de (341). Neste sistema de Johansen/Euler expandido, as variáveis são $\tilde{v}_{1}(t+1), \tilde{v}_{2}(t+1), q(t+1), \pi(t+1)$ para $t=1, \ldots, T$-1, e $k(t+1)$ 
para $t=0, \ldots, T-1$. Todos estes são vetores de taxas de crescimento conectando os anos $t \mathrm{e}$ $t+1$.

Para $\mathrm{t}=1$, a adição de (349) e (350) expande o sistema original, (341) de $2 h$ equações onde $h$ é o número de indústrias/setores. O sistema espandido para $t=1$ também contém $2 h+1$ novas variáveis: $k_{j}(2), f_{k j}(2)$ e $f_{k}(2)$. Assumindo que os $f$ s são definidos exogenamente, $\mathrm{o}$ sistema expandido para $\mathrm{t}=1$ pode agora determinar taxas de crescimento para $h$ variáveis exógenas anteriormente: $i_{j}(2)$ para $j=1, \ldots, h$. Depois de resolver o sistema expandido em $t=1$, pode-se como antes, computar $V(2)$. Então podese definir $t=2$ e resolver o sistema expandido para taxas de crescimento nas variáveis endógenas para o ano 3 e assim por diante.

\subsection{Equações auxiliares para simulação ano a ano}

Os modeladores AEG têm trabalhado na incorporação de novas teorias de investimento. Norén (1998) destaca a importância da transformação industrial numa economia aberta e propõe que, dado o modelo "vintage" de investimento, o investimento seja tratado endogenamente de modo que se consiga captar o desmantelamento ou não do estoque de capital em nível setorial. Mesmo em modelos de insumo-produto econométrico, como discute Israilevich (2002), também existe o problema do tratamento do comportamento do investimento em nível setorial. Ou seja como o investimento é alocado nos diferentes setores e ao longo do tempo. $\mathrm{O}$ autor propõe o uso de um modelo translog interindustrial para modelar a distribuição e alocação do capital entre os setores de uma economia. Piazolo (2001) discute um aspecto muito interessante para os modelos AEG desenvolvidos para os países em transição econômica. Este autor questiona a pressuposição de que os dados do ano base representem as características estruturais estável ou mesmo o "steady state" de uma economia. Ele também propõe que a formulação do custo de instalação do capital seja estendido com a inclusão dos custos de ajustamento que dependem da variação do nível de investimento. Tais mudanças dentro de um modelo AEG dinâmico levariam a um comportamento do investimento que refletisse os dados empíricos dos primeiros anos de 
transição. Ou seja, quanto maior a variação do nível de investimento menor é o custo de instalação do capital.

Tendo em vista a dificuldade do tratamento do investimento nos modelos aplicados de equilíbrio geral, as modificações no módulo de investimento do modelo MIBRA foi baseado em Adams et al. (2001) que explica a abordagem do investimento endógeno aplicado no modelo MMRF-GREEN. Na sequência são apresentadas as equações novas incorporadas no modelo MIBRA tal como é utilizado no TABLO (ver Anexo). Esta apresentação é interessante pois existem alguns detalhes sobre a modelagem do investimento que não são explícitos na teoria apresentada anteriormente.

\subsubsection{Taxa de retorno e investimento}

MMRF pode ser rodado de dois modos:

- Estática comparativa e

- Dinâmica ano a ano.

Estes modos requerem tratamentos alternativos da formação de capital.

No modo de estática comparativa, não existe relação fixa entre capital e investimento. O usuário decide a requerida relação baseada nos requerimentos da simulação específica. Freqüentemente é assumido que as variações percentuais no capital e no investimento são iguais, implicando que

$$
c a p_{-} t(j, q)=y(j, q) \quad j \in \operatorname{IND} q \in \text { REGDEST }
$$

Na dinâmica ano a ano, interpreta-se uma solução de modelo como um vetor de variações de variáveis entre dois anos adjacentes. Portanto, existe uma relação fixa entre capital e investimento. Capital disponível para produção no ano de solução $t$ é o estoque de capital no início do ano $t$. Isto é determinado pelo investimento no ano $t$-1 e pelo capital no início do ano $t$-1 após depreciação. Crescimento no capital entre o início e final de $t$ é determinado no modelo via mecanismo de taxas de retorno esperadas. Isto coloca no lugar o investimento para o ano $t$. Capital no final do ano $t$ é o capital disponível para produção no ano $t+1$. 
A parte que se refere a investimento e taxa de retorno no TABLO (Anexo) contém as equações que definem as atuais taxas de retorno sob expectativas estáticas, e equações que explicam investimento em simulações de estática comparativa.

\section{a) Taxas de retorno pós-imposto (E_del_eror)}

A equação E_del_ror explica a variação ordinária na atual taxa de retorno sobre o capital no $j$-ésimo setor formado sob a pressuposição de expectativas estáticas (del_ror). Para explicar esta equação inicia-se com uma expressão para o valor presente $(P V)$ de aquisição no ano de solução corrente, ano $t$, uma unidade do capital físico para uso m setor $j$ e na região $q$.

$$
\begin{aligned}
& P V_{t}(j, q)= \\
& -\Pi_{t}(j, q)+\frac{\left[\left(1-T_{t+1}\right) \times Q_{t+q}(j, q)\right]+\left((1-D(j, q)) \times \Pi_{t+1}(j, q)\right)+\left\{T_{t+q} \times D(j, q) \times \Pi_{t+1}(j, q)\right\}}{\left(1+I N T_{t} \times\left(1-T_{t+1}\right)\right)} \\
& j \in \text { IND } q \in \text { REGDEST }
\end{aligned}
$$

onde:

$\Pi_{t} \quad$ é o custo de comprar ou construir uma unidade de capital do setor $j$ no ano $t$;

$T_{t} \quad$ é a taxa de imposto de renda jurídica no ano $t$;

$Q_{t} \quad$ é a taxa de aluguel para o capital do setor $j$ no ano $t$ (equivalente ao custo do uso de uma unidade de capital no ano $t$ );

$D \quad$ é a taxa de depreciação (número como 0,05) e;

$I N T_{t}$ é a taxa de juros nominal no ano $t$.

Assume-se que unidades do capital no ano t produzem para o seu proprietário três benefícios no ano $t+1$ : um aluguel pós-imposto (o termo entre os colchetes), um valor de revenda depreciado (o termo entre parênteses) e uma dedução de imposto (o termo entre as chaves). Estes benefícios são convertidos para o valor presente no ano $t$ descontando a taxa de juros nominal pós-imposto. 
A soma dos valores presentes dos benefícios definidos anteriormente é convertida para uma taxa de retorno dividido pelo custo de comprar capital no ano $t$. Então define-se

$$
\begin{aligned}
& R_{-} R_{-} A C T_{t}(j, q)= \\
& -1+\frac{\left[\left(1-T_{t+1}\right) \times Q_{t+1}(j, q)\right]+\left((1-D(j, q)) \times \Pi_{t+1}(j, q)\right)+\left\{T_{t+1} \times D(j, q) \times \Pi_{t+1}(j, q)\right\}}{\Pi_{t}(j, q)\left(1+I N T_{t} \times\left(1-T_{t+1}\right)\right)} \\
& j \in \text { IND } q \in \text { REGDEST }
\end{aligned}
$$

para ser a atual taxa de retorno no ano t para unidades de capital investido no setor $j$.

Para esta pesquisa está sendo considerada a restrição de expectativas estáticas. Isto significa que os investidores não esperam qualquer mudança na taxa de impostos e esperam que as taxas de aluguel e os preços dos ativos aumentem uniformemente pela corrente taxa de inflação $(I N F)$. Assume-se também que os investidores esperam taxas de juros pós-imposto real igual a zero, deixando a taxa de juros pós-impostos igual a inflação $(I N F)$. Sob estas pressuposições, a expectativa estática de $R O R \_A C T$ é

$$
\operatorname{ROR}_{t}(j, q)=\left(1-T_{t}\right) \times\left\{\frac{Q_{t}(j, q)}{\Pi_{t}(j, q)}-D(j, q)\right\} \quad j \in \operatorname{IND} q \in \operatorname{REGDEST}
$$

E_del_ror é a forma em taxa de crescimento de (352). O mapa entre a notações utilizadas no TABLO (Anexo) em (352) é apresentado a seguir.

del_ror é a variação ordinária em $R O R$;

plcap é a variação em variação percentual em $Q$;

$p i$ é a variação percentual em $\Pi$;

$r k$ é a variação percentual em $T$;

CTAXR é o equivalente a $T$;

CAPITAL/VCAP é equivalente a $Q / \Pi$ e;

$D E P R$ é equivalente a $D$. 


\section{b) Equação da taxa de retorno pós-imposto média regional (E_del_ror_tot)}

Esta equação define as variações ordinárias na taxa de retorno média para cada região $q$ como uma média ponderada das variações ordinárias nas taxas de retorno para os setores em $q$.

\section{c) Distribuição de taxas de retorno pós-imposto nas simulações de estática comparativa de longo prazo (E_del_f_ror)}

Esta equação não tem papel nas simulações ano a ano e pode ser desativada através da endogeneização da variável de deslocamento del_f_ror. Quando ativada nas simulações de estática comparativa de longo prazo, a equação permite que variações nas taxas de retorno setoriais sejam positivamente correlacionadas com variações nos estoques de capital setorial. Setores que percebem um crescimento do capital relativamente forte (indicado por um valor alto e positivo para $c a p_{-} t(j, q)-k t(q)$ ) irão requerer aumentos relativamente grandes nas taxas de retorno ( indicado por um valor alto e positivo para del_ror(j,q)-del_nat_ror). Inversamente, setores percebendo fraco crescimento do capital irão requerer aumentos menores ou até diminuições nas taxas de retorno. A equação poderia ser interpretada como uma relação de risco com crescimento relativamente rápido ou lento dos setores requerendo prêmio ou desconto nas suas respectivas taxas de retorno. $\mathrm{O}$ parâmetro $B E T A \_R$ especifica a força desta relação.

\section{d) Equações do investimento real total (E_naty) e razões de investimento e capital $\left(\mathbf{E} \_\mathbf{y}\right)$}

As duas últimas equações do módulo de investimento e taxa de retorno no TABLO, define a variação percentual no investimento para o setor $j$ e a variação percentual na razão de investimento e capital para o setor $j$ e à região $q$. Várias variáveis de deslocamento são incluídas na equação E_y para permitir deslocamentos nas razões entre investimento e capital. Estas podem ser específicas ao setor e região $\left(r \_i n v_{-} c a p_{-} j q\right)$, específica somente à região $\left(r_{-} i n v_{-} c a p \_q\right)$, específica somente ao setor $\left(r_{-} i n v_{-} c a p_{-} j\right)$ ou não específica a qualquer setor ou região $\left(r_{-} i n v_{-} c a p\right)$. 
E_y é especialmente útil nos experimentos de estática comparativa de longo prazo, nas quais tipicamente assume-se que:

a) o estoque de capital agregado ajusta-se para preservar uma taxa de retorno para toda a economia determinada exogenamente $\left(R O R \_T O T\right)$;

b) a alocação do capital entre os setores regionais ajusta-se para satisfazer as relações especificadas exogenamente entre taxas de retorno relativos e crescimento relativo do capital (veja equação E_del_f_ror);

c) demandas setoriais por bens de investimento são determinadas pela razão entre investimento e capital especificada exogenamente (veja equação (351)).

\subsubsection{Equações de simulação ano a ano: investimento e capital, investimento e taxas de retorno esperadas}

As equações que se encontram no módulo de simulação ano a ano do TABLO são essenciais para as simulações dinâmicas traçando o caminho para as variáveis ao longo de vários anos. Existem dois conjuntos de equações:

a) equações descrevendo a relação entre capital e investimento, e entre crescimento do capital e taxas de retorno esperadas (assume-se expectativas estáticas) e;

b) equações que permitem, nas simulações de políticas, ano a ano, salários reais serem fixos no curto prazo e flexíveis no longo prazo.

Nas simulações ano a ano, o capital disponível para a produção no corrente ano de previsão (ano $t$ ) é dado pelas condições iniciais, com taxa de retorno no ano $t$ ajustando para acomodar o dado choque de capital. Equações são introduzidas para permitir variação percentual no capital disponível para a produção no ano $t$ (ou seja, variação percentual no início do ano $t$ ) para ser determinado dentro do modelo. São também especificadas as funções de oferta de capital que determinam as taxas de crescimento do capital setorial ao longo do ano $t$ (e também do investimento no ano $t$ ). As funções especificam que investidores querem ofertar quantidades maiores para o setor $j$ em resposta aos aumentos na $j$-ésima taxa de retorno esperada (são assumidas 
expectativas estáticas). Entretanto, investidores são cautelosos. Em qualquer ano, as funções de oferta de capital limitam o crescimento no estoque de capital do $j$-ésimo setor de modo que perturbação na $j$-ésima taxa de retorno seja eliminada somente gradualmente.

\section{a) Choques para iniciar capital nas simulações ano a ano (E_del_f_cap_t)}

Nas simulações ano a ano, capital disponível para a produção na solução do ano $t$, é o estoque de capital existindo no início do ano, ou no final do ano anterior, ano $t-1$. Denota-se este estoque de capital como $Q C A P$. A correspondente variável de variação percentual é curcap.

O valor apropriado para curcap em um cálculo ano a ano é a taxa de crescimento do capital entre o início do ano $t-1$ e o início do ano $t$. Algebricamente, utilizando a notação que enfatiza a duração de cada variável tem-se

$$
\operatorname{curcap}_{t}(j, q)=100 \times\left(\frac{Q C A P_{t}(j, q)}{\operatorname{QCAP}_{t-1}(j, q)}-1\right) \quad j \in \operatorname{IND} q \in \operatorname{REGDEST}
$$

onde $\operatorname{QCAP}_{t}(j, q)$ é a quantidade de capital disponível para produção no setor $j$ na região $q$ no início do ano da solução corrente $t$. Equação (353) podem ser rescritos como

$$
\begin{gathered}
\operatorname{curcap}_{t}(j, q)=100 \times\left(\frac{Q I N V_{t-1}(j, q)-D E P R(j, q) \times Q C A P_{t-1}(j, q)}{Q C A P_{t-1}(j, q)}\right) \\
j \in \operatorname{IND} q \in \operatorname{REGDEST}(354),
\end{gathered}
$$

onde $\operatorname{QINV}_{t-1}(j, q)$ é a quantidade de investimento no setor $j$ no ano $t-1$ e $D E P R$ é um parâmetro fixo representando a taxa de depreciação do capital para o setor $i$.

Fazendo o cálculo para o ano $t$, poder-se-ia tratar $\operatorname{curcap}_{t}(i)$ como uma variável exógena e calcular seus valores fora do modelo de acordo com a equação (354). É mais 
conveniente, entretanto, para computar valores para $\operatorname{curcap}_{t}(i)$ dentro do modelo. Isto é feito usando a equação E_del_f_cap_t.

Para entender a forma em nível de E_del_f_cap_t, inicia-se reescrevendo (354) como:

$$
\begin{aligned}
& Q C A P_{t}(j, q)-Q C A P_{t-1}(j, q)= \\
& \quad 100 \times\left(Q I N V_{t-1}(j, q)-\operatorname{DEPR}(j, q) \times Q C A P_{t-1}(j, q)\right)
\end{aligned}
$$

$$
j \in \text { IND } q \in \text { REGDEST }
$$

Nas simulações ano a ano é desejável que a solução inicial para o ano $t$ reflita valores para o ano $t$-1, uma vez que as mudanças simuladas são provenientes do ano $t-1$ para o ano $t$. Se isto é o caso, então o valor inicial de $Q C A P_{t}(i)$ é $Q C A P_{t-1}(i)$. O método de solução Euler requer que os valores iniciais (banco de dados) para variáveis formem uma solução para a delinear as formas em nível do modelo. A equação (355) torna isto claro a menos que o investimento líquido no ano $t$-1 seja zero no setor $j$. Neste caso o dado inicial para os cálculos do ano $t$ não será uma solução para (355).

Este problema de valor inicial é resolvido por uma saída puramente técnica de aumentar a equação (355) com uma variável exógena adicional UNITY como segue:

$$
\begin{aligned}
& Q C A P_{t}(j, q)-Q C A P_{t-1}(j, q)= \\
& \qquad N I T Y \times 100 \times\left(Q I N V_{t-1}(j, q)-\operatorname{DEPR}(j, q) \times Q C A P_{t-1}(j, q)\right) \\
& j \in \text { IND } q \in \text { REGDEST }
\end{aligned}
$$

Escolhe o valor inicial de UNITY como zero, de modo que (355) é satisfeita quando $Q C A P_{t}(i)$ toma o seu valor inicial desconsiderando o valor inicial de investimento líquido no setor $j$. A variável UNITY é geralmente referida como um fator "fudge", enquanto outros chamam de parâmetro homotópico. Mudando o valor de UNITY para um, permite-se o correto desvio na abertura do estoque de capital para o ano $t$ a partir do seu valor inicial na solução inicial, ou seja, o seu valor no ano $t-1$. 
A equação E_del_f_cap_t do TABLO é a versão em taxas de crescimento de (356), depois de modificada em termos de notação. No lado direito da igualdade, os coeficientes $Q I N V @ 1(j, q)$ e $Q C A P @ 1(j, q)$ são as versões em nível de $\operatorname{QINV}(j, q)$ e QCAP $(\mathrm{j}, \mathrm{q})$ na solução inicial para o ano $t$. Definido que a solução inicial é delineada a partir dos valores para o ano $t$-1, então $Q I N V @ 1(j, q)$ corresponde a $\operatorname{QINV}_{t-1}(j, q)$ em (356) e $Q C A P @ 1(j, q)$ a $Q C A P_{t-1}(j, q)$. A variável del_unity é variação ordinária de UNITY. Nas simulações ano a ano, del_unity é sempre definido igual a um. A variável del_f_cap_t $(j, q)$ é uma variável de deslocamento que pode ser desativada ou ativada. Nas simulações ano a ano esta variável será exógena fazendo com que $\operatorname{curcap}(j, q)$ seja definido de acordo com a equação (356). Nas simulações de estática comparativa, $d e l \_f \_c a p \_t(j, q)$ será endógena, desligando efetivamente E_del_f_cap_t para o setor $j$. Deixando del_f_cap_t $(j, q)$ endógena permitir-se-á que uma das taxas de retorno ou estoque de capital no setor $j$ seja exógena.

\section{b) Capital disponível no ano $t+1$ relacionada ao investimento no ano $t$ (E_cap_t1)}

A equação E_capt_t1 no TABLO explica a variação percentual no estoque de capital do setor $j$ na região $q$ no final do ano de solução. A versão em nível desta equação é:

$Q C A P_{-} T 1_{t}(j, q)=Q I N V_{t}(j, q)+(1-D E P R(j, q)) \times Q C A P_{-} T_{t}(j, q)$

$$
j \in \operatorname{IND} q \in \operatorname{REGDEST}(357) \text {. }
$$

onde $Q C A P_{-} T 1_{t}(j, q)$ é o estoque de capital no setor $j$ e na região $q$ no final do ano $t$ (ou no início do ano $t+1$ ). Note que a equação (357) é satisfeita pela solução inicial para o ano $t$, e assim não existe a necessidade de introduzir a variável homotópica.

Tomando as variações ordinárias de (357) tem-se, após tirar o índice tempo, a equação E_cap_t1. 


\section{c) Crescimento do capital entre o início e o final do ano de solução (E_del_k_gr)}

Nas simulações ano a ano, crescimento no capital entre o início e o final do ano é determinado pela taxas de retorno esperada sobre o capital $I$. Esta relação é modelada abaixo. Aqui é definido o nível da taxa de crescimento do capital para o setor $i$,

$$
K_{-} G R_{t}(j, q)=\frac{Q C A P_{-} T 1_{t}(j, q)}{Q C A P_{-} T_{t}(j, q)}-1 \quad j \in \operatorname{IND} q \in \text { REGDEST },
$$

e na equação E_del_k_gr explica a variação em que a taxa de crescimento em termos de variação percentual das variáveis $\operatorname{curcap}(j, q)$ e $\operatorname{cap} \_t l(j, q)$.

\section{d) Taxa de retorno esperada igual à taxa de retorno de equilíbrio esperada mais o desequilíbrio da taxa de retorno esperado (E_del_eeqror)}

Assume-se que a expectativa mantida no período t pelos proprietários do capital no $j$ ésimo setor para a taxa de retorno do $j$-ésimo setor no período $t+1$ pode ser separado em duas partes. Uma parte é chamada de taxa de retorno de equilíbrio esperada. Esta parte é a taxa de retorno esperada requerida para sustentar indefinidamente a corrente taxa de crescimento do capital no setor $j$. A segunda parte é uma medida de desequilíbrio na $j$ ésima taxa de retorno esperada. Em termos de notação do TABLO,

$$
\operatorname{EROR}(j, q)=\operatorname{EEQROR}(j, q)+\operatorname{DISEQROR}(j, q) \quad j \in \operatorname{IND} q \in \operatorname{REGDEST}
$$

onde $\operatorname{EROR}(j, q), \operatorname{EEQROR}(j, q)$ e $\operatorname{DISEQROR}(j, q)$ são os níveis no ano $t$ da taxa de retorno esperada, a taxa de retorno de equilíbrio esperada e o desequilíbrio na taxa de retorno esperada. E_del_eeqror é a versão em variação percentual de (358).

\section{e) E_f_eeqror_jq}

A teoria de investimento nas simulações ano a ano associa a taxa de retorno de equilíbrio esperada para o setor $j(\operatorname{EEQROR}(j, q))$ com a taxa de crescimento corrente do capital no setor $j\left(\mathrm{~K}_{-} G R(j, q)\right)$. Como mostra na Figura 16, a relação tem uma forma logística inversa que a seguinte forma algébrica: 
$\operatorname{EEQROR}(j, q)=R O R N(j, q)+F_{-} \operatorname{EEQROR}(j, q)+$

$$
\frac{1}{C A P \_S L O P E(j, q)} \times\{
$$

$\left[\log \left(K_{-} G R(j, q)-K_{-} G R_{-} M I N(j, q)\right) \quad-\log \left(K_{-} G R \_M A X(j, q)-K_{-} G R(j, q)\right)\right]-$

$\left[\log \left(T R E N D \_K(j, q)-K \_G R \_M I N(j, q)\right)-\log \left(K_{-} G R \_M A X(j, q)-T R E N D \_K(j, q)\right)\right]$

$$
\text { \} }
$$

$j \in \mathrm{IND} q \in \mathrm{REGDEST}$

onde:

RORN é um coeficiente representando a taxa de retorno historicamente normal do setor; F_EEQROR permite deslocamentos verticais na curva de oferta de capital (no TABLO, existem três variáveis de deslocamento permitindo movimentos em nível nacional, movimentos em nível regional e movimentos em nível regional e setorial);

CAP_SLOPE é um coeficiente correlacionado com a inversa da inclinação da curva de oferta de capital (Figure 4.12) na região em que $K \_G R=T R E N D \_K$;

K_GR_MIN é um coeficiente que define a taxa de crescimento mínimo possível do capital;

$K \_G R \_M A X$ é um coeficiente que define a taxa de cresimento máximo possível do capital e;

TREND_K é um coeficiente que define a taxa de crescimento do capital historicamente normal para os setores.

Suponha que $F_{\_} E E Q R O R$ e DISEQROR são inicialmente igual a zero. De acordo com (359) e (358), para um setor atrair investimento suficiente no ano $t$ para atingir a taxa de crescimento do capital de TREND_K é necessário ter uma taxa de retorno esperada igual a sua média de longo prazo $(R O R N)$. Para o setor atrair investimento suficiente no ano $t$ para que o seu crescimento de capital exceda a sua média de longo prazo (TREND_K), sua taxa de retorno esperada deve ser maior que RORN. 
Inversamente, se a taxa de retorno esperada para o capital do setor cai abaixo de $R O R N$, então os investidores restringirão as suas oferta de capital para o setor para um nível abaixo do requerido para manter o crescimento do capital na taxa TREND_K. A versão em taxas de crescimento de (359) é E_f_eeqror_jq.

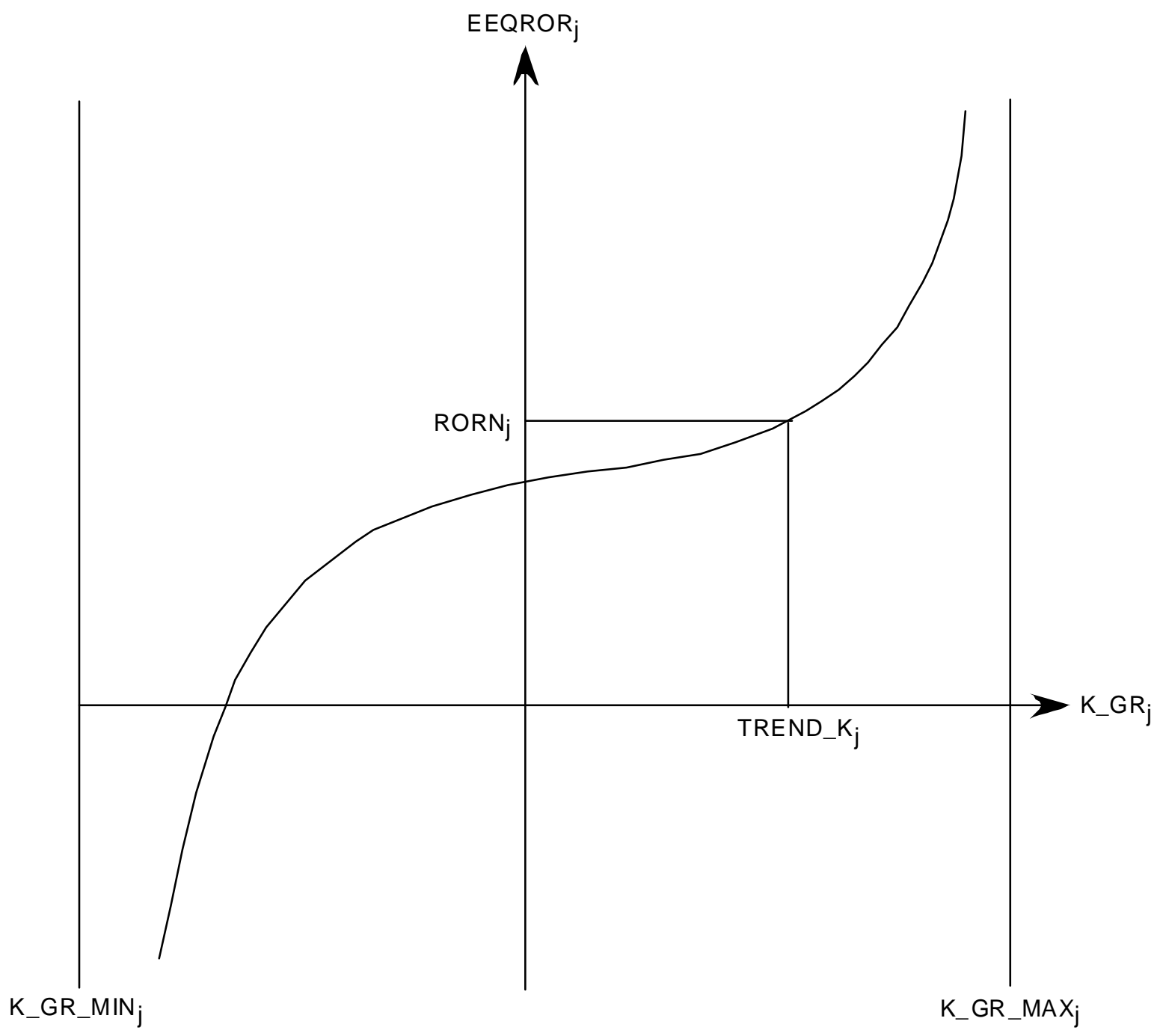

Figura 16 - O esquema da taxa de retorno esperada de equilíbrio para o setor $j$.

f) Ajustamento do desequilíbrio na taxa de retorno esperada tendendo a zero (E_del_diseqror)

O desequilíbrio inicial na taxa de retorno esperada (DISEQROR) é gradualmente eliminado ao longo do tempo seguindo a seguinte regra: 
$\operatorname{DISEQROR}(j, q)-\operatorname{DISEQROR} @ 1(j, q)=$

$-A D J \_C O E F F(j, q) \times D I S E Q R O R @ 1(j, q) \times U N I T Y$

$j \in \operatorname{IND} q \in$ REGDEST (360),

onde DISEQROR@1 é o valor inicial de DISEQROR na simulação para o ano $t$, e $A D J \_C O E F F$ é um parâmetro positivo (menor que um) determinando a velocidade com a qual DISEQROR move-se para zero. E_del_diseqror é a versão em taxas de crescimento de (360).

g) Taxa de retorno esperada igual a atual taxa de retorno sob expectativas estáticas (E_del_ror)

Esta equação garante a regra de que a taxa de retorno esperada sobre o capital no setor $j$ da região $q$ no ano $t$ seja igual a atual taxa de retorno do setor $j$ no ano $t$, sob as expectativas estáticas (veja equação (352)).

\subsubsection{Equações miscelâneas para facilitar as simulações ano a ano}

A última parte do TABLO contém as equações que são utilizadas para facilitar as simulações ano a ano.

\section{a) Manuseio flexível das variáveis twist (E_ftwist_src e E_ftwist_lk)}

Estas equações permitem o manuseio flexível das variáveis $t w i s t, t w i s t \_s r c(i, q)$ e twist_lk(i,q). Usando a equação E_ftwist_src, por exemplo, é possível impor uma mudança uniforme nas preferências da economia entre importados e domésticos para todas as mercadorias. Isto é feito deixando ftwist_twist $(i, q)$ endógena para todo $i$ e $q$ e aplicando choque uniforme em nattwist_src.

Equações deste tipo são muito úteis nas simulações de previsão. Na previsão, são necessários instrumentos que permitam exogeneizar o volume agregado de importações, 
emprego agregado e taxa de salário real. E_ftwist_src e E_ftwist_lk fornecem estes instrumentos na forma de nattwist_src e nattwist_lk. Para fixar, por exemplo, a taxa de salário real quando o emprego também é exógeno, ativa-se o mecanismo ftwist_lk e então troca-se nattwist_lk pela taxa de salário real nacional. Com este fechamento, o modelo determina a substituição necessária entre trabalho e capital que é necessário para reconciliar a definição exógena em nível nacional para emprego e taxa de salário real simultaneamente.

b) Manuseio flexível das variações tecnológicas e propensão média a consumo fora

da renda disponível das famílias (E_a1prim_elim, E_f_a1primgen e E_f_miscf001)

Estas equações são também úteis para simulações de previsão. O primeiro é utilizado para isolar certos setores do deslocamento setorial geral nas variações tecnológicas de fatores primários, alprimgen $(q)$. Para isolar o setor $j$ na região $q$, exogeneiza-se alprim_elim $(j, q)$ endogeneizando $\operatorname{alprim}(j, q)$. Esta troca assegura que $\operatorname{alprim}(j, q)$ seja igual a menos $\operatorname{alprimgen}(q)$, assim isolando o setor $j$ de alprimgen.

A segunda e terceira equações permitem impor deslocamento em nível nacional nas variáveis regionais alprim e natmiscf001.

c) Variações no uso geral da i-ésima mercadoria em tecnologias setoriais (E_a1o a E_a4marg)

A variável $a c(i, q)$ permite mudanças gerais no uso da mercadoria $i$ nas tecnologias setoriais para a produção corrente e (se $i=r$ é uma margem) para variações no uso de margens.

Como pode ser visto nas equações E_a1o a E_a4marg, com as variáveis de deslocamento $f \_a l o(i, j, q)$ a agreen $(i, j, q)$ definido exogenamente iguais a zero, um valor de 1,0 para $a c(i, q)$ e para $a c(r, q)(r=i)$ provoca $1 \%$ de aumento nas variáveis para $a 1 o(i, j, q)$ a $a 4 \operatorname{marg}(s, r)$ entre todas as dimensões $s, j$ e $q$. 


\subsection{Dados e Calibração}

O banco de dados é um dos itens mais importantes para o desenvolvimento e aplicação de um modelo AEG. A estrutura do banco de dados é baseada em Peter et. al. (1996b) e os dados propriamente ditos, é baseado em Casimiro Filho (2000) e Cardoso et al. (2000). Por isso, o banco de dados foi construído com base na matriz de insumoproduto do ano de 1995; nos resultados de vários trabalhos da literatura; em estatísticas como as do Instituto Brasileiro de Geografia e Estatística (IBGE); e ainda com informações do Banco Central do Brasil e da Fundação Getúlio Vargas.

Para a estimação do banco de dados de insumo-produto, cuja estrutura é apresentada na Figura 17, foram utilizados dados das matrizes de insumo-produto construídas pelo IBGE para o ano de 1995 (IBGE, 1997), do sistema inter-regional de insumo-produto construído para o Brasil para o ano de 1995 por Guilhoto ${ }^{11}$ e vários censos do IBGE. Casimiro Filho et al. (2000) consideraram os seguintes agentes: indústrias, famílias (considerando uma família para cada região), governo (um nível de governo) e exportações. No atual banco de dados, Cardoso et al. (2000) desagregaram o governo em dois níveis: federal e regional. O governo regional engloba os estados e municípios. Cardoso et al. (2000) também incorporaram ao banco de dados construído por Casimiro Filho et al. (2000) as bases de dados referentes às finanças governamentais, relações de acumulação, população regional e mercado de trabalho.

Neste trabalho de pesquisa, além da incorporar informações solicitadas pelas novas equações de investimento do modelo MIBRA, foram realizados ajustes do banco de dados para eliminar inconsistências encontradas durante os processos de modificação do sistema de equações do modelo, de fechamento e simulação. As novas informações incorporadas são apresentadas na seção seguinte.

Como o modelo MIBRA é inter-regional, as cinco macro-regiões consideradas são: Norte, formado pelos estados do Amazonas, Pará, Tocantins, Rondônia, Amapá e Acre; Nordeste, formado pelos estados do Ceará, Maranhão, Piauí, Rio Grande do Norte, Paraíba, Alagoas, Sergipe, Pernambuco e Bahia; Sul, formado pelos estados de Santa

${ }^{11}$ GUILHOTO, J.J.M. (Universidade de São Paulo. Escola Superior de Agricultura "Luiz de Queiroz". Departamento de Economia, Administração e Sociologia). Comunicação Pessoal, 1998. 
Catarina, Paraná e Rio Grande do Sul; Sudeste, composta por Minas Gerais, Espírito Santo, Rio de Janeiro e São Paulo e; o Centro-Oeste, formada pelos estados de Mato Grosso, Mato Grosso do Sul, Goiás e o Distrito Federal.

Pelo fato da abordagem ser inter-regional, trabalhou-se com um número reduzido ${ }^{12}$ de setores (Tabela 10) para diminuir o total de equações e variáveis necessárias, facilitando, assim, os cálculos numéricos do modelo. Note que a matriz de insumo-produto do IBGE, sem agregação, para o ano de 1995, possui 42 setores. Desta forma, o banco de dados básico do presente trabalho está desagregado para cinco macrorregiões e 16 setores econômicos.

Tratando-se de uma matriz de absorção ${ }^{13}$, a Figura 17 ilustra a estrutura do modelo, sendo que as linhas mostram a estrutura de compras feitas pelos agentes identificados nas colunas.

O modelo considera seis regiões de origem de produtos: Norte, Nordeste, CentroOeste, Sudeste, Sul e importações. Como regiões de destino, o modelo considera as regiões Norte, Nordeste, Centro-Oeste, Sudeste e Sul.

Foram consideradas duas margens: a de comércio e a de transporte. Essas margens são consideradas variáveis-chave em estudos sobre diferenças de desenvolvimento regional, principalmente, as margens de transporte, que permitem análises mais detalhadas sobre o impacto da infra-estrutura de transporte sobre os setores da economia.

\footnotetext{
${ }^{12}$ Detalhes sobre a agregação da matriz podem ser encontrados em Casimiro Filho et al. (2000).

${ }^{13}$ Detalhes sobre a construção da matriz de absorção são apresentados em Casimiro Filho et al. (2000) e em Cardoso et al. (2000).
} 


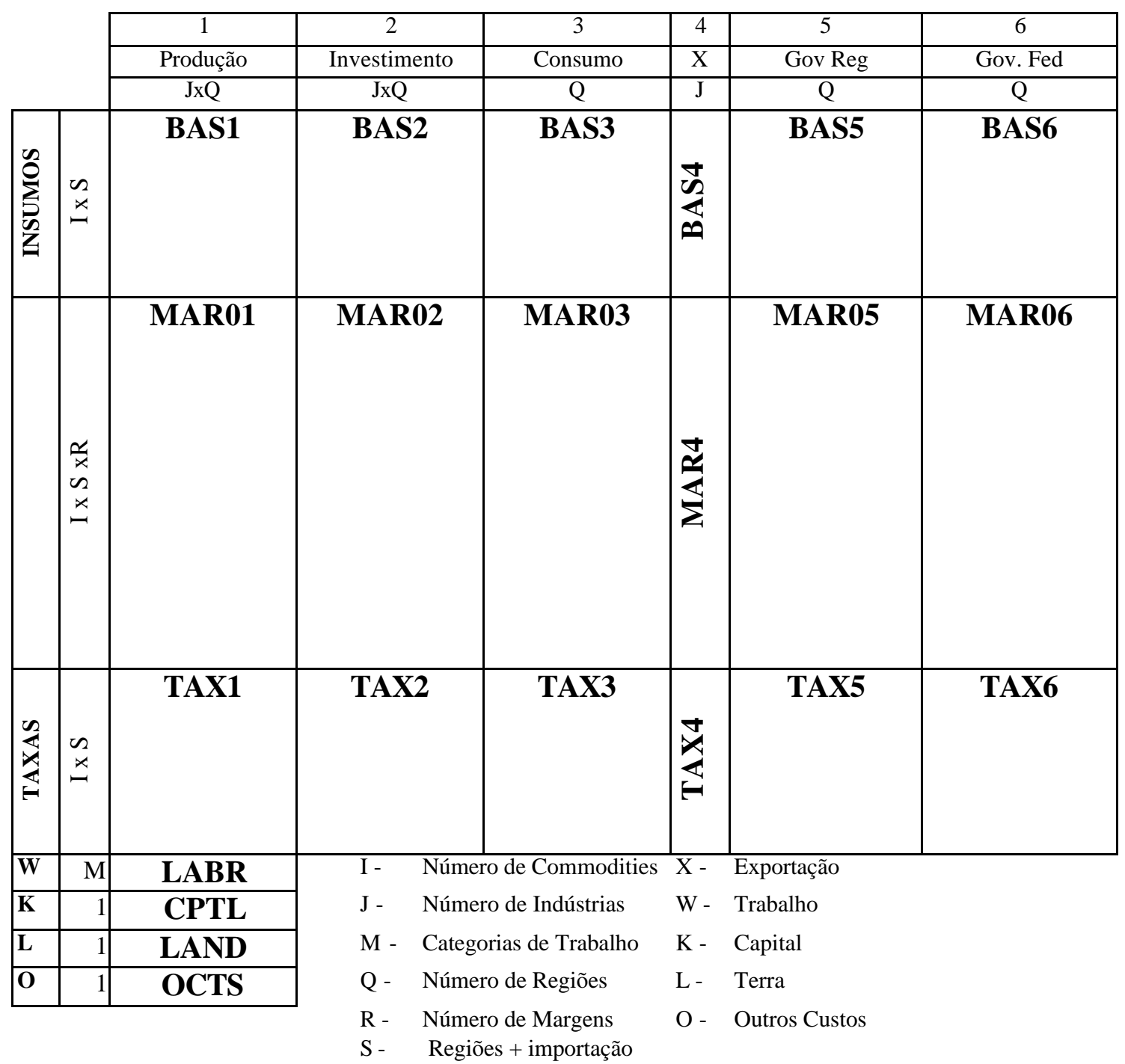

Figura 17 - Matriz de absorção do MIBRA. 
Tabela 10. Setores utilizados no MIBRA.

\begin{tabular}{rll}
\hline Número & Setores Agregados \\
\hline 1 & Agropecuária \\
3 & Mineração e Minerais não-metálicos \\
4 & Metalurgia \\
5 & Mecânica \\
6 & Material Elétrico \\
7 & Material de Transporte \\
8 & Madeira, Mobiliário, Celulose, Papel e Gráficos \\
9 & Químicos, Diversos, Farmacêutica \\
10 & Indústrias Têxtil, Vestuário e Calçados \\
11 & Produtos Alimentares \\
12 & Indústrias Diversas \\
13 & Serviço Ind. de Utilidade Pública ${ }^{1}$ e Comunicações \\
14 & Construção Civil \\
15 & Comércio \\
16 & Transportes \\
\hline
\end{tabular}

Fonte: Casimiro Filho et al. (2000)

${ }^{1}$ Água, energia e saneamento

No modelo, cada setor produz um único produto, cria um único capital e considera-se apenas uma categoria de trabalho.

As curvas de oferta e demanda dos produtos são determinadas a partir do "comportamento otimizador" dos agentes em mercados competitivos. Esse comportamento também determina as curvas de demanda por trabalho e capital. As decisões de produzir e consumir são função de variações nos preços, de modo que a solução de equilíbrio do modelo é do tipo walrasiano. 


\subsubsection{Complementação do banco de dados do modelo MIBRA}

Alguns coeficientes foram incluídos no banco de dados para permitir a inclusão das novas equações de investimento e de simulação ano a ano. As informações descritas na sequiência (Tabela 11) é a diferença básica entre o banco de dados do modelo MIBRA original e o modelo MIBRA com as novas equações de investimento e de simulação ano a ano.

Tabela 11. Relação das informações solicitadas pelas novas equações.

\begin{tabular}{|c|c|c|}
\hline Coeficiente novo & $\begin{array}{l}\text { Denominação no } \\
\text { banco de dados }\end{array}$ & Descrição \\
\hline CTAXR & TAXR & Alíquota do Imposto de Renda \\
\hline ADJC_COEFF & ADJC & $\begin{array}{l}\text { Velocidade de ajustamento do desequilíbrio na taxa de } \\
\text { retorno esperada tendendo a zero }\end{array}$ \\
\hline MURF_SLOPE & MURF & $\begin{array}{l}\text { Sensibilidade do modelo a crescimento do capital } \\
\text { diante de mudanças na taxa de retorno esperada de } \\
\text { equilíbrio. }\end{array}$ \\
\hline DIFF & DIFF & $\begin{array}{l}\text { Taxa de crescimento do capital máxima possível acima } \\
\text { de TREND_K }\end{array}$ \\
\hline F_EEQROR & FCSE & $\begin{array}{l}\text { Deslocador da taxa de retorno de equilíbrio esperada } \\
\text { em nível nacional }\end{array}$ \\
\hline F_EEQROR_Q & FSTQ & $\begin{array}{l}\text { Deslocador da taxa de retorno de equilíbrio esperada } \\
\text { em nível regional }\end{array}$ \\
\hline F_EEQROR_QJ & FSTA & $\begin{array}{l}\text { Deslocador da taxa de retorno de equilíbrio esperada } \\
\text { em níveis regional e setorial }\end{array}$ \\
\hline PINV & PINV & É o preço do investimento \\
\hline QCAP & QCAP & $\begin{array}{l}\text { Quantidade de capital disponível para a produção no } \\
\text { ano T }\end{array}$ \\
\hline RORN & RORN & Taxa de retorno após imposto \\
\hline TREND_K & TRND & Tendência do crescimento do capital \\
\hline
\end{tabular}

Fonte: Adaptado de Adams et al. (2001)

Utilizou-se o valor de 15\% para a alíquota do imposto de renda em nível nacional por ser o valor da faixa mais baixa tanto para pessoa física como para pessoa jurídica.

A taxa de depreciação nas novas equações não entra como fator de depreciação, mas apenas como a taxa propriamente dita. Portanto, diferentemente do modelo original, o valor do coeficiente da taxa de depreciação é 6,67\% para todos os setores.

Para a velocidade de ajustamento do desequilíbrio na taxa de retorno esperada tendendo a zero (ADJC) foi utilizado o mesmo valor do modelo MONASH em nível nacional que é de 0,5 . 
A sensibilidade do modelo de crescimento do capital a mudanças na taxa de retorno esperada de equilíbrio (MURF) tem o mesmo valor usado no modelo MONASH em nível nacional, que é de 0,114 .

Para a taxa de crescimento do capital máxima possível acima da tendência média de crescimento do capital (DIFF), o valor foi de 0,06, o mesmo utilizado pelo modelo MONASH em nível nacional.

Já para os deslocadores na taxa de retorno esperada (FCSE, FSTQ e FSTA), foram considerados valores pequenos, na grandeza de 0,01 , a semelhança do modelo MONASH em nível nacional.

O valor do preço do investimento em níveis regional e setorial (PINV) foi definido utilizando-se, como referência, a taxa de juros SELIC que, de 1999 a 2002, variou em torno de $18 \%$.

Para os valores da taxa de retorno normal após os impostos (RORN), foram utilizadas como base as taxa de retorno usadas em Guilhoto (1995). Como havia apenas valores para os diferentes setores, considerou que as regiões têm as mesmas taxas de retorno após os impostos.

A tendência de crescimento do capital foi definida tomando-se como base a médias das variações anuais da formação bruta de capital fixo, que foi de 2,55\%.

\subsection{Linearização e a eliminação do seu erro}

Assim como o MONASH e o MONASH-MRF, o MIBRA pertence à classe dos modelos Johansen-Orani, que têm como características as equações estruturais na forma linear (mudanças percentuais) e os resultados são dados em taxas de crescimento.

A linearização dos modelos, segundo Dixon et al. (1992), é realizada a partir da derivação do sistema de equações representado pela eq. (361) e tem o objetivo de gerar um sistema de equações no qual as variações percentuais das variáveis são lineares e os parâmetros são parcelas de custos e vendas. Para tanto é fundamental que o sistema apresente uma solução inicial

$$
F\left(V^{*}\right)=F\left(V_{1}^{*}, V_{2}^{*}\right)=0
$$

Pela diferenciação total da eq. (361) obtém-se: 


$$
F_{1}\left(V^{*}\right) d V_{1}+F_{2}\left(V^{*}\right) d V_{2}=0
$$

onde,

$F_{l}\left(V^{*}\right)$ é a matriz dos coeficientes das variáveis endógenas mensuradas no ponto $V^{*}$, de dimensão $p \times m$;

$F_{2}\left(V^{*}\right)$ é a matriz dos coeficientes das variáveis exógenas mensuradas no ponto $V^{*}$, de dimensão $p \times(n-m)$;

$d V_{1}$ é o vetor das variações percentuais nas variáveis endógenas, de dimensão $m \times 1$; e $d V_{2}$ é o vetor das variações percentuais nas variáveis exógenas, de dimensão $(n-m) \times 1$. Resolvendo-se a eq. (362) para $d V_{1}$ e assumindo a não-singularidade de $F_{l}\left(V^{*}\right)$,tem-se:

$$
d V_{1}=\left[F_{1}^{-1}\left(V^{*}\right) F_{2}\left(V^{*}\right)\right] d V_{2}
$$

ou na forma da eq. (363)

$$
d V_{1}=B\left(V^{*}\right) d V_{2}
$$

onde,

$B\left(V^{*}\right)$ é uma matriz de elasticidades das variáveis endógenas em relação às variáveis exógenas.

De acordo com Dixon et al. (1992), na derivação das equações a partir das equações não-lineares, são usadas três regras:

a regra do produto:

$$
R=\beta P Q \Rightarrow r=p+q
$$

a regra da potência:

$$
R=\beta P^{\alpha} \Rightarrow r=\alpha p
$$

e a regra da soma:

$$
R=P+Q \Rightarrow r=p S_{p}+q S_{q}
$$

onde $r, p$ e $q$ são mudanças percentuais em $R, P$ e $Q$, respectivamente. $\alpha$ e $\beta$ são parâmetros e $S_{p}$ e $S_{q}$ são as parcelas de $P$ e $Q$ em $P+Q$, ou seja,

$$
S_{p}=\frac{P}{P+Q} \quad \text { e } \quad S_{q}=\frac{Q}{P+Q}
$$

Cada uma das regras apresentadas através das eq. (364), (365) e (366), é obtida pela diferenciação total da expressão em nível. Dixon et al. (1992) alertam para que, na 
aplicação das regras, não ocorra divisão por zero. Formas de mudanças percentuais e logarítmicas são incompatíveis com variável cujo valor inicial é zero. Para resolver esse problema, é recomendado trabalhar com variáveis transformadas.

De acordo com Peter et al. (1996a), escrever as equações na forma linear tem vantagens dos pontos de vista computacional e econômico. Tal característica permite a especificação de modelos detalhados sem incorrer em restrições computacionais. Além disso, o tamanho do sistema pode ser reduzido usando-se equações do modelo para substituir as variáveis que são de importância secundária no estudo em questão. Em sistemas lineares, é fácil trabalhar algebricamente as equações para obter formulação explícita para essas variáveis secundárias, uma vez que este processo de substituição é direto. A intuição econômica é relativamente transparente quando se comparam os sistemas lineares com os não-lineares. Além disso, ao interpretar os resultados do sistema linear, relações das participações ponderadas simples entre variáveis podem ser exploradas através de cálculos elaborados para revelar as relações-chave de causa e efeito responsáveis pelo resultado do estudo em questão.

O custo potencial do uso da representação linearizada é a presença de erros de linearização nos resultados do modelo quando a variação em relação à solução inicial, devido a um choque nas variáveis exógenas, é grande. Esses erros correspondem à diferença entre a variação percentual estimada e a variação verdadeira que ocorre nas equações na forma não linear. Ou seja, a solução dos modelos do tipo Johansen é, na verdade, uma aproximação do resultado verdadeiro. Os erros de linearização são tanto maiores quanto maiores forem os choques dados nas variáveis exógenas.

Os erros de linearização podem ser suavizados através de um procedimento de solução em vários passos, como os métodos numéricos Euler, Midpoint e Gragg. Nesse caso, os choques são segmentados em vários choques menores, sendo que, em cada passo, as equações linearizadas são resolvidas para esses choques menores. Por isso, após cada passo, um novo ponto de equilíbrio é obtido e a partir desse ponto uma nova estimação é realizada até que se atinja o equilíbrio final. 
A acurácia da solução é uma função positiva do número de passos aplicados, o que permite ao usuário do modelo definir o grau de acurácia através da escolha do número de passos na solução do sistema.

Porém, quanto maior o número de passos, maior é a necessidade de tempo de computação ou capacidade computacional para a solução do modelo. Por isso, a extrapolação dos resultados a partir de duas ou três simulações com diferentes números de passos aumenta a precisão dos resultados sem necessitar de um tempo maior de computação ou maior capacidade computacional. A extrapolação é feita através de uma média ponderada do resultado das simulações. Guilhoto (1995), que apresenta mais detalhes sobre os métodos de eliminação de erros, verificou que os métodos Euler, Gragg e Midpoint não diferem muito entre si, sendo que o método Gragg tende a ser o mais preciso. Além disso, o autor recomenda a utilização do método Gragg com extrapolação dos resultados nos passos 2,4 e 6.

No trabalho de calibração e simulação do modelo MIBRA com as novas equações de investimento, foi utilizado incialmente o método de solução Johansen em 1 passo e as simulações definitivas com o método Gragg com extrapolação dos resultados nos passos 2, 4 e 6. A vantagem de usar o método Johansen em um passo na etapa inicial do processo de calibração e simulação é a rapidez das simulações, apesar da menor acuracidade dos resultados.

\subsection{Fechamento}

Uma das etapas mais importantes da construção de um modelo AEG é o fechamento. De acordo com Horridge et al. (1998), as equações dos modelos AEG são representadas como:

$$
F\left(V_{1}, V_{2}\right)=0
$$

onde,

$V_{l}$ é um vetor com $m$ variáveis endógenas;

$V_{2}$ é um vetor com $n-m$ variáveis exógenas; e

$F$ é um sistema com $p$ funções não lineares diferenciáveis. 
Como um modelo AEG geralmente apresenta um número maior de variáveis do que equações, é necessário definir quais variáveis devem ser exógenas e quais devem ser endógenas para que o número de variáveis endógenas seja igual ao número de equações do modelo. $\mathrm{O}$ fechamento do modelo e as hipóteses assumidas na construção de modelos AEG estão fortemente relacionadas com o pensamento das diferentes correntes de teoria econômica atuais. Ou seja, os modelos AEG devem ser fechados de acordo com a teoria que se julga mais próxima da realidade. Por isso, os resultados refletem o critério de fechamento que, em geral, são diferentes entre si. Discussões mais detalhadas sobre o fechamento de modelos $\mathrm{AEG}^{14}$ podem ser encontradas em Robinson (1989) e Guilhoto (1995).

A escolha das variáveis exógenas deve ser orientada considerando-se a estrutura das equações do sistema e a análise que se pretende fazer. Do ponto de vista da estrutura das equações, é necessário igualar o número de variáveis endógenas e ao número de equações do sistema. Assim é sugerido trabalhar com as equações agrupadas em módulos, o que facilita a identificação e localização das variáveis, uma vez que o modelo MIBRA é relativamente grande. Operacionalmente, é interessante realizar o mapeamento das variáveis e equações do sistema para que se consiga visualizar como os módulos estão interligados e quais variáveis são utilizadas para fazer essas ligações. O mapeamento é muito útil para identificar as variáveis naturalmente exógenas que não têm equações para a sua explicação no modelo e, por isso, são candidatas naturais para exogeneização (Horridge et al., 1993).

Pelo menos uma variável monetária deve ser incluída como exógena. Uma vez obtido um fechamento matemático, pode-se utilizar o módulo AnalyseGem Gempack para visualizar tantos as relações de variáveis exógenas e endógenas como os valores dos coeficientes e variáveis. Através do AnalyseGem ainda é possível identificar as variáveis substituídas e omitidas, bem como as que foram parcialmente exogenizadas. Note que omitir uma variável equivale a exogeneizar esta mesma variável com choque

\footnotetext{
${ }^{14}$ Note que a incorporação da dinâmica nos modelos AEG implica em vários tipos de fechamento, cujos detalhes são discutidos nas próximas seções.
} 
igual a zero no fechamento do modelo. Substituir uma variável equivale a deixar a variável endógena no fechamento do modelo.

A escolha das variáveis exógenas deve ser orientada de acordo com o que se pretende estudar. Por exemplo, se o estudo é sobre o impacto da redução dos impostos sobre a produção em nível setorial, a variável impostos em nível setorial deve ser exogenizada para permitir a aplicação de choques simulando a sua redução. Se a variável ou variáveis para as quais pretende-se aplicar choques não são exógenas no fechamento básico, é necessário realizar as trocas de variáveis exogeneizando uma variável de mesma dimensão ou várias, cujas dimensões somadas tenha o mesmo valor da dimensão da variável endogeneizada.

Quando a abordagem é dinâmica recursiva com investimento endógeno, é necessário realizar o fechamento his tórico para obter os valores das variáveis utilizadas para traçar o caminho de previsão do modelo. Essas variáveis obtidas no fechamento histórico são as referentes às mudanças tecnológicas e às preferências que, numa análise de curto prazo, são consideradas fixas e não são observáveis na prática. Variáveis macroeconômicas usualmente exógenas e variáveis demográficas para as quais se têm projeções calculadas por institutos de pesquisa e estatística como o IBGE e o IPEA devem ser utilizadas para proporcionar as condições dinâmicas suficientes para traçar o caminho de previsão do modelo. Detalhes sobre os fechamentos histórico e de previsão nos modelos na tradição de Johansen-Orani podem ser encontrados em Dixon e Parmenter (1996) e Dixon \& Rimmer (1998).

\subsection{Análise de sensibilidade}

A análise de sensibilidade aponta quanto os resultados da simulação no modelo de equilíbrio geral são sensíveis a variações nos parâmetros ou nos choques aplicados nas variáveis exógenas. Note que não é possível realizar a análise de sensibilidade para variações em parâmetros e em choques simultaneamente. A análise de sensibilidade permite responder quão realistas são os resultados da simulação, se uma política é muito sensível a valores específicos assumidos como parâmetros, ou se a previsão econômica depende criticamente de choques específicos aplicados em variáveis exógenas. As 
diferentes abordagens quanto à análise de sensibilidade são apresentadas na seqüência, tomando-se como base Harrison \& Pearson (2000).

\section{a) Análises de sensibilidade ad hoc e sistemática}

Existe um número razoável de abordagens quanto à análise de sensibilidade. A mais simples é a análise de sensibilidade ad hoc que consiste em selecionar um ou dois conjuntos de valores de parâmetros ou choques e resolvê- los para cada conjunto. Mas, a abordagem ad hoc fica menos prática quando se necessita avaliar os efeitos das incertezas independentes sobre os valores de vários parâmetros ou choques.

Por exemplo, considere que foram simulados os efeitos de um aumento uniforme de $10 \%$ das tarifas de importação num modelo com 20 mercadorias. Na prática pode-se imaginar que cada uma das 20 taxas de importação pode ser reduzida a valores que oscilam entre 5\% e 15\%. Para rodar as simulações aninhando todas as possíveis combinações $(5,10$ e 15\%) para todas as 20 mercadorias, seriam necessárias 3 bilhões de simulações (3 elevado à potência de 20). Evidentemente, não é viável realizar esse número de simulações e por isso, é necessário reduzir o número de simulações e resumir os resultados.

A estatística oferece uma forma de resumir os resultados de várias simulações e, também, uma forma de reduzir a quantidade de cálculos. Considere que seja possível postular sobre a distribuição de probabilidade para cada choque na tarifa. Suponha que para cada choque na tarifa, qualquer valor entre $5 \%$ e $15 \%$ é igualmente provável, ou seja, que cada choque na tarifa tenha uma distribuição uniforme ou retangular. É também possível postular que a distribuição para qualquer mercadoria é independente dos valores das tarifas para outras mercadorias, ou seja, a distribuição entre as 20 mercadorias tem correlação zero. Então, para cada variável endógena, pode-se resumir sua distribuição em dois números: a média e o desvio padrão. Embora as taxas de tarifa tenham uma distribuição uniforme, é quase impossível saber qual é o tipo de distribuição que cada variável endógena tem.

Entretanto, existem procedimentos para inferir informações úteis sobre os valores prováveis a partir da média e do desvio padrão. Pela desigualdade de Chebyshev, é 
possível assegurar que o valor de uma variável que tem média igual a 5 e desvio padrão igual a 1 vai estar entre 0,5 e 9,5 com 95\% de confiança. Esta confiança pode ser de 89\% e o valor situar entre 2 e 8 se o desvio padrão for 3 . Usualmente, o valor médio da variável endógena seria bem próximo, mas não idêntico ao valor que teria resultado se todas as variáveis exógenas, bem como todas as variações dos valores dos parâmetros e dos choques fossem os valores das suas respectivas médias. Portanto os resultados da análise de sensibilidade podem ser apresentados na forma de tabela com uma linha para cada variável endógena e três colunas compreendendo os resultados provenientes da simulação de referência, os valores médios e o desvio padrão associado aos valores médios. Essas informações compõem a essência da análise de sensibilidade sistemática.

\section{b) Análise de sensibilidade sistemática através de simulações aleatórias}

Outro tipo de análise de sensibilidade é a proveniente de simulações aleatórias. Sem a capacidade computacional ilimitada, é necessário estimar médias e desvios padrões a partir dos resultados provenientes de um número limitado de soluções do modelo. O método Monte Carlo é o mais mais popular para escolher os valores aleatórios a partir da distribuição de cada uma das variáveis. Considerando o exemplo inicial, deve-se utilizar os 20 choques para rodar a simulação. No Gempack, contudo, existe a limitação de realizar apenas 40 simulações, quando na verdade o ideal, pelo método Monte Carlo, seria rodar algumas milhares de simulações. Assim, não é viável realizar a análise de sensibilidade a partir de simulações aleatórias com os recursos disponíveis.

\section{c) Análise de sensibilidade sistemática via quadraturas}

Outro tipo de análise de sensibilidade sistemática é a via quadraturas. Essa abordagem utiliza um método de otimização ou programação para estimar médias e desvios padrões para todas as variáveis endógenas. Através dessa abordagem, selecionase a melhor escolha entre $n$ simulações, dada as distribuições de $m$ variáveis exógenas. Esse procedimento é conhecido como quadratura gaussiana. Considerando algumas pressuposições particulares sobre o modelo, o número de simulações e a distribuição de 
probabilidade dos choques, é possível calcular rapidamente conjuntos de valores de choque para um número relativamente pequeno de simulações que fornecem estimativas precisas de médias e desvios padrões.

O Gempack oferece duas formas de quadratura gaussiana: quadratura gaussiana de Stroud e a quadratura gaussiana de Liu. A diferença básica entre as duas formas é o número de pontos gerados na obtenção das distribuições por aproximação discreta. $\mathrm{Na}$ quadratura gaussiana de Stroud, são gerados $2 n$ pontos, o que equivale a dizer que o modelo é resolvido $2 n$ vezes. Já na quadratura gaussiana de Liu o número de pontos aumenta para $4 n$ e, por isso, o modelo é resolvido $4 n$ vezes. Mais detalhes sobre a análise de sensibilidade sistemática via quadratura gaussiana podem ser encontradas em Arndt (1996) e em Domingues (2001). Neste trabalho, é realizada a análise de sensibilidade sistemática via quadratura gaussiana de Liu. 


\section{RESULTADOS E DISCUSSÃO}

\subsection{Fechamentos utilizados}

Na seqüência, são apresentados os fechamentos utilizados para a realização das simulações desta pesquisa. Inicialmente, é apresentado o fechamento básico a partir do qual é feito o teste de homogeneidade do modelo e são obtidos os fechamentos para a análise das propostas de governo do PT em nível federal, do aumento dos investimentos em nível regional e do aumento da produtividade dos fatores em nível nacional. No final é apresentada uma sugestão de política com base nas simulações realizadas. Uma análise de sensibilidade é realizada na solução que serve de base para a sugestão de política pública tendo em vista um crescimento econômico sustentado.

\subsubsection{Fechamento Básico}

$\mathrm{Na}$ Tabela 12, é apresentada a relação das variáveis exogeneizadas para a obtenção do fechamento básico do modelo MIBRA. A partir deste fechamento básico são feitas as trocas necessárias para realizar as simulações de análise de políticas discutidas na seção seguinte.

Tabela 12. Fechamento básico com a relação das variáveis exógenas do modelo MIBRA.

\begin{tabular}{lrl}
\hline Variável & Dimensão & \multicolumn{1}{c}{ Descrição } \\
\hline natxi3 & 1 & Índice de preços ao consumidor \\
deltax & 16 & Variação percentual na taxa de imposto das vendas gerais \\
rk & 1 & Taxa de imposto - Renda de fator primário não-salário \\
powtaxm & 16 & Poder das tarifas \\
rpr & 5 & Taxa de imposto sobre a folha de pagamento \\
n & 80 & Uso da terra \\
miscf001 & 5 & Variável de deslocamento: função consumo
\end{tabular}


Tabela 12. Fechamento básico com a relação das variáveis exógenas do modelo MIBRA.

\begin{tabular}{|c|c|c|}
\hline Variável & Dimensão & Descrição \\
\hline curcap & 80 & Estoque de capital corrente \\
\hline $\mathrm{pm}$ & 16 & Preços das importações CIF em moeda estrangeira \\
\hline natf5gen & 1 & Deslocador geral para "outras" demandas regionais \\
\hline f5a & 480 & Deslocador para "outras" demandas regionais \\
\hline f5gen & 5 & Termo deslocador geral para "outras" demandas \\
\hline floct & 80 & Deslocadores para outros custos \\
\hline natf6gen & 1 & Deslocador geral para "outras" demandas federais \\
\hline f6a & 480 & Deslocador para "outras" demandas federais \\
\hline f6gen & 5 & Deslocador para "outras" demandas federais \\
\hline fep & 16 & Deslocador de preço (para cima) nas demandas por exportações \\
\hline feq & 16 & Deslocador de quantidade (direita) nas demandas por exportações \\
\hline frpri & 80 & Deslocador da taxa de imposto sobre a folha de pagamento \\
\hline softf001 & 6 & Variável de deslocamento: outros impostos indiretos \\
\hline softf004 & 6 & Variável de deslocamento: outras receitas \\
\hline softf005 & 6 & Variável de deslocamento: aumento nas provisões \\
\hline softf006 & 6 & Variável de deslocamento: outros outlays \\
\hline softf007 & 6 & Variável de deslocamento: dívida do governo \\
\hline softf011 & 1 & Deslocador para coleta federal de outros impostos indiretos \\
\hline hhldf001 & 5 & Variável de deslocamento: benefícios de desemprego \\
\hline hhldf002 & 5 & Variável de deslocamento: outros benefícios pessoais \\
\hline hhldf003 & 5 & Variável de deslocamento: outra renda (líquida) - hholds \\
\hline $\operatorname{miscf002}$ & 1 & Variável de deslocamento: taxas de impostos de renda relativa \\
\hline natfep & 1 & Deslocador das curvas de demanda por exportação em nível nacional \\
\hline faggnt_i & 12 & Deslocador por mercadoria \\
\hline faggnt_p4r & 5 & Deslocador sobre os preços agregados por região \\
\hline faggnt_x4r & 5 & Deslocador sobre as quantidades agregadas por região \\
\hline aggnt_feq & 5 & Deslocador de quantidade para exp ortações não-tradicionais \\
\hline aggnt_fep & 5 & Deslocador de preços das exportações não-tradicionais \\
\hline faggnt_is & 60 & Deslocador por mercadoria e região \\
\hline softy111 $1-5$ & 5 & Imposto de renda \\
\hline softy 1246 & 1 & Impostos sobre propriedades \\
\hline softq210 $1-5$ & 5 & Benefícios de desemprego \\
\hline f_oft & 6 & Deslocador de outras transações financeiras \\
\hline deldfudge & 1 & Variável binária na equação E_deldebt \\
\hline natfwage & 1 & Deslocador de salário geral \\
\hline fwagei & 80 & Deslocador de salário específico ao setor \\
\hline wage_diff 2-5 & 4 & Diferencial de salário real regional \\
\hline del_unr & 5 & Variação percentual na taxa de desemprego regional \\
\hline pr & 5 & Taxa de participação da força de trabalho regional \\
\hline del_g & 5 & $\begin{array}{l}\text { Variação ordinária na população natural (nascimentos-mortes): } \\
\text { Regiões }\end{array}$ \\
\hline del_fm & 5 & Variação ordinária migração estrangeira: regiões \\
\hline f_1 & 5 & Deslocador no emprego regional \\
\hline f_wpop & 5 & Deslocador na equação E_wpop \\
\hline f_pop & 5 & Deslocador na equação E_del_rm \\
\hline f_qhous & 5 & Deslocador na equação E_pop_interf \\
\hline delrpfudge & 5 & Binárias na equação E_del_rm \\
\hline delf_rm & 1 & Deslocador na equação E_rm_addup \\
\hline delf_rm_0 & 1 & Deslocador na equação E_rm_0 \\
\hline
\end{tabular}


Tabela 12. Fechamento básico com a relação das variáveis exógenas do modelo MIBRA.

\begin{tabular}{|c|c|c|}
\hline Variável & Dimensão & Descrição \\
\hline del_gt 1-4 & 4 & $\begin{array}{l}\text { Variação ordinária no crescimento natural da população regional para } \\
\text { atualização }\end{array}$ \\
\hline del_fgt 5 & 1 & Deslocador no crescimento natural da população regional no ano $\mathrm{T}$ \\
\hline del_fmt & 5 & Variação ordinária na migração estrangeira para atualização \\
\hline del_rmt0 1-4 & 4 & Variação ordinária na migração regional \\
\hline del_fpop1t 5 & 1 & Deslocador na população regional no ano T-1 \\
\hline delpopfudget & 1 & Fator "Fudge" na equação E_popt \\
\hline del_f_ror & 80 & Deslocador no mecanismo de distribuição de TDR de longo prazo \\
\hline del_nat_ror & 1 & $\begin{array}{l}\text { Deslocador nacional no mecanismo para distribuição de TDR em } \\
\text { longo prazo }\end{array}$ \\
\hline del_unity & 1 & Variável binária definida igual a um para simulação de previsão \\
\hline r_inv_cap_jq & 80 & Variações específicas setorial e regional na razão I/K \\
\hline r_inv_cap_j & 16 & Variação específica setorial na razão I/K \\
\hline r_inv_cap_q & 5 & Variação específica regional na razão $\mathrm{I} / \mathrm{K}$ \\
\hline r_inv_cap & 1 & Deslocador geral na razão $\mathrm{I} / \mathrm{K}$ \\
\hline del_f_eeqror & 1 & Deslocador escalar - TDR de equilíbrio esperado \\
\hline del_f_eeqror_q & 5 & Deslocador vetor - TDR de equilíbrio esperado \\
\hline $\mathrm{r} 0$ & 80 & Taxas de retorno corrente sobre o capital \\
\hline a1lab & 80 & Variação técnica aumentando trabalho \\
\hline a1cap & 80 & Variação técnica aumentando capital \\
\hline a1land & 80 & Variação técnica aumento de terra \\
\hline a1oct & 80 & Variação técnica de outros custos \\
\hline a2ind & 80 & Variação tecnológica neutra - criação de capital \\
\hline a 3 com & 80 & Variação nas preferências das famílias \\
\hline deltax1all & 1 & Variação percentual geral nas taxas de impostos indiretos, usuário 1 \\
\hline deltax2all & 1 & Variação percentual geral nas taxas de impostos indiretos, usuário 2 \\
\hline deltax3all & 1 & Variação percentual geral nas taxas de impostos indiretos, usuário 3 \\
\hline deltax4all & 1 & Variação percentual geral nas taxas de impostos indiretos, usuário 4 \\
\hline deltax 5all & 1 & Variação percentual geral nas taxas de impostos indiretos, usuário 5 \\
\hline deltax6all & 1 & Variação percentual geral nas taxas de impostos indiretos, usuário 6 \\
\hline deltaxdest & 5 & Deslocador dos impostos regionais (variação percentual) \\
\hline deltaxsource & 6 & Deslocador dos impostos regionais (variação percentual) \\
\hline a1marg & 10 & Variação técnica no uso de margens - produção corrente \\
\hline a2marg & 10 & Variação técnica no uso de margens - criação de capital \\
\hline a3marg & 10 & Variação técnica no uso de margens - vendas para famílias \\
\hline a4marg & 10 & Variação técnica no uso de margens - exportações \\
\hline nattwist_src & 1 & Substituição entre imp ortados e domésticos para toda a economia \\
\hline twist_src_i & 16 & Deslocador na substituição entre imp ort. e domést. por mercadoria \\
\hline twist_src_q & 5 & Deslocador na substituição entre importados e domésticos por região \\
\hline ftwist_src & 80 & Deslocador na substituição entre Imp/twist para i em q \\
\hline nattwist_lk & 1 & Substituição entre trabalho e capital para toda a economia \\
\hline twist_lk_j & 16 & Deslocador na substituição entre trabalho e capital por setor \\
\hline twist_lk_q & 5 & Deslocador na substituição entre trabalho e capital por região \\
\hline a1prim & 1 & Variação técnica em todos os fatores primários \\
\hline alprimgen & 5 & Variação tecnológica em todos os fatores primários - todos os setores \\
\hline natalprimgen & 1 & Deslocamento nacional uniforme em a1primgen(q) \\
\hline natmiscf001 & 1 & Propensão média nacional a consumir \\
\hline $\mathrm{ac}$ & 80 & Variação técnica no uso da i-ésima mercadoria \\
\hline
\end{tabular}


Tabela 12. Fechamento básico com a relação das variáveis exógenas do modelo MIBRA.

\begin{tabular}{lcl}
\hline Variável & Dimensão & \multicolumn{1}{c}{ Descrição } \\
\hline fa1o & 1280 & $\begin{array}{l}\text { Deslocamento da variação tecnológica aumentando os insumos } \\
\text { intermediários }\end{array}$ \\
agreen & 1280 & Termo de substituição intermediária para substituição geral \\
\hline
\end{tabular}

Fonte: Resultados da pesquisa

O teste de homogeneidade do modelo foi realizado com o fechamento básico, que consiste, basicamente, na aplicação do choque de $1 \%$ ou $10 \%$ no numerário do modelo. No caso do MIBRA, o numerário do sistema de equações pode ser, por exemplo, a taxa de câmbio (natphi) ou o índice de preços ao consumidor (natxi3). Os resultados do teste de homogeneidade aplicando choque de $1 \%$ no índice de preços ao consumidor são apresentados e discutidos na seção seguinte.

\subsubsection{Fechamentos para simulação das políticas do governo do PT}

Na Tabela 13 são apresentadas as trocas realizadas para simular os impactos do aumento de salário nominal e o aumento em nível regional dos gastos do governo e dos investimentos, bem como a elevação da e da produtividade dos fatores de produção.

Tabela 13. Relação das trocas de variáveis no fechamento básico para simulação das políticas de governo do PT.

\begin{tabular}{lll}
\hline Básico & Salário nominal & Investimento e Produtividade \\
\hline natxi3 & natphi & natphi \\
del_unr 1-4 & del_rm_0 1-4 & del_rm_0 1-4 \\
del_unr 5 & wage_diff 1 & wage_diff 1 \\
natfwage & natpwage & natrealwage \\
f5gen & Othreal5 & othreal5 \\
f6gen & Othreal6 & othreal6 \\
softf007 & Realdef & realdef \\
faggnt_s & faggnt_p4r & aggnt_s \\
\hline
\end{tabular}

Fonte: Resultado da pesquisa

No fechamento denominado salário nominal, considera-se o aumento do salário nominal de 5,5\%. Como é interessante verificar como se comporta a inflação, A taxa de 
câmbio foi exogeneizada para permitir a endogeneização do índice de preços ao consumidor em nível nacional (natxi3). Dessa forma, é possível verificar o comportamento da inflação.

Como o salário nominal em nível nacional (natpwage) não era exógena, trocour se esta variável com o deslocador de salários em nível nacional (natfwage), que é exógeno no fechamento básico.

Para verificar o efeito do aumento do salário nominal (natpwage) sobre o desemprego (del_unr), o desemprego foi endogeneizado trocando-se pelas variáveis migração regional (del_rm0 1-4)e diferencial de salário (wage_diff 1).

Os gastos reais do governo são definidos pelas variáveis "Outras" demandas reais do governo estadual (othreal5) e "Outras" demandas reais do governo federal (othreal6). Como os gastos do governo, nas simulações, devem originar da esfera federal, os gastos do governo estadual não variam. Na prática, equivale a aplicar choque igual a zero na variável "Outras" demandas reais do governo estadual (othreal5) e aplicar choques diferentes de zero para a variável "Outras" demandas reais do governo federal (othreal6). Ambas variáveis são definidas em nível regional, o que permite estabelecer choques diferenciados para as variáveis em cada uma das regiões.

Aumento dos gastos do governo nos setores e regiões-alvos de uma política acabam atraindo investimentos para esses setores e regiões. Por exemplo, se o governo define gastos para melhorar a infra-estrutura de transporte de uma determinada região, esses gastos geralmente são acompanhados por investimentos privados na região atraídos pelo melhor acesso e escoamento de produtos.

Assim, a variável estoque de capital corrente (curcap) é utilizada para definir a variação dos investimentos. Ou seja, considera-se que aumentos do estoque de capital corrente são provenientes dos aumentos dos investimentos necessários para o desenvolvimento e crescimento econômico sustentados nos diferentes setores e regiões. Como a variável estoque de capital corrente já é exógena, não é necessária a realização de troca de variável no fechamento básico. Portanto, apesar de estar sendo considerada a combinação de choques em ambas as variáveis, as variáveis "Outras" demandas reais do governo federal (othreal6) e estoque de capital corrente (curcap) são totalmente distintas. 
Aumento da produtividade dos fatores de produção capital, trabalho e terra é definido através de choques nas variáveis de variação tecnológica aumentando a necessidade de cada um dos fatores de produção, respectivamente a1cap, a1lab e a1land que já se encontram exógenas no fechamento básico.

A exogeneização do único componente da variável de diferencial de salário real regional (wage_diff) é para deixar livre as diferenças entre os salários reais regionais. No fechamento básico, os salários reais regionais estavam amarrados ao salário real em nível nacional.

Como o saneamento das finanças públicas é um dos pontos importantes das políticas do novo governo, exogeneizourse a variável déficit do orçamento público (realdef) para definir que a variação do déficit do orçamento público seja igual a zero. As variáveis associadas aos impostos, mais especificamente a taxa de imposto de renda (rk) e aos encargos trabalhistas que no modelo são denominadas taxas de imposto sobre a folha de pagamento (rpr), já são exógenas e recebem choques iguais a zero. A reforma tributária diminuirá a carga tributária sobre a economia e a coleta dos impostos tornarse-á mais eficiente, reduzindo drasticamente a sonegação. Assim, espera-se que as taxas de impostos, no máximo, não aumentem, o que equivale à variação igual a zero para as variáveis taxa de imposto de renda (rk) e taxa de imposto sobre a folha de pagamento (rpr). A variável deslocador agregado para região (faggnt_s) foi trocada pela variável no deslocador do preço agregado por região (faggnt_p4r) para melhorar a absorção dos choques em algumas variá veis relacionadas às exportações.

Nas simulações de aumento de investimento e aumento de produtividade foram realizadas algumas trocas em relação ao fechamento básico para permitir a aplicação de choques nas variáveis de mudança tecnológica no uso dos fatores trabalho, capital e terra combinados com os aumentos dos gastos do governo e dos investimentos. Nesta simulação foi analisado o impacto do aumento da produtividade combinado com gastos do governo e investimentos sobre o aumento do salário real em nível regional. Por isso, de acordo com a Tabela 12, foram mantidas exógenas a taxa de câmbio (natphi), a variável "Outras" demandas do governo federal (othreal6) e o diferencial regional do salário real (wage_diff). 
As restrições definidas no modelo, de acordo com as propostas do programa de governo do PT, foram mantidas na simulação do aumento dos gastos do governo e investimentos e do aumento da produtividade dos fatores de produção. Em relação ao fechamento básico, foram trocadas as variáveis deslocador de salário geral (natfwage) e salário real nacional (natrealwage). Note que, entre as variáveis desemprego nacionale salário nacional, uma deve ser exógena e a outra, endógena. Como o interesse maior é no desemprego, a variável salário nacional real foi exogeneizada. Como não ocorreu problemas na absorção dos choques por parte de algumas das variáveis relacionadas às exportações, não foi realizada a troca entre as variáveis quantidade de exportações nãotradicionais (aggnt_x4r) e preços de exportações não tradicionais (aggnt_p4r). As simulações foram realizadas nos módulos WinGem e RunGem do Gempack utilizandose o método de solução Gragg com extrapolação nos passos 2, 4 e 6 .

\subsection{Teste de homogeneidade}

O ponto de partida para trabalhar com um modelo de equilíbrio geral, seja qual for a abordagem, é o teste de homogeneidade. Assim, são apresentados na Tabela 14 os resultados das macrovariáveis do modelo que são suficientes para apontar se o modelo é consistente ou não. Como é possível verificar, o modelo apresenta bons resultados, apesar de algumas variáveis não serem exatamente iguais a 1, nas variáveis relacionadas a preços, ou igual a zero, nas variáveis relacionadas à quantidade. Note que na Tabela 14 existem algumas variáveis de variação ordinária que são praticamente iguais a zero devido à magnitude dos seus valores serem na ordem de mil ou milhões.

Tabela 14. Teste de homogeneidade para as variáveis macroeconômicas do modelo MIBRA.

\begin{tabular}{llr}
\hline Descrição da variável & Variável & Resultado \\
\hline Superávit da Balança Comercial como porcentagem do PIB & bstar & $-0,04$ \\
Deslocador para migração em T & del_frmt0 & $-0,01$ \\
Variação ordinária na migração estrangeira & del_natfm & 0,00 \\
Variação ordinária na população natural (nascimentos-mortes) & del_natg & 0,00 \\
Variação percentual na taxa de desemprego da economia & del_natunr & 0,00 \\
Variação ordinária no déficit real de comércio & delbt & $-0,51$ \\
Variação ordinária na dívida externa & deldebt & $-0,25$
\end{tabular}


Tabela 14. Teste de homogeneidade para as variáveis macroeconômicas do modelo MIBRA.

\begin{tabular}{|c|c|c|}
\hline Descrição da variável & Variável & Resultado \\
\hline Variação na razão dívida/PIB & deldebt_ratio & 0,00 \\
\hline Investimento do governo nominal & ig & 1,00 \\
\hline Investimento privado nominal & ip & 1,00 \\
\hline Nível da razão dívida/PIB & levdebt_ratio & 0,00 \\
\hline Consumo nominal total das famílias & natc & 1,00 \\
\hline Pagamentos agregados ao capital & natcaprev & 1,00 \\
\hline Consumo real total das famílias & natcr & 0,00 \\
\hline Variação ordinária na balança comercial & natdelb & 0,00 \\
\hline Emprego nacional & natemploy & 0,00 \\
\hline Exportações em valor de moeda estrangeira & natexport & 0,00 \\
\hline Volumes das exportações & natexpvol & 0,00 \\
\hline Deslocador geral para "outras" demandas federais & natf6gen & 0,00 \\
\hline Deslocador das curvas de demanda por exportação em nível nacional & natfep & 0,00 \\
\hline Deslocador geral de salários/remuneração & natfwage & 0,00 \\
\hline PIB nominal pelo lado das despesas & natgdpexp & 1,00 \\
\hline PIB nominal pelo lado da renda & natgdpinc & 1,00 \\
\hline PIB real pelo lado das despesas & natgdpreal & 0,00 \\
\hline Valor em moeda estrangeira das importações & natimp & 0,00 \\
\hline Volume das importações & natimpvol & 0,00 \\
\hline Investimento agregado nominal & natin & 1,00 \\
\hline Despesa de in vestimento real agregado & natir & 0,00 \\
\hline Estoque de capital agregado - ponderação de aluguel & natkt & 0,00 \\
\hline Emprego agregado - pesos & natl & 0,00 \\
\hline Pagamentos agregados para o trabalho & natlabrev & 1,00 \\
\hline Oferta de trabalho nacional & natlabsup & 0,00 \\
\hline Pagamentos agregados para a terra & natlndrev & 1,00 \\
\hline Pagamentos de outros custos agregados & natoctrev & 1,00 \\
\hline Valor nominal agregado de "outras" demandas regionais & natothnom5 & 1,00 \\
\hline Valor nominal agregado de "outras" demandas federais & natothnom6 & 1,00 \\
\hline "Outras" demandas regionais reais e agregadas & natothreal5 & 0,00 \\
\hline "Outras" demandas federais reais e agregadas & natothreal6 & 0,00 \\
\hline Aluguéis nominais agregados do capital & natp1cap & 1,00 \\
\hline Taxa de câmbio & natphi & 1,00 \\
\hline Salários nominais agregados para trabalhadores & natpwage & 1,00 \\
\hline Salários nominais agregados pagos pelos produtores & natpwage_p & 1,00 \\
\hline Salário real nacional do consumidor & natrealwage & 0,00 \\
\hline $\begin{array}{l}\text { Salários reais para produtores em nível nacional: deflacionados pelo } \\
\text { deflator do PIB }\end{array}$ & natrwage_p & 0,00 \\
\hline $\begin{array}{l}\text { Salários reais para trabalhadores em nível nacional: deflacionados } \\
\text { pelo IPC }\end{array}$ & natrwage $\mathrm{w}$ & 0,00 \\
\hline Receita agregada proveniente de todos os impostos indiretos & nattaxind & 1,00 \\
\hline Receita agregada de imp ostos indiretos sobre intermediários & nattaxrev1 & 1,00 \\
\hline Receita agregada de impostos indiretos sobre investimento & nattaxrev2 & 1,00 \\
\hline Receita agregada de impostos indiretos sobre as famílias & nattaxrev3 & 1,00 \\
\hline Receita agregada de impostos indiretos sobre exportações & nattaxrev4 & 1,00 \\
\hline $\begin{array}{l}\text { Receita agregada de impostos indiretos sobre "outras demandas" } \\
\text { regionais }\end{array}$ & nattaxrev5 & 0,00 \\
\hline $\begin{array}{l}\text { Receita agregada de impostos indiretos sobre "outras demandas" } \\
\text { federais }\end{array}$ & nattaxrev6 & 0,00 \\
\hline
\end{tabular}


Tabela 14. Teste de homogeneidade para as variáveis macroeconômicas do modelo MIBRA.

\begin{tabular}{llr}
\hline Descrição da variável & Variável & Resultado \\
\hline Receita de tarifa agregada & nattaxrevm & 1,00 \\
Termos de comércio em toda economia & nattot & 0,00 \\
Índice de preços para investimento & natxi2 & 1,00 \\
Índice de preços ao consumidor & natxi3 & 1,00 \\
Índice de preços às exportações & natxi4 & 1,00 \\
Índice de preços das "outras" demandas regionais & natxí & 1,00 \\
Índice de preços das "outras" demandas federais & natxi6 & 1,00 \\
Índice de preços do PIB - lado da despesa & natxigdp & 1,00 \\
Índice de preços das importações & natxim & 1,00 \\
Índice de preços das importações com imposto de imp ortação paga & natximp0 \\
Preços relativo de trabalho e capital & natxiplpk & 1,00 \\
Produto agregado: valor adicionado- pesos & natz_tot & 0,00 \\
Pagamento de benefícios pessoais & pbp & 0,00 \\
Índice de preços - comércio inter-regional total & pw & 0,03 \\
Taxa de imposto - remuneração, salários e suplementos & rl & 1,00 \\
Impostos sobre produtos menos subsídios (excluindo tarifas) & ti & 0,00 \\
Impostos de renda & ty & 1,21 \\
Benefício de desemprego & upb & 1,00 \\
Taxa de salário nominal antes do imposto & wn & 1,00 \\
Taxa de salário nominal depois do imposto & wnstar & 1,00 \\
Taxa de salário real pós-imposto & wrstar & 1,00 \\
Deflator do PIB & xiy & 0,00 \\
PIB a custo de fatores & yf & 0,94 \\
Renda salário antes do imposto & yl & 1,00 \\
Renda salário pós-imposto & ylstar & 1,00 \\
PIB nominal & yn & 1,00 \\
PIB real & yr & 0,94 \\
Impostos na folha de pagamento & z03 & 0,00 \\
Impostos sobre propriedades & z05 & 1,00 \\
Impostos sobre terra & z07 & 0,00 \\
Outros impostos indiretos & z09 & 0,00 \\
Vendas por compradores finais & zlo & 1,00 \\
\hline Fone: Resulo & 0,00 \\
\hline
\end{tabular}

Fonte: Resultados da pesquisa

O fato de algumas variáveis dadas em taxas de crescimento não estarem atendendo ao teste de homogeneidade está relacionado com algumas inconsistências no sistema de equações do modelo MIBRA que está em fase final de ajuste. A ocorrência dessas inconsistências é o custo de adaptar um modelo inicialmente desenvolvido para a Austrália para a realidade econômica brasileira. Ficam como sugestão de pesquisa futura os ajustes finais no sistema de equações do modelo MIBRA, de modo a eliminar as poucas inconsistências que ainda estão presentes nesta versão. 


\subsection{Fábula do governo Lula}

Nesta seção são apresentados os resultados da simulação do elevação do salário nominal, do aumento dos gastos do governo combinado com crescimento de investimentos e da produtividade. $\mathrm{Na}$ simulação do aumento dos gastos do governo combinado com aumento dos investimentos, é discutida a questão da alocação dos gastos do governo entre as regiões. Na simulação do aumento da produtividade, é tratada a importância da produtividade para um arescimento econômico mais equilibrado ou sustentado, como é citado no programa de governo do PT.

O valor percentual de 5,5 para o reajuste do salário nominal representa o aumento que o salário mínimo estipulado pelo governo poderia ter depois da última revisão do orçamento do governo federal realizado no segundo semestre de 2002. Ou seja, está em estudo o aumento no salário mínimo dos atuais R \$ 200,00 para R \$211,00. É interessante lembrar que o aumento do salário mínimo, teoricamente, afetaria apenas uma parte dos salários da economia brasileira. Nesta simulação, o aumento do salário mínimo é estendido para os salários de toda a economia brasileira.

Ainda na simulação do aumento do salário nominal e de acordo com o programa de governo do PT, foi aplicada uma variação nos gastos do governo em nível regional de $10 \%$ nas regiões Norte e Nordeste e zero nas demais. Nos investimentos também foi aplicada uma variação de $10 \%$ nas regiões Norte e Nordeste e zero nas demais. O valor do aumento da produtividade dos fatores de produção foi definido após algumas simulações preliminares. Para a simulação do aumento do salário nominal foi considerado o aumento de $0,5 \%$ para cada um dos três fatores de produção, valor esse que parece ser razoável.

A alocação diferenciada dos gastos do governo proposta no programa de governo do PT poderia limitar e até comprometer o desempenho global da economia brasileira ao privilegiar as regiões menos desenvolvidas. Então, para verificar tais possibilidades, foi realizada a simulação de duas situações de aumento dos gastos do governo e aumento dos investimentos: uma situação variando gastos de governo e investimentos apenas para 
as regiões Norte e Nordeste e outra considerando variações diferentes de zero em todas, mas ainda privilegiando Norte e Nordeste.

Na simulação com variação zero nas regiões Centro-Oeste, Sudeste e Sul nos gastos do governo e nos investimentos, foi aplicada a variação de $10 \%$ tanto para a região Norte como para a Nordeste. Na simulação com variação dos gastos do governo e dos investimentos em todas as regiões foi aplicada variação de $4 \%$ para as regiões Norte e Nordeste e variação de 3\% para o Centro-Oeste, o Sudeste e o Sul. Nesta simulação, a produtividade dos fatores de produção capital, trabalho e terra tiveram variações iguais a zero para que as variações nos resultados entre as diferentes situações fossem exclusivamente devido aos choques aplicados nos gastos do governo e nos investimentos.

$\mathrm{O}$ aumento da produtividade dos fatores de produção parece ter um papel importante no equilíbrio do crescimento da economia brasileira, que é referido como crescimento econômico sustentado no programa de governo do PT. Por isso foi realizada a simulação de duas situações de aumento da produtividade dos fatores de produção: em uma, há um aumento de $0,1 \%$ para cada um dos três fatores de produção e na outra, o aumento de cada um dos fatores de produção é de $0,5 \%$. Nesta simulação, consideroutse a mesma variação nos gastos do governo e nos investimentos em cada uma das cinco regiões. Ou seja, cada região teve um aumento de $4 \%$ nos gastos do governo combinado com um aumento também de $4 \%$ nos investimentos. Tais situações mostram como a produtividade é importante no equilíbrio do crescimento da economia.

Assim, foram simuladas as seguintes situações tendo como base as propostas de governo do PT: a) aumento do salário nominal em 5,5\%; b) aumento dos gastos do governo e dos investimentos privilegiando as regiões Norte e Nordeste com o objetivo de diminuir as diferenças regionais; e c) aumento da produtividade dos fatores de produção terra, trabalho e capital, dados os níveis de gastos do governo e de investimentos na economia. A relação dos choques aplicados, que diferenciam as simulações realizadas, é apresentada na Tabela 15.

O fechamento para a realização dessas três simulações foi apresentado nas Tabelas 12 e 13. Em função do grande número de variáveis do modelo, a discussão foi 
realizada apenas com aquelas mais importantes para analisar o impacto das prováve is políticas para a economia brasileira.

Tabela 15. Relação dos choques aplicados que diferenciam as simulações realizadas.

\begin{tabular}{|c|c|c|c|c|c|}
\hline \multirow[b]{2}{*}{ Variáveis } & \multicolumn{5}{|c|}{ Regiões (\%) } \\
\hline & Norte & Nordeste & $\begin{array}{r}\text { Centro- } \\
\text { Oeste }\end{array}$ & Sudeste & Sul \\
\hline \multicolumn{6}{|c|}{ Salário nominal } \\
\hline Salário nominal & 5,50 & 5,50 & 5,50 & 5,50 & 5,50 \\
\hline Gastos do governo & 10,00 & 10,00 & 0,00 & 0,00 & 0,00 \\
\hline Investimentos & 10,00 & 10,00 & 0,00 & 0,00 & 0,00 \\
\hline Produtividade do fator terra & 0,50 & 0,50 & 0,00 & 0,00 & 0,00 \\
\hline Produtividade do fator trabalho & 0,50 & 0,50 & 0,00 & 0,00 & 0,00 \\
\hline Produtividade do fator capital & 0,50 & 0,50 & 0,00 & 0,00 & 0,00 \\
\hline \multicolumn{6}{|c|}{ Investimento concentrado } \\
\hline Salário nominal & - & - & - & - & - \\
\hline Gastos do governo & 10,00 & 10,00 & 0,00 & 0,00 & 0,00 \\
\hline Investimentos & 10,00 & 10,00 & 0,00 & 0,00 & 0,00 \\
\hline Produtividade do fator terra & 0,00 & 0,00 & 0,00 & 0,00 & 0,00 \\
\hline Produtividade do fator trabalho & 0,00 & 0,00 & 0,00 & 0,00 & 0,00 \\
\hline Produtividade do fator capital & 0,00 & 0,00 & 0,00 & 0,00 & 0,00 \\
\hline \multicolumn{6}{|c|}{ Investimento desconcentrado } \\
\hline Salário nominal & - & - & - & - & - \\
\hline Gastos do governo & 4,00 & 4,00 & 3,00 & 3,00 & 3,00 \\
\hline Investimentos & 4,00 & 4,00 & 3,00 & 3,00 & 3,00 \\
\hline Produtividade do fator terra & 0,00 & 0,00 & 0,00 & 0,00 & 0,00 \\
\hline Produtividade do fator trabalho & 0,00 & 0,00 & 0,00 & 0,00 & 0,00 \\
\hline Produtividade do fator capital & 0,00 & 0,00 & 0,00 & 0,00 & 0,00 \\
\hline \multicolumn{6}{|c|}{ Produtividade: $0,1 \%$} \\
\hline Salário nominal & - & - & - & - & - \\
\hline Gastos do governo & 4,00 & 4,00 & 4,00 & 4,00 & 4,00 \\
\hline Investimentos & 4,00 & 4,00 & 4,00 & 4,00 & 4,00 \\
\hline Produtividade do fator terra & 0,10 & 0,10 & 0,10 & 0,10 & 0,10 \\
\hline Produtividade do fator trabalho & 0,10 & 0,10 & 0,10 & 0,10 & 0,10 \\
\hline Produtividade do fator capital & 0,10 & 0,10 & 0,10 & 0,10 & 0,10 \\
\hline \multicolumn{6}{|c|}{ Produtividade: $0,5 \%$} \\
\hline Salário nominal & - & - & - & - & . \\
\hline Gastos do governo & 4,00 & 4,00 & 4,00 & 4,00 & 4,00 \\
\hline Investimentos & 4,00 & 4,00 & 4,00 & 4,00 & 4,00 \\
\hline Produtividade do fator terra & 0,50 & 0,50 & 0,50 & 0,50 & 0,50 \\
\hline Produtividade do fator trabalho & 0,50 & 0,50 & 0,50 & 0,50 & 0,50 \\
\hline Produtividade do fator capital & 0,50 & 0,50 & 0,50 & 0,50 & 0,50 \\
\hline
\end{tabular}

Fonte: Resultados da pesquisa 
Para facilitar a visualização e comparação dos resultados, as três simulações são apresentadas juntas nas Tabelas 16 a 21.

Tabela 16. Resultados em nível nacional das simulações para as variáveis relevantes.

\begin{tabular}{lrrrrr}
\hline & \multicolumn{4}{c}{ Simulações } \\
\cline { 2 - 6 } & \multicolumn{4}{c}{ Investimento } & \multicolumn{2}{c}{ Produtividade } \\
\cline { 2 - 6 } & $\begin{array}{r}\text { Salário } \\
\text { nominal }\end{array}$ & $\begin{array}{r}\text { Concen- } \\
\text { trado }\end{array}$ & $\begin{array}{r}\text { Descon- } \\
\text { centrado }\end{array}$ & $0,1 \%$ & $0,5 \%$ \\
\hline Emprego & 2,03 & 1,74 & 2,77 & 6,99 & 3,82 \\
Consumo real & 1,13 & 1,89 & 2,33 & 5,73 & 3,17 \\
Volume das exportações & $-5,67$ & 0,56 & 5,00 & 17,36 & 9,11 \\
Volume das importações & 2,59 & 0,41 & 0,67 & 13,14 & 3,76 \\
Inflação & 6,42 & 0,42 & $-0,13$ & 6,90 & 1,29 \\
PIB real & 0,64 & 1,72 & 2,33 & 4,78 & 3,14 \\
Índice de preços no comércio inter-regional & 7,24 & 0,38 & $-0,42$ & 8,80 & 1,22 \\
\hline
\end{tabular}

Fonte: Resultados da pesquisa

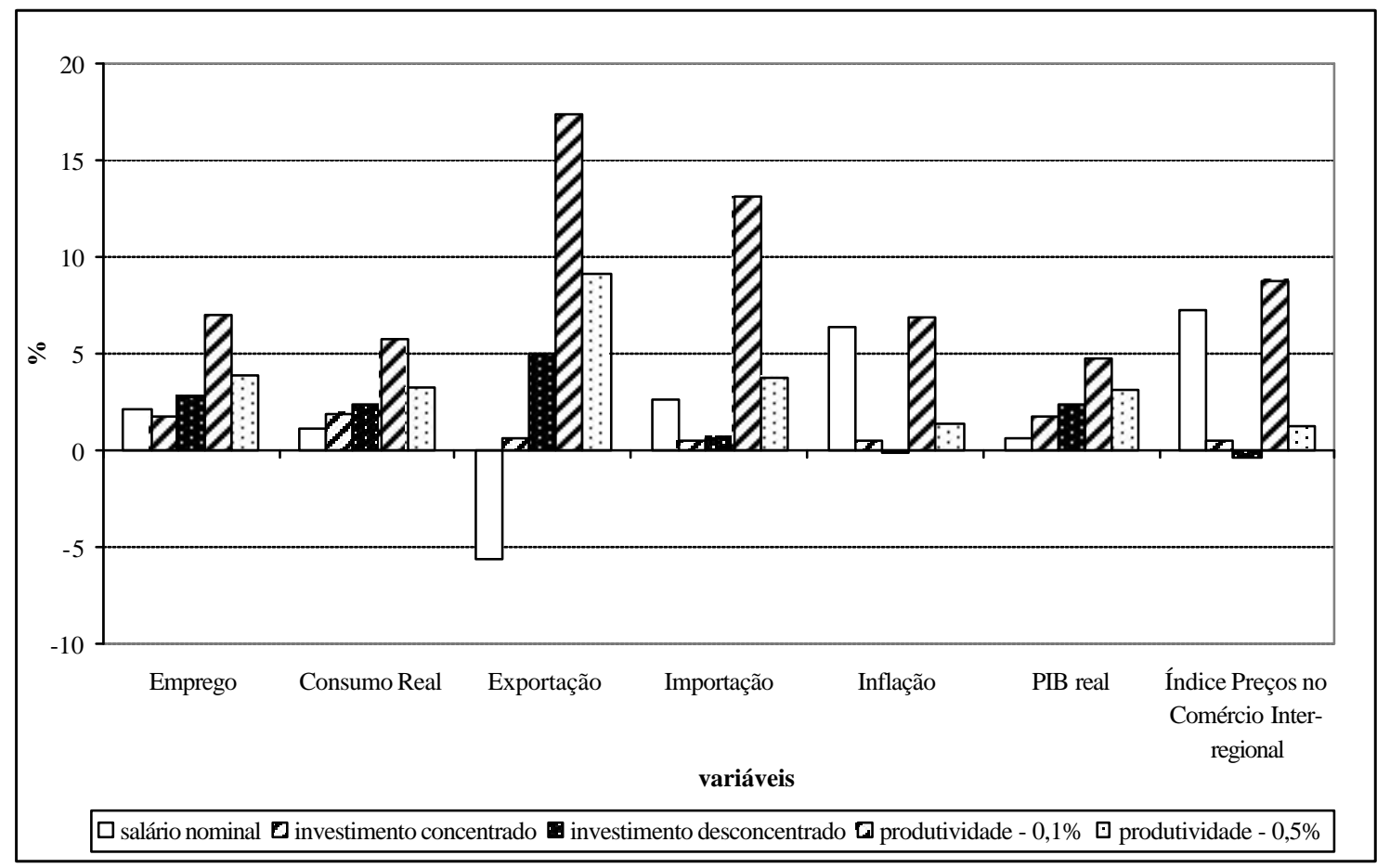

Figura 18 - Resultados em nível nacional das simulações para as variáveis relevantes.

Fonte: Resultados da pesquisa 
Tabela 17. Resultados em nível regional das simulações para as variáveis relevantes.

\begin{tabular}{|c|c|c|c|c|c|}
\hline & \multicolumn{5}{|c|}{ Simulações } \\
\hline & \multicolumn{3}{|c|}{ Investimento } & \multicolumn{2}{|c|}{ Produtividade } \\
\hline & $\begin{array}{r}\text { Salário } \\
\text { nominal }\end{array}$ & $\begin{array}{r}\text { Concen- } \\
\text { trado } \\
\end{array}$ & $\begin{array}{l}\text { Descon- } \\
\text { centrado }\end{array}$ & $0,1 \%$ & $0,5 \%$ \\
\hline \multicolumn{6}{|c|}{ Consumo real } \\
\hline Norte & 4,31 & 8,07 & 3,10 & 5,40 & 3,28 \\
\hline Nordeste & 3,68 & 3,99 & 1,42 & 4,83 & 2,46 \\
\hline Centro-Oeste & 0,15 & 0,66 & 2,00 & 6,23 & 3,19 \\
\hline Sudeste & 0,46 & 1,33 & 2,85 & 5,83 & 3,67 \\
\hline Sul & 0,59 & 0,96 & 1,34 & 5,87 & 2,11 \\
\hline \multicolumn{6}{|c|}{ Emprego } \\
\hline Norte & 10,95 & 11,47 & 3,96 & 4,82 & 3,66 \\
\hline Nordeste & 33,63 & 14,16 & 5,20 & 8,25 & 5,47 \\
\hline Centro-Oeste & $-3,51$ & $-0,52$ & 2,56 & 4,46 & 3,45 \\
\hline Sudeste & $-3,47$ & $-0,82$ & 2,53 & 7,77 & 4,01 \\
\hline Sul & $-3,53$ & $-0,46$ & 1,46 & 4,97 & 2,02 \\
\hline \multicolumn{6}{|c|}{ Volume das exportações } \\
\hline Norte & $-2,64$ & 24,12 & 4,96 & 17,80 & 6,16 \\
\hline Nordeste & $-28,16$ & 34,78 & 7,17 & 16,08 & 6,10 \\
\hline Centro-Oeste & $-2,02$ & $-4,58$ & 3,42 & 47,67 & 13,30 \\
\hline Sudeste & $-3,68$ & $-3,80$ & 5,53 & 11,65 & 9,64 \\
\hline Sul & $-2,73$ & $-3,45$ & 3,05 & 29,38 & 8,80 \\
\hline \multicolumn{6}{|c|}{ Volume das importações } \\
\hline Norte & 53,03 & 11,55 & 2,21 & 10,46 & 3,68 \\
\hline Nordeste & $-76,25$ & 5,99 & 4,00 & 8,86 & 6,03 \\
\hline Centro-Oeste & 0,52 & $-0,18$ & 2,11 & 8,43 & 4,22 \\
\hline Sudeste & 1,48 & $-0,61$ & 0,14 & 14,53 & 3,77 \\
\hline Sul & 3,35 & 0,05 & 1,28 & 10,80 & 3,33 \\
\hline \multicolumn{6}{|c|}{ Salário real } \\
\hline Norte & $-5,85$ & $-2,62$ & $-0,53$ & 1,34 & 0,02 \\
\hline Nordeste & $-19,85$ & $-7,65$ & $-2,80$ & $-1,63$ & $-2,41$ \\
\hline Centro-Oeste & 2,72 & 0,65 & $-0,28$ & 2,63 & 0,23 \\
\hline Sudeste & 3,03 & 1,61 & 0,69 & $-0,83$ & 0,34 \\
\hline Sul & 2,99 & 0,86 & 0,04 & 2,05 & 0,47 \\
\hline \multicolumn{6}{|c|}{ Inflação } \\
\hline Norte & 12,05 & 3,12 & 0,41 & 5,51 & 1,28 \\
\hline Nordeste & 31,39 & 8,44 & 2,61 & 9,11 & 3,63 \\
\hline Centro-Oeste & 2,70 & $-0,23$ & 0,17 & 4,20 & 1,07 \\
\hline Sudeste & 2,41 & $-1,17$ & $-0,79$ & 7,58 & 0,97 \\
\hline Sul & 2,43 & $-0,43$ & $-0,15$ & 4,77 & 0,83 \\
\hline
\end{tabular}


Tabela 17. Resultados em nível regional das simulações para as variáveis relevantes.

\begin{tabular}{|c|c|c|c|c|c|}
\hline & \multicolumn{5}{|c|}{ Simulações } \\
\hline & \multicolumn{3}{|c|}{ Investimento } & \multicolumn{2}{|c|}{ Produtividade } \\
\hline & $\begin{array}{c}\text { Salário } \\
\text { nominal }\end{array}$ & $\begin{array}{r}\text { Concen- } \\
\text { trado }\end{array}$ & $\begin{array}{l}\text { Descon- } \\
\text { centrado }\end{array}$ & $0,1 \%$ & $0,5 \%$ \\
\hline \multicolumn{6}{|c|}{ PIB real } \\
\hline Norte & 3,87 & 5,80 & 3,23 & 3,81 & 3,53 \\
\hline Nordeste & 0,56 & 2,88 & 2,42 & 4,00 & 3,13 \\
\hline Centro-Oeste & $-0,35$ & 0,43 & 1,97 & 5,10 & 2,97 \\
\hline Sudeste & 1,97 & 1,99 & 2,91 & 3,92 & 3,61 \\
\hline Sul & 0,12 & 1,01 & 2,17 & 5,26 & 3,03 \\
\hline \multicolumn{6}{|c|}{ Volume de exp ortação no comércio inter-regional } \\
\hline Norte & $-2,03$ & $-0,32$ & 3,02 & 4,27 & 4,07 \\
\hline Nordeste & $-1,71$ & 0,87 & 2,94 & 4,25 & 3,91 \\
\hline Centro-Oeste & $-0,60$ & 0,83 & 2,61 & 4,13 & 3,42 \\
\hline Sudeste & 3,46 & 3,22 & 2,43 & 3,26 & 2,91 \\
\hline Sul & 0,28 & 2,05 & 3,49 & 5,28 & 4,36 \\
\hline \multicolumn{6}{|c|}{ Volume de importação no comércio inter-regional } \\
\hline Norte & 5,25 & 9,50 & 3,81 & 2,84 & 3,69 \\
\hline Nordeste & 14,78 & 8,87 & 3,32 & 3,51 & 3,56 \\
\hline Centro-Oeste & $-1,41$ & 0,08 & 2,61 & 2,63 & 3,46 \\
\hline Sudeste & $-1,97$ & 0,36 & 3,40 & 4,80 & 4,37 \\
\hline Sul & $-0,64$ & 0,42 & 1,77 & 3,93 & 2,52 \\
\hline \multicolumn{6}{|c|}{ Necessidade de financiamento das finanças do governo } \\
\hline Norte & 12,05 & 3,12 & 0,41 & 5,51 & 1,28 \\
\hline Nordeste & 31,39 & 8,44 & 2,61 & 9,11 & 3,63 \\
\hline Centro-Oeste & 2,70 & $-0,23$ & 0,17 & 4,20 & 1,07 \\
\hline Sudeste & 2,41 & $-1,17$ & $-0,79$ & 7,58 & 0,97 \\
\hline Sul & 2,43 & $-0,43$ & $-0,15$ & 4,77 & 0,83 \\
\hline Federal & 6,42 & 0,42 & $-0,13$ & 6,90 & 1,29 \\
\hline
\end{tabular}

Fonte: Resultados da pesquisa

Tabela 18. Resultados em nível setorial das simulações para o emprego por setor.

\begin{tabular}{|c|c|c|c|c|c|}
\hline & \multicolumn{5}{|c|}{ Simulações } \\
\hline & \multicolumn{3}{|c|}{ Investimento } & \multicolumn{2}{|c|}{ Produtividade } \\
\hline & $\begin{array}{c}\text { Salário } \\
\text { nominal }\end{array}$ & $\begin{array}{r}\text { Concen- } \\
\text { trado }\end{array}$ & $\begin{array}{l}\text { Descon- } \\
\text { centrado }\end{array}$ & $0,1 \%$ & $0,5 \%$ \\
\hline \multicolumn{6}{|c|}{ Emprego por setor $(\%)$} \\
\hline Agropecuária & 7,47 & 3,26 & 1,62 & 10,18 & 3,08 \\
\hline Mineração e Minerais não-metálicos & 4,48 & 3,29 & 3,19 & 5,50 & 3,81 \\
\hline Metalurgia & $-2,34$ & 0,36 & 2,75 & 4,30 & 3,37 \\
\hline Mecânica & $-1,40$ & 0,63 & 2,77 & 3,74 & 3,30 \\
\hline Material Elétrico & $-0,83$ & 2,03 & 2,88 & 3,70 & 3,12 \\
\hline
\end{tabular}


Tabela 18. Resultados em nível setorial das simulações para o emprego por setor.

\begin{tabular}{|c|c|c|c|c|c|}
\hline & \multicolumn{5}{|c|}{ Simulações } \\
\hline & \multicolumn{3}{|c|}{ Investimento } & \multicolumn{2}{|c|}{ Produtividade } \\
\hline & $\begin{array}{c}\text { Salário } \\
\text { nominal }\end{array}$ & $\begin{array}{r}\text { Concen- } \\
\text { trado }\end{array}$ & $\begin{array}{l}\text { Descon- } \\
\text { centrado }\end{array}$ & $0,1 \%$ & $0,5 \%$ \\
\hline \multicolumn{6}{|c|}{ Emprego por setor $(\%)$} \\
\hline Material de Transporte & $-1,95$ & 0,10 & 2,80 & 4,99 & 3,69 \\
\hline Madeira, Mobiliário, Celulose, Papel e Gráficos & $-0,79$ & 1,61 & 2,72 & 4,00 & 3,08 \\
\hline Químicos, Diversos, Farmacêutica & $-0,41$ & 1,55 & 2,87 & 3,78 & 3,16 \\
\hline Indústrias Têxtil, Vestuário e Calçados & 0,99 & 1,49 & 3,00 & 4,01 & 3,68 \\
\hline Produtos Alimentares & 0,23 & 1,48 & 2,67 & 4,76 & 3,22 \\
\hline Indústrias Diversas & $-1,13$ & 0,87 & 2,80 & 4,54 & 3,44 \\
\hline Serviço Ind, de Utilidade Pública e Comunicações & 1,61 & 2,11 & 2,94 & 4,25 & 3,48 \\
\hline Construção Civil & 12,35 & 6,45 & 3,61 & 6,98 & 4,22 \\
\hline Comércio & 4,94 & 2,82 & 2,95 & 8,20 & 4,11 \\
\hline Transportes & 0,19 & $-0,91$ & 2,32 & 21,11 & 6,53 \\
\hline Serviços & 1,76 & 1,58 & 2,77 & 6,76 & 3,79 \\
\hline
\end{tabular}

Fonte: Resultados da pesquisa

Tabela 19. Resultados em nível setorial nas simulações para o nível de atividade.

\begin{tabular}{|c|c|c|c|c|c|}
\hline & \multicolumn{5}{|c|}{ Simulações } \\
\hline & \multicolumn{3}{|c|}{ Investimento } & \multicolumn{2}{|c|}{ Produtividade } \\
\hline & $\begin{array}{c}\text { Salário } \\
\text { nominal }\end{array}$ & $\begin{array}{r}\text { Concen- } \\
\text { trado }\end{array}$ & $\begin{array}{l}\text { Descon- } \\
\text { centrado }\end{array}$ & $0,1 \%$ & $0,5 \%$ \\
\hline \multicolumn{6}{|c|}{ Nível de atividade (\%) } \\
\hline Agropecuária & $-5,27$ & 2,36 & 4,19 & 2,29 & 4,47 \\
\hline Mineração e Minerais não-metálicos & 2,18 & 0,02 & 2,89 & 16,91 & 6,48 \\
\hline Metalurgia & $-2,01$ & 1,17 & 3,77 & $-7,63$ & 3,36 \\
\hline Mecânica & 10,42 & 7,54 & 3,84 & 6,30 & 4,82 \\
\hline Material Elétrico & $-0,48$ & $-1,01$ & 2,45 & 10,56 & 4,86 \\
\hline Material de Transporte & $-0,67$ & 2,59 & 3,04 & $-14,23$ & 0,19 \\
\hline Madeira, Mobiliário, Celulose, Papel e Gráficos & 7,58 & 5,74 & 3,05 & 7,74 & 4,41 \\
\hline Químicos, Diversos, Farmacêutica & 1,43 & 1,71 & 2,74 & 10,45 & 4,90 \\
\hline Indústrias Têxtil, Vestuário e Calçados & 1,69 & 2,02 & 2,54 & 16,83 & 5,53 \\
\hline Produtos Alimentares & $-1,46$ & 1,67 & 3,15 & 3,01 & 3,50 \\
\hline Indústrias Diversas & 3,50 & 5,18 & 3,37 & 8,49 & 4,98 \\
\hline Serviço Ind, de Utilidade Pública e Comunicações & 4,62 & 4,85 & 3,22 & 6,48 & 4,35 \\
\hline Construção Civil & 2,72 & 2,63 & 3,23 & 4,16 & 4,03 \\
\hline Comércio & 2,05 & 2,77 & 2,59 & 7,93 & 4,10 \\
\hline Transportes & 3,50 & 1,63 & 2,33 & 13,32 & 5,12 \\
\hline Serviços & 1,01 & 1,06 & 1,58 & 4,01 & 2,36 \\
\hline
\end{tabular}

Fonte: Resultados da pesquisa 
Tabela 20. Resultados em nível setorial nas simulações para o índice de preços no comércio inter-regional por produto.

\begin{tabular}{lrrrrr}
\hline & \multicolumn{4}{c}{ Simulações } \\
\cline { 2 - 6 } & \multicolumn{4}{c}{ Investimento } \\
\cline { 2 - 6 } & $\begin{array}{r}\text { Salário } \\
\text { nominal }\end{array}$ & $\begin{array}{r}\text { Concen- } \\
\text { trado }\end{array}$ & $\begin{array}{c}\text { Descon- } \\
\text { centrado }\end{array}$ & $0,1 \%$ & $0,5 \%$ \\
\hline \multirow{2}{*}{ Agropecuária } & Índice de preços no comércio & inter-regional & por produto $(\%)$ \\
Mineração e Minerais não-metálicos & 11,93 & 0,96 & $-3,68$ & 13,22 & $-0,97$ \\
Metalurgia & 9,36 & 4,52 & 0,44 & $-5,63$ & $-1,10$ \\
Mecânica & 7,18 & $-1,20$ & $-2,78$ & 36,66 & 2,42 \\
Material Elétrico & 2,60 & 0,09 & $-1,16$ & 9,34 & $-0,10$ \\
Material de Transporte & 7,72 & 4,52 & 0,44 & 2,27 & 0,27 \\
Madeira, Mobiliário, Celulose, Papel e Gráficos & 3,71 & $-2,85$ & $-1,60$ & 32,66 & 5,35 \\
Químicos, Diversos, Farmacêutica & 2,67 & 0,81 & $-0,14$ & $-2,85$ & $-0,92$ \\
Indústria Têxtil, Vestuário e Calçados & 9,57 & $-0,36$ & $-0,46$ & $-4,18$ & $-1,33$ \\
Produtos Alimentares & 5,59 & $-0,95$ & 0,24 & $-12,54$ & $-1,46$ \\
Indústrias Diversas & 10,50 & $-0,05$ & $-2,45$ & 9,90 & $-0,07$ \\
Serviço Ind, de Utilidade Pública e Comunicações & 4,08 & $-0,26$ & $-0,07$ & 0,23 & $-0,18$ \\
Construção Civil & 4,79 & 0,24 & 0,02 & 3,20 & 0,51 \\
Comércio & 8,27 & 0,92 & $-0,36$ & 8,54 & 1,06 \\
Transportes & 7,60 & $-0,34$ & 0,33 & 4,93 & 1,30 \\
Serviços & 3,05 & $-0,91$ & 0,28 & 8,20 & 2,04 \\
\hline
\end{tabular}

Fonte: Resultados da pesquisa

Tabela 21. Resultados das simulações para o índice de preços no fluxo de comércio inter-regional, por regiões de origem e de destino.

\begin{tabular}{lrrrrr}
\hline \multirow{2}{*}{ Região de origem } & \multicolumn{5}{c}{ Região de destino (\%) } \\
\cline { 2 - 6 } & Norte & Nordeste & Centro-Oeste & Sudeste & Sul \\
\cline { 2 - 6 } Norte & \multicolumn{5}{c}{ Salário nominal } \\
Nordeste & 13,79 & 17,99 & 26,04 & 24,46 & 30,08 \\
Centro-Oeste & 40,10 & 35,16 & 42,95 & 44,02 & 43,67 \\
Sudeste & 2,38 & 2,21 & 1,99 & 0,77 & 1,90 \\
Sul & 2,28 & 2,29 & 2,23 & 1,98 & 1,60 \\
& 3,03 & 3,99 & 3,26 & 4,99 & 3,03 \\
Norte & \multicolumn{5}{c}{ Investimento Concentrado } \\
Nordeste & 4,11 & 4,35 & 9,05 & & \\
Centro-Oeste & 8,49 & 8,68 & 9,02 & 6,16 & 8,41 \\
Sudeste & $-0,35$ & $-0,60$ & $-0,39$ & $-1,07$ & $-0,37$ \\
Sul & $-0,94$ & $-1,39$ & $-0,96$ & $-1,41$ & $-1,04$ \\
& $-0,50$ & $-0,86$ & $-0,45$ & $-1,07$ & $-0,45$
\end{tabular}

Investimento Desconcentrado 
Tabela 21. Resultados das simulações para o índice de preços no fluxo de comércio inter-regional, por regiões de origem e de destino.

\begin{tabular}{lrrrrr}
\hline & \multicolumn{5}{c}{ Região de destino (\%) } \\
\cline { 2 - 6 } Região de origem & Norte & Nordeste & Centro-Oeste & Sudeste & Sul \\
\cline { 2 - 6 } Norte & 0,49 & $-0,03$ & 0,19 & 0,39 & $-0,33$ \\
Nordeste & 2,87 & 2,84 & 3,00 & 2,17 & 2,81 \\
Centro-Oeste & 0,07 & $-0,31$ & $-0,04$ & $-1,01$ & 0,30 \\
Sudeste & $-0,87$ & $-1,54$ & $-1,26$ & $-1,02$ & $-0,34$ \\
Sul & $-0,69$ & $-1,24$ & $-1,24$ & $-1,90$ & $-0,99$ \\
& & Produtividade: $0,1 \%$ & & & \\
Norte & 6,60 & 4,42 & 3,78 & 4,07 & 4,55 \\
Nordeste & 8,76 & 9,97 & 8,10 & 6,27 & 6,90 \\
Centro-Oeste & 3,03 & 2,49 & 4,85 & 4,85 & 4,93 \\
Sudeste & 7,49 & 6,90 & 8,80 & 10,50 & 10,10 \\
Sul & 3,88 & 4,04 & 6,10 & 5,31 & 5,79 \\
& \multicolumn{7}{c}{ Produtividade: $0,5 \%$} & & & \\
Norte & 1,39 & 0,33 & 0,17 & 0,39 & $-0,14$ \\
Nordeste & 3,76 & 3,92 & 3,71 & 2,73 & 3,40 \\
Centro-Oeste & 0,71 & 0,32 & 0,97 & 0,03 & 1,35 \\
Sudeste & 0,59 & 0,05 & 0,32 & 1,16 & 1,59 \\
Sul & $-0,02$ & $-0,36$ & $-0,38$ & $-0,84$ & $-0,06$ \\
\hline
\end{tabular}

Fonte: Resultados da pesquisa

Tabela 22. Resultados das simulações para a variável quantidade do fluxo de comércio inter-regional, por regiões de origem e de destino.

\begin{tabular}{lcrrrr}
\hline \multirow{2}{*}{ Região de origem } & \multicolumn{5}{c}{ Região de destino (\%) } \\
\cline { 2 - 5 } & Norte & Nordeste & Centro-Oeste & Sudeste & Sul \\
\cline { 2 - 5 } Norte & \multicolumn{5}{c}{ Aumento do Salário nominal } \\
Nordeste & 2,12 & 12,44 & $-1,92$ & $-2,37$ & $-2,67$ \\
Centro-Oeste & 0,81 & 14,37 & $-1,49$ & $-1,96$ & $-1,75$ \\
Sudeste & 0,06 & 14,15 & $-0,79$ & $-1,81$ & $-0,01$ \\
Sul & 6,51 & 15,92 & $-1,37$ & $-1,27$ & $-0,47$ \\
& 3,76 & 11,56 & $-1,32$ & $-1,96$ & $-1,25$ \\
Norte & Gastos do governo e investimentos privilegiando Norte e Nordeste & \\
Nordeste & 7,78 & 9,38 & $-0,83$ & $-0,60$ & $-0,45$ \\
Centro-Oeste & 9,16 & 7,74 & 0,18 & 0,32 & 0,24 \\
Sudeste & 8,90 & 7,71 & 0,13 & 0,29 & 0,62 \\
Sul & 9,61 & 9,46 & 0,18 & 0,26 & 0,47 \\
& 9,35 & 7,19 & 0,01 & 0,71 & 0,14
\end{tabular}

Gastos do governo e investimentos menos concentrados 
Tabela 22. Resultados das simulações para a variável quantidade do fluxo de comércio inter-regional, por regiões de origem e de destino.

\begin{tabular}{lrrrrr}
\hline & \multicolumn{5}{c}{ Região de destino (\%) } \\
\cline { 2 - 6 } Região de origem & Norte & Nordeste & Centro-Oeste & Sudeste & Sul \\
\cline { 2 - 6 } Norte & 3,28 & 3,67 & 2,50 & 3,30 & 2,29 \\
Nordeste & 4,01 & 2,87 & 2,50 & 3,09 & 2,21 \\
Centro-Oeste & 3,80 & 2,92 & 2,39 & 3,06 & 1,57 \\
Sudeste & 3,79 & 3,53 & 2,66 & 2,51 & 1,73 \\
Sul & 3,79 & 2,71 & 2,49 & 3,70 & 1,90 \\
& Aumento da produtividade dos fatores em $0,1 \%$ & & \\
Norte & 3,44 & 3,84 & 4,29 & 4,51 & 3,64 \\
Nordeste & 3,99 & 4,35 & 4,68 & 4,37 & 3,80 \\
Centro-Oeste & 4,27 & 5,32 & 4,51 & 3,89 & 4,44 \\
Sudeste & 2,17 & 2,88 & 1,83 & 3,67 & 3,90 \\
Sul & 4,72 & 5,13 & 4,45 & 5,42 & 3,54 \\
& \multicolumn{5}{c}{} \\
Norte & Aumento da produtividade dos fatores em $0,5 \%$ & & \\
Nordeste & 3,37 & 3,85 & 3,71 & 4,39 & 3,28 \\
Centro-Oeste & 4,11 & 3,32 & 3,69 & 4,14 & 3,17 \\
Sudeste & 3,91 & 3,62 & 3,53 & 3,94 & 2,27 \\
Sul & 3,57 & 3,60 & 3,37 & 3,36 & 2,45 \\
\hline
\end{tabular}

Fonte: Resultados da pesquisa

\subsubsection{Aumento do salário nominal}

Aumentando-se o salário nominal em 5,5\%, dadas as propostas de políticas públicas do governo do PT, o PIB real praticamente não se altera, apesar dos gastos do governo combinados com aumento de investimentos e ganhos de produtividade dos fatores (Tabela16). A inflação, dada pelo índice de preços ao consumidor, aumenta consideravelmente, o que também acontece no índice de preços no fluxo de comércio inter-regional. $\mathrm{O}$ volume das exportações cai e o das importações aumenta, prejudicando a balança comercial tão importante para a economia brasileira. A Tabela 16 e a Figura 18 mostram que, apesar do aumento do emprego, a inflação, o aumento do índice de preços no fluxo de comércio inter-regional, e a situação desfavorárvel na balança comercial não compensam o pequeno aumento do PIB real, tendo em vista que o Brasil, após um longo período de inflação elevada, conseguiu controlá-la a partir de 1994 com a aplicação do Plano Real. É importante lembrar que o principal beneficiado do controle 
da inflação em níveis baixos foi a população mais pobre, que praticamente não tinha mecanismo de proteção do seu salário contra a inflação. Por isso, o aumento do salário nominal parece não ser interessante tendo como base as propostas de políticas do governo do PT.

Note que o PIB real no modelo MIBRA é deflacionado pelo deflator implícito do PIB e a Inflação é dada pelo índice de preços ao consumidor.

Em nível regional (Tabela 17) confirmam-se os resultados obtidos em nível nacional, só que fornecendo mais detalhes do que está provocando as variações mais relevantes. Os gastos do governo e dos investimentos alocados nas regiões Norte e Nordeste, assim como o aumento de produtividade nessas regiões definido na simulação, provocaram variações elevadas em boa parte das variáveis analisadas nessas regiões. A política simulada beneficiou as regiões Norte e Nordeste em termos de emprego mas com o sacrifício do aumento de desemprego nas outras áreas do país. O PIB real cresce efetivamente na região Norte, seguido pela região Sudeste. A região Nordeste, apesar de ser privilegiada em termos de gastos do governo, não consegue resultados mais interessantes para o PIB real, o que, por sua vez, é conseguido pela região Sudeste sem receber os gastos do governo e os investimentos. O melhor resultado do Sudeste em relação ao Nordeste é devido à importância que a região Sudeste tem para o crescimento das demais. Esta questão é discutida na simulação seguinte.

O resultado positivo do emprego em nível nacional (Tabela 16) é devido ao elevado valor do emprego que ocorre na região Nordeste (Tabela 17). O Nordeste tem algumas peculiaridades discutidas nas próximas simulações e na próxima seção que proporcionam resultados sistematicamente diferentes das demais regiões para algumas variáveis. A região Nordeste, segundo Gomes \& Vergolino (1995), depende muito dos gastos do governo devido ao problema econômico e social causado pela seca. Por isso, para manter a população do semi-árido nordestino, o governo mantém cargos públicos, muitas vezes, sem necessidade.

O emprego (Tabela 18), o nível de atividades por setor (Tabela 19) e o índice de preços no comércio inter-regional por produto (Tabela 20) demonstram o desequilíbrio 
que a política simulada proporciona, principalmente quando se compara com as outras simulações.

Os resultados que envolvem o índice de preços e a quantidade do fluxo de comércio inter-regional por região de origem e região de destino (Tabela 21 e Tabela 22), evidenciam, mais uma vez, a importância do Sudeste em relação às demais regiões,

principalmente às regiões Norte e Nordeste. Essa simulação mostra também o desequilíbrio em termos de resultados, principalmente no que diz respeito ao índice de preços no fluxo de comércio inter-regional das regiões Norte e Nordeste com as demais como origem.

Outro resultado desfavorável dessa simulação é o aumento elevado da necessidade de financimento das finanças do governo tanto em nível regional como em federal.

A dispersão dos resultados e os desequilíbrios encontrados em níveis mais desagregados mostram que os choques aplicados nesta simulação não proporcionam um crescimento ideal da economia brasileira e muito menos um crescimento sustentado. Comparando-se os resultados da simulação de aumento de salário nominal com as demais simulações, fica evidente essa questão.

\subsubsection{Aumento dos gastos do governo e dos investimentos}

Como o tratamento diferenciado para as regiões Norte e Nordeste em termos de gastos do governo delineado, pelo programa de governo do PT, chamou bastante atenção, foram realizadas duas simulações analisando a alocação dos gastos do governo e dos investimentos entre as diferentes regiões. Uma das simulações considerou a mesma variação e alocação utilizada na simulação do aumento de salário nominal. E a outra considerou uma variação menor, mas alocada de forma menos concentrada. Note que, nessas duas simulações, as variações no aumento da produtividade dos fatores foram consideradas iguais a zero para isolar os efeitos das diferentes alocações. Por isso, o único choque diferente de zero foi aplicado nos gastos do governo e nos investimentos.

Os resultados em nível nacional (Tabela 16) mostram que os ganhos em termos de crescimento econômico são melhores quando todas as regiões - e não só as regiões 
Norte e Nordeste -, sobretudo a Sudeste, são incluídas na política de desenvolvimento e crescimento econômico equilibrado. Isto fica evidente nos resultados em nível regional (Tabela 17), principalmente pelas variações observadas nos volumes de exportação e importação do comércio inter-regional. Nas Tabelas 18, 19 e 20 são evidenciados os melhores resultados também em nível setorial, quando a alocação não é concentrada em apenas duas regiões. Note que, mesmo com aumento menor no total dos investimentos e dos gastos do governo, a melhor alocação entre as regiões resulta em mais emprego por setor, maior nível de atividade setorial e uma inflação no fluxo de comércio interregional menor. Os resultados do nível de atividades por setor são importantes indicadores para a orientação da formulação de políticas setoriais.

Os resultados mostram também que as regiões mais desenvolvidas, principalmente a Sudeste, são fornecedoras da maior parte dos insumos e bens de capitais utilizados na produção das regiões Norte e Nordeste. Além disso, existem muito bens de consumo exportados pelas regiões Centro-Oeste, Sudeste e Sul para as regiões Norte e Nordeste. Assim, o desenvolvimento e crescimento econômico das regiões Norte e Nordeste depende do crescimento das demais regiões.

O índice de preços e a quantidade no fluxo de comércio (Tabela 21 e 22) mostram claramente que os desequilíbrios que ocorrem quando os gastos do governo e os investimentos são concentrados nas regiões Norte e Nordeste são eliminados com uma melhor alocação dos recursos públicos e dos investimentos. Outro indicador do melhor equilíbrio é a necessidade de financiamento das finanças do governo (Tabela 17), que obtém seus melhores resultados quando a alocação dos gastos do governo e dos investimentos é menos concentrada. Assim sendo, as políticas públicas para a diminuição das diferenças regionais devem ser ajustadas para conseguir um crescimento maior e mais equilibrado da economia brasileira. Ou seja, o Brasil cresce mais e de forma equilibrada se a política de investimentos e gastos públicos for direcionada para todas as regiões e não somente para as menos desenvolvidas. 


\subsubsection{Aumento da produtividade}

Nesta simulação, as variações do nível de gastos do governo e de investimentos são mantidas em $4 \%$ e a produtividade dos fatores de produção varia entre $0,1 \%$ e $0,5 \%$. Essa simulação mostra como o aumento da produtividade é importante para um desenvolvimento e crescimento econômico equilibrado ou sustentado, como é definido no programa de governo do petista. Como o novo governo deve aplicar políticas públicas voltadas para o social, é importante identificar e definir quais seriam as formas de proporcionar o crescimento econômico sustentado sem perder o caráter social, que é sempre bem vinda num país de grandes desigualdades sociais como o Brasil. Através das simulações. Constata-se que o governo do PT pode ter o caráter social, desde que se façam alguns ajustes nas suas políticas públicas propostas, entre os quais o aumento da produtividade resultante dos gastos do governo e dos investimentos.

Os resultados do aumento de $0,1 \%$ na produtividade dos fatores de produção parecem ser melhores, se não fosse por alguns detalhes que na economia brasileira são pontos críticos. Um desses é a inflação bem mais elevada na situação do aumento de $0,1 \%$ da produtividade dos fatores de produção. Para uma economia que conseguiu sair de um problema crônico de inflação alta, não é interessante correr o risco de ê-lo novamente, apesar dos melhores resultados em nível nacional (Tabela 16) em termos de emprego, PIB real, consumo real e nível de atividade. Note que a inflação e o índice de preços no comércio inter-regional geral têm variações maiores com o aumento de $0,1 \%$ na produtividade dos fatores. Outra piora ocorre na diferença entre os volumes das exportações e das importações que diminui.

Em nível regional, observa-se a mesma tendência (Tabela 17). Ou seja, os resultados para consumo real, emprego, salário real, PIB real e volume das exportações no comércio inter-regional são melhores para a situação de aumento de $0,1 \%$ da

produtividade dos fatores, com exceção da inflação que é muito elevada quando comparada à situação de aumento de $0,5 \%$ na produtividade dos fatores. Neste cenário, A inflação e o volume de importações têm variações menores.

Outro ponto crítico desfavorável para o aumento da produtividade dos fatores em $0,1 \%$ é o desequilíbrio que ocorre quando se analisam os resultados mais desagregados. 
Em nível regional (Tabela 17), observam-se maiores necessidades de financiamento das finanças públicas para a situação de aumento de $0,1 \%$ da produtividade dos fatores de produção. Os resultados do emprego por setor, do nível de atividade setorial e do índice de preços no fluxo de comércio inter-regional por produto apresentados na Tabela 18, 19 e 20, respectivamente, dão claros sinais de desequilíbrios no caso do aumento de $0,1 \%$ da produtividade dos fatores, apesar de apresentarem valores mais elevados. Note que os desequilíbrios também ocorrem nos resultados da variável índice de preços no fluxo de comércio inter-regional por regiões de origem e de destino (Tabela 21) para aumentos de $0,1 \%$ da produtividade dos fatores.

Já para aumentos de $0,5 \%$ dos fatores de produção, os índices de preços apresentam-se com variações pequenas com exceção do Nordeste como origem. Em relação a essa região, fica clara a necessidade de estudos sobre os valores elevados que ocorrem sistematicamente tanto para a inflação como para a necessidade de financimanto das finanças públicas em nível regional (Tabela 17) e também para o índice de preços no fluxo de comércio inter-regional (Tabela 21). Note que, em termos da quantidade do fluxo de comércio inter-regional (Tabela21), os valores para a região Nordeste estão bem próximos dos valores das demais áreas do país. Tais valores indicam alguma característica peculiar na região Nordeste que deve ser tratada com mais atenção pelos formuladores de políticas públicas e que mereceria um estudo detalhado para identificar o que está gerando estas diferenças.

Os desequilíbrios verificados nos resultados mais agregados são bem visíveis em nível setorial e regional. Os resultados do nível de atividade por setor e por região obtidos nas simulações de aumento dos gastos do governo e do investimentos e de aumento na produtividade dos fatores de produção estão nas Tabelas 23, 24, 25 e 26.

Note que os desequilíbrios discutidos anteriormente são bem visíveis nos resultados para o nível de atividades por setor e região nas situações de alocação concentrada (Tabelas 23) e de aumento insuficiente da produtividade dos fatores dado o nível de investimento (Tabela 25). Por outro hdo, verifica-se o maior equilíbrio nos resultados nas Tabelas 24 e 26, que são justamente as simulações que consideram uma 
alocação menos concentrada e aumentos de produtividade dos fatores de produção adequados para o nível de investimentos, respectivamente.

Tabela 23. Resultados em níveis setorial e regional para o nível de atividades na simulação de aumento dos gastos do governo e dos investimentos privilegiando as regiões Norte e Nordeste.

\begin{tabular}{lrrrrr}
\hline & \multicolumn{5}{c}{ Regiões (\%) } \\
\cline { 2 - 6 } Setores & Norte & Nordeste & $\begin{array}{r}\text { Centro- } \\
\text { Oeste }\end{array}$ & Sudeste & Sul \\
\hline Agropecuária & & & & & \\
Mineração e Minerais não-metálicos & 3,76 & 7,11 & 0,13 & 0,92 & 0,16 \\
Metalurgia & 3,47 & 9,89 & $-0,28$ & $-3,76$ & $-2,33$ \\
Mecânica & 8,24 & $-1,55$ & 0,20 & 1,45 & 2,57 \\
Material Elétrico & 10,23 & 11,45 & $-0,31$ & $-0,55$ & $-0,41$ \\
Material de Transporte & 0,21 & 8,57 & $-1,52$ & $-1,39$ & $-1,12$ \\
Madeira, Mobiliário, Celulose, Papel e Gráficos & 3,72 & 7,87 & 1,86 & 2,35 & 2,42 \\
Químicos, Diversos, Farmacêutica & 16,30 & 9,39 & $-0,68$ & $-1,07$ & $-0,59$ \\
Indústria Têxtil, Vestuário e Calçados & 9,90 & 17,77 & 0,03 & 0,15 & 0,23 \\
Produtos Alimentares & 11,48 & 19,20 & 0,03 & 0,11 & 0,08 \\
Indústrias Diversas & 6,28 & $-2,21$ & 0,88 & 1,90 & 1,37 \\
Serviço Ind. de Utilidade Pública e Comunicações & 9,19 & 15,75 & $-0,21$ & 0,27 & 0,16 \\
Construção Civil & 11,01 & 11,20 & 0,21 & 0,28 & 0,47 \\
Comércio & 10,03 & 10,13 & $-0,01$ & $-0,06$ & $-0,02$ \\
Transportes & 8,36 & 9,76 & 0,15 & 0,47 & 0,43 \\
Serviços & 9,64 & 8,94 & $-0,73$ & $-1,06$ & $-0,76$ \\
\hline
\end{tabular}

Fonte: Resultados da pesquisa

Tabela 24. Resultados em níveis setorial e regional para o nível de atividades na simulação de aumento dos gastos do governo e dos investimentos com alocação menos concentrada.

\begin{tabular}{lrrrrr}
\hline \multirow{2}{*}{ Setores } & \multicolumn{5}{c}{ Regiões (\%) } \\
\cline { 2 - 6 } & Norte & Nordeste & $\begin{array}{r}\text { Centro- } \\
\text { Oeste }\end{array}$ & Sudeste & Sul \\
\hline Agropecuária & 5,88 & 2,79 & 2,98 & 5,67 & 3,17 \\
Mineração e Minerais não-metálicos & 2,96 & 4,36 & 2,80 & 2,67 & 2,12 \\
Metalurgia & 3,66 & $-0,72$ & 2,72 & 4,92 & 7,39 \\
Mecânica & 3,94 & 4,40 & 3,15 & 2,96 & 2,67 \\
Material Elétrico & 2,54 & 3,32 & 2,64 & 2,50 & 1,90 \\
Material de Transporte & 3,26 & 3,75 & 2,87 & 3,18 & 2,47 \\
Madeira, Mobiliário, Celulose, Papel e Gráficos & 4,20 & 3,45 & 2,46 & 2,33 & 1,76 \\
Químicos, Diversos, Farmacêutica & 3,64 & 6,14 & 2,73 & 2,50 & 2,10 \\
Indústria Têxtil, Vestuário e Calçados & 3,82 & 5,92 & 2,63 & 2,56 & 2,02
\end{tabular}


Tabela 24. Resultados em níveis setorial e regional para o nível de atividades na simulação de aumento dos gastos do governo e dos investimentos com alocação menos concentrada.

\begin{tabular}{|c|c|c|c|c|c|}
\hline \multirow[b]{2}{*}{ Setores } & \multicolumn{5}{|c|}{ Regiões (\%) } \\
\hline & Norte & Nordeste & $\begin{array}{r}\text { Centro- } \\
\text { Oeste }\end{array}$ & Sudeste & Sul \\
\hline Produtos Alimentares & 3,50 & $-0,44$ & 2,48 & 3,83 & 2,77 \\
\hline Indústrias Diversas & 3,64 & 5,34 & 3,03 & 2,75 & 2,02 \\
\hline Serviço Ind. de Utilidade Pública e Comunicações & 4,01 & 4,14 & 2,71 & 2,86 & 2,23 \\
\hline Construção Civil & 4,00 & 4,04 & 2,98 & 2,96 & 2,87 \\
\hline Comércio & 3,05 & 3,81 & 2,23 & 2,43 & 1,68 \\
\hline Transportes & 2,88 & 4,01 & 2,81 & 1,85 & 1,71 \\
\hline Serviços & 2,11 & 1,77 & 2,14 & 1,51 & 1,14 \\
\hline
\end{tabular}

Fonte: Resultados da pesquisa

Tabela 25. Resultados em nível setorial e regional para o nível de atividades na simulação do aumento da produtividade em 0,1 .

\begin{tabular}{|c|c|c|c|c|c|}
\hline \multirow[b]{2}{*}{ Setores } & \multicolumn{5}{|c|}{ Regiões (\%) } \\
\hline & Norte & Nordeste & $\begin{array}{r}\text { Centro- } \\
\text { Oeste }\end{array}$ & Sudeste & Sul \\
\hline Agropecuária & 0,04 & 3,83 & 3,28 & 1,11 & 2,78 \\
\hline Mineração e Minerais não-metálicos & 6,06 & 6,12 & 8,43 & 27,07 & 24,27 \\
\hline Metalurgia & 0,87 & $-4,56$ & 0,02 & $-13,96$ & $-28,09$ \\
\hline Mecânica & 4,30 & 5,41 & 8,60 & 9,26 & 9,98 \\
\hline Material Elétrico & 5,87 & 6,02 & 10,62 & 11,32 & 11,08 \\
\hline Material de Transporte & $-9,50$ & $-6,01$ & $-11,94$ & $-13,87$ & $-18,49$ \\
\hline Madeira, Mobiliário, Celulose, Papel e Gráficos & 12,97 & 4,98 & 10,78 & 11,57 & 10,53 \\
\hline Químicos, Diversos, Farmacêutica & 5,49 & 11,69 & 8,01 & 10,94 & 9,09 \\
\hline Indústria Têxtil, Vestuário e Calçados & 9,85 & 14,83 & 16,59 & 17,31 & 17,15 \\
\hline Produtos Alimentares & 3,30 & 0,86 & 3,75 & 2,59 & 3,05 \\
\hline Indústrias Diversas & 7,61 & 8,60 & 9,86 & 8,61 & 8,42 \\
\hline Serviço Ind. de Utilidade Pública e Comunicações & 5,51 & 6,39 & 6,04 & 8,08 & 6,33 \\
\hline Construção Civil & 4,02 & 4,14 & 4,02 & 4,26 & 3,95 \\
\hline Comérc io & 6,48 & 8,94 & 6,55 & 8,52 & 6,68 \\
\hline Transportes & 7,67 & 7,45 & 14,86 & 15,04 & 15,62 \\
\hline Serviços & 2,86 & 2,95 & 4,90 & 3,97 & 4,74 \\
\hline
\end{tabular}

Fonte: Resultados da pesquisa 
Tabela 26. Resultados em nível setorial e regional para o nível de atividades na simulação do aumento da produtividade em $0,5 \%$.

\begin{tabular}{|c|c|c|c|c|c|}
\hline \multirow[b]{2}{*}{ Setores } & \multicolumn{5}{|c|}{ Regiões (\%) } \\
\hline & Norte & Nordeste & $\begin{array}{r}\text { Centro- } \\
\text { Oeste }\end{array}$ & Sudeste & Sul \\
\hline Agropecuária & 5,53 & 3,04 & 3,87 & 5,57 & 3,92 \\
\hline Mineração e Minerais não-metálicos & 4,27 & 5,02 & 4,97 & 8,64 & 6,85 \\
\hline Metalurgia & 3,68 & $-0,97$ & 3,46 & 3,64 & 4,63 \\
\hline Mecânica & 4,23 & 4,91 & 5,23 & 5,25 & 4,84 \\
\hline Material Elétrico & 3,86 & 4,12 & 5,17 & 5,15 & 4,18 \\
\hline Material de Transporte & 1,40 & 2,23 & 0,65 & 0,40 & $-1,22$ \\
\hline Madeira, Mobiliário, Celulose, Papel e Gráficos & 5,38 & 3,98 & 5,04 & 5,02 & 3,89 \\
\hline Químicos, Diversos, Farmacêutica & 4,14 & 7,03 & 4,74 & 4,94 & 3,98 \\
\hline Indústria Têxtil, Vestuário e Calçados & 4,71 & 7,23 & 6,03 & 5,78 & 5,21 \\
\hline Produtos Alimentares & 3,45 & $-0,13$ & 3,21 & 3,97 & 3,18 \\
\hline Indústrias Diversas & 4,65 & 6,00 & 5,57 & 4,89 & 3,91 \\
\hline Serviço Ind. de Utilidade Pública e Comunicações & 4,38 & 4,95 & 4,30 & 4,69 & 3,59 \\
\hline Construção Civil & 4,03 & 4,08 & 4,03 & 4,04 & 3,88 \\
\hline Comércio & 3,76 & 5,15 & 3,79 & 4,20 & 2,90 \\
\hline Transportes & 3,75 & 5,70 & 6,15 & 5,26 & 4,59 \\
\hline Serviços & 2,19 & 2,18 & 3,25 & 2,32 & 2,08 \\
\hline
\end{tabular}

Fonte: Resultados da pesquisa

As variações não são muito grandes quando se combina aumento dos gastos e, investimentos do governo com aumento da produtividade dos fatores de produção já que aumentar a produtividade dos fatores de produção capital, terra e trabalho implica na incorporação de investimentos na forma de novas tecnologias, na realização de pesquisas científicas e maior capacitação profissional da força de trabalho. Essas melhorias podem ser percebidas no aumento do volume das exportações, o que significa que a economia brasileira tornou-se mais competitiva e, por isso, conseguiu aumentar as suas vendas externas. Já as importações aumentam proporcionalmente menos que as exportações, indicando o efeito do aumento da produtividade dos fatores de produção. É importante lembrar que a incorporação de novas tecnologias, obtenção efetiva dos resultados de pesquisas e da melhor formação e capacitação profissional da força de trabalho não são imediatas. Ou seja, essas melhorias provenientes do aumento da produtividade dos fatores levam um certo tempo até que sejam incorporadas no processo produtivo. Provavelmente, uma análise dinâmica poderia mostrar melhor o efeito dos 
investimentos e gastos do governo orientados para o aumento da produtividade dos fatores de produção na economia brasileira. De qualquer forma, para conseguir um aumento na produtividade dos fatores de produção, é necessário realizar investimentos que têm resultados de médio e longo prazos. Isto significa que o novo governo deverá pensar em planejamento e investimentos públicos num período de tempo maior que os quatro anos do mandato, deixando de lado a visão imediatista que geralmente não contempla essas mudanças na estrutura produtiva brasileira.

De acordo com os resultados apresentados nas simulações, o que parece ser mais interessante no longo prazo é a combinação das políticas de governo do PT em nível federal com investimentos e gastos do go verno orientados efetivamente para o aumento de produtividade dos fatores de produção. Ou seja, um aumento de $4 \%$ nos gastos do governo e nos investimentos em todas as regiões, orientados para aumentar a produtividade dos fatores de produção em pelo menos $0,5 \%$, consegue aumentar o PIB real em 3,14\%, controlar a inflação, aumentar o emprego em 4,03\% e o consumo real em $3,17 \%$. Além disso, consegue-se elevar as exportações em 9,11\% aumentando as importações em apenas $3,76 \%$, o que favorece a balança comercial brasileira e aumenta as reserva internacionais.

Mas, o resultado mais interessante é o aumento da competividade brasileira internacionalmente proveniente do aumento da produtividade dos fatores de produção, que diminui a vulnerabilidade externa - citada nas propostas de governo do PT - e aumenta o consumo real na economia. Por isso, realizar políticas sociais que não melhorem a formação educacional e profissional da população brasileira pode limitar o resultados da política voltada ao social delineada nas propostas de governo do PT. O pior de tudo, como mostram as simulações, é a possibilidade da inflação voltar como era antes do Plano Real, perdendo-se assim todo o esforço e sacrifício da economia e da população brasileira desde 1994.

Com alguns ajustes, a política pública apresentada no programa de governo do PT para os próximos quatro anos, pode promover aumento do emprego, do consumo real, da produção real e, simultaneamente, manter a inflação sob controle. Por isso, o uso de modelos aplicados de equilíbrio geral se prestam como instrumento poderoso para a 
definição e planejamento das políticas públicas, principalmente quando o modelo é inter-regional, característica fundamental para um país como o Brasil, que precisa resolver os problemas das diferenças econômicas e sociais em nível regional.

\subsection{Análise de sensibilidade}

De acordo com a apresentação feita no capítulo da metodologia, a análise de sensibilidade permite verificar como o resultado da simulação varia se aumentar ou diminuir um ou mais parâmetros ou variáveis exógenas. Note que a análise de sensibilidade é similar à análise do preço-sombra da programação linear.

A análise de sensibilidade pelo método Liu foi realizada na solução de uma simulação de aumento de $5 \%$ dos investimentos e gastos do governo combinado com um aumento uniforme de $0,5 \%$ da produtividade do trabalho, do capital e da terra. A análise de sensibilidade sistemática pode ser realizada em parâmetros como os de distribuição de investimento BETR ou em variáveis exógenas, como as produtividade dos fatores de produção. Dessa forma, utilizou-se a variável produtividade do fator de produção trabalho para fins de análise de sensibilidade sistemática. A variável produtividade do fator de produção trabalho é, na verdade, um bloco de variáveis com dimensão 80, ou seja, 16 setores e 5 macrorregiões. Para verificar o efeito da variação do choque aplicado em cada um dos elementos da variável, é necessário, de acordo com o método Liu, realizar 256 simulações. A variação definida para esta análise de sensibilidade foi de $10 \%$.

Na Tabela 27 são apresentados os resultados da análise de sensibilidade para as variáveis em nível nacional, variando o choque na variável produtividade do fator trabalho. Note que a apresentação típica dos resultados de análise de sensibilidade são em três colunas: a primeira com o resultado obtido na simulação original, a segunda com a média dos resultados e a terceira com o desvio padrão, ambas obtidas nas simulações da análise de sensibilidade sistemática. 
Tabela 27. Resultado em nível nacional da análise de sensibilidade sobre a variável produtividade do fator trabalho.

\begin{tabular}{lrrr}
\hline & Observado & Média & Desvio padrão \\
\hline Desemprego & $-4,91$ & $-4,82$ & 1,01 \\
Consumo real & 3,97 & 3,99 & 0,92 \\
Volume das exportações & 11,56 & 11,82 & 3,33 \\
Volume das importações & 5,25 & 5,28 & 2,76 \\
Inflação & 1,22 & 1,26 & 0,72 \\
PIB real & 3,76 & 3,82 & 0,85 \\
\hline
\end{tabular}

Fonte: Resultados da pesquisa

Para a variável desemprego, o valor médio, em módulo, ficou abaixo do observado o que significa que existem combinações em nível setorial e regional que permitem obter resultados menores em módulo. O desvio padrão para a variável desemprego indica que, nas 256 simulações da análise de sensibilidade, os resultados variaram 1,01\% em torno da média $-4,82 \%$. Os modelos aplicados de equilíbrio geral são não-estocásticos e a análise de sensibilidade permite, ainda que de forma simples, que sejam utilizados alguns ferramentais comuns aos modelos estocásticos nos modelos aplicados de equilíbrio geral. Assim, com o número de simulações, a média e o desvio padrão obtidos na análise de sensibilidade, é possível calcular o intervalo de confiança para os resultados obtidos na simulação. A análise de sensibilidade mostra que os resultados em nível nacional obtidos na simulação original são menores que a média.

Na Tabela 28 são apresentados os resultados da análise de sensibilidade sistemática do choque sobre a variável produtividade do fator de produção trabalho para algumas variáveis em nível regional.

Tabela 28. Resultados da análise de sensibilidade do choque sobre a variável produtividade do fator de produção trabalho.

\begin{tabular}{llrrr}
\hline & Observado & Média & Desvio padrão \\
\hline Consumo Real & Norte & 4,12 & 4,22 & 2,05 \\
& Nordeste & 3,13 & 3,10 & 1,39 \\
& Centro-Oeste & 3,91 & 3,95 & 0,60 \\
& Sudeste & 4,78 & 4,75 & 0,91 \\
& Sul & 2,10 & 2,23 & 1,46
\end{tabular}


Tabela 28. Resultados da análise de sensibilidade do choque sobre a variável produtividade do fator de produção trabalho.

\begin{tabular}{llrrr}
\hline & & Observado & Média & Desvio padrão \\
\hline Inflação & Norte & 1,19 & 1,10 & 1,67 \\
& Nordeste & 5,11 & 4,65 & 1,75 \\
& Centro-Oeste & 0,94 & 0,96 & 0,36 \\
& Sudeste & 0,68 & 0,84 & 0,65 \\
& Sul & 0,49 & 0,49 & 0,94 \\
PIB real & Norte & & & \\
& Nordeste & 4,41 & 4,51 & 1,34 \\
& Centro-Oeste & 3,86 & 3,94 & 1,17 \\
& Sudeste & 3,53 & 3,58 & 0,64 \\
& Sul & 4,32 & 4,29 & 0,50 \\
& & 3,59 & 3,66 & 0,92 \\
Salário real & & & 1,06 \\
& Norte & 0,04 & 0,16 & 1,11 \\
& Nordeste & $-4,03$ & $-3,52$ & 0,39 \\
& Centro-Oeste & 0,29 & 0,30 & 0,37 \\
& Sudeste & 0,60 & 0,46 & 0,51 \\
& Sul & 0,74 & 0,77 & 1,37 \\
& & & & 2,06 \\
Emprego & Norte & 4,55 & 4,57 & 0,88 \\
& Nordeste & 8,25 & 7,57 & 1,10 \\
& Centro-Oeste & 4,16 & 4,23 & 0,73 \\
\hline & Sudeste & 4,82 & 5,00 &
\end{tabular}

Fonte: Resultados da Pesquisa

Em nível regional, verifica-se que a dispersão dos resultados para as regiões Norte e Nordeste são, de uma maneira geral, maiores que para as demais o que permite inferir que a variação no choque aplicado na variável produtividade do fator de produção trabalho tem efeitos diferentes no resultado da simulação. Esta maior dispersão dos resultados quando se varia o choque na variável produtividade do fator trabalho mostra as diferenças existentes dentro das economias das regiões Norte e Nordeste em relação às outras macrorregiões do país.

Tendo como base a solução da simulação que considera aumento de $5 \%$ nos investimentos e gastos do governo combinado com crescimento de $0,5 \%$ da produtividade dos fatores de produção trabalho, terra e capital, foi realizada uma análise de sensibilidade sistemática no parâmetro de distribuição do investimento que também 
tem dimensão 80, ou seja, 16 setores e cinco regiões. A variação usada nesta análise de sensibilidade foi de $10 \%$, o mesmo valor usado na análise de sensibilidade anterior. Também pelo método Liu, foram realizadas 256 simulações para obter os resultados da análise de sensibilidade apresentados nas Tabelas 29 e 30.

Tabela 29. Resultados em nível nacional da análise de sensibilidade sobre o parâmetro de distribuição de investimento (BETR).

\begin{tabular}{lrrr}
\hline & Observado & Média & Desvio padrão \\
\hline Desemprego & $-4,91$ & $-4,57$ & 0,44 \\
Consumo real & 3,97 & 3,94 & 0,13 \\
Volume das exportações & 11,56 & 12,17 & 0,13 \\
Volume das importações & 5,25 & 5,63 & 0,07 \\
Inflação & 1,22 & 1,21 & 0,11 \\
PIB real & 3,76 & 3,77 & 0,05 \\
\hline
\end{tabular}

Fonte: Resultados da pesquisa

Mudanças no parâmetro de distribuição dos investimentos (BETR) proporcionam uma dispersão menor nos resultados da sua análise de sensibilidade (Tabela 29) quando comparadas com a análise de sensibilidade realizada no choque da variável produtividade do fator trabalho, apresentada na Tabela 27. Em termos de medida de tendência central, não existe um padrão definido em relação aos resultados obtidos na simulação original.

Os resultados apresentados na Tabela 30 mostram que não existe um padrão típico tanto em relação à medida de tendência central como para a medida de dispersão, conforme constatado na análise do choque na variável produtividade do fator trabalho (Tabela 28). A magnitude dos valores da dispersão é menor para análise de sensibilidade do parâmetro de distribuição do investimento quando comparada com os resultados da análise de sensibilidade para o choque na variável produtividade do fator trabalho. 
Tabela 30. Resultados da análise de sensibilidade do choque sobre o parâmetro distribuição de investimento (BETR).

\begin{tabular}{|c|c|c|c|c|}
\hline & & Observado & Média & $\begin{array}{l}\text { Desvio } \\
\text { padrão }\end{array}$ \\
\hline \multirow[t]{5}{*}{ Consumo Real } & Norte & 4,12 & 3,99 & 0,19 \\
\hline & Nordeste & 3,13 & 2,77 & 0,46 \\
\hline & Centro-Oeste & 3,91 & 3,98 & 0,03 \\
\hline & Sudeste & 4,78 & 4,80 & 0,09 \\
\hline & Sul & 2,10 & 2,08 & 0,07 \\
\hline \multirow[t]{5}{*}{ Inflação } & Norte & 1,19 & 1,13 & 0,10 \\
\hline & Nordeste & 5,11 & 4,03 & 1,14 \\
\hline & Centro-Oeste & 0,94 & 0,97 & 0,02 \\
\hline & Sudeste & 0,68 & 0,87 & 0,07 \\
\hline & Sul & 0,49 & 0,54 & 0,02 \\
\hline \multirow[t]{5}{*}{ PIB real } & Norte & 4,41 & 4,43 & 0,01 \\
\hline & Nordeste & 3,86 & 3,87 & 0,05 \\
\hline & Centro-Oeste & 3,53 & 3,60 & 0,02 \\
\hline & Sudeste & 4,32 & 4,18 & 0,13 \\
\hline & Sul & 3,59 & 3,60 & 0,07 \\
\hline \multirow[t]{5}{*}{ Salário real } & Norte & 0,04 & 0,08 & 0,01 \\
\hline & Nordeste & $-4,03$ & $-2,89$ & 1,08 \\
\hline & Centro-Oeste & 0,29 & 0,24 & 0,10 \\
\hline & Sudeste & 0,60 & 0,37 & 0,19 \\
\hline & Sul & 0,74 & 0,66 & 0,13 \\
\hline \multirow[t]{5}{*}{ Emprego } & Norte & 4,55 & 4,40 & 0,19 \\
\hline & Nordeste & 8,25 & 6,47 & 1,85 \\
\hline & Centro-Oeste & 4,16 & 4,33 & 0,10 \\
\hline & Sudeste & 4,82 & 5,10 & 0,12 \\
\hline & Sul & 1,78 & 1,89 & 0,09 \\
\hline
\end{tabular}

Fonte: Resultados da pesquisa

Outro resultado que reforça a necessidade de um estudo mais detalhado para a região Nordeste é a dispersão apresentada nas variáveis emprego, consumo real, salário real e inflação. A população da região semi-árida do Nordeste é praticamente mantida por transferências de recursos públicos através da previdência social e de outros benefícios sociais, bem como por meio da manutenção de empregos por parte do governo sem muita necessidade (Gomes \& Vergolino, 1995). Por isso, os aumentos dos gastos públicos na região Nordeste acabam sendo carreados para o consumo e não para 
os investimentos necessários para um desenvolvimento e crescimento econômico sustentados.

Uma provável solução dos desequilíbrios encontrados nos resultados das simulações para a região Nordeste é um tratamento diferenciado em termos de políticas para que os recursos públicos gastos também sejam convertidos em investimentos nos pólos dinâmicos do Nordeste, como as regiões metropolitanas e a Zona da Mata, aos quais se refere Gomes \& Vergolino (1995).

O fato de existir a possibilidade de melhorar os resultados da economia aumentando a produtividade do fator trabalho, como foi verificado nos resultados da análise de sensibilidade sistemática, reforça a idéia de que o desenvolvimento e crescimento econômico sustentados podem ser efetivamente voltados para o social se as políticas públicas concentrarem o foco na produtividade do fator trabalho. De acordo com Bonelli (2002), a produtividade do trabalho na economia brasileira aumentou na década de 90, revertendo a trajetória de taxas decrescentes no aumento da produtividade na década de 80 . Boa parte desse ganho de produtividade, como destaca o autor, foi convertido em aumentos no PIB real, também revertendo a tendência observada na década anterior.

Estudos específicos sobre a produtividade do trabalho utilizando modelos AEG regional como MIBRA poderiam fornecer informações importantes sobre os impactos do aumento de produtividade do trabalho em níveis regional e setorial. Bonelli (2002) destaca por exemplo, que na década de 90 os setores de serviços, transporte e comércio foram os que menos tiveram aumentos de produtividade do trabalho. Apesar do autor não ter conseguido resultados mais abrangentes, ele destaca a necessidade de aumentar a produtividade do trabalho nesses setores. Essa medida é de suma importância para não correr o risco de prejudicar o aumento da produtividade agregada e também pelo fato que esses setores são responsáveis pela maior parcela de empregos na economia brasileira. 


\section{CONCLUSÕES}

As propostas do novo governo, agora em nível federal, merecem análises fundamentadas, principalmente aquelas que tentam diminuir as diferenças sociais e regionais e propõem os investimentos e gastos do governo para incentivar o aumento da produtividade dos fatores de produção, sobretudo do trabalho. Por isso, o sucesso da nova gestão federal depende da atenção e do cuidado em relação aos investimentos e gastos públicos que devem ser orientados para o aumento da produtividade dos fatores. É interessante lembrar que outros pontos críticos, como a reforma tributária, maior eficiência na coleta de impostos e na gestão fiscal, além da reforma da previdências entre outras também devem ser resolvidos. Só combinando os investimentos e gastos do governo com o aumento da produtividade dos fatores de produção é possível aumentar emprego, PIB real, exportações e o consumo real sem perder o controle da inflação. Por isso, as políticas do novo governo precisam ser orientadas de modo que o caráter social melhore não só a qualidade de vida do trabalhador mas também a sua formação e capacitação profissional sem penalizar a economia brasileira e as finanças públicas.

Outro aspecto importante, ainda ligado à produtividade dos fatores, é o investimento em pesquisas e desenvolvimento tecnológico com o objetivo de aumentar a nacionalização dos produtos e bens de capital que têm insumos ou componentes importados e tornar a economia brasileira competitiva e menos vulnerável internacionalmente. Por isso, políticas voltadas para diminuição da fome e da pobreza através dos gastos do governo com repasse direto à população mais necessitada são compatíveis com desenvolvimento e crescimento econômico sustentados desde que se procedam alguns ajustes. Esses são necessários para que os gastos públicos sejam 
convertidos tanto em melhorias sociais como em aumentos da produtividade do fator trabalho.

Os resultados da simulação do aumento de 5,5\% do salário nominal mostra que aumento de salário nominal combinado com as propostas de políticas do governo do PT são incompatíveis. Por isso, o aumento geral dos salários na economia deve ser acompanhado por uma compensação que, de acordo com as outras simulações realizadas neste trabalho seria o aumento da produtividade do fator trabalho.

A região Sudeste, de maneira mais expressiva, é importante para o desenvolvimento e crescimento das demais, o que chama a atenção para a distribuição do investimento e gastos do governo entre todas as regiões. O Sudeste tem o papel de fornecer insumos, bens de capital e alguns bens de consumo para as demais regiões. Como foi observado nos resultados, um menor valor total de gastos do governo e de investimentos alocados de forma menos concentrada proporcionou melhores resultados que um valor maior de gastos e investimentos concentrados em duas regiões. Dessa forma, estimular e dar condições para o crescimento de todas as regiões e não de forma diferenciada, proporcionam um crescimento maior da economia brasileira com diminuição das diferenças sociais e econômicas em nível regional de forma efetiva. Mas, por outro lado, é importante destacar que a maior dependência das regiões menos desenvolvidas em relação aos insumos básicos e aos bens de capital pode ser diminuída e, eventualmente, eliminada, desde que os políticos e governantes abandonem a visão imediatista e passem a formular as políticas de desenvolvimento e crescimento econômico tendo como horizonte um longo prazo, muito além dos seus mandatos. Assim, seria possível mudar a estrutura de produção em nível regional e diminuir as diferenças regionais.

Os desequilíbrios que ocorrem entre as regiões ficam mais visíveis quando se analisam as informações do fluxo de comércio inter-regional. A variação observada, por exemplo, nos índices de preços do fluxo de comércio inter-regional permitiu visualizar como a concentração dos gastos do governo afeta o fluxo de comércio das regiões Norte e Nordeste. Assim, o modelo MIBRA também pode fornecer informações para políticas regionais de forma a aumentar os fluxos de comércio inter-regional ou identificar as 
limitações em níveis setorial e regional que restringem uma maior interação comercial entre as regiões. Uma análise muito interessante, que fica como sugestão de trabalhos futuros, seria verificar como o setor de transportes no Brasil afeta o fluxo de comércio inter-regional, bem como toda a economia brasileira.

Apesar de ter deixado exógena a variável salário real em nível nacional para permitir a observação do comportamento da variável desemprego em nível nacional, é possível verificar de forma bem evidente a transferência do aumento da produtividade dos fatores de produção através dos incrementos nas variáveis consumo real, PIB real e oferta de emprego.

A análise de sensibilidade sistemática mostroutse bastante útil na avaliação do impacto da variação do choque em variáveis exógenas e do impacto da variação de parâmetros do modelo. Através da análise de sensibilidade, verificou-se que a variação dos choques na produtividade do fator trabalho proporciona resultados para as regiões Norte e Nordeste com dispersão elevada. Isso indica diferentes respostas ao aumento da produtividade do fator trabalho e, por isso, devem ser tratadas com mais atenção nessas duas regiões. A análise de sensibilidade no parâmetro distribuição de investimento mostrou que os resultados da simulação não mudam de forma significativa quando se varia esse parâmetro. Por isso, o aumento da produtividade do fator trabalho é mais sensível a políticas do que a mudanças na distribuição do investimento em níveis setorial e regional.

Através dos resultados para emprego, inflação e salário real, a região Nordeste mostrou ter algumas diferenças em relação as demais. Tais diferenças justificam um estudo mais detalhado da economia em níveis setorial e regional pois provavelmente pode requerer um tratamento diferenciado em termos de políticas do governo federal que não seja de investimentos e gastos públicos. Como foi discutido na seção da análise de sensibilidade sistemática, as diferenças nos resultados da região Nordeste em relação às demais podem ser explicadas pelos repasses dos recursos públicos através da previdência social e de benefícios sociais, bem como por meio da manutenção de empregos públicos para atender à população do Nordeste semi-árido. É interessante lembrar que o Nordeste tem os seus pólos econômicos dinâmicos, que são as regiões 
metropolitanas e a Zona da Mata que podem e devem ser estimulados de modo que compensem a estagnação econômica do restante da região.

$\mathrm{O}$ aumento da produtividade dos fatores de produção, é importante no médio e longo prazos para o desenvolvimento e crescimento econômico sustentados, discutidos no programa de governo do PT. Boa parte do efeito do aumento da produtividade ocorre através da incorporação de novas tecnologias de produção, no desenvolvimento de pesquisas e novas tecnologias, na melhor formação e capacitação do trabalhador brasileiro.

O aumento da produtividade dos fatores de produção proporciona aumentos nas exportações com aumento de importações proporcionalmente menor, o que significa maior competitividade da economia brasileira internacionalmente e menor dependência externa em termos de tecnologia. É importante lembrar que a incorporação de novas tecnologias, obtenção efetivas dos resultados de pesquisas e a melhor formação e capacitação profissional da força de trabalho, não são imediatas. Essas melhorias provenientes do aumento da produtividade dos fatores levam um certo tempo até que sejam incorporadas no processo produtivo. Assim, o aumento na produtividade dos fatores de produção depende de investimentos que têm resultados de médio e longo prazos. Isso significa que o novo governo deverá pensar em planejamento e investimentos públicos num período de tempo maior que os quatro anos do mandato, deixando de lado a visão imediatista que geralmente não contempla essas mudanças na estrutura produtiva brasileira.

Tendo como base a discussão realizada na seção de análise de sensibilidade sobre a questão da produtividade do trabalho, ressalta-se que o fator de produção trabalho precisa aumentar, sobretudo nos setores de serviço, transporte e comércio - que são responsáveis pela maior parcela de emprego na economia brasileira - para que o PIB real também aumente. Dessa forma, uma sugestão de trabalho futuro é analisar de forma específica a questão sobre como aumentar a produtividade do trabalho nestes setores.

Outro resultado interessante obtido nas simulações é como a necessidade de financiamento do governo tem variações positivas menores quando os choques são aplicados de forma a ter resultados mais equilibrados em todos os níveis. Assim, a 
tentativa de não aumentar a dívida pública pode ser conseguida como subproduto de uma política de desenvolvimento e crescimento econômico bem aplicada e conduzida.

A aplicação do modelo MIBRA com novas equações de investimento para análise das propostas de governo do PT em nível federal, bem como o teste de homogeneidade, apresentam resultados bons e interessantes, confirmando que o modelo está consistente. Mas, como ainda está na fase final de adaptação à realidade brasileira, faltam alguns ajustes que permitirão utilizar o modelo MIBRA na abordagem de dinâmica recursiva e eliminar algumas possíve is inconsistências na estrutura do sistema de equações que não tenham sido identificadas nos ajustes realizados até o momento. Por isso sugerem-se, como trabalhos futuros no modelo MIBRA: realizar os ajustes finais para completar a total adaptação do modelo MIBRA à realidade brasileira; atualizar o banco de dados para um ano mais recente, como 1999, por exemplo, e com um número maior de setores para permitir uma efetiva análise das políticas em nível setorial; e melhorar a modelagem das equações do módulo de finanças do governo e do módulo demográfico. Muitos pesquisadores concordam com a importância do módulo demográfico dentro dos modelos aplicados de equilíbrio geral, mas, há poucos trabalhos sendo desenvolvidos para melhorar as suas equações.

O uso de modelos aplicados de equilíbrio geral é, portanto, um instrumento poderoso para a definição e planejamento das políticas públicas, principalmente quando o modelo é inter-regional, característica importante para um país como o Brasil que precisa resolver os problemas das diferenças econômicas e sociais em nível regional. 
ANEXO 
!

\section{1: PRELIMINARES}

1.1: Modelo Inter-regional para a Economia Brasileira (MIBRA) 2: Modulo central do MIBRA

2.1: Arquivos para TODOS os modulos

2.2: Nomes de Conjunto e subconjunto comuns para TODOS os modulos

2.3: Declaracoes de variaveis para o modulo central

2.3.1: Sistema de nomes para variaveis no modulo central AEG

2.3.2: Variaveis macro nacionais em ordem alfabetica

2.3.3: Variaveis vetores nacionais em ordem alfabetica

2.3.4: Variaveis macro regionais em ordem alfabetica

2.3.5: Variaveis vetores regionais in ordem alfabetica

2.3.6: Variaveis matrizes regionais em ordem alfabetica

2.4: Declaracao de coeficientes para o modulo central

2.4.1: Sist. de nomes p/ os fluxos de bens no banco de dados de ins.-prod.

2.4.2: Fluxos de bens do banco de dados de insumo-produto

2.4.3: Fluxos de fatores primarios do banco de dados de insumo-produto

2.4.4: Fluxos de importacoes e tarifas do banco de dados de insumo-produto

2.4.5: Elasticidades de substituicao (Armington) e outros parametros

2.4.6: Valores das aquisicoes

2.4.7: Agregados de pagamento de fatores

2.4.8: Demanda final agregada

2.4.9: Impostos agregados

2.4.10: $P I B$

2.4.11: Fluxos de comercio inter-regional

2.4.12: Elasticidades e parametros para demandas das familias

2.4.13: Custos e vendas agregadas

2.4.14: Coeficientes de mapeamento para domestico/estrangeiro e tiny

2.5: Declaracoes de leitura para o modulo central

2.5.1: Pagto. de fatores e fluxos de bens do banco de dados de ins. -prod.

2.5.2: Parametros

2.6: Declaracoes de atualizacao para o modulo central

2.7: Formulas para o modulo central

2.7.1: Formulas para tarifas

2.7.2: Formulas para valores das aquisicoes

2.7.3: Formulas para agregados de pagamento de fator

2.7.4: Formulas para agregados de demanda final

2.7.5: Formulas para agregados de importacao

2.7.6: Formulas para agregado de receita de imposto

2.7.7: Formulas para O PIB /Formulae for GDP

2.7.8: Formulas para o fluxos de comercio inter-regional

2.7.9: Formulas para demandas da familia

2.7.10: Formulas para custos e vendas agregadas

2.7.11: Formulas para variaveis binarias e tiny

2.8: Equacoes do modulo central em ordem tematica

2.8.1: Demandas para insumos intermediarios por industrias - usuario 1

2.8.2: Demandas de fator primario, precos e ofertas

2.8.3: Demandas por criacao de capital por industria - usuario 2

2.8.4: Demandas das familias por mercadorias - usuario 3

2.8.5: Taxas de impostos

2.8.6: Precos de compra das mercadorias

2.8.7: Receitas de impostos

2.8.8: Demandas por exportacoes

2.8.9: Demandas por mercadorias para outros gastos regionais

2.8.10: Demandas por mercadorias para outros gastos federais

2.8.11: Margin usage of commodities

2.8.12: Oferta igual a demanda por mercadorias domesticas e importadas

2.8.13: Precos basicos /Basic prices

2.8.14: Componentes do PIB regional, real e nominal

2.8.15: PIB nacional, real e nominal e seus componentes

2.8.16: Indices de preco regional e nacional

2.8.17: Definicoes de salario dinheiro 
2.8.18: Definicoes miscelaneas de precos fatores

2.8.19: Agregados de Emprego

3: MODULO DE FINANCAS DO GOVERNO

3.1: Sistema de nomes no modulo de financas do governo

3.2: Declaracoes de variavel para o modulo de financas do governo

3.3: Declaracoes de coeficientes para o modulo de financas do governo

3.4: Declaracoes de leitura para o modulo de financas do governo

3.5: Declaracoes de atualizacao para modulo de financas do governo

3.6: Formulas para o modulo de financas do governo

3.7: Coef. comuns ao mod. de finan. do gov. e de merc.de trab./migrac. reg.

3. 8: Equacoes do modulo de financas do governo

3.8.1: Componentes do valor adicionado do produto regional

3.8.2: Produto regional bruto e seus componentes

3.8.3: Variaveis intermediarias

3.8.4: Componentes de renda e gastos das financas do governo

3.8.5: Rendas das familias e seus componentes

3.8.6: Equacoes miscelaneas do modulo de financa do governo

4: MODULO DE INVESTIMENTO E TAXA DE RETORNO

4.1: Declaracoes de variaveis

4.2: Declaracoes de coeficientes

4.3: Leituras, Atualizacoes e Formulas

4.4: Equacoes

5: MODULO DE SIMULACAO ANO A ANO

5.1a: Declaracoes de variaveis

5.2a: Declaracoes de coeficientes

5.3a: Leituras, atualizacoes e formulas

5.4a: Equacoes

6: MODULO DE ACUMULACAO DA DIVIDA EXTERNA

6.1: Conjuntos e variaveis para o modulo de acumulacao da divida externa

6.2: Declaracoes de coeficientes para o modulo de acumulacao da divida externa

6.3: Declaracoes de leitura e atualizacao para acumulacao da divida externa

6.4: Formulas e telas para o modulo da acumulacao da divida externa

6.5: Equacoes do modulo de acumulacao da divida externa

7: MODULO DE MERCADO DE TRABALHO E MIGRACAO REGIONAL

7.1: Declaracoes de variavel para o mod. de merc. de trab. e migrac. reg.

7.2: Declaracoes de coeficiente para o mod. de merc. de trab. e migrac. reg.

7.3: Leituras e atualizacoes para o mod. merc. de trab. e migrac. reg.

7.4: Formulas para o mod. de mercado de trabalho e migracao regional

7.5: Equacoes do mod. de mercado de trabalho e migracao regional

8: MODULO DE OUTRAS VARIAVEIS E EQUACOES PARA FACILITAR AS SIMULACOES DE PREVISAO ANO A ANO

8.1a: Variaveis

8.2a Equacoes

8.1b: Variaveis

$8.2 b$ Equacoes

! Parte 1: PRELIMINARES !

! Secao 1.1: Modelo Inter-regional para a Economia Brasileira (MIBRA) !

! MIBRA e um modelo aplicado de equilibrio geral para a economia brasileira. o modelo reconhece 5 macro-regioes.

Neste arquivo tab, as equacoes do modelo sao apresentados em cinco modulos:

(i) o modulo central do modelo MIBRA

(ii) o modulo de financas do governo

(iii) o modulo de capital e taxa de retorno

(iv) o modulo de acumulacao da divida

(v) o modulo de mercado de trabalho e migracao regional

o modulo central: consiste de equacoes e variaveis do modulo central do modelo original MONASH - MRF (veja Peter et al. 1996) que por sua vez e baseado no modelo ORANI com subscripto regional adicionado (veja Dixon, Parmenter, Sutton e Vincent (DPSV), 1982 para a versao original do ORANI). Este modulo e separado em quatro principais blocos de equacoes definindo: 
(a) demanda dos consumidores;

(b) precos dos consumidores e produtores;

(c) condicoes de equilibrio de mercado (market clearing);

(d) variaveis macroeconomicas com somatoria de variaveis microeconomicas.

o modulo de financa do governo incorpora equacoes definindo:

(a) produto brutode cada regiao proveniente dos lados da renda e da despesas;

(b) fontes de renda e varias contas de despesas para governos federal e regional.

o modulo de capital e investimento e o modulo de acumulacao da divida sao adicionados para endogeinizar:

(a) variacoes no investimento total e estoque de capital ao longo do periodo previsao;

(b) a acumulacao da divida externa.

A secao de acumulacao de capital do module de capital e investimento e e baseado em um dos tres tratamentos alternativos implementado no modelo MONASH. O modulo todo de acumulacao da divida e baseado no modelo ORANI-F (veja Horridge et al., 1993)

o modulo de mercado de trabalho e migracao regional define equacoes definindo a populacao regional tomando em consideracao:

(1) crescimento natural;

(2) migracao inter-regional e;

(3) migracao estrangeira.

A oferta de trabalho regional e associada a populacao regional atraves das identidades contabeis, as quais permitem deslocamentos na relacao entre populacao regional e a populacao de idade de trabalho e taxa de participacao na forca de trabalho. o modulo tambem inclui equacoes definindo variacoes nas taxas de desemprego regional.

Parte 2 e 6 deste arquivo TABLO apresenta cinco modulos na ordem listada na parte 1.!

! Parte 2: modulo central do MIBRA !

! Primeira versao!

! O modulo central do MIBRA e baseado no modulo central do MONASH - MRF. Por isso algumas informacoes adicionais sao apresentadas a seguir:

* A pressuposicao de Armington tornou duas funcoes CES aninhadas. Industria, produtores de capital e familias combinam bens provenientes de 5 macro-regioes para formar um bem composto brasileiro. Importacoes sao combinadas com o composto brasileiro para formar um composto de todas as fontes.

* Cada regiao exporta independentemente para o resto do mundo. A demanda agregada e o preco das exportacoes brasileiras nao tem conteudo comportamental.

* 'Outras demandas' sao dividas por regiao. Existe tambem uma 'outra demanda' federal por regiao os quais representam os gastos do governo em cada regiao.

* Um conjunto compreensivo de "addups" foram especificados. Os nomes com prefixo "Nat" tem carater nacional (addup).

* Margens sobre bens usados pelas industrias, criadores de capital, governos regionais e familias sao assumidos serem produzidos no ponto do consumo. Margens sobre as exportacoes sao assumindas serem produzidas no ponto da producao.

* Taxas de tarifas de importacao sao assumidas serem uniformes nas regioes.

* Industrias produzindo um unico produto sao assumidos. 
* Possibilidades de substituicao CES entre diferentes tipos de trabalho do que CRESH.

* As mudancas tecnicas realizadas do modelo oRANI para o modelo MONASH-MRF nao sao apresentadas na totalidade.

* Variacoes dos impostos sao expressas em duas formas:

1.variacao ponto-percentual na taxa de imposto ad valorem. As suas variaveis tem nomes com o prefixo deltax. Portanto deltax $=5$ significa que a taxa de de imposto foi de 20 para 25 porcento, ou de 24 para 29 porcento. Todas as variaveis impostos com este prefixo estao no modulo central.

2. variacao percentual na taxa de imposto. Por exemplo, taxa de imposto de renda $=25$ significa que se a taxa de imposto inicial era 40 porcento, entao houve um aumento de 50 porcento, isto e, $100 *(50-40) / 40=25$. Todas as variaveis impostos com este tipo de variacao estao no modulo de financa do do governo.

* Variacoes das tarifas sao expressas como variacoes percentuais no poder da tarifa. O poder da tarifa e definido como um mais a taxa da tarifa. Se a taxa de tarifa e 20 porcento, o poder da tarifa e 1.20. Se a taxa da tarifa e aumentada de 20 para 25 porcento, variacao percentual no poder da tarifa e 4, isto $e, 100 *(1.25-1.20) / 1.20=4$.

! Secao 2.1: Arquivos para TODOS os modulos!

FILE MDATA

\# Arquivo contendo matrizes de insumo-produto para o modulo central CEG \#;

FILE ELAST

\# Arquivo contendo elasticidades e outros dados para o modulo central CEG \#;

FILE YDATA

\# Arquivo contendo dados sobre debito, invest. e valor do ativo de capital \#;

FILE NDATA

\# Arquivo contendo componentes de renda e despesa de estat. das fin.do Gov. \#; FILE PDATA

\# Arquivo contendo dados sobre populacao e mercado de trabalho \#;

FILE (NEW, TEXT) DISFILE

\# Arquivo texto de saída para verificacao dos valores da base de dados \#;

! Secao 2.2: Conjunto e subconjunto de nomes comuns a TODOS os modulos!

SET IND \# Setores \# (Agropec,Mineracao,Metalurg, Mecanica, Mat Eletr, Mat_Transp, Mad_Mob_CPG, Quim_Farm,

Text_Vest_Ca,Prod_Alim, Ind_Dive,SIUP_Com, Constr,

Comercio, Transporte, Servicos);

SET MARGIND \# Setores margens \# (Comercio, Transporte);

SUBSET MARGIND is subset of IND;

SET NONMARGIND = IND - MARGIND;

SET COM \# mercadorias \# (Agropec, Mineracao, Metalurg,Mecanica, Mat_Eletr, Mat_Transp, Mad_Mob_CPG, Quim_Farm,

Text_Vest_Ca,Prod_Alim,Ind_Dive,SIUP_Com, Constr,

Comercio, Transporte, Servicos);

SET MARGCOM \# mercadorias margens \# (Comercio, Transporte);

SUBSET MARGCOM is subset of $\mathrm{COM}$;

SET NONMARGCOM = COM - MARGCOM;

SET TEXP \# Exportacoes tradicionais \# (Agropec,Metalurg,Prod_Alim,Mat_Transp) ;

SUBSET TEXP is subset of $\mathrm{COM}$;

SET NTEXP = COM - TEXP;

SET FAC \# Fatores Primarios \# (labour, capital, land);

SET OCC \# Tipos de ocupacao \# SIZE 1;

SET ALLDEST \# Destinacao de bens \#

(Norte, $\mathrm{NEB}, \mathrm{COB}, \mathrm{SEB}, \mathrm{Sul}$, fede, estr) ; 


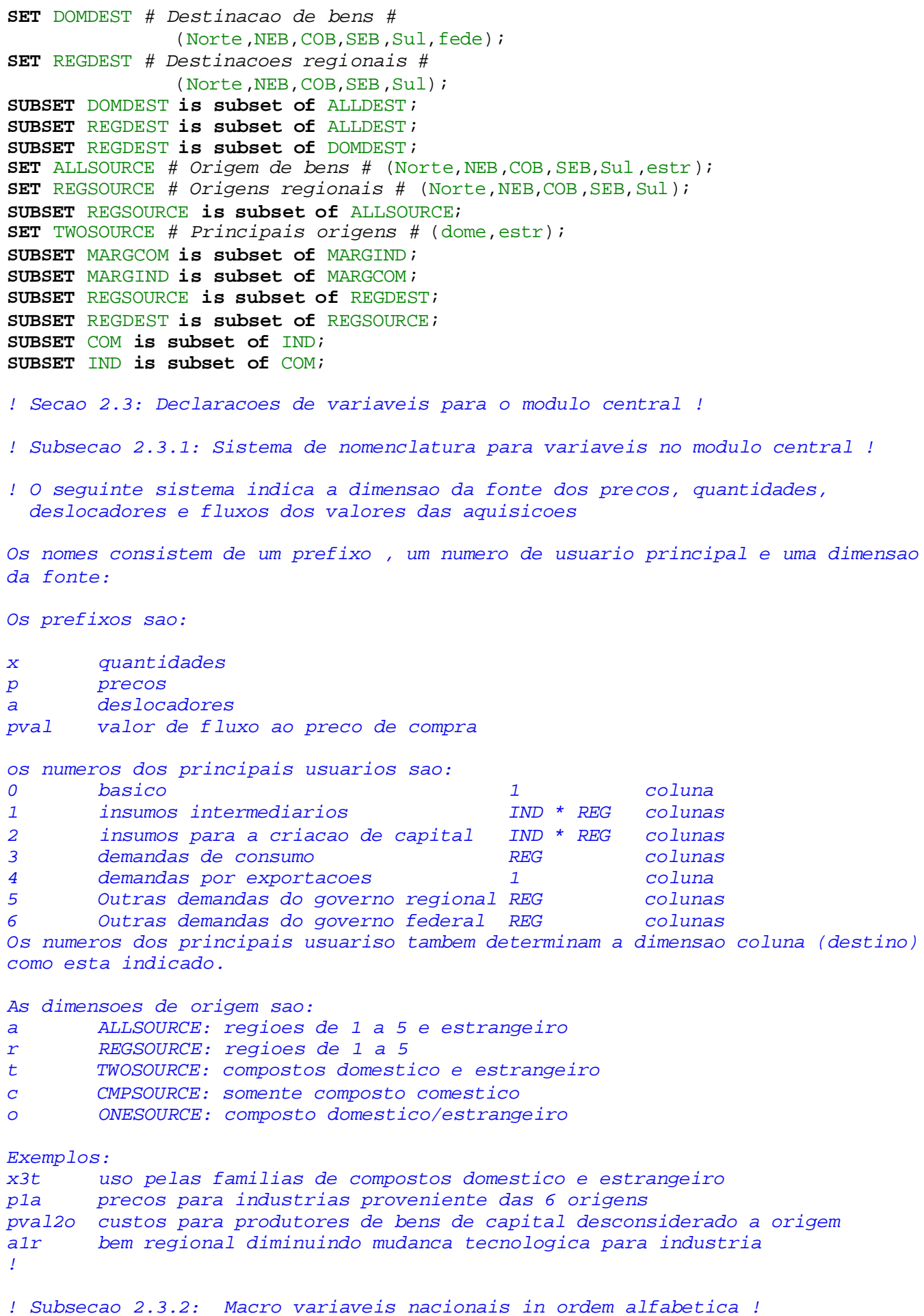

\section{VARIABLE}

deltaxlall \# variac. ponto perc. geral nas taxas de imposto indir., usuar.1 \#; (change)

deltax2all \# variac. ponto perc. geral nas taxas de imposto indir., usuar.2 \#; (change) 


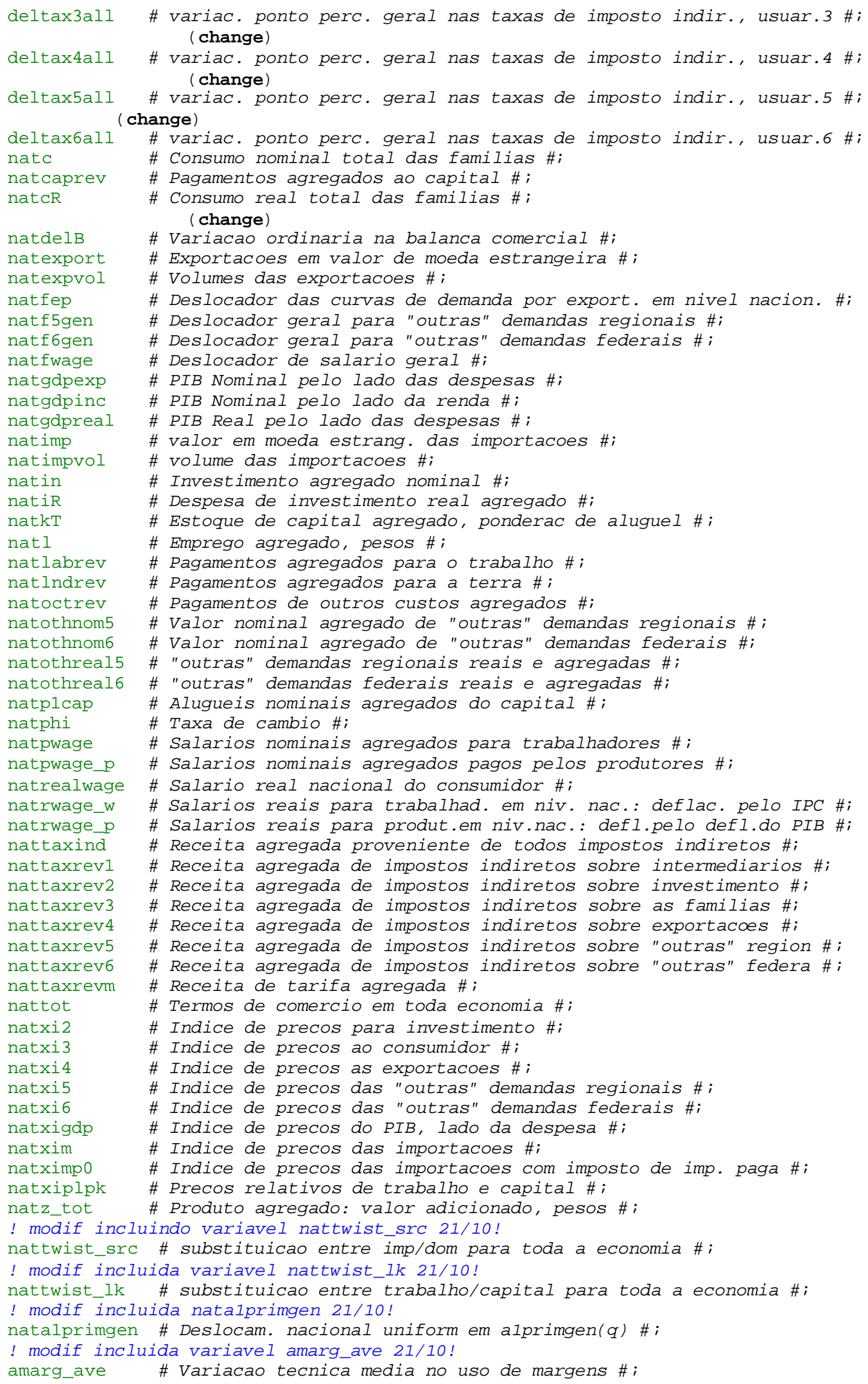


! Subsecao 2.3.3: Variaveis vetores nacionais em ordem alfabetica!

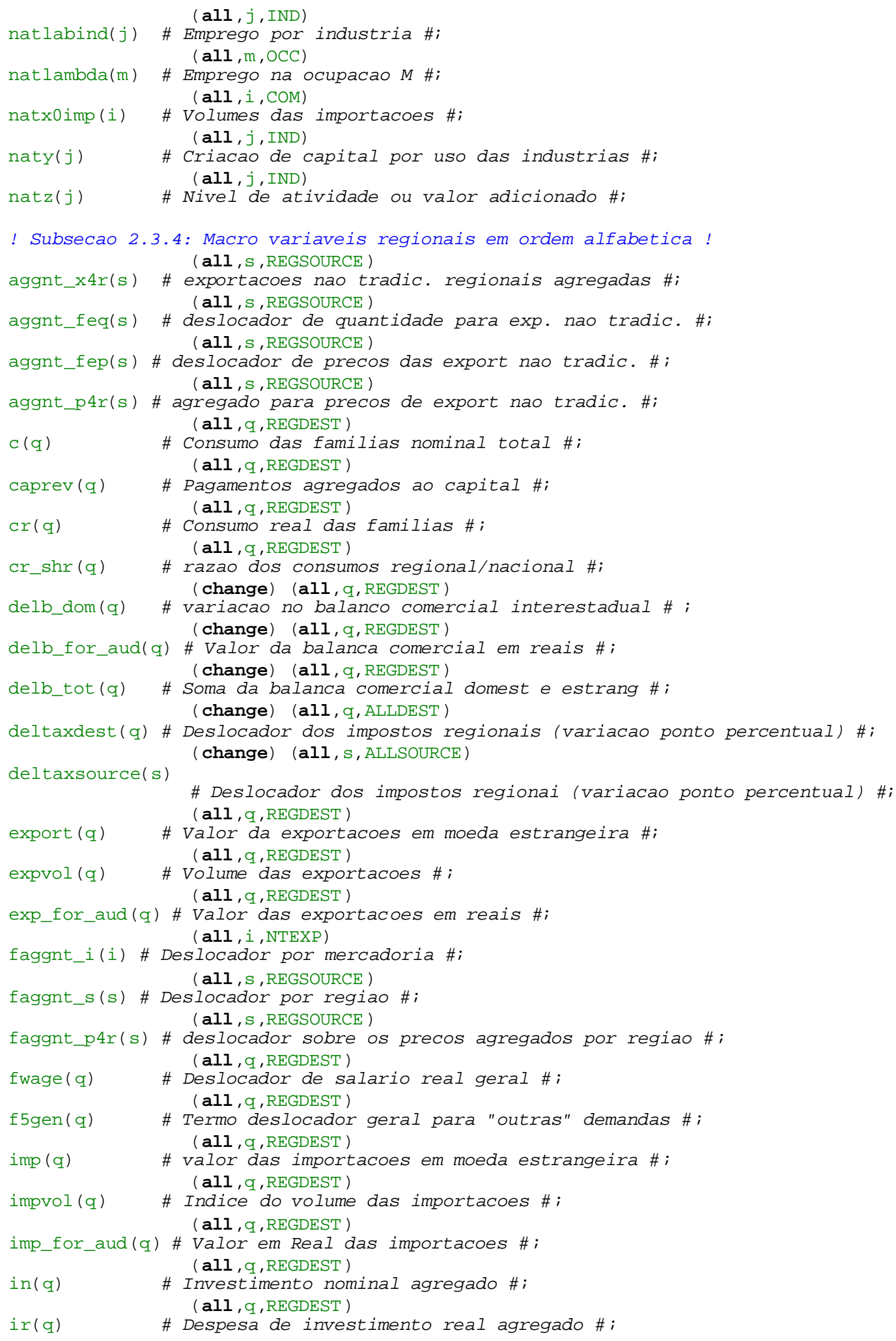




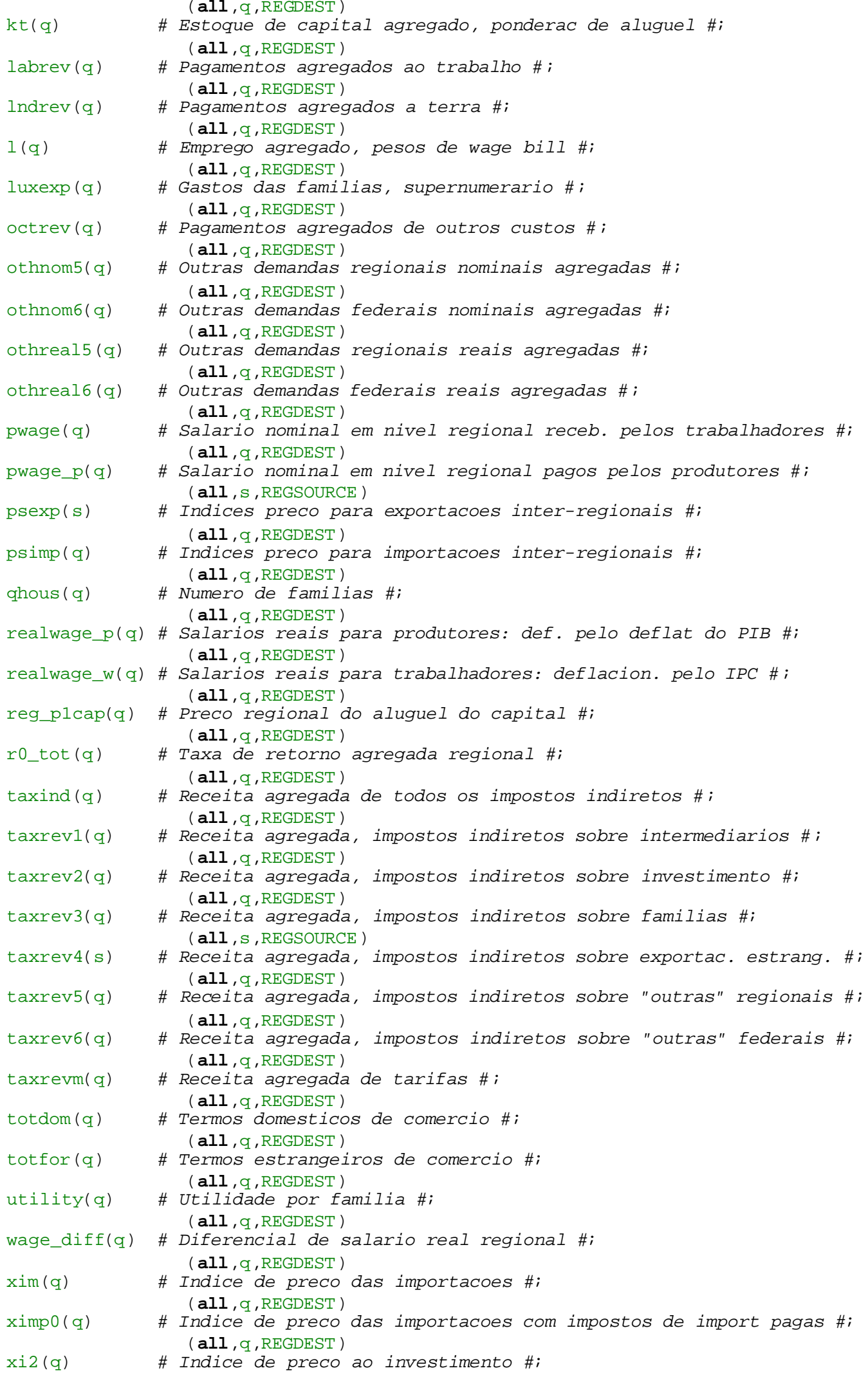




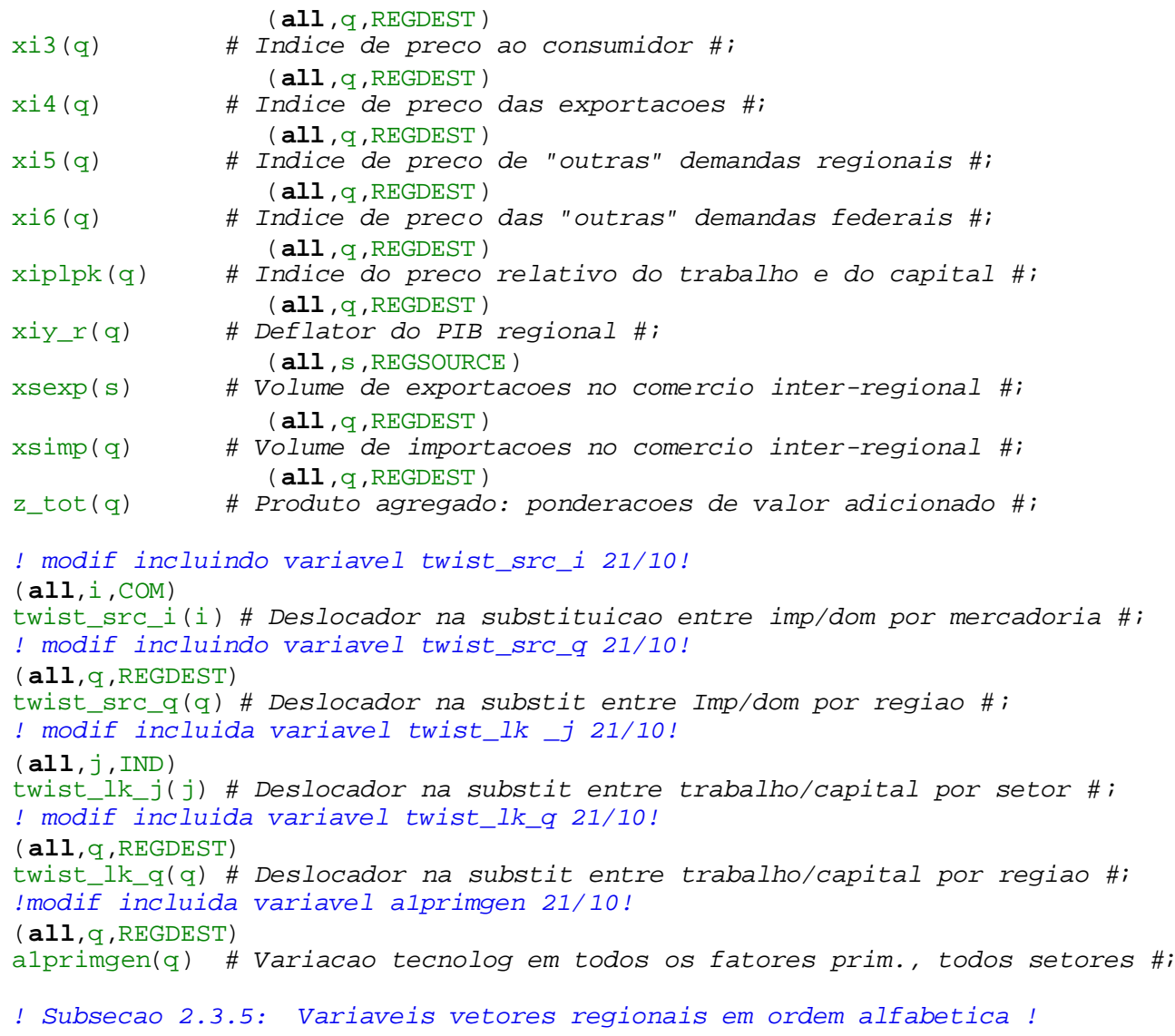




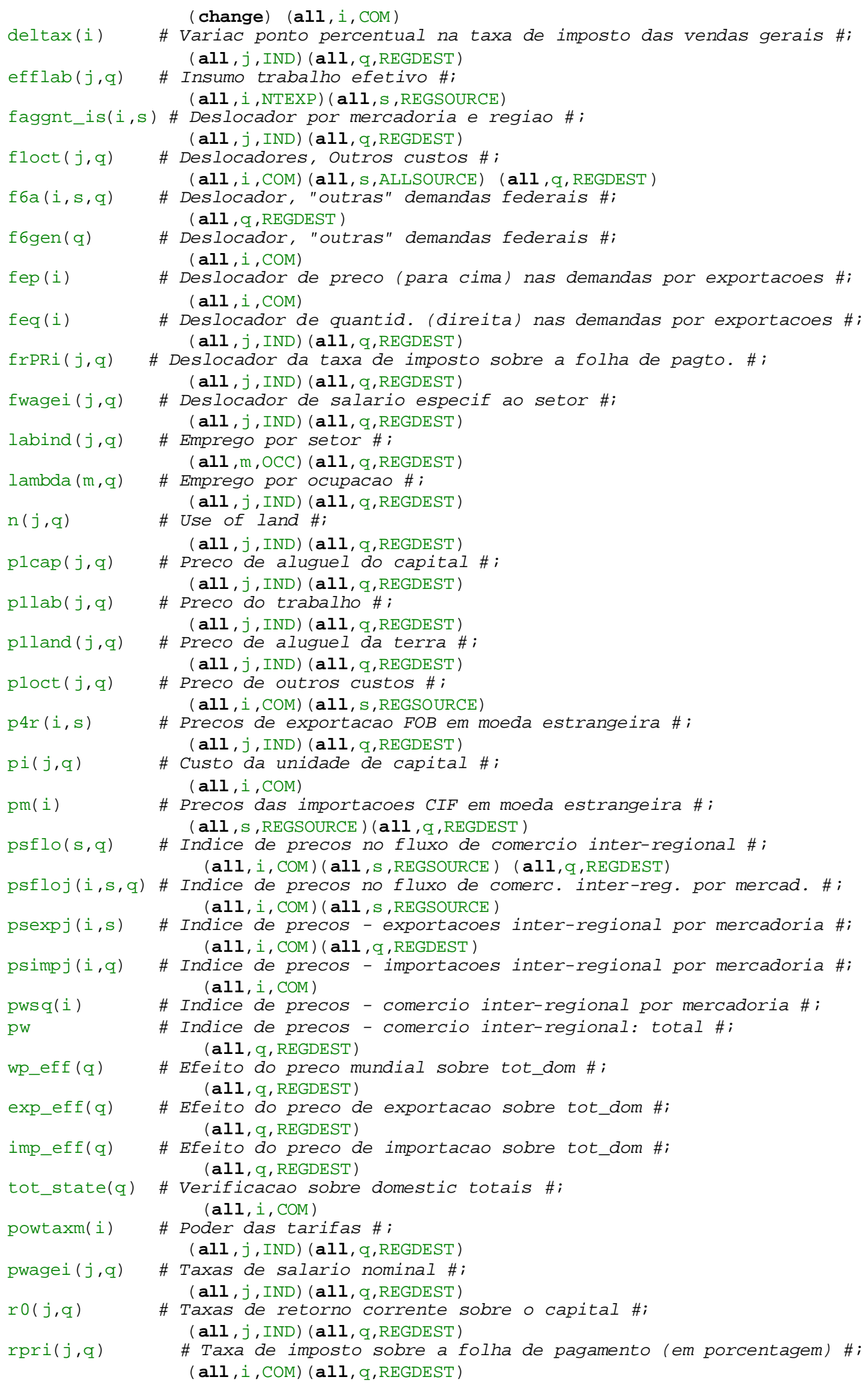




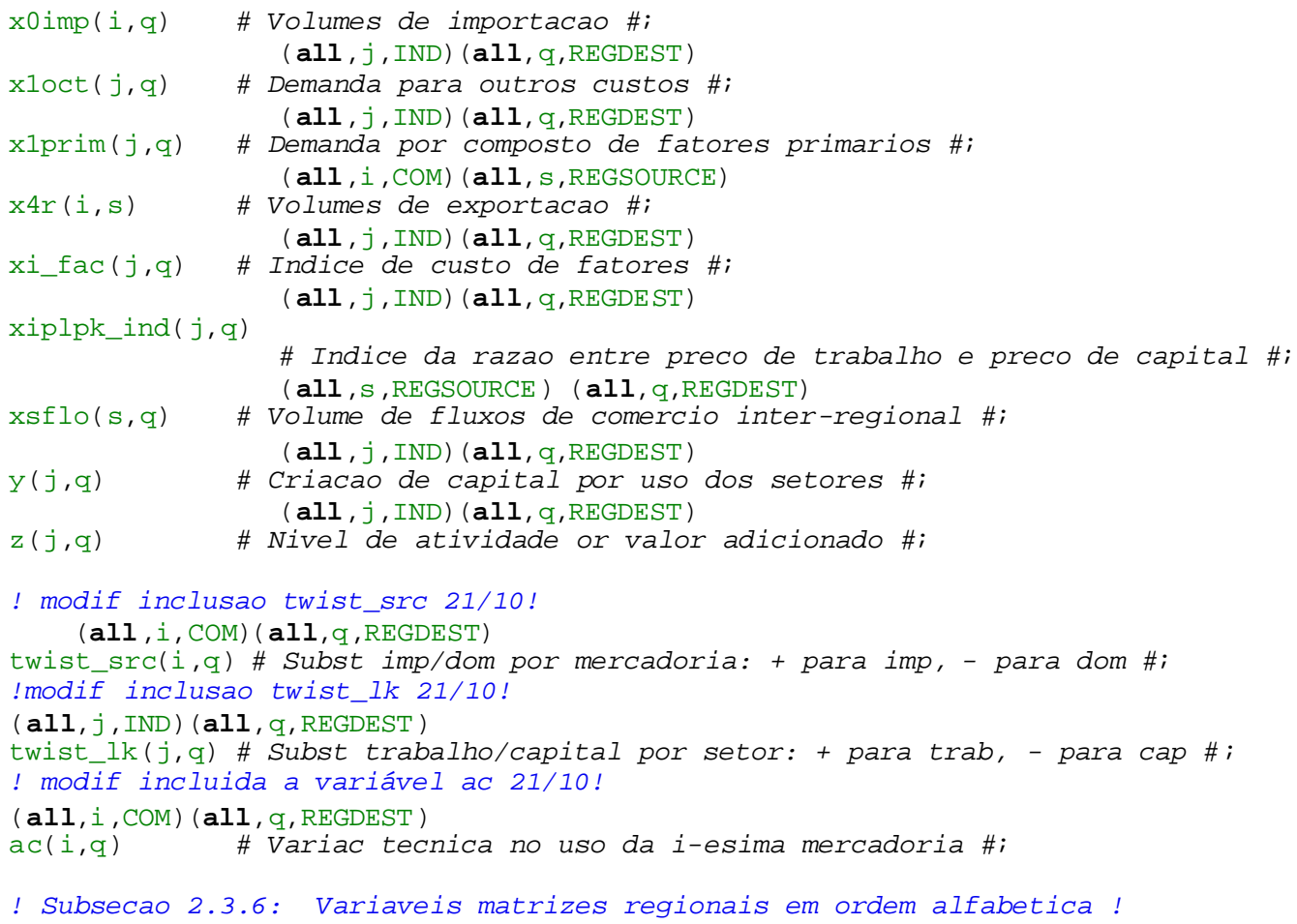


(all, i, COM) (all, j, IND) (all, q, REGDEST )

p2o (i,j,q) \# Precos, insumo para criacao de capital \#

(all, i, COM) (all, q, REGDEST)

p3o (i, q) \# Preco, insumos para familias \#;

(all, i, COM) (all, s, ALLSOURCE) (all, j, IND) (all, q, REGDEST)

xla $(i, s, j, q)$ \# Demandas por insumos para producao corrente \#;

(all, i, COM) (all, s, ALLSOURCE) (all, j, IND) (all, q, REGDEST )

$\mathrm{x} 2 \mathrm{a}(i, \mathrm{~s}, j, q)$ \# Demandas por insumos para criacao de capital \#;

(all, i, COM) (all, s, ALLSOURCE) (all, q, REGDEST)

x3a (i, s, q) \# Demandas das familias por bens \#;

$\times 5 a(i, s, q) \quad$ \# "Outras" demandas regionais \#;

(all, i, COM) (all, s, ALLSOURCE) (all, q, REGDEST)

x6a (i,s, q) \# "Outras" demandas federais em cada regiao \#;

(all, i, COM) (all, j, IND) (all, q, REGDEST)

x1c $(i, j, q)$ \# Demandas por insumos para producao corrente \#;

(all, i, COM) (all, j, IND) (all, q, REGDEST)

x2c $(i, j, q)$ \# Demandas por insumos para criacao de capital \#;

(all, i, COM) (all, q, REGDEST)

$\times 3 c(i, q) \quad$ \# Demandas por insumos pelas familias \#;

(all, i, COM) (all, j, IND) (all, q, REGDEST)

$\mathrm{x} 1 \circ(\mathrm{i}, \mathrm{j}, \mathrm{q})$ \# Demandas por insumos para producao corrente \#;

(all, i, COM) (all, j, IND) (all, q, REGDEST)

x20 (i,j,q) \# Demandas por insumos por insumos para criacao de capital \#;

(all, i, COM) (all, q, REGDEST)

x3o (i, q) \# Demandas por insumos para as familias \#;

(all, j, IND) (all, q, REGDEST) (all, m, OCC)

xllaboi $(j, q, m)$

xlmarg $(i, s, j, q, r)$

\# Emprego da ocupacao do tipo m na industria $j$ \#;

(all, i, COM) (all, s, ALLSOURCE) (all, j, IND)

(a)

\# Margens - producao corrente \#;

(all, i, COM) (all, s, ALLSOURCE) (all, j, IND )

$x 2 \operatorname{marg}(i, s, j, q, r)$

(all, q, REGDEST) (all, r, MARGCOM)

\# Margens - criacao de capital \#;

(all, i, COM) (all, s, ALLSOURCE)

(all, r, MARGCOM) (all, q, REGDEST)

x3marg (i, s, $q, r)$

\# Margens - sobre as vendas para as familias \#;

(all, i, COM) (all, s, REGSOURCE) (all, r, MARGCOM)

x4marg $(i, s, r)$ \# Margens - sobre as exportacoes \#;

$x 5 \operatorname{marg}(i, s, q, r)$

(all, i, COM) (all, s, ALLSOURCE) (all, q, REGDEST) (all, r, MARGCOM)

\# Margens - "outras" demandas regionais \#;

$\times 6 \operatorname{marg}(i, s, q, r)$

(all, i, COM) (all, s, ALLSOURCE) (all, q, REGDEST) (all, r, MARGCOM)

! modif incluida alo 21/10!

(all, i, COM) (all, j, IND) (all, q, REGDEST)

alo $(i, j, q)$ \# Variacao tecnica aumentando o uso de insumo intermediario \# ;

! modif incluida almarg 21/10!

(all, q, REGDEST) (all, r, MARGCOM)

almarg $(q, r)$ \# Variacao tecnica no uso de margens - producao corrente \#;

! modif incluida a2marg 21/10!

(all, q, REGDEST) (all, r, MARGCOM)

a2marg $(q, r)$ \# Variacao tecnica no uso de margens - criacao de capital \#;

! modif incluida a3marg 21/10!

(all, r, MARGCOM) (all, q, REGDEST)

a3marg $(q, r)$ \# Variacao Tecnica no uso de margens - vendas para familias \#;

!modif incluida a4marg 21/10!

(all, s, REGSOURCE) (all, r, MARGCOM)

a4marg $(s, r)$ \# Variacao tecnica no uso de margens - exportacoes \#;

! Secao 2.4 : Declaracoes de coefic. para o modulo central do modelo MIBRA!

! Subsecao 2.4.1 : Sistema de nomenclatura para fluxos de bens da base de dados 
insumo-produto!

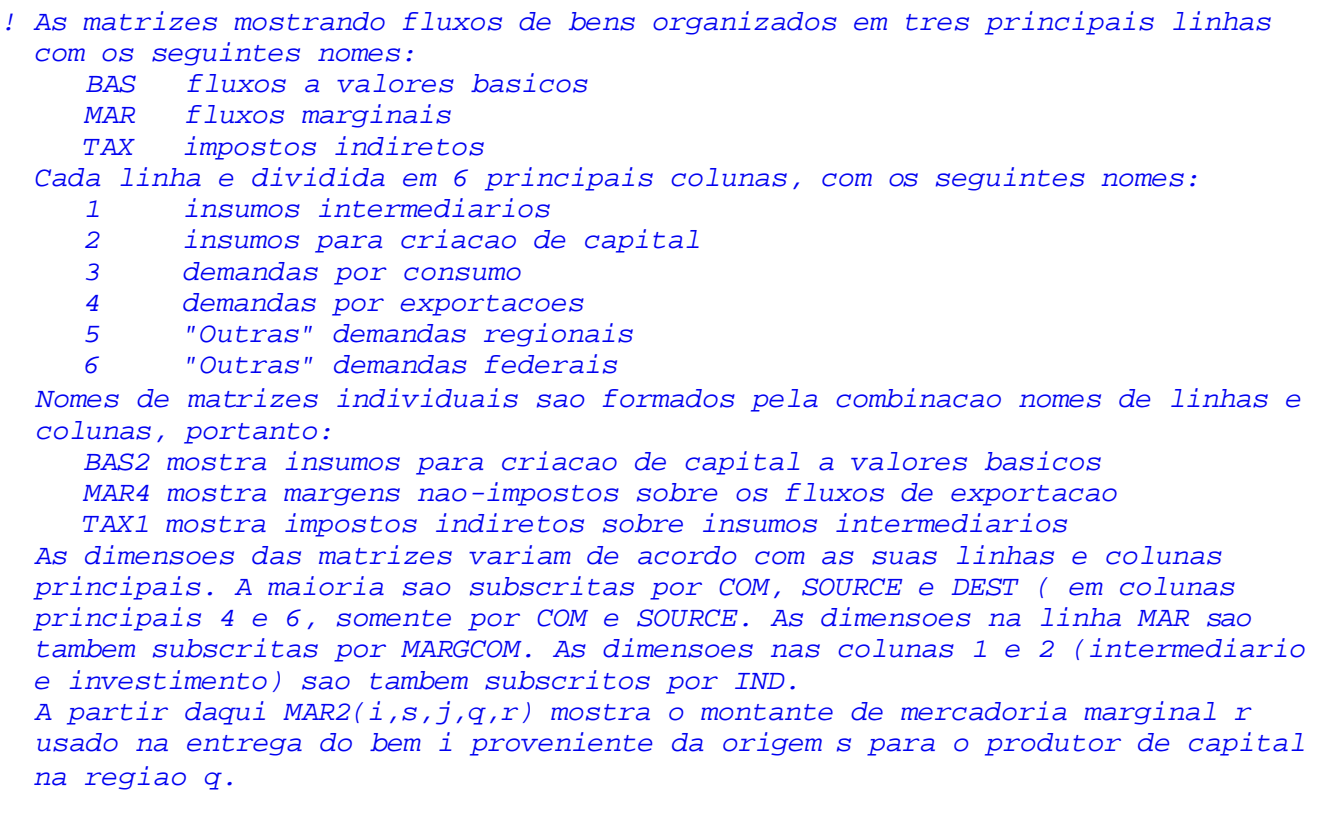

ZERODIVIDE OFF;

! Subsecao 2.4.2: Fluxos de bens da base de dados insumo-produto!

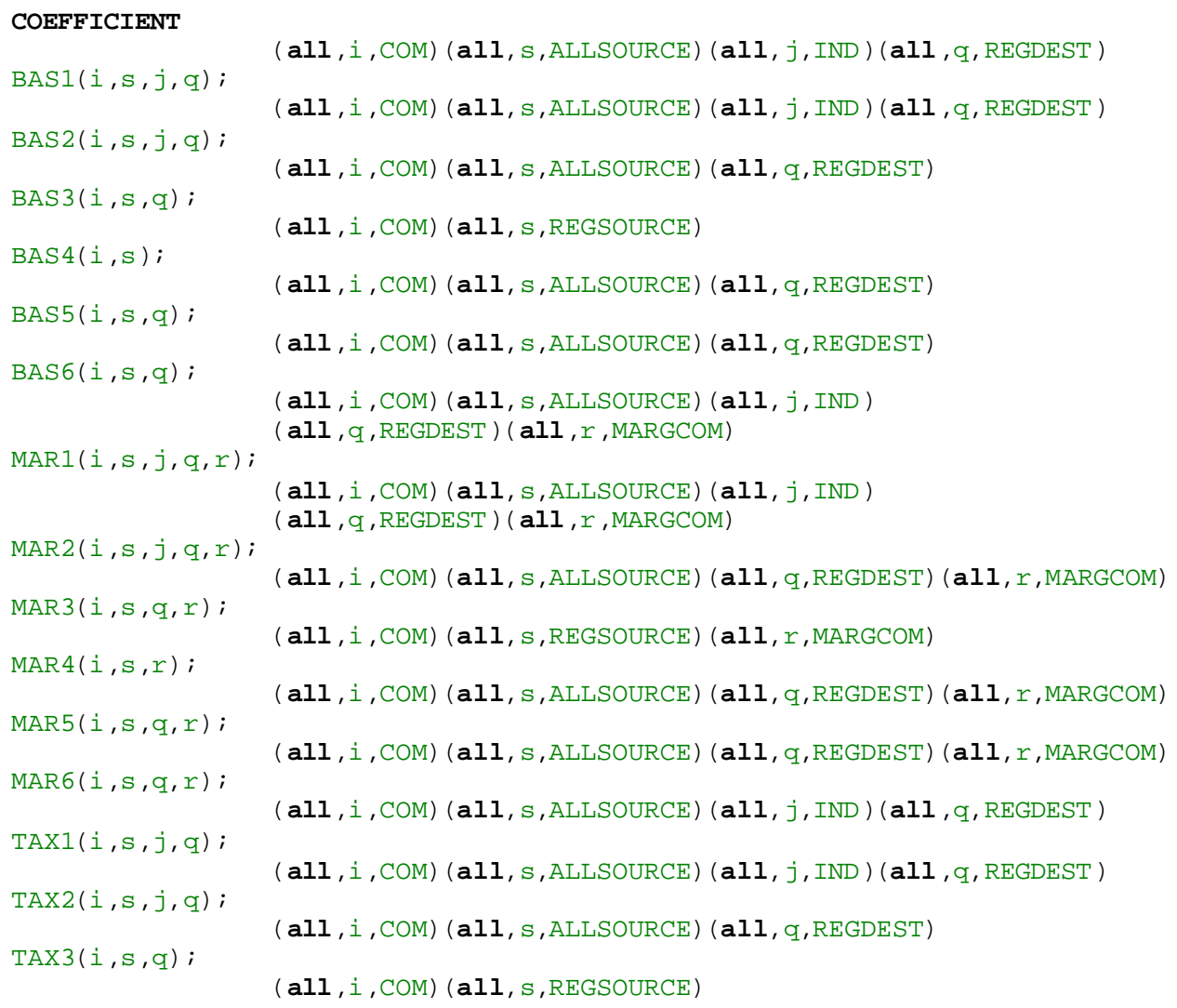




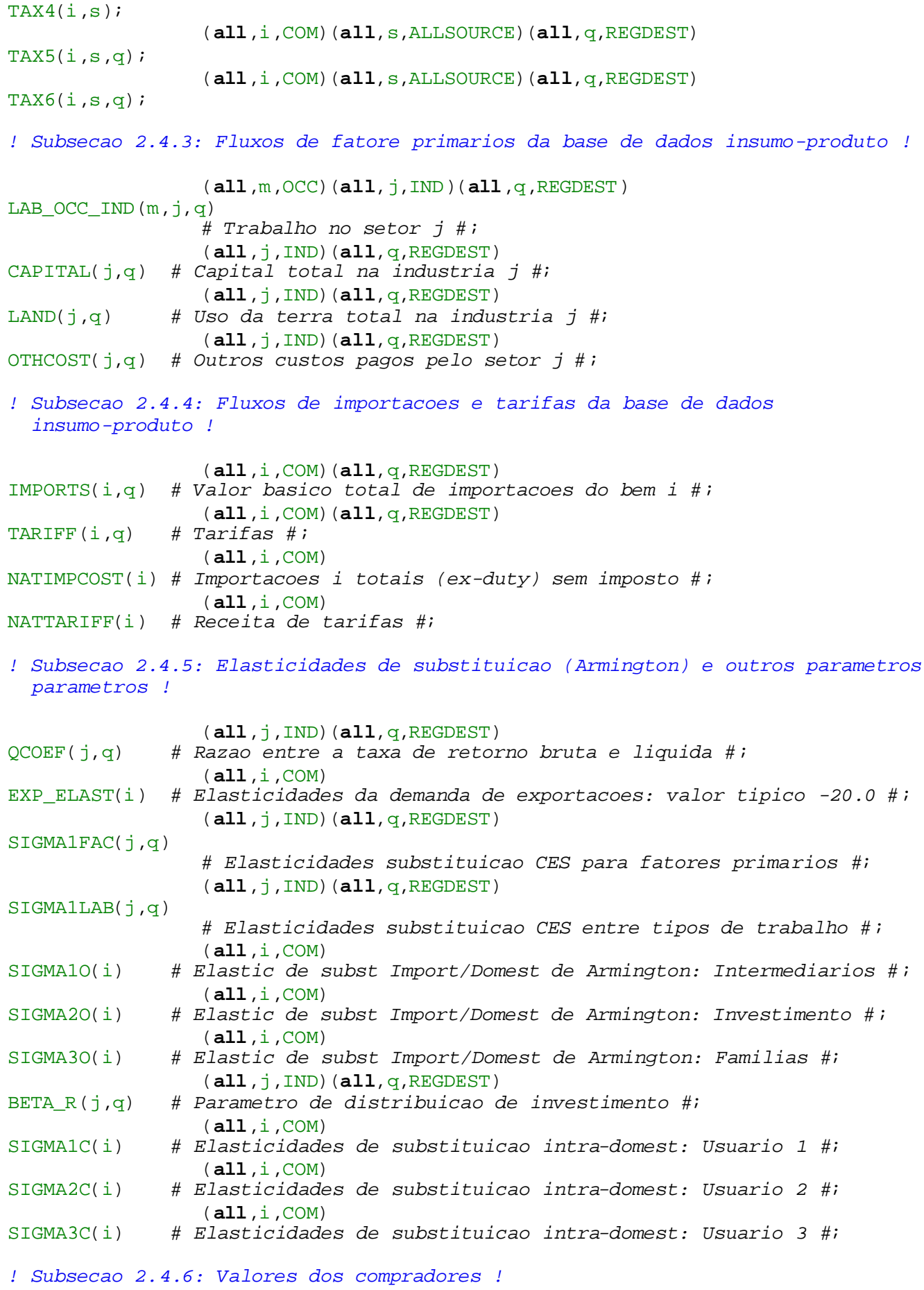




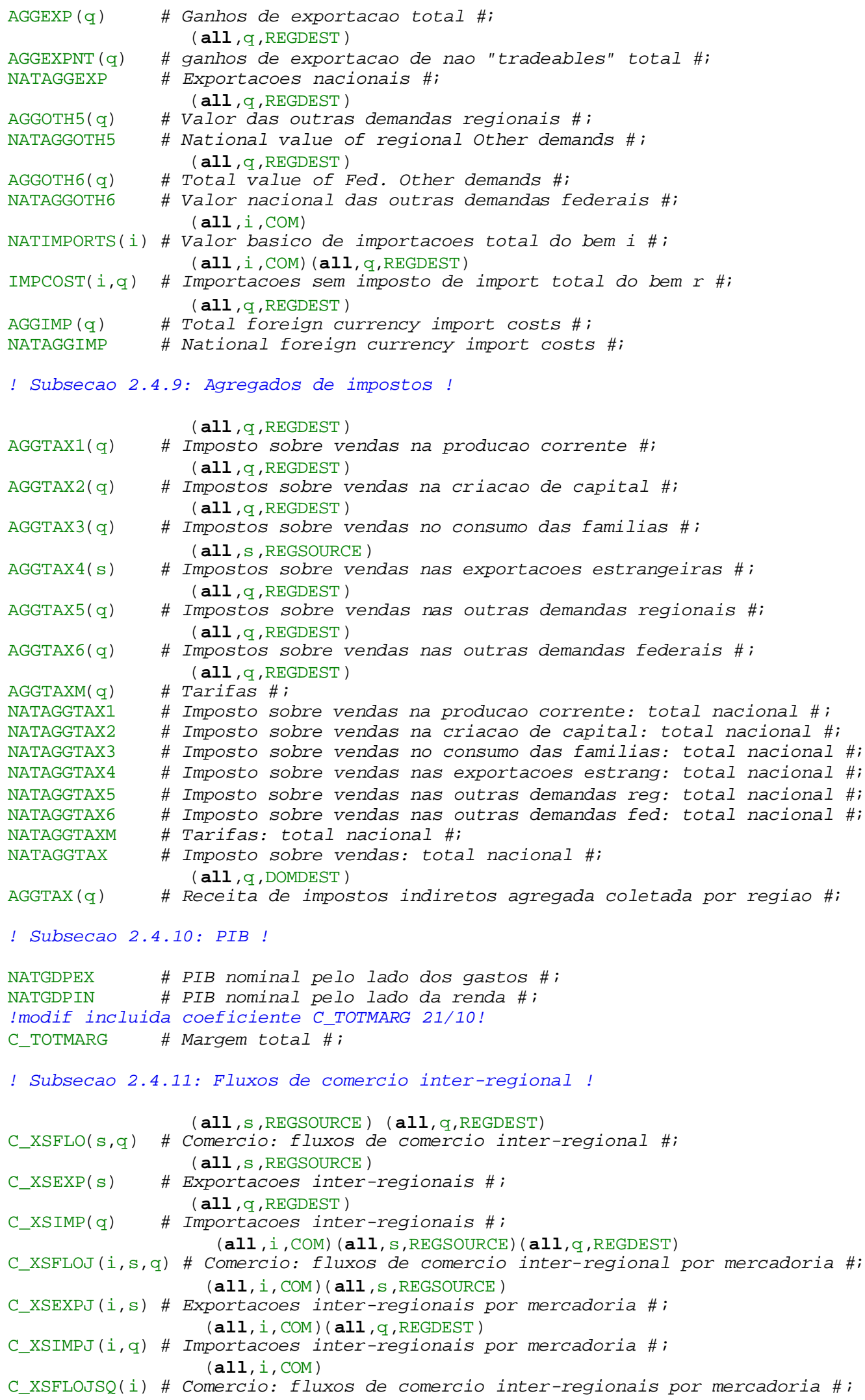




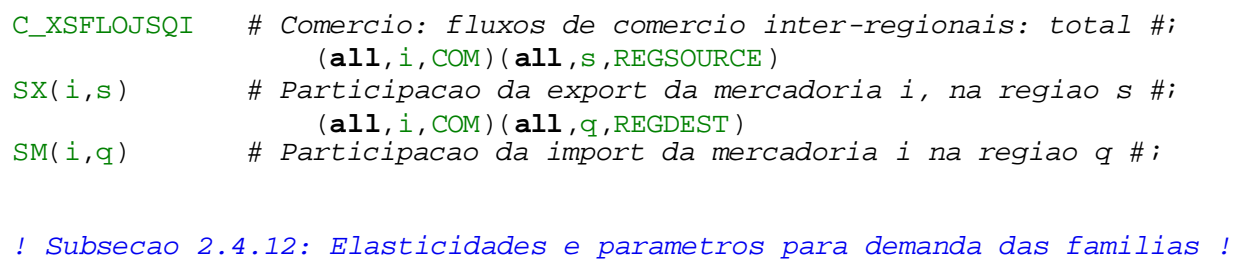

(all, q, REGDEST)

FRISCH (q) \# Parametro de Frisch \#;

(all, i, COM) (all, q, REGDEST)

DELTA $(i, q) \quad$ \# Participacoes do orcamento das familias marginais \#;

(all, i, COM) (all, q, REGDEST)

$\operatorname{S3COM}(i, q)$

\# Participacoes no total das despesa das familias \#;

(all, q, REGDEST)

ALPHA (q) \# Participacao do supernumerario no total das despesas \#;

(all, i, COM) (all, q, REGDEST)

EPS $(i, q) \quad$ \# Elasticidades da despesa das famílias \#;

(all, i, COM) (all, q, REGDEST)

ALPHA_I $(i, q)$ \# Supernumerario gasto com bem $i /$ despesa total com o bem i \#;

! Subsecao 2.4.13: Custos de vendas de agregados!

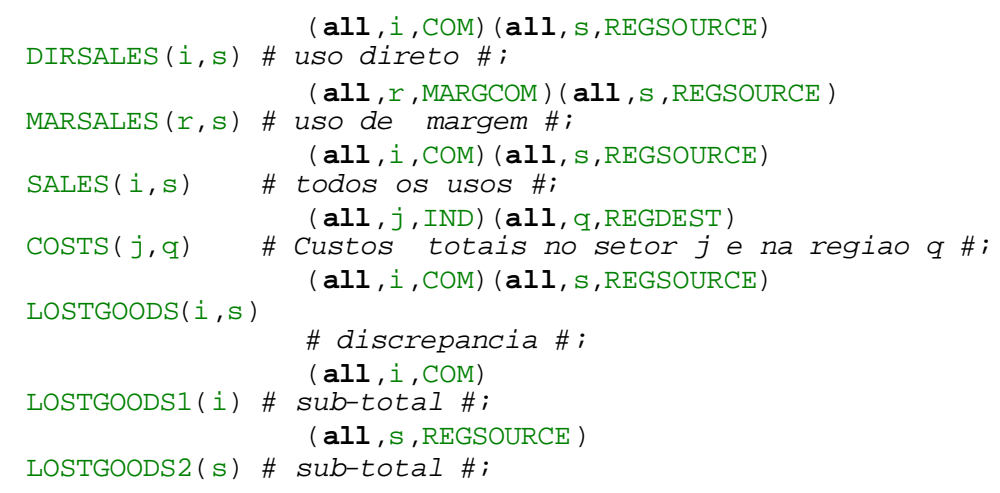

! Subsecao 2.4.14: Coeficientes de mapeamento para domest./estrangeiro e tiny!

$\begin{array}{ll}\text { (all,s,ALLSOURCE) } \\ \text { IS_DOM (s) } & \text { \# variavel binaria 1 \#; } \\ \text { (all,s,ALLSOURCE) } \\ \text { IS_IMP (s) } & \text { \# variavel binária } 2 \text { \#; } \\ \text { TINY } & \text { \# Um numero muito pequeno \#; }\end{array}$

! Secao 2.5: Declaracao de leituras para o modulo central do MIBRA !

! Subsecao 2.5.1: Leituras de fluxos de bens e pagamentos de fatores da base de dados insumo-produto!

READ

BAS1 from file MDATA header "BASI";

BAS2 from file MDATA header "BAS2";

BAS3 from file MDATA header "BAS3";

BAS 4 from file MDATA header "BAS4";

BAS 5 from file MDATA header "BAS5";

BAS 6 from file MDATA header "BAS6";

MARI from file MDATA header "MARI";

MAR2 from file MDATA header "MAR2";

MAR3 from file MDATA header "MAR3";

MAR4 from file MDATA header "MAR4";

MAR5 from file MDATA header "MAR5";

MAR6 from file MDATA header "MAR6";

TAX1 from file MDATA header "TAXI"; 


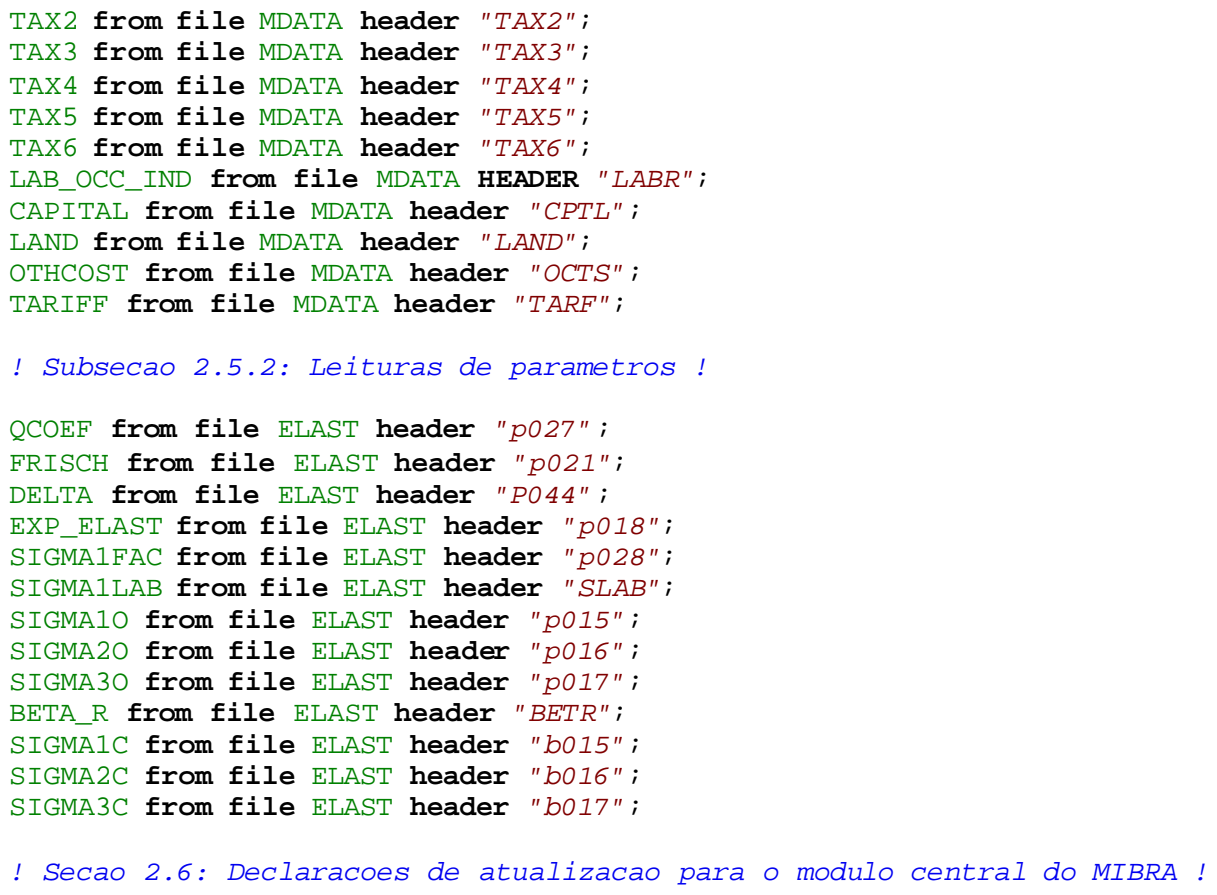

UPDATE

(all, i, COM) (all, s, ALLSOURCE) (all, j, IND) (all, q, REGDEST)

$\operatorname{BAS} 1(i, s, j, q)=p 0 a(i, s) * x 1 a(i, s, j, q)$;

(all, i, COM) (all, s, ALLSOURCE) (all, j, IND) (all, q, REGDEST)

$\operatorname{BAS} 2(i, s, j, q)=p 0 a(i, s) * x 2 a(i, s, j, q) ;$

(all, i, COM) (all, S, ALLSOURCE) (all, q, REGDEST)

$\operatorname{BAS} 3(i, s, q)=p 0 a(i, s) * \times 3 a(i, s, q)$;

(all, i, COM) (all, S, REGSOURCE)

$\operatorname{BAS} 4(i, s)=p 0 a(i, s) * \times 4 r(i, s)$;

(all, i, COM) (all, s, ALLSOURCE) (all, q, REGDEST)

$\operatorname{BAS} 5(i, s, q)=p 0 a(i, s) * \times 5 a(i, s, q) ;$

(all, i, COM) (all, s, ALLSOURCE) (all, q, REGDEST)

$\operatorname{BAS} 6(i, s, q)=p 0 a(i, s) * \times 6 a(i, s, q) ;$

(all, i, COM) (all, s, ALLSOURCE) (all, j, IND )

(all, q, REGDEST) (all, r, MARGCOM)

$\operatorname{MAR} 1(i, s, j, q, r)=p 0 a(r, q) * x 1 m a r g(i, s, j, q, r)$;

(all, i, COM) (all, s, ALLSOURCE) (all, j, IND )

(all, q, REGDEST) (all, r, MARGCOM)

$\operatorname{MAR} 2(i, s, j, q, r)=p 0 a(r, q) * x 2 \operatorname{marg}(i, s, j, q, r)$;

(all, i, COM) (all, s, ALLSOURCE) (all, q, REGDEST) (all, r, MARGCOM)

$\operatorname{MAR3}(i, s, q, r)=p 0 a(r, q) * \times 3 \operatorname{marg}(i, s, q, r)$;

(all, i, COM) (all, s, REGSOURCE) (all, r, MARGCOM)

$\operatorname{MAR} 4(i, s, r)=p 0 a(r, s) * x 4 \operatorname{marg}(i, s, r)$;

(all, i, COM) (all, s, ALLSOURCE) (all, q, REGDEST) (all, r, MARGCOM)

$\operatorname{MAR5}(i, s, q, r)=p 0 a(r, q) * \times 5 \operatorname{marg}(i, s, q, r)$;

(all, i, COM) (all, s, ALLSOURCE) (all, q, REGDEST) (all, r, MARGCOM)

$\operatorname{MAR} 6(i, s, q, r)=p 0 a(r, s) * x 6 \operatorname{marg}(i, s, q, r)$;

(explicit) (all, i, COM) (all, s, ALLSOURCE) (all, j, IND) (all, q, REGDEST)

$\operatorname{TAX} 1(i, s, j, q)=\operatorname{TAX} 1(i, s, j, q)+[\operatorname{BAS} 1(i, s, j, q) * \operatorname{deltax} 1(i, s, j, q)+$ $\operatorname{TAX} 1(i, s, j, q) *\{\times 1 a(i, s, j, q)+p 0 a(i, s)\}] / 100 ;$

(explicit) (all, $i$, COM) (all, s, ALLSOURCE) (all, j, IND) (all, q, REGDEST)

$\operatorname{TAX} 2(i, s, j, q)=\operatorname{TAX} 2(i, s, j, q)+[\operatorname{BAS} 2(i, s, j, q) * \operatorname{deltax} 2(i, s, j, q)+$

$\operatorname{TAX} 2(i, s, j, q) *\{\times 2 a(i, s, j, q)+p 0 a(i, s)\}] / 100$;

(explicit) (all, $i, \mathrm{COM}$ ) (all, s, ALLSOURCE) (all, q, REGDEST)

$\operatorname{TAX} 3(i, s, q)=\operatorname{TAX} 3(i, s, q)+[\operatorname{BAS} 3(i, s, q) * \operatorname{deltax} 3(i, s, q)+$ $\operatorname{TAX} 3(i, s, q) *\{\times 3 a(i, s, q)+p 0 a(i, s)\}] / 100$;

(explicit) (all, i, COM) (all, s, REGSOURCE)

$\operatorname{TAX} 4(i, s)=\operatorname{TAX} 4(i, s)+[\operatorname{BAS} 4(i, s) * \operatorname{deltax} 4(i, s)+$

$\operatorname{TAX} 4(i, s) *\{\times 4 r(i, s)+\mathrm{p} 0 a(i, s)\}] / 100 ;$ 
(explicit) (all, i, COM) (all, s, ALLSOURCE) (all, q, REGDEST)

$\operatorname{TAX} 5(i, s, q)=\operatorname{TAX} 5(i, s, q)+[\operatorname{BAS} 5(i, s, q) * \operatorname{deltax} 5(i, s, q)+$

$\operatorname{TAX} 5(i, s, q) *\{\times 5 a(i, s, q)+p 0 a(i, s)\}] / 100$;

(explicit) (all, i, COM) (all, s, ALLSOURCE) (all, q, REGDEST)

$\operatorname{TAX} 6(i, s, q)=\operatorname{TAX} 6(i, s, q)+[\operatorname{BAS} 6(i, s, q) * \operatorname{deltax} 6(i, s, q)+$

$\operatorname{TAX} 6(i, s, q) *\{\times 6 a(i, s, q)+p 0 a(i, s)\}] / 100$;

(all, m, OCC) (all, j, IND ) (all, $q$, REGDEST)

LAB_OCC_IND $(m, j, q)=\operatorname{pllaboi}(j, q, m) * x 1 l a b o i(j, q, m) ;$

(all, j, IND) (all, q, REGDEST)

$\operatorname{CAPITAL}(j, q)=p 1 \operatorname{cap}(j, q) * \operatorname{curcap}(j, q) ;$

(all, $j$, IND) (all, $q$, REGDEST)

$\operatorname{LAND}(j, q)=p 1 l$ and $(j, q) *_{n}(j, q)$;

(all, $j, I N D)(a l l, q, R E G D E S T)$

$\operatorname{OTHCOST}(j, q)=\operatorname{ploct}(j, q) * x 1 \operatorname{oct}(j, q) ;$

(change) (all, i, COM) (all, q, REGDEST)

$\operatorname{TARIFF}(i, q)=\operatorname{Tariff}(i, q) *\{p m(i)+\operatorname{natphi}+x 0 i m p(i, q)\} / 100+$

$\operatorname{IMPORTS}(i, q) * \operatorname{powtaxm}(i) / 100$;

(explicit) (all, j, IND) (all, $q$, REGDEST)

$\operatorname{eCOEF}(j, q)=\operatorname{eCOEF}(j, q) *\{1.0+[1.0-\operatorname{eCOEF}(j, q)] *[\operatorname{plcap}(j, q)-p i(j, q)] / 100\} ;$

(explicit) (all, $q$, REGDEST)

$\operatorname{FRISCH}(q)=\operatorname{FRISCH}(q) *(1.0+[\operatorname{luxexp}(q)-c(q)] / 100.0) ;$

$\operatorname{DELTA}(i, q)=\operatorname{ar} \operatorname{lux}(i, q)$;

(all, i, COM) (all, q, REGDEST)

! Secao 2.7: Formula para o modulo central do MIBRA !

! Subsecao 2.7.1: Formulas para tarifas!

FORMULA

TINY $=0.000000000001 ;$

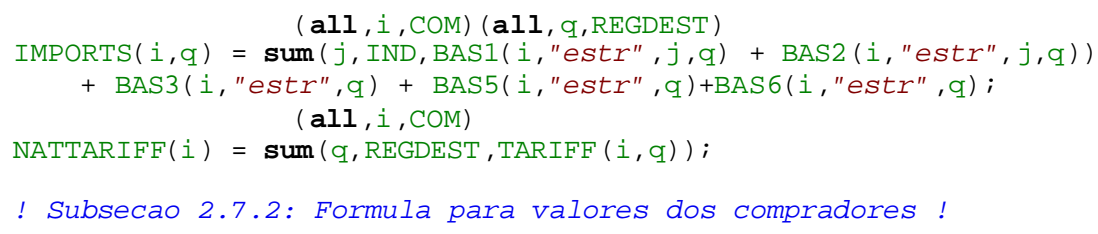

(all, i, COM) (all, q, REGDEST)

(all, i, COM) (all, s, ALLSOURCE) (all, j, IND) (all, q, REGDEST)

$\operatorname{PVAL1A}(i, s, j, q)=\operatorname{BAS} 1(i, s, j, q)+\operatorname{TAX} 1(i, s, j, q)+\operatorname{sum}(r, \operatorname{MARGCOM}, \operatorname{MAR} 1(i, s, j, q, r))$;

(all, $i, C O M)$ (all, $j$, IND) (all, $q$, REGDEST)

PVAL1T ( $i$, "dome", j, q) =sum ( s, REGSOURCE, PVAL1A ( $i, s, j, q)$ );

(all, i, COM) (all, j, IND) (all, q, REGDEST )

PVAL1T $(i$, "estr", j, q) = PVAL1A (i, "estr", j, q) ;

(all, i, COM) (all, j, IND) (all, q, REGDEST)

$\operatorname{PVAL10}(i, j, q)=\operatorname{sum}(a a, \operatorname{TWOSOURCE}, \operatorname{PVAL1T}(i, \mathrm{aa}, j, q))$;

(all, i, COM) (all, s, ALLSOURCE) (all, j, IND) (all, q, REGDEST)

$\operatorname{PVAL} 2 A(i, s, j, q)=\operatorname{BAS} 2(i, s, j, q)+\operatorname{TAX} 2(i, s, j, q)+\operatorname{sum}(r, \operatorname{MARGCOM}, \operatorname{MAR} 2(i, s, j, q, r))$;

(all, $i, C O M)(a l l, j$, IND ) (all, $q$, REGDEST )

PVAL2T ( $i, " d o m e ", j, q)=\operatorname{sum}(s, \operatorname{REgSOURCE}, \operatorname{PVAL} 2 A(i, s, j, q))$;

(all, $i, \mathrm{COM})(a l l, j$, IND ) (all, $q, \mathrm{REGDEST})$

$\operatorname{PVAL} 2 \mathrm{~T}(i$, "estr", $j, q)=\operatorname{PVAL} 2 \mathrm{~A}(i$, "estr", $j, q)$;

(all, i, COM) (all, j, IND) (all, q, REGDEST)

$\operatorname{PVAL} 20(i, j, q)=\operatorname{sum}(a a, \operatorname{TWOSOURCE}, \operatorname{PVAL} 2 \mathrm{~T}(i, \mathrm{aa}, j, q))$;

(all, i, COM) (all, s, ALLSOURCE) (all, q, REGDEST)

$\operatorname{PVAL} 3 A(i, s, q)=\operatorname{BAS} 3(i, s, q)+\operatorname{TAX} 3(i, s, q)+\operatorname{sum}(r, \operatorname{MARGCOM}, \operatorname{MAR} 3(i, s, q, r))$;

(all, i, COM) (all, q, REGDEST)

PVAL3T ( $i$, "dome", q) =sum (, , REGSOURCE, PVAL3A $(i, s, q)$ );

(all, i, COM) (all, q, REGDEST)

PVAL3T (i, "estr", q) = PVAL3A $(i$, "estr", q) ;

(all, i, COM) (all, q, REGDEST)

$\operatorname{PVAL} 30(i, q)=\mathbf{s u m}(a a, \operatorname{TWOSOURCE}, \operatorname{PVAL} 3 \mathrm{~T}(i, a a, q))$;

(all, i, COM) (all, s, REGSOURCE)

PVAL4R $(i, s)=\operatorname{BAS} 4(i, s)+\operatorname{TAX} 4(i, s)+\operatorname{sum}(r, \operatorname{MARGCOM}, \operatorname{MAR} 4(i, s, r))$;

(all, i, COM) (all, s, ALLSOURCE) (all, q, REGDEST)

PVAL5A $(i, s, q)=\operatorname{BAS} 5(i, s, q)+\operatorname{TAX} 5(i, s, q)+\operatorname{sum}(r, \operatorname{MARGCOM}, \operatorname{MAR} 5(i, s, q, r))$;

(all, i, COM) (all, s, ALLSOURCE) (all, q, REGDEST) 
$\operatorname{PVAL} 6 \mathrm{~A}(i, s, q)=\operatorname{BAS} 6(i, s, q)+\operatorname{TAX} 6(i, s, q)+\operatorname{sum}(r, \operatorname{MARGCOM}, \operatorname{MAR} 6(i, s, q, r)) ;$
! Subsecao 2.7.3: Formula para os agregados de fator de pagamento!

(all, j, IND) (all, 9, REGDEST)

$\operatorname{LABOUR}(j, q)=\operatorname{sum}\left(m, O C C, \operatorname{LAB} \_O C C \_I N D(m, j, q)\right) ;$

(all, j, IND)

$\operatorname{NATLABOUR}(j)=\boldsymbol{s u m}(q, \operatorname{REGDEST}, \operatorname{LABOUR}(j, q))$;

(all, m, OCC) (all, q, REGDEST)

$\operatorname{LAB} \_O C C(m, q)=\operatorname{sum}\left(j, \operatorname{IND}, \operatorname{LAB} \_O C C \_I N D(m, j, q)\right)$;

(all, $\mathrm{m}, \mathrm{OCC}$ )

$\operatorname{NATLAB} O \mathrm{OCC}(\mathrm{m})=\boldsymbol{\operatorname { s u m }}\left(\mathrm{q}, \operatorname{REGDEST}, \mathrm{LAB} \_\mathrm{OCC}(\mathrm{m}, \mathrm{q})\right)$;

(all, $q$, REGDEST )

$\operatorname{AGGLAB}(q)=\operatorname{sum}(j, \operatorname{IND}, \operatorname{LABOUR}(j, q))$;

$\operatorname{NATAGGLAB}=\operatorname{sum}(q, \operatorname{REGDEST}, \operatorname{AGGLAB}(q))$;

(all , q, REGDEST)

$\operatorname{AGGCAP}(q)=\operatorname{sum}(j, \operatorname{IND}, \operatorname{CAPITAL}(j, q))$;

$\operatorname{NATAGGCAP}=\boldsymbol{s u m}(q, \operatorname{REGDEST}, \operatorname{AGGCAP}(q))$;

(all, q, REGDEST )

$\operatorname{AGGLND}(q)=\operatorname{sum}(j, \operatorname{IND}, \operatorname{LAND}(j, q))$;

$\operatorname{NATAGGLND}=\operatorname{sum}(q, \operatorname{REGDEST}, \operatorname{AGGLND}(q))$;

(all, q, REGDEST )

$\operatorname{TOTFAC}(q)=\operatorname{AGGLAB}(q)+\operatorname{AGGCAP}(q)+\operatorname{AGGLND}(q)$;

$\operatorname{NATTOTFAC}=\operatorname{sum}(q, \operatorname{REGDEST}, \operatorname{TOTFAC}(q))$;

(all, q, REGDEST)

$\operatorname{AGGOCT}(q)=\operatorname{sum}(j, \operatorname{IND}, \operatorname{OTHCOST}(j, q)) ;$

NATAGGOCT $=\operatorname{sum}(q, \operatorname{REGDEST}, \operatorname{AGGOCT}(q))$;

$(a l l, j, I N D)(a l l, q, R E G D E S T)$

$\operatorname{TOTFACIND}(j, q)=\operatorname{LABOUR}(j, q)+\operatorname{CAPITAL}(j, q)+\operatorname{LAND}(j, q) ;$

(all, j, IND)

$\operatorname{NATTOTFACIND}(j)=\operatorname{sum}(q, \operatorname{REGDEST}, \operatorname{TOTFACIND}(j, q))$;

! Subsecao 2.7.4: Formula para agregados de demanda final!

$(\mathrm{all}, j, \mathrm{IND})(\mathrm{all}, \mathrm{q}, \mathrm{REGDEST})$

$\operatorname{INVEST}(j, q)=\operatorname{sum}(i, \operatorname{COM}, \operatorname{PVAL} 20(i, j, q)) ;$

$(a l l, j$, IND)

$\operatorname{NATINVEST}(j)=\boldsymbol{s u m}(q, \operatorname{REGDEST}, \operatorname{INVEST}(j, q))$;

(all, $q$, REGDEST )

$\operatorname{AGGINV}(q)=\operatorname{sum}(j, \operatorname{IND}, \operatorname{INVEST}(j, q))$;

$\operatorname{NATAGGINV}=\operatorname{sum}(q, \operatorname{REGDEST}, \operatorname{AGGINV}(q))$;

(all, q, REGDEST)

$\operatorname{AGGCON}(q)=\operatorname{sum}(i, \operatorname{COM}, \operatorname{PVAL} 30(i, q))$;

$\operatorname{NATAGGCON}=\operatorname{sum}(q, \operatorname{REGDEST}, \operatorname{AGGCON}(q))$;

(all , q, REGDEST)

$\operatorname{AGGEXP}(q)=\operatorname{sum}(i, \operatorname{COM}, \operatorname{PVAL} 4 \mathrm{R}(i, q))$;

(all, q, REGDEST)

$\operatorname{AGGEXPNT}(q)=\operatorname{suM}(i, \operatorname{NTEXP}, \operatorname{PVAL} 4 r(i, q))$;

NATAGGEXP $=\operatorname{sum}(q, \operatorname{REGDEST}, \operatorname{AGGEXP}(q))$;

(all, $q$, REGDEST )

$\operatorname{AGGOTH5}(q)=\operatorname{sum}(i, \operatorname{COM}, \operatorname{sum}(s, \operatorname{ALLSOURCE}, \operatorname{PVAL} 5 \mathrm{~A}(i, s, q)))$;

NATAGGOTH5 = sum $(q, \operatorname{REGDEST}, \operatorname{AGGOTH5}(q))$;

(all, q, REGDEST)

AGGOTH6 (Q) = sum (i, COM, sum(s, ALLSOURCE, PVAL6A (i, s, q)) ) i

NATAGGOTH6 = sum $(i, \operatorname{COM}, \operatorname{sum}(s, \operatorname{ALLSOURCE}, \boldsymbol{s u m}(q, \operatorname{REGDEST}, \operatorname{PVAL} 6 \mathrm{~A}(i, s, q))))$;

! Subsecao 2.7.5: Formula para agregados de importacao!

(all, i, COM)

$\operatorname{NATIMPORTS}(i)=\operatorname{sum}(q, \operatorname{REGDEST}, \operatorname{IMPORTS}(i, q))$;

(all, $i, \mathrm{COM})$ (all, $\mathrm{q}, \mathrm{REGDEST})$

$\operatorname{IMPCOST}(i, q)=\operatorname{IMPORTS}(i, q)-\operatorname{TARIFF}(i, q)$

(all, $i, \mathrm{COM})$

NATIMPCOST $(i)=\operatorname{NATIMPORTS}(i)-\operatorname{NATTARIFF}(i)$;

(all, q, REGDEST )

$\operatorname{AGGIMP}(q)=\operatorname{sum}(i, \operatorname{COM}, \operatorname{IMPCOST}(i, q))$;

NATAGGIMP $=\operatorname{sum}(i, \operatorname{COM}, \operatorname{NATIMPCOST}(i))$; 
! Subsecao 2.7.6: Formula para agregados de receita dos impostos!

(all, q, REGDEST)

$\operatorname{AGGTAX1}(q)=\operatorname{sum}(i, \operatorname{COM}, \operatorname{sum}(s, \operatorname{ALLSOURCE}, \operatorname{sum}(j, \operatorname{IND}, \operatorname{TAX} 1(i, s, j, q))))$;

(all, q, REGDEST)

$\operatorname{AGGTAX} 2(q)=\operatorname{sum}(i, \operatorname{COM}, \boldsymbol{\operatorname { s u m }}(\mathrm{s}, \operatorname{ALLSOURCE}, \boldsymbol{\operatorname { s u m }}(j, \operatorname{IND}, \operatorname{TAX} 2(i, s, j, q))))$;

(all, q, REGDEST)

$\operatorname{AGGTAX} 3(q)=\operatorname{sum}(i, \mathrm{COM}, \boldsymbol{s u m}(s, \operatorname{ALLSOURCE}, \operatorname{TAX} 3(i, s, q)))$;

(all, S, REGSOURCE)

$\operatorname{AGGTAX} 4(s)=\operatorname{sum}(i, \operatorname{COM}, \operatorname{TAX} 4(i, s))$;

(all, q, REGDEST)

$\operatorname{AGGTAX} 5(q)=\operatorname{sum}(i, \operatorname{COM}, \boldsymbol{s u m}(s, \operatorname{ALLSOURCE}, \operatorname{TAX} 5(i, s, q)))$;

(all, q, REGDEST )

$\operatorname{AGGTAX} 6(q)=\operatorname{sum}(i, \operatorname{COM}, \operatorname{sum}(s, \operatorname{ALLSOURCE}, \operatorname{TAX} 6(i, s, q)))$;

(all, $q$, REGDEST)

$\operatorname{AGGTAXM}(q)=\operatorname{sum}(i, \operatorname{COM}, \operatorname{Tariff}(i, q))$;

NATAGGTAX1 = sum $(q, \operatorname{REGDEST}, \operatorname{AGGTAX1}(q))$;

$\operatorname{NATAGGTAX2}=\operatorname{sum}(q, \operatorname{REGDEST}, \operatorname{AGGTAX} 2(q))$;

$\operatorname{NATAGGTAX3}=\boldsymbol{s u m}(q, \operatorname{REGDEST}, \operatorname{AGGTAX} 3(q))$;

NATAGGTAX4 = sum ( $\mathrm{s}, \operatorname{REGSOURCE}, \operatorname{AGGTAX} 4(\mathrm{~s}))$;

$\operatorname{NATAGGTAX5}=\boldsymbol{s u m}(q, \operatorname{REGDEST}, \operatorname{AGGTAX} 5(q))$;

NATAGGTAX 6 = sum $(q, \operatorname{REGDEST}, \operatorname{AGGTAX} 6(q))$;

$\operatorname{NATAGGTAXM}=\operatorname{sum}(q, \operatorname{REGDEST}, \operatorname{AGGTAXM}(q))$;

NATAGGTAX = NATAGGTAX1 + NATAGGTAX2 + NATAGGTAX3 + NATAGGTAX4 +

NATAGGTAX5 + NATAGGTAX6 + NATAGGTAXM;

(all, q, REGDEST)

$\operatorname{AGGTAX}(q)=\operatorname{AGGTAX1}(q)+\operatorname{AGGTAX} 2(q)+\operatorname{AGGTAX} 3(q)+\operatorname{AGGTAX} 5(q)$;

AGGTAX $($ fede") = NATAGGTAX4 + NATAGGTAX6 + NATAGGTAXM;

! Subsecao 2.7.7: Formula para O PIB!

NATGDPEX $=$ NATAGGCON + NATAGGINV

+ NATAGGOTH5 + NATAGGOTH 6 + NATAGGEXP - NATAGGIMP;

NATGDPIN = NATTOTFAC + NATAGGOCT + NATAGGTAX;

! modif inclusao do coef C_tOTMARG da eq E_amarg_ave 21/10!

C_TOTMARG $=$

[ $\operatorname{sum}(i, C O M, \operatorname{sum}(r, \operatorname{MARGCOM}, \operatorname{sum}(q, R E G D E S T, \operatorname{sum}(s, A L L S O U R C E, \operatorname{sum}(j$, IND, $\operatorname{MAR} 1(i, s, j, q, r)+(\operatorname{MAR} 2(i, s, j, q, r))+\operatorname{MAR} 3(i, s, q, r))))+$ $\operatorname{sum}(s, \operatorname{REGSOURCE}, \operatorname{MAR} 4(i, S, r))))]$;

! Subsecao 2.7.8: Formula para fluxos de comercio inter-regional !

(all, s, REGSOURCE) (all, q, REGDEST)

C_XSELO $(s, q)=\operatorname{sum}(i, \operatorname{COM}, \operatorname{sum}(j, \operatorname{IND}, \operatorname{BAS} 1(i, s, j, q)))$

$+\operatorname{sum}(i, \mathrm{COM}, \operatorname{sum}(j, \operatorname{IND}, \operatorname{BAS} 2(i, s, j, q)))$

$+\operatorname{sum}(i, C O M, \operatorname{BAS} 3(i, s, q))$

$+\operatorname{sum}(I, C O M, \operatorname{BAS} 5(I, S, Q))$;

(all, S, REGSOURCE)

C_XSEXP $(s)=\operatorname{sum}\left(q, \operatorname{REGDEST}, \mathrm{C} \_X \operatorname{SELO}(s, q)\right)-\mathrm{C} \_X \operatorname{SFLO}(s, s)$;

(all, q, REGDEST)

C_XSIMP $(q)=\operatorname{sum}\left(s, \operatorname{REGSOURCE}, \mathrm{C} \_X S F L O(s, q)\right)$ - C_XSFLO $(q, q)$;

(all, i, COM) (all, s, REGSOURCE) (all, q, REGDEST)

C_XSFLOJ $(i, s, q)=\operatorname{sum}(j, \operatorname{IND}, \operatorname{BAS} 1(i, s, j, q))$

$+\operatorname{sum}(j, \operatorname{IND}, \operatorname{BAS} 2(i, s, j, q))$

$+\operatorname{BAS} 3(i, s, q)$

$+\operatorname{BAS5}(I, S, q)$;

(all, i, COM) (all, s, REGSOURCE)

C_XSEXPJ $(i, s)=\operatorname{sum}\left(q, \operatorname{REGDEST}, \mathrm{C} \_X \operatorname{XSEOJ}(i, s, q)\right)$

- C_XSFLOJ $(i, s, s)$;

(all, i, COM) (all, q, REGDEST)

C_XSIMPJ $(i, q)=\operatorname{sum}\left(s, \operatorname{REGSOURCE}, \mathrm{C} \_X S E L O J(i, s, q)\right)$

- C_XSFLOJ $(i, q, q)$;

(all, i, COM)

C_XSFLOJSQ $(i)=\operatorname{sum}\left(s, \operatorname{REGSOURCE}, \boldsymbol{s u m}\left(q, \operatorname{REGDEST}, \mathrm{C} \_X S E L O J(i, s, q)\right)\right)$;

C_XSFLOJSQI $=\operatorname{sum}\left(i, C O M, C \_X S F L O J S Q(i)\right)$;

(all, i, COM) (all, s, REGSOURCE)

$\operatorname{SX}(i, s)=C \_X S E X P J(i, s) / C \_X S E X P(s)$; 
(all, i, COM) (all, q, REGDEST)

$\operatorname{SM}(i, q)=C \_X S I M P J(i, q) / C \_X S I M P(q)$;

! Subsecao 2.7.9: Formula para demandas das familias!

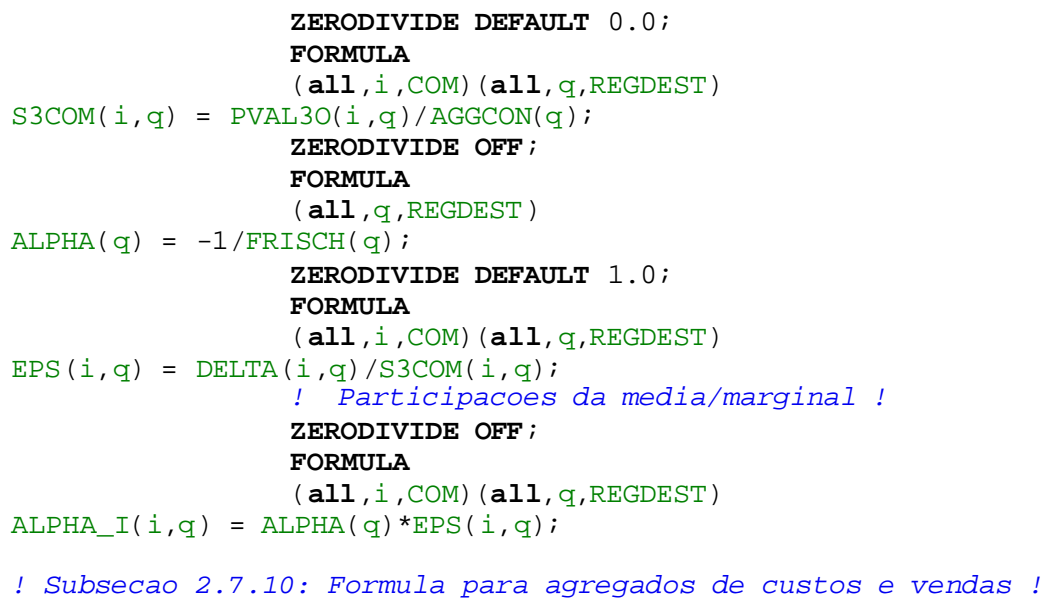


(all, s, REGSOURCE)

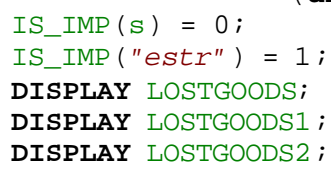

! Secao 2.8: Equacoes do modulo central do MIBRA ordem tematica!

! Subsecao 2.8.1: Demandas por industrias para insumos intermediarios - Usuario 1 !

! Armington local e nacional aninha insumos intermediarios para producao corrente. Aninhamento nacional fornece possibilidade de substituicao entre insumos nacional e estrangeiro e o aninhamento local fornece possibilidade de substituicao entre insumos das cinco regioes!

EQUATION

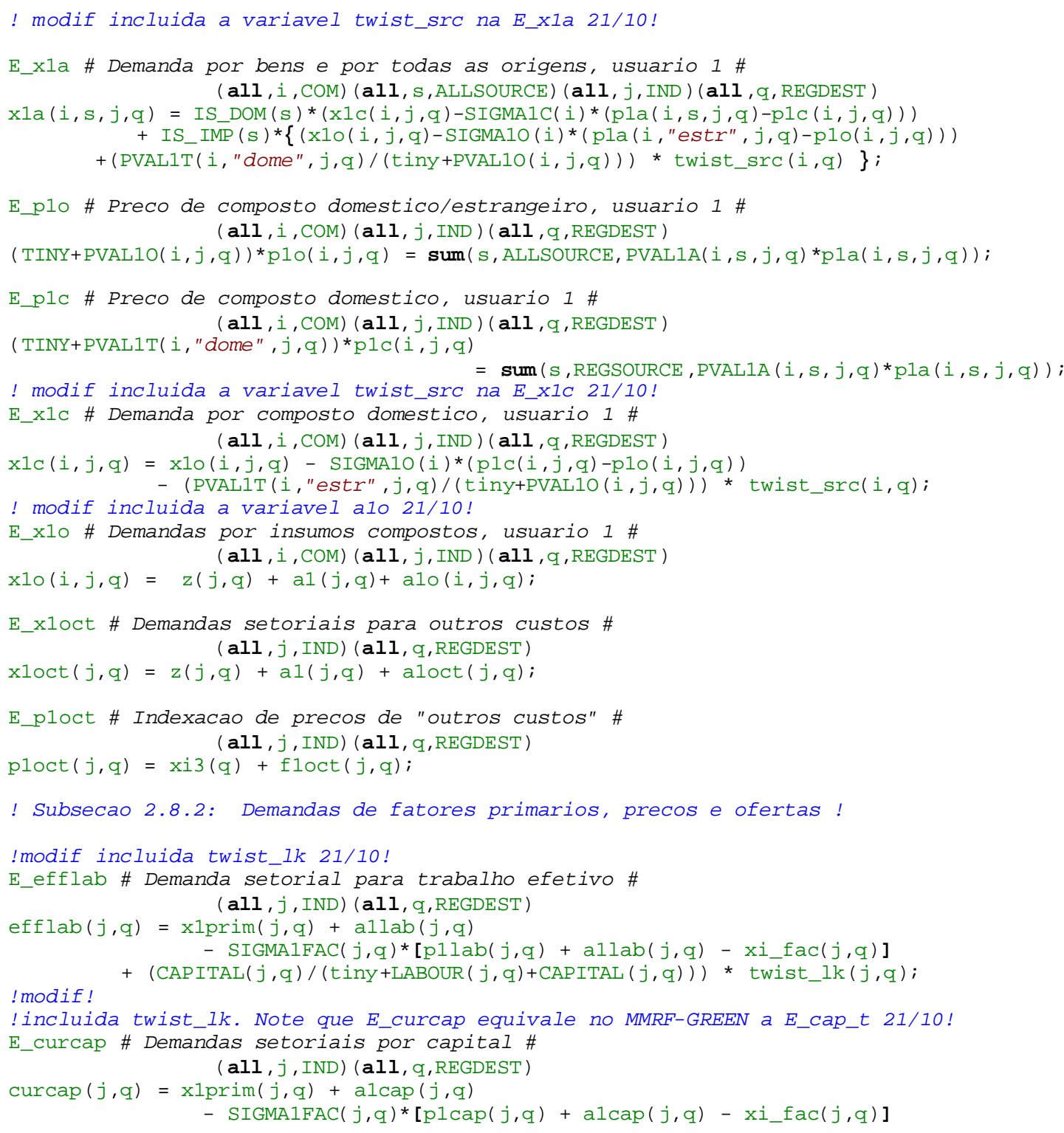


- $(\operatorname{LABOUR}(j, q) /(\operatorname{tiny}+\operatorname{LABOUR}(j, q)+\operatorname{CAP} \operatorname{ctal}(j, q)))$ *twist_lk $(j, q)$;

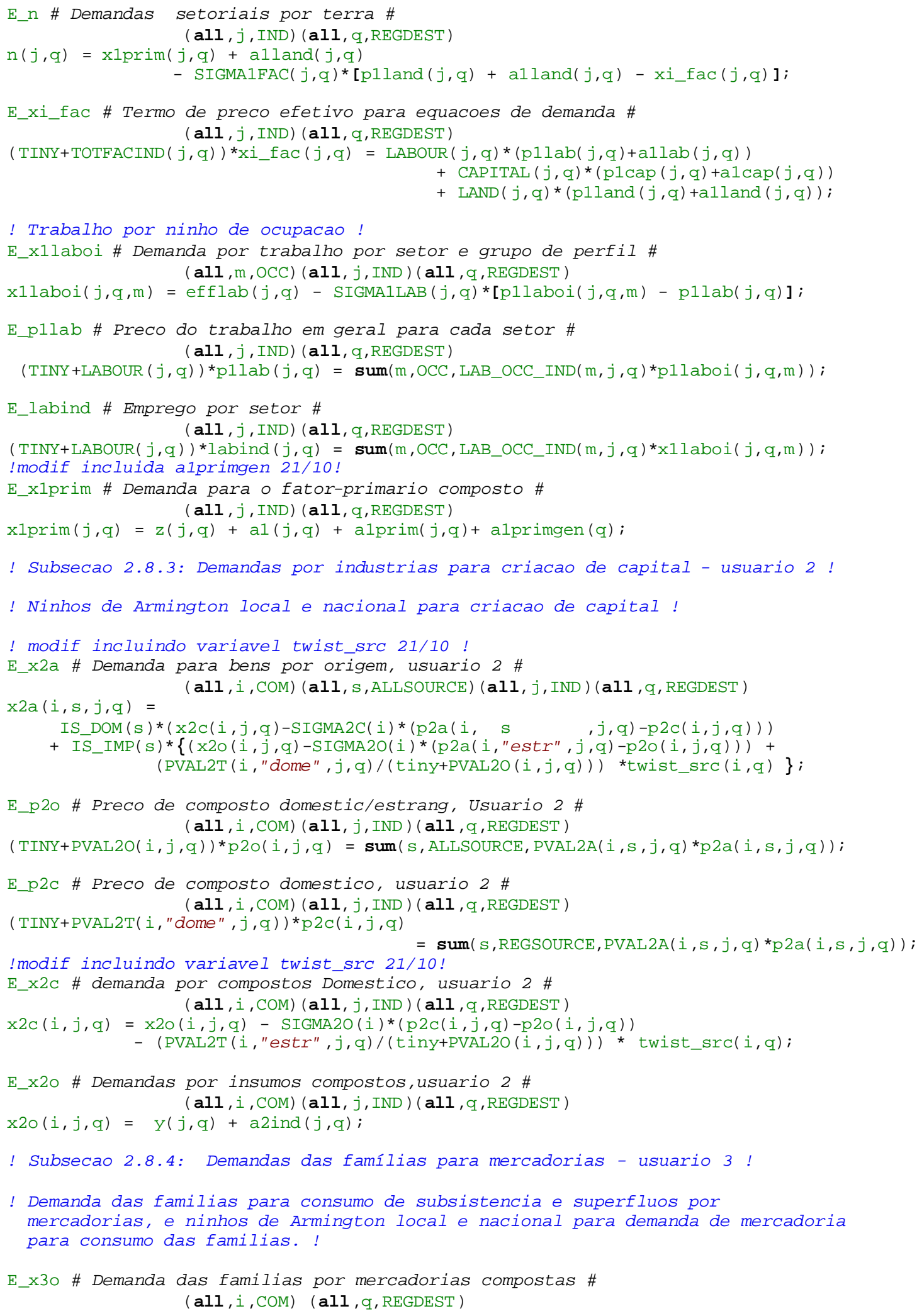




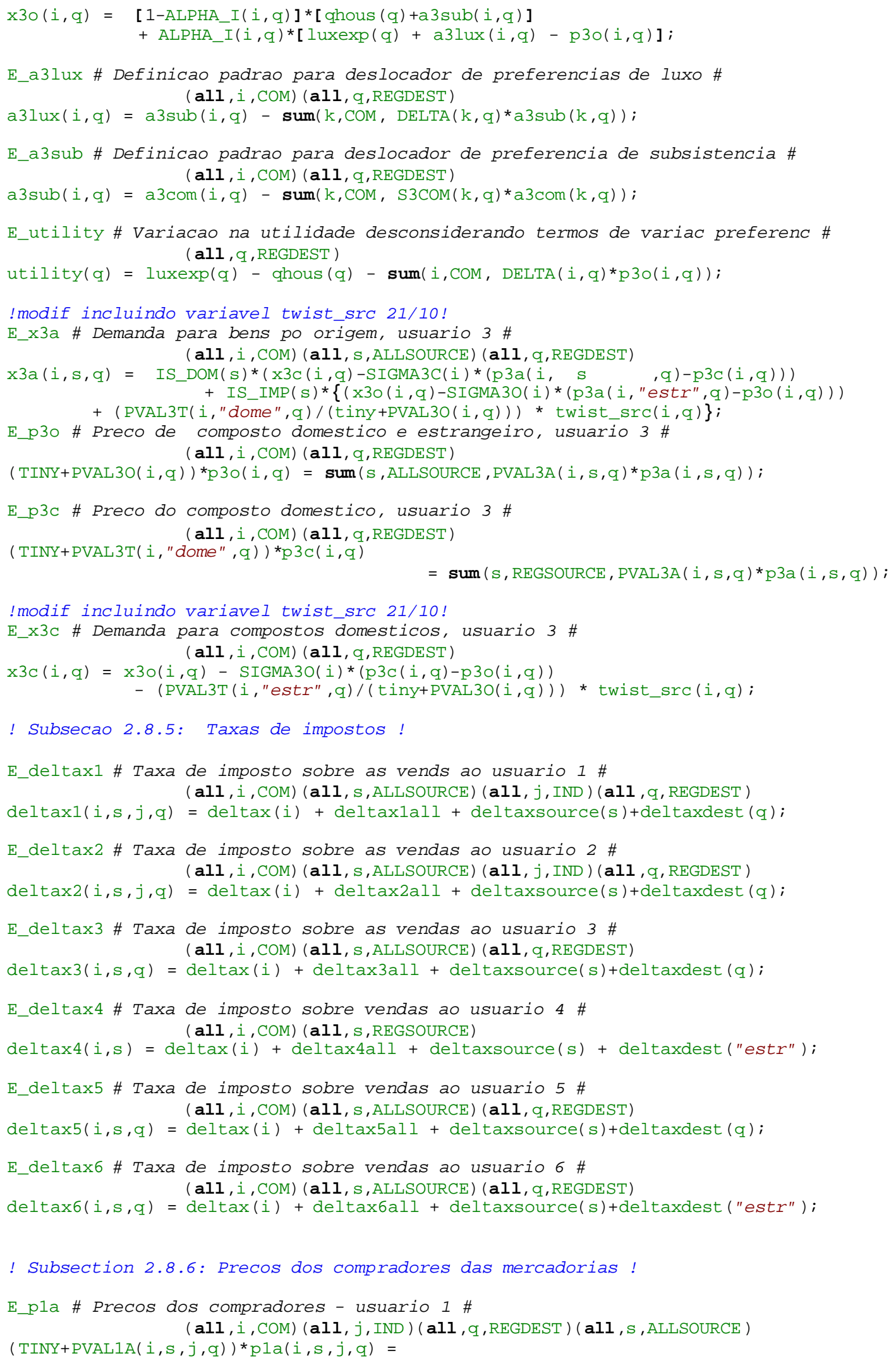




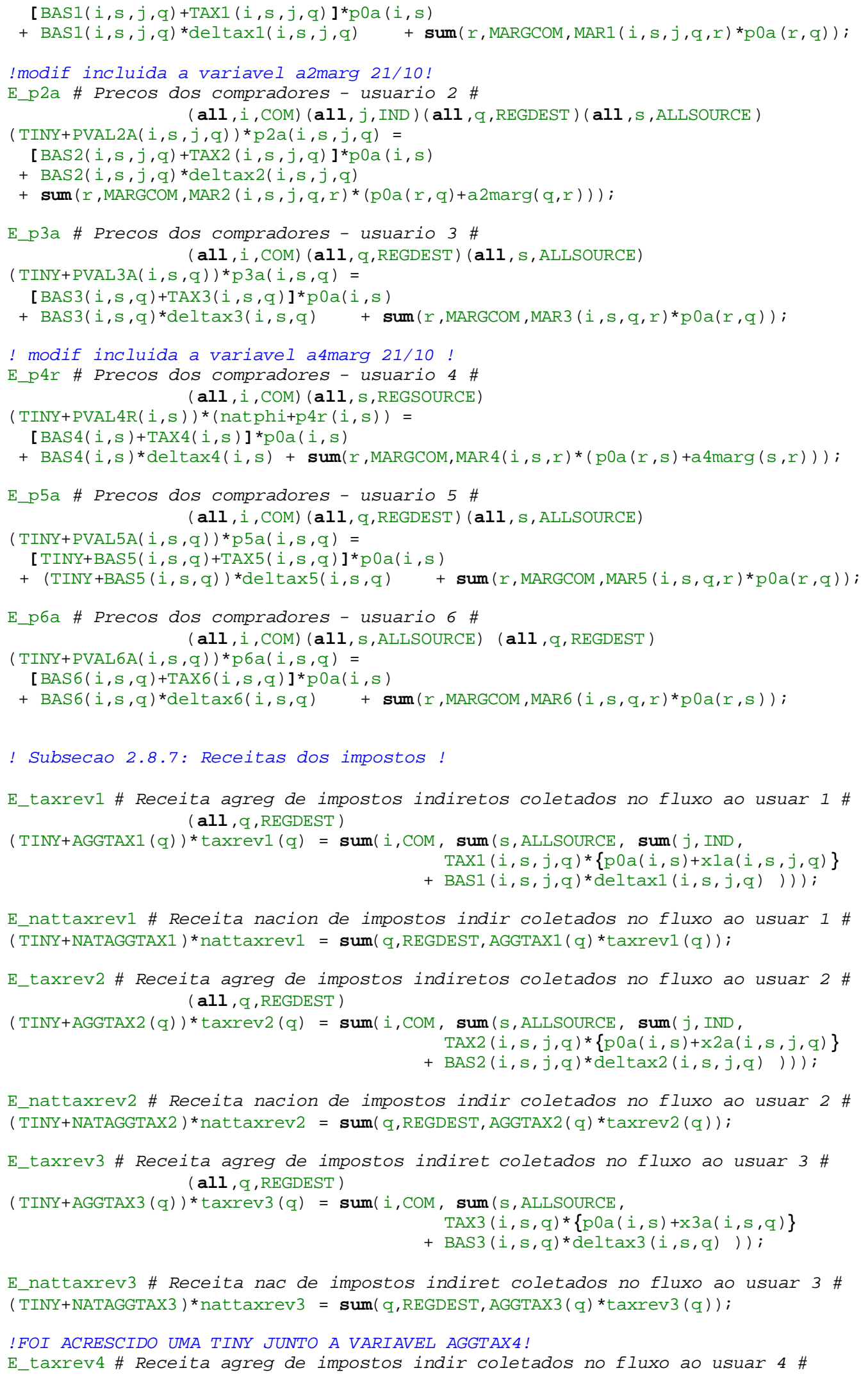


(all, s, REGSOURCE)

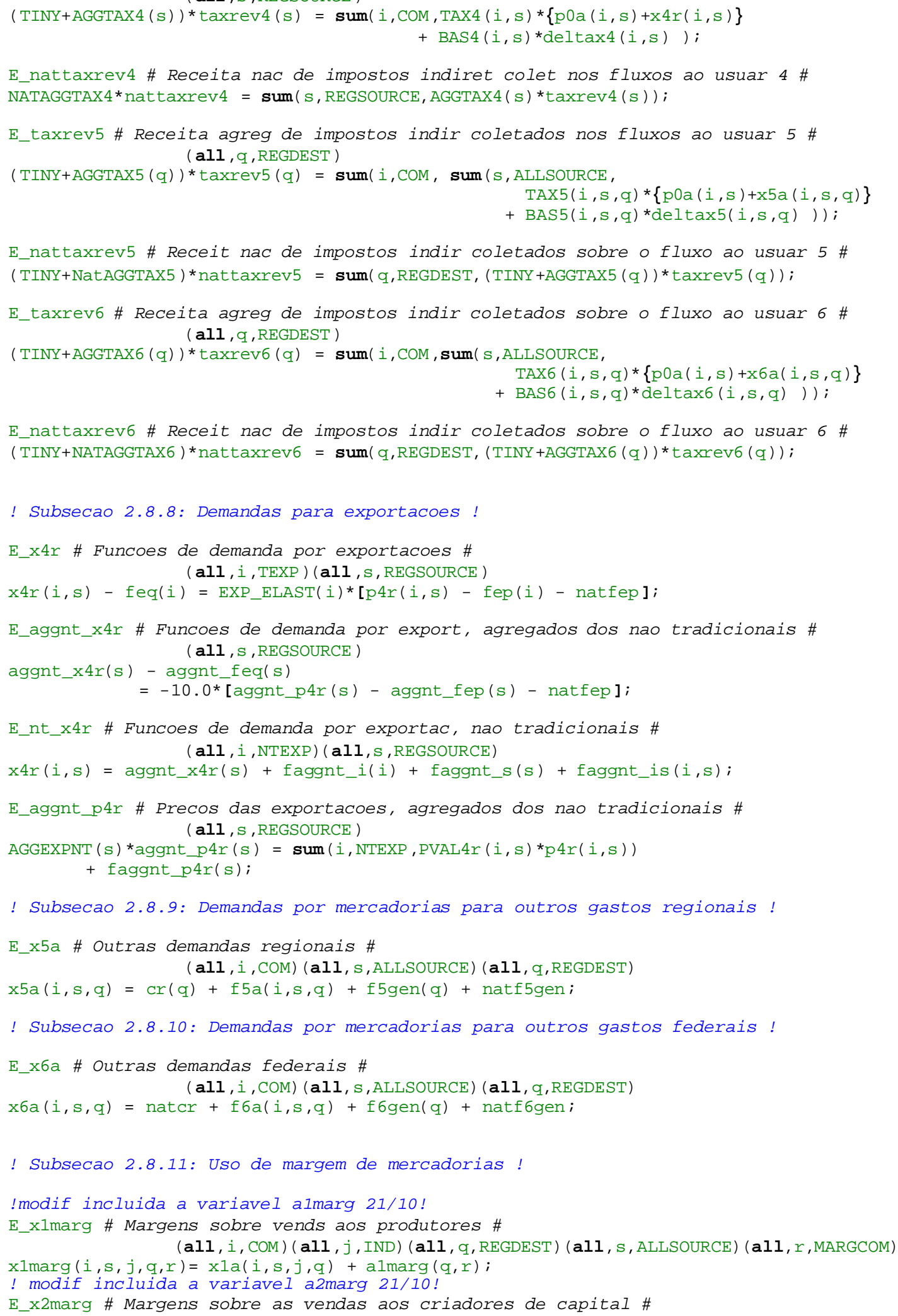


(all, s, ALLSOURCE) (all, r, MARGCOM)

$x 2 \operatorname{marg}(i, s, j, q, r)=x 2 a(i, s, j, q)+\operatorname{armarg}(q, r)$

! modif incluida a variavel a3marg 21/10!

E_x3marg \# Margens sobre as vendas ao consumo das familias \#

(all, i, COM) (all, s, ALLSOURCE) (all, q, REGDEST) (all, r, MARGCOM)

$x \operatorname{marg}(i, s, q, r)=x 3 a(i, s, q)+\operatorname{a3marg}(q, r) ;$

!modif incluida a variavel a3marg 21/10!

E_x4marg \# Margens sobre exportacoes: portao da fabrica ao porto \#

(all, i, COM) (all, r, MARGCOM) (all, s, REGSOURCE)

$x 4 \operatorname{marg}(i, s, r)=x 4 r(i, s)+\operatorname{a} 4 \operatorname{marg}(s, r)$;

E_x5marg \# Margens sobre as vendas para outras demandas regionais \#

(all, i, COM) (all, s, ALLSOURCE) (all, q, REGDEST) (all, r, MARGCOM)

$x 5 \operatorname{marg}(i, s, q, r)=x 5 a(i, s, q)$;

E_x6marg \# Margens sobre as vendas para outras demandas fed em cada regiao \#

(all, i, COM) (all, r, MARGCOM) (all, s, ALLSOURCE) (all, q, REGDEST)

$x 6 \operatorname{marg}(i, s, q, r)=x 6 a(i, s, q)$;

! Subsecao 2.8.12: Oferta igual demanda por mercadorias domest. e importadas!

E_mkt_clear_margins \# Demanda igual a oferta para margens em mercadorias \#

(all, r, MARGCOM) (all, s, REGSOURCE)

$(\operatorname{TINY}+\operatorname{SALES}(r, s)) * z(r, s)=$

$\operatorname{sum}\left(j, I N D, \operatorname{sum}\left(q, \operatorname{REGDEST}, \operatorname{BAS} 1(r, s, j, q) x_{x} 1 a(r, s, j, q)\right.\right.$

$\operatorname{BAS} 2(r, s, j, q) * x 2 a(r, s, j, q)))$

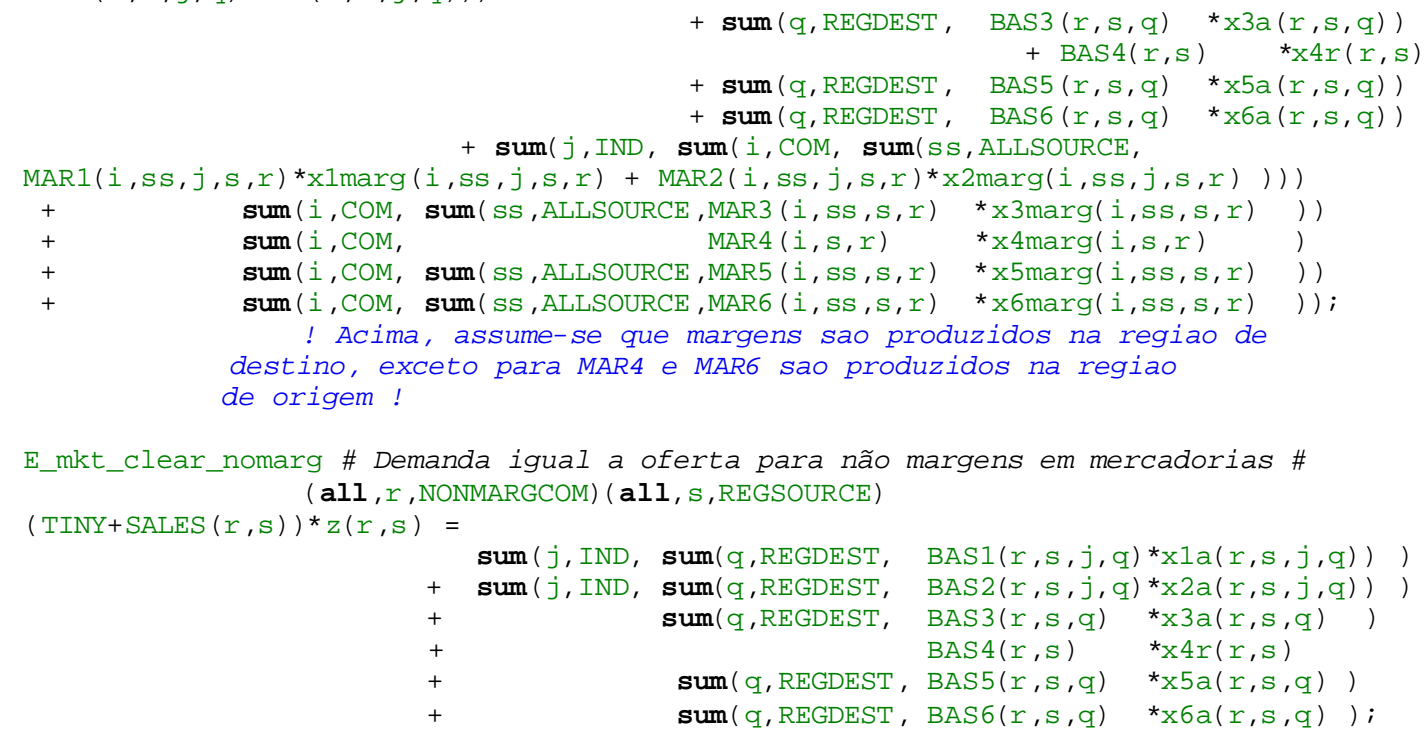

E_x0impa \# volumes de importacoes de mercadorias por regiao \#

(all, i, COM) (all, q, REGDEST)

$(\operatorname{TINY}+\operatorname{IMPORTS}(i, q)) * \times 0 i m p(i, q)$

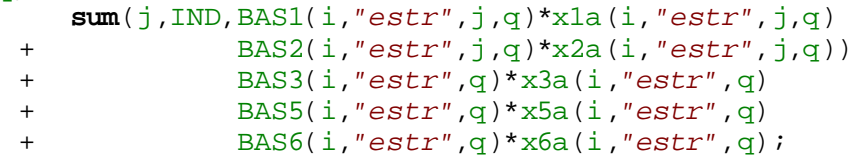

E_natx0imp \# Volumes de importacoes \#

(all, i, COM)

$(\operatorname{TINY}+\operatorname{NATIMPORTS}(i))$ *natx0imp $(i)=\operatorname{sum}(q, \operatorname{REGDEST}, \operatorname{IMPORTS}(i, q) * x 0 i m p(i, q))$;

! Subsecao 2.8.13: Precos basicos!

E_p0a \# Lucros puros zero na producao corrente \# 
(all, $j$, IND) (all, $q$, REGDEST)

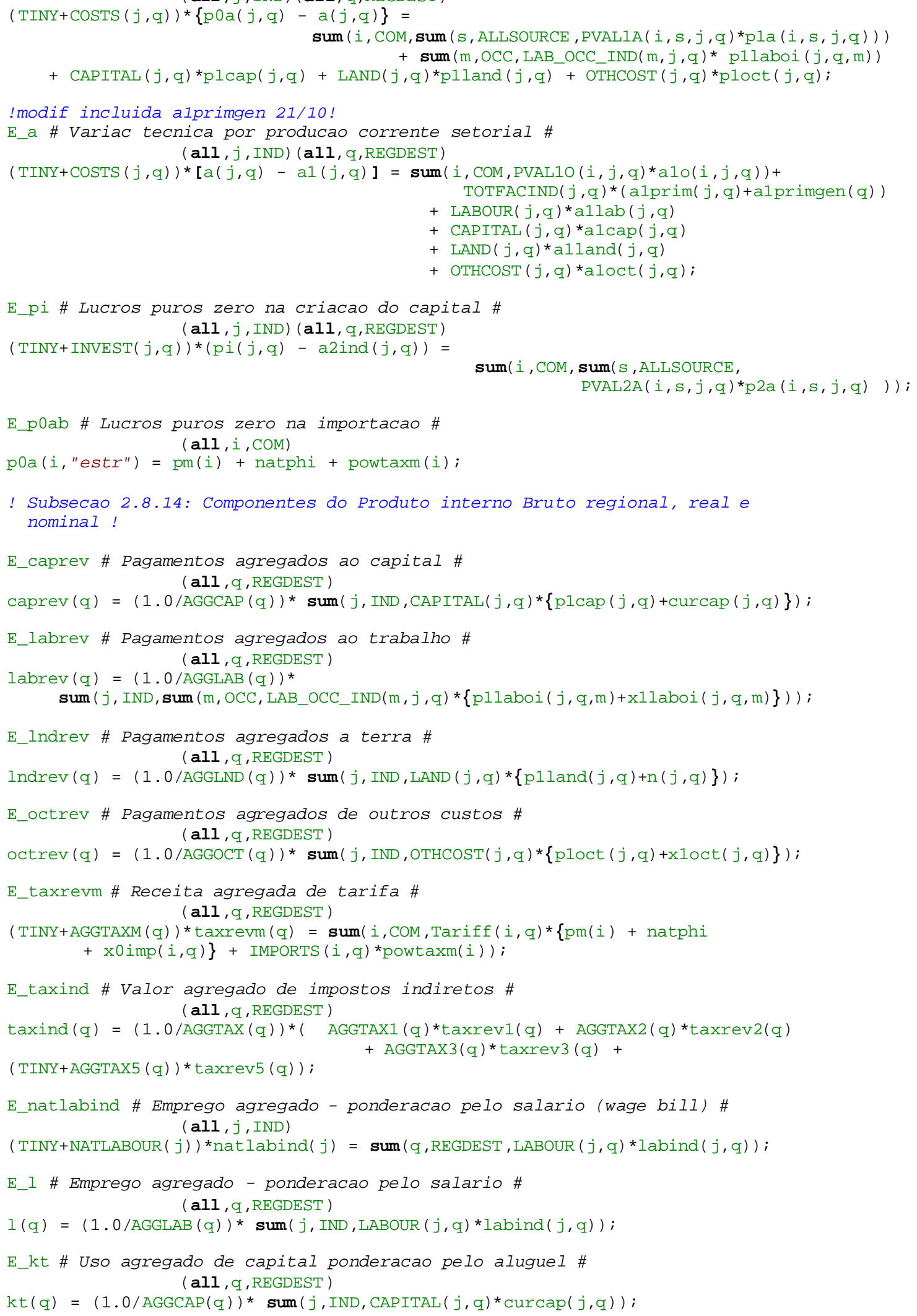




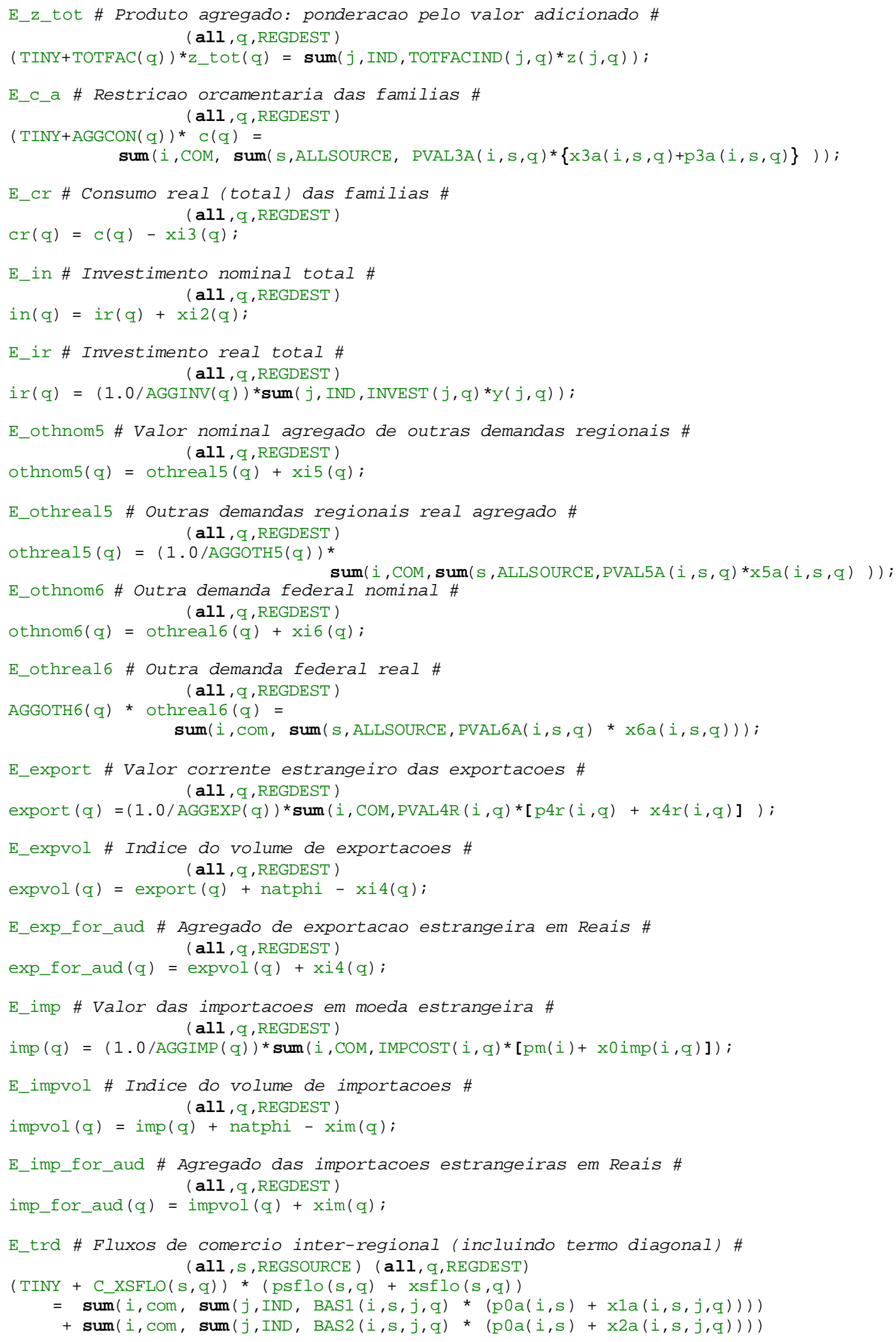




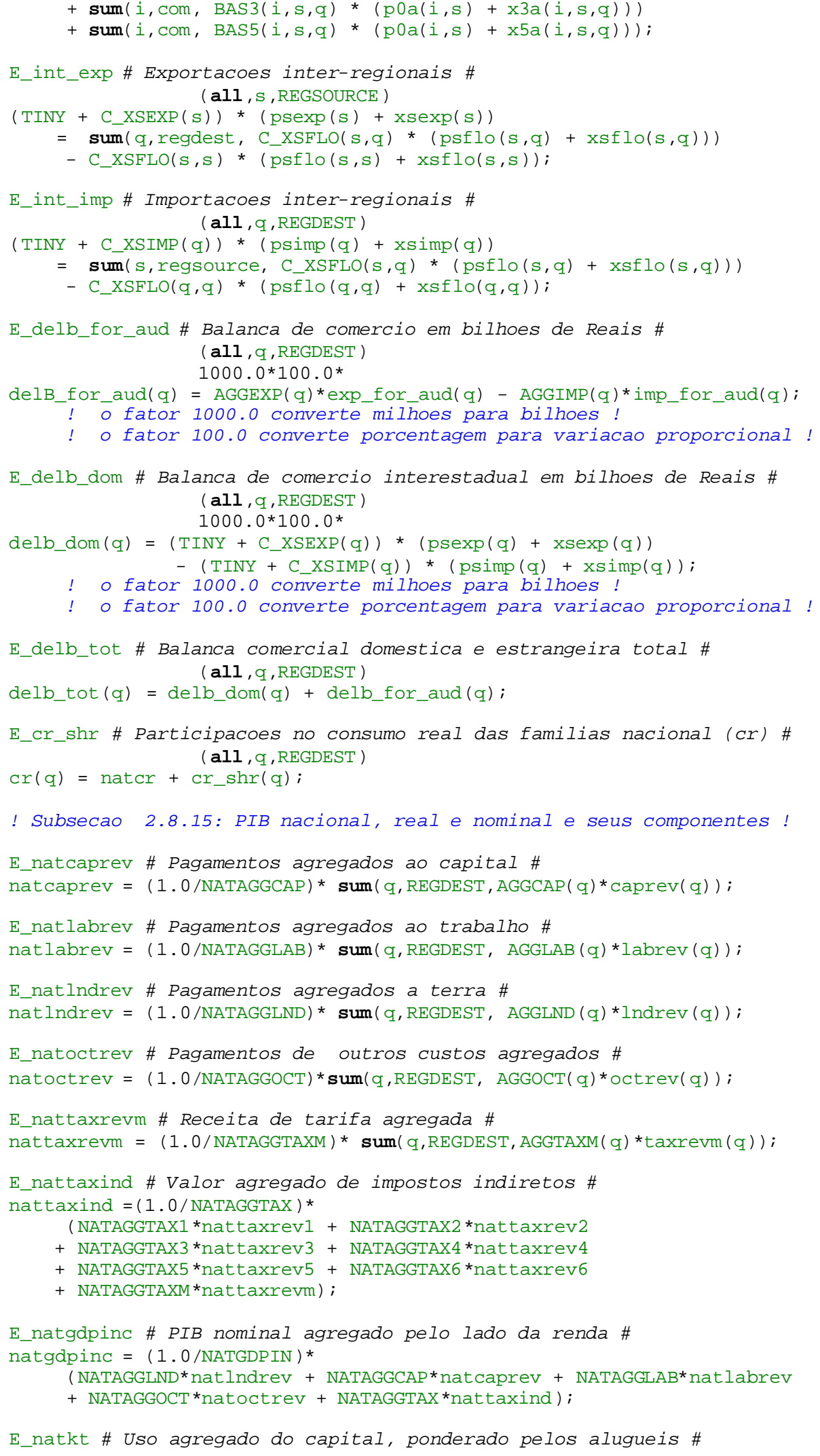




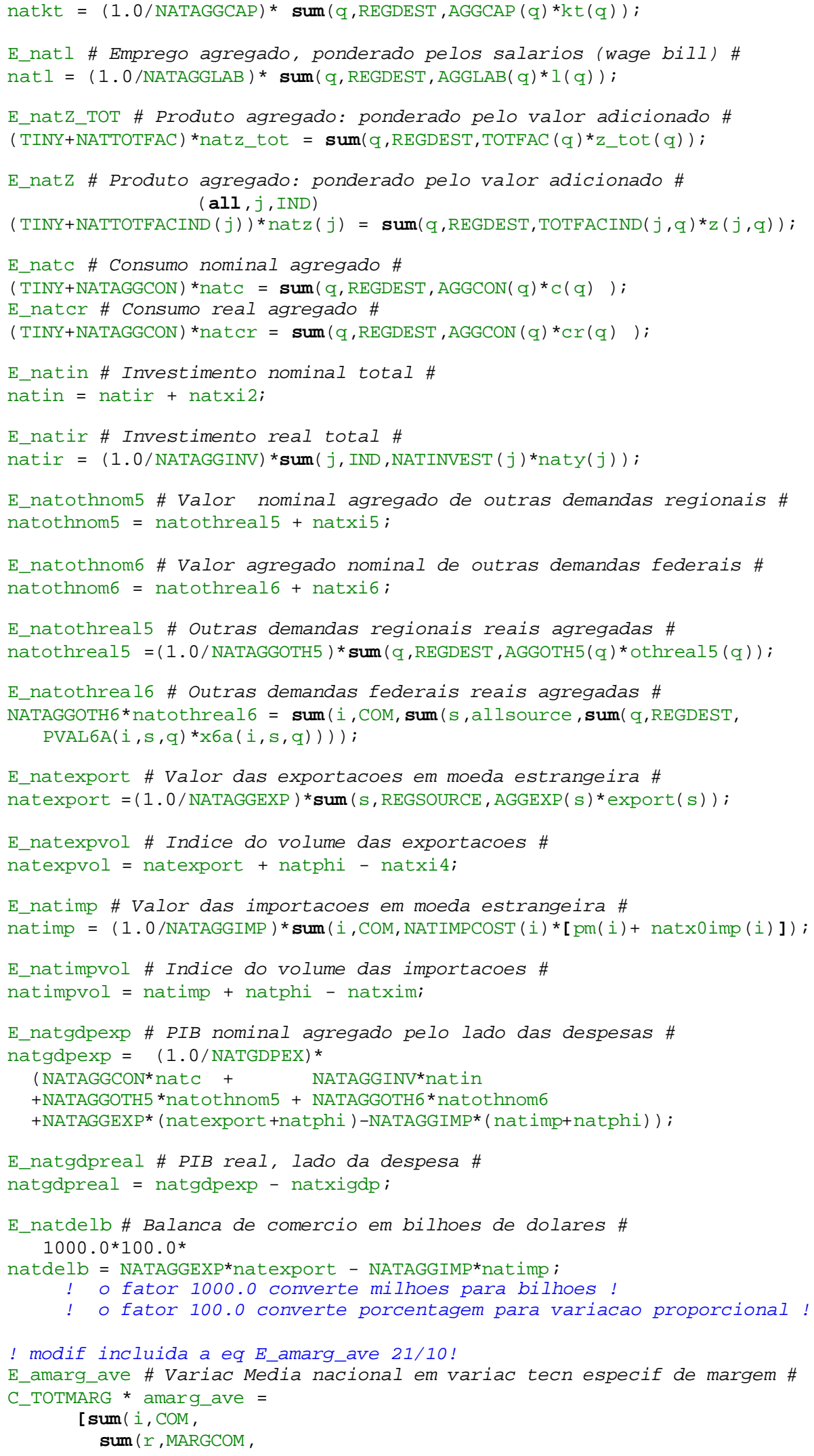




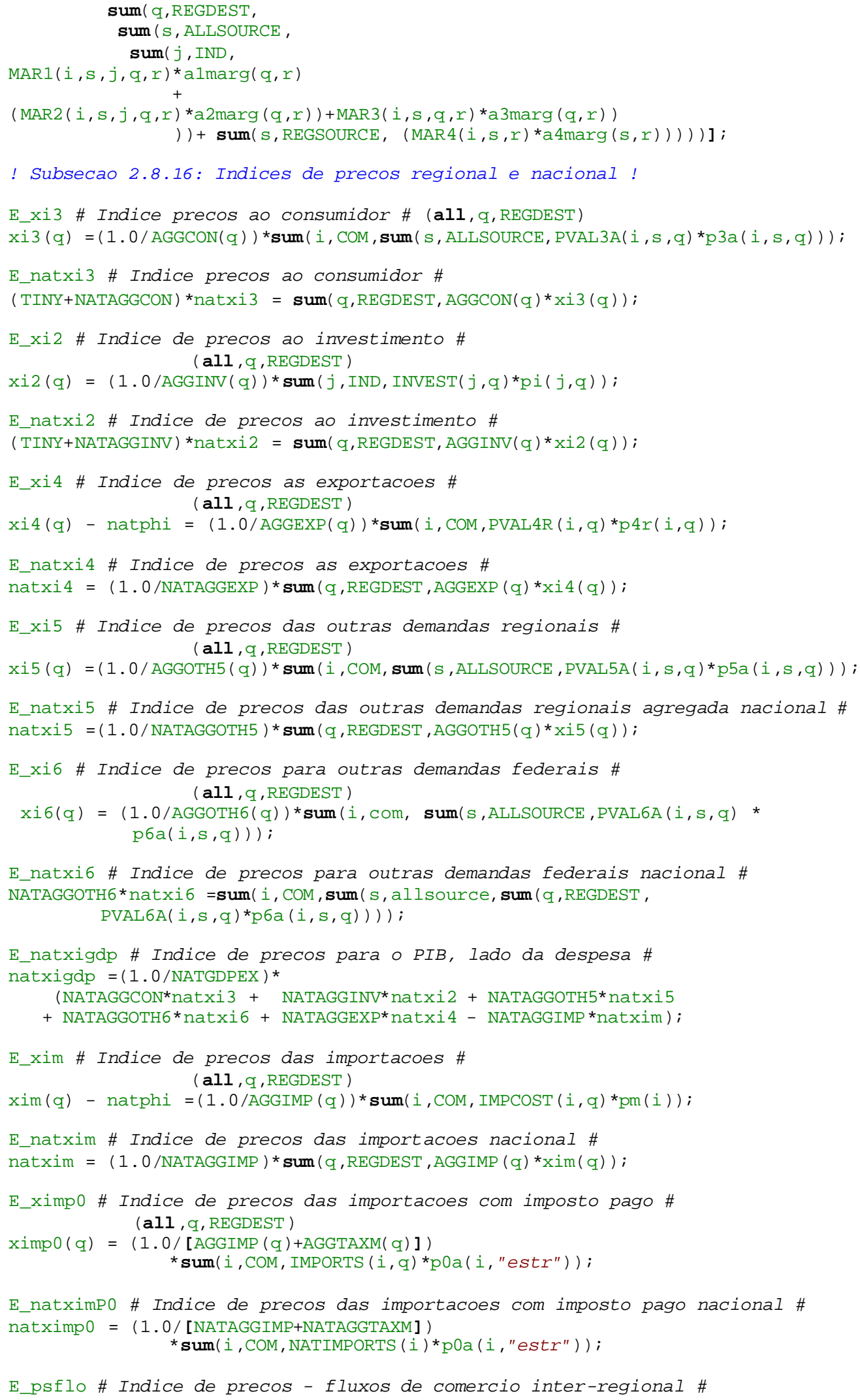




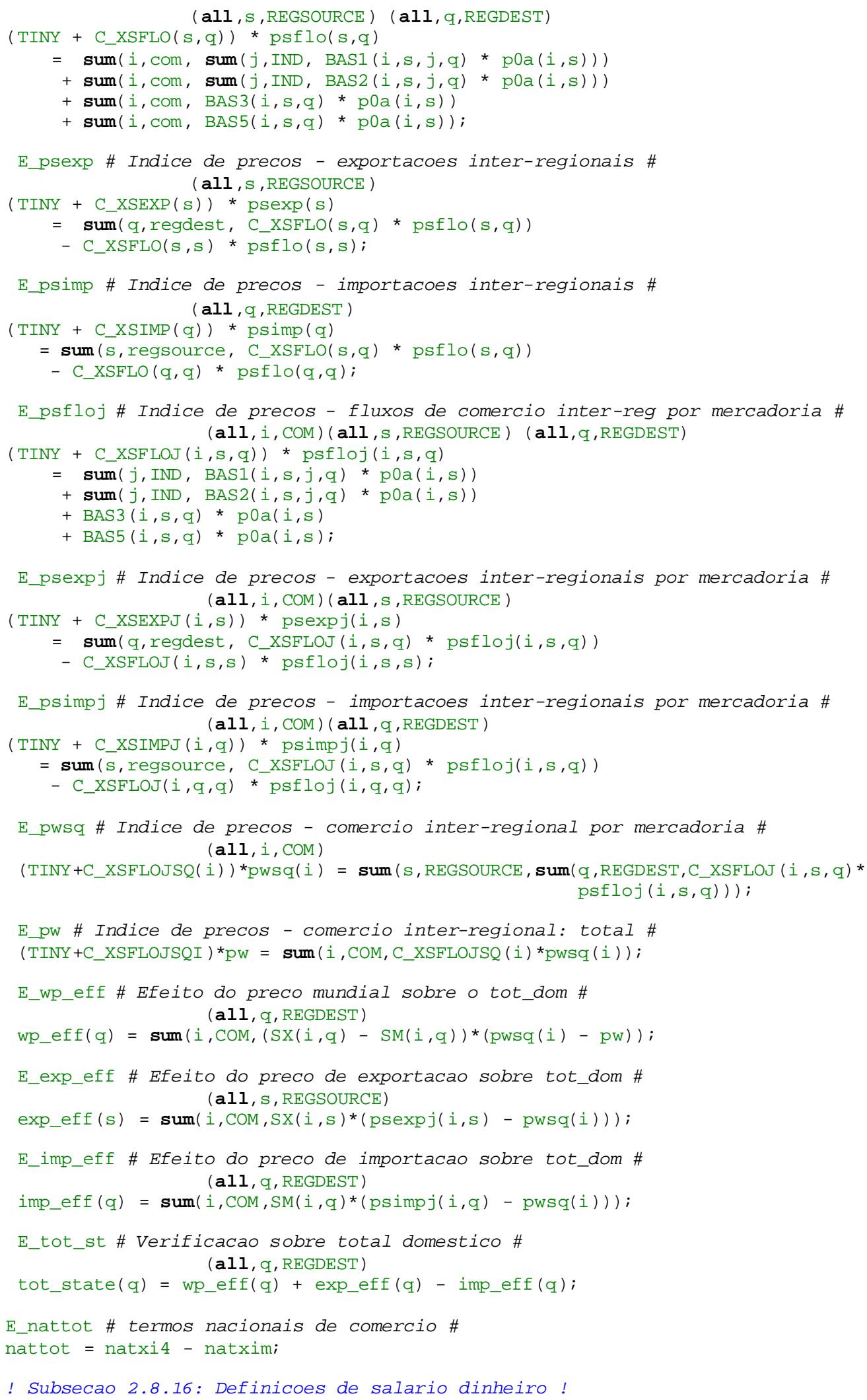




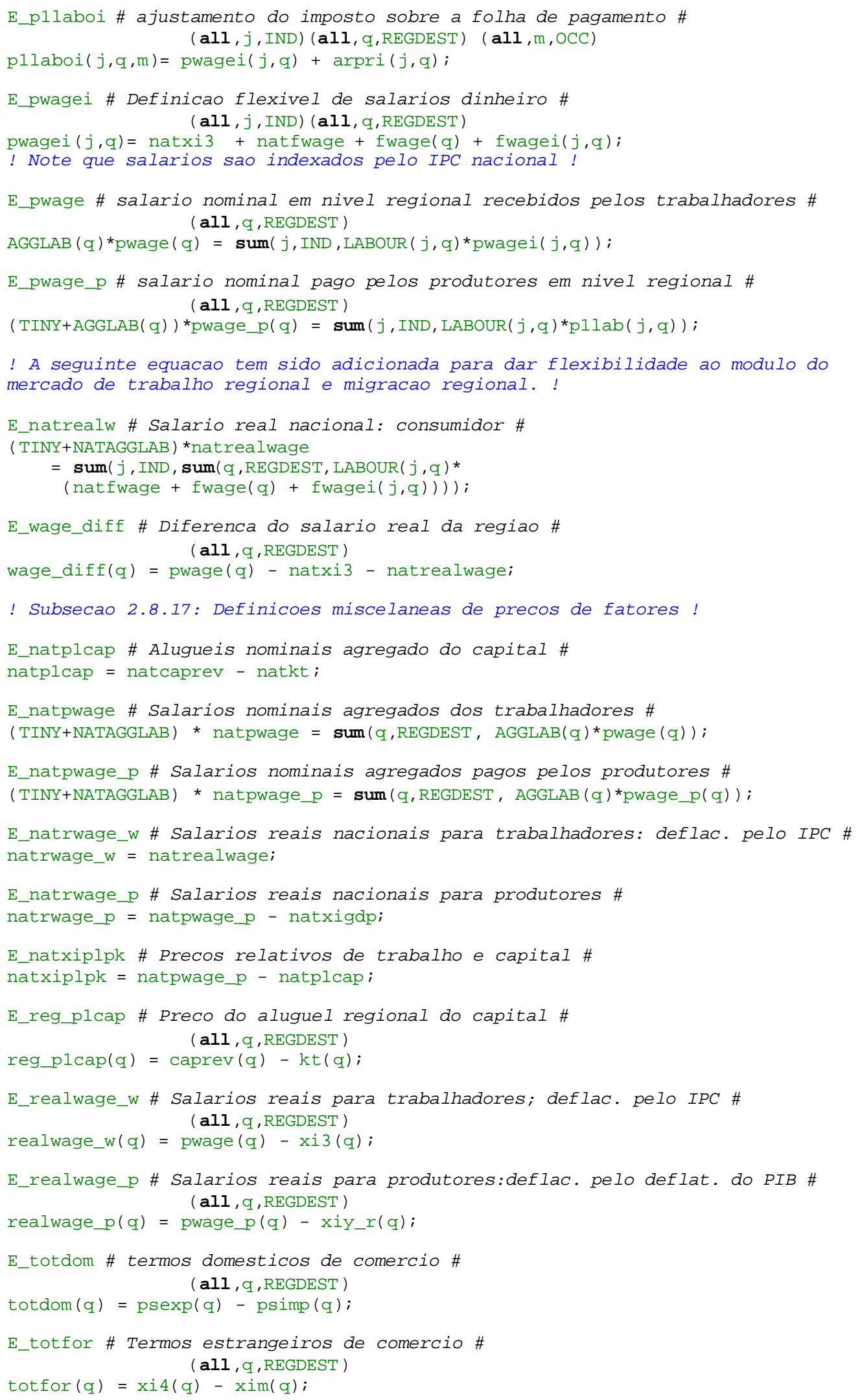




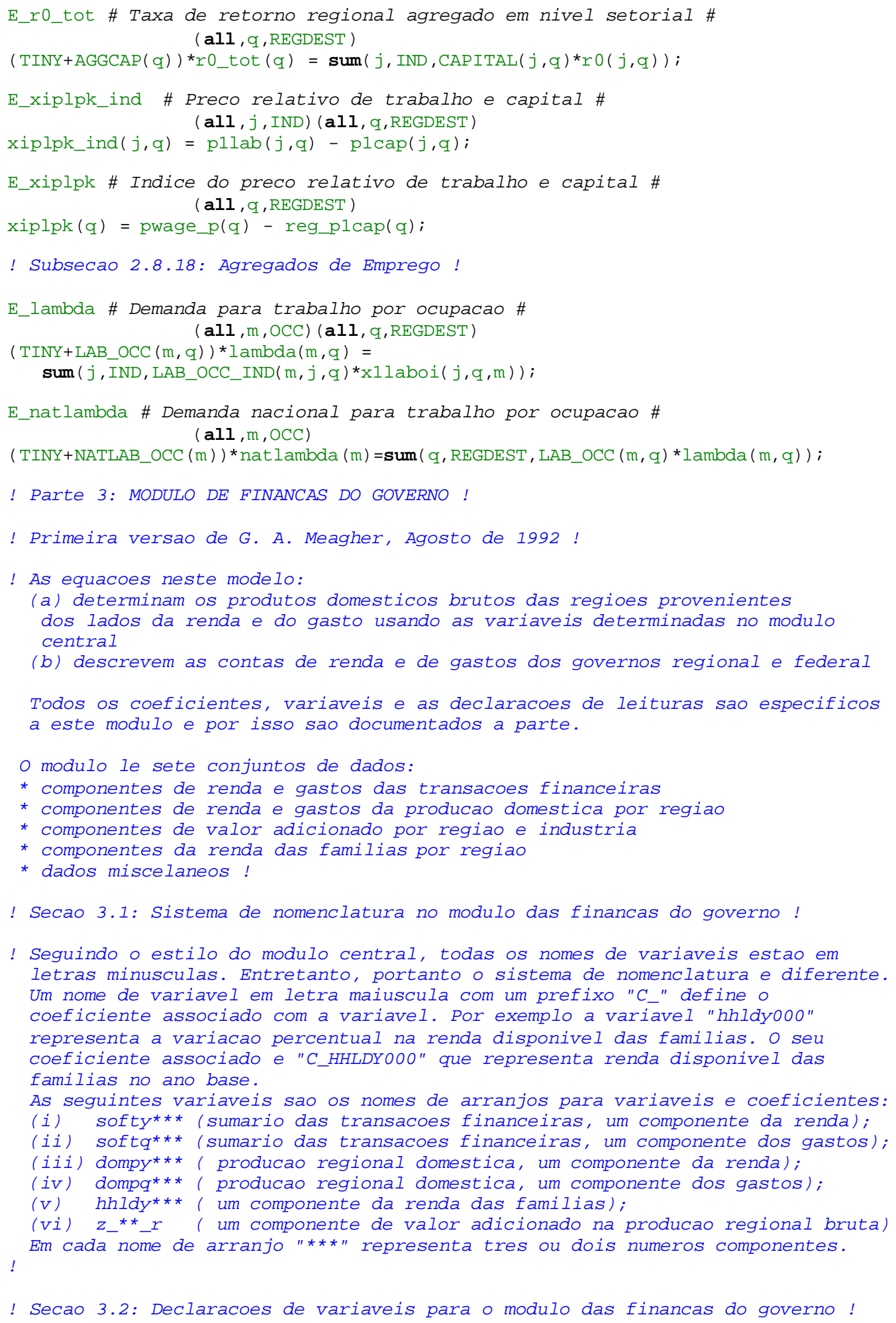




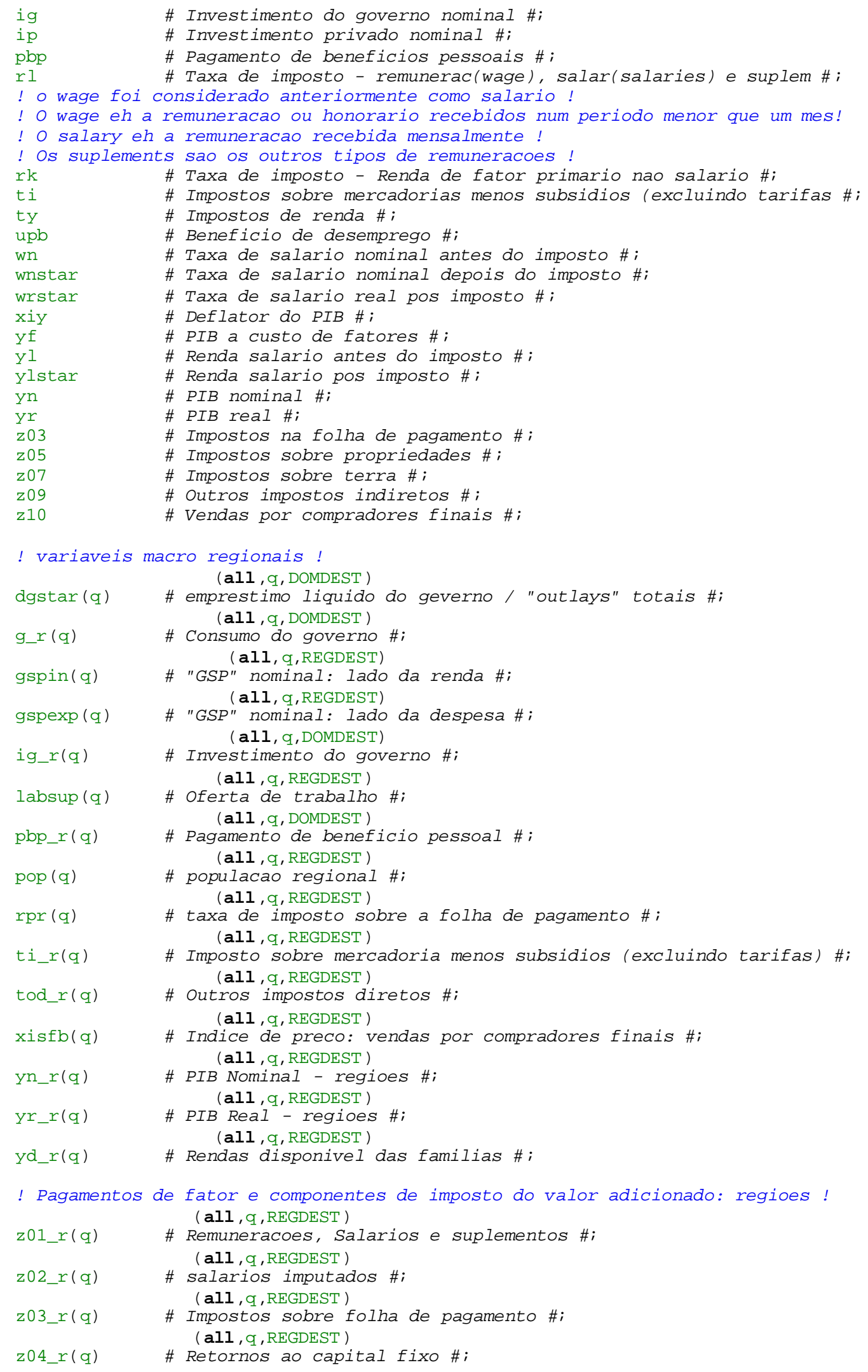




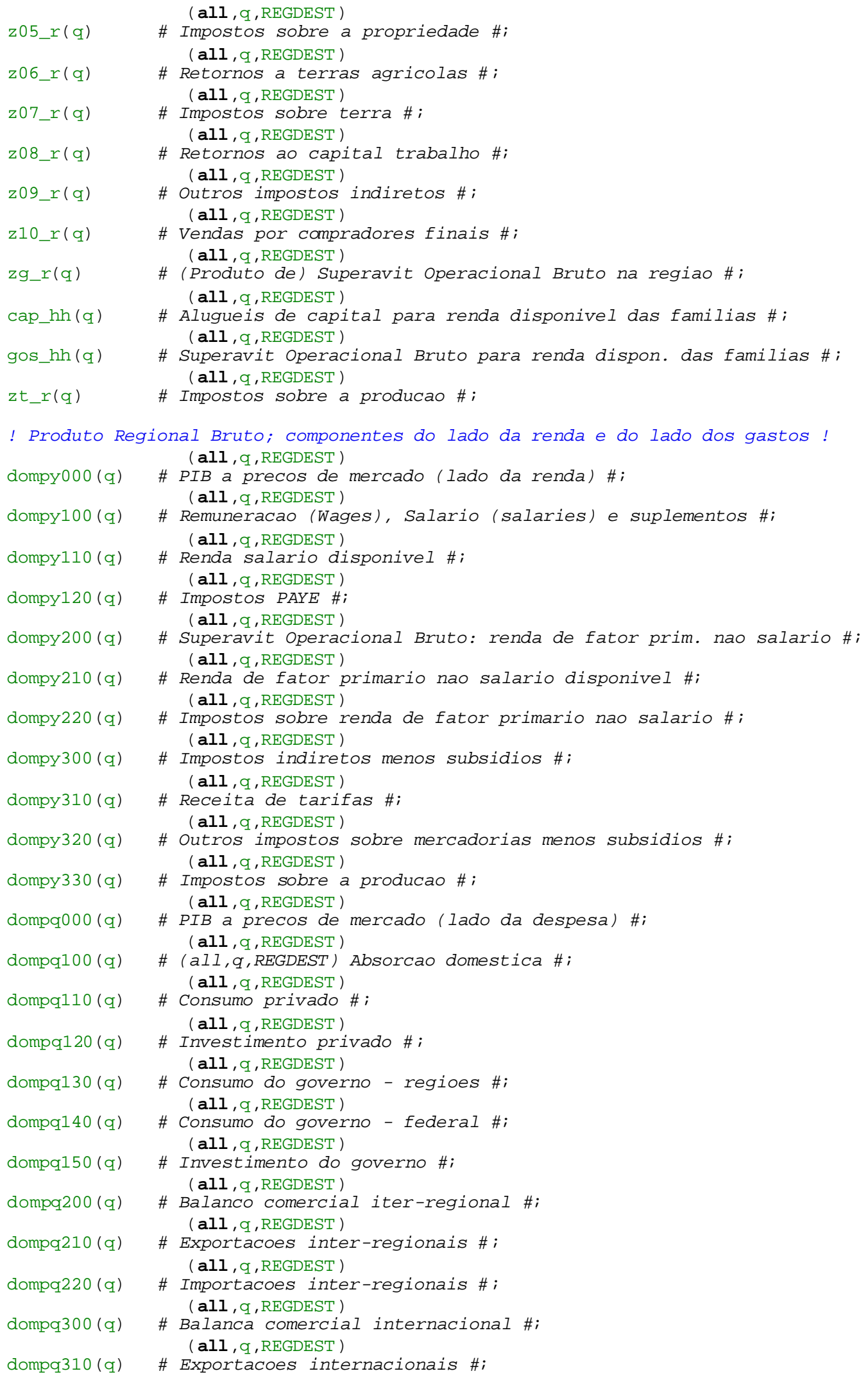




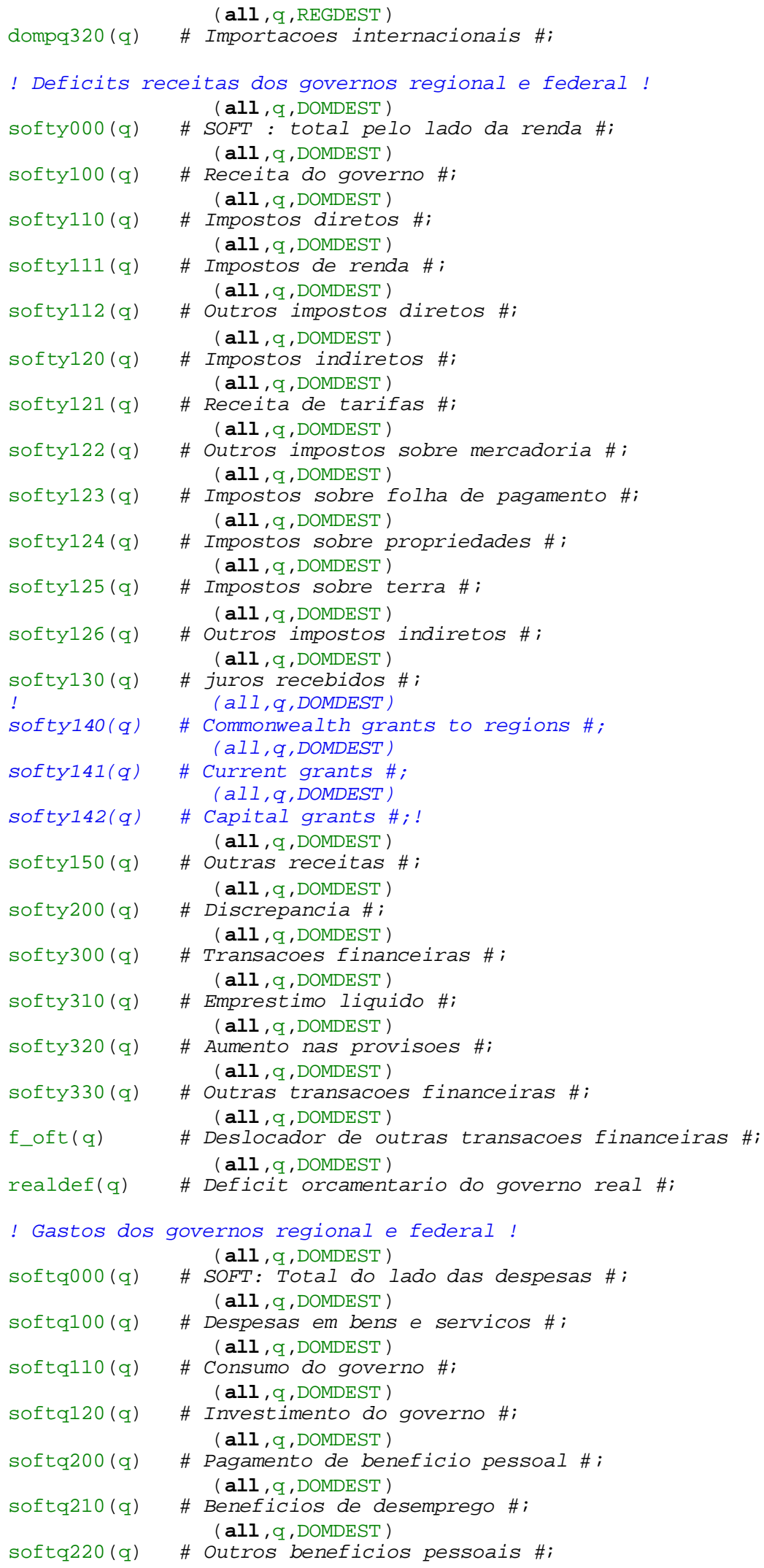




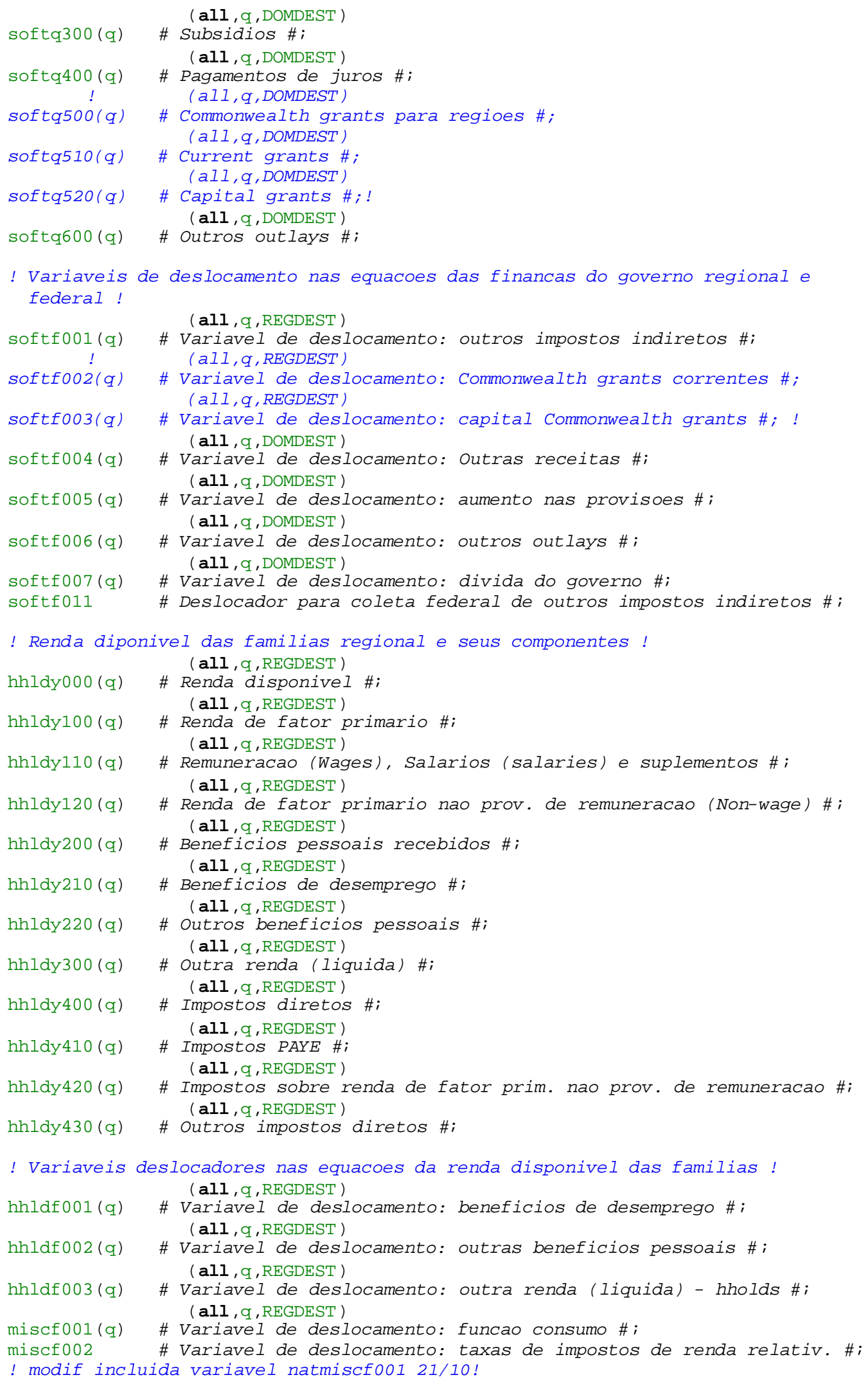




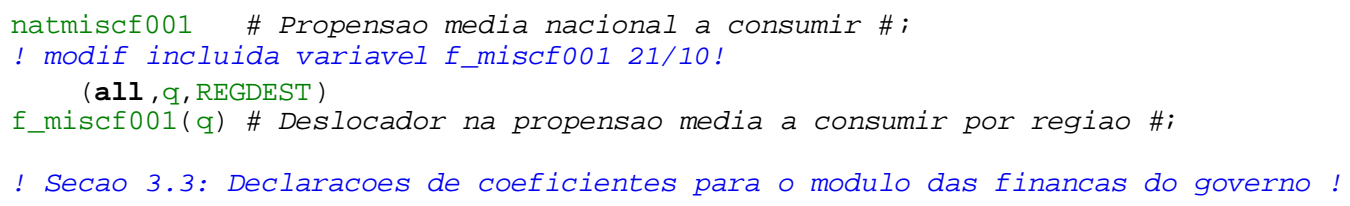

\section{COEFFICIENT}

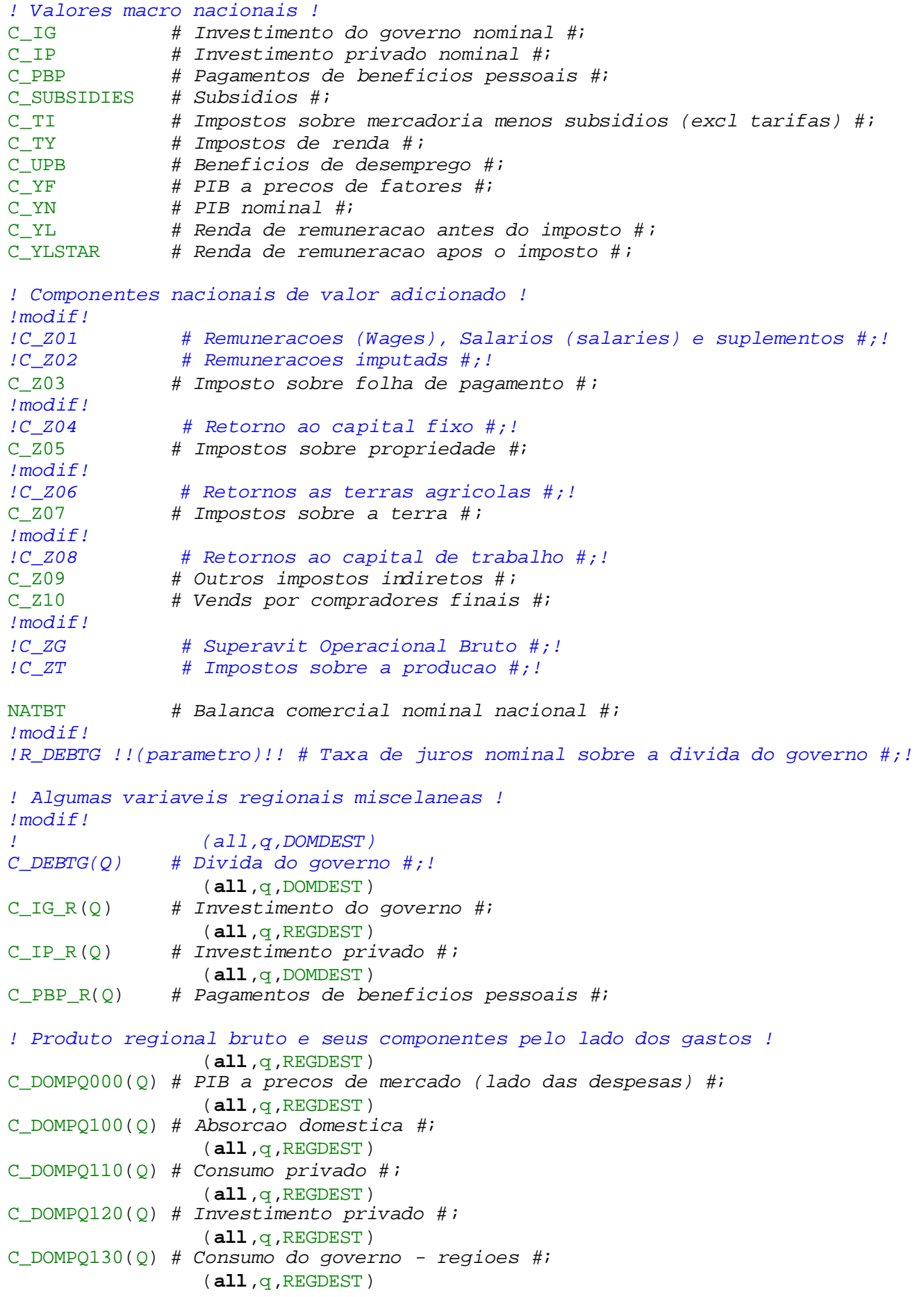




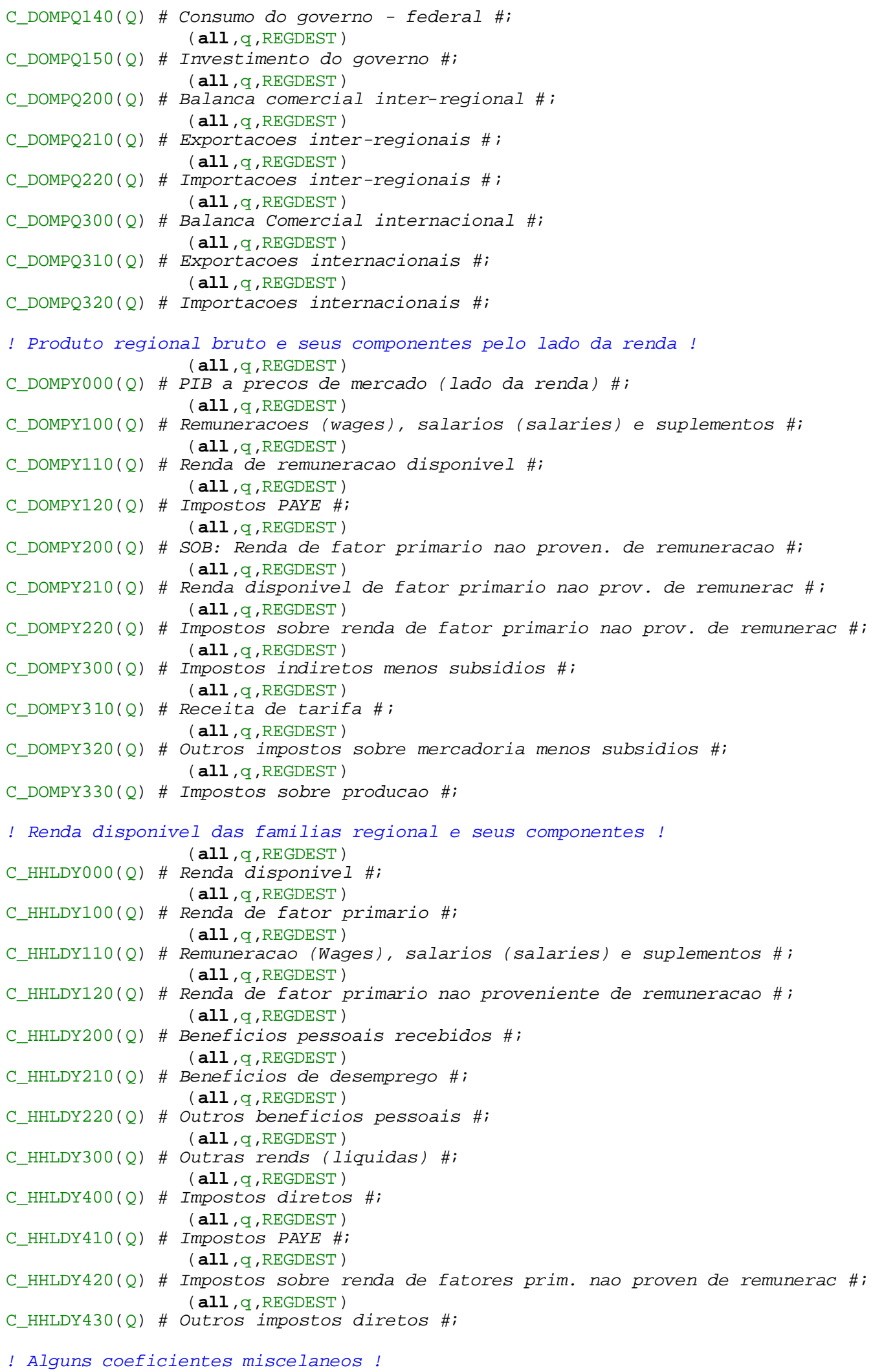




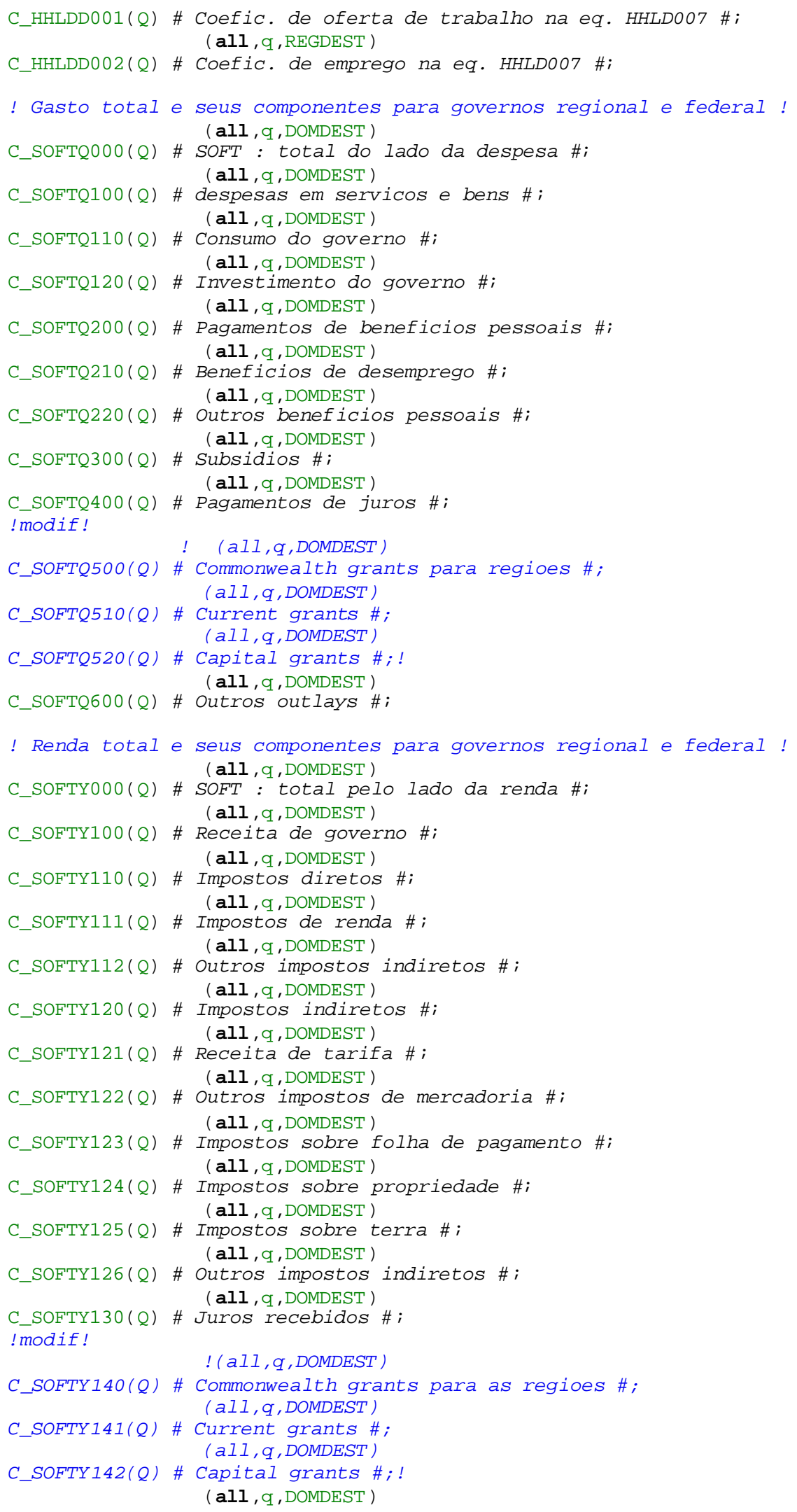




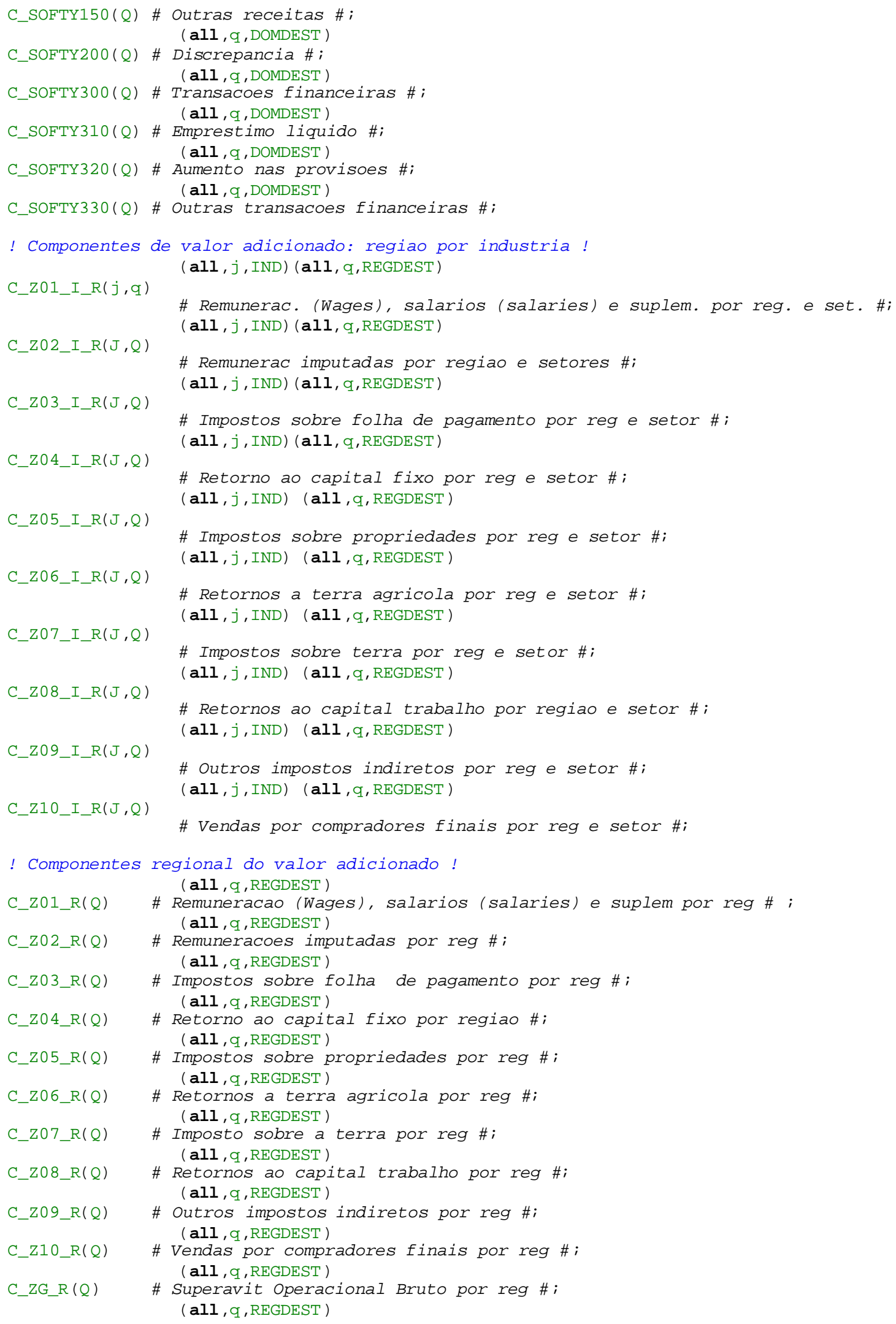




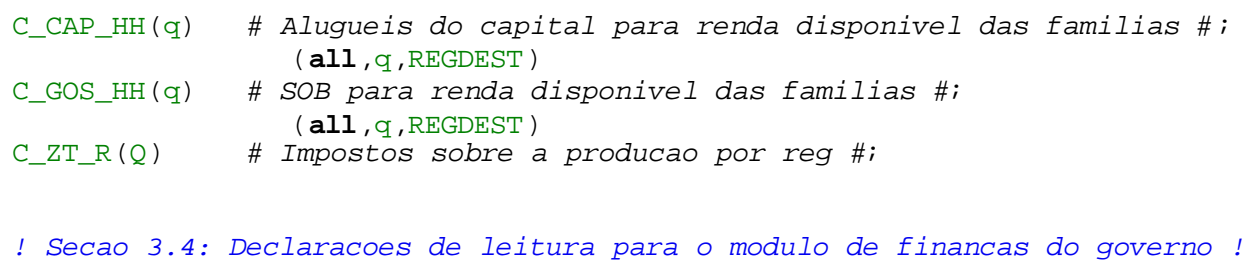

C_HHLDY200(Q) from file NDATA header "HAO5"; 


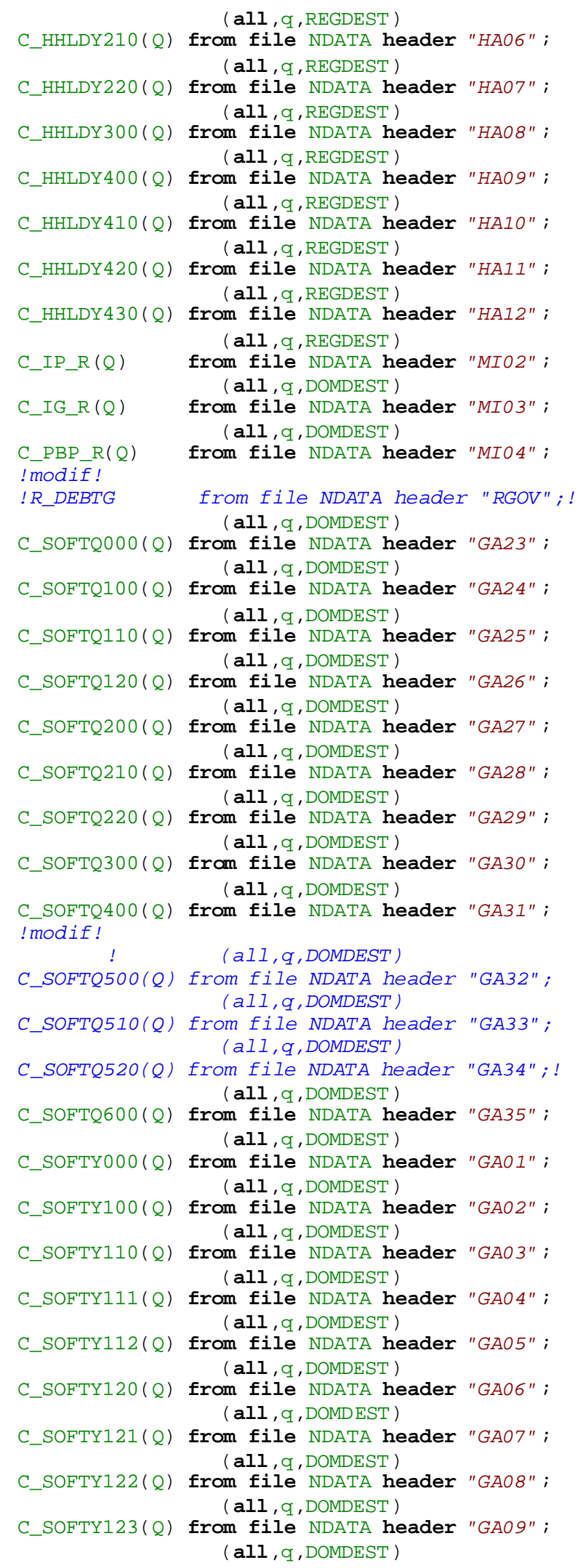




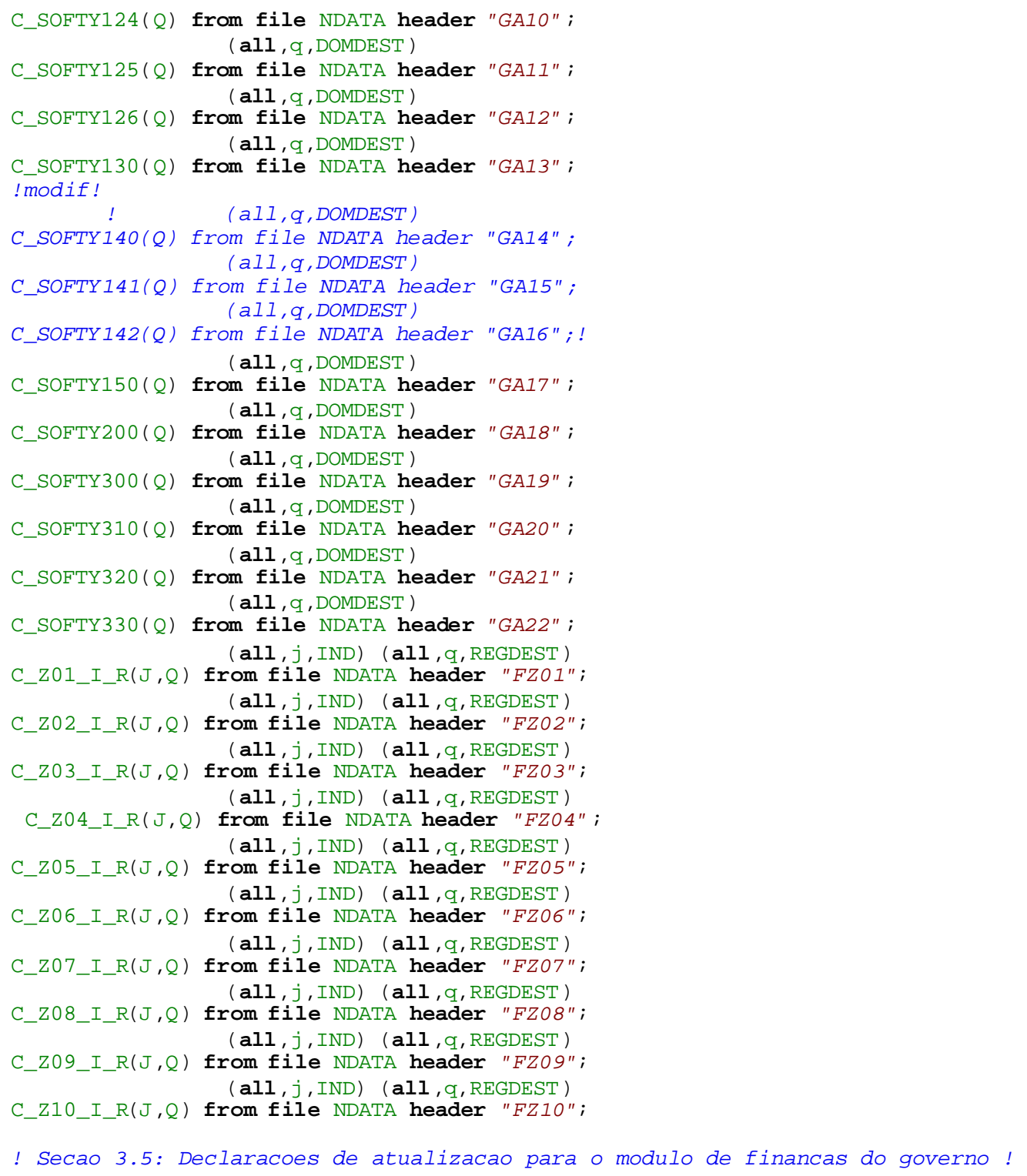

\section{UPDATE}

(all, q, REGDEST)

C_DOMPQO00(q) = dompq000(q) ;

(all, q, REGDEST)

C_DOMPQ100 (q) = dompq100(q);

(all, q, REGDEST )

C_DOMPQ110 (q) = dompq110(q);

(all, q, REGDEST )

C $\operatorname{DOMPQ120}(\mathrm{q})=\operatorname{dompq120}(\mathrm{q})$;

(all, q, REGDEST )

C_DOMPQ130 (q) = dompq130(q);

(all, q, REGDEST )

C_DOMPQ140(q) = dompq140(q);

(all, $q$, REGDEST )

C_DOMPQ150 (q) = dompq150(q) ;

(all, q, REGDEST)

C_DOMPQ200 (q) = dompq200(q);

(all, q, REGDEST )

C_DOMPQ210 (q) = dompq210(q); 
(all, q, REGDEST )

C_DOMPQ220 (q) = dompq220(q) ;

(all, q, REGDEST)

C_DOMPQ300 (q) = dompq300(q) ;

(all, q, REGDEST)

C_DOMPQ310 (q) = dompq310(q);

(all, q, REGDEST)

C_DOMPQ320 (q) = dompq320(q) ;

(all, q, REGDEST)

C_DOMPYOOO(q) = dompy000(q);

(all, q, REGDEST )

C $\operatorname{DOMPY} 100(q)=\operatorname{dompy} 100(q)$;

(all, q, REGDEST )

C_DOMPY110 (q) = dompy110(q);

(all, q, REGDEST)

C_DOMPY120 (q) = dompy120(q);

(all, q, REGDEST )

C_DOMPY200 (q) $=\operatorname{dompy} 200(q)$;

(all, q, REGDEST)

C_DOMPY210 (q) = dompy $210(q)$;

(all, q, REGDEST)

C_DOMPY220 (q) = dompy $220(q)$;

(all, q, REGDEST )

C_DOMPY300 (q) = dompy300(q);

(all, $q$, REGDEST)

C_DOMPY310 (q) $=\operatorname{dompy} 310(q)$;

(all, $q$, REGDEST)

C_DOMPY320 (q) $=\operatorname{dompy} 320(q)$;

(all, q, REGDEST)

C_DOMPY330 (q) $=\operatorname{dompy} 330(q)$;

(all, q, REGDEST )

C_HHLDY000 (q) = hhldy000(q);

(all, q, REGDEST)

C_HHLDY100 (q) = hhldy100(q);

(all, q, REGDEST)

C_HHLDY110 (q) = hhldy110(q);

(all, q, REGDEST)

C_HHLDY120 (q) = hhldy120(q);

(all, q, REGDEST)

C_HHLDY200 (q) = hhldy200(q);

(all, q, REGDEST)

C_HHLDY210 (q) = hhldy210(q);

(all, q, REGDEST)

C_HHLDY220 (q) = hhldy220(q);

(all, $q$, REGDEST)

C_HHLDY300 (q) $=\operatorname{hhldy} 300(q)$;

(all, q, REGDEST)

C_HHLDY 400 (q) $=\operatorname{hhldy} 400(q)$;

(all, q, REGDEST )

C_HHLDY410 (q) $=\operatorname{hhldy} 410(q)$;

(all, q, REGDEST)

C_HHLDY420 (q) = hhldy420(q);

(all, q, REGDEST)

C_HHLDY430 (q) $=\operatorname{hhldy} 430(q)$;

C_IG_R $(q)$ = ig_r $(q)$;

(all, q, DOMDEST )

C_IP_R (q) $=$ in $(q)$;

(all, $q$, REGDEST )

C_PBP_R(q) = pbp_r $(q)$;

(all, q, DOMDEST)

C_SOFTQ000 (q) = softq000(q);

(all, q, DOMDEST)

C_SOFTQ100 (q) = $\operatorname{softq100}(q)$;

(all, q, DOMDEST)

C_SOFTQ110 $(q)=\operatorname{softq110}(q)$;

(all, q, DOMDEST )

C_SOFTQ120 (q) = $\operatorname{softq120}(q)$; 
(all, q, DOMDEST)

C_SOFTQ200(q) = $\operatorname{softq} 200(q)$;

(all, q, DOMDEST)

C_SOFTQ210 (q) = $\operatorname{softq210}(q)$;

(all, $q$, DOMDEST)

C_SOFTQ220 (q) $=$ softq220(q);

(all, q, DOMDEST )

C_SOFTQ300(q) $=\operatorname{softq300}(q)$;

(all, q, DOMDEST)

C_SOFTQ400(q) $=\operatorname{softq} 400(q)$;

!modif!

$1 \quad(a 11, q, D O M D E S T)$

C_SOFTQ500 (q) = softq500 (q);

(all, q, DOMDEST)

C_SOFTQ510 (q) $=\operatorname{softq510}(q)$; (aIl, q, DOMDEST)

C_SOFTQ520 (q) $=\operatorname{softq520}(q) ;$ !

(all, q, DOMDEST)

C_SOFTQ600 $(q)=\operatorname{softq600}(q)$;

(all, q, DOMDEST )

C_SOFTY000(q) = softy000(q);

(all, q, DOMDEST)

C_SOFTY100 (q) $=\operatorname{softy100}(q)$;

(all, q, DOMDEST )

C_SOFTY110 (q) = $\operatorname{softy} 110(q)$;

(all, q, DOMDEST)

C_SOFTY111(q) = $\operatorname{softy111}(q)$;

(all, q, DOMDEST)

C_SOFTY112 $(q)=\operatorname{softy} 112(q)$;

(all, q, DOMDEST )

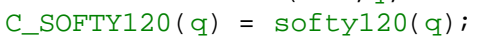

(all, q, DOMDEST)

C_SOFTY121 (q) = $\operatorname{softy121}(q)$;

(all, $q$, DOMDEST )

C_SOFTY122(q) = $\operatorname{softy122}(q)$;

(all, q, DOMDEST)

C_SOFTY123(q) = $\operatorname{softy123(q);~}$

(all, q, DOMDEST)

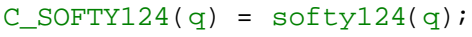

(all, q, DOMDEST)

C_SOFTY125 (q) $=$ softy125(q);

(all, q, DOMDEST )

C_SOFTY126(q) $=\operatorname{softy} 126(q)$;

(all, q, DOMDEST)

C_SOFTY130 (q) $=\operatorname{softy} 130(q)$;

!modif!

$! \quad(a \perp l, q, D O M D E S T)$

C_SOFTY140 (q) $=\operatorname{softy140}(q)$;

(aIl, q, DOMDEST)

C_SOFTY141 (q) $=\operatorname{softy141}(q)$; (aIl, q, DOMDEST)

C_SOFTY142 (q) $=\operatorname{softy142}(q) ;$ !

(all, q, DOMDEST)

C_SOFTY150 (q) $=$ softy150(q);

(all, q, DOMDEST )

C_SOFTY200 (q) = softy $200(q)$;

(all, q, DOMDEST)

C_SOFTY300 (q) $=\operatorname{softy} 300(q)$;

(all, q, DOMDEST )

C_SOFTY310 $(q)=\operatorname{softy} 310(q)$;

(all, $q$, DOMDEST )

C_SOFTY320 (q) $=\operatorname{softy} 320(q)$;

(all, q, DOMDEST)

C_SOFTY330 (q) $=\operatorname{softy} 330(q)$;

(all, $q, \operatorname{REGDEST}) \quad$ (all, j, IND )

C_Z01_I_R $(j, q)=\operatorname{labind}(j, q)$ * pwagei $(j, q)$;

(all, q, REGDEST) (all, j, IND )

C_Z02_I_R $(j, q)=\operatorname{labind}(j, q)$ * $\operatorname{pwagei}(j, q)$; 
(all, q, REGDEST) (all, j, IND )

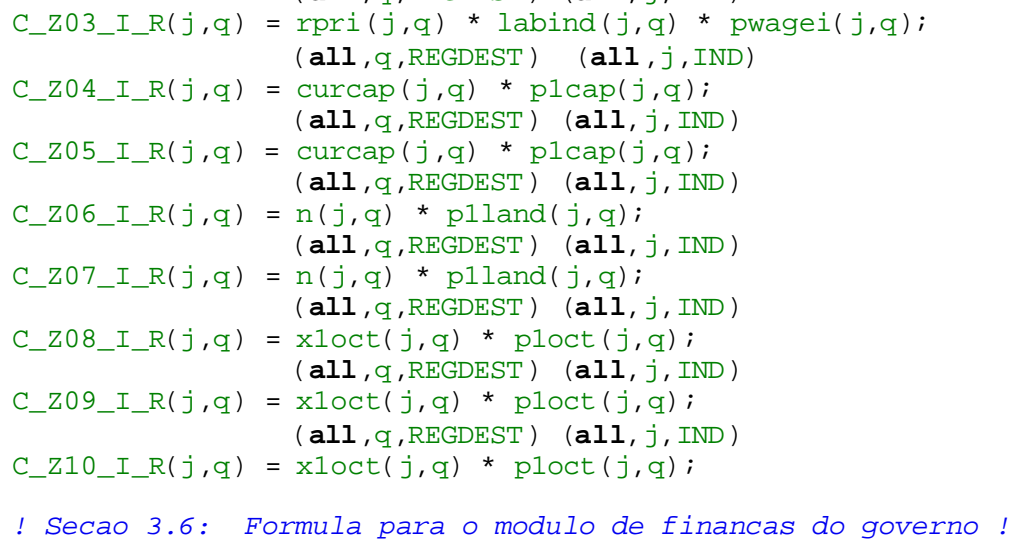

\section{FORMULA}

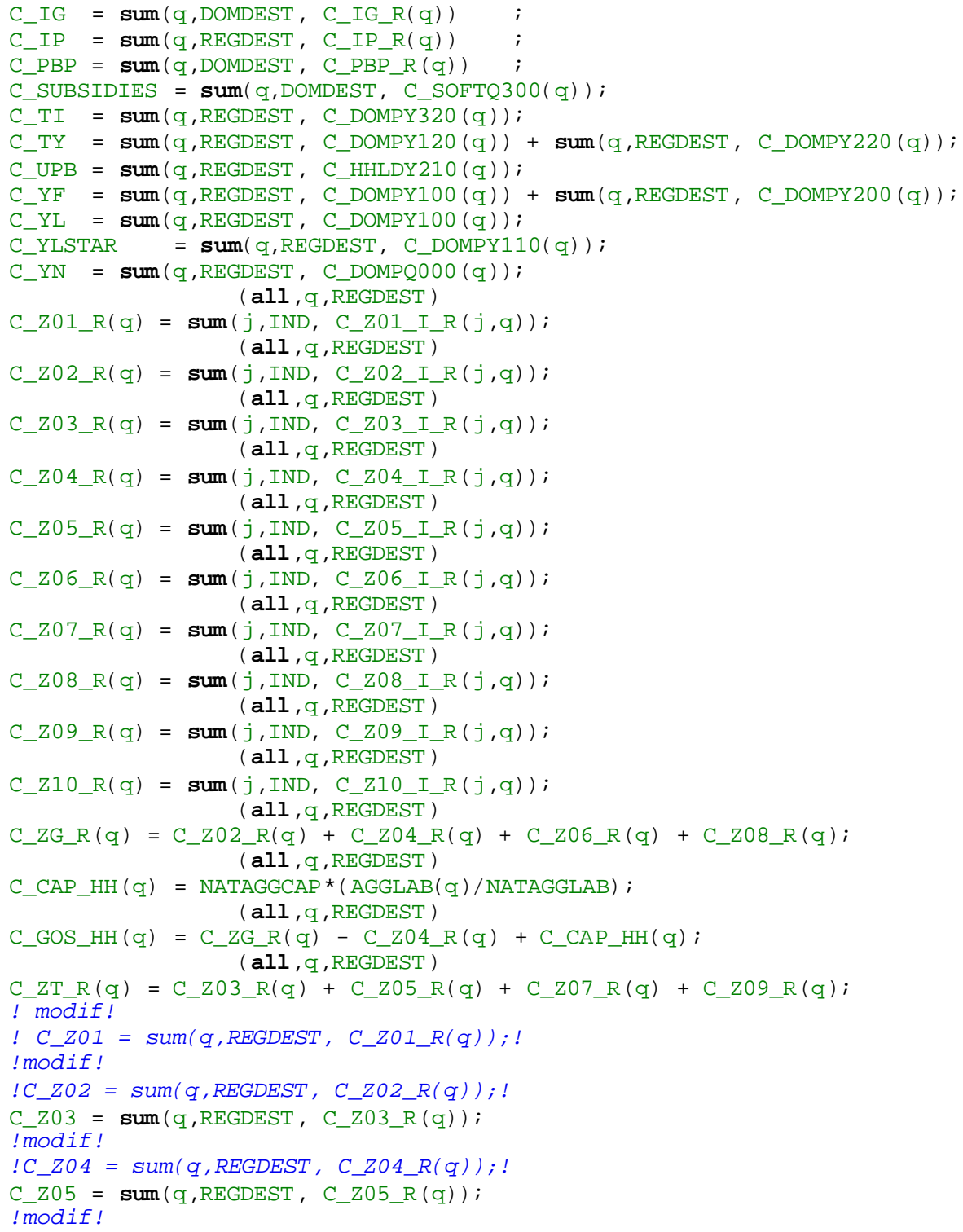




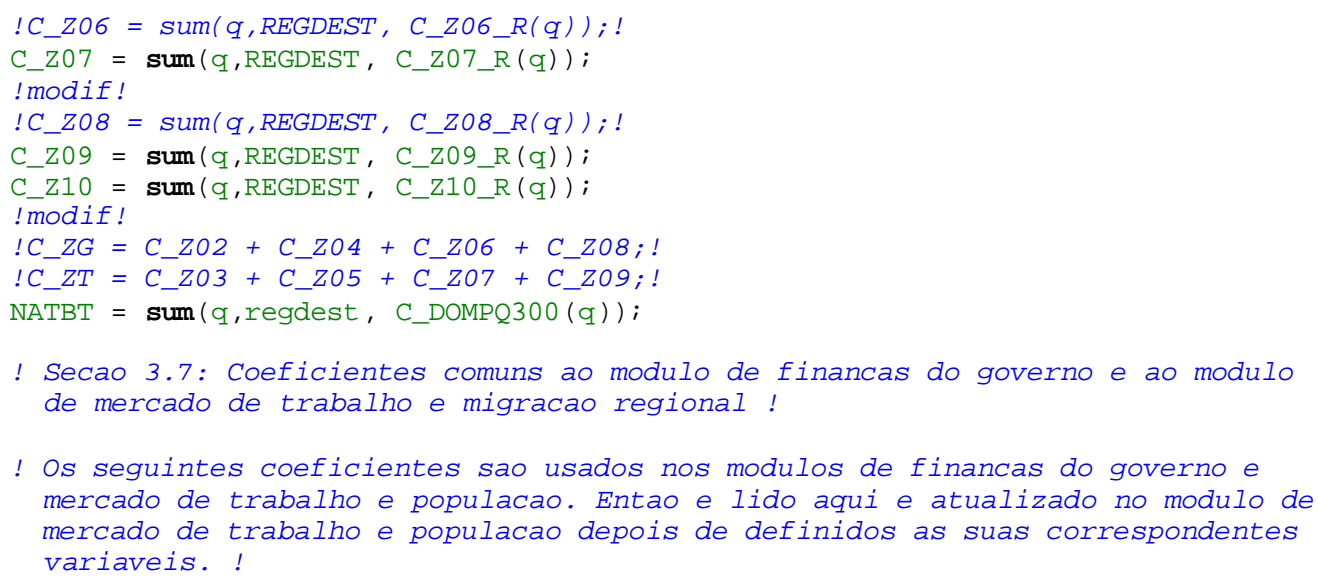




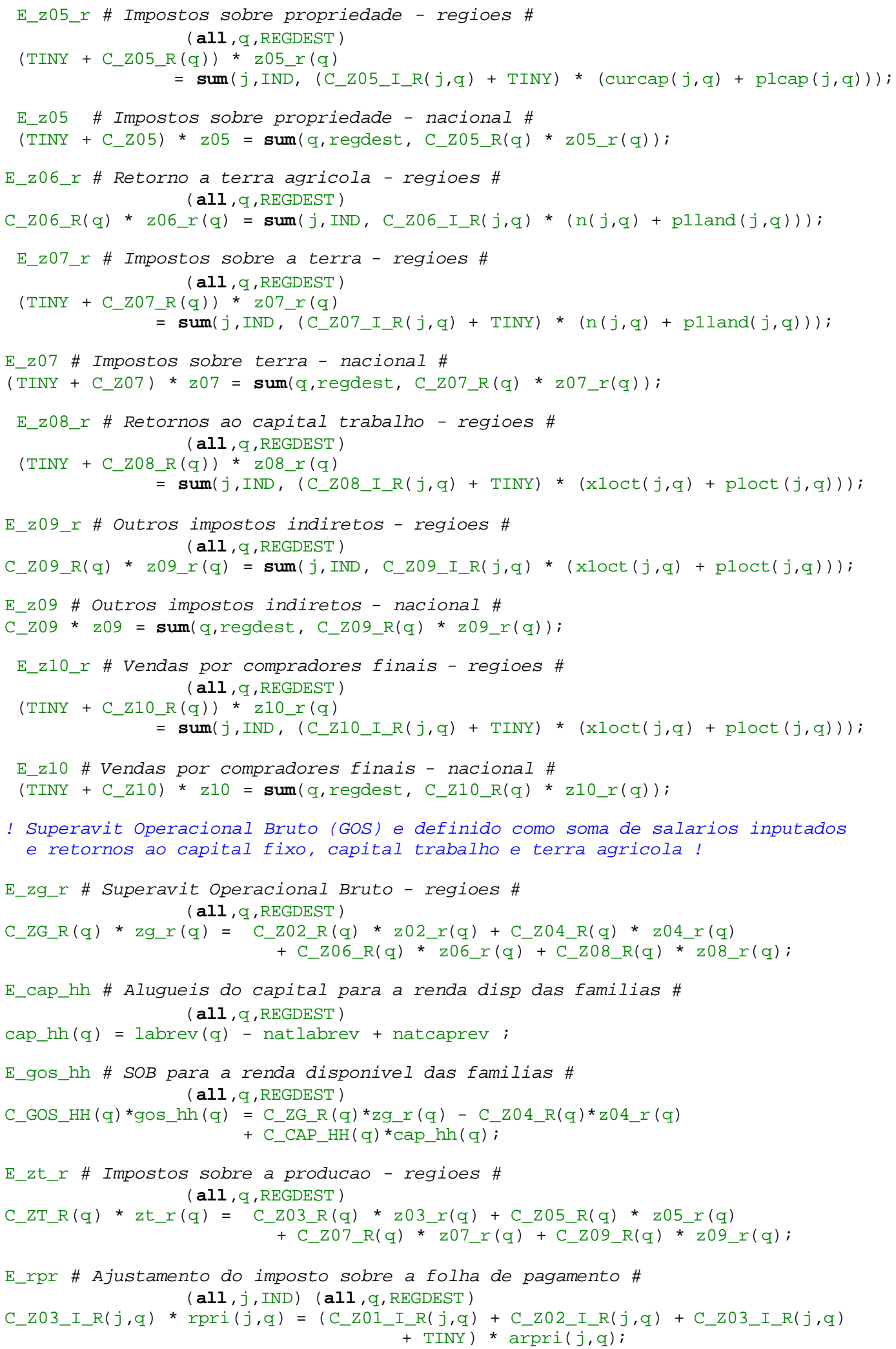




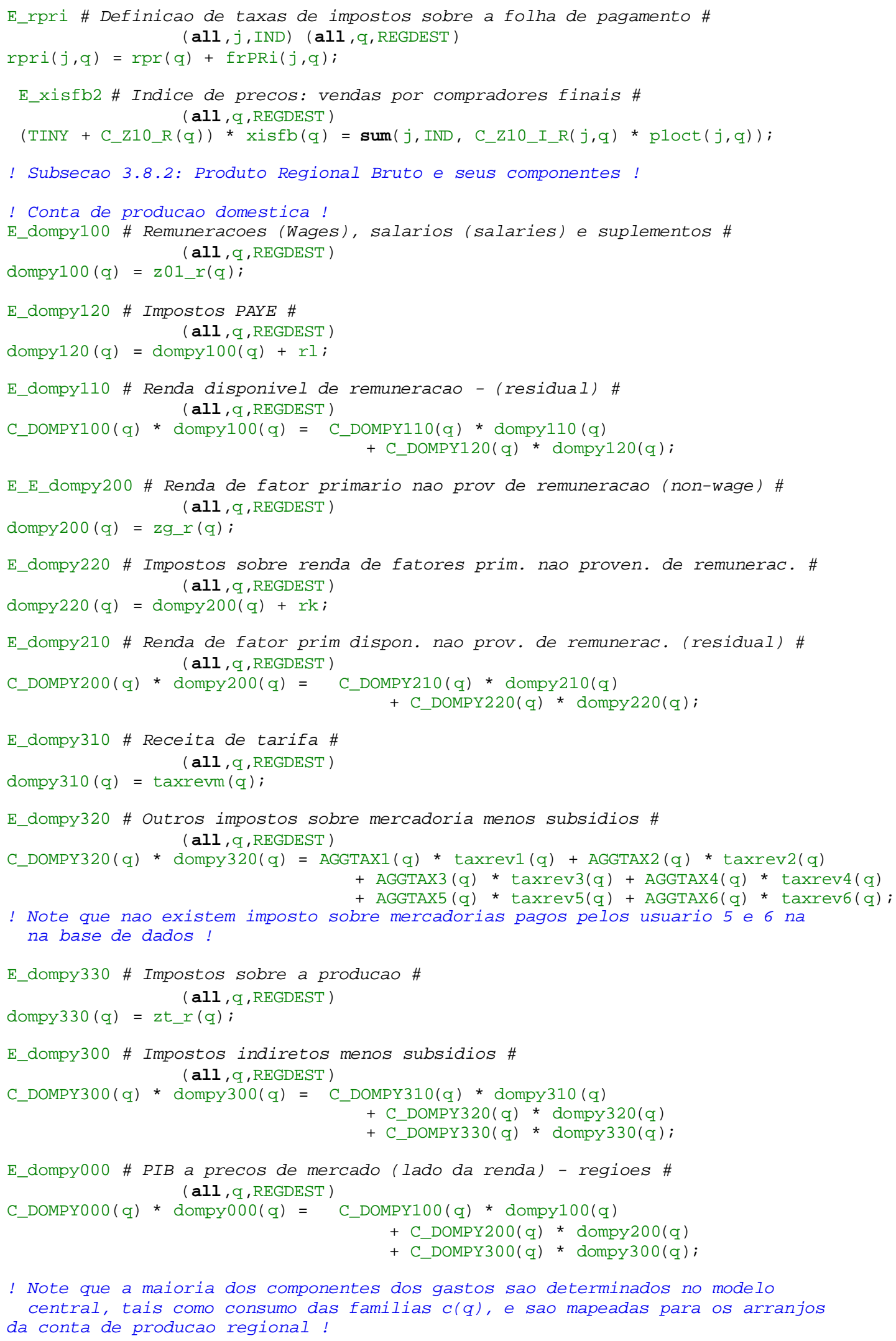




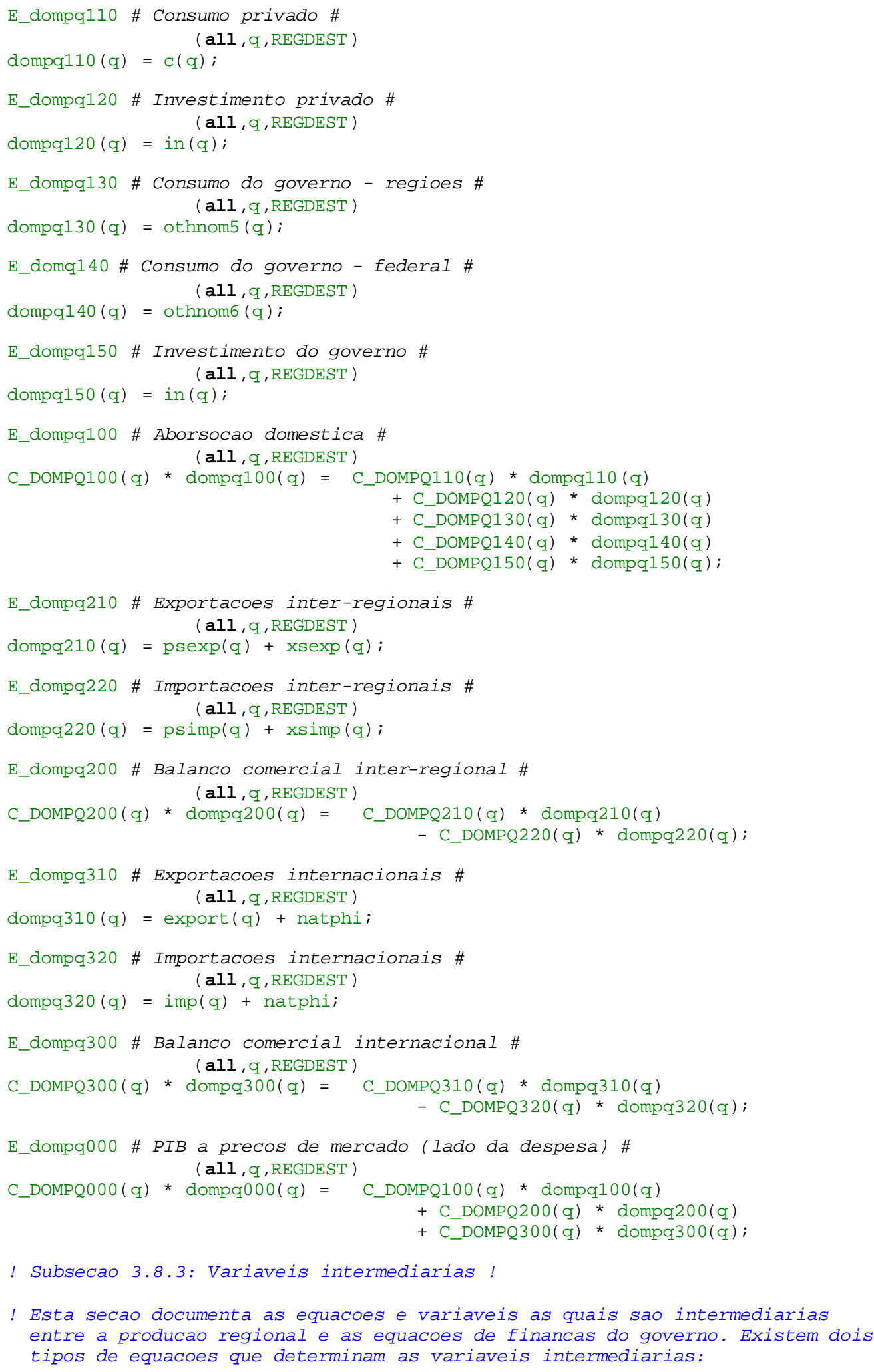

(i) Equacoes agregadas. As equacoes de producao regional documentada abaixo 
(secao 3.7.2) determinam macros regionais, tais como o produto regional. As equacoes desta subsecao computa macros nacionais pela agregacao dos valores macros regionais. Estas sao usadas no modulo de financas do governo.

(ii) Equacoes de mapeamento. Estas equacoes computam as variaveis intermediarias para mapear variaveis de producao regionais para as contas de financa de governo.

Por ex., "outros impostos sobre mercadorias" sao determinados pelas equacoes de producao regional bruta e informadas como um componente de renda nas estatisticas de financas do governo. Similarmente, " produto domestico regional nominal" e determinado pela equacao de producao regional e e usada para computar "commonwealth grants" no modulo de financas do governo.

E_tir \# Impostos de mercadoria menos subsidios (excl. tarifas) \#

(all, q, REGDEST )

ti_r $(q)=$ dompy320 $(q)$;

E_ti \# Impostos sobre mercadoria menos subsidios (excl. tarifas) \#

C_TI * tI = sum (q, REGDEST, C_DOMPY320 (q) * dompy320(q));

E_yn_r \# Produto domestico regional nominal: equivalente ao nucleo do AEG \#

(all, $q$, REGDEST )

yn_r $(q)=$ dompq000 (q) ;

E_yn \# PIB nominal: equivalente ao nucleo do AEG \#

C_YN * yN $=\operatorname{sum}\left(q, \operatorname{REGDEST}, \mathrm{C}_{\mathrm{N}} \mathrm{DOMPQ000}(\mathrm{q})\right.$ * dompq000(q)) ;

E_xiy_r \# Deflator do PIB: equivalente ao nucleo do AEG \#

(all, $q, \mathrm{REGDEST}$ )

C_DOMPQ000 (q) * xiy_r $(q)=$ C_DOMPQ110 (q) * xi3(q)

+ C_DOMPQ120 (q) * xi2 (q)

+ C DOMPQ130 (q) * xi5 $(\mathrm{q})$

+ C_DOMPQ140(q) * xi6 (q)

+ C_DOMPQ150(q) * xi2 (q)

+ C_DOMPQ210(q) * psexp (q)

- C_DOMPQ220(q) * psimp $(q)$

+ C_DOMPQ310(q) * xi4 (q)

- C_DOMPQ320(q) * xim(q);

E_xiy \# Deflator do PIB: equivalente ao nucleo do AEG \#

C_YN * $x i y=\operatorname{sum}(q, R E G D E S T, C$ C_DOMPQ000 (q) *xiy_r(q));

E_yr_r \# Produto Domestico regional real: equivalente ao nucleo do AEG \#

(all, q, REGDEST )

yr_r $(q)=y n \_r(q)-x i y \_r(q)$;

E_yr \# PIB real: equivalente ao nucleo do AEG \#

$\mathrm{y} r=\mathrm{yn}-\mathrm{xiy} ;$

E_yf \# PIB a custo de fatores \#

C_YF * yf $=\operatorname{sum}(q, \operatorname{REGDEST}$, C_DOMPY100 (q) * dompy100(q))

+ $\operatorname{sum}(q, R E G D E S T$, C_DOMPY200(q) * dompy200(q)) ;

E_bstar \# Superavit da balanca comercial em relacao ao PIB: variac ponto perc \#

C_YN * bstar $=\operatorname{sum}\left(q, \operatorname{REGDEST}, C_{\text {_DOMPQ300 }}(q)\right.$ * dompq300 (q)) - NATBT * yn;

E_ty \# Impostos de renda \#

C_TY $* t Y=\operatorname{sum}(q, \operatorname{REGDEST}$, C_DOMPY120(q) * $\operatorname{dompy} 120(q))$

$+\operatorname{sum}(q, \operatorname{REGDEST}$, C_DOMPY220(q) * dompy220(q)) ;

E_gspin \# GSP nominal: lado da renda \#

(all, q, REGDEST)

gspin $(q)=\operatorname{dompy000(q);~}$

E_gspexp \# GSP nominal: lado da despesa \#

(all, q, REGDEST) 


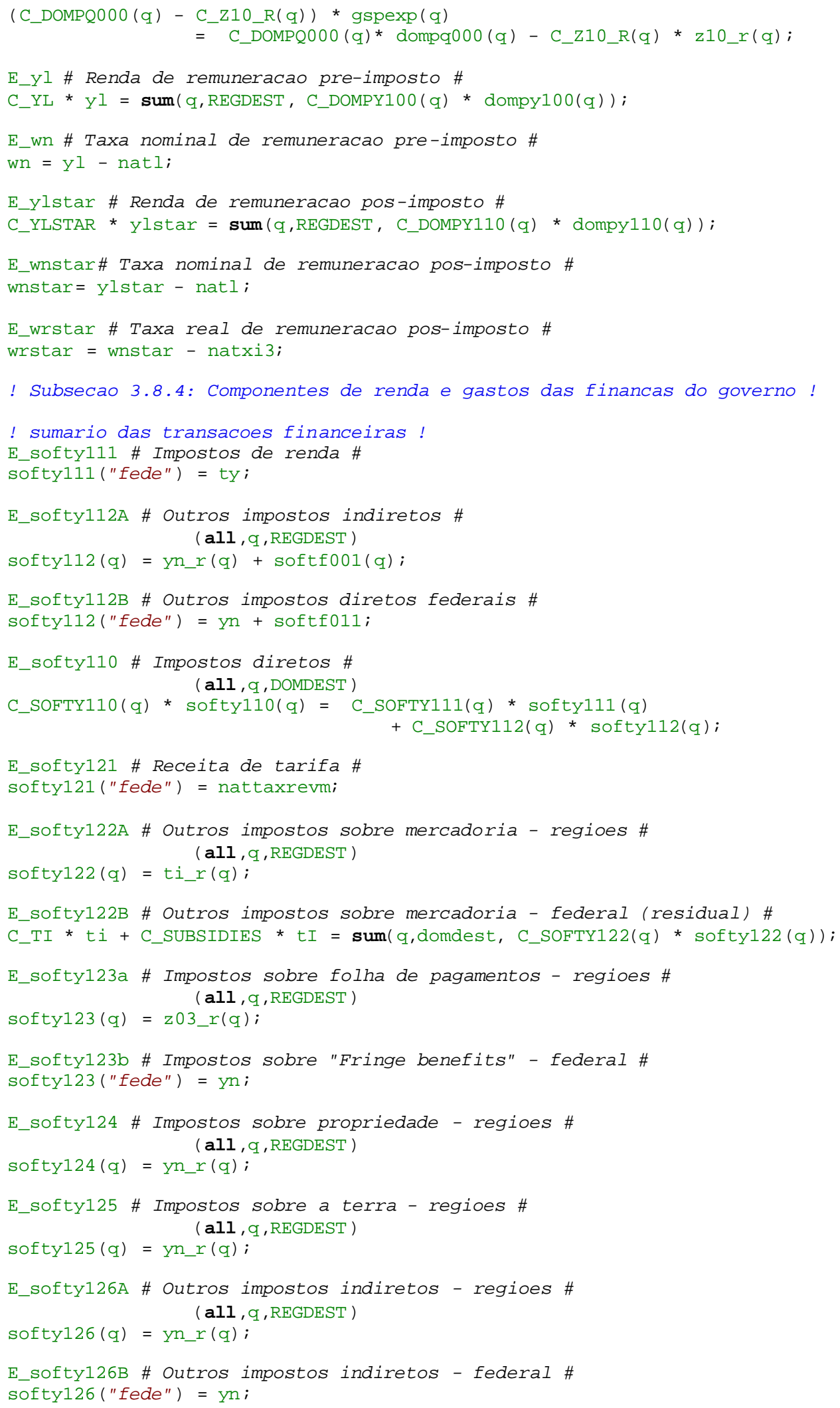




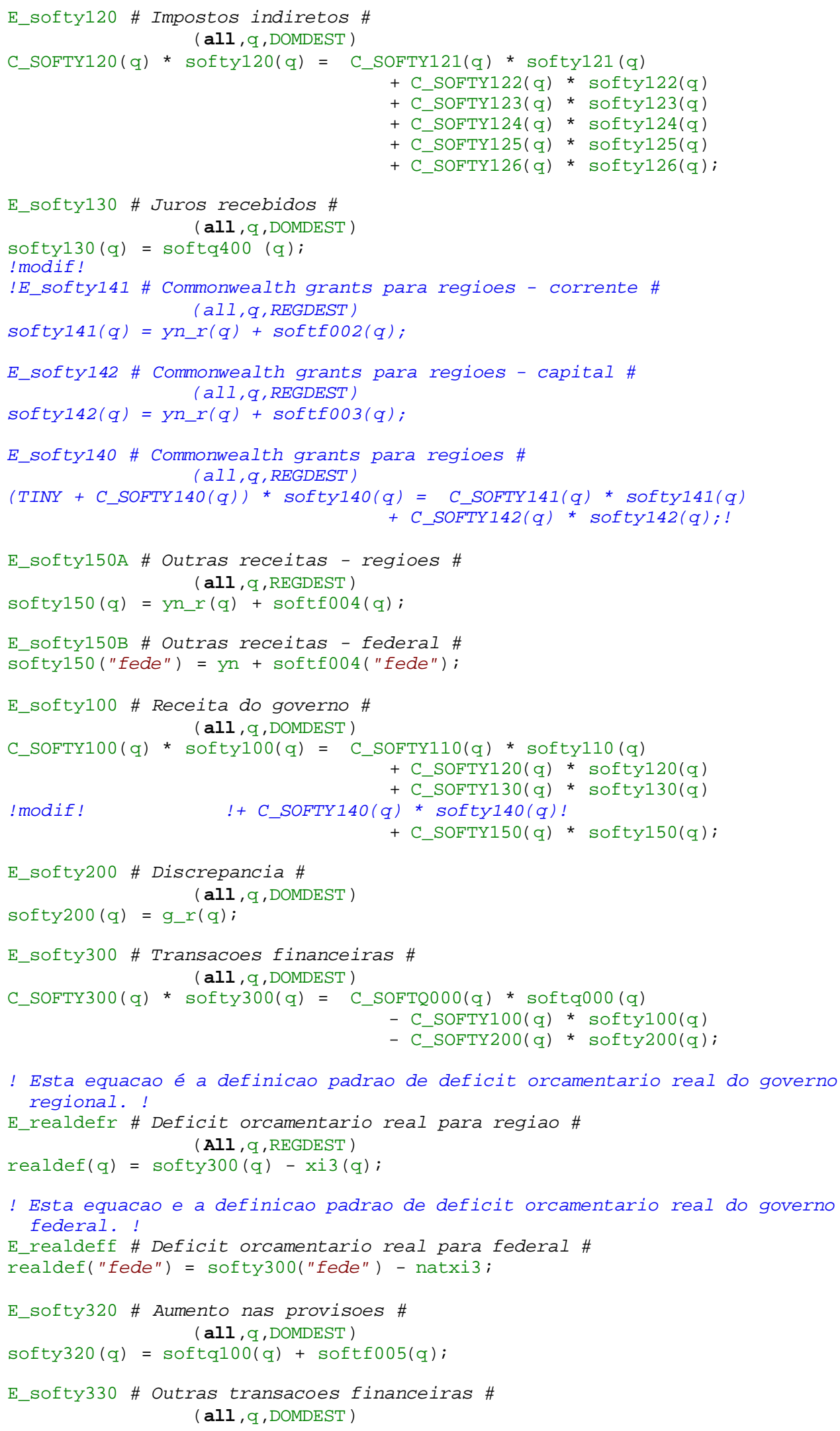




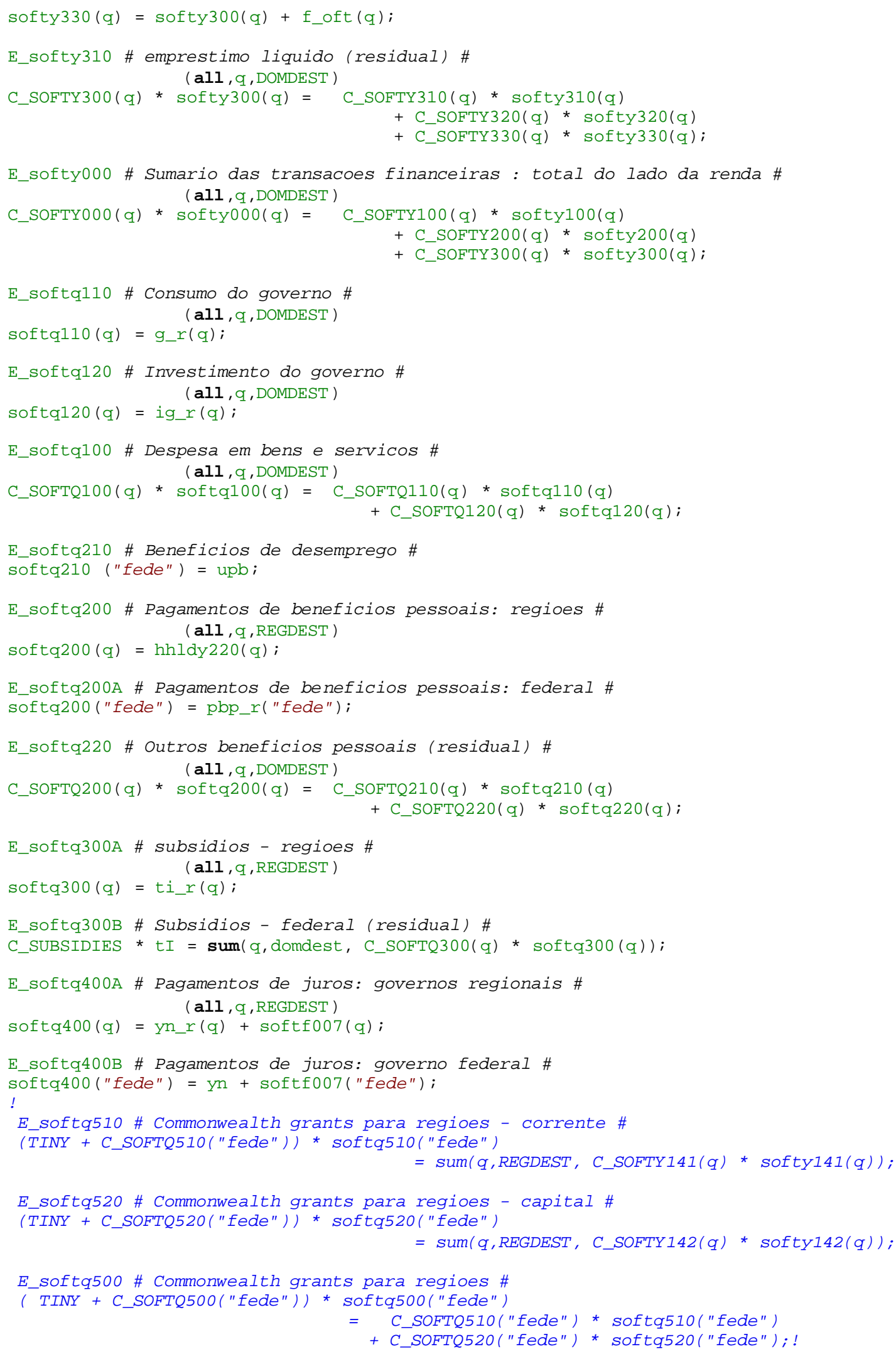




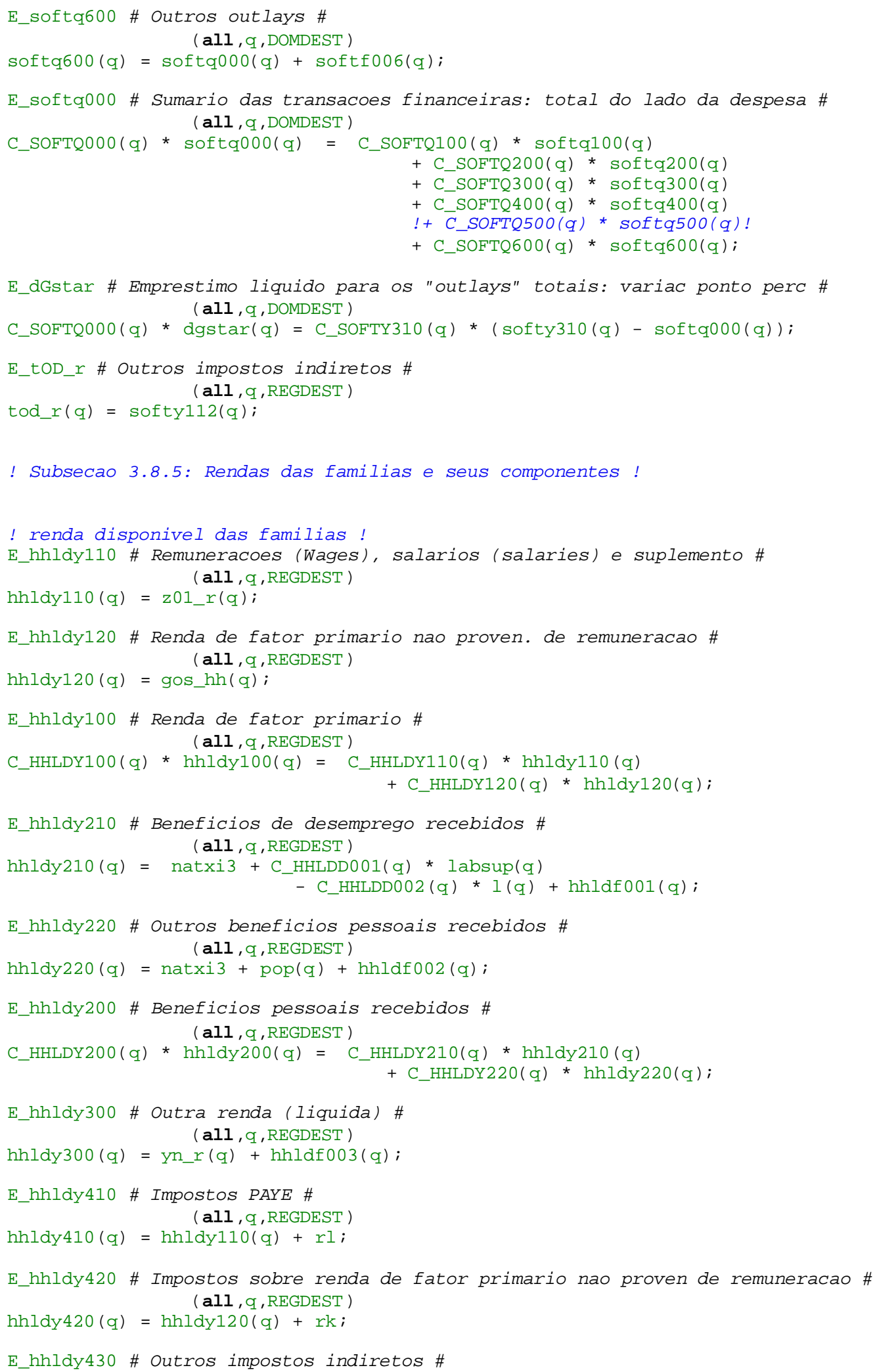




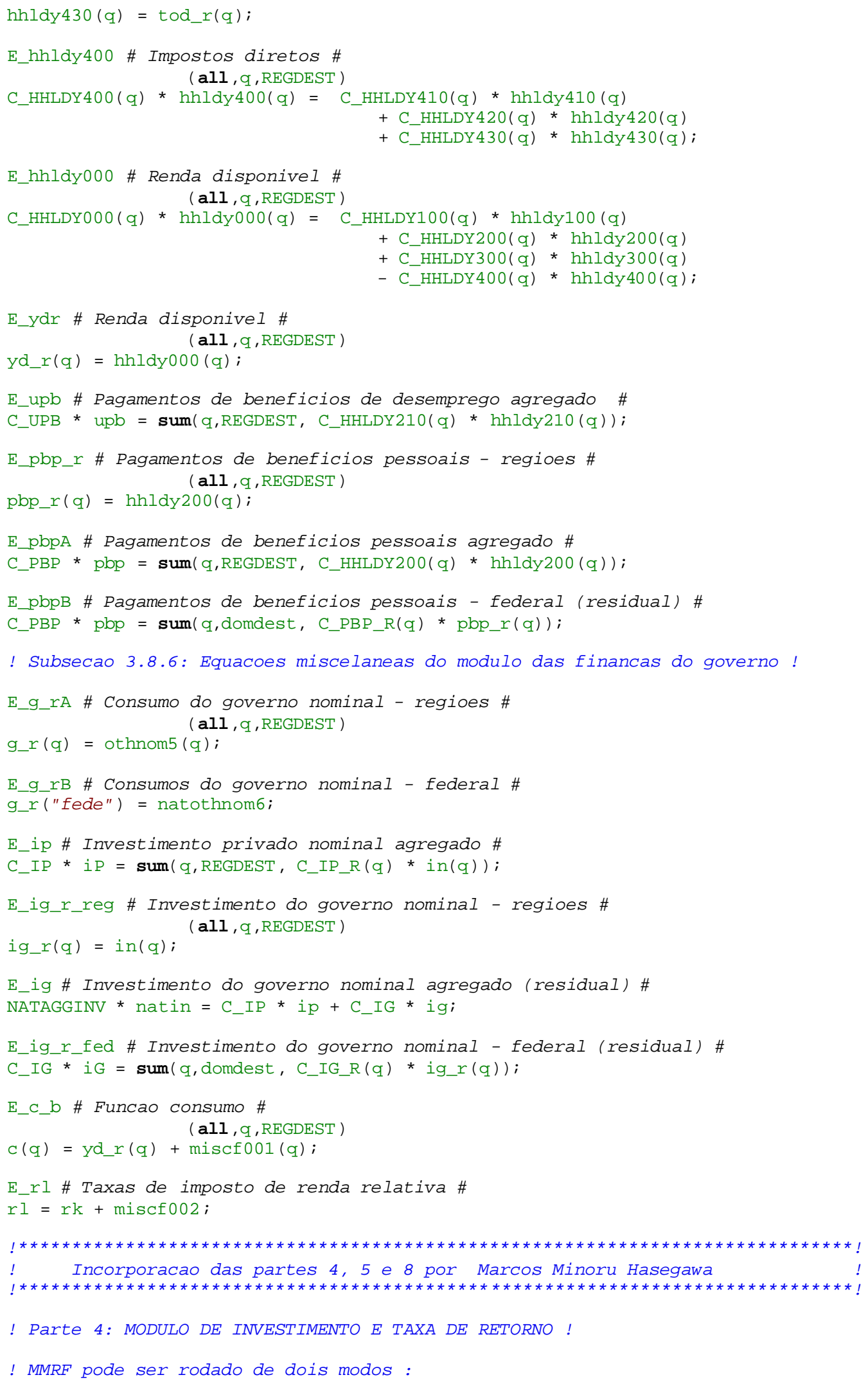


(i) estatica comparativa e

(ii) previsao ano a ano.

Estes modos requerem tratamentos alternativos para a formacao de capital.

No modo de estatica comparativa, existe relacao nao fixa entre capital e

investimento. O usuario decide a relacao requerida com base nos requerimentos

da especificacao da simulacao. Por exemplo, é geralmente assumido que as

as variacoes percentuais no capital e no investimento sao iguais, implicando que $k(j)=y(j)$.

Na previsao ano a ano, demanda por investimento no ano da solucao corrente (ano $T$ ) e determinado via uma relacao de acumulacao ligando investimento em $T$ para a diferenca entre capital no inicio do ano $T$ e o capital no final do ano $T$ (ou seja, no inicio do ano $T+1$ ) considerando a depreciacao. Crescimento no capital ao longo de $T$ e determinado via um mecanismo de taxa de esperada de retorno. Em outras palavras, capital no inicio do ano $T$ e capital disponivel para producao no ano $T$. Isto e dado pelas condicoes iniciais, que e pelo investimento no ano $\mathrm{T}-1$ e o capital no inicio do ano $\mathrm{T}-1$ considerando a depreciacao.

Esta parte contem equacoes para explicar investimento e simulacoes de estatica

comparativa. Tambem incluem equacoes definindo taxas de retorno correntes.

! Secao 4.1: Declaracoes de variaveis!

Variable

(change) (all, $j, I N D)$ (all, $q$, REGDEST)

del_ror(j,q) \# Taxa de retorno(TDR) pos imposto sobre capital (num.como 0.01) \#; (change) (all, q, REGDEST)

del_ror_tot (q) \# TDR pos imposto agregado regional (numero como 0.01) \#;

(change) (all, j, IND) (all, q, REGDEST)

del_f_ror $(j, q)$ \# Deslocador no mecanismo de distrib.de TDR de longo Prazo CSS \#; (change)

del nat ror

\# Deslocador nacional no mecanismo para distrib. de TDR em Iongo Prazo CSS \#; (change)

del_unity \# Variavel binaria definido igual a um para simul. de previsao \#; (all, j, IND) (all, $q$, REGDEST)

r_inv_cap_jq(j,q) \# Variacoes especifica setorial e regional na razao I/K \#; $(a 11, j, I N D)$

r_inv_cap_j(j) \# Variacao especifica setorial na razao I/K \#;

(all, q, REGDEST)

r_inv_cap_q(q) \# Variacao especifica regional na razao I/K \#;

r_inv_cap \# Deslocador geral na razao I/K \#;

! Secao 4.2: Declaracoes de coeficientes!

\section{Coefficient}

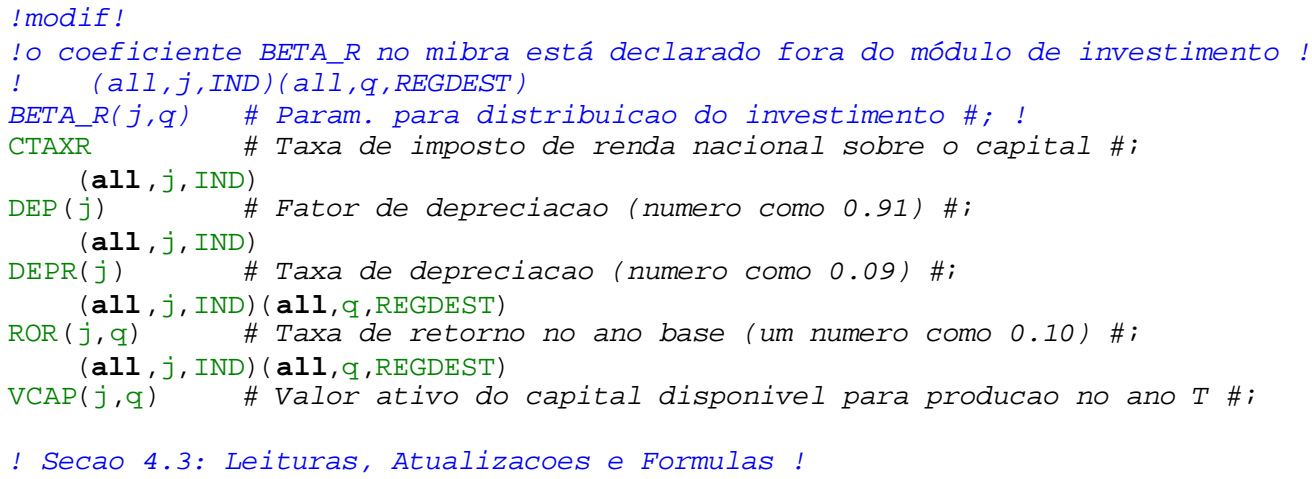

Read

!modif!

!BETA_R from file ELAST Header "BETR"; 


$\begin{array}{ll}\text { CTAXR } & \text { from file YDATA Header "TAXC"; } \\ D E P R & \text { from File YDATA Header "DPRC"; } \\ \text { VCAP } & \text { from File YDATA Header "VALK"; }\end{array}$

!modif!

!na atualizaçao abaixo foi substituída a variável cap_t (estoque de capital disponível para produção por curcap que é estoque de capital corrente!

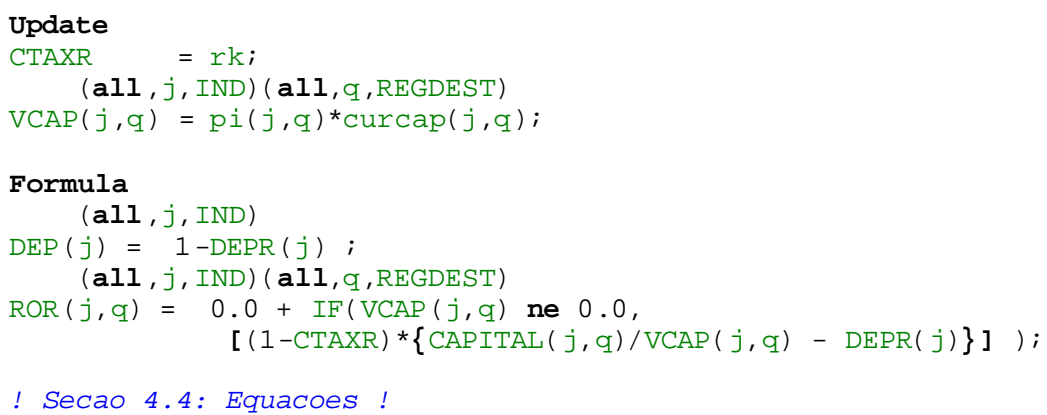

! Este modulo contem equacoes que sao usadas nas simulacoes ano a ano (ou seja, simulacoes tracando caminhos para variaveis para anos sucessivos).

Tres conjuntos de equacoes sao introduzidas aqui:

(a) equacoes descrevendo a relacao entre capital e investimento, e entre 
crescimento do capital e a taxa de retorno esperada ( assume-se expectativas estaticas) e;

(b) equacoes que permitem, em simulacoes de politicas ano a ano, para salario real para ser fixa no curto prazo e flexivel no longo prazo; e

Nas simulacoes ano a ano, o capital disponivel para producao no ano de previsao corrente (ano $T$ ) e dado pelas condicoes iniciais, com a taxa de retorno no ano $T$ ajustando para acomodar o dado estoque de capital. E introduzido equacoes para permitir a variacao percentual no capital disponivel para a producao no ano $T$ ( ou seja, a variacao percentual no capital no comeco do ano T) para ser determinado dentro do modelo. Sao tambem especificadas as funcoes de oferta de capital que determinam a taxa de crescimento do capital setorial ao longo do ano $T$ (e portanto o investimento do ano T). As funcoes especificam que os investidores estao desejando ofertar fundos maiores para o setor j em resposta ao aumento na j-ésima taxa de retorno esperada (assume-se expectativas estaticas). Entretanto, os investidores sao cautelosos. Em qualquer ano, as funcoes de oferta de capital limitam o crescimento o estoque de capital do j-esimo setor de modo que os desvios na j-esima taxa de retorno sao eliminadas somente gradualmente.

Na maioria das analises AEG, uma das duas seguintes pressuposicoes e assumida:

(1) salario real ajusta a um choque e por isso nao tem efeito sobre o emprego (nacional) ou;

(2) salario real permanece nao afetado e emprego se ajusta.

Introduz-se equacoes que permitem uma terceira, em posicao intermediaria. Assume-se que o desvio na taxa de salario real proveniente do fechamento de previsao aumenta na mesma proporccao que o desvio no emprego nacional tambem no fechamento basico de previsao. O coeficiente de proporcionalidade e escolhido de forma que o efeito emprego de um choque sejam quase totalmente eliminadas depois de 5 anos.

! Secao 5.1a: Declaracoes de variaveis!

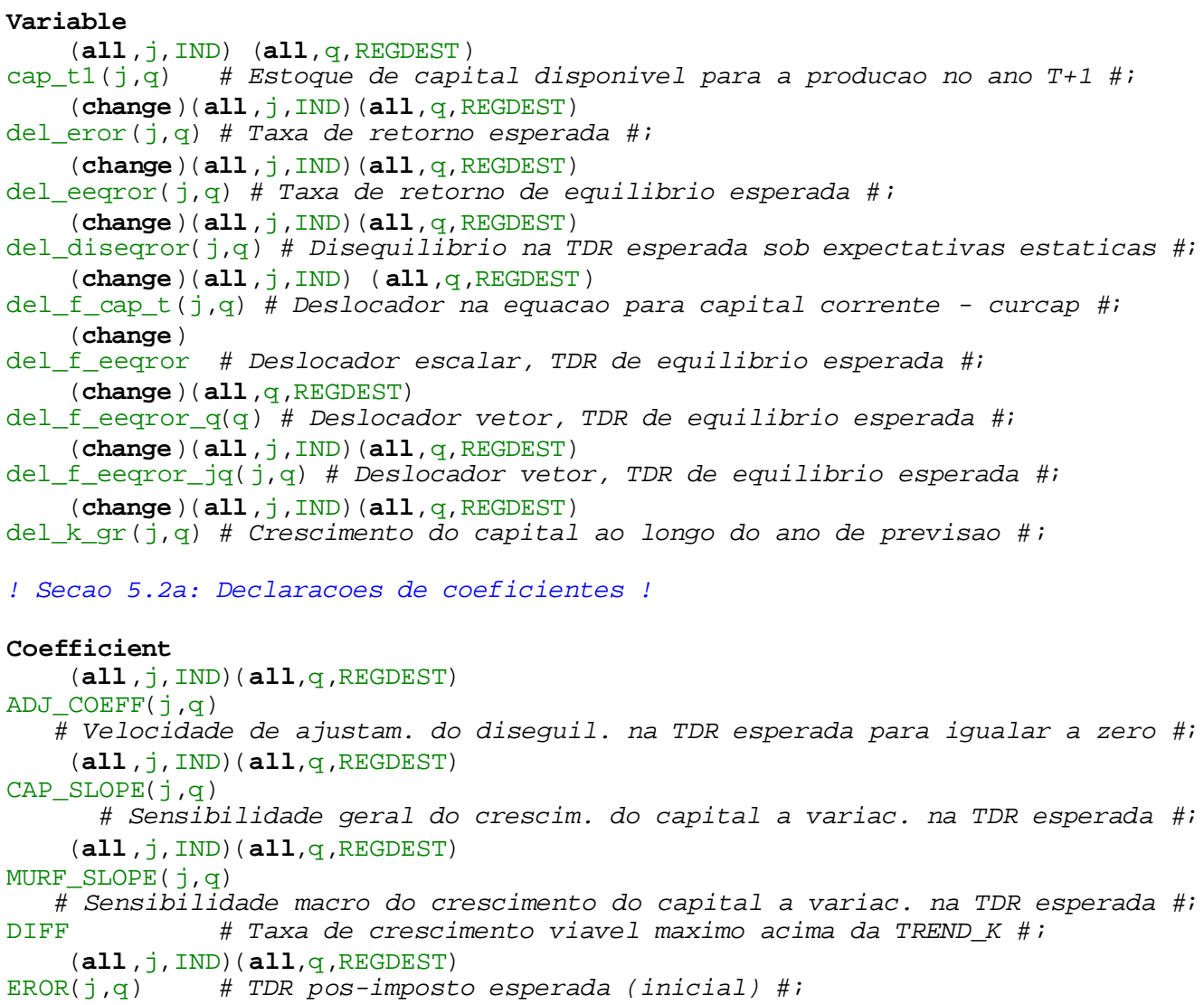


(all, j, IND) (all, $q$, REGDEST)

$\operatorname{EEQROR}(j, q)$ \# TDR esperada pos-imposto de equilibrio \#;

(all, j, IND) (all, q, REGDEST)

DISEQROR $(j, q)$ \# Diseq. na j-esima TDR pos-imposto esperada corrente (inicial) \#;

F_EEQROR \# Deslocador vetor, TDR de equilibrio esperada \#;

(all, q, REGDEST)

F_EEQROR_Q(q) \# Deslocador vetor, TDR de equilibrio esperada \#;

(all, j, IND) (all, q, REGDEST)

F_EEQROR_JQ $(j, q)$ \# Deslocador vetor, TDR de equilibrio esperada \#;

(all, j, IND) (all, q, REGDEST)

K_GR(j,q) \# Taxa de crescimento do capital entre inicio e final do ano $T-1$ \#;

(all, j, IND) (all, q, REGDEST)

K_GR_MAX $(j, q)$ \# Crescimento do capital possivel maximo \#;

(all, j, IND) (all, q, REGDEST)

K_GR_MIN $(j, q)$ \# Crescimento do capital possivel minimo \#;

(all, $j$, IND) (all, q, REGDEST)

$\operatorname{PINV}(j, q) \quad$ \# Preco do investimento \#;

(all, j, IND) (all, q, REGDEST)

$\operatorname{QCAP}(j, q) \quad$ \# Quantidade de capital disponivel para producao no ano $T$ \#;

(all, j, IND) (all, q, REGDEST)

QCAP@1 $(j, q)$ \# Quantidade inicial de capital disponivel no no $T$ \#;

(all, j, IND) (all, $q$, REGDEST)

QCAP T1 $(j, q)$ \# Quantidade de capital disponivel para producao no ano $T+1$ \#; $(a l 1, j$, IND) (all, $q$, REGDEST)

QINV@1 $(j, q)$ \# Quantidade inicial de investimento no ano $T$ \#;

(all, j, IND) (all, q, REGDEST)

RORN $(j, q)$ \# TDR pos-imposto normal, dado como dado \#;

(all, j, IND) (all, q, REGDEST)

TREND_K $(j, q)$ \# Tendencia de crescimento no capital \#;

! Secao 5.3a: Leituras, atualizacoes e formulas!

\section{Read}

ADJ_COEFF from file YDATA Header "ADJC";

MURF_SLOPE from file YDATA Header "MURF";

DIFF from file YDATA Header "DIFF";

F_EEQROR from file YDATA Header "FCSE";

F_EEQROR_Q from file YDATA Header "FSTQ";

F_EEQROR_JQ from file YDATA Header "FSTA";

PINV from File YDATA Header "PINV";

QCAP from File YDATA Header "QCAP";

RORN from file YDATA Header "RORN";

TREND_K from file YDATA Header "TRND";

!modif!

!na autualização abaixo foi substituída a variável cap_t (estoque de capital disponível para produçãoo por curcap (estoque de capital corrente)!

Update

$$
\text { (change) }
$$

F_EEQROR

= del_f_eeqror;

(change) (all, $q, \mathrm{REGDEST}$ )

F_EEQROR_Q (q) = del_f_eeqror_q (q) ;

(change) (all, j, IND) (all, q, REGDEST )

F_EEQROR_JQ $(j, q)=$ del_f_eeqror_jq $(j, q)$;

(all, $j$, IND) (all, $q$, REGDEST)

$\operatorname{PINV}(j, q) \quad=\operatorname{pi}(j, q)$;

(all, $j$, IND) (all, $q$, REGDEST)

$\operatorname{QCAP}(j, q) \quad=\operatorname{curcap}(j, q)$;

\section{Formula}

(Initial) (all, j, IND) (all, q, REGDEST)

$\operatorname{QCAPQ1}(j, q)=\operatorname{QCAP}(j, q)$;

(Initial) (all, j, IND) (all, $q$, REGDEST)

$\operatorname{QINVQ1}(j, q)=\operatorname{INVEST}(j, q) / \operatorname{PINV}(j, q)$;

(all, $j$, IND) (all, $q$, REGDEST)

$\operatorname{QCAP} \_T 1(j, q)=\operatorname{INVEST}(j, q) / \operatorname{PINV}(j, q)+\operatorname{DEP}(j) * \operatorname{QCAP}(j, q)$.

(all, j, IND) (all, $q$, REGDEST) 


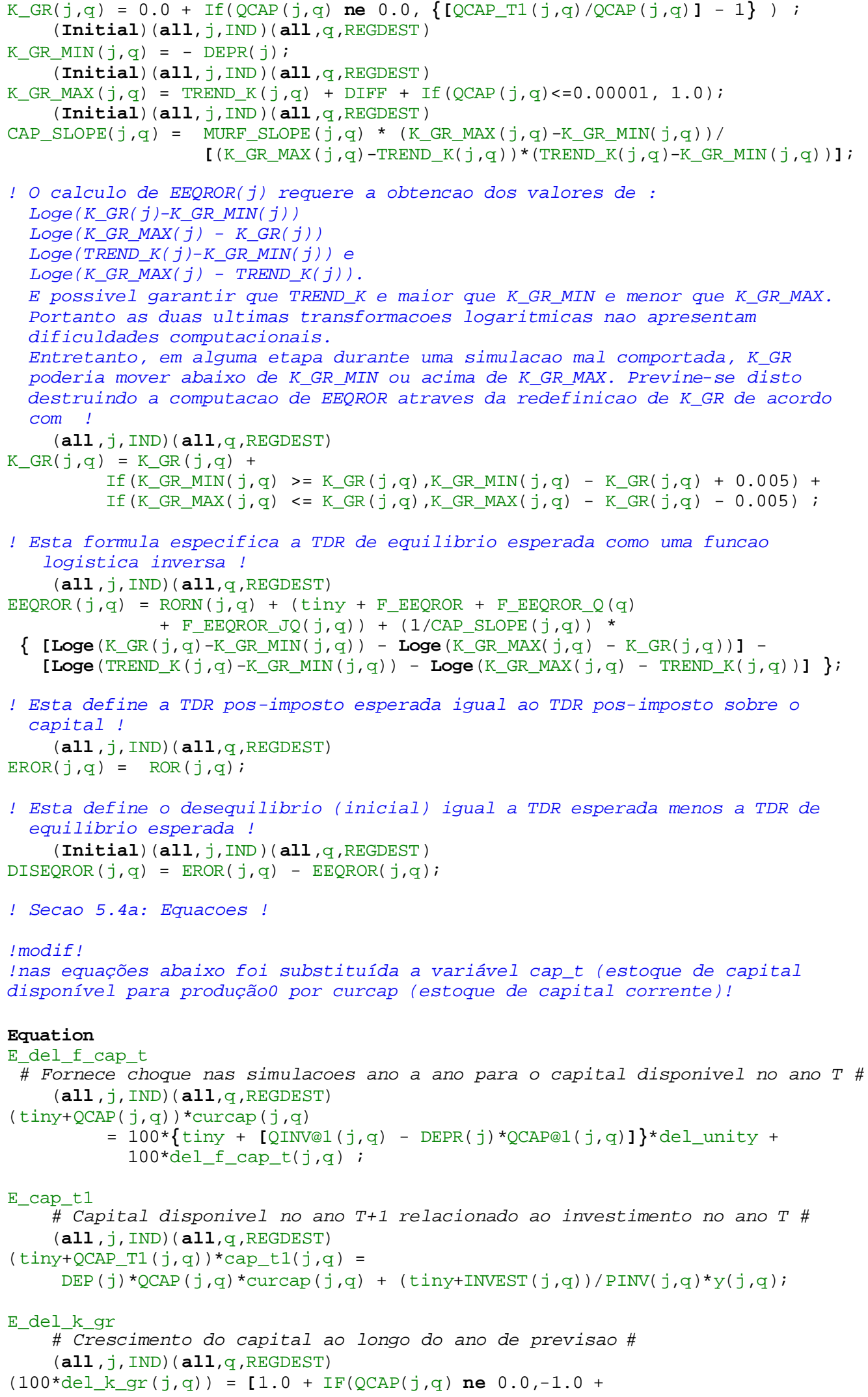




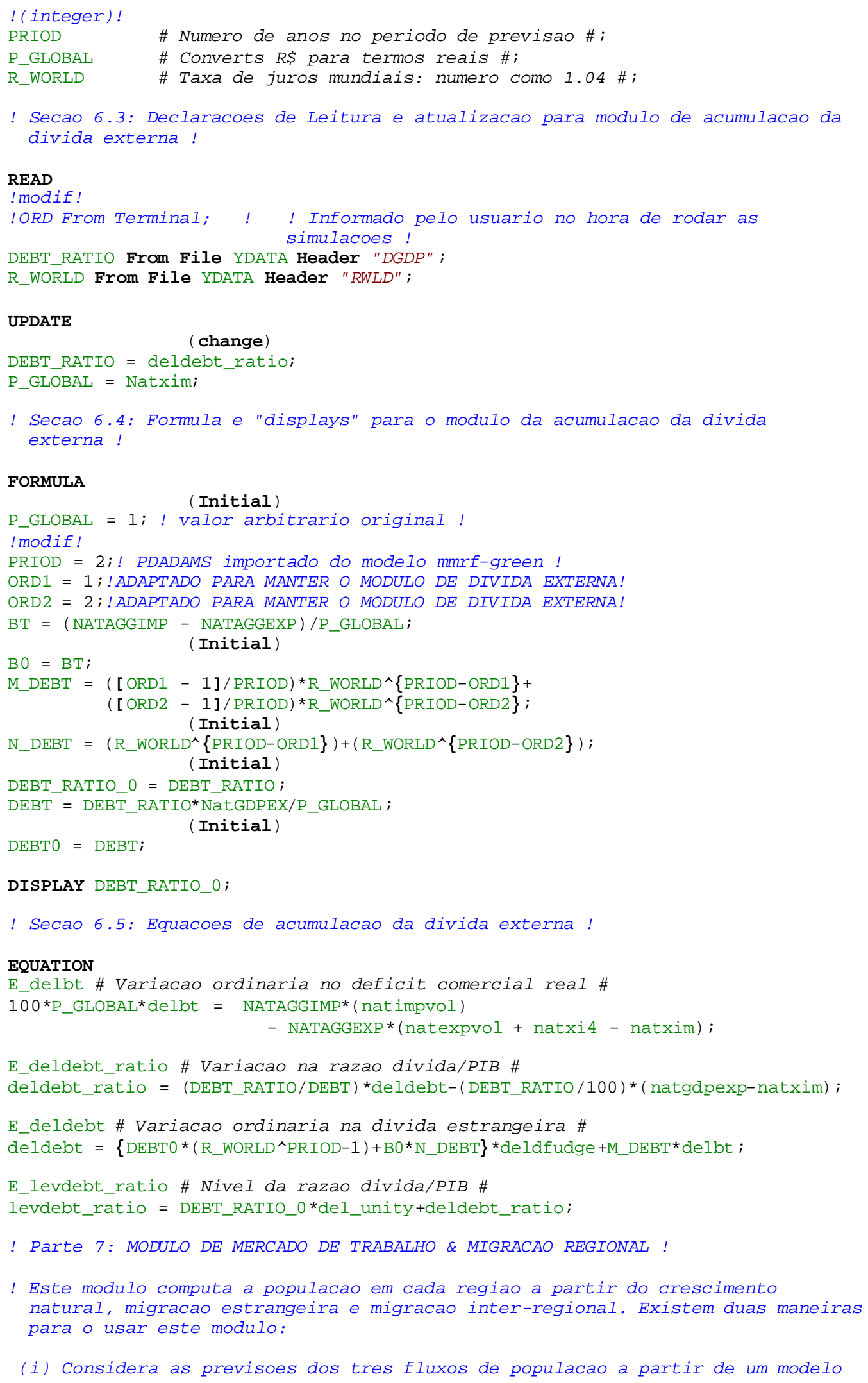


demografico portanto determinando exogenamente as populacoes regionais. Permite o modulo de mercado de trabalho \& migracao determinar a oferta regional de trabalho a partir de populacao regional especificada exogenamente e a partir de definicoes dadas de taxas de participacao regional e movimentos nas razoes entre populacao e populacao economicamente ativa. Com a oferta de trabalho determinada, o modulo de mercado de trabalho e migracao regional determinara tambem diferenciais de salarios inter-regionais, (dada as taxas de desemprego regional) ou taxas de desemprego regional (dados os diferenciais de salario regional). Com as dadas taxas de desemprego regional e oferta de trabalho regional, desemprego regional e determinado como um residuo e o diferenciais de salarios ajustam para acomodar os valores do mercado de trabalho. Fixando diferenciais de salarios determina-se a demanda por trabalho e assim que com a dada oferta de trabalho regional, o modelo determinara as taxas de desemprego regional como residuo.

(ii) Alternativamente, exogenamente especifica-se diferenciais de salario regional e taxas de desemprego regional. O modulo mercado de trabalho e a migracao de regional determinara, entao, oferta de trabalho e populacao regional para dadas definicoes de taxas de participacao regional e razoes de populacao e populacao economicamente ativa.

O modulo tem sido designado com suficiente flexibilidade para permitir variacoes sobre os metodos gerais descritos acima. De forma importante, para previsao, o modulo permite para algumas regioes para ser sujeito ao metodo (i) e outras regioes para serem sujeitos ao metodo (ii) na mesma simulacao.

!

! Secao 7.1: Declaracoes de variavel para o modulo de mercado de trabalho e migracao de regional !

\section{VARIABLE}

del nat fm

del_natg

del_natunr

delf_rm

del_frmt 0

delf_rm_0

delpopfudget

nat labsup

natemploy

del_fgt (q)

del_fm (q)

del_fmt (q)

del_fpoplt (q)

del_g (q)

del_gt (q)

del_pop1t (q)

del_rm (q)

del_rm_o (q)

del_rmt (q) (change)

\# Variacao ordinaria na migracao estrangeira \#; (change)

\# Variacao ordinaria na populacao natural (nascimento-mortes) \#; (change)

\# Variacao ponto perc na taxa de desemprego da economia \#; (change)

\# Deslocador na eq E_RM_Addup \#;

\# Deslocador para migracao regional em $T$ \#; (change)

\# Deslocador na eq E_RM_O \#; (change)

\# Fator "Fudge"na eq E_popt \#;

\# Oferta de trabalho nacional \#;

\# Emprego nacional \#; (change) (all, q, REGDEST)

\# Deslocador no crescim natural da populac regional no ano $T$ \#; (change) (all, q, REGDEST)

\# Variacao ordinaria migracao estrangeira: regioes \#; (change) (all, q, REGDEST)

\# Variacao ordinaria na migracao estrangeira para atualizacao \#; (change) (all, q, REGDEST)

Deslocador na populacao regional no ano $T-1$ \#; (change) (all, $q, \mathrm{REGDEST}$ )

\# Variac ordin na populac natural (nascimentos-mortes): regioes \#; (change) (all, q, REGDEST)

\# Variac ordin no crescim natural da pop regional para atualiz \#; (change) (all, q, REGDEST)

\# Variac ordin na populacao regional no ano $\mathrm{T}-1$ \#; (change) (all, $\mathrm{q}, \mathrm{REGDEST}$ )

\# Variac ordinaria na migracao inter-regional \#; (change) (all, $q, \mathrm{REGDEST}$ )

\# Previsao de migracao inter-regional \#;

(change) (all, $q, \mathrm{REGDEST}$ )

\# Variacao ordinaria na migracao regional para atualizacao \#; 


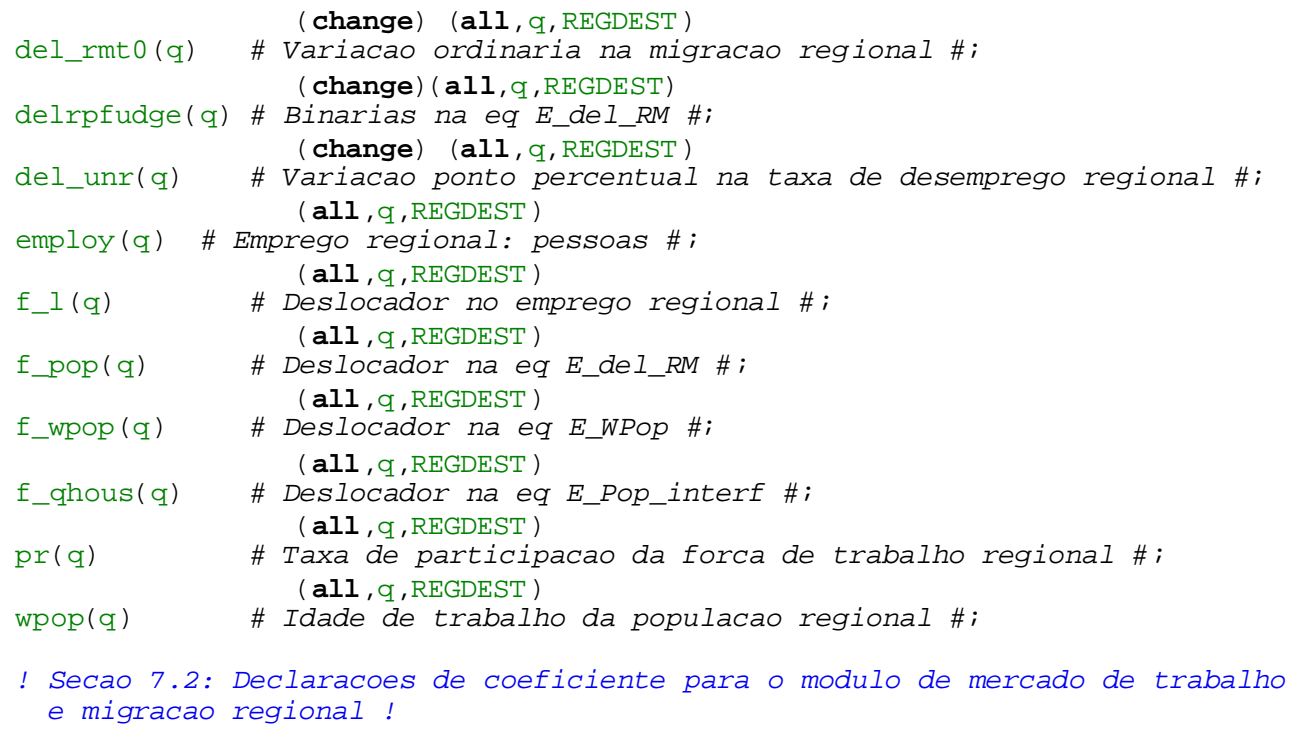




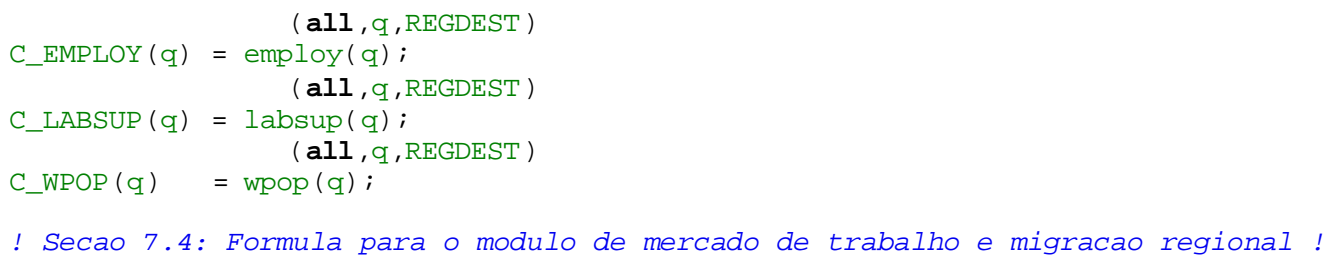




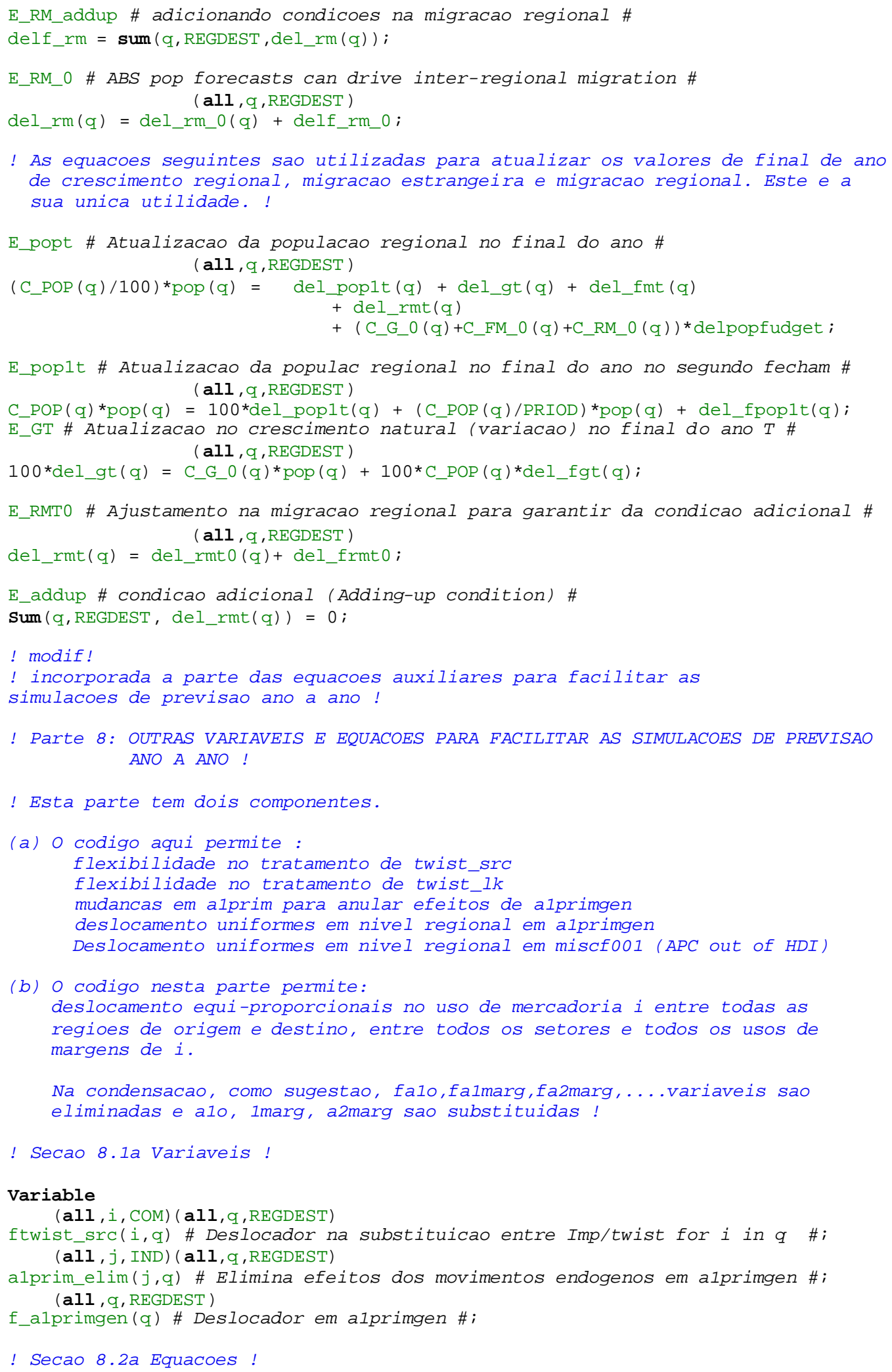

Variable

(all, i, COM) (all, q, REGDEST)

ftwist_src(i,q) \# Deslocador na substituicao entre Imp/twist for $i$ in $q$ \#; (all, j, IND) (all, q, REGDEST)

alprim_elim(j,q) \# Elimina efeitos dos movimentos endogenos em alprimgen \#; (all, q, REGDEST)

f_alprimgen (q) \# Deslocador em alprimgen \#;

! Secao 8.2a Equacoes ! 


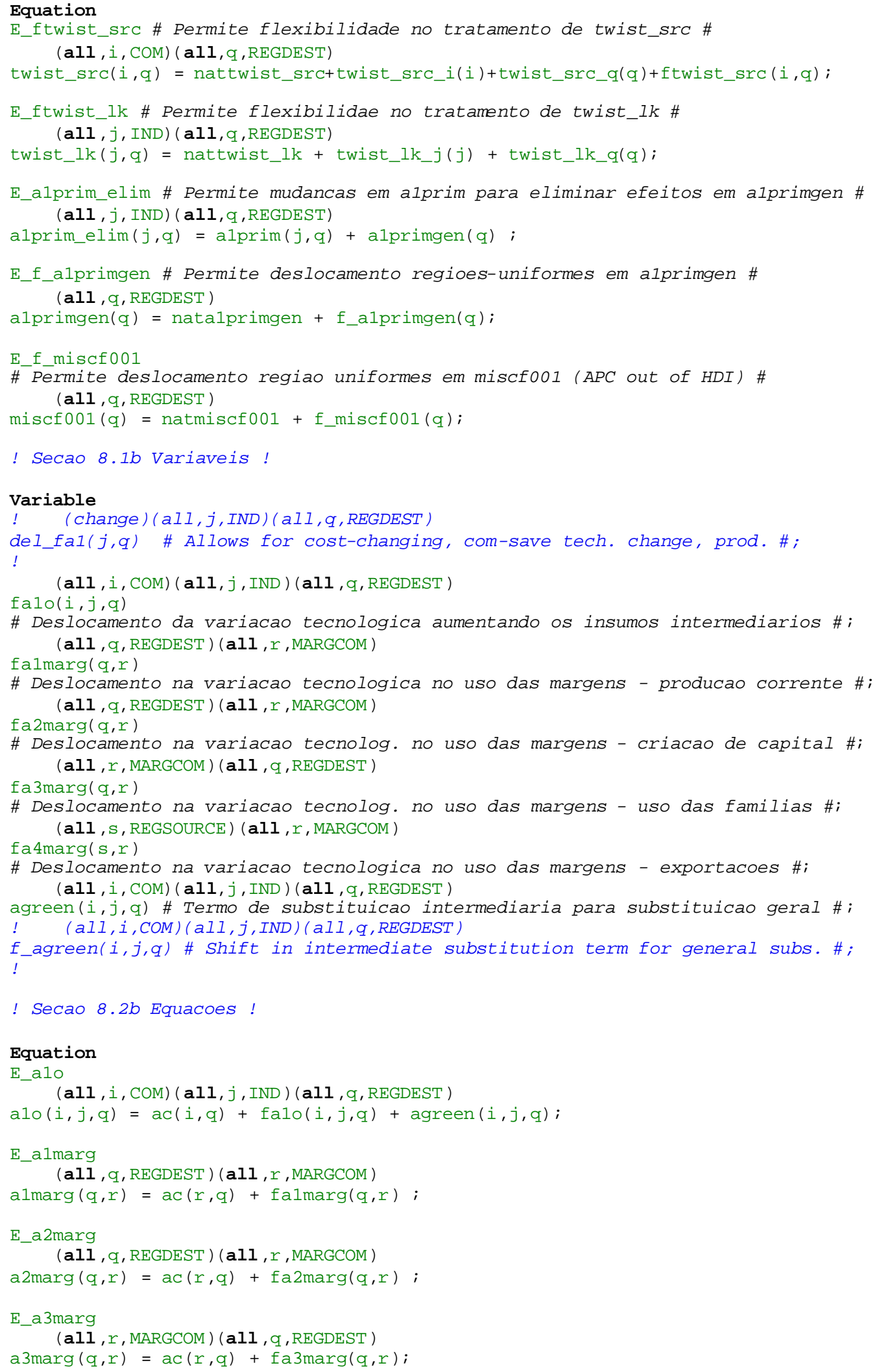




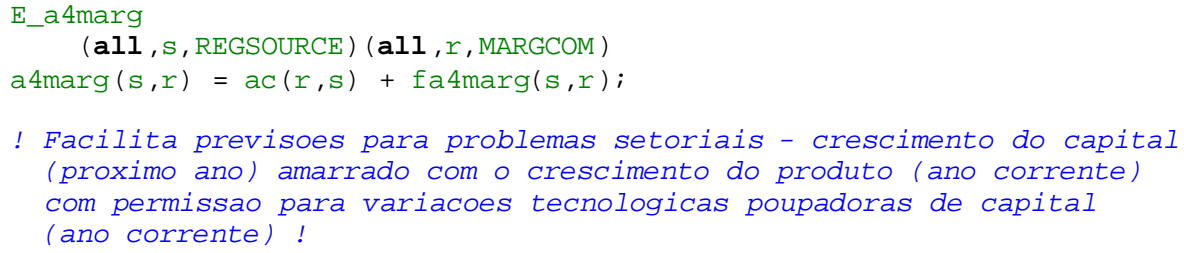

\section{Equation}

E_f_cap_t1

(all, j, IND) (all, q, REGDEST)

cap_t1 $(j, q)=z(j, q)+\operatorname{alcap}(j, q)+\operatorname{alprim}(j, q)+\operatorname{alprimgen}(q)+f \_c a p \_t 1(j, q) ;$ 


\section{REFERÊNCIAS BIBLIOGRÁFICAS}

ADAMS, P.D. MMRF-GREEN: a dynamic multi-regional applied general equilibrium model of the australian economy, based on the MMR and MONASH models. Clayton: Monash University, Centre of Policy Studies, 2001. 93p. (Draft documentation)

ADAMS, P.D.; DIXON, P.B.; McDONALD, D.; MEAGHER, G.A.; PARMENTER, B.R. Forecasts for australian economy using the Monash model. International Journal of Forecasting, v.10, p.557-571, 1994.

ADAMS, P.D.; HUFF, K.M.; McDOUGALL, R.; PEARSON K.R.; POWELL, A.A. Medium and long run consequences for Australia of APEC free-trade area: CGE analysis using the GTAP and MONASH models. Asia Pacific Economic Review, v.3, n.1, p.19-42, 1997.

ADAMS, P.D.; HORRIDGE, J.M.; PARMENTER, B.R. MMRF-GREEN: a dynamic, multi-sectoral, multi-regional model of Australia. Clayton: Monash University, Centre of Policy Studies, 2000. 23p. (Preliminary Working Paper, OP-94)

ADELMAN, I.; ROBINSON, S. Income distribution policies in developing countries. Stanford: Stanford University Press, 1978. 346p.

ADELMAN, I.; ROBINSON, S. Macroeconomic adjustment and income distribution. Journal of Development Economics, v.29, n.1, p.23-44, 1988.

ALMONACID, R.D.; SCRIMINI, G. O desequilíbrio externo e a taxa de câmbio.

Economia Aplicada, v.3, p.119-134, mar. 1999. Número especial. ANUÁRIO ESTATÍSTICO DO BRASIL - v.56-58, 1996-98. 
ARNDT, C. An introduction to systematic sensitivity analysis via gaussian quadrature. West Lafayette: Purdue University, Center for Global Trade Analysis, 1996. 12p. (GTAP Technical Paper, 2)

BACHA, E. O Plano Real uma avaliação. In: MERCADANTE, A. O Brasil pós-Real: a política econômica em debate. Campinas: Unicamp, 1998. p.11-69.

BATISTA JÚNIOR, P.N. O Brasil depois do Plano Real. Economia Aplicada, v.3, p.95-107, mar. 1999. Número especial.

BOLETIM DO BANCO CENTRAL DO BRASIL. Brasília, v.33, n.2, fev. 1997.

BOLETIM DO BANCO CENTRAL DO BRASIL. Brasília, v.35, n.2, fev. 1999.

BOLETIM DO BANCO CENTRAL DO BRASIL. Brasília, v.37, n.1, jan. 2001.

BONELLI, R. Labor productivity in Brazil during the 1990's. Rio de Janeiro: Instituto de Pesquisa Econômica Aplicada, 2002. 36p. (Texto para Discussão, 906)

BERCK, P.; GOLAN, E.; SMITH, B. State tax policy, labor, and tax revenue feedback effects. Industrial Relations, v.36, n.4, p.399-418, Oct. 1997.

CAMPOS FILHO, L. Unilateral liberalisation and mercosul: implications for resource allocation. Revista Brasileira de Economia, v.52, n.4, p.601-636, out./dez. 1998.

CARDOSO, C.E.L.; ISTAKE, M.; HASEGAWA, M.M.; MARTINS, P.C.; LOPES, R.L.; ZEN, S. Modelo inter-regional brasileiro: MIBRA. Piracicaba, 2000. 47p. (Relatório Final da disciplina de Modelos Aplicados de Equilíbrio Geral)

CASIMIRO FILHO, F; ROCHA, M.T.; LIMA, P.V.P.S.; MIRANDA, S.H.G.; GUILHOTO, J.J.M. MIBRA: an interregional applied equilibrium model for the brazilian economy (compact disc). In: WORLD CONGRESS OF THE REGIONAL SCIENCE ASSOCIATION INTERNATIONAL, 6., Lugano, 2000. Proceedings. Lugano: Universitá della Svizzera Italiana, 2000.

CAVALCANTE, J.; MERCENIER, J. Uma avaliação dos ganhos dinâmicos do Mercosul usando equilíbrio geral. Pesquisa e Planejamento Econômico, v.29, n.2, p.153-184, ago. 1999.

CONJUNTURA ECONÔMICA. Rio de Janeiro, v.54, n.2, p.119-149, ago. 2000. 
COMISSÃO DE PROGRAMA DE GOVERNO DO PARTIDO DOS TRABAlHADORES. Programa de Governo 2002 Coligação Lula Presidente: um Brasil para todos. São Paulo: Comitê Lula Presidente, 2002. 73p. http://www.pt.org.br/ (01 out. 2002)

BANCO CENTRAL DO BRASIL. Departamento Econômico - DEPEC. Finanças públicas: sumários dos planos brasileiros de estabilização e glossário de instrumentos e normas relacionadas à política econômico-financeira. Ed. rev. Brasília, 2000. 190p.

DESSUS, S.; BUSSOLO, M. Is there a trade-off between trade liberalization and pollution abatement ? A computable general equilibrium assessment applied to Costa Rica. Journal of Policy Modeling, v.20, n.1, p.11-31, 1998.

DIXON, P.B.; PARMENTER, B.R. Computable general equilibrium modelling for policy analysis and forecasting. In: AMMAN, H.M.; KENDRICK, D. A.; RUST, J. Handbook of computational economics. Amsterdam: Elsevier Science, 1996. cap. 1, p.3-85.

DIXON, P.B.; PARMENTER, B.R.; POWELL, A.A.; WILCOXEN, P.J. Notes and problems in applied general equilibrium economics. Amsterdam: Elsevier Science Publishing, 1992. 392p. (Advanced Textbooks in Economics, 32)

DIXON, P.B.; PARMENTER, B.R.; SUTTON, J.; VINCENT, D.P.; ORANI: a multisectoral model of the australian economy. Amsterdam: North-Holland, 1982. $371 \mathrm{p}$.

DIXON, P.B.; RIMMER, M.T. Monash forecasts of output and employment for australian industries: 1994-95 to 2002-03. Australian Bulletin of Labour, v.22, n.4, p.237-264, Dec. 1996.

DIXON, P.B.; RIMMER, M. Forecasting and policy analysis with a dynamic CGE model of Australia. Clayton: Monash University, Centre of Policy Studies, 1998. 76p. (Preliminary working paper, OP-90)

DIXON, P.B.; RIMMER, M.T. Changes in indirect taxes in australia: a dynamic general equilibrium analysis. The Australian Economic Review, v.32, n.4, p.327-348, 1999. 
DIXON, P.B.; RIMMER, M.T. An overview of MONASH. In: CONFERENCE ON GLOBAL ECONOMIC ANALYSIS, 3., Lafayette, 2000. Proceedings. Lafayette: Global Trade Analysis Project, 2000. http://www.monash.edu.au/policy/conf/ 66Dixon.pdf(29 Oct. 2001)

DOMINGUES, E.P. Sensitivity analysis in applied general equilibrium models: an empirical assessment for mercosur free trade areas agreements. Urbana: University of Illinois at Urbana-Champaign, Regional Economics Applications Laboratory, 2001. 25p. (Discussion Paper, REAL T-1)

ENDERS, W. Applied econometric time series. New York: John Wiley \& Sons, 1995. 433p.

ENGLE, R.F.; GRANGER, C.W.J. Co-integration and error correction: representation, estimation and testing. Econometrica, v.55, n.2, p.251-276, Mar. 1987.

FERREIRA FILHO, J.B.S. Ajuste estrutural e agricultura na década de 80: uma abordagem de equilíbrio geral. Pesquisa e Planejamento Econômico, v.27, n.2, p.397-432, ago. 1997.

FERREIRA FILHO, J.B.S. Trade liberalization, the Mercosur integration process and the agriculture-industry transfers: a general equilibrium analysis. Revista Brasileira de Economia, v.53, n.4, p.499-522, out/dez. 1999.

GARCIA, M.G.P. Um modelo de consistência multissetorial para a economia brasileira. Pesquisa e Planejamento Econômico, v.18, n.2, p.401-452, ago. 1988.

GOMES, G.M.; VERGOLINO, J.R. A macroeconomia do desenvolvimento nordestino: 1960-1994. Rio de Janeiro: Instituto de Pesquisa Econômica Aplicada, 1995. 123p. (Texto para Discussão, 372)

GONZAGA, G.M.; TERRA, M.C.T.; CAVALCANTE, J. O impacto do mercosul sobre o emprego setorial no Brasil. Pesquisa e Planejamento Econômico, v.28, n.3, p.475-508, dez. 1998.

GRANGER, C.W.J.; NEWBOLD, P. Spurious regressions in econometrics. Journal of Econometrics, v.2, p.111-120, 1974.

GUILHOTO, J.J.M. A model for economic planning and analysis for the brazilian economy. Urban-Champaign, 1986. 267p. Thesis (Ph.D.) - University of Illinois. 
GUILHOTO, J.J.M. Um modelo computável de equilíbrio geral para planejamento e análise de políticas agrícolas (PAPA) na economia brasileira. Piracicaba, 1995. 258p. Tese (Livre-Docência) - Escola Superior de Agricultura “Luiz de Queiroz", Universidade de São Paulo.

GUILHOTO, J.J.M.; LOPES, R.L.; MOTTA, R.S. Impactos ambientais e regionais de cenários de crescimento da economia brasileira: 2002/2012. Rio de Janeiro: Instituto de Pesquisa Econômica Aplicada, 2002. 17p. (Texto para Discussão, 892)

HADDAD, E.A. Regional inequality and structural changes: lessons from the brazilian experience. Aldershot: Ashgate, 1999. 209p.

HADDAD, E.A.; DOMINGUES, E.P. EFES : um modelo aplicado de equilíbrio geral para a economia brasileira: projeções setoriais para 1999-2004. Estudos Econômicos, v.31, n.1, p.89-125, 2001.

HARRIS, R.I.D. Using cointegration analysis in econometric modelling. New York: Prentice Hall, 1995. 178p.

HARRISON, J.; PEARSON, K. An introduction to GEMPACK: GPD-1. 2.ed. Clayton: Monash University, 1994a. 147p.

HARRISON, J.; PEARSON, K. User's guide to TABLO, GEMSIM and TABLOgenerated programs : GPD-2. 2.ed. Clayton: Monash University, 1994b. 141p.

HARRISON, J.; PEARSON, K. Installing and using the source-code version of GEMPACK on DOS/Windows PCs, with Lahey Fortran: GPD-6. 7.ed. Clayton: Monash University, 1997. 40p.

HORRIDGE, J.M.; PARMENTER, B.R.; PEARSON, K.R. ORANI-F: A general equilibrium model of the australian economy. Economic and Financial Computing, v.3, n.2, p.71-140, Summer 1993.

INSTITUTO BRASILEIRO DE GEOGRAFIA E ESTATÍSTICA - IBGE. Matriz de insumo-produto: Brasil, 1995. Rio de Janeiro, 1997.

INSTITUTO BRASILEIRO DE GEOGRAFIA E ESTATÍSTICA. Departamento de Contas Nacionais. Tabela 3 - Produto interno bruto per capita do Brasil, por grandes regiões e unidades da federação - 1995-1998. http://www.ibge.gov.br/ ibge/estatistica/economia/contasregionais/tab3n.shtm (29 maio 2001a) 
INSTITUTO BRASILEIRO DE GEOGRAFIA E ESTATÍSTICA. Departamento de Contas Nacionais. Tabela 2 - Produto interno bruto do Brasil a preço de mercado corrente, por grandes regiões e unidades da federação - 1995-1998. http://www.ibge.gov.br/ibge/estatistica/economia/contasregionais/tab2n.shtm maio 2001b)

INSTITUTO DE PESQUISA ECONÔMICA APLICADA. IPEADATA. http://www.ipeadata.gov.br/ (29 nov. 2001)

ISARD, W.; AZIS， I.J.; DRENNAN， M.P.; MILLER， R.E.; SALTZMAN， S.; THORBECKE, E. Methods of interregional and regional analysis. Aldershot: Ashgate, 1998. 490p.

ISRAILEVICH, P.R. Frame-shifting in regional general equilibrium models. In: HEWINGS, G.J.D.; SONIS, M.; BOYCE, D. Trade, networks and hierarchies: modeling regional and interregional economies. Berlim: Springer-Verlag, 2002. cap.21, p.387-405.

JOHANSEN, L. A multi-sectoral study of economic growth Amsterdam: NorthHolland, 1974. 274p.

JOHANSEN, S. Statistical analysis of cointegration vectors. Journal of Economic Dynamics and Control, v.12, p.231-254, 1988.

JOHANSEN, S.; JUSELIUS, K. Maximum likelihood estimation and inference on cointegration: with applications to the demand for money. Oxford Bulletin of Economics and Statistics, v.52, n.2, p.169-210, 1990.

JOHANSEN, S. Estimation and hypothesis testing of cointegration vectors in gaussian vector autoregressive models. Econometrica, v.59, n.6, p.1551-1580, nov. 1991.

KADOTA, D.K.; PRADO, E.F.S. Modelo de equilíbrio geral para análise da política industrial. Rio de Janeiro: IPEA/INPES, 1985. 184p. (Estudos de Política Industrial e Comércio Exterior, 4)

KILDEGAARD, A. Liquidity, risk, and the collapse of the mexican peso: a dynamic CGE interpretation. Southern Economic Journal, v.63, n.2, p.460-472, Oct. 1996. KIM, E. Economic gain and loss from public infrastructure investment. Growth and Change, v.29, p.445-469, Fall 1999. 
KING, R.G.; PLOSSER, C.I.; STOCK, J.H.; WATSON, M.W. Stochastic trends and economic fluctuations. The American Economic Review, v.81, n.4, p.819-840, Sep. 1991.

LYSY, F.J.; TAYLOR, L. A general equilibrium income distribution model for Brazil. In: TAYLOR, L.; BACHA, E.; CARDOSO, E.A.; LYSY, F.J. Models of growth and distribution for Brazil. New York: Oxford University Press, 1980. p.128-139.

McKIBBIN, W.J.; WILCOXEN, P.J. The theoretical and structure of the g-cubed model. Washington: Brooking Institution, 1995. 61p. (Brooking Discussion Papers in International Economics, 118). http://www.brook.edu/views/papers/mckibbin/ 118.htm (25 Oct. 2001)

McKIBBIN, W.J.; WANG, Z. The G-cubed (agriculture) model: a tool for analysing agriculture in a globalizing world. Washington: Brooking Institution, 1998. 70p. (Brooking Discussion Papers in International Economics, 139). http:// www.brook.edu/views/papers/mckibbin/139.htm (25 Oct. 2001)

McKITRICK, R.R. The econometric critique of computable general equilibrium modeling: the role of functional forms. Economic Modeling, v.15, p.543-573, 1998.

MERCENIER, J.; SOUSA, M.C.S. Structural adjustment and growth in a highly indebted market economy: Brazil. In: MERCENIER, J.; SRINIVASAN, T.N. Applied general equilibrium and economic development: present achievements and future trends. Ann Arbor: The University of Michigan Press, 1994. cap.9, p.281-315: Structural adjustment and growth in a highly indebted market economy: Brazil.

MOREIRA, A.R.B. Um modelo multissetorial de consistência da economia brasileira. Pesquisa e Planejamento Econômico, v.22, n.3, p.401-436, 1992.

MOREIRA, A.R.B.; FIORENCIO, A.; LIMA, E.C.R. Os impactos das políticas monetária e cambial no Brasil Pós-Plano Real. In: INSTITUTO DE PESQUISA ECONÔMICA APLICADA. A economia brasileira em perspectiva. Rio de Janeiro: IPEA, 1998. cap.1, p.27-56.

MOREIRA, A.R.B.; URANI, A. Um modelo multissetorial de consistência para a região nordeste. Rio de Janeiro: IPEA, 1994. 58p. (Texto para Discussão, 352) 
MILLER, R.E.; BLAIR, P.D. Input-output analysis: foundations and extensions. Englewood Cliffs: Prentice-Hall, 1985. 464p.

NAJBERG, S.; RIGOLON, F.J.Z.; VIEIRA, S.P. Modelo de equilíbrio geral computável com instrumento de política econômica: uma análise de câmbio $\mathrm{x}$ tarifas. Rio de Janeiro: BNDES, 1995. 24p. (Texto para Discussão, 30)

NAQVI, F.; PETER, M.W. A multiregional, multisectoral model of the australian economy with illustrative application. Australian Economic Papers, v.35, n.66, p.94-113, June 1996.

NELSON, C.R.; PLOSSER, C.I. Trends and random walks in macroeconomics time series. Journal of Monetary Economics, v.10, p.139-162, 1982.

NETTO, A. D. O Plano Real e armadilha do crescimento. In: MERCADANTE, A. O Brasil pós-Real: a política econômica em debate. Campinas: Unicamp, 1998. p.89100.

NORÉN, R. Industrial transformation in the open economy: a multisectoral view. Journal of Policy Modeling, v.20, n.1, p.111-117, 1998.

PARTRIDGE, M.D.; RICKMAN, D.S. Regional computable general equilibrium modelling: a survey and critical appraisal. International Regional Science Review, v.21, n.3, p.205-248, 1998.

PEREIRA, A.M.; SHOVEN, J.B. Survey of dynamic computational general equilibrium models for tax policy evaluation. Journal of Policy Modelling, v.19, n.3, p.401-436, 1988.

PETER, M.W.; HORRIDGE, M.; MEGHER, G.A.; NAVQI, F.; PARMENTER, B.R. The theoretical structure of MONASH-MRF. Clayton: Centre of Policy Studies, 1996a. 121p. (Preliminary working paper, OP-85)

PETER, M.W.; HAN, S.H.; MEAGHER, G.A.; NAQVI, F. The database of MONASH-MRF. Clayton: Centre of Policy Studies, 1996b. 44p.

PIAZOLO, D. Investment behaviour in transition countries and computable general equilibrium models. Applied Economics, v.33, p.829-837, 2001. 
PINHEIRO, A.C.; GIAMBIAGI, F.; GOSTKORZEWICZ, J. O desempenho macroeconômico do Brasil nos anos 90. In: GIAMBIAGI, F.; MOREIRA, M.M. A economia brasileira nos anos 90. Rio de Janeiro: BNDES, 1999. cap.1, p.11-41: O desempenho macroeconômico do Brasil nos Anos 90.

PROGRAMA DAS NAÇÕES UNIDAS PARA O DESENVOLVIMENTO - PNUD. Desenvolvimento humano e condições de vida: indicadores brasileiros. Brasília, 1998. 140p. (Coleção Desenvolvimento Humano)

RIJCKEGHEM, W. An intersectorial consistency model for economic planning in Brazil. In: ELLIS, H.S. The economy of Brazil. Berkeley: University of California Press, 1969. p.376-402.

ROBINSON, S. Multisectorial models. In: CHENERY, H.; SRINIVASAN, T.N. Handbook of development economics. Amsterdam: Elsevier Science Publishing, 1989. v.2, cap.18, p.885-947: Multisectorial models. (Handbooks in Economics, 9)

ROCHA, M.T.; GUILHOTO, J.J.M.; LIMA, P.V.P.S.; CASIMIRO FILHO, F; MIRANDA, S.H. MIBRA, exchange rate vs. tariff policies in Brazil: results from MIBRA, an interregional applied general equilibrium model of the brazilian economy. In: NORTH AMERICAN MEETINGS OF THE REGIONAL SCIENCE ASSOCIATION INTERnAtiOnAL, 47., Chicago, 2000. Proceedings. Chicago: Regional Science Association International, 2000.

RODRIGUES, R.L.; SILVEIRA, S.F.R.; SAMPAIO, A.V.; GUILHOTO, J.J.M.; DMRBR: um modelo aplicável de equilíbrio geral utilizado para análise dos efeitos de políticas econômicas no Brasil. Pesquisa Planejamento Econômico, v.28, n.1, p.159-206, abr. 1998.

SCARF, H.E.; HANSEN, T. The computation of economic equilibrium. New Haven: Yale University Press, 1973. 249p.

SEUNG, C.K.; KRAYBILL, D.S. Tax incentives in an economy with public goods. Growth and Change, v.30, p.128-147, Winter 1999.

SHOVEN, J.B.; WHALLEY, J. Applying general equilibrium. Cambridge: Cambridge University Press, 1995. 299p. 
SILVA, A.B.O.; MEDINA, M.H. Produto interno bruto por unidade da federação: 1985 - 1998. Rio de Janeiro: IPEA, 1999. 19p. (Texto para discussão, 677)

SOUSA, M.C.S. Impactos de políticas econômicas alternativas sobre o desempenho na agricultura: uma análise de equilíbrio geral. Estudos Econômicos, v.15, n.1, p.109125, jan./abr. 1985.

SOUSA, M.C.S. Proteção, crescimento e distribuição de renda no Brasil: uma abordagem de equilíbrio geral. Revista Brasileira de Economia, v.41, n.1, p.99116, jan./mar. 1987a.

SOUSA, M.C.S. Avaliação econômica do Programa Nacional do Álcool (PROÁlCOOL): uma análise de equilíbrio geral. Pesquisa e Planejamento Econômico, v.17, n.2, p.381-410, ago. 1987b.

SOUSA, M.C.S.; HIDALGO, A.B. Um modelo de equilíbrio geral computável para o estudo de políticas de comércio exterior no Brasil. Pesquisa e Planejamento Econômico, v.18, n.2, p.379-400, ago. 1988.

STOCK, J.H.; WATSON, M.W. Variable trends in economics time series. Journal of Economic Perspectives, v.2, n.3, p.147-174, 1988.

STORM, S. Agriculture under trad policy reform: a quantitative assessment for India. World Development, v.25, n.3, p.425-436, Mar. 1997.

TEIXEIRA, E.C. Impact of the uruguai round agreement and mercosul on the brazilian economy. Revista Brasileira de Economia, v.52, n.3, p.441-462, jul./set. 1998.

TREIZ, G.I.; RICKMAN, D.S.; SHAO, G. The REMI economic-demographic forecasting and simulation model. International Regional Science Review, v.14, n.3, p.221-253, 1992.

URANI, A. Políticas de estabilização e eqüidade no Brasil: uma análise contrafactual 1981/83. Pesquisa e Planejamento Econômico, v.23, n.1, p.65-98, abr. 1993.

WERNECK, R.L.F. Desequilíbrio externo e reorientação do crescimento e dos investimentos na economia brasileira. Pesquisa e Planejamento Econômico, v.14, n.1, p.311-352, 1984. 
WILLUNSEN, M.J.F.; CRUZ, R. O impacto das exportações sobre a distribuição de renda no Brasil. Pesquisa e Planejamento Econômico, v.20, n.3, p.557-580, dez. 1990.

WILlUNSEN, M.J.; CRUZ, R.D.; TROTTIER, A. Economic activities and deforestation in Brazil's Carajás region: examining production deforestation linkages. Economia Aplicada, v.1, n.2, p.169-198, abr./jun. 1997.

YANG, Z. A coupling algorithm for computing large-scale dynamic computable general equilibrium models. Economic Modelling, v.16, p.455-473, 1999.

ZHANG, X.Z. Macroeconomic effects of $\mathrm{CO}_{2}$ emission limits: a computable general equilibrium analysis. Journal of Policy Modeling, v.20, n.2, p.213-250, 1998. 